\title{
Combined Evaporation and Freeze-Thaw Effects in Polymer Amended Mature Fine Tailings
}

\author{
by \\ Manuel A. Sanchez Sardon \\ B.Eng., Carleton University, 2013
}

A thesis submitted to the Faculty of Graduate and Postdoctoral Affairs in partial fulfillment of the requirements for the degree of

\author{
Master of Applied Science \\ in \\ Civil Engineering \\ Department of Civil and Environmental Engineering \\ Carleton University \\ Ottawa, Ontario \\ (C) 2016, Manuel A. Sanchez Sardon
}




\section{Abstract}

Evaporation and freeze-thaw phenomena are known to contribute to dewatering and densification of fine tailings streams generated from oil sands bitumen extraction. This thesis reports on studies of 1-Dimensional freezing of polymer-amended mature fine tailings that have different stress histories with respect to degree of desiccation by evaporation and self-weight consolidation. Freezing is accomplished using an electric cooling plate specially mounted in an insulated column. Polymer-amended tailings are placed at a lift of one half-meter, which has been allowed to consolidate. Temperature is recorded using thermocouples, while the densification and dewatering is tracked by monitoring of water content, pore water pressure, and cryo-suctions. After one freezethaw cycle is applied, the samples are cored and then loaded to examine differences in consolidation behaviour post-freezing. Results with respect to dewatering indicate that desiccation and one freeze-thaw cycle enhanced the dewatering process and increased the average solids content of the tailings by $6 \%$ when compared to MFT that only underwent consolidation. Also, when comparing the self-weight consolidation and desiccation phases for the three Column Tests, it was found that desiccation increases the efficiency of the freezing process. Lastly, no significant differences in compressibility and permeability properties were found between tailings that underwent just self-weight consolidation and tailings that underwent self-weight consolidation and one freeze-thaw cycle. 


\section{Dedication}

To my wonderful grandmother and mother, Emma and Consuelo, who have always supported me and given me the best no matter what.

To my sister, Maria, who is always an inspiration because of her hard work and persistence.

To my family in Peru, who have always been a source of inspiration and dedication.

To Rebekah, who through her support and care has inspired and helped me complete my Masters degree. 


\section{Acknowledgements}

The completion of my Master`s degree was possible because of the help of many people who encouraged me and supported throughout this journey. I would like to acknowledge everyone who got involved during my studies.

The opportunity to pursue a Master's degree would not have been possible without the support and encouragement of my two supervisors, Dr. Paul Simms and Dr. Mohammad Rayhani. I am grateful for the opportunity they have given me to advance my engineering career.

I am also grateful to the Civil and Environmental Engineering technical staff who spent many hours helping me complete the experimental component of my thesis. I would like to thank Stan, Marie, Jason, Ben, Ken, and Pierre for being so supportive whenever I was in need of help.

Thank you Sahar for the encouragement and motivation you gave me to pursue my Master`s degree. Your constant guidance and support helped me go through the transition from undergrad to grad studies.

Thank you Shabnam for always being there when I had a "quick" question or in need of an extra hand in the lab. It has been a pleasure to meet you, to work with you, and to learn from you.

Lastly, I would like to thank the friends who also ventured with me into grad studies from our undergraduate days. Thank you Colin, Talal, Jenn, and Amin. Thanks to you people, graduate studies became a bit more entertaining. 


\section{Table of Contents}

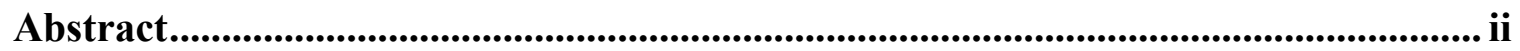

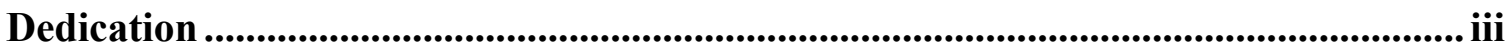

Acknowledgements ....................................................................................................... iv

Table of Contents ....................................................................................................................... v

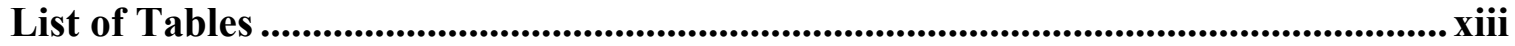

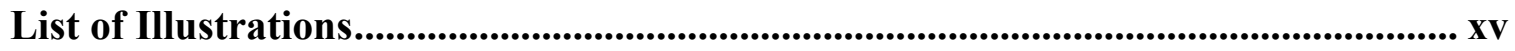

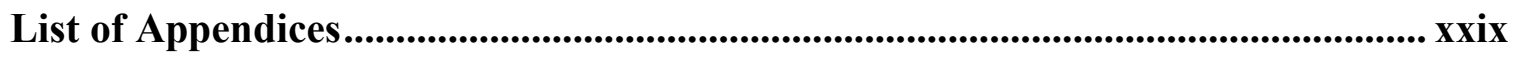

1 Chapter: Introduction ................................................................................. 1

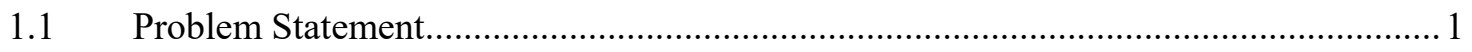

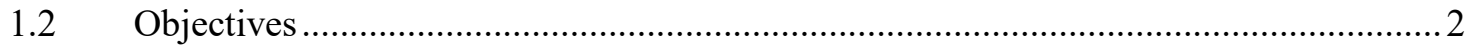

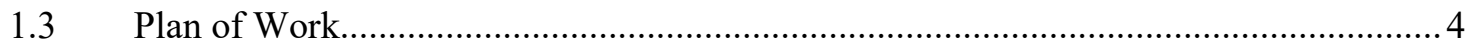

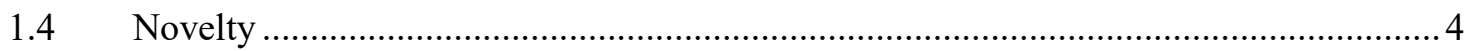

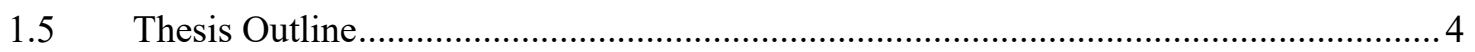

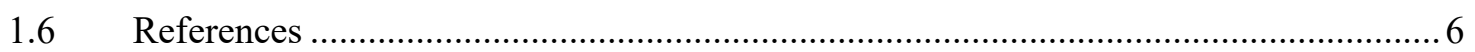

2 Chapter: Literature Review ............................................................................ 7

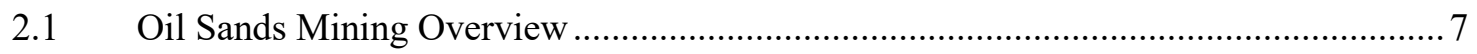

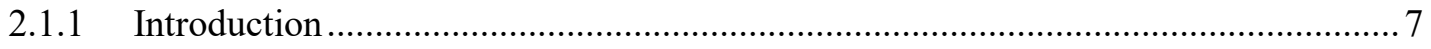

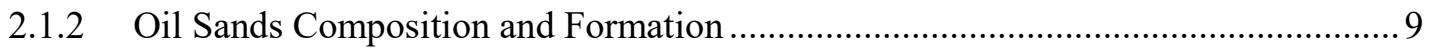

2.1.3 Oil Sands Extraction and Bitumen Separation ................................................... 11

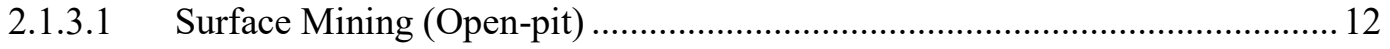

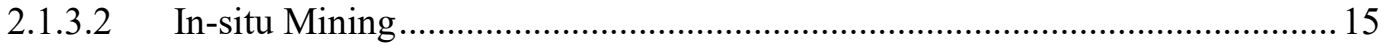

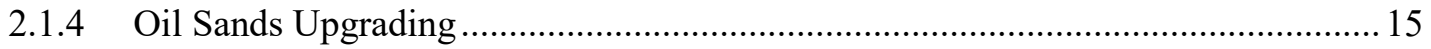

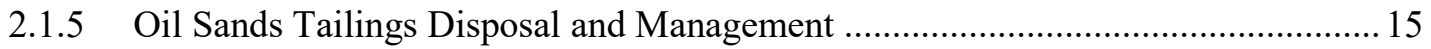


2.1.6 Mature Fine Tailings (MFT): The Dewatering Challenge …................................. 17

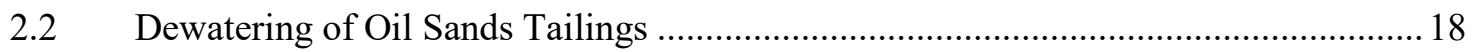

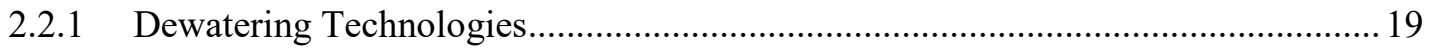

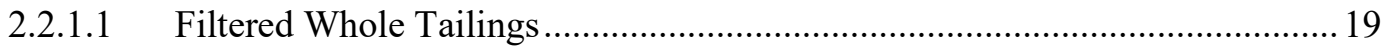

2.2.1.2 Composite/Consolidation Tailings (CT) .....................................................2 20

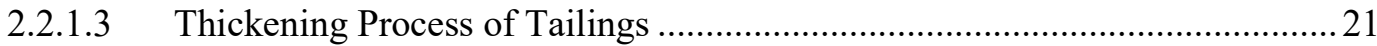

2.2.1.4 In-line Thickened Tailings (ILTT) Technology ............................................21

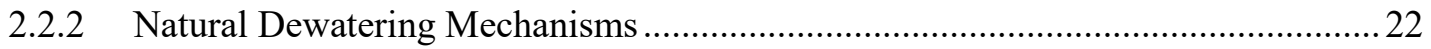

2.2.2.1 Sedimentation and Self-weight Consolidation ............................................22

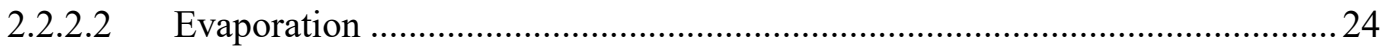

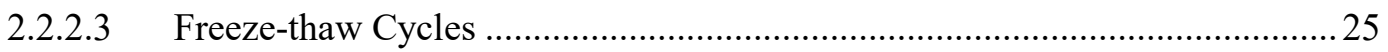

2.3 Geotechnical Properties of Mature Fine Tailings (MFT) …....................................26

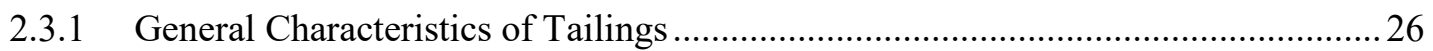

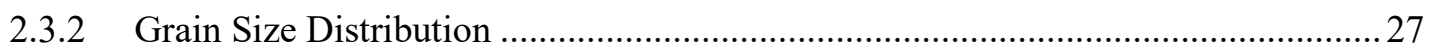

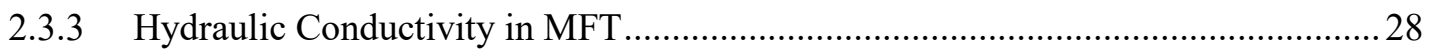

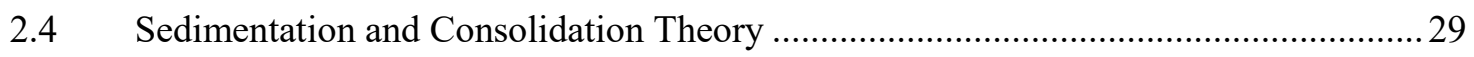

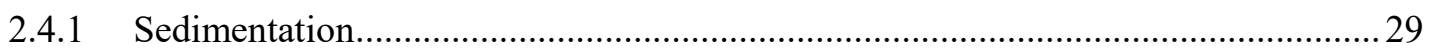

2.4.2 Classical Theory: 1-Dimensional Consolidation Theory ....................................... 30

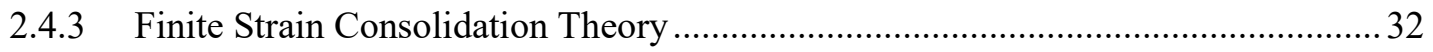

2.4.3.1 Compressibility and Hydraulic Conductivity Relationships ............................ 34

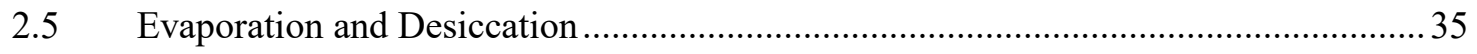

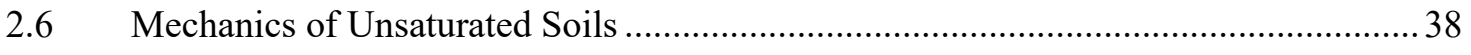

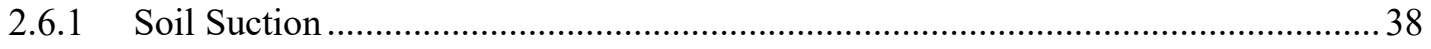

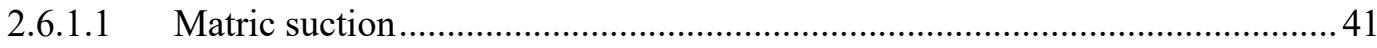

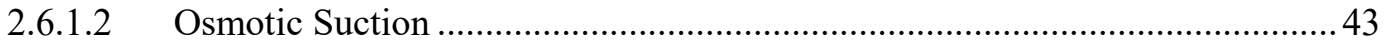

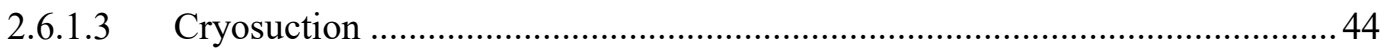




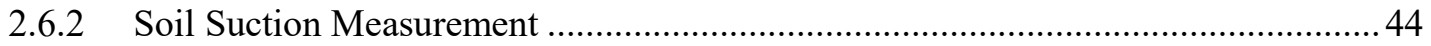

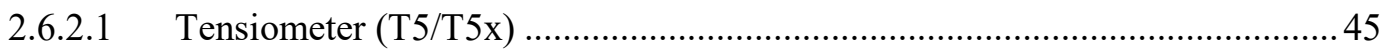

2.6.2.2 Dielectric Water Potential Sensor (MPS-6)................................................ 46

2.6.2.3 Chilled-mirror Dewpoint Potentiameter (WP4-T) ...................................... 49

2.6.3 Soil Water Characteristic Curve (SWCC)............................................................ 49

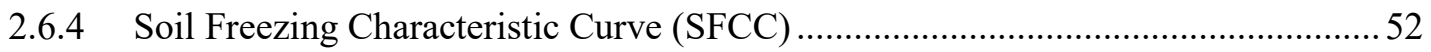

2.7 Frozen Ground and Effect of Freeze-Thawing on Soils ............................................56

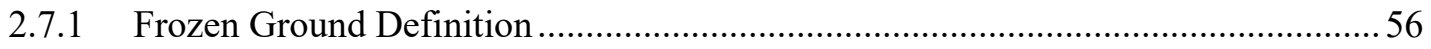

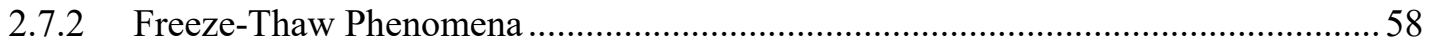

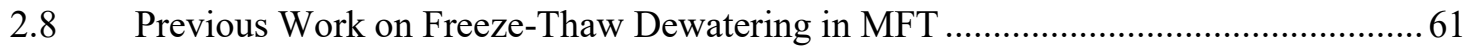

2.9 Freeze-thaw Phenomenon in Oil Sands Tailings Ponds .............................................. 76

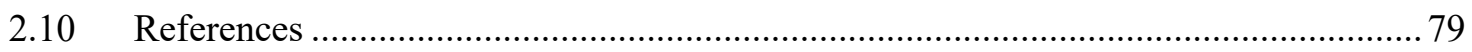

3 Chapter: Methodology and Material .................................................................. 87

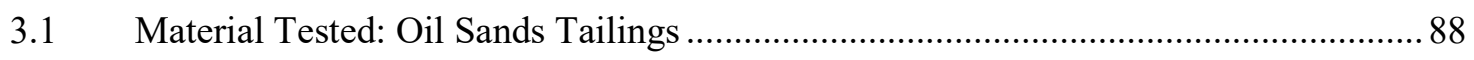

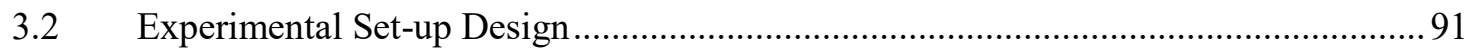

3.2.1 Effects of Sample Size on Temperature in Freeze-Thaw Tests ............................. 91

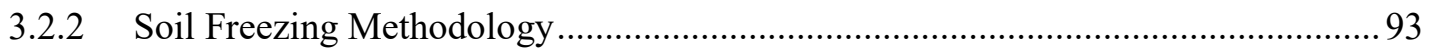

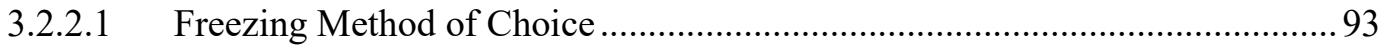

3.2.2.1.1 Freezing Temperature Designation ....................................................... 97

3.2.2.1.2 Number of Freeze-Thaw Cycles .......................................................... 98

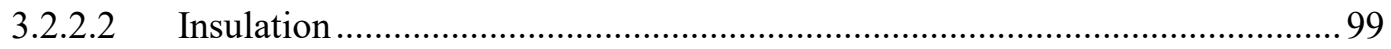

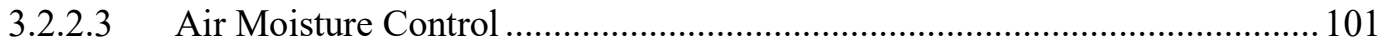

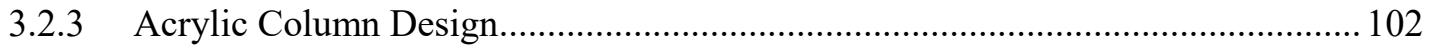

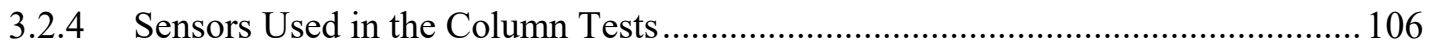

3.2.4.1 5TE Water Content, EC, and Temperature Sensor....................................... 106

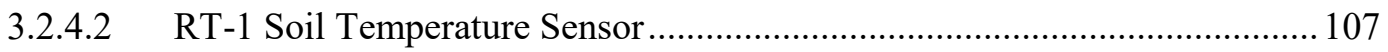




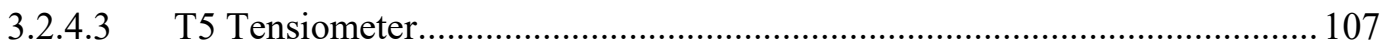

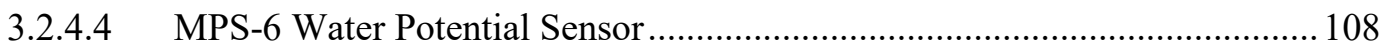

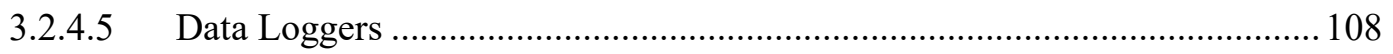

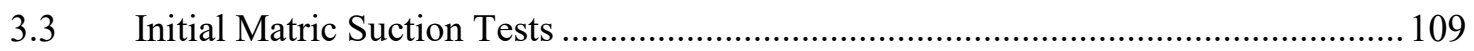

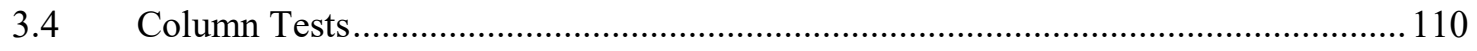

3.4.1 Column Test \#1: Self-Weight Consolidation with Ambient Drying and Freeze-Thaw Cycle 110

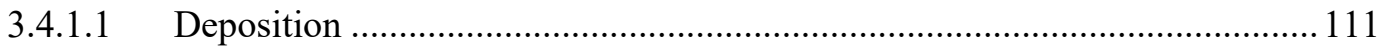

3.4.1.2 Self-weight Consolidation with Ambient Drying Phase .............................. 114

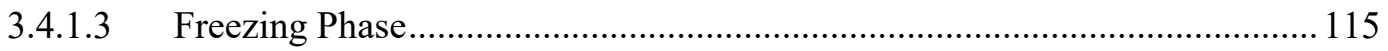

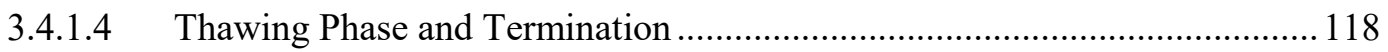

3.4.2 Column Test \#2: Self-Weight Consolidation with Ambient Drying....................... 119

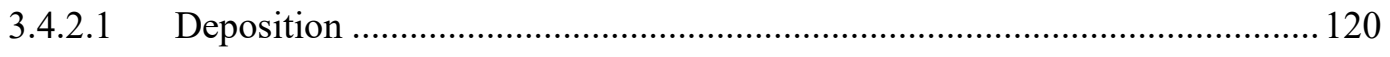

3.4.2.2 Self-Weight Consolidation with Ambient Drying Phase............................... 122

3.4.3 Column Test \#3: Self-Weight Consolidation with Ambient Drying, Accelerated

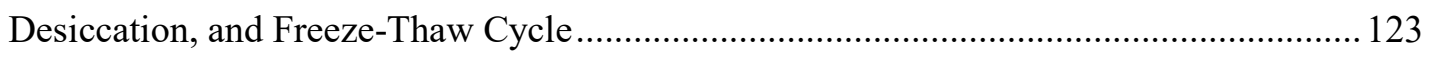

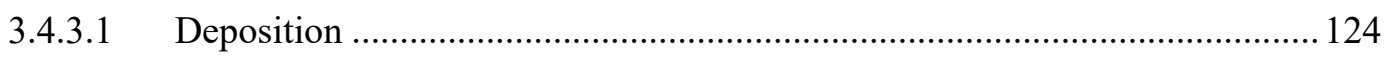

3.4.3.2 Self-Weight Consolidation with Ambient Drying Phase .............................. 125

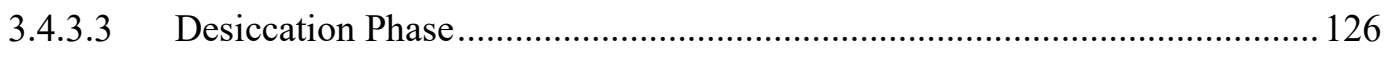

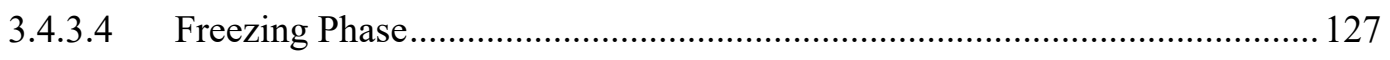

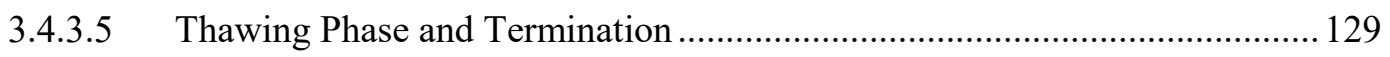

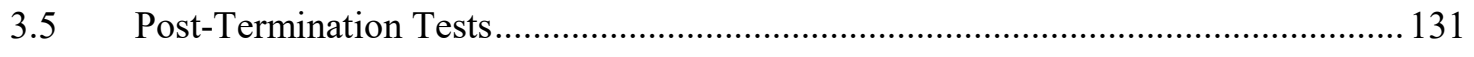

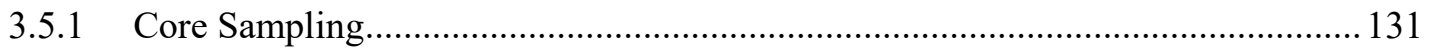

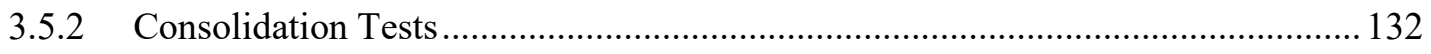

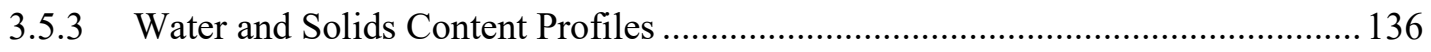

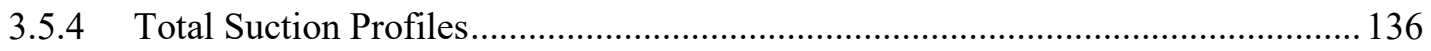




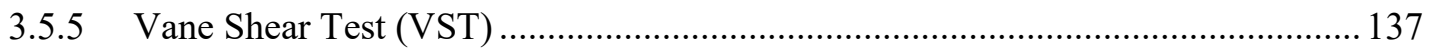

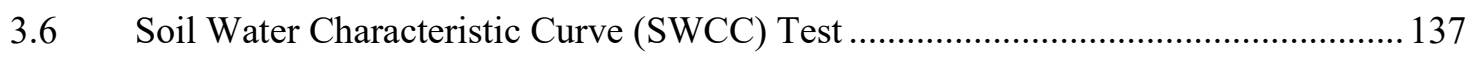

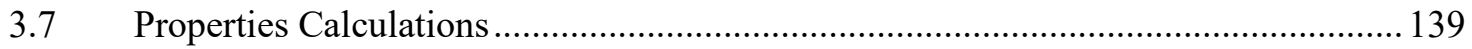

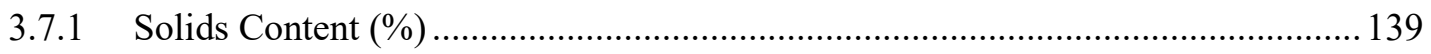

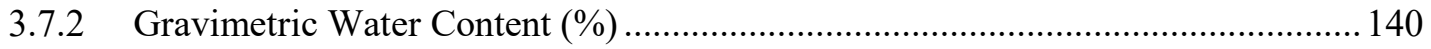

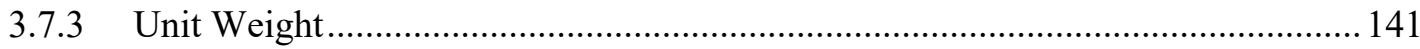

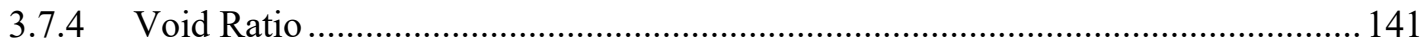

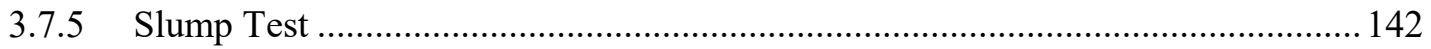

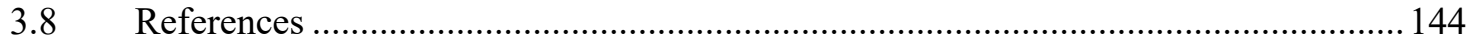

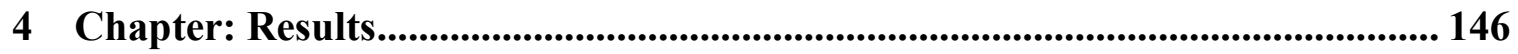

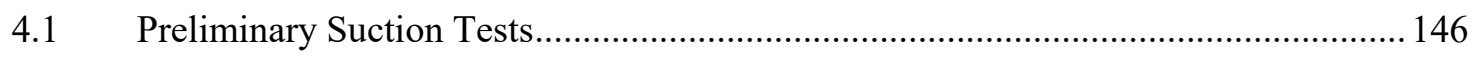

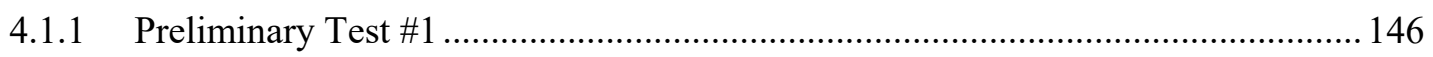

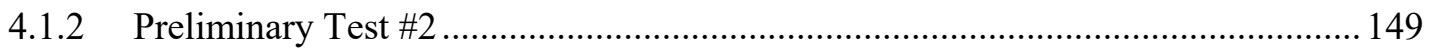

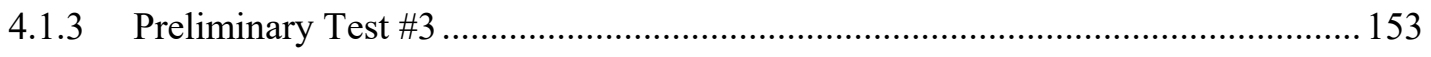

4.2 Column Test \#1: Self-Weight Consolidation with Ambient Drying and Freeze-Thaw Cycle 155

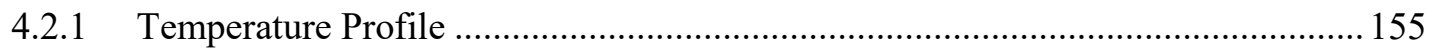

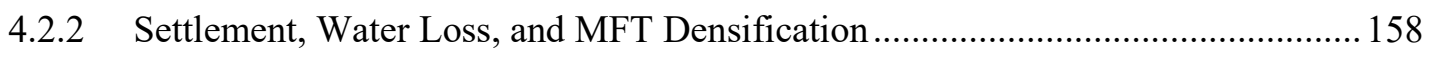

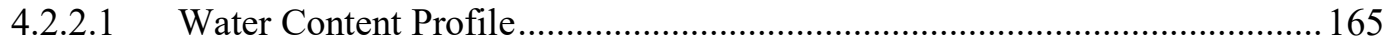

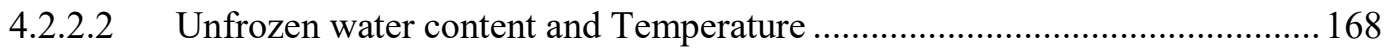

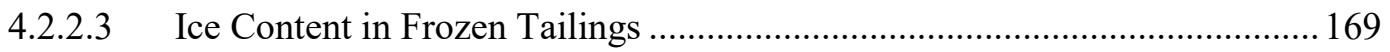

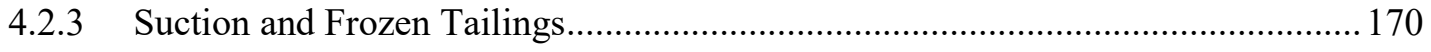

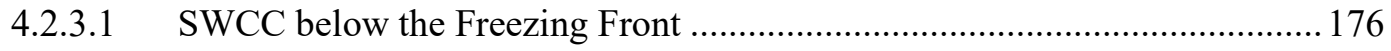

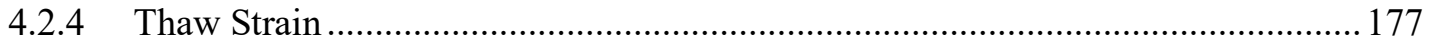

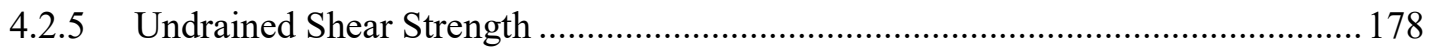

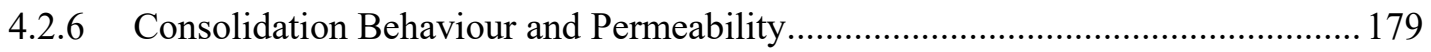


4.3 Column Test \#2: Self-Weight Consolidation with Ambient Drying 185

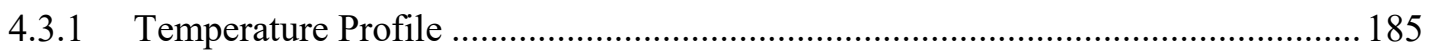

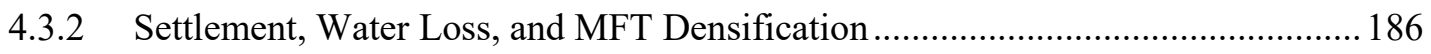

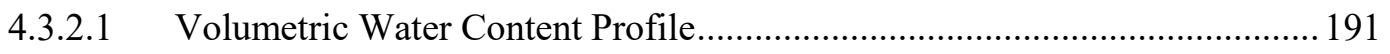

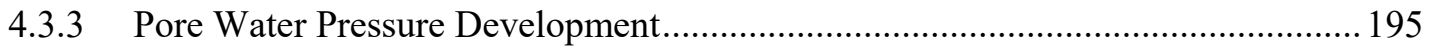

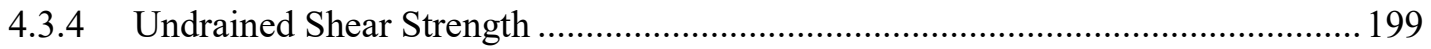

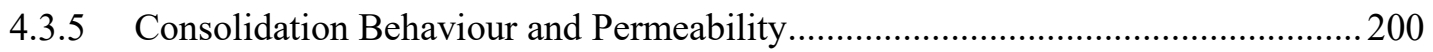

4.4 Column Test \#3: Self-Weight Consolidation with Ambient Drying, Accelerated

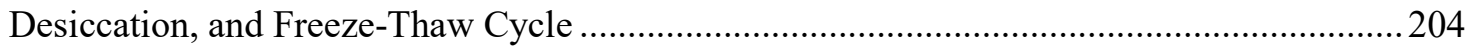

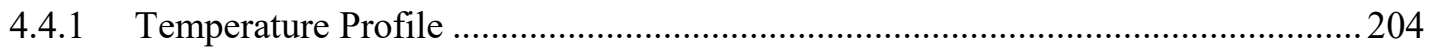

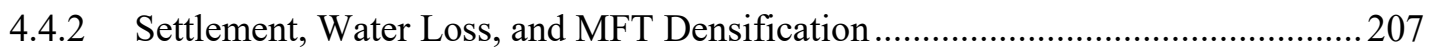

4.4.2.1 Water Content Profile............................................................................. 215

4.4.2.2 Unfrozen Water Content and Temperature …............................................ 218

4.4.2.3 Ice Content in Frozen Polymer Amended MFT ...........................................220

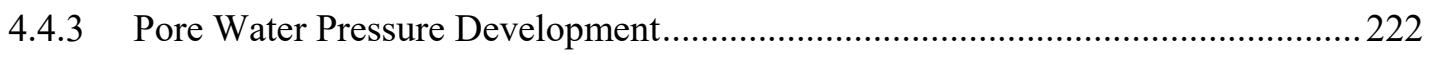

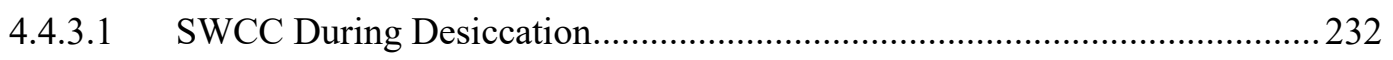

4.4.3.2 SWCC Below the Freezing Front................................................................ 233

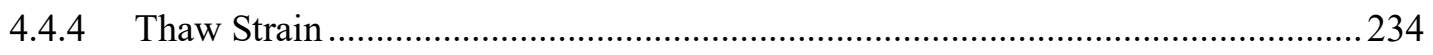

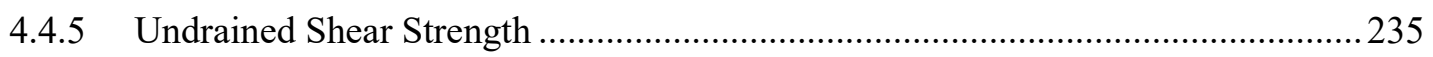

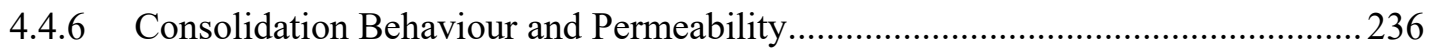

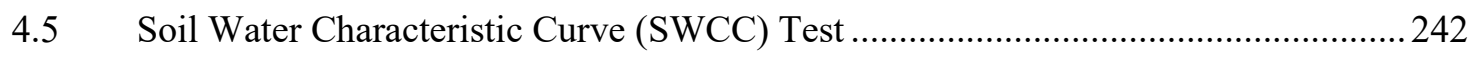

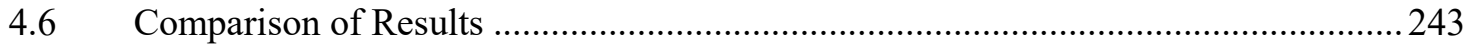

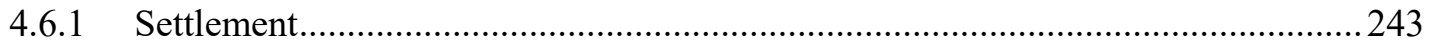

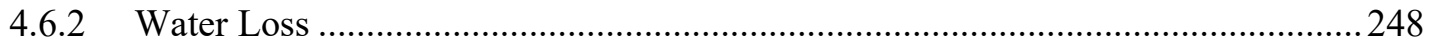

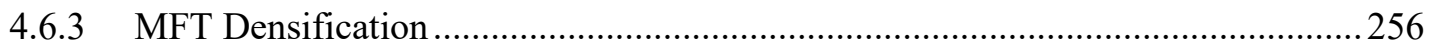


4.6.4 Measured SWCC and SFCC in Different Stages of Dewatering During the Freezing Stage 259

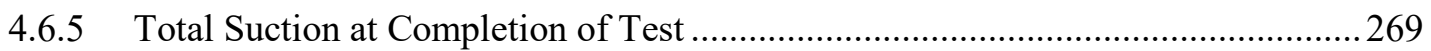

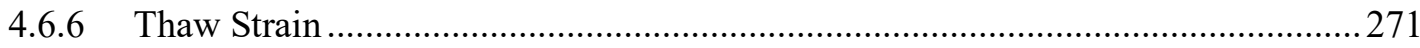

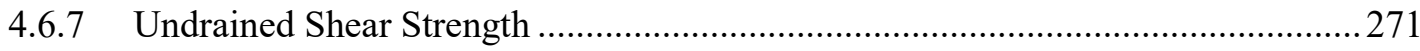

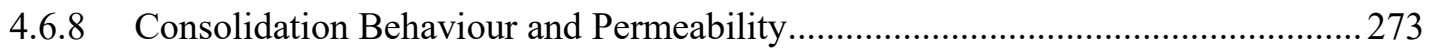

4.7 Qualitative Observations During One Freeze-thaw Cycle .......................................2 275

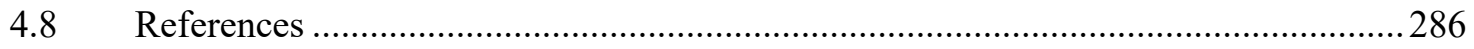

5 Chapter: Summary, Conclusions and Recommendations ................................ 288

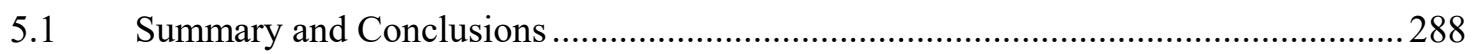

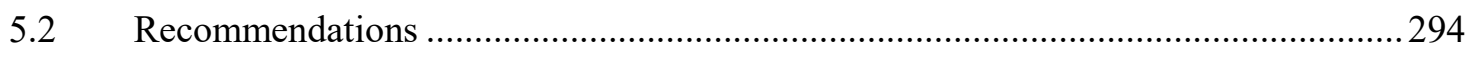

5.2.1 Recommendations on Experimental Methodology ...........................................2. 295

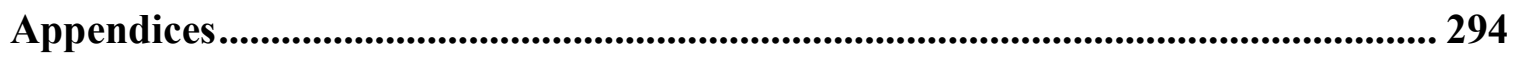

Appendix A : Consolidation Data for Column Test \#1 ........................................................... 294

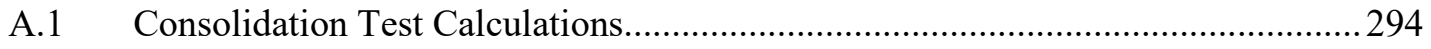

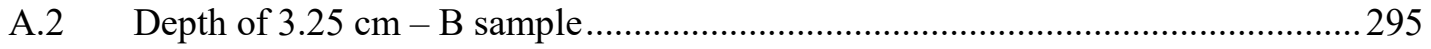

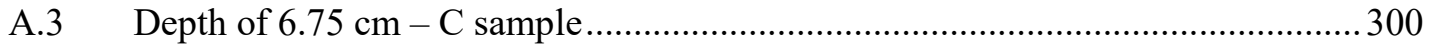

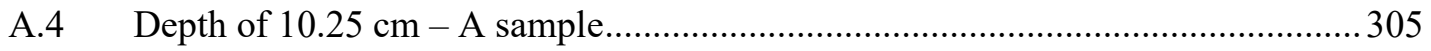

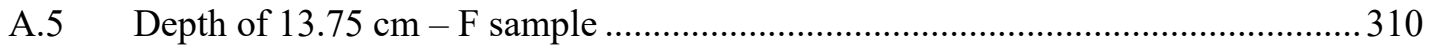

Appendix B : Consolidation Data for Column Test \#2 …................................................ 315

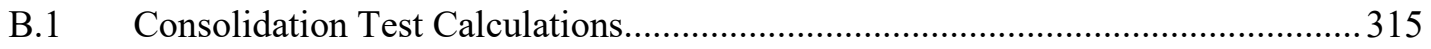

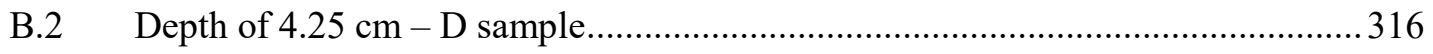

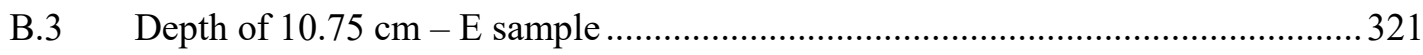

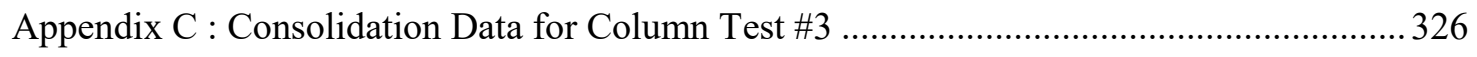

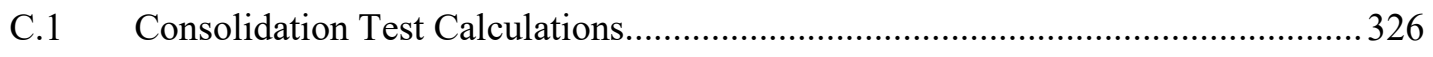

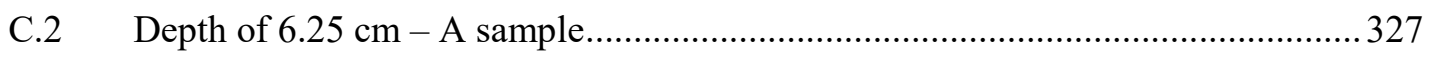


C.3 Depth of $12.75 \mathrm{~cm}-\mathrm{F}$ sample 332

Appendix D : Other Tables and Graphs .. 337

D.1 Experiments Events Timeline. 337

D.2 Slump Test Data. 338

D.3 Summary of Other Freeze-Thaw Tests by Henry (2007). 338

D.4 Soil Freezing Characteristic Curve (SFCC) Data... .339 


\section{List of Tables}

Table 1. Oil Sands Tailings Composition (Beier et al., 2013) .......................................... 16

Table 2. Basic Properties of MFT (modified after BGC Engineering Inc., 2010) ........... 26

Table 3. Dielectric Permittivity of Sensor Materials (modified after Decagon, 2014)..... 47

Table 4. The effect of freeze-thaw cycles on solids content of pure sludge (Johnson et al., 1993) 62

Table 5. The effect of sand-sludge configuration on the increase of sludge solids content

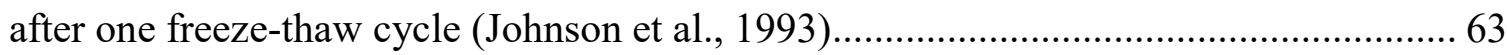

Table 6. Average solids content before and after freeze-thaw cycles (Johnson et al., 1993) 64

Table 7. Experimental phases in each of the three column tests ..................................... 88

Table 8. Properties of raw MFT and MFT mixed with polymer (Mizani et al., 2013).... 89

Table 9. Mineral composition of raw MFT (Mizani et al., 2013)................................... 89

Table 10. Initial water and solids content for each column test...................................... 90

Table 11. Fort McMurray climate data for the last 3 winters (Government of Canada) .. 97

Table 12. Thermal properties of insulating materials .................................................. 100

Table 13. Type and sensor location for column test \#1 ............................................... 111

Table 14. Type and sensor location for column test \#2 ............................................. 120

Table 15. Type and sensor location for column test \#2.............................................. 124

Table 16. Consolidation test samples' number and location. ....................................... 133

Table 17. Initial and final values for during negative pore pressure development......... 175

Table 18. MFT consolidation properties summary for column test \#1 .......................... 182

Table 19. Consolidation properties for column test \#2 ………………….................... 203 
Table 20. Consolidation properties (column test \#3) .............................................. 239

Table 21. Thaw strains for column test \#1 and \#3 ................................................ 271

Table 22. Calculations prior test - Column Test \#1 ................................................ 294

Table 23. Calculations post test (a) - Column Test \#1 ................................................. 294

Table 24. Calculations post test (b) - Column Test \#1 ............................................. 294

Table 25. Compressibility data at depth of $3.25 \mathrm{~cm}$ - Column Test \#1 ........................ 295

Table 26. Compressibility data at depth of $6.75 \mathrm{~cm}$ - Column Test \#1 ........................ 300

Table 27. Compressibility data at depth of $10.25 \mathrm{~cm}$ - Column Test \#1 ...................... 305

Table 28. Compressibility data at depth of $13.75 \mathrm{~cm}$ - Column Test \#1 ....................... 310

Table 29. Calculations prior test - Column Test \#2 ............................................. 315

Table 30. Calculations post test (a) - Column Test \#2 _.............................................. 315

Table 31. Calculations post test (b) - Column Test \#2 ............................................ 315

Table 32. Compressibility data at depth of $4.25 \mathrm{~cm}$ - Column Test \#2 ........................ 316

Table 33. Compressibility data at depth of $10.75 \mathrm{~cm}$ - Column Test \#2 ....................... 321

Table 34. Calculations prior test - Column Test \#3 ............................................... 326

Table 35. Calculations post test (a) - Column Test \#3 ............................................. 326

Table 36. Calculations post test (b) - Column Test \#3 ............................................ 326

Table 37. Compressibility data at depth of $6.25 \mathrm{~cm}$ - Column Test \#3 ......................... 327

Table 38. Compressibility data at depth of $12.75 \mathrm{~cm}$ - Column Test \#3 ...................... 332

Table 39. Events timeline for Column Test \#1 .......................................................... 337

Table 40. Events timeline for Column Test \#2 ..................................................... 337

Table 41. Events timeline for Column Test \#3 ...................................................... 337

Table 42. Slump tests summary for all three column tests. ..................................... 338 


\section{List of Illustrations}

Figure 1. Oil Sands Deposit in the Province of Alberta (Alberta Energy, 2014) ............. 8

Figure 2. Oil Sands Composition (Government of Alberta, 2009) ................................ 9

Figure 3. Oil Migration Path in the Western Canada Sedimentary Basin (Oil Sands

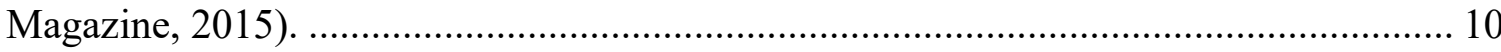

Figure 4. Surface Mining vs In-situ Mining (Oil Sands Magazine, 2015) ..................... 12

Figure 5. Oil Sands Reserves Available for Surface Mining (Gosselin, et al., 2010) ...... 13

Figure 6. Open-pit mining process (Gosselin, et al., 2010)........................................ 14

Figure 7. Oil Sands Tailings Pond and Particle Segregation (Beier et al., 2009)............ 17

Figure 8. Particle Size Distribution of MFT (Islam, 2014)......................................... 27

Figure 9. Hydraulic Conductivity vs Void Ratio for MFT (Jeeravipoolvarn, 2005) ........ 28

Figure 10. Compressibility of Fine Tailings (Jeeravipoolvarn et al., 2008)................... 34

Figure 11. Hydraulic Conductivity of Fine Tailings (Jeeravipoolvarn et al., 2008)........ 35

Figure 12. Components of Total Suction (Fredlund et al., 2010) ................................ 40

Figure 13. Capillary and adsorptive forces in the soil matrix................................... 41

Figure 14. Capillary rise within a capillary tube........................................................ 42

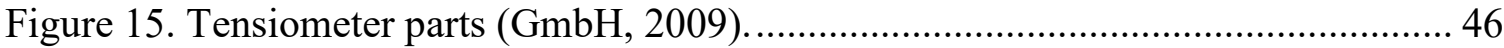

Figure 16. Dielectric Water Potential Sensor (Decagon Devices, 2014)....................... 47

Figure 17. Soil Water Characteristic Curve for MPS-6 Sensors (Decagon Devices, 2014). 48

Figure 18. Dewpoint Potentiameter (Decagon Devices, 2003).................................. 49

Figure 19. Typical SWCC for a silty soil (Fredlund et al., 1994) ................................. 50 
Figure 20. Saturation stages in the SWCC (Vanapalli et al, 1996).

Figure 21. Water variation at different degrees of saturation of a SWCC (Vanapalli et al, 1996). 52

Figure 22. Comparison between SFCC at a depth of $29 \mathrm{~cm}$ and $46 \mathrm{~cm}$ and SWCC at a

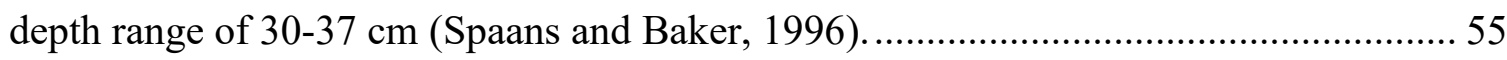

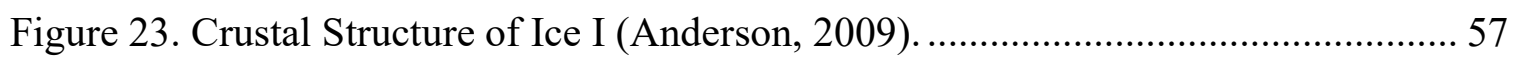

Figure 24. Experimental models for dewatering pure oil sands sludge (Johnson et al., 1993) 62

Figure 25. Change in final solids content in relation to initial solids content and freezethaw cycle (Johnson et al., 1993). 65

Figure 26. Compressibility and hydraulic conductivity results from sulfuric acid and quicklime ameneded MFT (modified after Proskin, 1998) 67

Figure 27. Laboratory experiment results performed by Dawson et al., (1999). 69 Figure 28. Initial vs final solids content for laboratory and field tests (Dawson et al., 1999) 70

Figure 29. Initial solids content vs thaw-strain (Dawson et al., 1999) 71

Figure 30. Void ratio vs Permeability (Dawson et al., 1999) ...................................... 72

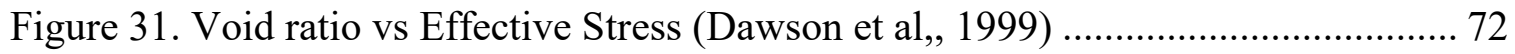
Figure 32. Consolidation test results after one and two freeze-thaw cycles (modified after

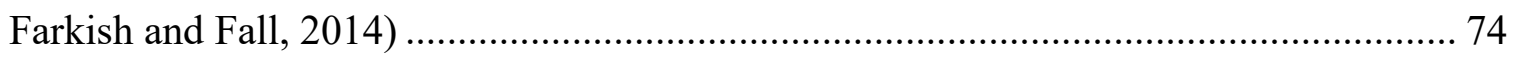
Figure 33. Material balance during winter operations in the Suncor facilities (Suncor

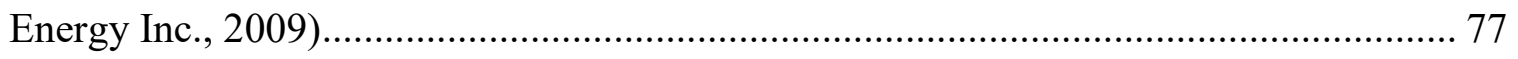
Figure 34. Hourly air, soil surface and soil at $5 \mathrm{~cm}$ temperatures vs time (Henry, 2007) 92 
Figure 35. CP-121 Peltier-thermoelectric cold plate cooler (TE Technology Inc.)......... 95

Figure 36. Cooling plate, temperature control, and power supply.............................. 96

Figure 37. Thermistor located in between the tailings' surface and the cooling plate (TE

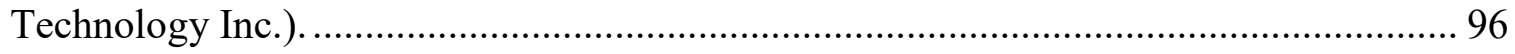

Figure 38. Insulating case around the acrylic column. ......................................... 100

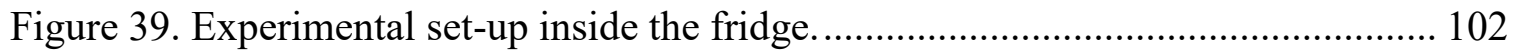

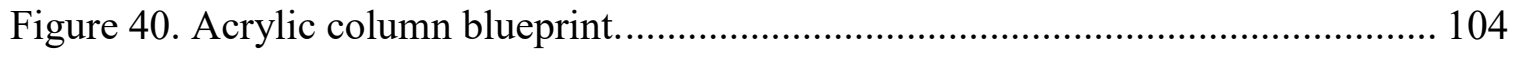

Figure 41. Sensors attached to acrylic column at prior the deposition of tailings......... 105

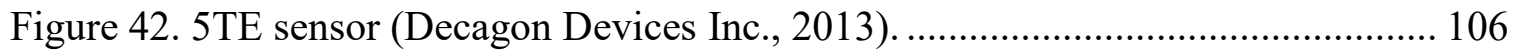

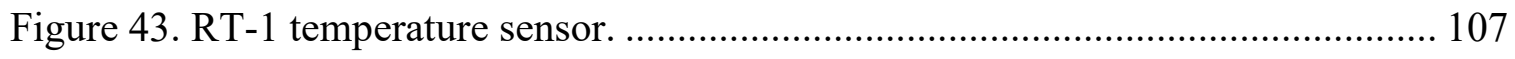

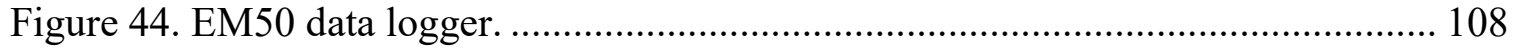

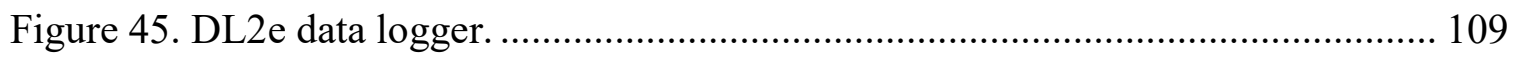

Figure 46. Test set-up for initial matric suction testing...................................... 110

Figure 47. Experimental set-up of column test \#1 prior deposition. ........................... 112

Figure 48. Experimental set-up of column test \#1 during deposition.......................... 113

Figure 49. Experimental set-up of column test \#1 post deposition.............................. 113

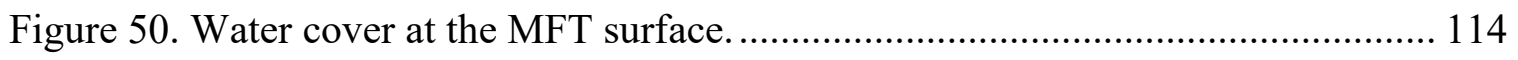

Figure 51. Experimental set-up of column test \#1 at day 51. Height of MFT column $=$

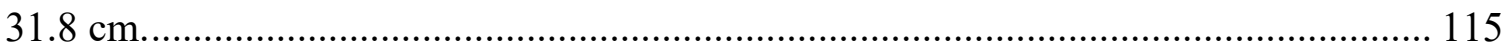

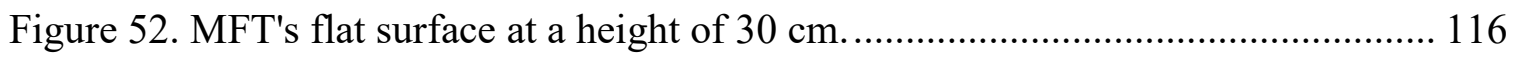

Figure 53. Experimental set-up of column test \#1 at the beginning of the freezing phase.

Figure 54. Experimental set-up of column test \#1 inside modified fridge. ................... 117 
Figure 55. Experimental set-up of column test \#2 at the beginning of the thawing phase.

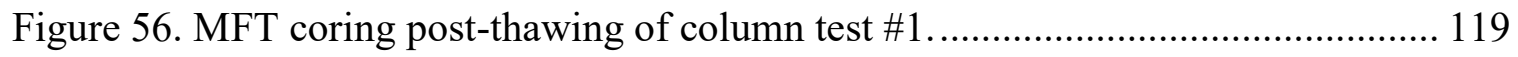

Figure 57. Experimental set-up of column test \#2 right after deposition. ..................... 121

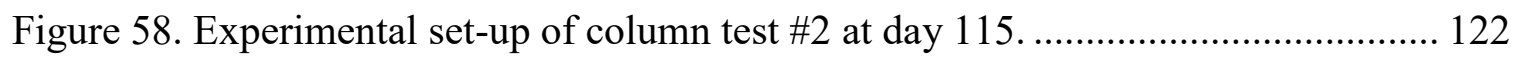

Figure 59. Experimental set-up of column test \#3 right after deposition of the tailings. 125

Figure 60. Experimental set-up of column test \#3 at the end of the self-weight

consolidation with ambient drying phase. ........................................................... 126

Figure 61. Experimental set-up of test column \#3 during the desiccation phase. .......... 127

Figure 62. Experimental set-up of column test \#3 during the freezing phase. ............... 129

Figure 63. Experimental set-up of column test \#3 during the thawing phase................. 130

Figure 64. Core Sampler used in this research. .................................................... 132

Figure 65. Equipment used to push consolidation ring into MFT sample..................... 135

Figure 66. Consolidation ring inside MFT sample............................................. 135

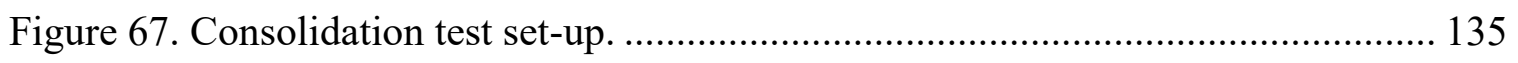

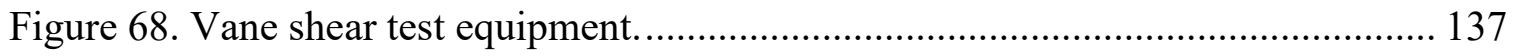

Figure 69. SWCC Fredlund device (GCTS Testing Systems) .................................. 139

Figure 70. Diagram for slump test (Pashias et al., 1996)........................................ 142

Figure 71. Temperature and Matric Suction results at room temperature. .................. 147

Figure 72. Temperature and Matric Suction results for freezing tailings. .................... 147

Figure 73. Temperature vs Matric Suction for Preliminary Test \#1 ........................... 149

Figure 74. Pore water pressure and temperature over time (top sensor). ..................... 150

Figure 75. Pore water pressure and temperature over time (bottom sensor). ................ 150 
Figure 76. Temperature vs Matric Suction for Preliminary test \#2 (top sensor). 152

Figure 77. Temperature vs Matric Suction for Preliminary test \#2 (bottom sensor)...... 152

Figure 78. Pore water pressure and temperature profile (top sensor - test \#3).............. 153

Figure 79. Pore pressure and temperature profile (bottom sensor - test \#3).................. 154

Figure 80. Temperature profile of column test \#1 ................................................ 155

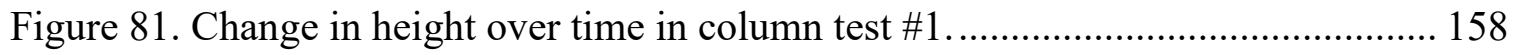

Figure 82. Cumulative water loss measurements for column test $\# 1$. ......................... 160

Figure 83. Average solids content development in column test \#1 ............................ 162

Figure 84. Solids content profile at termination of experiment (Column test \#1)......... 163

Figure 85. Surface dewatering process in column test \#1 ........................................ 164

Figure 86. Volumetric water content over time in column test \#1............................. 165

Figure 87. Gravimetric water content profile at termination (Column test \#1)............ 167

Figure 88. Unfrozen water content with respect to temperature ............................... 168

Figure 89. Volumetric ice content during the freezing period at a height of $15 \mathrm{~cm} . \ldots . .169$

Figure 90. Volumetric ice content during the freezing period at a height of $10 \mathrm{~cm} \ldots \ldots .170$

Figure 91. Matric suction from MPS-6 sensor and temperature development over time at

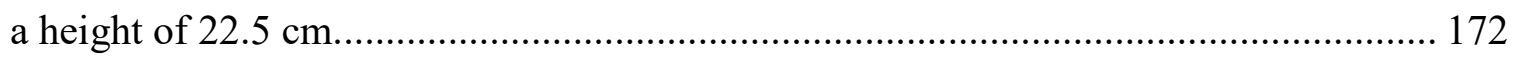

Figure 92. Matric suction measured by MPS-6 sensor and temperature development over

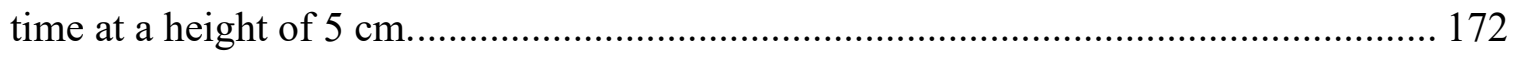

Figure 93. Matric suction (MPS-6) and temperature development over time for

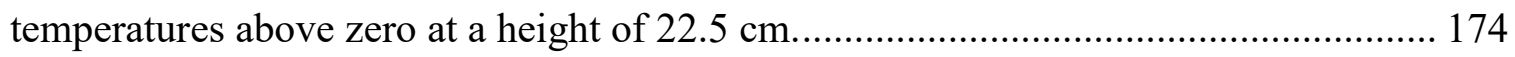

Figure 94. Total suction profile at termination of column test $\# 1$.............................. 176 
Figure 95. SWCC right below the freezing front at a height of $5 \mathrm{~cm}$ in column tests $\# 1$.

Figure 96. MFT height before and after the thawing phase.................................... 178

Figure 97. Vane shear test results for column test $\# 1$............................................ 179

Figure 98. Consolidation test results at different depths for column test \#1. ................ 180

Figure 99. Hydraulic conductivity results for column test $\# 1$................................. 183

Figure 100. Vertical ice lenses in MFT column (column test \#1).............................. 184

Figure 101. Temperature profile and surface sensor height location in column test \#2. 185

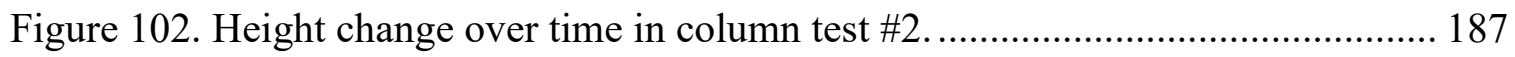

Figure 103. Cumulative water loss due to evaporation and drainage in column test \#2. 188

Figure 104. Surface shrinkage in column test $\# 2$..................................................... 189

Figure 105. Solids content development over time in column test \#2 ......................... 190

Figure 106. Solids content profile at the end of column test $\# 2$................................. 191

Figure 107. Volumetric water content profile at different heights and surface height

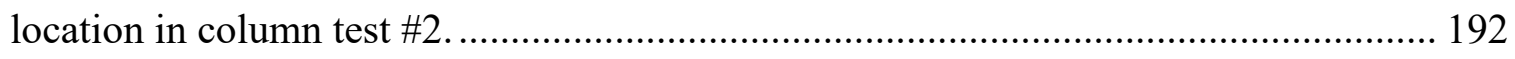

Figure 108. Water accumulation at the bottom of the column. ................................. 194

Figure 109. Gravimetric water content at termination of column test \#2 ..................... 195

Figure 110. Tensiometer data at a height of $22.5 \mathrm{~cm}$ from the bottom........................ 196

Figure 111. Tensiometer data for the $22.5 \mathrm{~cm}$ sensor during the first 36 days of the

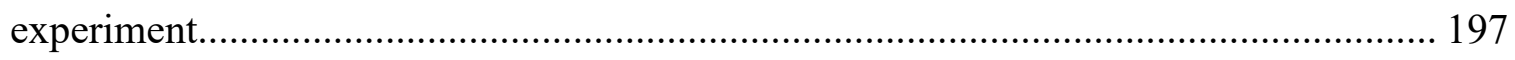

Figure 112. Tensiometer data at a height of $5 \mathrm{~cm}$ from the bottom............................. 198

Figure 113. Total suction profile at completion of Column Test 2. ........................... 199

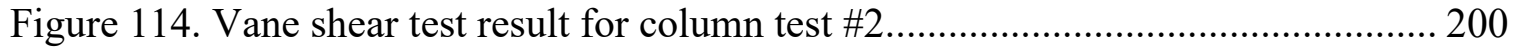




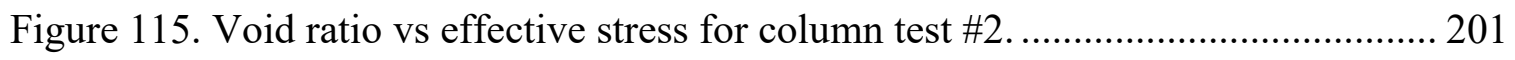

Figure 116. Permeability vs void ration for column test \#2. ................................... 203

Figure 117. Temperature profile and surface sensor location for column test \#3......... 204

Figure 118. Top portion of the MFT column at the end of the desiccation phase (column

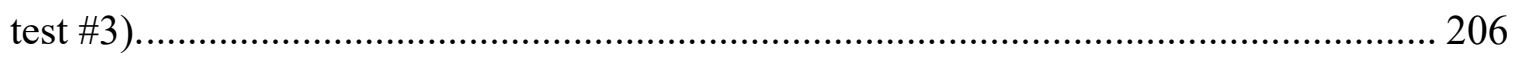

Figure 119. Height changes over time in column test \#3. ...................................... 208

Figure 120. Ice build-up on and around MFT column (column test \#3). ..................... 209

Figure 121. Water loss due to drainage and evaporation over time (column test \#3)... 210

Figure 122. Solids content development over time for column test \#3 . ....................... 212

Figure 123. Solids content profile at the end of column test \#3 ................................ 213

Figure 124. Surface changes at different phases in column test \#3........................... 215

Figure 125. Volumetric water content profile and surface height location during column

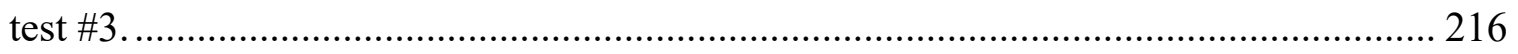

Figure 126. Gravimetric water content profile obtained at the end of the thawing phase

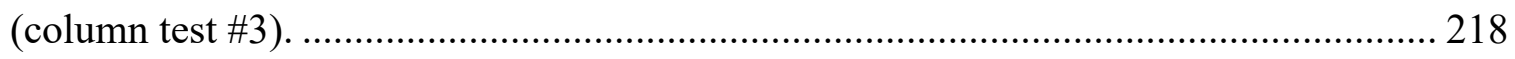

Figure 127. Unfrozen water content with respect to temperature .............................. 219

Figure 128. Ice content at the surface during the freezing phase ............................... 220

Figure 129. Ice content at a height of $22.5 \mathrm{~cm}$ during the freezing phase................... 221

Figure 130. Ice content at a height of $15 \mathrm{~cm}$ during the freezing phase..................... 221

Figure 131. Matric suction throughout the experiment obtained by the MPS- 6 sensor at a

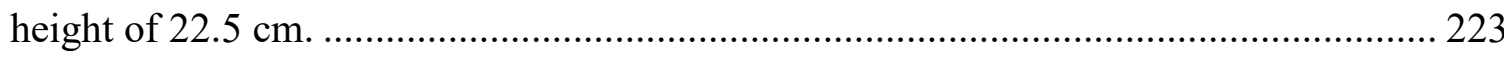

Figure 132. Pore water pressures throughout the experiment obtained by a tensiometer at

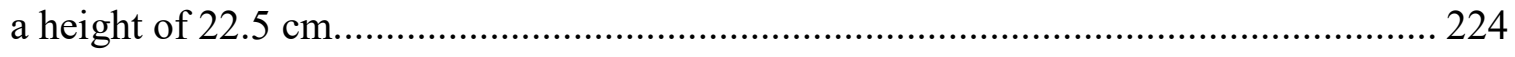


Figure 133. Comparison between data obtained from a MPS-6 sensor and a tensiometer at

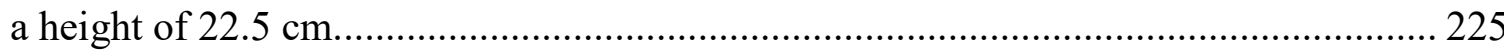

Figure 134. Matric suction obtained by a MPS-6 sensor at a height of $15 \mathrm{~cm} \ldots \ldots \ldots \ldots . . . .227$ Figure 135. Matric suction throughout the experiment obtained by a MPS-6 sensor at a height of $5 \mathrm{~cm}$. 228

Figure 136. Pore water pressures throughout the experiment obtained by a tensiometer at a height of $5 \mathrm{~cm}$ 229

Figure 137. Comparison between data obtained by a MPS- 6 sensor and a tensiometer at a height of $5 \mathrm{~cm}$. 230

Figure 138. Total suction profile obtained at completion of column test \#3 ................. 231

Figure 139. SWCC at a height of $22.5 \mathrm{~cm}$ during the desiccation phase. ..................... 232 Figure 140. SWCC right below the freezing front at a height of $15 \mathrm{~cm}$ in column tests \#3.

Figure 141. SWCC right below the freezing front at a height of $5 \mathrm{~cm}$ in column tests \#3.

Figure 142. MFT column before and after the thawing phase .................................. 235

Figure 143. Vane shear test results for column test \#3....................................... 236

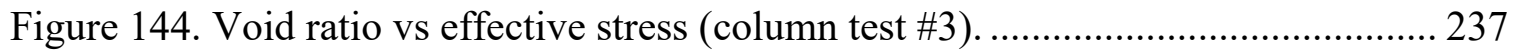

Figure 145. Hydraulic conductivity vs void ratio (column test \#3)............................ 239

Figure 146. Ice formations perpendicular to the direction of freezing in column test \#3.

Figure 147. SWCC for freshly made polymer-amended MFT................................ 242 
Figure 148. Comparison of height change over time between column test \#2 and column test \#3.

Figure 149. Height change over time comparison between self-weight consolidation with ambient drying phase of column test \#1, column test \#2, and self-weight consolidation with ambient drying \& desiccation phase of column test \#3. 246 Figure 150. Height change over time comparison between thawing phases of column test \#1 and column test \#3. 247

Figure 151. Water loss comparison between column test \#3 and column test \#2. Figure 152. Water loss during the self-weight consolidation with ambient drying phase comparison between column test \#1, \#2, and \#3. 251

Figure 153. Evaporation contribution to total water loss during the self-weight consolidation with ambient drying phase between column test \#1, \#2 (first 51 days), and \#3 252

Figure 154. Under-drainage contribution to total water loss during the self-weight consolidation with ambient drying phase comparison between column test \#1, \#2, and \#3.

Figure 155. Water loss during the thawing phase comparison between column test \#1 and \#3. 254

Figure 156. Evaporation contribution to total water loss during the thawing phase comparison between column test $\# 1$ and $\# 3$. 255 Figure 157. Under-drainage contribution to total water loss during the thawing phase comparison between column test \#1 and \#3. 255 
Figure 158. Solids content development comparison between column test \#2 and column test \#3. 256

Figure 159. Solids content development comparison between self-weight consolidation with ambient drying phases of column test \#1 \& \#2, and self-weight consolidation with ambient drying and desiccation phases of column test \#3. 257

Figure 160. Solids content development during the thawing phase comparison between column test \#1 and column test \#3. 258

Figure 161. Solids content profile at completion of test comparison between column test $\# 1, \# 2$, and \#3. 259

Figure 162. Measured and calculated soil freezing characteristic curve (SFCC) at a height of $22.5 \mathrm{~cm}$ for Column Test 3. 260

Figure 163. Trend line (red) show the increasing negative pore water pressures in the SFCC at a height of $22.5 \mathrm{~cm}$ in Column Test 3. 261

Figure 164. Summary of theoretical SFCCs for Column Test 1 and 3 263

Figure 165. Comparison between soil water characteristic curves (SWCCs) below the freezing front and soil freezing characteristic curves (SFCCs) for Column Test 1 and 3.

Figure 166. Total suction profile at completion of test for column test \#1, \#2, and \#3.. 270 Figure 167. Undrained shear strength profile at completion of test for column test \#1, \#2, and $\# 3$. 272

Figure 168. Void ratio vs. effective stress data from all column tests. 274

Figure 169. Hydraulic conductivity vs. void ratio data from all column tests............... 275 Figure 170. Ice lens formation in column test \#1 (front side). 277 
Figure 171. Ice lens formation in column test \#1 (right side)................................... 278

Figure 172. Ice lens formation in column test \#1 (left side).................................... 279

Figure 173. Ice lens formations in column test \#3 (front side)................................ 281

Figure 174. Ice lens formation in column test \#3 (lower front side). .......................... 282

Figure 175. Ice lens formation in column test \#3 (left side)..................................... 283

Figure 176. Eroded surface condition of column test \#1 at the end of the thawing phase. 284

Figure 177. Eroded surface condition of column test \#3 at the end of the thawing phase 285

Figure 178. Void ratio vs Effective stress (depth of $3.25 \mathrm{~cm}$ ) - Column Test \#1 ......... 295

Figure 179. Permeability results (depth of $3.25 \mathrm{~cm}$ ) - Column Test \#1 ........................ 296

Figure 180. Casagrande analysis for $1 \mathrm{~kg}-$ Column Test \#1................................... 296

Figure 181. Casagrande analysis for $2 \mathrm{~kg}$ - Column Test \#1.................................... 297

Figure 182. Casagrande analysis for $4 \mathrm{~kg}$ - Column Test \#1................................... 297

Figure 183. Casagrande analysis for $8 \mathrm{~kg}-$ Column Test \#1................................... 298

Figure 184. Casagrande analysis for $16 \mathrm{~kg}$ - Column Test \#1.................................. 298

Figure 185. Casagrande analysis for $32 \mathrm{~kg}$ - Column Test \#1.................................. 299

Figure 186. Casagrande analysis for $64 \mathrm{~kg}$ - Column Test \#1................................... 299

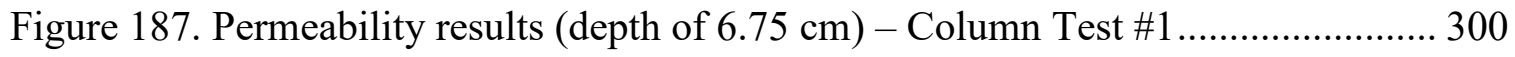

Figure 188. Void ratio vs Effective stress (depth of $6.75 \mathrm{~cm}$ ) - Column Test \#1 ......... 301

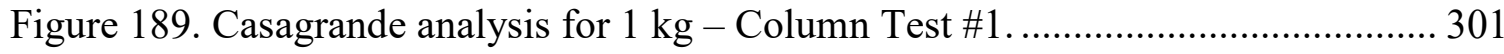

Figure 190. Casagrande analysis for $2 \mathrm{~kg}-$ Column Test \#1................................... 302

Figure 191. Casagrande analysis for $4 \mathrm{~kg}$ - Column Test \#1.................................... 302 
Figure 192. Casagrande analysis for $8 \mathrm{~kg}$ - Column Test \#1 .................................... 303

Figure 193. Casagrande analysis for $16 \mathrm{~kg}$ - Column Test \#1................................... 303

Figure 194. Casagrande analysis for $32 \mathrm{~kg}$ - Column Test \#1................................... 304

Figure 195. Casagrande analysis for $64 \mathrm{~kg}$ - Column Test \#1.................................... 304

Figure 196. Void ratio vs Effective stress (depth of $10.25 \mathrm{~cm}$ ) - Column Test \#1 ....... 305

Figure 197. Permeability results (depth of $10.25 \mathrm{~cm}$ ) - Column Test \#1..................... 306

Figure 198. Casagrande analysis for $1 \mathrm{~kg}-$ Column Test \#1.................................... 306

Figure 199. Casagrande analysis for $2 \mathrm{~kg}$ - Column Test \#1 .................................... 307

Figure 200. Casagrande analysis for $4 \mathrm{~kg}$ - Column Test \#1.................................... 307

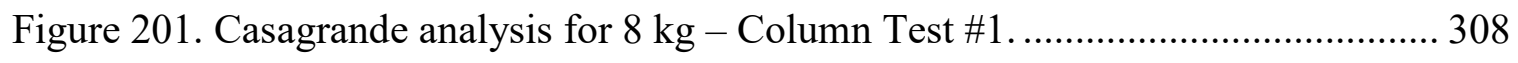

Figure 202. Casagrande analysis for $16 \mathrm{~kg}$ - Column Test \#1.................................. 308

Figure 203. Casagrande analysis for $32 \mathrm{~kg}$ - Column Test \#1.................................. 309

Figure 204. Casagrande analysis for $64 \mathrm{~kg}$ - Column Test \#1.................................. 309

Figure 205. Permeability results (depth of $13.75 \mathrm{~cm}$ ) - Column Test \#1..................... 310

Figure 206. Void ratio vs Effective stress (depth of $13.75 \mathrm{~cm}$ ) - Column Test \#1 ....... 311

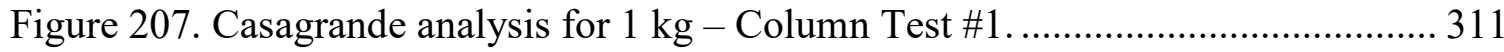

Figure 208. Casagrande analysis for $2 \mathrm{~kg}$ - Column Test \#1 .................................. 312

Figure 209. Casagrande analysis for $4 \mathrm{~kg}$ - Column Test \#1................................... 312

Figure 210. Casagrande analysis for $8 \mathrm{~kg}$ - Column Test \#1 .................................. 313

Figure 211. Casagrande analysis for $16 \mathrm{~kg}$ - Column Test \#1................................. 313

Figure 212. Casagrande analysis for $32 \mathrm{~kg}$ - Column Test \#1.................................. 314

Figure 213. Casagrande analysis for $64 \mathrm{~kg}$ - Column Test \#1................................. 314

Figure 214. Void ratio vs Effective stress (depth of $4.25 \mathrm{~cm}$ ) - Column Test \#2 „........ 316 
Figure 215. Permeability results (depth of $4.25 \mathrm{~cm}$ ) - Column Test \#2 2....................... 317

Figure 216. Casagrande analysis for $1 \mathrm{~kg}-$ Column Test \#2 ................................... 317

Figure 217. Casagrande analysis for $2 \mathrm{~kg}$ - Column Test \#2 .................................. 318

Figure 218. Casagrande analysis for $4 \mathrm{~kg}$ - Column Test \#2 .................................... 318

Figure 219. Casagrande analysis for $8 \mathrm{~kg}$ - Column Test \#2 ................................... 319

Figure 220. Casagrande analysis for $16 \mathrm{~kg}$ - Column Test \#2.................................. 319

Figure 221. Casagrande analysis for $32 \mathrm{~kg}$ - Column Test \#2.................................. 320

Figure 222. Casagrande analysis for $64 \mathrm{~kg}$ - Column Test \#2 .................................. 320

Figure 223. Void ratio vs Effective stress (depth of $10.75 \mathrm{~cm}$ ) - Column Test \#2 ....... 321

Figure 224. Permeability results (depth of $10.75 \mathrm{~cm}$ ) - Column Test \#2 ...................... 322

Figure 225. Casagrande analysis for $1 \mathrm{~kg}$ - Column Test \#2 ..................................... 322

Figure 226. Casagrande analysis for $2 \mathrm{~kg}$ - Column Test \#2 .................................. 323

Figure 227. Casagrande analysis for $4 \mathrm{~kg}$ - Column Test \#2 ................................... 323

Figure 228. Casagrande analysis for $8 \mathrm{~kg}$ - Column Test \#2 .................................... 324

Figure 229. Casagrande analysis for $16 \mathrm{~kg}$ - Column Test \#2.................................. 324

Figure 230. Casagrande analysis for $32 \mathrm{~kg}$ - Column Test \#2 ................................. 325

Figure 231. Casagrande analysis for $64 \mathrm{~kg}$ - Column Test \#2................................. 325

Figure 232. Void ratio vs Effective stress (depth of $6.25 \mathrm{~cm}$ ) - Column Test \#3 ......... 327

Figure 233. Permeability results (depth of $6.25 \mathrm{~cm}$ ) - Column Test \#3 ....................... 328

Figure 234. Casagrande analysis for $1 \mathrm{~kg}-$ Column Test \#3 ................................... 328

Figure 235. Casagrande analysis for $2 \mathrm{~kg}$ - Column Test \#3 .................................... 329

Figure 236. Casagrande analysis for $4 \mathrm{~kg}$ - Column Test \#3................................... 329

Figure 237. Casagrande analysis for $8 \mathrm{~kg}$ - Column Test \#3................................... 330 
Figure 238. Casagrande analysis for $16 \mathrm{~kg}$ - Column Test \#3................................. 330

Figure 239. Casagrande analysis for $32 \mathrm{~kg}$ - Column Test \#3.................................. 331

Figure 240. Casagrande analysis for $64 \mathrm{~kg}$ - Column Test \#3.................................. 331

Figure 241. Void ratio vs Effective stress (depth of $12.75 \mathrm{~cm}$ ) - Column Test \#3 ........ 332

Figure 242. Permeability results (depth of $12.75 \mathrm{~cm}$ ) - Column Test \#3 ...................... 333

Figure 243. Casagrande analysis for $1 \mathrm{~kg}-$ Column Test \#3.................................... 333

Figure 244. Casagrande analysis for $2 \mathrm{~kg}$ - Column Test \#3.................................... 334

Figure 245. Casagrande analysis for $4 \mathrm{~kg}$ - Column Test \#3 .................................... 334

Figure 246. Casagrande analysis for $8 \mathrm{~kg}$ - Column Test \#3................................... 335

Figure 247. Casagrande analysis for $16 \mathrm{~kg}$ - Column Test \#3................................. 335

Figure 248. Casagrande analysis for $32 \mathrm{~kg}$ - Column Test \#3.................................. 336

Figure 249. Casagrande analysis for $64 \mathrm{~kg}$ - Column Test \#3.................................. 336

Figure 250. Summary of previous freeze-thaw experiments gathered by Henry (2007).338

Figure 251. Trend line (red) show the increasing negative pore water pressures in the

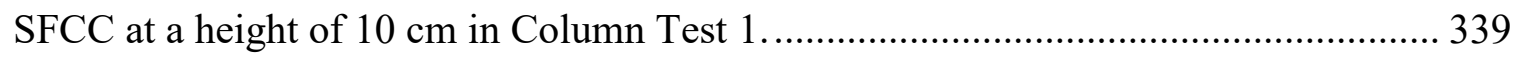

Figure 252. Trend line (red) show the increasing negative pore water pressures in the

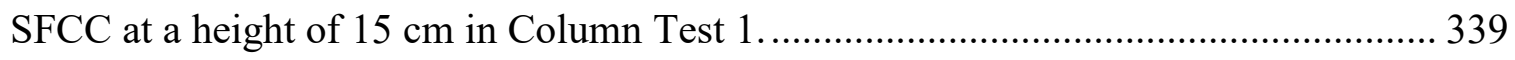

Figure 253. Measured and calculated soil freezing characteristic curve (SFCC) at a height

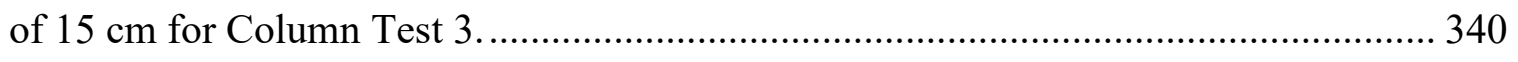

Figure 254. Trend line (red) show the increasing negative pore water pressures in the

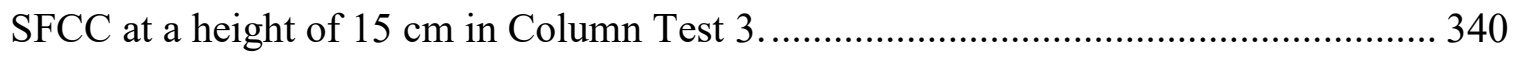




\section{List of Appendices}

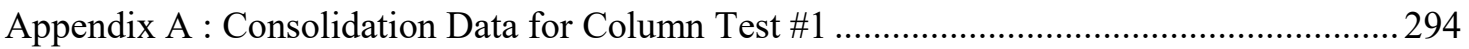

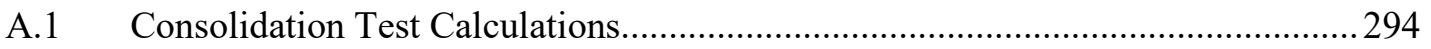

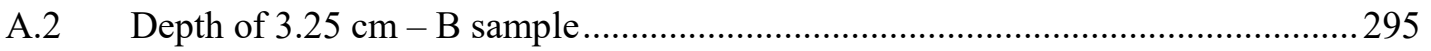

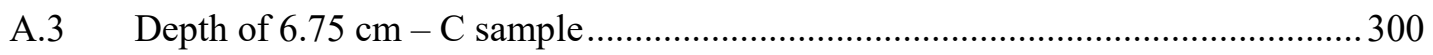

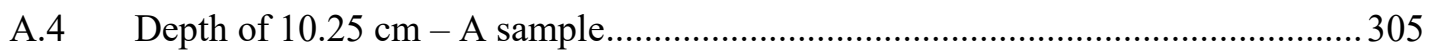

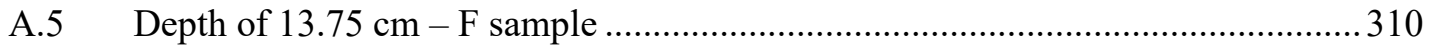

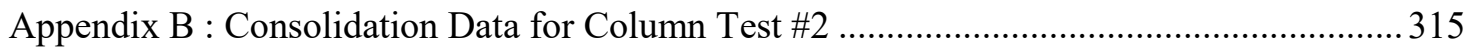

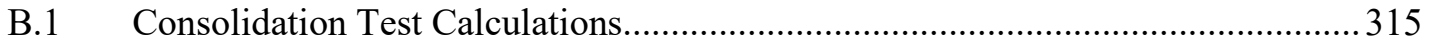

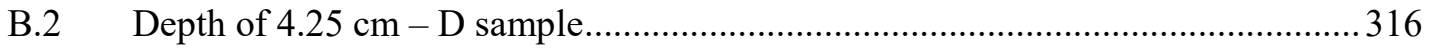

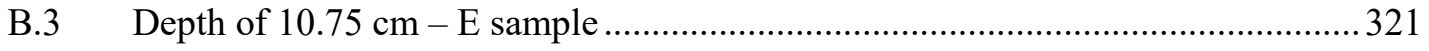

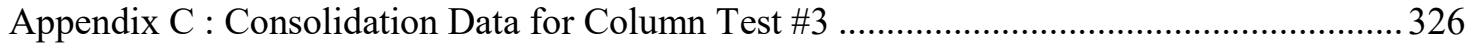

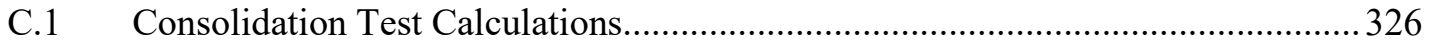

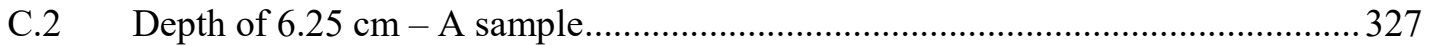

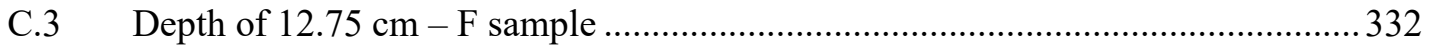

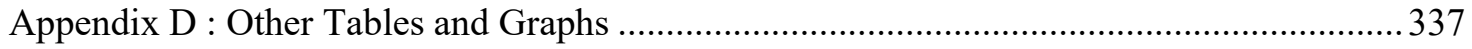

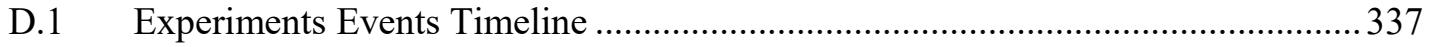

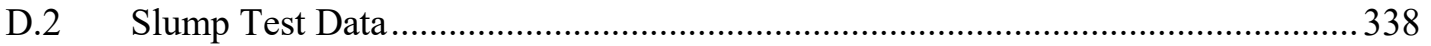

D.3 Summary of Other Freeze-Thaw Tests by Henry (2007) ..................................... 338

D.4 Soil Freezing Characteristic Curve (SFCC) Data......................................................339 


\section{Chapter: Introduction}

\subsection{Problem Statement}

The oil industry in the province of Alberta is a major economic driver for Canada. It has been reported by Statistics Canada that the oil sands industry constitutes approximately 2.2\% of Canada's GDP in 2015 (Statistics Canada, 2015). As of 2014, there were six major producing mining projects. These mining operations are in charge of the extraction and processing of oil sand deposits to obtain bitumen, a precursor of synthetic crude oil. During the separation process of bitumen from the sand matrix, large amounts of hot water are used producing a waste slurry, which is later stored in large tailings ponds.

The large scale of the mining operations leads to large amounts of mining waste being produced. For example, according to Morgestern et al. (1988), a mining complex producing $15900 \mathrm{~m}^{3} /$ day of synthetic crude oil will require processing 100000 bank $\mathrm{m}^{3}$ of ore which creates $238500 \mathrm{~m}^{3} /$ day of tailings. These large volume water content tailings are deposited in large ponds for their storage at $8 \%$ solids content. After some time, the fines within the tailings settle to $30-35 \%$ solids content and they are referred to mature fine tailings or MFT. As of 2014, approximately $767 \mathrm{~km}^{2}$ of land has been disturbed by oil sand activities and $176 \mathrm{~km}^{2}$ are occupied by oil sands tailing ponds alone.

Mature fine tailings are mainly a mixture of water, sand, clay, silt, and residual bitumen. The use of caustic soda promotes the swelling of clay particles found in the 
water film that surrounds the sand particles enhancing inter-particle repulsion and leading to ore disintegration (Chalaturnyk et al., 2002). Particle repulsion promotes dispersion of particles leading to poor consolidation and sedimentation. MFT also exhibits thixotropic behaviour that negatively affects water release (Scott et al. 2013).

Due to the high water content of the tailings, disposal and deposition of MFT is currently one of the biggest challenges the oil sands mining industry is facing. Therefore, accelerating the dewatering of MFT is desirable, to increase the strength of the tailings and facilitate reclamation of tailings ponds for ecological restoration or other land use. Dewatering processes such as centrifuge dewatering, in-line polymer injection, and composite tailings are currently used or trialed at a large scale by the oil industry. Also, natural dewatering processes such as evaporation and natural freezethaw cycles are a cost-effective alternative to manage and reduce the water content in tailings. This work studies the combined effects of evaporation and freeze-thaw cycles on dewatering of polymer amended MFT.

\subsection{Objectives}

The main objectives of this research are the following:

1) To determine a realistic and adequate approach to freeze-thaw MFT in a laboratory setting by:

a. Reviewing the literature and analyzing previous freeze-thaw test methodologies. 
b. Implementing a freeze-thaw experimental setup and assessing its pros and cons.

c. Recommending improvements to the freeze-thaw setup to optimize future testing.

2) To gain better understanding of dewatering through freeze-thaw cycles of polymer amended MFT by:

a. Reporting the difference in dewatering behaviour between tailings that undergo stress conditions.

b. Investigating the development of pore water pressures and solids content under self-weight consolidation with ambient drying, desiccation, and freeze-thaw.

3) To study the consolidation properties of these tailings post thawing, including:

a. The effect of water content and matric suction with depth on consolidation.

b. The correlation of shear strength with consolidation properties. 


\subsection{Plan of Work}

The following scope of work was followed in order to accomplish the main objectives:

1) Prepare polymer amended MFT in the laboratory similar to the field MFT.

2) Perform 3 column tests under different consolidation conditions (1. Self-weight consolidation with ambient drying, 2. self-weight consolidation with ambient drying and freeze-thawing, and 3. self-weight consolidation with ambient drying, desiccation and freeze-thaw) to study and identify the dewatering characteristics of MFT after one freeze-thaw cycle.

3) Extract core samples after post-thawing to study the consolidation properties of MFT with respect to solids content and matric potential. Compare the results of the 3 column tests.

\subsection{Novelty}

This is the first academic study on the influence of freeze-thaw on polymer amended MFT, and the first study to examine the complementary effects of evaporation and freeze-thaw in polymer amended MFT.

\subsection{Thesis Outline}

This thesis contains the following outline:

* Chapter 2 - Literature Review: An overview of the oil sands mining industry including oil extraction processes, dewatering technologies, and geotechnical 
properties of MFT. Also, it contains a compilation of previous studies involving freeze-thaw dewatering of fine tailings.

* Chapter 3 - Methodology and Materials: A detailed description of the experimental setup used in the 3 column tests. Also, the history and characteristics of the tailings used in this work.

* Chapter 4 -Results: A comprehensive record and discussion of the results obtained from preliminary freezing tests, 3 column tests, and the post-thawing consolidation tests.

Chapter 5 -Conclusions and Recommendations: A summary of the experiment and major findings, along with a list of recommendations for future research based on the work presented in this thesis. 


\subsection{References}

BGC Engineering Inc. (2010). Oil Sands Tailings Technology Review. Oil Sands Research and Information Network (Vol. OSRIN Repo, p. OSRIN Report No. TR-1. 136 pp.). Edmonton, Alberta.

Chalaturnyk, R.J., Scott, D., and Ozum, B. 2002 Management of oil sands tailings. Petroleum Science and Technology, 20(9\&10):1025-1046.

Morgenstern, N.R., Fair, A.E., and McRoberts, E.C. 1988. "Geotechnical engineering beyond soil mechanics - a case study". Canadian Geotechnical Journal, 25: 637661.

Scott, J.D., Jeeravipoolvarn, S., Kabwe, L., Wilson G.W., (2013). Properties Which Affect the Consolidation Behaviour of Mature Fine Tailings. In Proceedings of the 17th International conference on Tailings and Mine Waste, November 3-6, 2013, Banff, Alberta

Statistics Canada (2015). "Gross domestic product (GDP) at basic prices, by North American Industry Classification System (NAICS)”. Available: http://www5.statcan.gc.ca/cansim/a26?lang=eng\&retrLang=eng\&id=3790031\& $\&$ pattern $=\&$ stByVal $=1 \& p 1=1 \& p 2=31 \&$ tabMode $=$ dataTable $\&$ csid 


\section{Chapter: Literature Review}

This chapter comprises a brief introduction and review of the oil sands mining industry, the technologies used to dewater oil sands tailings, the geotechnical properties of said tailings, a summary of the consolidation theory and the mechanics of unsaturated soils governing tailings, the effect of freeze-thaw cycles on soils, and a review of previous work done on freeze-thaw dewatering of MFT.

\subsection{Oil Sands Mining Overview}

\subsubsection{Introduction}

The oil sand industry in Alberta, Canada is an important economic engine that drives the province and the country as one of the leading oil producers in the world. It has been reported that Alberta has around 170 billion barrels of economically recovered oil reserves, which ranks them third in the world right after Venezuela and Saudi Arabia (Alberta Energy, 2014). Between 2012 and 2013, Alberta produced 1.9 million of barrels a day, which were equivalent to $\$ 3.56$ million in royalties.

There are three major oil sands deposits in Alberta: the Peace River deposit, the Cold Lake deposit, and the Athabasca deposit, as seen in Fig. 1. These three deposits compose a total area of $142,000 \mathrm{Km} 2$. However, only 4,800 Km2 are clear for oil sands mining (Alberta Energy, 2014). Currently, there are $618 \mathrm{Km} 2$ of land that are part of active operations, which have produced approximately 830 million cubic meters of mature fine tailings as of 2010 (Grant et al., 2013). Large ponds are used to store the 
mature fine tailings. The ponds function as large basins to separate solids from the liquid element in the tailings, as well as containers of free-released water, which is recycled in the bitumen extraction process.

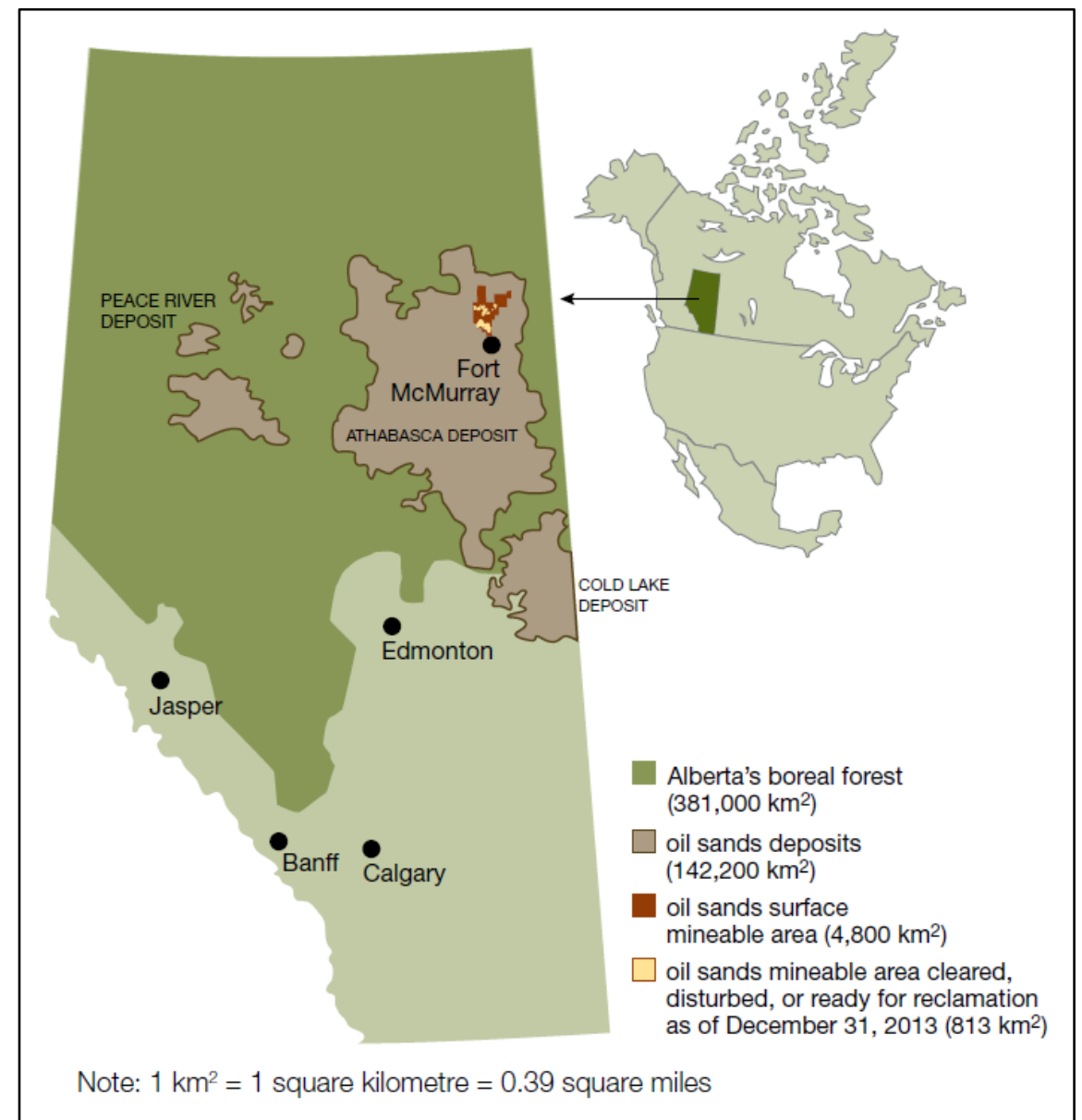

Figure 1. Oil Sands Deposit in the Province of Alberta (Alberta Energy, 2014)

The following sections describe the oil sands' composition and formation, the extraction, processing and upgrading of bitumen, disposal and management of tailings, and dewatering challenges. 


\subsubsection{Oil Sands Composition and Formation}

Oil sands are comprised of bitumen (8-14\%), water (3-5\%), and solids (83-88\%) in the form of coarse silica sand and fine clays (Fig. 2). The solids are present in an unconsolidated form and surrounded by bitumen, as seen in the figure below (Gosselin, et al., 2010).

The clay components present in the oil sands are kaolinite (40-70\%), illite (28-45\%), and montmorillonite (1-15\%) (Chalaturnyk, et al., 2002). These types of particles play an important role in the bitumen separation process due to their physical and chemical characteristics. For example, montmorillonite has a high affinity to water and it tends to swell when it is exposed to water while illite and kaolinite have really low to none affinity to water (Rogers, 1953).

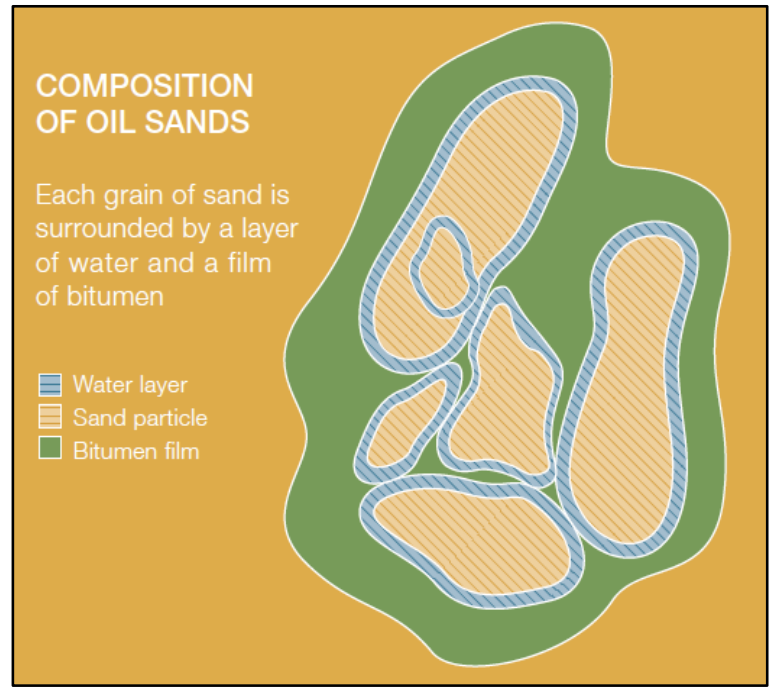

Figure 2. Oil Sands Composition (Government of Alberta, 2009) 
Bitumen is a heavy complex hydrocarbon, which is formed from the biodegradation of algae and marine life. It is believed that the Western Canadian Sedimentary Basin, in which the oil sands deposits are found, was formed from a large water body that covered most of Western Canada (Oil Sands Magazine, 2015). As the Rocky Mountains were forming, they pushed the sedimentary layer containing the bitumen east towards the Alberta/Saskatchewan area, as seen in Fig. 3. Biodegradation of bitumen continued until the heavy and complex hydrocarbon found in the province of Alberta was formed (Oil Sands Magazine, 2015). Most oil sands deposit found at shallow depths with economic value are found in the Wabiskaw-McMurray Deposit near the Athabasca River valley (Gosselin, et al., 2010).

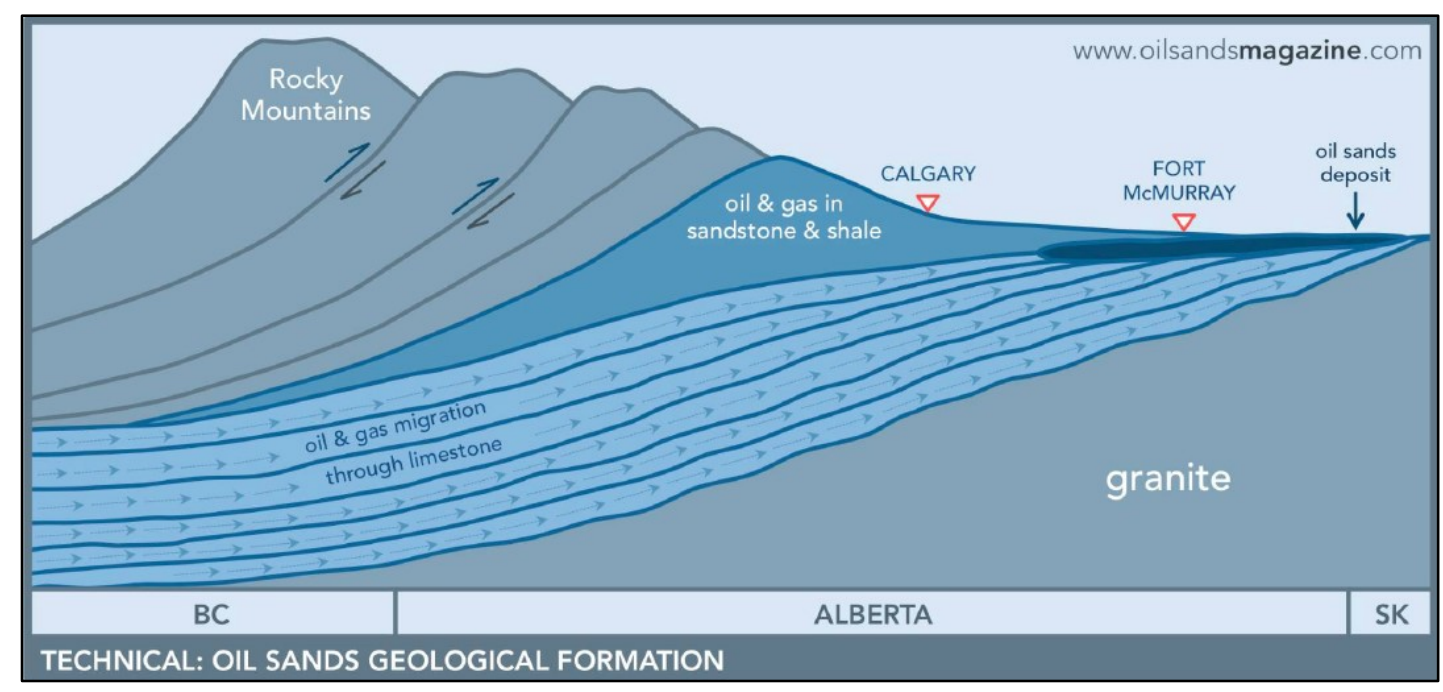

Figure 3. Oil Migration Path in the Western Canada Sedimentary Basin (Oil Sands Magazine, 2015). 
Due to its sedimentary formation, the oil sands deposits found in Alberta are unique when compared to other oil sands deposits. They are considered to be 'waterwet' oil sands due to the liquid water found coating the bitumen and solids. This liquid water is also referred to as connate water and it helps determine the pressuretemperature history of the rock during its formation. Furthermore, the main advantage of connate water found in bitumen is that it facilitates the separation of bitumen from the solids fraction by steam or water based separation processes. In contrast, 'oil-wet' oil sands, found in places like Venezuela and Utah, do not have the connate water. The absence of liquid water in its composition complicates the separation process since large amounts of solvents and chemicals are needed to obtain bitumen (Oil Sands Magazine, 2015).

\subsubsection{Oil Sands Extraction and Bitumen Separation}

There are two main extraction processes for the mining of oil sands. These

processes are dependent on the depth of the oil sands deposit (Fig. 4). The first extraction process is 'surface' mining or 'open-pit' mining. Surface mining is only viable for $20 \%$ of the total recoverable reserves in the Athabasca region because it recovers bitumen at a maximum depth of 75 meters. The second extraction process is 'in-situ' mining or 'in-place' mining. This extraction process is viable for the other $80 \%$ of the recoverable reserves and it operates to depths of at least 200 meters. Both processes can be seen and compared in Figure 4 (Oil Sands Magazine, 2015). 


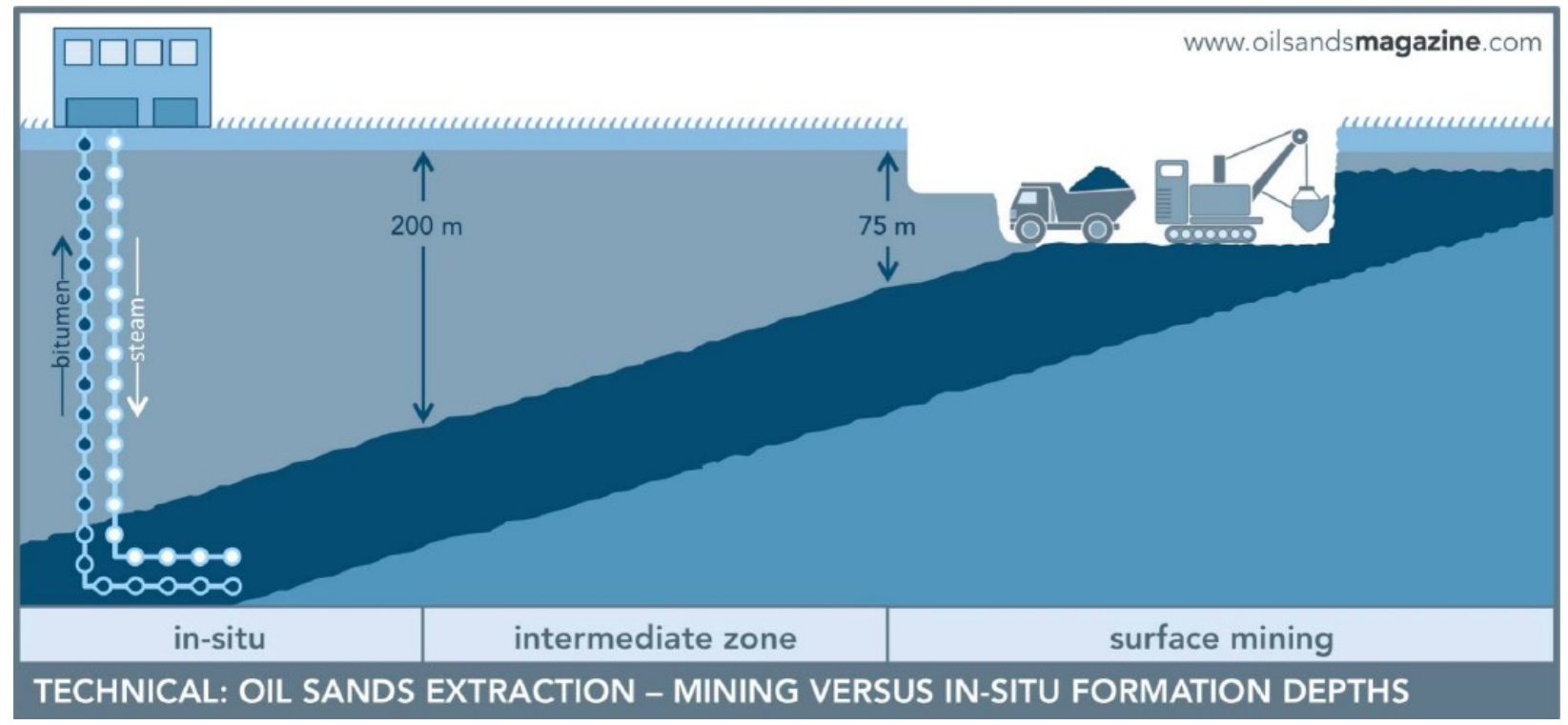

Figure 4. Surface Mining vs In-situ Mining (Oil Sands Magazine, 2015)

Both extraction processes are explained in detailed in the sections below.

\subsubsection{Surface Mining (Open-pit)}

As mentioned previously, surface mining is put into action on deposits which depths do not exceed 75 meters. Figure 5 shows the reserves available for surface mining in the Athabasca deposit. The extraction process is described by Gosselin, et al. (2010) as follows: the extraction process uses large trucks and power shovels to remove the musket and overburden soil above the oil sands deposit. The musket is stored so it can be eventually used in the reclamation process while the overburden soil is used to build access roads and dykes used to store oil sands tailings. 


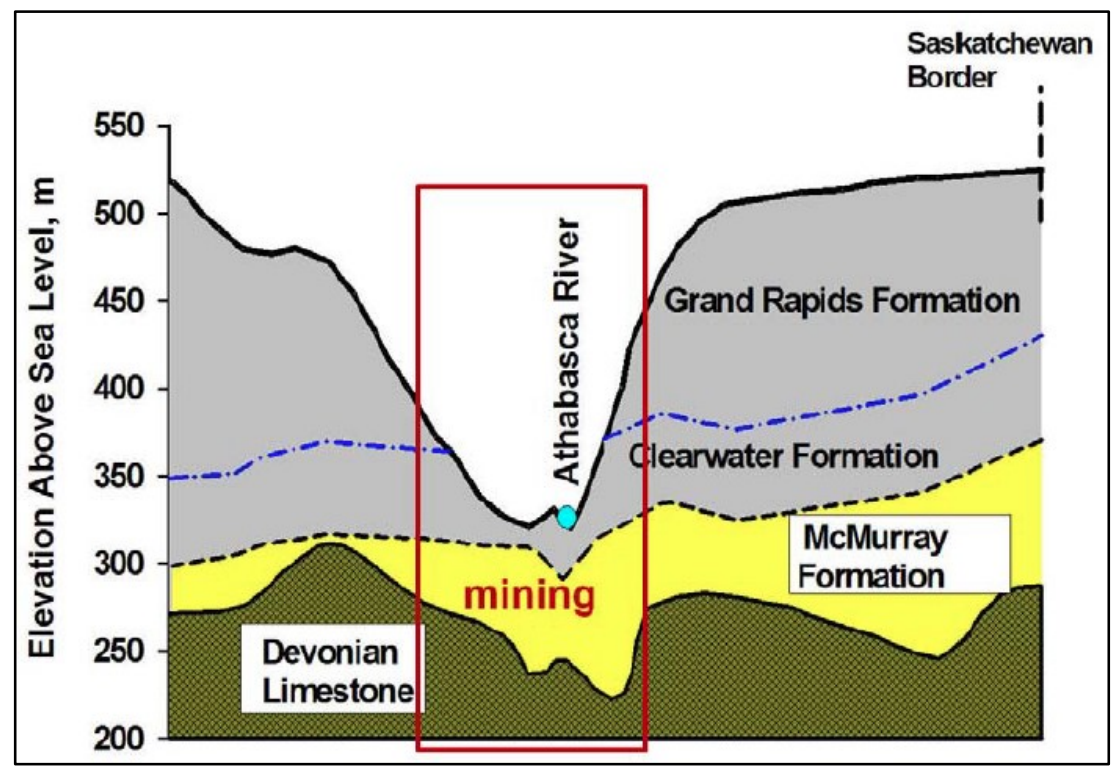

Figure 5. Oil Sands Reserves Available for Surface Mining (Gosselin, et al., 2010)

Once the oil sands are exposed, they are transported to crushers to be reduced to small ore fractions and then taken to a slurry preparation plant. Approximately, two tons of oil sands ore must be extracted to obtain one barrel of crude oil (Alberta Energy, 2014). Then, hot water is added to the oil sands ore to keep its temperature between 45 and $60{ }^{\circ} \mathrm{C}$. Also, chemical aids (e.g. Sodium hydroxide) are added to facilitate the separation of bitumen from the solids fraction. The next step is to transport the slurry to large particle separation cells (PSC) through a hydro-transport pipeline. High speeds in the hydro-transport pipeline produce hydrodynamic forces that separate the bitumen from the sand particles and promote the attachment of bitumen droplets to air bubbles. This process facilitates the separation of bitumen by gravity. Once the slurry arrives at the PSC, the aerated bitumen floats upwards through the slurry and it is collected as primary bitumen froth. Meanwhile, coarse particles settle down in the PSC, as well as some un-aerated bitumen droplets that did not attached to any air bubbles in the hydro- 
transport pipeline. The denser part of the slurry comprised of coarse particles is removed from the cells and considered as tailings. The low-density slurry found in the middle of the PSC is transported for further processing to flotation machines. More air is added at this point to enhance bitumen-air attachment. Again, bitumen is collected from the top of the flotation machines as secondary bitumen froth. Depending on the cleanliness of the secondary bitumen froth, it can be sent back to the PSC for further cleaning or it can be added to the first bitumen froth and sent for froth treatment. At the froth cleaning plant, the bitumen froth is de-aired and cleaning solvent is added. The solvent's main purpose is to reduce the viscosity of the bitumen froth to facilitate further release of air and fine particles by gravity. Lastly, the solvent is recovered for recycling. At this point the bitumen recovered contains $98 \%$ wt bitumen, 1-2\% wt water, and $0.5 \% \mathrm{wt}$ solids and it is ready for upgrading. Figure 6 shows the bitumen extraction process by open-pit mining.

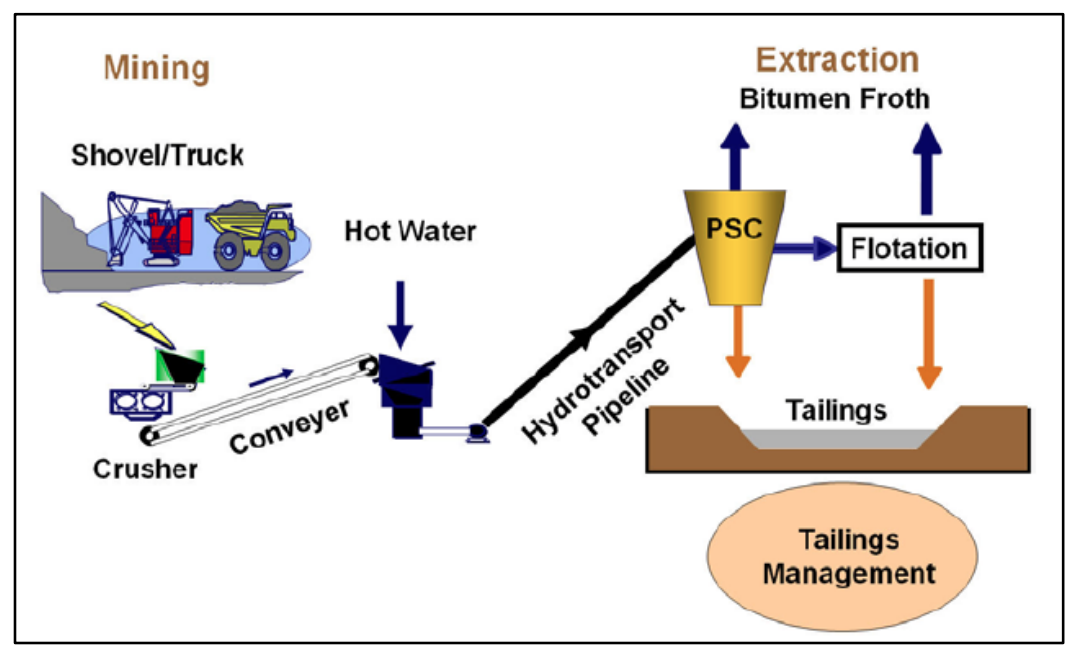

Figure 6. Open-pit mining process (Gosselin, et al., 2010). 


\subsubsection{In-situ Mining}

In-situ mining is used to recover bitumen that is too deep (200 meters or more) to be surface mined and too viscous to flow on its own. Oil sands bitumen has a viscosity of $5 \times 10^{5} \mathrm{~m} \cdot \mathrm{Pa} \cdot \mathrm{s}$ and it is too viscous to move on its own. In-situ mining uses thermal energy to decrease the viscosity of bitumen (i.e. bitumen viscosity decreases by 100-fold at $50^{\circ} \mathrm{C}$ ) to facilitate its extraction (Gosselin, et al., 2010).

\subsubsection{Oil Sands Upgrading}

The term upgrading refers to the process that bitumen undergoes to be turned into marketable commodities, such as gasoline, diesel, and aviation fuel (Alberta Energy, 2014). However, before the highly viscous bitumen becomes a final product, it needs to be upgraded to synthetic crude oil (SCO) before it is sent to refineries (Gosselin, et al., 2010). The upgrading of oil sands bitumen involves the use of temperature, pressure, and catalysts to break apart or 'crack' complex molecules into simpler ones. In 2005 , close to $50 \%$ of Alberta's oil production was upgraded into synthetic crude oil. The remainder crude bitumen was diluted and transported to refineries for further processing (Alberta Energy, 2014).

\subsubsection{Oil Sands Tailings Disposal and Management}

The whole tailings obtained from the bitumen extraction process come in the form of slurry. The slurry contains a mixture of sand and fine particles, water, and residual bitumen, and surfactants. These whole tailings can be either hydraulically 
transported to large tailings ponds or classified through a cyclone separator and thickener before deposition.

When hydraulically transported, the whole tailings are discharged into large tailing ponds. The sand particles segregate and settle quickly to form a beach. These coarse particles are then extracted, compacted and re-used in the construction of other containment cells. The table below (Table 1) outlines the oil sands tailings composition by percentages.

Table 1. Oil Sands Tailings Composition (Beier et al., 2013)

\begin{tabular}{|c|c|c|}
\hline Parameter & $\begin{array}{l}\text { Whole tailings } \\
\text { (typical values) }\end{array}$ & $\begin{array}{l}\text { Mature fine tailings } \\
\text { (typical values) }\end{array}$ \\
\hline Solids content (\%) & 55 & $30-35$ \\
\hline Sand content ( $\%$ by dry mass) & 82 & $<5$ \\
\hline $\begin{array}{l}\text { Fines content (\% by total dry } \\
\text { mass including bitumen) }\end{array}$ & 17 & $>95$ \\
\hline $\begin{array}{l}\text { Clay content (\% by dry mass } \\
\text { of fines) }\end{array}$ & - & $30-50$ \\
\hline
\end{tabular}

The fine particles settle rapidly to $20 \%$ wt solids content (Chalaturnyk et al., 2002). After a few years the fine particles will settle to $30-35 \%$ wt solids content. These tailings are referred to mature fine tailings or MFT. Due to the MFT's poor consolidation properties, the MFT will remain in a fluid state for decades (Chalaturnyk et al., 2002). The MFT's fluid state is determined by its low strength, which is usually lower than $1 \mathrm{kPa}$. (Wells et al., 2011). Figure 7 conceptualizes the segregation 
following deposition. Note that a substantial amount of fines may be trapped in the matrix and the sand particles (REF).

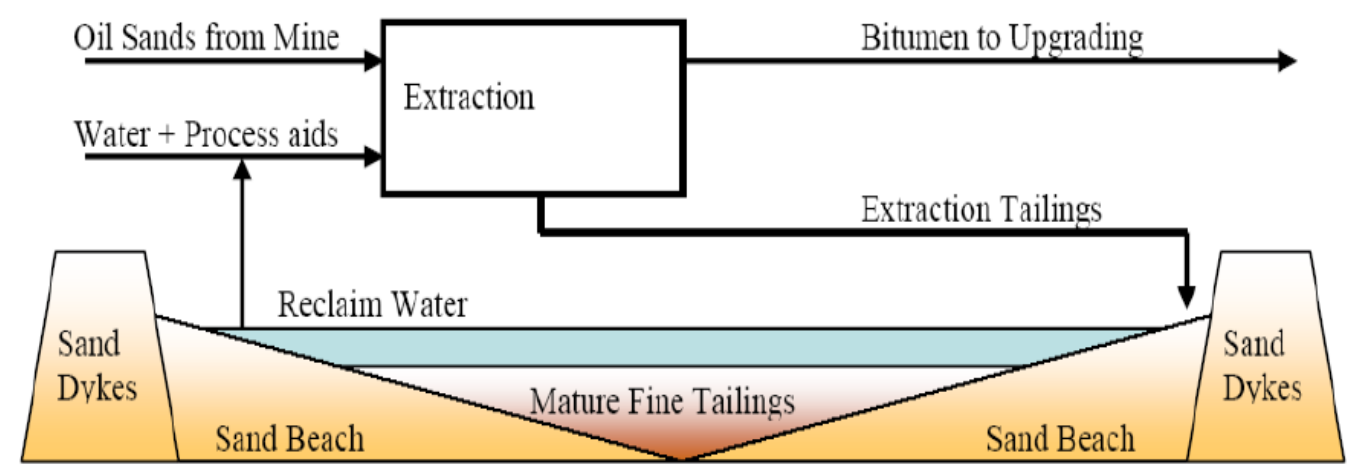

Figure 7. Oil Sands Tailings Pond and Particle Segregation (Beier et al., 2009)

According to Beier and Sego (2008), approximately $1 \mathrm{~m}^{3}$ of sand and $0.25 \mathrm{~m}^{3}$ of MFT have been produced for one barrel of oil being produced. This means that as of 2010, approximately $830 \mathrm{~m}^{3}$ of MFT have been produced which required tailings ponds for long-term storage (Grant et al., 2013).

\subsubsection{Mature Fine Tailings (MFT): The Dewatering Challenge}

As previously mentioned, MFT has poor consolidation properties, which is due to the dispersive nature of the clay fraction as a result of the extraction process (Beier et al., 2013). This inability for consolidation leads the tailings to retain water and remain in a fluid state (i.e. $35 \% \mathrm{wt}$ solids content). In order to contain the tailings, large fluid containment structures are needed for long-term storage (BGC Engineering Inc., 2010). 
Moreover, Chalaturnyk et al., (2001) points out that if current tailings management operations continue by the year 2020, the accumulated amount of MFT will reach one billion cubic meters. This large amount of tailings will require more containment structures, which could create environmental hazards and long-term environmental liability. Therefore, it is necessary to improve the consolidation properties of MFT in an economic and environmentally friendly manner.

\subsection{Dewatering of Oil Sands Tailings}

The main objective in the dewatering process of oil sands tailings is to increase the solids content in the material by the removal of water. This process will allow for a load-bearing surface to be achieved and it will allow future reclamation of the site. Furthermore, there are several dewatering techniques available for the oil sands industry. These technologies can be applied individually or as a combination of two or more depending on the circumstances/challenges the facility is facing and material used. These techniques involve physical/mechanical processes, natural processes, chemical/biological amendments, and/or permanent storage. A report produced by BGC Engineering in 2010 discusses and analyzes 34 different technologies currently available. A brief summary of the most relevant dewatering techniques will be presented in the sub-sections below. 


\subsubsection{Dewatering Technologies}

\subsubsection{Filtered Whole Tailings}

The filtering of whole, or unaltered, tailings is a mechanical process, which its main goal is to separate water from the solids fraction of the tailings (BGC Engineering Inc., 2010). Filtering can be achieved by using pressure either produced by stacked plates or vacuum force. The filtration of water can be enhanced by the addition of flocculants, which increase the hydraulic conductivity of the tailings and therefore increase the filtration rate. Once the tailings have been filtered, the filtered cake can be transported to a disposal site (BGC Engineering Inc., 2010). Xu et al. (2008) performed laboratory experiments to investigate the filterability of tailings under different parameters and conditions. They concluded that fine particles play an important role in the filterability of the tailings unaltered by polymers. When fine particles are $4 \%$ or higher, it is not practical to filter the whole tailings. This is due to the fine particles filling the pores of the filtering cake reducing water drainage and increasing the filterability resistance. For tailings with $18 \%$ fines, polymer must be used to achieve higher filtering. However, at a commercial scale the filtering area required would be too large and therefore this method would be impractical. Also in 2008, Syncrude Ltd. reassessed their tailings technologies and decided to eliminate filtration of whole tailings due to the high costs associated with this technology (Syncrude Canada Ltd., 2008). 


\subsubsection{Composite/Consolidation Tailings (CT)}

CT technology involves the mixture of densified extraction tailings (from cyclone underflow), MFT, and gypsum to form a non-segregating slurry with $60 \%$ SC (BGC Engineering Inc., 2010). According to Tang (1997), once the mixture is produced sand particles remain held within the clay structure forming a stronger clay matrix. The weight of the sand particles aids in the self-compression of the clay matrix forcing the

pore fluid out, which increases the permeability and consolidation rate of the composite tailings. The amount of clay content, gypsum dosage, and bitumen present in the MFT determine the consolidation rate of CT (Tang, 1997). Tang (1997) performed several tests using CT with varying clay contents: $36 \%, 55 \%$, and $70 \%$. She observed that CT with $70 \%$ clay content underwent the highest change in initial void ratio and therefore the larger consolidation rate. This sample had the lowest bitumen content $(1.6 \%)$. The CT sample with $55 \%$ clay content had the largest bitumen content $(2.5 \%)$ and it experienced the lowest change in initial void ratio and lowest consolidation rate. Tang (1997) concluded that the bitumen content plays an important role in the consolidation rate of CT material.

In 1995, Syncrude Ltd. and Suncor Energy partnered to launch a pilot for this technology in the Mildred Lake site (COSIA, 2013). From the year 2000, Syncrude Canada has continued using this technology successfully in the same site. CT technology can be put into effect at low cost and produces a rapidly consolidated material, which facilitates reclamation (BGC Engineering Inc., 2010). The reclamation 
process over the CT material is at an advance stage. Forested and wetlands areas have been constructed making this site one of its kind (COSIA, 2013).

\subsubsection{Thickening Process of Tailings}

Thickening of tailings or TT technology involves the addition of chemicals (flocculants) to aid in the flocculation, and therefore consolidation, of fine particles found in tailings (BGC Engineering Inc., 2010). This process also produces water that can be re-used in the bitumen extraction process. The thickening of tailings takes places in large vessels called thickeners. It has been reported that thickened tailings can approximately yield up to $30 \%$ solids content in a half an hour treatment (Devenny \&

Nelso, 2009). Comparatively, the same solids content can take several years in a tailings pond by consolidation due to gravity. Lastly, some advantages of TT technology include the capture of new fine particles that will not make more MFT, the recovery of water for re-use purposes, a faster densification of tailings, and the placement of more stable deposits (BGC Engineering Inc., 2010).

\subsubsection{In-line Thickened Tailings (ILTT) Technology}

Similar to the TT technology, ILTT technology injects flocculants/coagulants into the high fines content cyclone overflow tailings. This process occurs in an in-line multi stage manner (BGC Engineering Inc., 2010). The formation of flocs increases the hydraulic conductivity within the tailings improving settling, consolidation, and strength behavior (BGC Engineering Inc., 2010). Jeeravipoolvarn (2010) studied field 
tests. He observed from a pilot field test operated by Suncorn that deposited tailings went from $3.7 \%$ to $31.2 \%$ solids content in approximately 7 days. The tailings consolidated even further to about $50 \%$ solids content in 4 months. He also observed a consistent fines content profile averaging $89 \%$.

Lastly, this technology promotes the rapid dewatering of cyclone overflow tailings; the tailings produced required a relatively small storage area, and they have increased undrained shear strength when compared to standard MFT (BGC Engineering Inc., 2010).

\subsubsection{Natural Dewatering Mechanisms}

Natural dewatering processes involve the use of the environment and geophysical mechanisms to remove water from tailings.

\subsubsection{Sedimentation and Self-weight Consolidation}

This process utilizes the force of gravity to allow water to dissipate from the solid particles and it has been used in the industry for over 40 years. There are two states of consolidation that can be observed when particles start to settle. The first state, or hindered settling, occurs when inter-particle forces are absent below some critical density. This increases the hydraulic resistance within the tailings and therefore the settling rate is reduced. In this state, the weight of the sediment is counterbalanced by buoyancy and pore water pressure above the hydrostatic level (BGC Engineering Inc., 2010). The second state of consolidation occurs when the solids fraction is above the 
critical density and a sediment network structure is formed. This network is able to carry a part of its own weight (BGC Engineering Inc., 2010).

During sedimentation and consolidation, initial released water travels downslope towards the end of the cell by gravity. This migration of water occurs in the first couple of days after deposition (Barr Engineering, 2012). The initial released water is then drained using pumps to allow the tailings' surface release water by evaporation. Another way water leaves the tailings during consolidation is through under-drainage. Water exits the cell containing the tailings due to the development of a downward hydraulic gradient. The base of the cell is made of permeable material that allows under-drainage. It is estimated that under-drainage accounts approximately for 10 $\mathrm{mm} / \mathrm{month}$ of dissipated water. This process stops when the solids content reaches approximately 75\% (Barr Engineering, 2012).

The main advantages of dewatering through self-weight consolidation are the low cost of operation and low maintenance requirements. However, this method requires large areas for MFT disposal and chemical treatment prior disposal may be needed to increase consolidation (BGC Engineering Inc., 2010).

A more scientific description of sedimentation and consolidation is presented in Section 2.4. 


\subsubsection{Evaporation}

This natural process consists of depositing thin MFT lifts and allowing them to desiccate by evaporation drying. Evaporation occurs due to a vapor pressure gradient (Barr Engineering, 2012). This method is considered to be the most cost-effective way to dewater fine-grained tailings (BGC Engineering Inc., 2010); however, it is weather dependant.

The climate in Northern Alberta allows for evaporation to be higher than precipitation on an annual average basis. The deficit is approximately $215 \mathrm{~mm}$ (BGC Engineering Inc., 2010). This allows the MFT to exist in a constantly evaporative environment. Evaporation will only occur during months in which the average temperature in greater than zero (i.e. April to October).

Furthermore, once at the tailings ponds, the initial surface water either from precipitation or consolidation must be properly drained to allow the tailings to dry. If the tailings surface is properly drained, the potential evaporation rate is limited to 3 $\mathrm{mm}$ /day (BGC Engineering Inc., 2010). At the same time, geotechnical properties such as particle size distribution, hydraulic conductivity, and soil-water characteristic curve can hinder the flow of water towards the evaporation surface. For example, as the tailings surface starts drying and becomes unsaturated, suction takes places and it leads to crack formation, which can improve the evaporation rate (Barr Engineering, 2012). Equally, the amount of residual bitumen in the tailings can limit the evaporation 
process. Residual bitumen can form a coating layer at the tailings' surface, which will impede the evaporation of water (BGC Engineering Inc., 2010).

Lastly, dewatering through evaporation can lead to a trafficable surface that can allow for more MFT layers to be placed on top or the beginning of the reclamation process. Another advantage is the development of cracks as shrinkage of the surface occurs. Cracks allow the horizontal movement of water and increase the evaporative surface of the tailings. On the other hand, this method requires surface water management, large areas for MFT deposition, high operational costs, and it limits tailings' treatment to summer months only (BGC Engineering Inc., 2010). A more scientific description of the evaporation process is presented in Section 2.5.

\subsubsection{Freeze-thaw Cycles}

Dewatering though freeze-thaw cycles involves the freezing of multiple thin MFT layers during the winter months and the thawing of said layers during the summer months (BGC Engineering Inc., 2010). The freezing process causes the formation of ice lenses and ice channels within the tailings. When thawing begins, the ice matrix melts leaving behind small channels that promote and increase water drainage. Several tests have been performed to measure the effectiveness of freeze-thaw cycles in the dewatering process of tailings to this date. These tests and the mechanical processes that take place during freezing and thawing will be explain in detailed in Section 2.8. 
Furthermore, the main advantages offered by freeze-thaw cycles are the low capital costs, the possibility to freeze many layers during the same time frame increasing the active thickness, and it is suitable for hydraulic sand capping. On the other hand, this method requires large areas for MFT containment, it is weatherdependent, labor can be considered intensive during winter, and the post-thaw tailings are soft and saturated in nature (BGC Engineering Inc., 2010). A more scientific description of the freeze-thaw cycle process is presented in Section 2.7.

\subsection{Geotechnical Properties of Mature Fine Tailings (MFT)}

\subsubsection{General Characteristics of Tailings}

As previously mentioned, mature fine tailings only settle up to $30-35 \mathrm{wt} \%$ solids content and behave in a fluid manner. The table below (Table 2) outlines the basic geotechnical properties of MFT.

Table 2. Basic Properties of MFT (modified after BGC Engineering Inc., 2010)

\begin{tabular}{cc}
\hline Property & Raw MFT \\
\hline Mean Particle Size & $5-10 \mu \mathrm{m}$ \\
Solids Content & $30-35 \mathrm{wt} \%$ \\
Hydraulic Conductivity & $10^{-6}-10^{-9} \mathrm{~m} / \mathrm{s}$ \\
Liquid Limit & $40 \%-75 \%$ \\
Plastic Limit & $10 \%-20 \%$ \\
Shear Strength & $<1 \mathrm{KPa}$ (acts as a fluid)
\end{tabular}




\subsubsection{Grain Size Distribution}

Analysis of the grain size distribution for mature fine tailings has been performed by Islam (2014) and Proskin (1998), among others. The figure below (Fig. 8) shows the particle size distribution for MFT, which was obtained with a laser particle size analyzer. It shows that the MFT contains $82.5 \%$ silt and $17.5 \%$ clay-size solids, approximately. Please note that the grain size distribution shown below may vary slightly for other types of MFT.

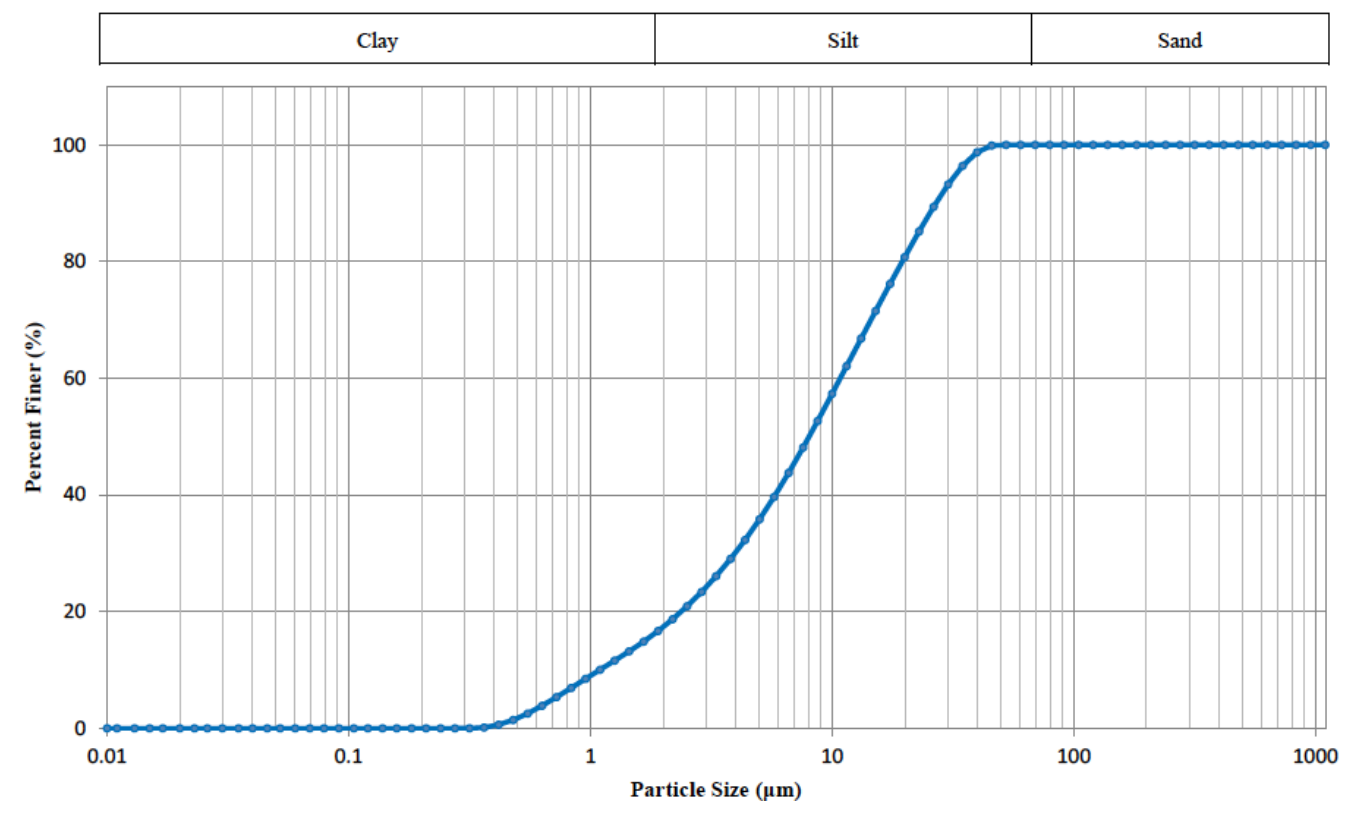

Figure 8. Particle Size Distribution of MFT (Islam, 2014) 


\subsubsection{Hydraulic Conductivity in MFT}

Since fine grains are the dominant type of particles in MFT, the hydraulic conductivity values are not high. Jeeravipoolvarn (2005) summarized 11 different hydraulic conductivity tests conducted on mature fine tailings, as seen in Figure 9.

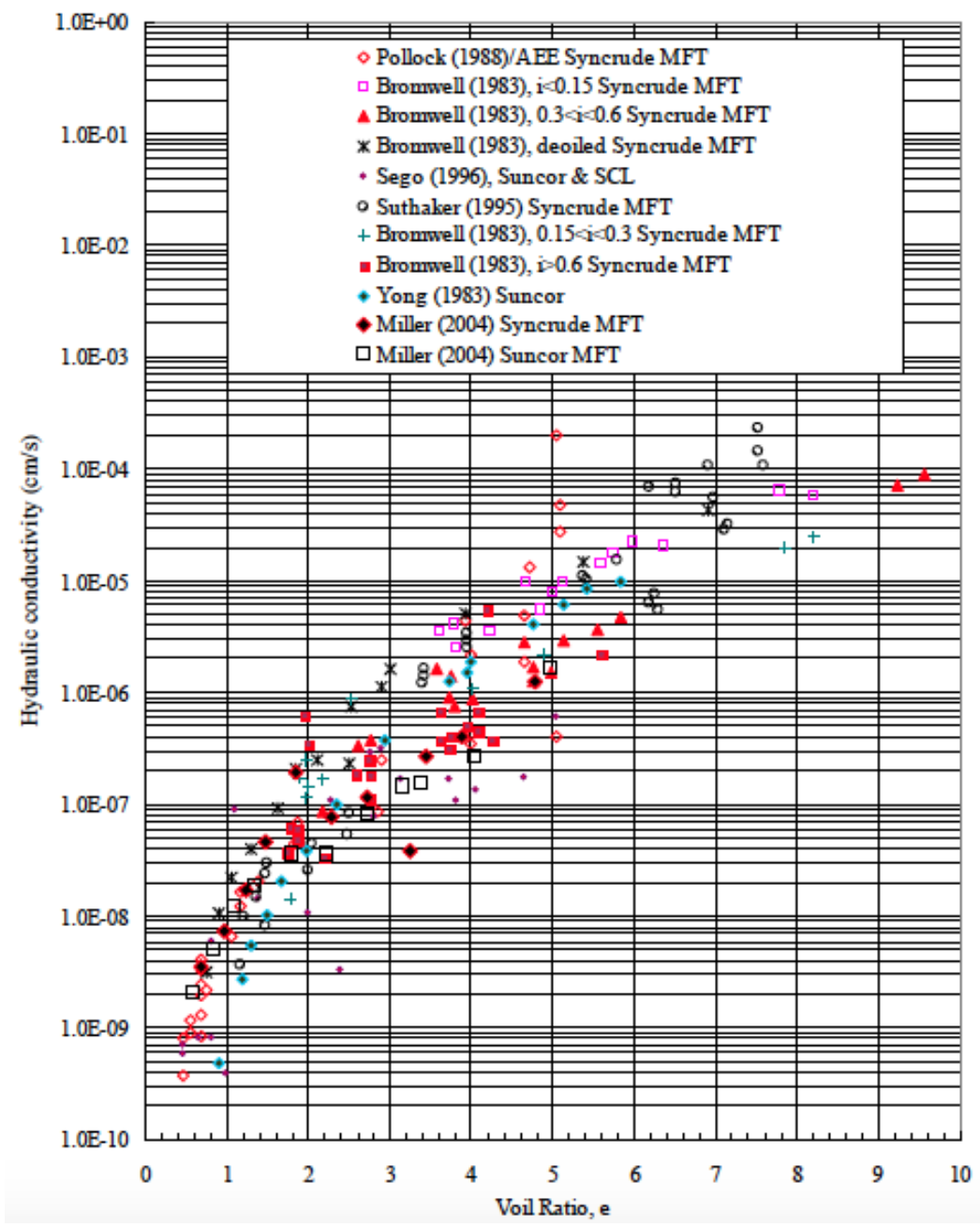

Figure 9. Hydraulic Conductivity vs Void Ratio for MFT (Jeeravipoolvarn, 2005) 
The low hydraulic conductivity coefficient for MFT is a main contributor to the material's poor dewatering properties. Thixotropy, or the change in viscosity due to the application of stress, is also a main factor for poor dewatering in MFT.

\subsection{Sedimentation and Consolidation Theory}

Consolidation is the process in which soils with low permeability decrease volume due to the expulsion of pore water when a static load is being applied. This process occurs when the stress being applied to the soil forces the soil particles to rearrange in a more compacted manner. If the soil is fully saturated with water, water will be squeezed out reducing the bulk density of the soil. Two theories on how to predict consolidation in soils are discussed in the sections below.

\subsubsection{Sedimentation}

Sedimentation refers to the phenomenon in which suspended particles settle all together or en-masse within a liquid (Jeeravipoolvarn, 2010). During this process an interface between the settling volume and the supernatant fluid develops and it moves down gradually over time (Jeeravipoolvarn, 2010). Been and Sills (1981) stated that in this interface there are not effective stresses present when the solids contents are low. Also, as the soil particles continue to settle, a zone in which suspended particles become part of the soil mass develops. In this zone, the difference between sedimentation and consolidation is not properly defined (Jeeravipoolvarn, 2010). The sedimentation process ends when effective stresses begin to develop, as grain-to-grain interaction is present. A sediment layer is formed and it holds large amounts of water. 
Consequently, the consolidation process begins as water is squeezed out of the sediment layer due to the weight of the overlying sediment (Wijermars, 2011).

Kynch (1952) developed a sedimentation theory, which states that the speed of the suspended particles depends only on the particle's density $(\rho)$. He developed the following relationship that defines the number of particles crossing a horizontal section per unit area per time. This equation is also referred as particle flux and it was developed from the continuity equation and $S=\rho v$.

$$
\frac{\delta \rho}{\delta t}-V(\rho) \frac{\delta \rho}{\delta x}=\rho v
$$

Where,

$$
\begin{aligned}
& \mathrm{S}=\text { Particle flux; } \\
& \rho=\text { Particle density; } \\
& \mathrm{V}(\rho)=\text { Fall velocity }=-\frac{\delta S}{\delta \rho} ; \\
& \mathrm{dt}=\text { time variant; } \\
& \mathrm{dx}=\text { height variant. }
\end{aligned}
$$

\subsubsection{Classical Theory: 1-Dimensional Consolidation Theory}

Karl von Terzaghi proposed the 1-Dimensional Consolidation Theory in 1925. The theory couples the continuity equation for 1-dimensional flow, Darcy's equation, and the Principle of Effective Stress. Mathematically, the Terzaghi's 1-dimensional consolidation equation can be expressed as: 


$$
C_{v} \frac{\partial^{2} u}{\partial z^{2}}=\frac{\partial u}{\partial t}
$$

Where,

$$
\begin{aligned}
& C_{v}=\text { Coefficient of consolidation; } \\
& \mathrm{u}=\text { excess pore water pressure; } \\
& \mathrm{t}=\text { time; } \\
& \mathrm{z}=1 \text {-dimensional vertical coordinate. }
\end{aligned}
$$

In other words, the coefficient of consolidation, $C_{v}$, represents how quickly the soil consolidates.

Equation 2.2 is a basic differential equation and can be solved with proper boundary conditions. Moreover, the theory is subjected to the following assumptions:
a) Homogeneous soil layer
b) Soil is saturated
c) Darcy's law is valid
d) The compression of the soil layer is due to change in volume only.
e) Soil deformation occurs only in the direction of the load application (vertical).
f) The coefficient of consolidation, $C_{v}$, is constant during the consolidation period.

Terzaghi's consolidation theory entitles that once a vertical stress is applied to a saturated fine-grained soil sample, the pore water increases its magnitude by the same 
amount as the vertical stress. This increase in pore water pressure is also referred to as excess pore water pressure. Over time, the soil starts to compress, the excess pore water pressure dissipates through drainage allowing the soil skeleton to carry the load being applied, and the effective stress increases. At the end of this process, all the excess pore water pressure has been transferred to the soil's effective stress.

Even though the classical consolidation theory is widely used in geotechnical engineering, it is not applicable for oil sands tailings. Jeeravipoolvarn (2010) indicated that due to the soft nature of the oil sands tailings, the underlying assumptions of material homogeneity and small strain are not applicable for tailings. Large settlements in soft tailings rule out the small strain assumption and the non-linearity in compressibility and hydraulic conductivity make the material non-homogeneous. These variances have led to the development of the Finite Strain Consolidation Theory for a more accurate consolidation description for oil sands tailings.

\subsubsection{Finite Strain Consolidation Theory}

The finite strain consolidation theory developed by Gibson et al. in 1967 is used to model the consolidation process of saturated clays or slurries, such as the case of oil sands tailings. The ability to predict the consolidation of slurries is very important because it facilitates the design of tailings ponds. Furthermore, this theory builds on Terzaghi's consolidation theory by stating that large strain consolidation is present and

the hydraulic conductivity of the material is not constant (Gibson et al., 1967). The governing equation of this theory has the following form in terms of void ratio: 


$$
\pm\left(\frac{\rho_{s}}{\rho_{f}}-1\right) \frac{d}{d e}\left[\frac{k(e)}{1+e}\right] \frac{\partial e}{\partial z}+\frac{\partial}{\partial z}\left[\frac{k(e)}{\rho_{f}(1+e)} \frac{d \sigma^{\prime}}{d e} \frac{\partial e}{\partial z}\right]+\frac{\partial e}{\partial t}=0
$$

Where,

$$
\begin{aligned}
& \rho_{s}=\text { solids density; } \\
& \rho_{f}=\text { fluid density; } \\
& e=\text { void ratio; } \\
& k=\text { hydraulic conductivity; } \\
& \sigma^{\prime}=\text { effective stress; } \\
& t=\text { time; } \\
& z=\text { depth coordinate. }
\end{aligned}
$$

This equation was developed assuming the following:

a) The soil skeleton is homogeneous and possesses no intrinsic time effects and;

b) The fluids and solids are incompressible.

The formulation in Equation 2.2 utilizes the Lagrangian coordinate height system (z). In finite strain consolidation problems, the thickness of the material is changing constantly. The upper boundary condition is always moving and is time dependent. This occurrence causes problems for each soil element. However, "the use of Lagrangian coordinates overcomes this problem because the material spatial coordinate is fixed thus already in its exact location" (Jeeravipoolvarn, 2010). 


\subsubsection{Compressibility and Hydraulic Conductivity Relationships}

Equation 2.3 needs functions for compressibility and permeability in order to generate solutions to model the consolidation behavior of saturated clay or slurries as the void ratio changes. Figure 10 and 11 show two constitutive relationships developed by Jeeravipoolvarn (2008) for oil sands fine tailings.

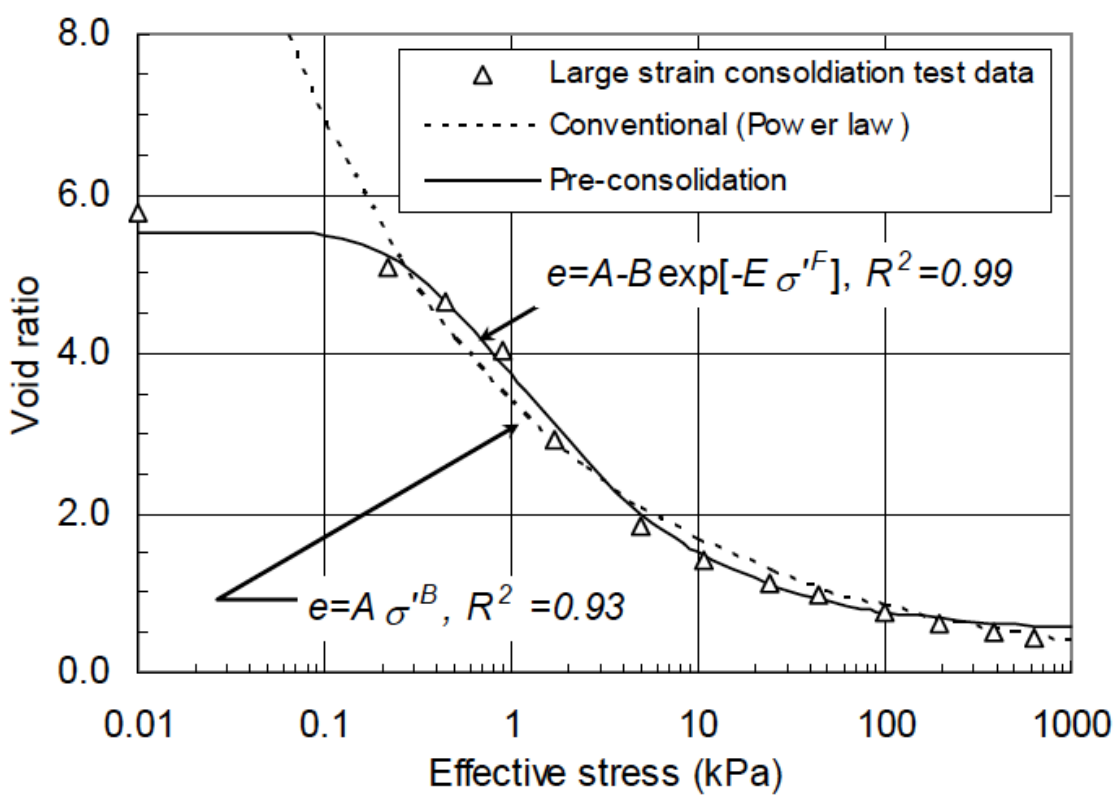

Figure 10. Compressibility of Fine Tailings (Jeeravipoolvarn et al., 2008). 


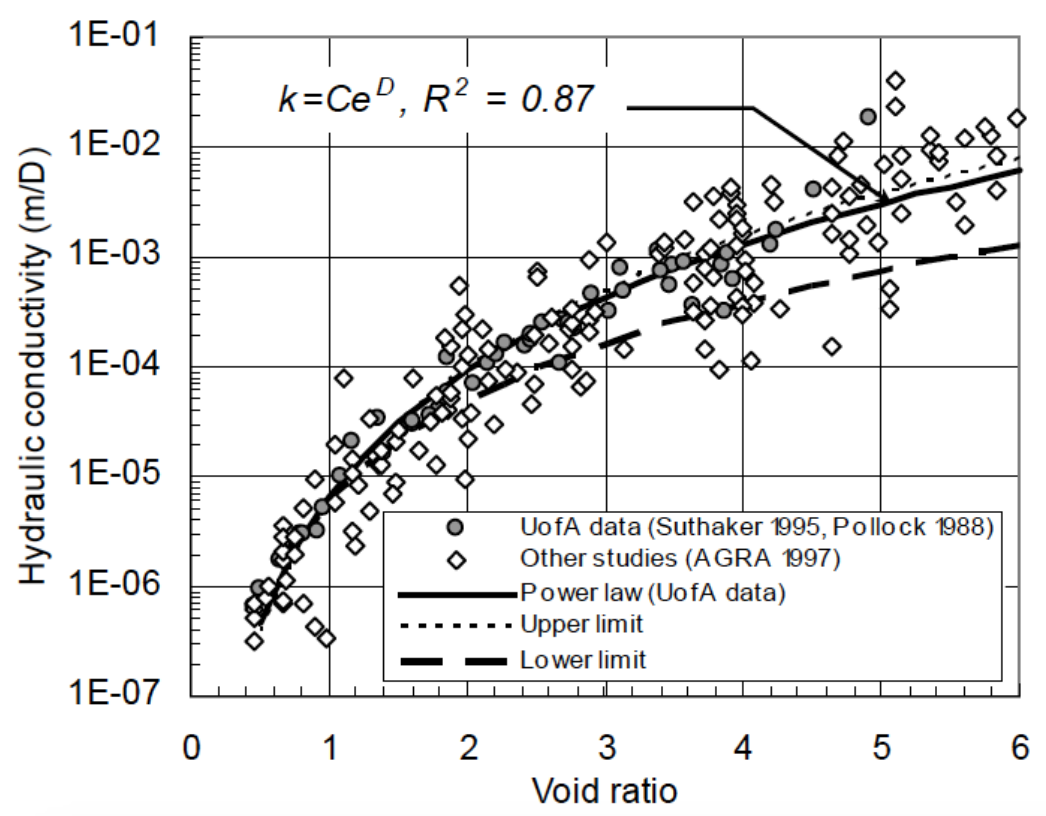

Figure 11. Hydraulic Conductivity of Fine Tailings (Jeeravipoolvarn et al., 2008).

\subsection{Evaporation and Desiccation}

Evaporation is the process in which the liquid water present in bare soil changes phase to water vapor and it transported to the atmosphere (Lal \& Shukha, 2004). According to Bernard-Innocent (2013), there are three main stages in the evaporation of water in soils:

1. Liquid water is transported to the soil surface.

2. Due to a source of heat (i.e. solar energy) water undergoes a phase change from liquid to vapor,

3. The difference in vapor pressure between the soil and the air above the soil surface allows the water vapor to mobilize towards the atmosphere by convective and diffusive processes. 
Actual and potential evaporation are two other concepts relevant in the evaporation of water from soil process. Actual evaporation, or AE, is defined as the "amount of water evaporated from the ground or an open source of water" (World Meteorological Organization, 2012). Comparatively, potential evaporation, or PE, is defined as the "amount of water vapor that could be emitted by the ground under the existing conditions" (World Meteorological Organization, 2012). For measurement purposes, actual evaporation can be calculated in laboratory setting by measuring the weight of the soil sample at equal intervals of time. If drainage is present it should be taken into account in the weight measurements. Meanwhile, to calculate the potential evaporation, the Penman-Monteith equation can be used. Howard Penman and John Monteith developed this equation in 1948. The equation has the following form:

$$
P E=\frac{\Delta\left(R_{n}-G\right)+\rho_{a} C_{p}\left(e_{s}-e_{a}\right) / r_{a}}{\Delta+\gamma\left(1+\frac{r_{s}}{r_{a}}\right)}
$$

Where,

$$
\begin{aligned}
& \mathrm{PE}=\text { Potential Evaporation }(\mathrm{mm} / \text { day }) \\
& R_{n}=\text { Net radiation }\left(\mathrm{MJ} \mathrm{m}^{2} / \text { day }\right) ; \\
& \mathrm{G}=\text { Soil heat flux }\left(\mathrm{MJ} \mathrm{m}{ }^{2} / \text { day }\right) ; \\
& \gamma=\text { Psychometric constant }\left(\mathrm{kPa} /{ }^{\circ} \mathrm{C}\right) \\
& \Delta=\text { Slope of saturation vapor curve }\left(\mathrm{kPa} /{ }^{\circ} \mathrm{C}\right) ; \\
& e_{s}=\text { Mean saturation pressure }(\mathrm{kPa}) ; \\
& e_{a}=\text { Actual vapor pressured derived from relative humidity }(\mathrm{kPa}) ;
\end{aligned}
$$




$$
\begin{aligned}
& e_{s}-e_{a}=\text { Saturation vapor pressure deficit }(\mathrm{kPa}) ; \\
& r_{s}=\text { Soil surface resistance }(\mathrm{s} / \mathrm{m}) ; \\
& r_{a}=\text { Bulk surface aerodynamic resistance to water pressure }(\mathrm{s} / \mathrm{m}) ; \\
& \rho_{a}=\text { Density of air }\left(\mathrm{kg} / \mathrm{m}^{3}\right) ; \\
& C_{p}=\text { Specific heat of air }\left(1.013 \times 10^{-3} \mathrm{MJ} / \mathrm{kg}^{\circ} \mathrm{C}\right) .
\end{aligned}
$$

Furthermore, desiccation is a process of extreme dryness. In clay soils, desiccation occurs when the tensile stress developed in the soil originated from the matrix suction exceeds the tensile stress of the soil (Kodikara, Barbour, \& Fredlund, 2000). Also, it is known that desiccation has an effect on consolidation because it changes the stress, degree of saturation, and drainage path. Usually, a desiccation model is applied on areas where the actual evaporation is higher than the precipitation (Jeeravipoolvarn, 2010).

During desiccation, orthogonal and non-orthogonal cracking occurs. Orthogonal cracking occurs in a sequential manner by the development of a primary crack that, in time, will develop secondary cracks within it. Non-orthogonal cracks form simultaneously and end up connecting forming a block pattern (Kodikara et al., 2000). Lastly, once cracks are formed, they can be considered as another way for water to flow in the evaporative process, which can accelerate the densification of tailings. 


\subsection{Mechanics of Unsaturated Soils}

Unsaturated mechanics are applicable when the pore spaces within the soils are filled with water and partially with air. Unsaturated soils are known to be a three-phase system: solids, water, and air. However, Fredlund and Morgenstern (1977) argued that a fourth-phase, the air-water interphase or contractile skin, should be also taken into account. When the air phase is continuous, the contractile skin acts as a membrane that has the ability to change the water content, volume, and shear strength in the soil as it undergoes stress changes (Fredlund et al., 2010). Furthermore, as the unsaturated portion of the soil begins to desaturate, the pore pressure becomes negative. This negative change is associated with soil suction and it will be discussed in the following sections.

\subsubsection{Soil Suction}

When the soil water pressure is less than the atmospheric pressure, it is referred as soil suction. From the thermodynamics point of view, soil suction is related to free energy state of soil-water and can be measured in terms of the partial vapor pressure adjacent to the soil water (Fredlund et al., 2010). The soil suction takes the following form:

$$
\psi=-\frac{R T}{v_{w 0} \omega_{v}} \ln \left(\frac{v_{V}}{v_{V 0}}\right)
$$


Where,

$$
\begin{aligned}
& \psi=\text { total suction; } \\
& \mathrm{R}=\text { universal gas constant; } \\
& \mathrm{T}=\text { absolute temperature; } \\
& v_{w 0}=\text { specific volume of water; } \\
& \omega_{v}=\text { molecular mass of water vapour; } \\
& v_{V}=\text { partial pressure of pore water vapour; } \\
& v_{V 0}=\text { saturation pressure of vapour above pure water. }
\end{aligned}
$$

The relationship in Equation 2.5 states that the reference state to calculate suction is the vapour pressure above a flat surface of pure water (Fredlund et al., 2010). Furthermore, the term $\frac{v_{V}}{v_{V 0}}$ is also referred to as relative humidity $(\mathrm{RH})$. Meaning that, as soil suction $(\psi)$ nears zero the relative humidity $(\mathrm{RH})$ nears $100 \%$. Similarly, if the relative humidity is below $100 \%$, it indicates that there is suction occurring within the soil.

Soil suction has two main components: matric and osmotic suction. In other words, total soil suction can be represented as the sum of both, matric and osmotic, suctions.

$$
\psi=\left(u_{a}-u_{w}\right)+\pi
$$


Where,

$$
\begin{aligned}
& \left(u_{a}-u_{w}\right)=\text { matric suction, } \\
& u_{a}=\text { pore air pressure; } \\
& u_{w}=\text { pore water pressure; } \\
& \pi=\text { osmotic suction. }
\end{aligned}
$$

Figure 12 shows the components of the total suction with respect to the free energy of the soil-water.

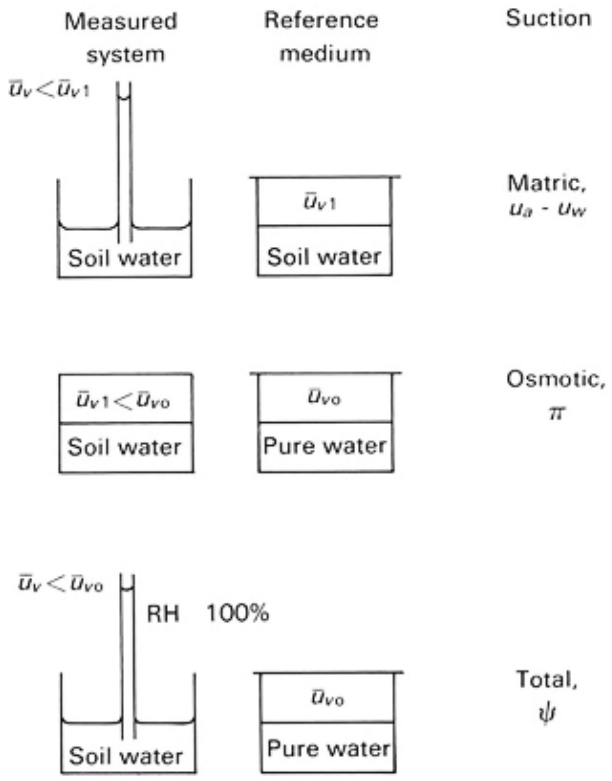

Figure 12. Components of Total Suction (Fredlund et al., 2010). 


\subsubsection{Matric suction}

Matric suction is originated from the combination of capillarity and adsorptive forces within the soil skeleton, as seen in Figure 13.

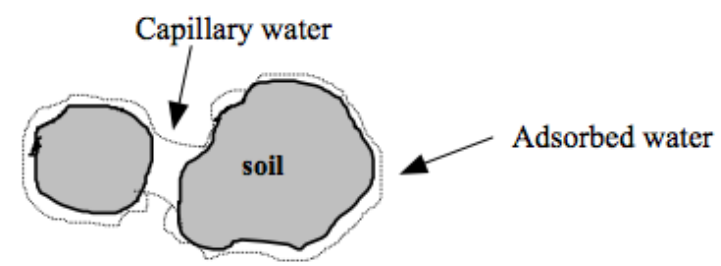

Figure 13. Capillary and adsorptive forces in the soil matrix.

The capillarity forces are caused by the liquid-gas interface (i.e. surface tension of water) and the irregular pore geometry of soil particles. Meanwhile, the adsorptive forces are caused by the adhesion of water to solid surfaces (soil grains) due to Londonvan der Waals forces (Or et al., 2003).

The liquid-gas interaction between air and pore water within the soil leads to capillary rise to take place. The capillary rise is associated with the rise of a water surface in a capillary tube, as seen in Figure 14. The smaller the capillary tube's radius, the higher the water will rise. 


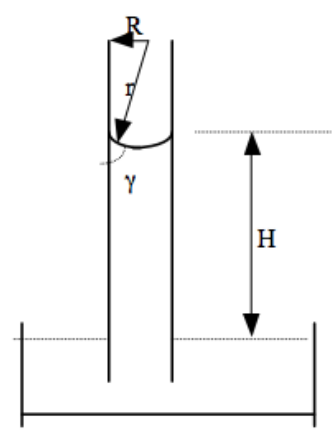

Figure 14. Capillary rise within a capillary tube.

In soils, the pores in between soil grains act as capillary tubes with small radii, which rises soil-water above the water table due to the capillary rise created by the soil. As seen in the figure above, the capillary water has negative pressure in comparison to the air pressure $\left(u_{a}=0\right)$. When the soil is partially saturated, pore water can achieve high negative pressures. Additionally, the adsorptive forces are believed to help sustaining such negative pressures (Fredlund et al, 2010).

In a capillary tube, the water surface has a concave shape and it is referred as meniscus. However, the water surface in a larger container (i.e. water table) is flat. This means that the partial pressure of the water vapor above the curved surface of soil water, $\bar{u}_{v}$, is less than the partial pressure of water vapor above a flat surface of the same soil water, $\bar{u}_{v 1}$. To put it another way, the capillary rise decreases the relative humidity of the soil due to curved water surface or radius of curvature of water. The difference between air and water pressures across the surface, $\left(u_{a}-u_{w}\right)$, or matric suction, is inversely proportional to the radius of curvature in a capillary tube or pore (Fredlund et al., 2010). Matric Suction can be expressed in terms of surface tension as: 


$$
\text { Matric Suction }=\left(u_{a}-u_{w}\right)=-\rho g h=\frac{2 T_{s}}{R_{s}}
$$

Where,

$$
\begin{aligned}
& \rho=\text { density of water; } \\
& g=\text { acceleration of gravity; } \\
& h=\text { height of rise; } \\
& T_{S}=\text { surface tension; } \\
& R_{S}=\text { radius of curvature. }
\end{aligned}
$$

\subsubsection{Osmotic Suction}

Osmotic suction is referred to the decrease in potential energy and relative humidity due to the presence of dissolves salts in the pore water (Fredlund et al., 2010). The effects of osmotic suction become significant when there is a high amount of dissolved ions in the pore water; otherwise its effects are considered negligible (Or et al., 2003). Also, osmotic suction can be related to electro conductivity of the soil. Many relationships have been developed, such as:

$$
\begin{array}{ll}
\pi=0.0191 E C^{1.074} & \text { (U.S.D.A., 1950) } \\
\pi=0.0240 E C^{1.065} \quad \text { (Romero, 1999) }
\end{array}
$$


Where,

$$
\begin{aligned}
& \pi=\text { osmotic suction; } \\
& \mathrm{EC}=\text { electro-conductivity. }
\end{aligned}
$$

\subsubsection{Cryosuction}

Cryosuction is referred to the suction developed by ice as the soil temperature drops below $0{ }^{\circ} \mathrm{C}$. As soil freezes and ice starts to form, liquid water is restricted in smaller spaces. This process reduces the free energy of the remaining liquid water. Since a variation of free energy is occurring, a free energy gradient develops leading to a mass transfer. The free energy of the water near the ice is lower than the free energy of the water further away from the freezing front. This differential causes the migration of more liquid water towards the freezing front (Williams and Smith, 1989).

For clarification purposes, William and Smith (1989) commented that the term 'water potential' is synonym with the term 'free energy', which is also synonym to the term 'suction' in this context.

\subsubsection{Soil Suction Measurement}

In this study, three different methods were used to measure suction: tensiometers (T5 and T5x), dialectric water potential sensors (MPS-6), and a chilledmirror dewpoint hygrometer (WP4-T). These methods will be discussed below. 


\subsubsection{Tensiometer ( $T 5 / T 5 x)$}

Tensiometers are used to measure matric potential. They use a porous cup made from porous ceramic. The porous cup is usually connected to a sensor body through a water-filled tube, as seen in Figure 15. The sensor body uses piezoelectric principles (i.e. it converts mechanical pressure into an electrical signal) to measure the soil water tension in comparison to atmospheric pressure $(\mathrm{GmbH}, 2009)$. When taking measurements in unsaturated soils, the porous cup needs to be in full contact with the soil. As the matric potential of the soil becomes lower than inside the tensiometer, water migrates from the tensiometer to the soil through a potential energy gradient. The water leaves the sensor through the porous cup creating suction, which is sensed by the sensor body. The movement of water continues until equilibrium has been reached and the matric potential of the sensor is the same as the matric potential of the soil. In fully saturated soils, the procedure is the same with the distinction that water will migrate from the soil to the tensiometer until equilibrium has been reached (Or et al., 2003). 


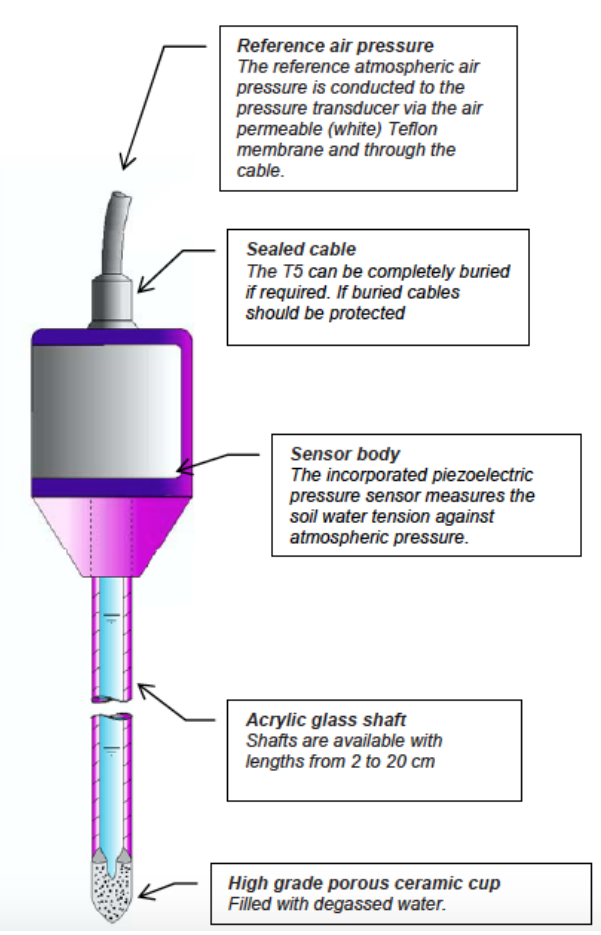

Figure 15. Tensiometer parts (GmbH, 2009).

The tensiometer ranges from $-85 \mathrm{KPa}$ to $+100 \mathrm{KPa}$ for $\mathrm{T} 5$ tensiometers and $160 \mathrm{KPa}$ tp $+100 \mathrm{KPa}$ for T5x tensiometers.

\subsubsection{Dielectric Water Potential Sensor (MPS-6)}

Dielectric water potential sensors measure matric water potential in a porous material. This technique uses a known material with a static matrix of pores (i.e. porous ceramic disks) that comes into contact with the soil. See Figure 16. Once the sensor has been installed, both materials reach hydraulic equilibrium, which means that the water potential of the soil is the same as the water potential of the static soil matrix. 
Therefore, the water potential of the soil can be inferred from the water potential of the solid matrix (Decagon Devices, 2014).

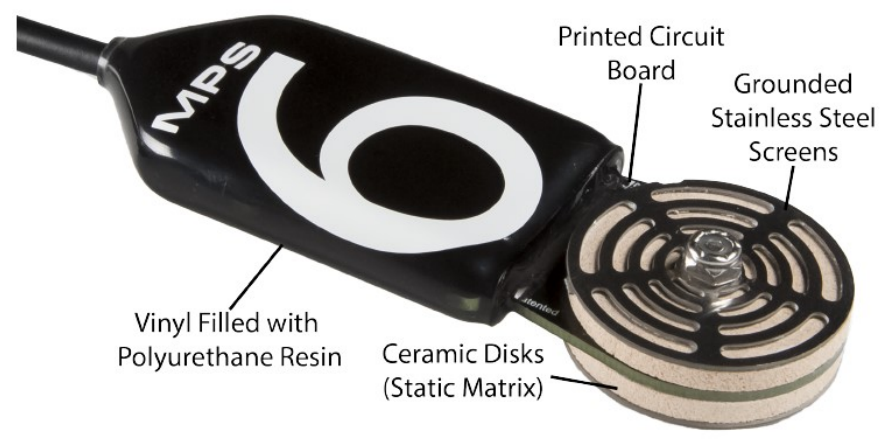

Figure 16. Dielectric Water Potential Sensor (Decagon Devices, 2014).

Furthermore, dielectric water potential sensors measure water potential by measuring the dielectric permittivity of the solid matrix, which depends on the water content present in the ceramic disk pore spaces (Decagon Devices, 2014). The table below (Table 3) shows the different dielectric permittivity values relevant to the dielectric water potential sensors:

Table 3. Dielectric Permittivity of Sensor Materials (modified after Decagon, 2014)

\begin{tabular}{cc}
\hline Material & Dielectric Permittivity (dimensionless) \\
\hline Air & 1 \\
Solid Ceramic & 5 \\
Water & 80
\end{tabular}


Once the dielectric permittivity of the solid matrix has been measured, the water content of the ceramic discs can be resolved. Water content and water potential of a geo-material can be related by using a soil water characteristic curve (explained further in Section 2.6.3). This relationship (Fig. 17) allows inferring the water potential of the soil from the water content of ceramic disc.

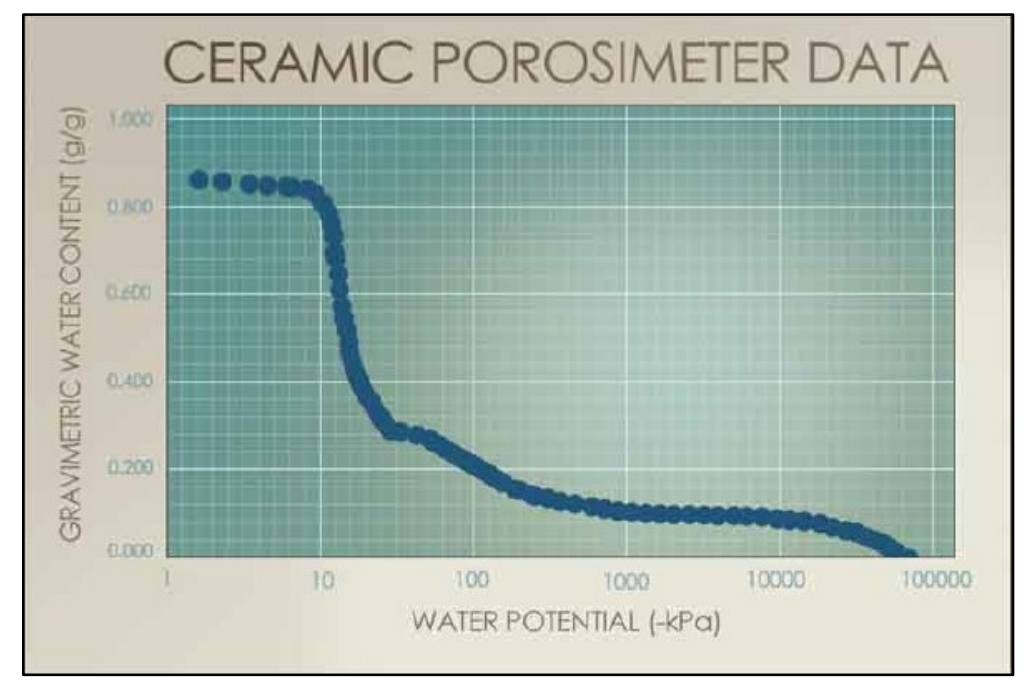

Figure 17. Soil Water Characteristic Curve for MPS-6 Sensors (Decagon Devices, 2014).

The MPS-6 water potential sensor measurements range from -9 KPa to -100000 $\mathrm{KPa}$ (air-dry) with an accuracy of $\pm(10 \%$ of reading $+2 \mathrm{kPa})$. This wide range is possible due to the large range of pore sizes within the ceramic discs. The variability of different pore sizes determines the water potential at which the pore drains. Therefore, it is important for the dielectric sensor's ceramic disc to drain over a wide water potential range (Decagon Devices, 2014). 


\subsubsection{Chilled-mirror Dewpoint Potentiameter (WP4-T)}

A Potentiameter (Fig. 18) uses the chilled-mirror dewpoint technique to measure the total water potential of a soil sample. The chiller-mirror dewpoint technique involves the equilibration of the soil sample with the headspace of a seal chamber that contains a mirror capable of measuring the condensation of said mirror. Once equilibrium has been reached, the water potential of the air in the chamber is the same as the water potential of the sample (Decagon Devices, 2003). The potentiometer measurements range from 0 to $-300 \mathrm{MPa}$ with an accuracy of $\pm 0.05 \mathrm{MPa}$.

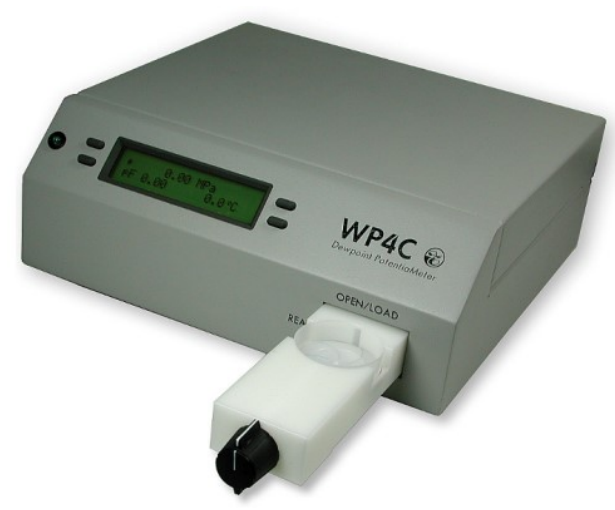

Figure 18. Dewpoint Potentiameter (Decagon Devices, 2003).

\subsubsection{Soil Water Characteristic Curve (SWCC)}

The soil water characteristic curve or SWCC provides a relationship between the mass, or volume, of water to the energy state of the water phase. This relationship helps understand the distribution of water within the voids in the soil. Also, the SWCC helps to establish other unsaturated soil properties such us hydraulic conductivity, shear strength, and volume change (Fredlund et al., 2010). 
Figure 19 shows a typical SWCC. The graph presents the volumetric water content versus the soil suction.

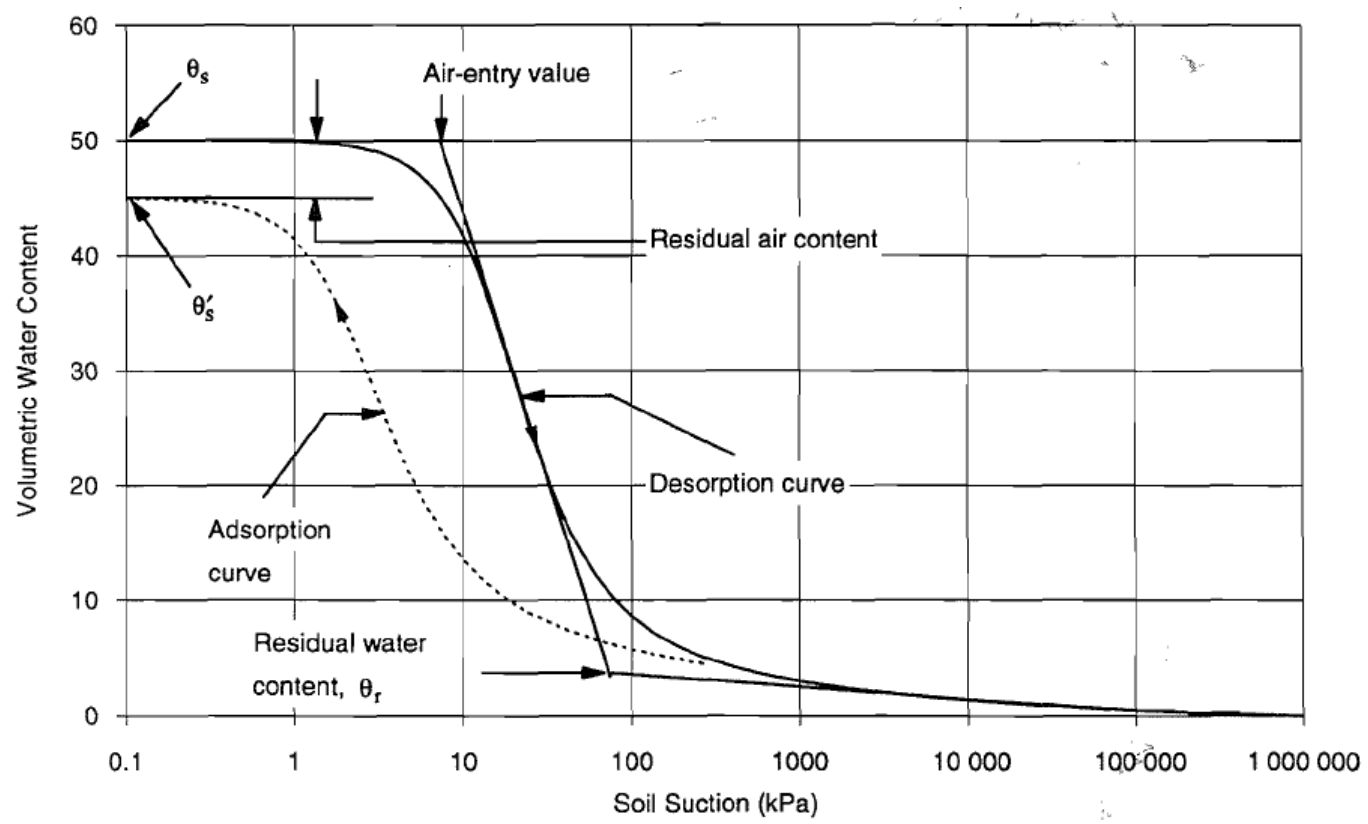

Figure 19. Typical SWCC for a silty soil (Fredlund et al., 1994)

The slope in the graph represents different saturation stages as desaturation occurs in the soil. Vanapalli et al. (1996) described three distinctive unsaturation stages as follows:

a) Boundary Effect Stage: At this stage, the voids within the soil are filled with water (i.e. saturated soil) and all the water menisci are constant. Also, the airentry value is present at this stage. This point represents a suction value at which air enters the largest pores of the soil. 
b) Transition Stage: Here, the soil begins to desaturate. The water content decreases significantly as the suction value increases. Also, the water menisci are not longer continuous and begin to decrease.

c) Residual Stage of Unsaturation: Lastly, as the soil continues to desaturate, large increases in suction are related to small changes in water content. The water menisci are really small and the remaining water is referred to as residual water.

Figures 20 and 21 show the three stages of desaturation in the SWCC and the water distributions as the soil desaturates.

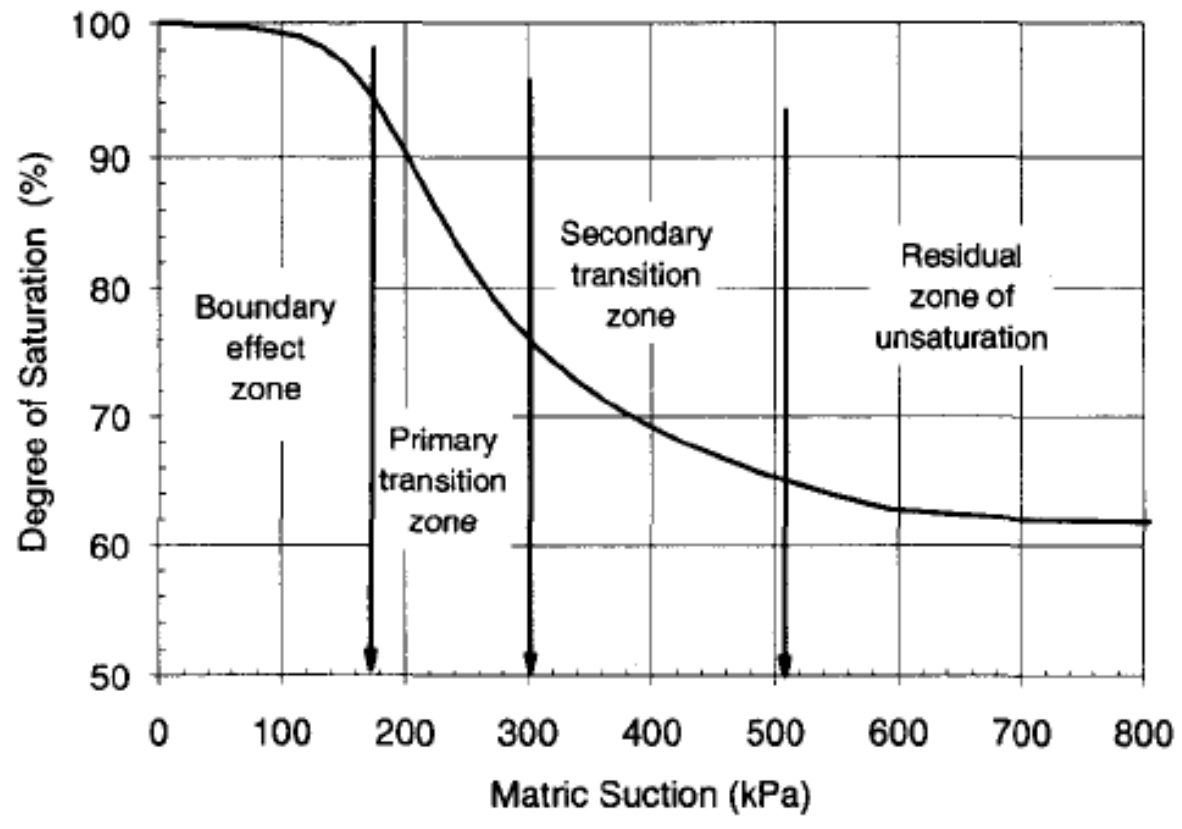

Figure 20. Saturation stages in the SWCC (Vanapalli et al, 1996). 

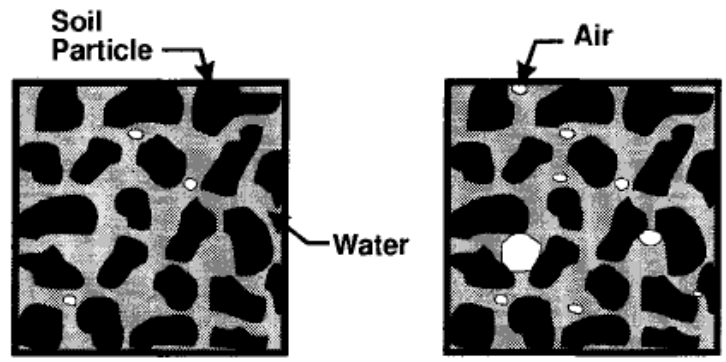

(a) Boundary effect stage

(b) Primary transition stage

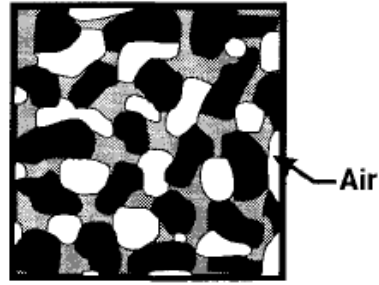

(c) Secondary transition stage

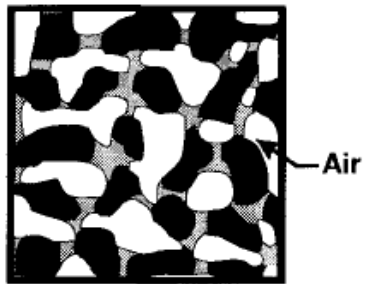

(d) Residual stage of unsaturation

Figure 21. Water variation at different degrees of saturation of a SWCC (Vanapalli et al, 1996).

\subsubsection{Soil Freezing Characteristic Curve (SFCC)}

The soil freezing characteristic curve (SFCC) is analogous to the soil water characteristic curve (SWCC) since it is also utilized to represent the relationship between soil water potential and unfrozen water content in fully or partially frozen soils. According to Spaans and Baker (1996), the SFCC represents the "relationship between the quantity and the energy status of liquid water in frozen soil".

Furthermore, there has been extensive research to determine the theoretical connection between the SFCC and SWCC. Works performed by Spaans and Baker (1996); Bittelli et al. (2003); and Flerchinger et al. (2004 and 2006) are commonly used 
to determine SWCC from SFCC as it is easily to perform, especially when the degree of saturation and water potential are low. Usually, to determine the SFCC, time domain reflectometry (TDR) is used to measure the unfrozen water content and the Clapeyron equation is used to calculate the pore water potential in frozen soils (Spaans and Baker, 1996). Spaans and Baker (1996) proposed a variation of the Clapeyron equation to calculate the matric water potential of unfrozen pore water. This equation is presented below:

$$
\psi_{L}=-712.38 \ln \left(\frac{T}{T_{o}}\right)+5.545\left(T-T_{o}\right)-3.14 \times 10^{-3}\left(T^{2}-T_{o}^{2}\right)-\Pi_{L}
$$

Where,

$$
\begin{aligned}
& \psi_{L}=\text { Matric potential of unfrozen water }(\mathrm{kJ} / \mathrm{kg}) ; \\
& T=\text { Soil temperature }(\mathrm{K}) ; \\
& T_{o}=\text { Reference state temperature }(273.15 \mathrm{~K}) ; \\
& \Pi_{L}=\text { Osmotic potential of unfrozen water }(\mathrm{kJ} / \mathrm{kg}) .
\end{aligned}
$$

The equation uses pure water at atmospheric pressure and a temperature $\left(T_{o}\right)$ of 273.15 $\mathrm{K}$ as reference states. Also, this relationship assumes that the liquid water potential is caused by temperature and ice pressure only and that solutes have been rejected from the ice phase (Spaans and Baker, 1996).

Consequently, the osmotic potential $\left(\Pi_{L}\right)$ of unfrozen water can be estimated from electrical conductivity and volumetric water content measurements, as seen in the 
relationship below. The underlying assumption is that the precipitation of salts would not occur when water is frozen out of solution (Spaans and Baker, 1996).

$$
\Pi_{L}=-39 \sigma_{s p} \frac{\left(W_{s p} \rho_{b}\right)}{\left(\theta_{L} \rho_{L}^{2}\right)\left(\frac{T}{298}\right)}
$$

Where,

$$
\begin{aligned}
& \sigma_{s p}=\text { Electrical conductivity }(\mathrm{mS} / \mathrm{cm}) ; \\
& W_{s p}=0.5=\text { Wetness }(\mathrm{kg} / \mathrm{kg}) ; \\
& \rho_{b}=\text { Bulk density }\left(\mathrm{kg} / \mathrm{m}^{3}\right) ; \\
& \theta_{L}=\text { Volumetric water content }\left(\mathrm{m}^{3} / \mathrm{m}^{3}\right) ; \\
& \rho_{L}=\text { Density of water }\left(\mathrm{kg} / \mathrm{m}^{3}\right) ; \\
& \mathrm{T}=\text { Soil temperature }(\mathrm{K}) .
\end{aligned}
$$

The following figure (Fig. 22) represents SWCC and SFCC data obtained by Spaans and Baker (1996). The data corresponds to field measurements from an experimental station at the University of Minnesota. Constant water potential and unfrozen water content measurements were taken to construct the SFCC. The soil was classified as silt loam. As mentioned previously, unfrozen water content was measured using TDR technology, while pore water potential was calculated using Equation 2.10. The matric potential data is shown with respect to gravimetric water content instead of volumetric water potential to account for the differences between bulk densities at different depths. 

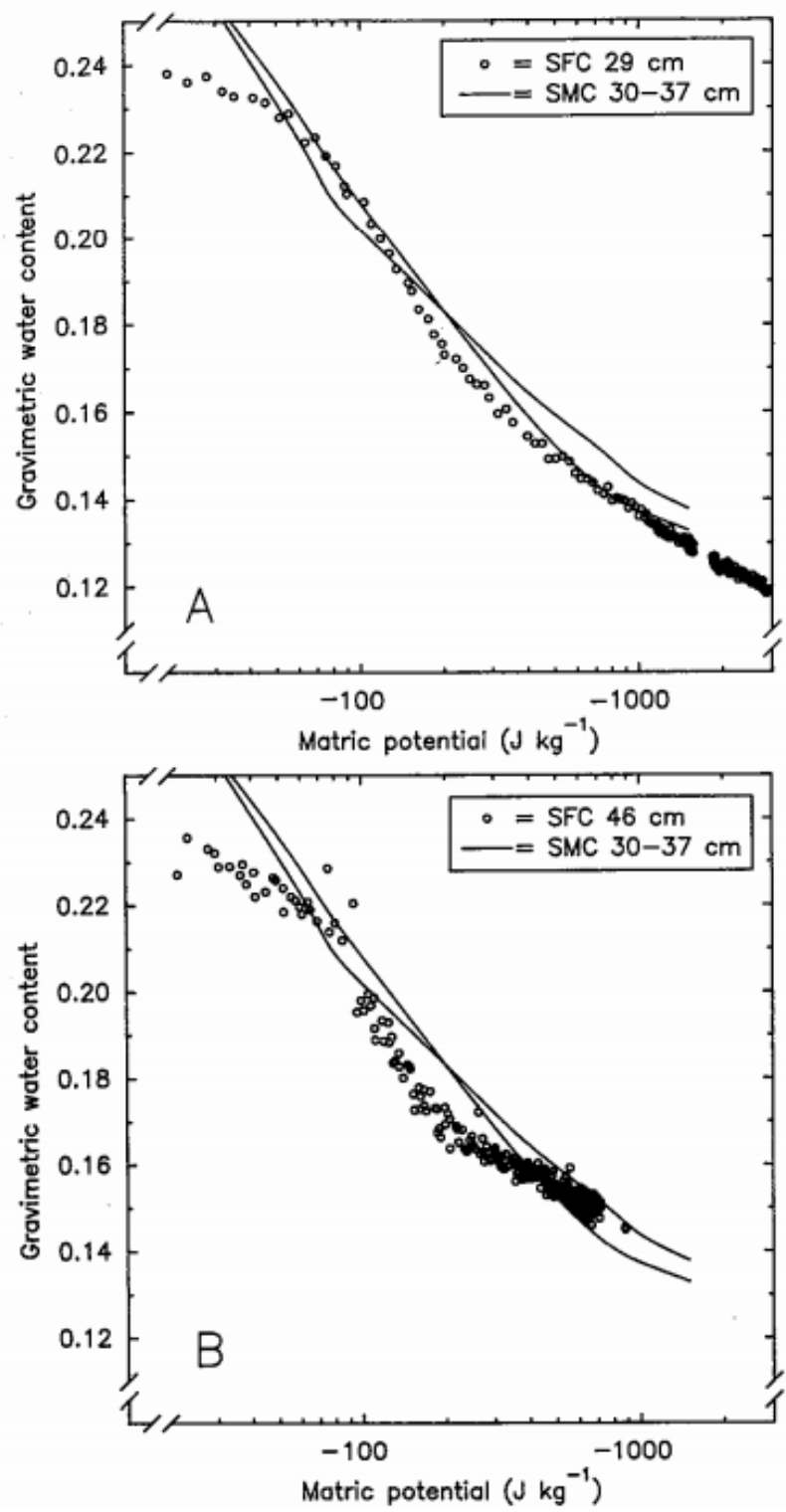

Figure 22. Comparison between SFCC at a depth of $29 \mathrm{~cm}$ and $46 \mathrm{~cm}$ and SWCC at a depth range of 30-37 cm (Spaans and Baker, 1996).

Lastly, there are some limitations in measuring the SFCC to determine the SWCC in soils. Spaans and Baker (1996) highlighted the difficulty in obtaining reliable SFCC data at high volumetric water contents. The slow temperature variations and slow 
phase change present in sub-surface soil, favor the dewatering of soil before it freezes making it difficult to measure matric potential at high water contents. Also, in temperatures below zero degrees, the contribution of osmotic potential to the total suction increases leading to larger uncertainties in its calculation.

\subsection{Frozen Ground and Effect of Freeze-Thawing on Soils}

\subsubsection{Frozen Ground Definition}

Frozen ground is considered to be a four-phase natural formation in which each component has its own properties and are bound to each other. These phases are the following (Tsytovich, 1975):

a) Solid Mineral Particles: Similar to unfrozen ground, the shape, size, and the mineralogical composition of the soil particles influences soil properties in frozen ground. The shape of soil particles determines the magnitude of forces being carried to the frozen soil from external loads. Meanwhile, the soil particle size dictates the interaction of particles with the unfrozen pore water within the soil. And lastly, the mineral composition determines the chemical interactions among mineral particles, unfrozen water, and ice.

b) Plastic Ice Inclusions: Ice is considered to be a monomineralic cryohydrate rock with highly unique physiochemical properties. Currently, there are 17 (XVII) recognized modifications of ice in which their formation depends on the 
temperature and pressure they were subjected at the time of formation (Chaplin, 2016). They differ from "standard" ice because they have different crystal structure, which leads to different melting points and physical properties (i.e. strength). Furthermore, the most common modification of ice is 'ice I' and it is commonly found in nature. It exists at ordinary pressures and at temperatures between $0{ }^{\circ} \mathrm{C}$ and $-100{ }^{\circ} \mathrm{C}$ approximately.

Ice I is the most important component in frozen soils because it determines the mechanical properties of the soil. It has a hexagonal form and it is considered anisotropic, see Figure 23. When loaded, ice I shows its largest visco-plastic deformation in the direction perpendicular to the principal optical axis (i.e. direction in which light does not undergoes double refraction). Moreover, due to the mobility of hydrogen atoms in its crystal lattice, the properties of ice I (e.g. structure, viscosity, etc) will vary under thermodynamic changes, such as pressure, temperature, etc. This makes the properties of ice I, and therefore frozen ground, unstable.

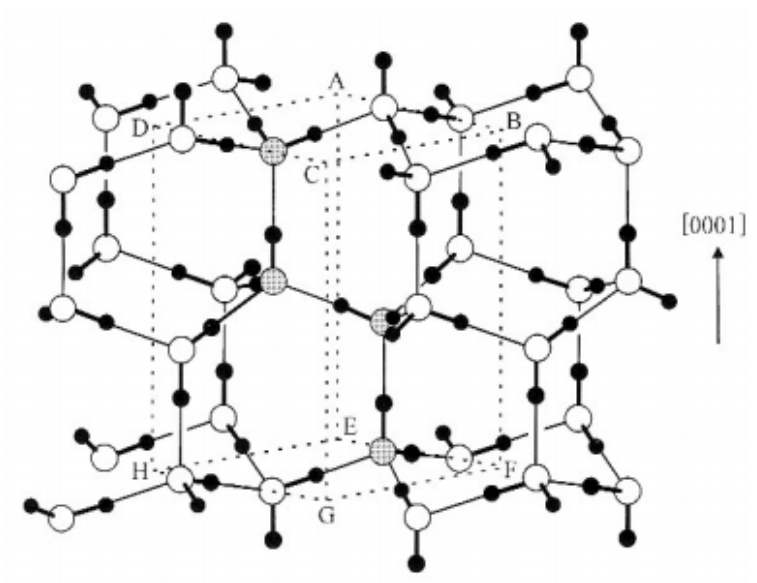

Figure 23. Crustal Structure of Ice I (Anderson, 2009). 
From this point onwards, ice I will be referred just as ice to avoid confusion.

a) Liquid Water: Unfrozen water in the liquid phase is also present in frozen grounds at temperatures below $0{ }^{\circ} \mathrm{C}$. The unfrozen water content determines in many ways the physical/mechanical properties of frozen ground making it of great value in the mechanics of frozen ground.

b) Gaseous Components: These entitle water vapor and other gases, assuming the soil is not fully saturated by water or ice. Water vapor helps in the redistribution of moisture along a vapor gradient during temperature changes. Lastly, other gases may be present depending on the type of soil and organic matter content.

It is important to mention that other mineral can exist in frozen grounds that are only formed at temperatures below zero. These minerals can include cryohydrates of sodium carbonate, magnesium chlorite, among others.

\subsubsection{Freeze-Thaw Phenomena}

As mentioned in the previous section, the loss of water content due to freezethaw cycles is a known natural dewatering process. When fine-grained soils undergo freezing, negative pore water pressures develop within the soil mass. This occurs specifically between the water surrounding the soil particles and the ice filling the 
voids. In freezing soils, negative pore water pressures, or suctions, occur due to the difference in surface tension between ice and water surrounding soil particles. This difference in pressure causes water from the unfrozen soil below to migrate towards the growing ice crystals (Dawson et al. 1999), which form the frozen front.

Similarly, Eigenbrod et al. (1996) describes the development of pore water pressures as a continuous cycle in the frozen front. As temperature drops below zero, ice lenses begin to form within the soil mass. They start exerting pressure on the water surrounding the soil particles in the unfrozen part of the soil, which increases pore water pressure and decreases the effective stress below the freezing front. This reduction in effective stress is favourable and necessary for the further development of ice lenses (Miller, 1978). The continuous increase of pore water pressures in the unfrozen section of the soil due to the presence of ice lenses in the freezing front leads and promotes suction of unfrozen water towards the already frozen soil. As suctions are developed, the initial pore water pressures decrease and negative pore water pressures become present. Consequently, the effective stress acting on the soil mass increases and the soil starts to compress. Soil compression leads more water to be available and pore water pressures begin to increase once again. Thus, effective stress increases which leads to more ice lens formations and the whole process repeats itself again.

Moreover, Dawson et al. (1999) describes two types of ice lens formations in the boundary layer between the freezing front and the unfrozen soil mass underneath. In an open system, which has a constant water supply from the unfrozen soil below, 
horizontal ice lenses form above the $0{ }^{\circ} \mathrm{C}$ freezing level. Likewise, in a closed system, which lacks a water supply from below, horizontal ice lenses do not develop but a matrix of non-uniform ice structures form, which draws water from within the frozen front. Consequently, the formation of ice lenses leads to an increase in the soil's volume, which is also known as frost heave. Osterkamp and Burn (2002) state that finegrained soils hold water in tension at their surface in the form of mobile films. They also state that the large excess in water volume from oversaturation separates soil particles to form ice lenses in the freezing soil. This is another reason why frost heave is a common occurrence in fine grain soils.

Consequently, after a freeze-thaw cycling ends, noticeable changes in the mechanical properties of soils have been reported in the literature. Chamberlain and Gow (1978) reported changes in the permeability of soils after a freeze-thaw cycle due to the change in soil structure triggered by the formation of ice lenses. They studied four different types of clays and concluded that permeability increases significantly as freeze-thaw cycles increase. They noted that the change in permeability is heavily linked with vertical cracks formed after thawing. Othman and Benson (1993) reported that the permeability of clays increases as the freeze-thaw cycles increase. However, it was also noted that after three cycles no further change in permeability occurs. In a similar fashion, changes in void ratio are described in the literature. Konrad (2010) performed tests in low plasticity till under a vertical stress of $40 \mathrm{KPa}$. He noted that the void ratio decreases after four freeze-thaw cycles. Viklander (1998) conducted tests on fine-grained till. He reported that void ratio decreases in samples with high initial void 
ratio and increases in samples with lower void ratio. He also concluded that all tested samples achieved a residual void ratio after one to three freeze-thaw cycles. Lastly, the literature reports mixed findings in Atterberg limits changes. Eigenbrod (1996) tested four different clays and reported no significant changes in the clay's Atterberg limits before and after freeze-thaw cyling. On the other hand, Yong et al. (1985) showed that natural clays decrease their liquid limit value by $30 \%$ after $8-16$ cycles. However, in samples prepared in the lab, no changes in the liquid limit value occurred.

\subsection{Previous Work on Freeze-Thaw Dewatering in MFT}

Johnson et al.'s work on oil sands sludge dewatering by freeze-thaw and evapotransporation in 1993:

Johnson et al. (1993) performed small-scale laboratory tests on un-amended sludge from a Syncrude tailings pond. The samples were obtained in 1986 and they contained an initial solids content of $29 \%$ and $35 \%$. Sample sizes varied in weight $(3 \mathrm{~kg}$ to $20 \mathrm{~kg})$ and depth $(5 \mathrm{~cm}$ to $30 \mathrm{~cm})$, and they were frozen in a freezer at a temperature of $-24{ }^{\circ} \mathrm{C}$. The containers holding the tailings were only insulated at the bottom leading to 2-dimensional freezing. Freeze-thaw cycles varied from 1 to 3 , as well as freezing time (not clearly indicated). After thawing, samples showed an increase in the final solids content ranging from $43 \%$ to $51 \%$ after one freeze-thaw cycle. See Table 4 for more results. Also, the authors noticed that at different freezing rates the post-thaw sediments 
varied. One-day freeze-thawing led to grainy sediment meanwhile 2-week freezing led to platelet size sediment.

Table 4. The effect of freeze-thaw cycles on solids content of pure sludge (Johnson et al., 1993)

\begin{tabular}{|c|c|c|}
\hline $29 \%$ sludge starting material & & $\begin{array}{l}\text { Percent solids by } \\
\text { freeze-thaw cycle }\end{array}$ \\
\hline Sludge depth & 1 & $\underline{2}$ \\
\hline $5 \mathrm{~cm}$ & 45 & 48 \\
\hline $15 \mathrm{~cm}$ & 47 & 52 \\
\hline $30 \mathrm{~cm}$ & 43 & 50 \\
\hline
\end{tabular}

$35 \%$ sludge starting material

$15 \mathrm{~cm}$

$51 \quad 55 \quad 57$

Johnson et al. (1993) performed other tests that involved the enhancement of drainage during thawing. For these tests, un-amended oil sands sludge was used at 35\% solids content along with dyke sand, which was used as a drainage path within the container holding the tailings, as seen in Figure 24. Tubes crossed the sand layer at different point to collect the water after thawing. Different configurations of containers with sand as drainage paths were used. Tests were performed only once for each configuration. Sample volumes varied from a few liters to 200 liters.

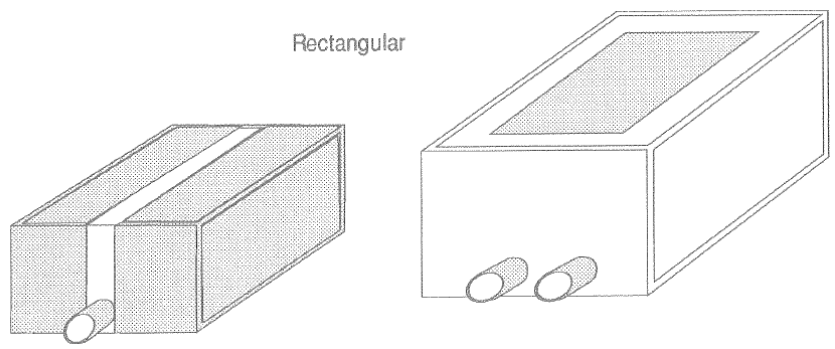

Figure 24. Experimental models for dewatering pure oil sands sludge (Johnson et al., 1993) 
One of the conclusions draw by this experiment was that by altering the potential drainage area and surrounding the sludge with sand, more water was drained. Also, the authors found that sand capillary forces are able to draw more water out than by drainage due to gravity alone. Table 5 shows the final solids concentrations for the different configurations used in this experiment.

Table 5. The effect of sand-sludge configuration on the increase of sludge solids content after one freeze-thaw cycle (Johnson et al., 1993)

\begin{tabular}{lccc}
\hline \multicolumn{1}{c}{ Configuration $^{!}$} & \multicolumn{3}{c}{ Sludge solids content (\%) } \\
\cline { 2 - 4 } & $\frac{\text { Initial }}{35}$ & $\frac{\text { Final }}{52}$ & $\frac{\text { Increase }}{17}$ \\
$\begin{array}{l}\text { Rectangular } \\
\text { (sand in middle) }\end{array}$ & 35 & 62 & 27 \\
$\begin{array}{l}\text { Rectangular } \\
\text { (sand around sides) }\end{array}$ & 35 & 59 to 63 & 24 to $28^{2}$ \\
Concentric & 35 & 57 & 22 \\
Surcharge & & & \\
\hline
\end{tabular}

Lastly, Johnson et al., (1993) also performed large-scale experiments. The tailings were placed in a large metal drum, which was placed within a large polyethylene drum. In between the two containers insulation material was placed to ensure that one-dimensional freezing from the top occurred alone. Four different samples with initial solids content of $15 \%, 25 \%, 35 \%$ and $45 \%$ were tested. Each sample contained approximately $45 \mathrm{~L}$ of un-amended tailings. The samples were frozen at $-24{ }^{\circ} \mathrm{C}$ and thermocouples were placed at different depths to monitor the internal temperature of the tailings. Freezing was considered completed when all the thermocouples reached a temperature of $-24{ }^{\circ} \mathrm{C}$. During and after thawing, surface 
water was removed and the samples were covered to prevent evaporation. Three freezethaw cycles were applied in this experiment.

Table 6 shows the initial and final solids content at the end of each freeze-thaw cycle. From these results, the authors indicate that the initial solids content has a dramatic effect on the amount of water the tailings can dewater. As seen in the table below, low initial solids content leads to a large amount of released water. Consequently, as the initial solids content increases, the rate of dewatering drops.

Table 6. Average solids content before and after freeze-thaw cycles (Johnson et al., 1993)

\begin{tabular}{ccccc}
\hline $\begin{array}{c}\text { Mix } \\
\#\end{array}$ & $\begin{array}{c}\text { Original } \\
\text { \% solids }\end{array}$ & $\begin{array}{c}\text { \% Solids after } \\
\text { 1 cycle }\end{array}$ & $\begin{array}{c}\text { \% Solids after } \\
\text { 2 cycles }\end{array}$ & $\begin{array}{c}\text { \% Solids after } \\
3 \text { cycles }\end{array}$ \\
\hline 1 & 45.4 & 51.3 & 57.8 & 60.4 \\
2 & 37.4 & 47.9 & 55.1 & 59.6 \\
3 & 26.2 & 38.7 & 46.4 & 52.7 \\
4 & 16.3 & 35.4 & 46.2 & 49.5 \\
\hline
\end{tabular}

Johnson et al., (1993) proposed a relationship that predicts the final solids content from the initial solids content.

$$
Y=249.4-8.93 x+0.08 x^{2}
$$

Where,

$$
\begin{aligned}
& Y=\text { final solids content }(\%) \\
& x=\text { initial solids content }(\%)
\end{aligned}
$$


This equation was draw from the experimental data presented above and it is derived from the relationship between initial solids content and the degree of dewatering through freeze-thaw (Figure 25).

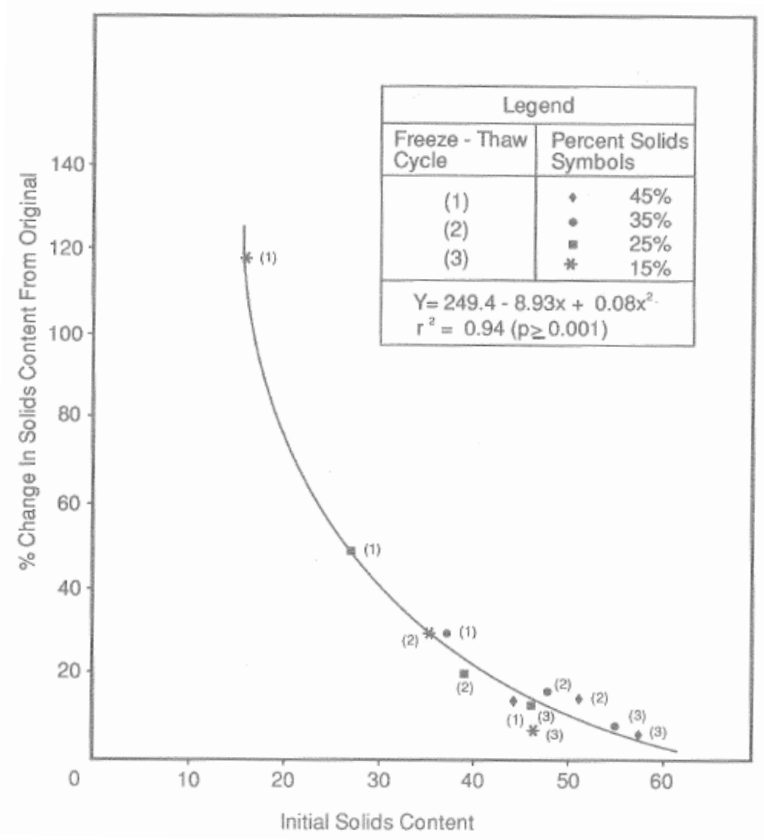

Figure 25. Change in final solids content in relation to initial solids content and freeze-thaw cycle (Johnson et al., 1993)

Other conclusions drawn by the authors include the amount of time require to freeze the sample. They stated that longer times were needed to freeze samples with low solids content. In other words, the higher the solids content, the less energy is required to turn water into ice. It was also point out that the dewatering rate of tailings decrease after one freeze-thaw cycle. The degree of desaturation was significantly reduced in the second and third freeze-thaw cycle. 


\section{Proskin's work on freeze-thaw dewatering of oil sands tailings in 1998:}

Samuel A. Proskin investigated the geotechnical behavior of freeze-thaw on Suncor MFT post thawing. Proskin (1998) tested and compared never-frozen MFT, MFT subjected to one freeze-thaw cycle, and sulfuric acid and quicklime amended MFT subjected to one freeze-thaw cycle as well. Consolidation and compressibility tests were also performed using a large strain consolidation and constant head hydraulic conductivity apparatus specially designed for these tests. The specimens' size was 10 $\mathrm{cm}$ in diameter and $14 \mathrm{~cm}$ in height.

Two samples of the never-frozen MFT were tested with initial solids content of $31 \%$ and $42 \%$. Proskin (1998) reported that the lower solids content sample has a higher compressibility index of 1.4 compared to the higher lower solids content sample, which has a compressibility index of 1.1. Both samples present different compressibility curves, however, at effective stresses greater than $10 \mathrm{KPa}$ they concur on a common curve.

Additionally, 5 samples of the MFT that underwent one freeze-thaw cycle were tested. From the compressibility test results, Proskin (1998) reported the immediate reduction in void ratio when compared to never-frozen MFT. After thawing, the void ratios from the 5 samples range between 2.4 and 3.7 due to the variability of the material. Some the samples have lower in magnitude and flatter slopes compared to the never-frozen samples, meaning that they are less compressible. At stresses greater than 
$20 \mathrm{KPa}$, the slopes become flat again and intersect the never-frozen curve. Form the hydraulic conductivity test, Proskin (1998) reported an increase of up to 2 orders of magnitude in hydraulic conductivity when compared to never-frozen samples' results.

Lastly, the results of 4 samples from the sulfuric acid and quicklime amended MFT after one freeze-thaw cycle yielded positive results, as seen in Figure 26. From the compressibility test, 3 out of 4 samples showed a lower slope when compared to the never-frozen samples, inferring lower compressibility. The slopes from these 4 samples intersect the never-frozen samples at $100 \mathrm{KPa}$ and 0.9 void ratio. From the hydraulic conductivity test, the results are shown to be significantly higher than the never-frozen samples at equal void ratios.
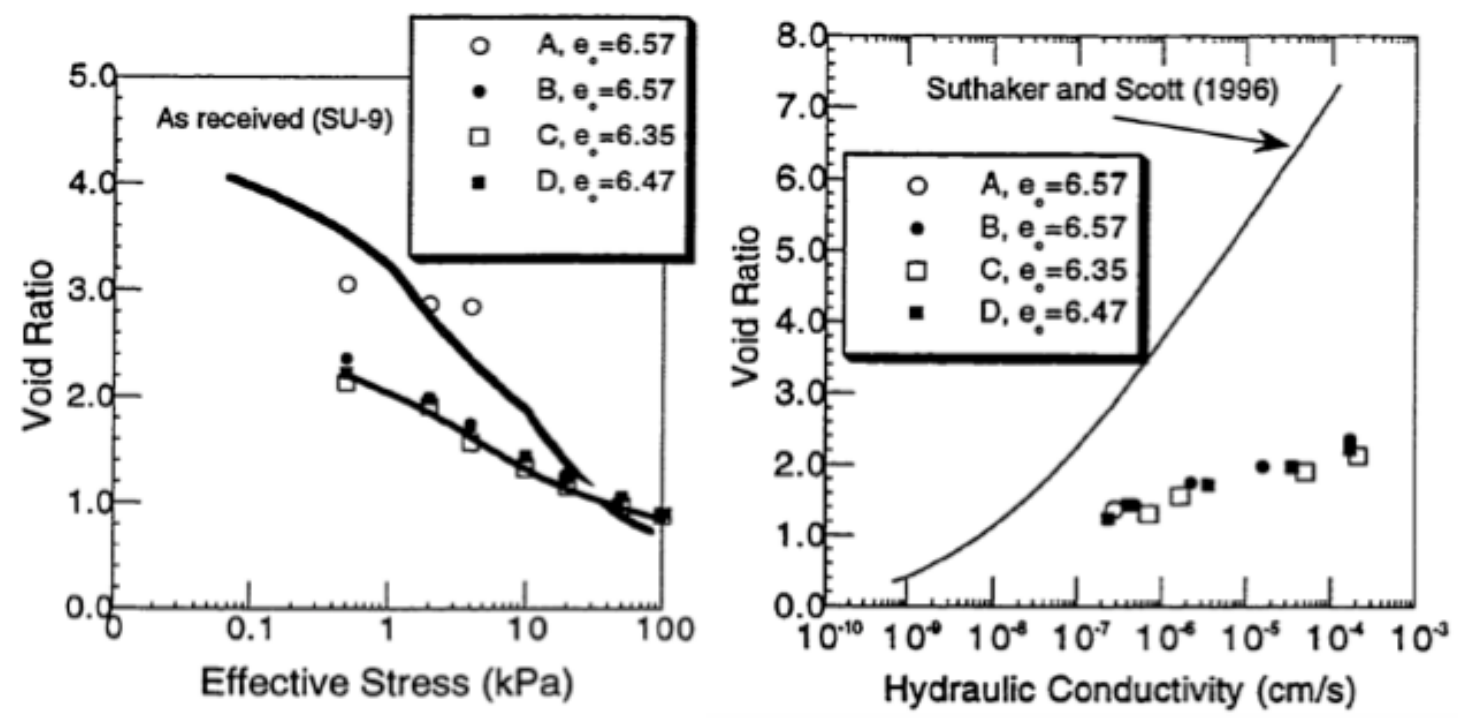

Figure 26. Compressibility and hydraulic conductivity results from sulfuric acid and quicklime ameneded MFT (modified after Proskin, 1998) 
After concluding these experiments Proskin (1998) concluded the following:

- The compressibility of MFT was found to be dependent on the initial solids content.

- A freeze-thaw cycle it has been proven to reduce compressibility and initial void ratio.

- For the amended samples, compressibility is also reduced and results are more repeatable.

- After a freeze-thaw cycle, decrease in hydraulic conductivity is significant. The reduction from never-frozen to frozen and amended frozen samples is up to 2 orders of magnitude.

- Freeze-thaw cycles are found to help self-weight consolidation of MFT due to the additional release of water provoked by the increase of the effective stress during freezing.

Dawson, Sego, and Pollock's work on freeze-thaw dewatering of oil sands tailings in 1999:

Dawson et al., (1999) performed laboratory and field tests to show that one freeze-thaw cycle on oil sands tailings lead to substantial dewatering. The results were presented in terms of thaw-strain, which is defined as the change in volume due to thawing divided by the initial volume. Laboratory tests were performed at the University of Alberta using tailings obtained from operations that used hot water and sodium hydroxide for bitumen extraction. The tests used $15 \mathrm{~cm}$ thick layers placed 
between two cooling plates. The bottom plate was set to $-8{ }^{\circ} \mathrm{C}$ and the top plate to -15 ${ }^{\circ} \mathrm{C}$ to develop a temperature gradient. After freezing, the tailings were allowed to thaw and the excess water was drained. Solids content were measured after thawing and are presented in Figure 27. Dawson et al., (1999) pointed out the variability in solids content among the samples. For example, the Syncrude tailings increased from 30\% initial solids content to $35 \%$ solids content post thawing, while the OSLO tailings increased by $18 \%$ from the same initial solids content, which translates to approximately $50 \%$ increase in thaw-strain. Further chemical analysis of the pore water of the samples indicated that the OSLO tailings contained a low sodium concentration ( $84 \mathrm{mg} / \mathrm{L}$ ) when compared to the other samples (Suncor: $400 \mathrm{mg} / \mathrm{L}$ and Syncrude: 480 $\mathrm{mg} / \mathrm{L}$ ). The authors concluded that pore water chemistry could influence the thaw-strain behavior of tailings. Mineralogy tests of the samples were also performed and showed that all the tailings contained similar mineral composition.

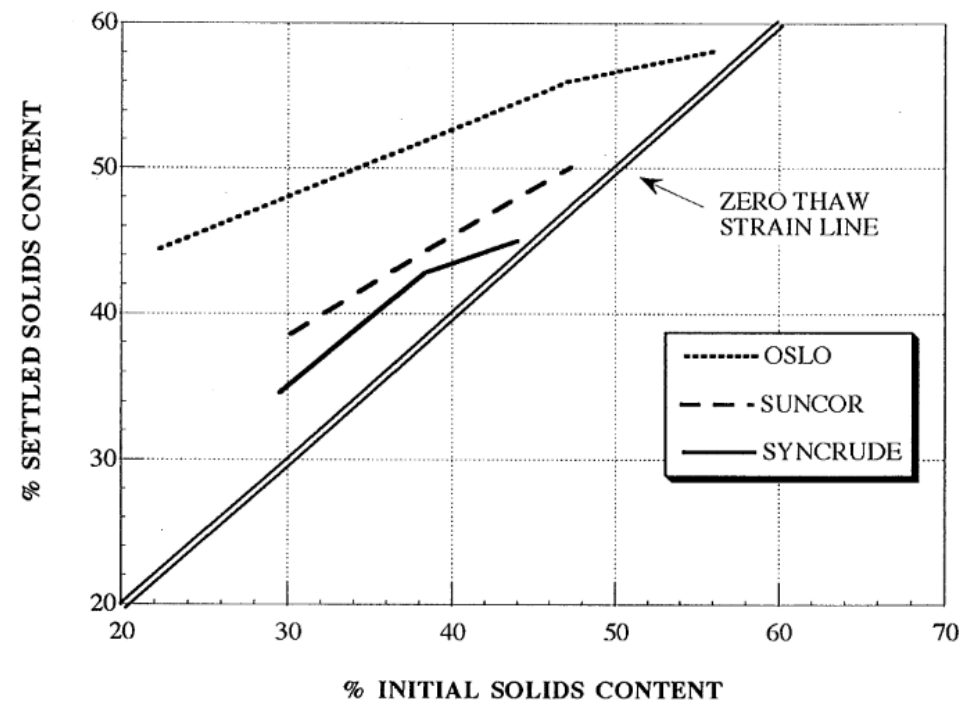

Figure 27. Laboratory experiment results performed by Dawson et al., (1999) 
Furthermore, Dawson et al., (1999) also presented field test results from a pilot plant located near Fort McMurray. The tailings contain 45-50\% clay-sized particles and $2-4 \%$ bitumen. Seventeen frozen core samples were taken at different location throughout the pilot plant at different times: 12 on February 1992 (labeled 1-12) and 5 on March 1992 (labeled A-G). The samples were taken to the University of Alberta for thaw and post-thaw laboratory analysis. They were placed in a Plexiglas oedometer under low stress conditions $(0.5 \mathrm{KPa})$ to measure thaw strain, compressibility and permeability. Figure 28 shows the initial and final solids content relationship post thawing for the laboratory and field tests. The authors explain that both trends are parallel but the field tests show a better thaw behavior in comparison to lab tests. This difference in behavior is attributed to the $0.5 \mathrm{KPa}$ applied to the field tests and to the direction of freezing in the samples. Laboratory samples were frozen from top and bottom meanwhile field samples were frozen only from the top.

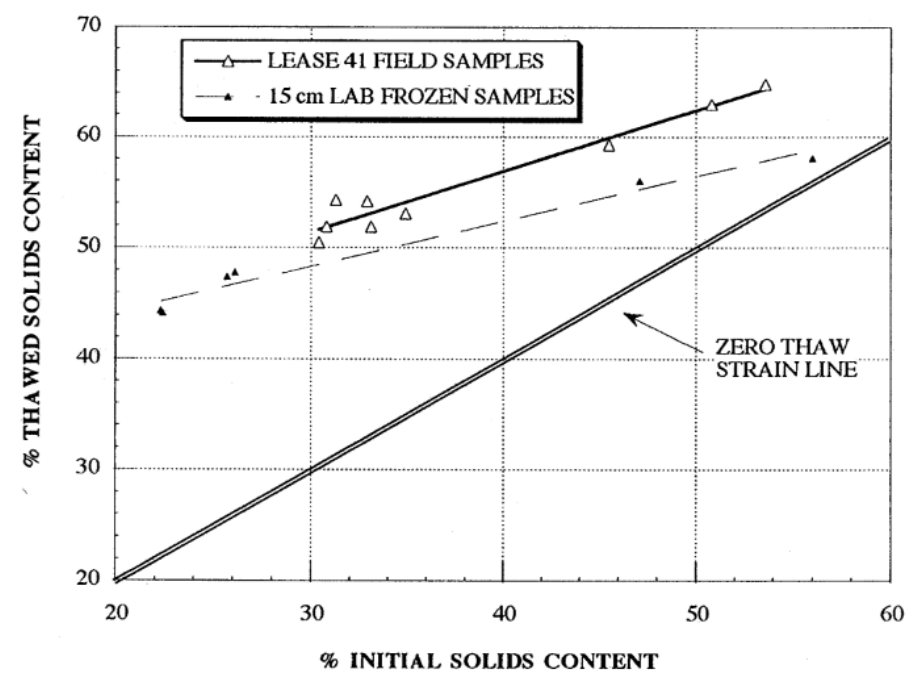

Figure 28. Initial vs final solids content for laboratory and field tests (Dawson et al., 1999) 
The following figure (Fig. 29) shows the relationship between initial solids content and thaw-strain. Dawson et al., (1999) indicated that after one freeze-thaw cycle, thaw-strains could exceed $50 \%$. Also, the trend suggests there is no change in volume as the initial solids content reaches $70 \%$.

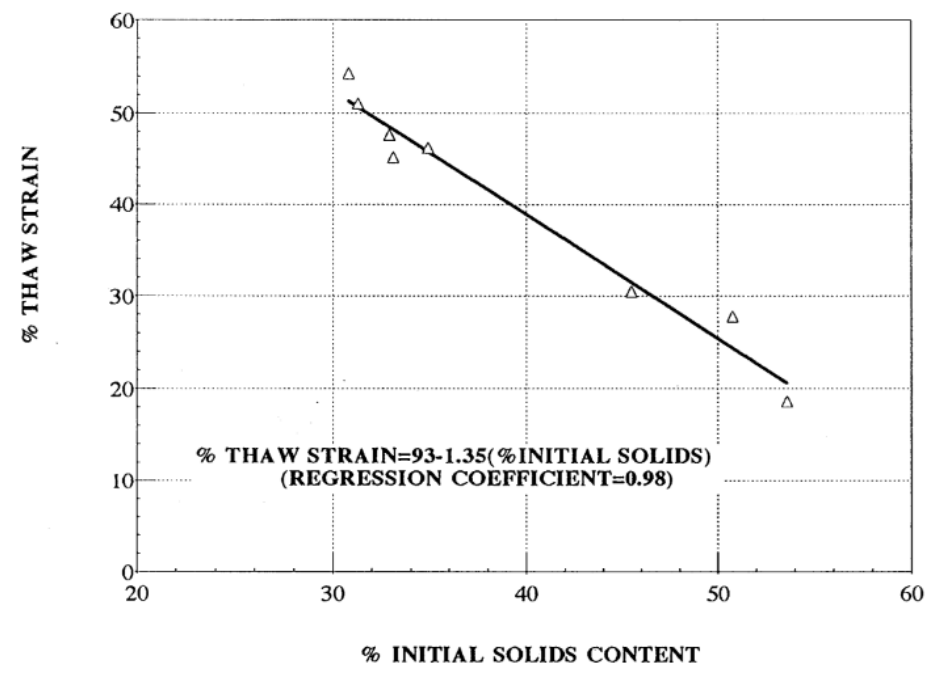

Figure 29. Initial solids content vs thaw-strain (Dawson et al., 1999)

Lastly, Figure 30 and Figure 31 shows the compressibility and permeability behavior of the tailings tested by Dawson et al., (1999). From those results the authors concluded that thawed tailings behave like overconsolidated soil and at stresses greater than $10 \mathrm{KPa}$, tailings approach the never frozen tailings compressibility line. Also, post-thawing, tailings show greater permeability behavior (increment of up to 2 orders of magnitude) when compared to never frozen tailings at similar void ratios upon thaw. 


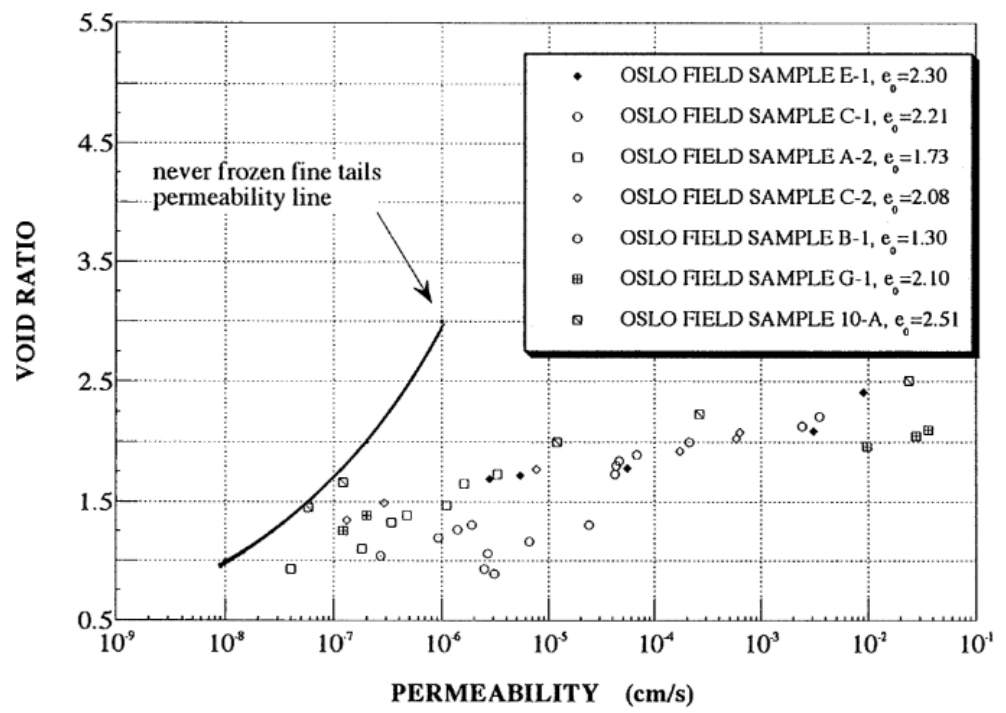

Figure 30. Void ratio vs Permeability (Dawson et al., 1999)

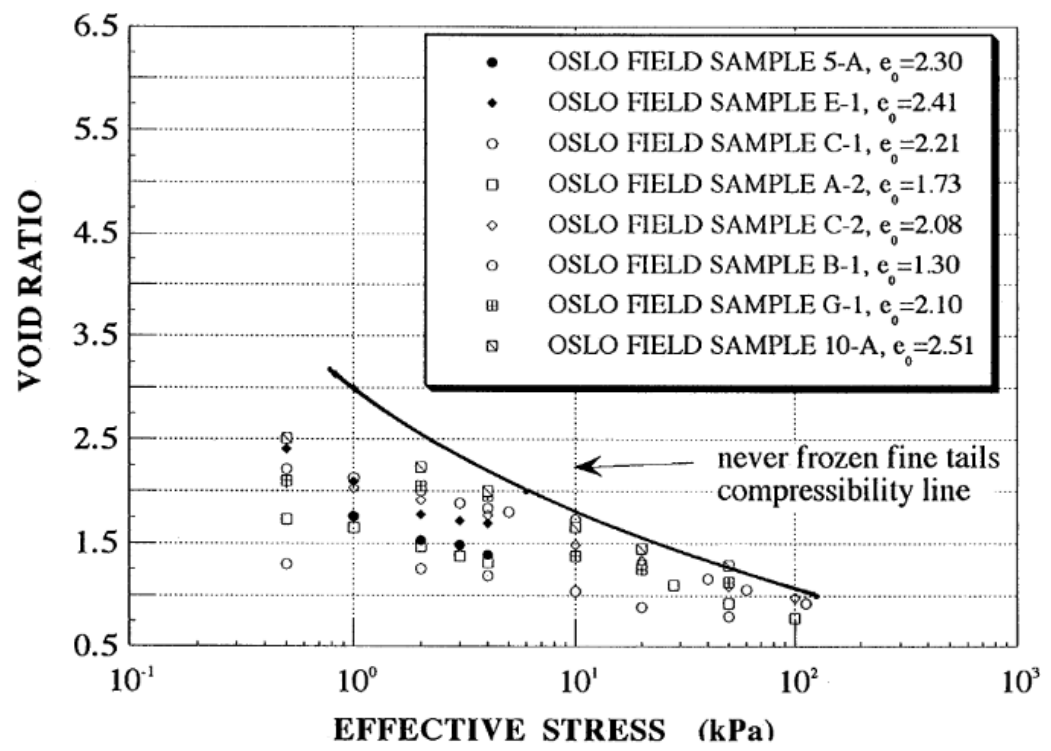

Figure 31. Void ratio vs Effective Stress (Dawson et al,, 1999) 
The authors concluded their investigation by presenting different models for design consideration to reduce waste volume by using the freeze-thaw cycles and the dewatering processes of oil sands tailings. The proposed suggestions are not included in this section since they are outside of the scope of the research presented in this document.

Farkish and Fall's work on SAP rapid dewatering of oil sands mature fine tailings in 2014:

Farkish and Fall (2014) examined, in a laboratory setting, the change in consolidation and hydraulic conductivity properties of dewatered MFT with super adsorbent polymer sachets after 2 freeze-thaw cycles. Upon the removal of the sachets, samples (63.5 $\mathrm{mm}$ in diameter and $25 \mathrm{~mm}$ in height) were frozen for 24 hours prior the consolidation and permeability tests. The hydraulic conductivity readings were obtained by a constant head test. The consolidation results showed that the initial void ratio could decrease by 30 to $40 \%$ after one freeze-thaw cycle (see Fig. 32). Also, it was reported that after a second freeze-thaw cycle the compressibility of the MFT is reduced (See Fig. 32); as well as the significant decrease in void ratio and increase in solids content. 

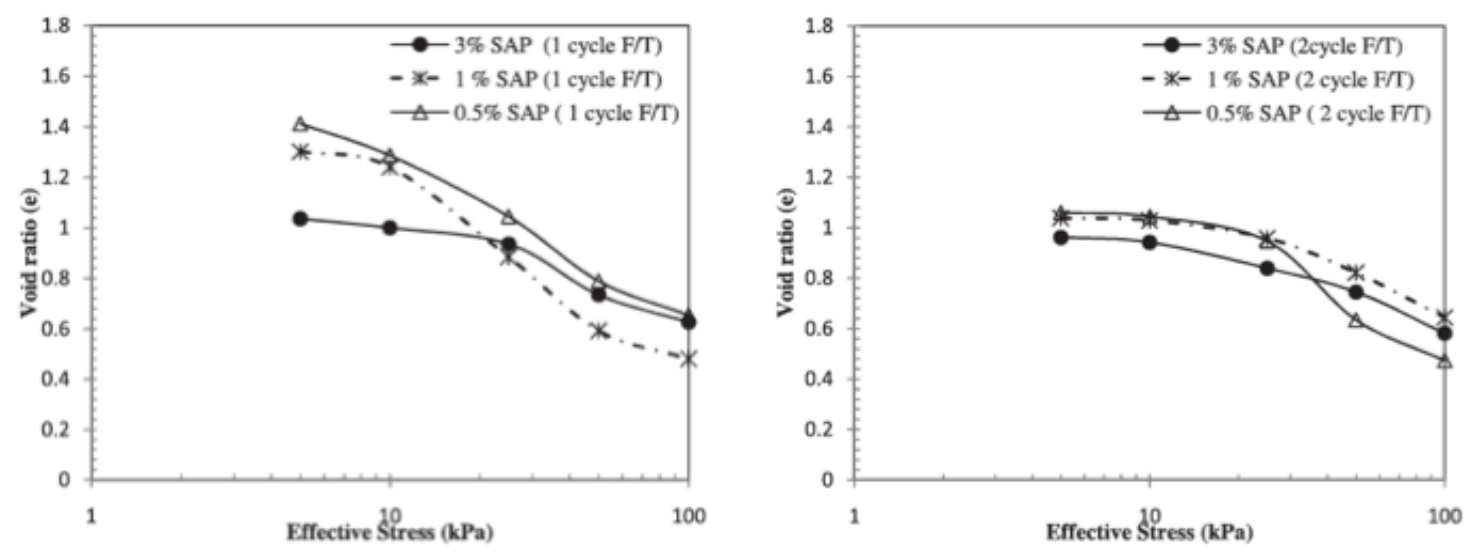

Figure 32. Consolidation test results after one and two freeze-thaw cycles (modified after Farkish and Fall, 2014)

Farkish and Fall (2014) also commented on the high hydraulic conductivity at low effective stresses of tailings after 2 freeze thaw cycles. It was noted that permeability decreases as effective stress increases. The authors point out that these results do not follow results from the literature. This was attributed to the change in the macro-structure of the tailings due to the formation of ice crystals when freezing. The frozen water crystals form ice channels so that when thawing started, they are used as drainage channels.

Lastly, it was concluded that, at lower stresses, samples than underwent dewatering due to the use of SAP and freeze-thaw cycles show higher hydraulic conductivity when compared to samples dewatered just by the use of SAP. The higher permeability is attributed to the ice channels formed when tailings were being frozen. 
From the review of previous work done in the freeze-thaw of oil sands tailings presented above, it is possible to draw the following conclusions.

- Different size samples for the freezing of tailings are used in the literature. They range from the small and thin, as presented by Proskin (1998), Farkish and Fall (2014), and Dawson et al., (1999); to the very large, as presented by Johnson et al., (1993).

- The number of freeze-thaw cycles applied on oil sands tailings is also not fixed and it largely depends on the researcher's judgment. The reviewed works vary from one to three freeze-thaw cycles. Each cycle also differs in its duration. The freezing period could last a few hours, days, or weeks.

- The direction of freezing and temperature below zero also varies. Even though, one-dimensional freezing is commonly used (Johnson et al., (1993), Proskin (1998), and Dawson et al., (1999)), two-dimensional freezing has been used as well (Johnson et al., 1993).

- Since the testing samples tend to be small, internal temperature, water content distributions, pore water pressures dissipation, and location of the freezing front within the tailings seem to be not too relevant to be studied. However, most the researchers and their work presented above (Proskin (1998), Dawson et al., (1999), and Farkish and Fall (2004)) agree on the detailed study of the consolidation and permeability properties of the thawed tailings. The common conclusion is that at least one freeze-thaw cycle can reduce the compressibility and initial void ratio of MFT. 
- Lastly, they all agree that the initial solids content increases after at least onefreeze thaw due to the water being release. This phenomenon aids in the selfweight consolidation of tailings.

The variability in freeze-thaw methodologies is not present only in freeze-thaw research of oil sands tailings. Henry (2007) compiled information about freeze-thaw research methodologies in different types of soil and the variability of methodologies is also present. The compilation of results and methodologies can be seen in Appendix D.

The work performed and explained in this report tackles the freeze-thaw study of oil sands tailings from a different angle. Having the summary of previous work done on this topic as a precedent, the research methodology used in this research attempts to re-create field conditions as much as possible. For example, the size of the testing sample has a height of $0.5 \mathrm{~m}$ since that is the lift height used at the time of deposition of tailings; the freezing temperature assigned for the experiments is taken from the climatological data from Fort McMurray, Alberta; and lastly, the use of a close system will be implemented in the freezing process since tailings under filed conditions do not have access to water from the soil underneath them. The detailed experimental methodology is explained in Chapter 3.

\subsection{Freeze-thaw Phenomenon in Oil Sands Tailings Ponds}

In 2009, Suncor Energy Inc. presented a Dedicated Disposal Area (DDA) Plan to the Energy Resources Conservation Board in Alberta for its activities east of the 
Athabasca River. In this report, Suncor reported that the main dewatering mechanism during the winter season is through freeze-thaw of tailings (Suncor Energy Inc., 2009). After the MFT has been placed on the deposition cells and it is allowed to freeze, water segregates from the soil particles in the form of ice crystals. After the thawing, water is released and drained and evaporated from the deposit. Suncor also reported that after thawing approximately 1,520 tons ( $46 \%$ of total initial weight) of water are released and 169 tons (5\% of total initial weight) are evaporated from the tailings. All this water comes from 3,333 tons of treated MFT prior freezing (Suncor Energy Inc. 2009). The following figure (Fig. 33) shows the material balance during winter operations in the Suncor's operation facilities.

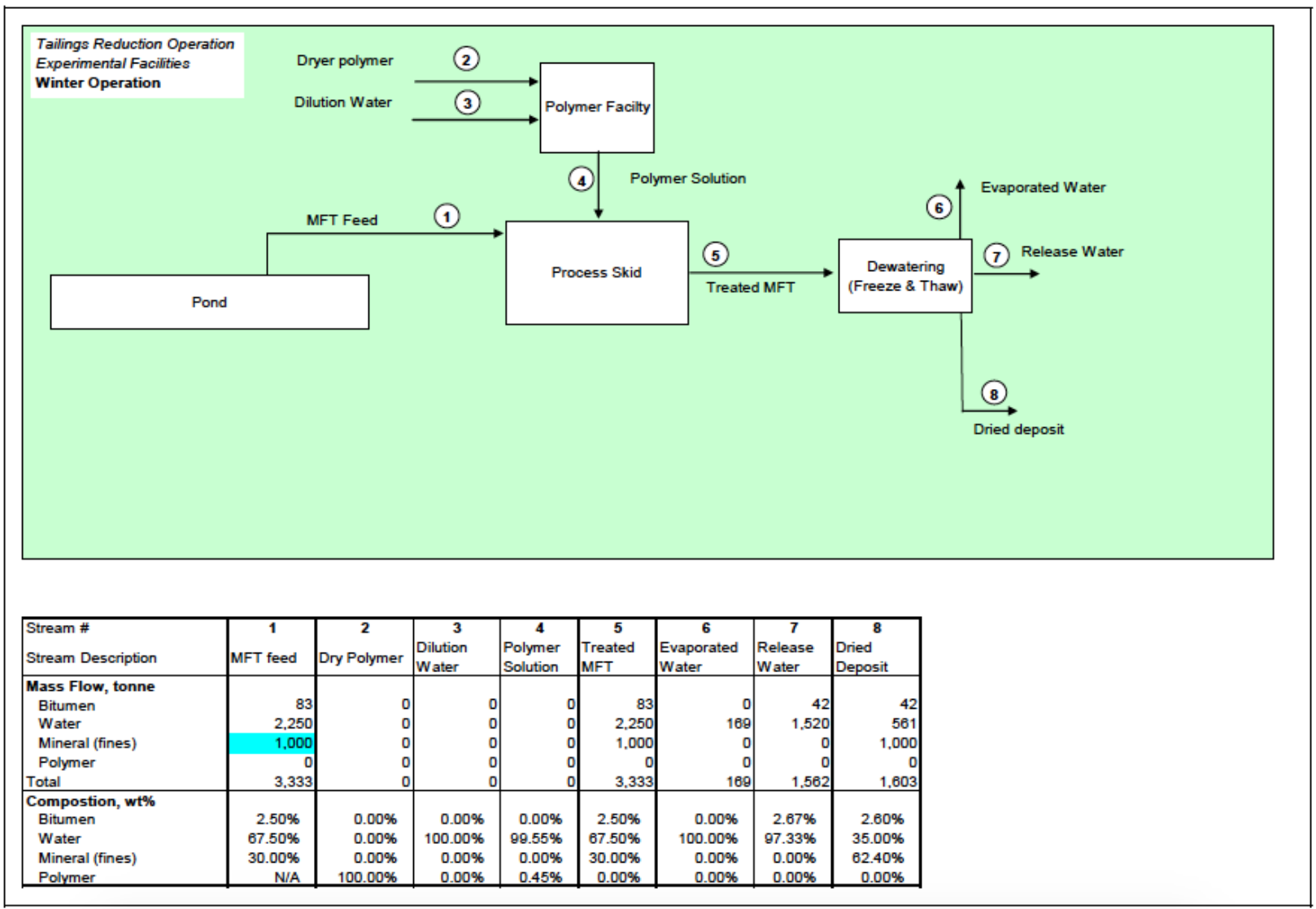

Figure 33. Material balance during winter operations in the Suncor facilities (Suncor Energy Inc., 
Suncor also performed thin layer MFT freeze thaw tests as part of pilot programs in 1992 and 1996. From these tests, it was concluded there is a considerable volume reduction due to dewatering. For every $1 \mathrm{~m} 3$ placed there was a $0.5 \mathrm{~m} 3$ reduction (CTMC 2012). It was also stated that the freeze-thaw method for dewatering of tailings became less effective at higher solids contents. At the end of the tests, the solids content increased from $35 \%$ to $65 \%$ and the consolidation rates increased as well (CTMC, 2012). 


\subsection{References}

Alberta Energy. (2014). Alberta's Oil Sands. Retrieved April 14, 2016, from Alberta Government: http://www.oilsands.alberta.ca/resource.html

Allen, E. W. (2008). Process Water Treatment in Canada's Oil Sands Industry: I. A Review of Emerging Technologies. Journal of Environmental Engineering and Science (7), 499-524.

Alvarez, J., \& Han, S. (2013). Current Overview of Cyclic Steam Injection Process. Journal of Petroleum Science Research , 2 (3), 116-127.

Anderson, N. (2009). The Many Phases of Ice. Retrieved July 12, 2016, from Iowa State University website: http://www.physics.iastate.edu/staff/travesset/phasesofice.doc

Barr Engineering. (2012). Atmospheric Fines Drying (AFD) Deposition Optimization: Multi-lift versus Deep Stacking. Shell Canada Limited. Barr Engineering and Environmental Science Canada Ltd. and O'Kane Consultants Inc.

Been, K., \& Sills, C. (1981). Self-weight consolidation of soft soils. Geotechnique, 31 (4), 519-535.

Beier, N., \& Sego, D. (2008, June). The oil sands tailings research facility. Geotechnical News , 72-77.

Beier, N., Alostaz, M., \& Sego, D. (2009, November 4). Natural dewatering strategies for oil sands fine tailings. Edmonton, Alberta, Canada: Tailings and Mine Waste 09 Conference. 
Beier, N., Wilson, W., Dunmola, A., \& Sego, D. (2013). Impact of flocculation-based dewatering on the shear strength of oil sands fine tailings. Canadian Geotechnical Journal (50), 1001-1007.

Bernard-Innocent, T. (2013). Evaporation, cracking, and salinity in thickened oil sands tailings. $\mathrm{PhD}$ Thesis, Carleton University, Civil and Environmental Engineering, Ottawa, ON, Canada.

BGC Engineering Inc. (2010). Oil Sands Tailings Technology Review. Edmonton, Alberta: Oil Sands Research and Information Network.

Bittelli, M., Flury, M., and Campbell, G. S. (2003). A thermodielectric analyzer to measure the freezing and moisture characteristic of porous media. Water Resour. Res., 39(2), 1041.

Canada's Oil Sands Innovative Alliance (COSIA). (2013). Composite Tailings Process Addresses Challenging Tailings Material.

Chalaturnyk, R. J., Scott, J. D., \& Ozum, B. (2002). Management of Oil Sands. Petroleum Science and Technology, 20, 1025-1046.

Chamberlain, E., \& Gow, A. J. (1978). Effect of Freezing and Thawing on the Permeability and Structure of Soils. Eng. Geol. , 13 (1-4), 73-92.

Chaplin, M. (2016, June 09). Ice Phases. Retrieved July 12, 2016, from London South Bank University website: http://wwwl.1sbu.ac.uk/water/ice_phases.html

CTMC - Consortium of Oil Sands Tailings Management Consultants. (2012). Oil Sands Tailings Roadmap - Project Report - Component 1 Results. Calgary, Alberta, Canada: Alberta Innovates - Energy and Environment Solutions. 
Dawson, R., Sego, D., \& Pollock, G. (1999). Freeze-thaw dewatering of oil sands fine tails. Canadian Geotechnical Journal (36), 587-598.

Decagon Devices. (2014, December 04). MPS-2 \& MPS-6 Dialectric Water Potential Sensors. Decangon Devices Inc.

Decagon Devices. (2003). WP4-T Dewpoint PotentiaMeter: Operator's Manual. Decagon Devices Inc.

Devenny, D., \& Nelso, R. (2009). Economic screening of tailings options foi oil sands plants. IN: Tailings and Mine Waste 2009, Banff, Alberta. Edmonton, Alberta: University of Alberta, Department of Civil and Environmental Engineering.

Dunbar, B. (2009). Canada's Oil Sands - A World-Scale Hydrocarbon Resource. Calgary: Strategy West Inc.

Egbert, J. A., Spaans, A., \& Baker, J. M. (1996). The Soil Freezing Characteristic: It's Measurement and Similarity to the Soil Moisture Characteristic. Soil Sci. Soc. Am. Journal (60), 13-19.

Eigenbrod, K. (33, 4). Effects of Cyclic Freezing and Thawing on Volume Chnages and Permeabilities of Soft Fine-Grained Soils. Canadian Geotechnical Journal, 529-537.

Eigenbrod, K., Knutsson, S., \& Sheng, D. (1996). Pore-water Pressures in Freezing and Thawing Fine-grained Soils. Cold Regions engineering , 10 (2), 77-92.

Farkish, A., \& Fall, M. (2014). Consolidation and Hydraulic Conductivity of Oil Sand Mature Fine Tailings Dewatered by Using Super Absorbent Polymer. $J$. Geotech. Geoenviron. Eng. (140), 6. 
Flerchinger, G. N., Seyfried, M. S., and Hardegree, S. P. (2004). Estimation of the soil moisture characteristic curve from the soil freezing characteristic. ASAE/CSAE Annual Int. Meeting, Washington, DC, 1-13.

Flerchinger, G. N., Seyfried, M. S., and Hardegree, S. P. (2006). Using soil freezing characteristics to model multi-season soil water dynamics. Vadose Zone J., 5(4), 1143-1153

Flint, L. (2004). Bitumen and Very Heavy Crude Upgrading Technoly. LENEF Consulting Ltd.

Fredlund, D., \& Morgenstern, N. R. (1977). Stress state variables for unsaturated soils. Journal of the Geotechnical Engineering Division, 103 (5), 447-466.

Fredlund, D., Rahardjo, H., \& Fredlund, M. (2010). Unsaturated Soil Mechanics in Engineering Practice. John Wiley \& Sons.

Fredlund, D., Xing, A., \& Huang, S. (1994). Predicting the permeability function for unsaturated soils using the soil-water characteristic curve. Canadian Geotechnical Journal (31), 533-546.

Gibson, R. E., England, G. L., \& Hussey, M. J. (1967). THE THEORY OF ONEDIMENSIONAL CONSOLIDATION OF SATURATED CLAYS . Geotechnique, 17, 261-273.

GmbH, U. (2009, December). User Manual: T5/T5x Pressure Tranducer Manual. 12. Munchen: UMS GmbH Munchen.

Gosselin, P., Hrudey, S., Naeth, M., Plourde, A., Therrien, R., Van Der Kraak, G., et al. (2010, December). Environmental and Health Impacts of Canada's Oil Sands Industry. 
Government of Alberta. (2009, September). Alberta Library. Retrieved April 21, 2016, from Oil Sands Aberta: http://environment.gov.ab.ca/info/library/8042.pdf

Grant, J., Angen, E., \& Dyer, S. (2013). Forecasting the impacts of oil sands expansion: Measuring the land disturbance, air quality, water use, greenhouse gas emissions, and tailings production associated with each barrel of bitumen production. Pembina Institute.

Henry, H. (2007). Soil freeze-thaw cycle experiments: Trends, methodological weaknesses and suggested improvements. Soil Biology and Biochemistry (39), 977-986.

Islam, S. (2014, December). Thickening of Mature Fine Oil Sands Tailings. London, Ontario, Canada: Electronic Thesis and Dissertation Repository.

Jeeravipoolvarn, S. (2010). Geotechnical Behavior of In-Line Thickened Oil Sands Tailings . Edmonton, Alberta, Canada: University of Alberta Libraries.

Jeeravipoolvarn, S. (2005). Compression Behaviour of Thixotropic Oil Sands Tailings. Edmonton, Alberta, Canada: University of Alberta.

Jeeravipoolvarn, S., Chalaturnyk, R. J., \& Scott, J. D. (2008). Consolidation Modeling of Oil Sands Fine Tailings: History Matching. GeoEdmonton '08, (pp. 190-197). Edmonton.

Johnson, R., Bork, P., Aller, E., James, W., \& Koverny, L. (1993). Oil sands sludge dewatering by freeze-thaw and evapotransporation. Syncrude Canada LTD.

Kodikara, J., Barbour, S., \& Fredlund, D. (2000, May). Desiccation cracking of soil layers. Asian Conference of Unsaturated Soils , 693-698. 
Konrad, J. (2010). Hydraulic conductivity changes of a low-plasticity till subjected to freeze-thaw cycles. Geotechnique, 60 (9), 679-690.

Lal, R., \& Shukha, M. K. (2004). Principles of Soil Physics. Basel, Switzerland: Marcel Dekker, Inc.

Miller, R. (1978). Frost Heaving in Noncolliodal Soils . Proc. 3rd Int. Conf. on Permafrost, Edmonton, Alta., Canada. Ottawa, Ont.: Nat. Res. Council of Canada.

Oil Sands Magazine. (2015, February 01). Oil Sands Deposit. Retrieved April 21, 2016, from Oil Sands Magazine: http:/www.oilsandsmagazine.com/oil-sands-deposit/

Or, D., Tuller, M., \& Wraith, J. M. (2003, September 13). University of Connecticut. Retrieved July 07, 2016, from Soil Water Potential: http://www.engr.uconn.edu/environ/envphys/pdf/vadose_pdf/Potentia_revised0 1.pdf

Osterkamp, T., \& Burn, C. (2002). Permafrost. In Encyclopedia for Atmospheric Sciences (pp. 1717-1729). New York Academic Press.

Othman, M., \& Benson, C. (1993). Effect of Freeze-thaw on the Hydraulic Conductivity and Morphology of Compacted Clay. Can. Geotech. J. , 30 (2), 236-246.

Proskin, S. A. (1998). A Geotechnical Investigation of Freeze-Thaw Dewatering of Oil Sands Fine Tailings. PhD Thesis, University of Alberta, Civil and Environmental Engineering, Edmonton. 
Rogers, W. (1953). Composition and Properties of Oil Well Drilling Fluid. Houston, Texas: Gulf Publishing Company.

Romero, E. (1999). PhD Thesis. "Characterisation and thermo-hydromechanical behaviour of unsaturated Boom Clay: an experimental study . Universitad Politecnica de Cataluna.

Spaans, E. J. A., and Baker, J. M. (1996). The soil freezing characteristic: Its measurement and similarity to the soil moisture characteristic. Soil Sci. Soc. Am. J., 60(1), 13-19.

Suncorn Energy Inc. (2009). DDA Plan Prepared in accordance with Directive 074 Appendix C. Fort McMurray, Alberta: Suncor Energy Inc.

Syncrude Canada Ltd. (2008). Syncrude application for approval of the Southwest Sand Conversion Project. Energy Resources Conservation Board and Alberta Environment .

Tang, J. (1997). Fundamental Behaviour of Composite Tailings . University of Alberta. Edmonton: University of Alberta Library.

Temizel, C., Gorucu, S. E., Erdogan, S. S., \& Tiwari, A. (2015). Optimization of Cyclic Steam Stimulation (CSS) Under Geomechanics-Dependent Permeability. SPE Russian Petroleum Technology Conference. Society of Petroleum Engineers.

Tsytovich, N. (1975). The Mechanics of Frozen Ground. (G. Swinsow, Ed., \& Scripta Book Company, Trans.) Moscow: Vyssshaya Shkola Press.

U.S.D.A. (1950). Diagnosis and improvement of saline and alkali soils. Agricultural Handbook n. 60. 
Vanapalli, S., Fredlund, D., Pufahl, D., \& Clifton, A. (1996). Model of the prediction of sheat strength with respect to soil suction. Canadian Geotechnical Journal (33), 379-392.

Viklander, P. (1998). Permeability and Volume Changes in Till due to Cyclic FreezeThaw . Canadian Geotechnical Journal, 35 (3), 471-477.

Wells, P., Revington, A., \& Omotoso, O. (2011). Mature fine tailings drying technology update. In R. Jewel, \& A. Fourie (Ed.), Paste 2011 (pp. 155-166). Perth, Australia: Australia Centre for Geomechanics.

Wijermars, E. (2011). Sedimentaion of Oil Sands Tailings. Civil Engineering and GeoSciences. The Netherlands: Deft University of Technology.

World Meteorological Organization. (2012). International Glossary of Hydrology. Geneva, Switzerland: World Meteorological Organization (WMO).

Xu, Y., Dabros, T., \& Kan, J. (2008). Filterability of Oil Sands Tailings. Process Safety and Environmental Protection, 86 (4), 268-276.

Yong, R., Boonsinsuk, P., \& Yin, D. Alteration of Soil Behaviour After Cyclic Freezing and Thawing . 4th International Conference on Ground Freezing, (pp. 187-195). Sapporo. 


\section{Chapter: Methodology and Material}

This chapter describes the experimental set-up including the experimental sample size of choice, the soil freezing methodology, acrylic column design, and the sensors used in all the experiments. Also, it describes other tests performed that were supportive of the main column tests.

Three column tests were conducted using an initial tailings thickness of $50 \mathrm{~cm}$ (thick lift). The use of the chosen thickness allows a proper balance between optimized drying rates and practical implementation for deposition (Suncor Energy Inc., 2009). For all tests, flocculate oil sands tailings were deposited in an acrylic column with the following dimensions: $22 \mathrm{~cm}$ in length, $17 \mathrm{~cm}$ in width, and $55 \mathrm{~cm}$ in height. Each column test had different testing phases as seen in Table 7. Column test \#1 involved self-weight consolidation with ambient drying of the tailings and one freeze-thaw cycle; column test \#2 involved self-weight consolidation with ambient drying of the tailings only; and column test \#3 involved self-weight consolidation with ambient drying, accelerated desiccation, and one freeze-thaw cycle. On a chronological basis, column test \#1 was performed first, while column test $\# 2$ and $\# 3$ were performed at the same time after column test \#1 was concluded. 
Table 7. Experimental phases in each of the three column tests

\begin{tabular}{|c|c|c|}
\hline Test \#2 & Test \#1 & Test \#3 \\
\hline Self-weight & Self-weight & Self-weight \\
Consolid. + & Consolid. + & Consolid. + \\
Ambient Drying & Ambient Drying & Ambient Drying \\
\hline- & Freeze-Thaw & Accelerated \\
& cycle & Desiccation \\
\hline- & - & Freeze-Thaw \\
& & cycle \\
\hline
\end{tabular}

\subsection{Material Tested: Oil Sands Tailings}

The materials used in these experiments are raw mature fine tailings (MFT) from an active oil sands operation near Fort McMurray, Alberta, Canada and high molecular weight anionic polymer as dry flocculant (FLOPAM A-3338). Table 8 and 9 outline the tailings' properties and mineral composition of raw MFT and MFT mixed with polymer. 
Table 8. Properties of raw MFT and MFT mixed with polymer (Mizani et al., 2013).

\begin{tabular}{ccc}
\hline Property & Raw MFT & MFT \& Polymer \\
\hline Initial Solids Content & $35.5 \%$ & $35.4 \%$ \\
Specific Gravity & 2.2 & $2.5 *$ \\
Liquid Limit (LL) & $55.0 \%$ & $77 \% *$ \\
Plastic Limit (PL) & $26.7 \%$ & $43 \% *$ \\
\hline
\end{tabular}

Table 9. Mineral composition of raw MFT (Mizani et al., 2013).

\begin{tabular}{cc}
\hline Mineral Composition & Quantity \\
\hline Quartz & $30.3 \%$ \\
Kaolinite & $28.5 \%$ \\
Muscovite & $19.0 \%$ \\
Rutile & $0.5 \%$ \\
Amorphous & $23.6 \%$ \\
\hline
\end{tabular}

During shipping of the tailings, the MFT underwent consolidation and a water cover was formed. As a consequence of this, the MFT was stirred using an electrical mixer for two days in order to achieve homogeneity and consistency in the material. After the mixing period, the water content and solids concentration of the MFT for each test is presented below (Table 10): 
Table 10. Initial water and solids content for each column test.

\begin{tabular}{lcc} 
& \multicolumn{1}{c}{ Grav. Water Content (\%) } & Solids Content (\%) \\
\hline Column Test \#1 & 188.1 & 34.7 \\
\hline Column Test \#2 & 191.7 & 34.3 \\
\hline Column Test \#3 & 208.8 & 32.4 \\
\hline
\end{tabular}

Furthermore, the flocculant agent was prepared by mixing the anionic polymer with reclaimed water, also from Fort McMurray, at a concentration of $0.4 \% \mathrm{w} / \mathrm{w}$. A dosage of $650 \mathrm{mg} / \mathrm{kg}$ mass of flocculant per dry mass of tailings was used to thicken the tailings. This dosage is recommended by Soleimani et al. (2014) to maximize dewatering due to self-weight consolidation.

The mixing procedure for the MFT and polymer is described in detail in Mizani et al. (2013). It is outlined to replicate the properties of polymer emended MFT from the field. A summary of the mixing process is presented below:

- A four-blade impeller (radius $=8.5 \mathrm{~cm}$ ) attached to an electronic mixer was immersed into a container holding $3.6 \mathrm{~kg}$ of MFT.

- The mixing process was done at a fixed rate of $250 \mathrm{rpm}$.

- The flocculant solution was added near and around the impeller to ensure proper mixing.

- Mixing of the MFT and flocculant lasted 10 seconds. 
As previously stated, mixing occurred in badges of $3.6 \mathrm{~kg}$ each. At every other mixing badge, water content and slump tests were taken to ensure homogeneity of the tailings (See Appendix D). Slump tests are used to estimate the yield stress of the material using the method of Pashias et al., (1996).

\subsection{Experimental Set-up Design}

\subsubsection{Effects of Sample Size on Temperature in Freeze-Thaw Tests}

Henry (2007) pointed out that there is a wide variation in methodologies on how freeze-thaw manipulations should be conducted. This leads to inconsistencies and, sometimes, contradictory results obtained from freeze-thaw experiments. He also added that one of the issues is the unrealistic temperatures that testing samples are exposed to in current freeze-thaw methodologies. Under field conditions, temperature fluctuations at the soil surface are directly affected by air temperature. However, at depths of as low as $5 \mathrm{~cm}$, said fluctuations are significantly reduced, as seen in Figure 34 . The soil shown in the figure below lacks any type of insulation by natural vegetation, however the differences between surface and $5 \mathrm{~cm}$-depth temperatures are highly noticeable. In colder climates, the same dampening of temperature between air temperature and $5 \mathrm{~cm}$ depth soil can be found, especially in the absence of snow cover (i.e. bare soil).

Most test specimens obtained from the field are from depths of 10 to $20 \mathrm{~cm}$ and are tested in small volumes. These small samples equilibrate quickly with the air temperature (i.e. below $0{ }^{\circ} \mathrm{C}$ ) exposing sub-surface material to unrealistic negative temperatures. According to Henry (2007), this problem is intensified when the sample 
is frozen from all around its sides (i.e. three-dimensional freezing) because it is exposing the sub-surface soil to unrealistic and extreme temperatures that will not naturally occur in the field.

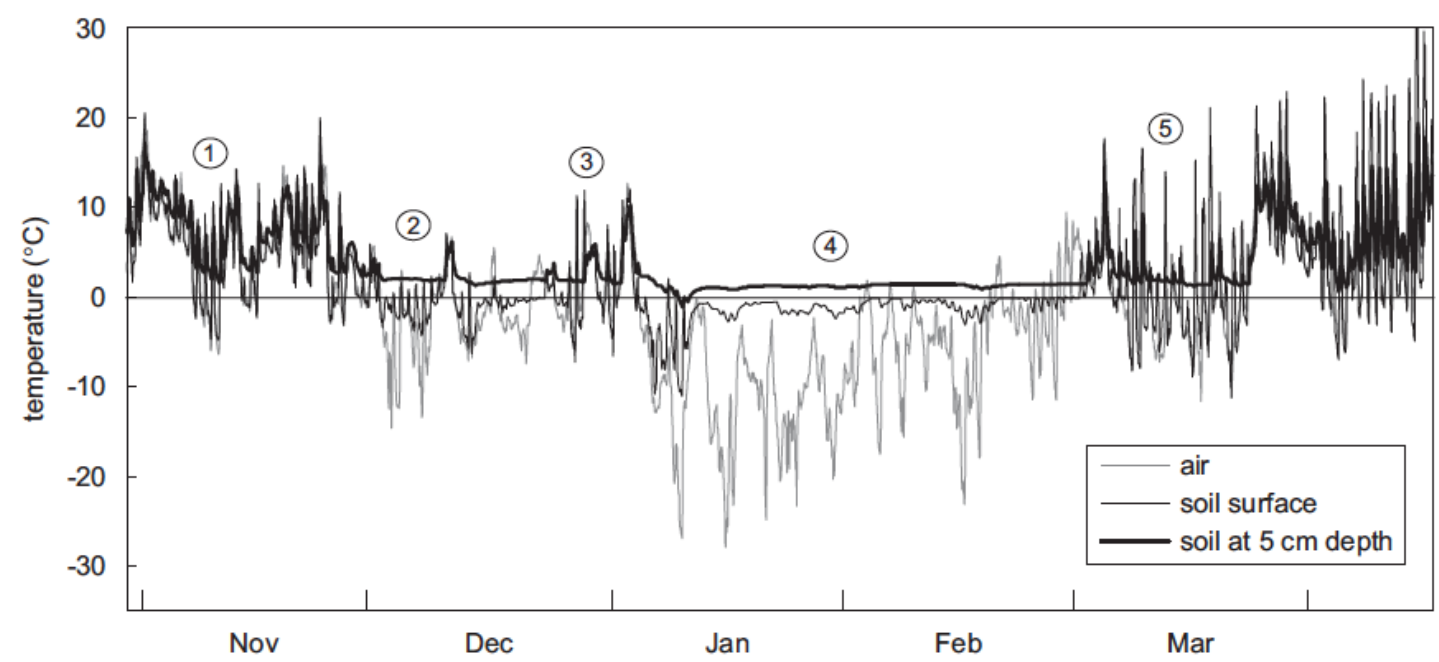

Figure 34. Hourly air, soil surface and soil at $5 \mathrm{~cm}$ temperatures vs time (Henry, 2007)

In small volume samples, the rate of change in temperature will occur really fast leading to the formation of small ice crystals (Hobbs, 1974). This phenomenon could lead to the minimization of the disruption of soil aggregates within the sample (Henry, 2007). In other words, it is possible that in many of the freeze-thaw studies performed to date, the effects of freeze-thaw cycles on soil may have been over-exaggerated. Henry (2007) added that the different chosen temperatures used among the experiment might account for the variability in results found in the literature. 
For the column tests involved in this research, larger samples $(22 \mathrm{~cm} \mathrm{x} 17 \mathrm{~cm} \mathrm{x}$ $50 \mathrm{~cm}$ ) are used to avoid the over-exaggeration of the freeze-thaw effects on tailings. The specifics of why those dimensions for the column were chosen are discussed in Section 3.2.3.

\subsubsection{Soil Freezing Methodology}

\subsubsection{Freezing Method of Choice}

The American Society for Testing and Materials (ASTM-STP-599) has the following recommendations on how to artificially freeze soil samples (Baker, 1976):

- Unidirectional freezing is recommended (one-dimensional).

- The mold or container used to comprise the soil must be made from or covered with material with good insulating properties.

- Access to free water must be provided from the non-freezing end of the sample to replenish the water migrating towards the freezing front.

- Thermistors should be placed along the sample to record the freezing rate.

Baker (1976) gives other recommendations, however they are not applicable for oil sands tailings. These recommendations involve compaction and saturation methods for air-dried soil.

All the previously mentioned suggestions were taken into consideration when designing the column tests with exception of the third point since the column tests are 
considered closed systems (i.e. no access to free water from the bottom of the column). Moreover, the testing apparatus was chosen to be a closed system one, meaning that the tailings being frozen did not have an external source of water to feed the freezing front as ice crystals form. This is the same case as in the field since each layer of tailings deposited in the tailings ponds do not have a source of water (i.e. water table) to feed the growing ice crystals. Also, freezing of low permeability tailings deposited in lifts is practically different than studying freeze-thaw in natural undisturbed soil.

Lastly, the ASTM-STP-599 recommends the use of a thermoelectric cooling plate for a more accurate control of the freezing process. Said cooling plates operate using the Peltier effect, which, in simple terms, involves the release or absorption of heat due to an electric current passing a junction between two materials. The main advantage of cooling plates is the ability to control with high precision the rate of heat removal (Williams, 1968), which is suitable for one-dimensional freezing of soils.

The chosen cooling plate for these sets of experiments is the CP-121 PeltierThermoelectric Cold Plate Cooler offered by TE Technology Inc. (See Figure 35). This particular cooling plate has the ability to heat up and cool down to temperatures of +70 ${ }^{\circ} \mathrm{C}$ and $-30{ }^{\circ} \mathrm{C}$, respectively. 


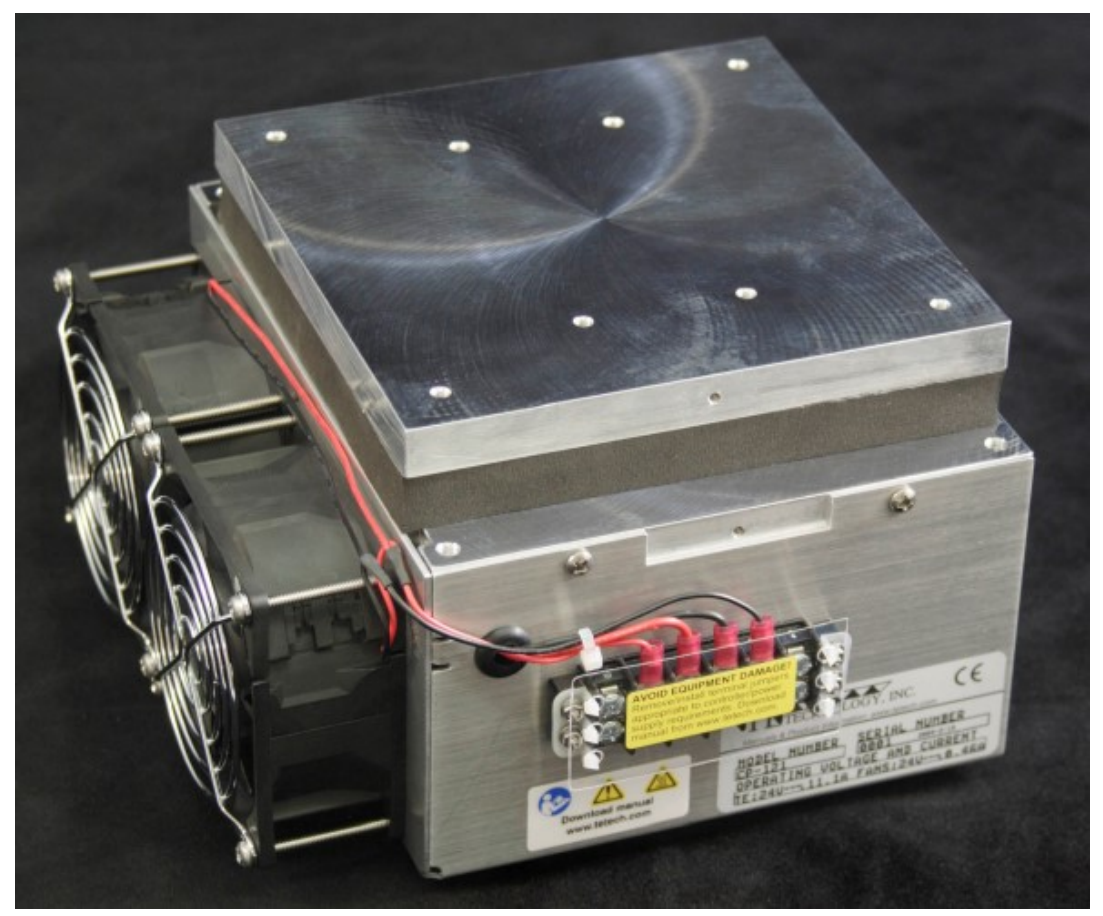

Figure 35. CP-121 Peltier-thermoelectric cold plate cooler (TE Technology Inc.).

The CP-121 Peltier-Thermoelectric Cold Plate Cooler operates along a temperature controller, TC-48-20, powered by a power supply also offered by TE Technology Inc (Fig. 36). The temperature controller allows an easy control of the cooling plate temperature either manually or by software usage. Also, it has the capability to add a direct-contact thermistor attached to the cooling plate for precision temperature control (TE Technology Inc.). The thermistor, see Figure 37, is used as a surface temperature reader on the tailings since it is located right in between the tailings' surface and the cooling plate during the freezing phase of the experiment. 


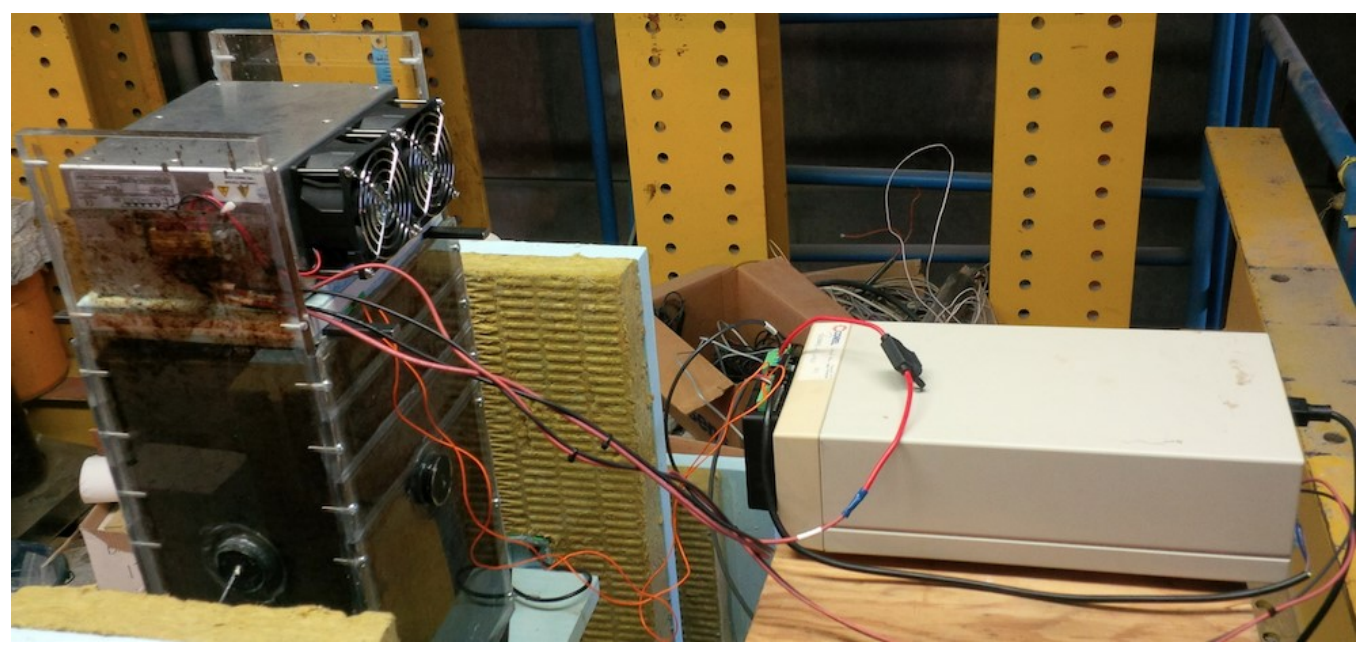

Figure 36. Cooling plate, temperature control, and power supply.

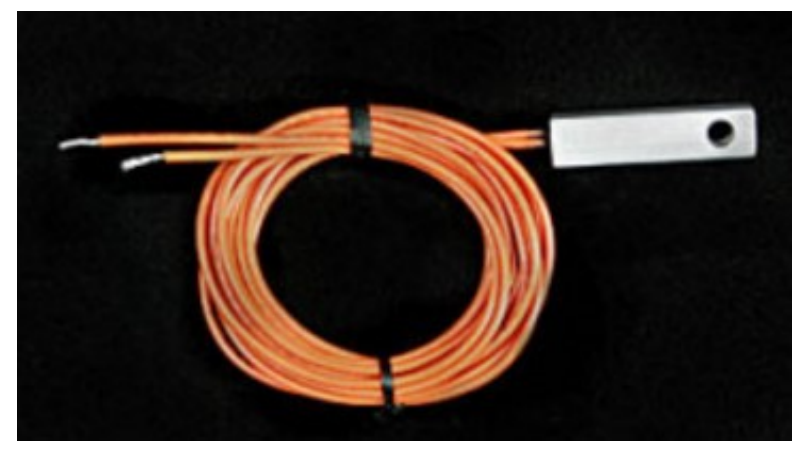

Figure 37. Thermistor located in between the tailings' surface and the cooling plate (TE Technology Inc.).

Once the cooling plate has been properly set up and the freezing phase is about to commence, it is place on direct contact at the surface of the tailings. Two metal rods were attached at the sides of the cooling plate as supporting devices. This way, the cooling plate rests on the acrylic column at any required height. The width and length 
of the cold plate are $15.2 \mathrm{~cm}$ and $18.8 \mathrm{~cm}$, respectively. The cooling plate fitted comfortably at the top part of the column with some room to spare around it that was filled with waterproof silicon. This was done to avoid the scape of cold air from the small air gap between the MFT and the cooling plate.

\subsection{Freezing Temperature Designation}

Local weather and thermal properties of the soil determine the amount of material that can be frozen or thawed during winter and spring seasons. Table 11 shows the Fort McMurray climate data corresponding to winters of 2012/2013, 2013/2014, and $2014 / 2015$. The data shows that the freezing period is approximately five months (November to March) having an average mean temperature of $-14.1{ }^{\circ} \mathrm{C}$. This temperature value was taken into consideration when assigning a freezing temperature for the column tests. The chosen freezing temperature was $-15^{\circ} \mathrm{C}$.

Table 11. Fort McMurray climate data for the last 3 winters (Government of Canada)

\begin{tabular}{ccc} 
Month/Year & Mean Temperature $\left({ }^{\circ} \mathbf{C}\right)$ & Mean Precipitation (mm) \\
\hline November 2012 & -11.7 & 10.4 \\
December 2012 & -19.3 & 10.1 \\
January 2013 & -18.0 & 17.7 \\
February 2013 & -9.4 & 5.2 \\
March 2013 & -9.4 & 3.9 \\
\hline November 2013 & -9.8 & 7.6
\end{tabular}




\begin{tabular}{ccc} 
December 2013 & -23.6 & 20.4 \\
January 2014 & -16.8 & 9.0 \\
February 2014 & -19.5 & 5.7 \\
March 2014 & -11.4 & 8.5 \\
\hline November 2014 & -12.2 & 6.1 \\
December 2014 & -14.2 & 11.5 \\
January 2015 & -14.9 & 15.2 \\
February 2015 & -17.5 & 19.8 \\
March 2015 & -3.3 & 10.2 \\
\hline
\end{tabular}

It is necessary to point out that the effects of variations from these mean values was not taken into consideration in this study.

\subsection{Number of Freeze-Thaw Cycles}

The freeze-thaw experimental literature reports experimental tests having a wide variety of freeze-thaw cycles that range from 1 to 49. Henry (2007) summarized several freeze-thaw tests from the literature based on the number of freeze-thaw cycles (See Appendix D). Henry (2007) reported that the most common number of cycles is one. Therefore, due to simplicity, one freeze-thaw cycle was chosen for the column tests. The choice of one freeze-thaw cycle will reduce the testing time needed to complete the freezing phase since the required time to freeze tailings is lengthy, as observed in Section 3.4. 


\subsubsection{Insulation}

As recommended by the ASTM-SPT-599, an outer insulating case was built for the acrylic column in order to ensure one-dimensional freezing (Fig. 38). The outer case consists of two different materials: mineral wool insulation and Styrofoam insulation. Both materials were glued using regular silicon. The total thickness of the insulation case is $5 \mathrm{~cm}$. Also, the bottom of the column only contained Styrofoam insulation due to room restrictions between the column and the metal stand that holds the column. The approximate heat loss between the frozen tailings $\left(\right.$ at $\left.0^{\circ} \mathrm{C}\right)$ and the lab temperature (at $22^{\circ} \mathrm{C}$ ) would range from $0.87 \mathrm{~W}$ to $1.3 \mathrm{~W}$. Also, sporadic temperature readings from the interface between the acrylic column and the insulating case were taken using a thermocouple to ensure one-dimensional freezing. These temperatures readings were always above zero degrees and were in-sync with the internal temperature of the fridge $\left(2{ }^{\circ} \mathrm{C}\right.$ to $\left.10^{\circ} \mathrm{C}\right)$. The absence of ice crystals forming outside the acrylic column were another indicative that the freezing process was occurring one-dimensionally. Table 12 contains the thermal properties of both insulating materials used in the insulating case. 


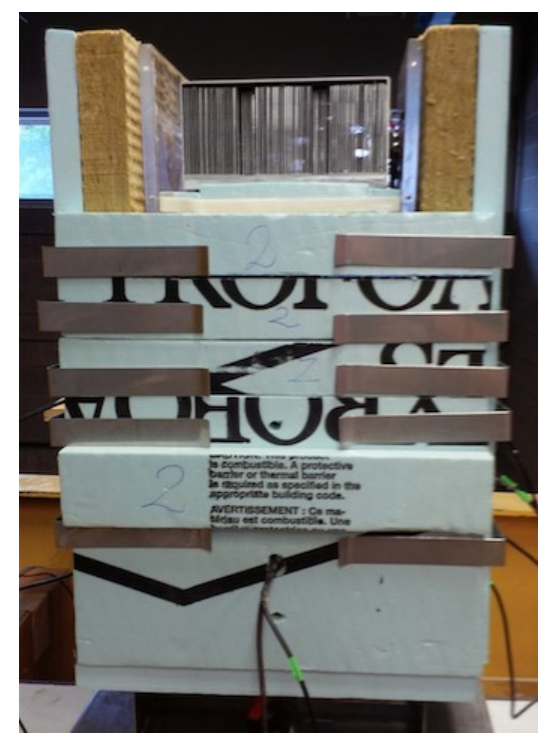

Figure 38. Insulating case around the acrylic column.

Table 12. Thermal properties of insulating materials

\begin{tabular}{cccc}
\hline \multirow{2}{*}{ Material } & \multicolumn{3}{c}{ Thermal Properties } \\
\cline { 2 - 4 } & Thickness & $\begin{array}{c}\text { Thermal } \\
\text { Conductivity } @ \mathbf{~ 2 4}^{\circ} \mathbf{C}\end{array}$ & $\begin{array}{c}\mathbf{R}-\text { value } \\
\left(\mathbf{m}^{2}{ }^{\circ} \mathbf{C} / \mathbf{W}\right)\end{array}$ \\
\hline Styrofoam & $2 \mathrm{~cm}$ & $0.033 \mathrm{~W} / \mathrm{m}^{\circ} \mathrm{C}$ & 1.97 per cm \\
Mineral Wool & $3 \mathrm{~cm}$ & $0.044 \mathrm{~W} / \mathrm{m}^{\circ} \mathrm{C}$ & 1.57 per cm \\
\hline
\end{tabular}

During column test \#1, especially fabricated metal clamps held the insulating case together, as seen in Figure 38. Meanwhile, in column test \#3 bolts held the insulating case together. This method was proven to be more effective in avoiding gaps 
in between the insulation and the acrylic column. Column test \#2 did not have a freezing phase; therefore, there was no need for column insulation.

\subsubsection{Air Moisture Control}

During the freezing phase of column test \#1, it was noted that air moisture, from the lab in which the experiment was taking place, would seep through small holes in the sealing silicon to small gaps in between the cooling plate and the tailings. Since the cooling plate was set at $-15^{\circ} \mathrm{C}$, the entering-air-moisture started to condensate in between the freezing tailings and the cooling plate. Therefore, excess ice build-up was starting to form. The naturally formed ice due to the freezing of the tailings along with the ice formed from the entering-air-moisture became a problem. Ice build-up started to push the cooling plate upwards. This, in effect, created more holes in the silicon allowing more air moisture to enter the system, which ended up creating more ice in an endless cycle.

To avoid the ice build-up problem, it was necessary to be able to minimize the air moisture around the column test. Since the room in which the test was taking place was not an environmental chamber, it was decided that the current and future freezing tests would take place inside a conventional fridge (See Fig. 39). The fridge would decrease the temperature around the column test reducing the air moisture at the same time. A conventional fridge was modified to fit the entire experimental set up and it was set to the minimum cooling setting. A thermometer was placed inside the fridge to measure the temperature for said setting. It was measured that the temperature inside 
the fridge would oscillate between $2{ }^{\circ} \mathrm{C}$ and $10{ }^{\circ} \mathrm{C}$ allowing for one-dimensional freezing to continue. No more ice build-up problems occurred after the introduction of the fridge to the experimental set-up.

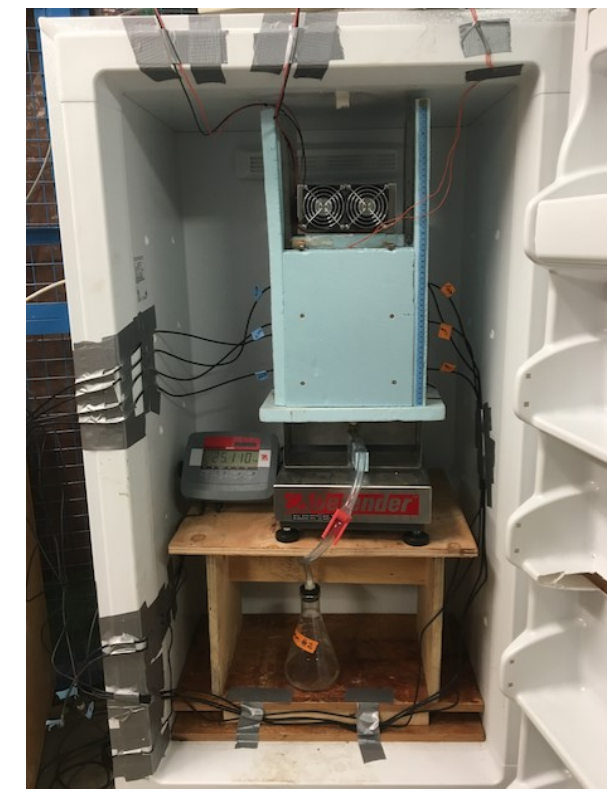

Figure 39. Experimental set-up inside the fridge.

\subsubsection{Acrylic Column Design}

When designing the acrylic column, there were two main key parameters for its dimensions: the cooling plate dimensions for the column's width and length and the MFT's lift thickness at the time of deposition $(0.5 \mathrm{~m})$ for the column's height. The final dimensions for the column were set to $17 \mathrm{~cm}$ for the width, $22 \mathrm{~cm}$ for the length, and 55 $\mathrm{cm}$ for the height, as seen in Figure 40. Also, it was determined that two opposite sides of the column were going to have removable sections at $15 \mathrm{~cm}, 20 \mathrm{~cm}, 25 \mathrm{~cm}$, and 30 $\mathrm{cm}$ from the column's top to allow the downward displacement of the cooling plate. At the time of construction, two different thicknesses of clear acrylic were used, $1 / 2$ inch 
and $1 / 4$ inch. The thinner sheet of plexiglass was used on the sides that have removable sections. These sections' ends are screwed into the thicker sides for a sturdier design. The last component in the design process was to locate the holes in which the sensors were placed. The sensors' locations were designated keeping in mind the settlement of the polymer amended MFT prior freezing. Four different heights from the bottom were chosen to drill 1.5-inch holes to accommodate the sensors: $5 \mathrm{~cm}, 10 \mathrm{~cm}, 15 \mathrm{~cm}$, and $22.5 \mathrm{~cm}$. One last $1 / 2$-inch hole with threads was drilled at the bottom of the column to allow drainage.

The drainage system consisted of a plastic tube attached to the bottom of the column, which is resting on a metal stand. The water collected from the drainage system is deposited in an Erlenmeyer flask. Daily weight measurements of the flask were taken to measure the drained water volume. 


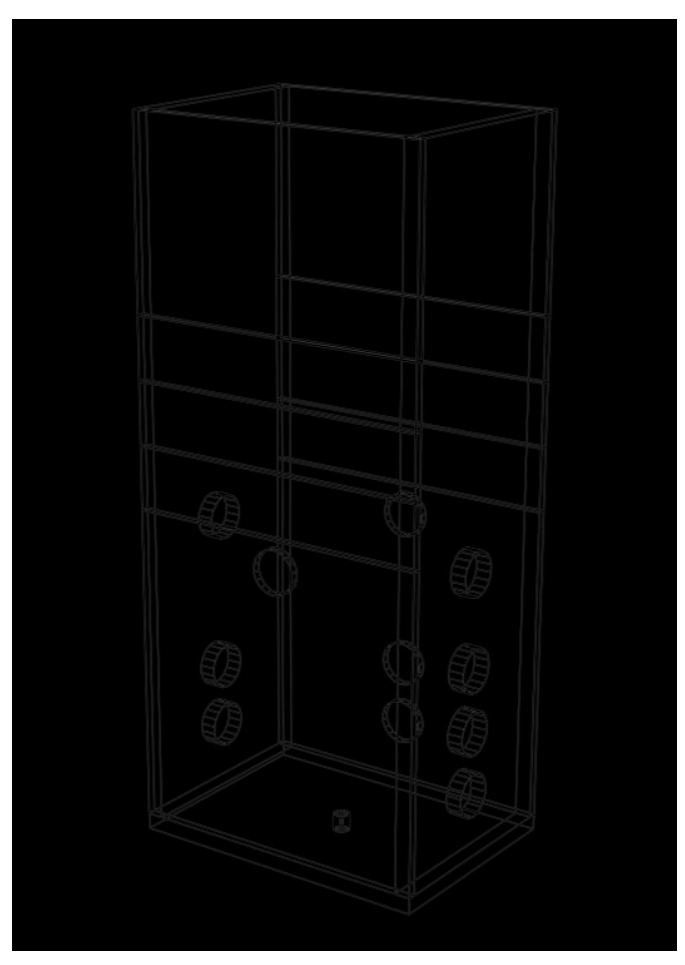

Figure 40. Acrylic column blueprint.

Moreover, nine 3/4-inch rubber stoppers with $5 \mathrm{~mm}$-diametre holes in the middle were used to hold the sensors in the column's holes. The sensors were used to measure electro-conductivity, volumetric water content, negative and positive pore water pressure, and soil temperature. All sensors' cables were placed and glued with silicone in the middle of the rubber stoppers, which were also glued into the column's holes prior the deposition of the MFT (See Fig. 41). The sensors were connected to data loggers in order to continuously read and record the acquired data. 


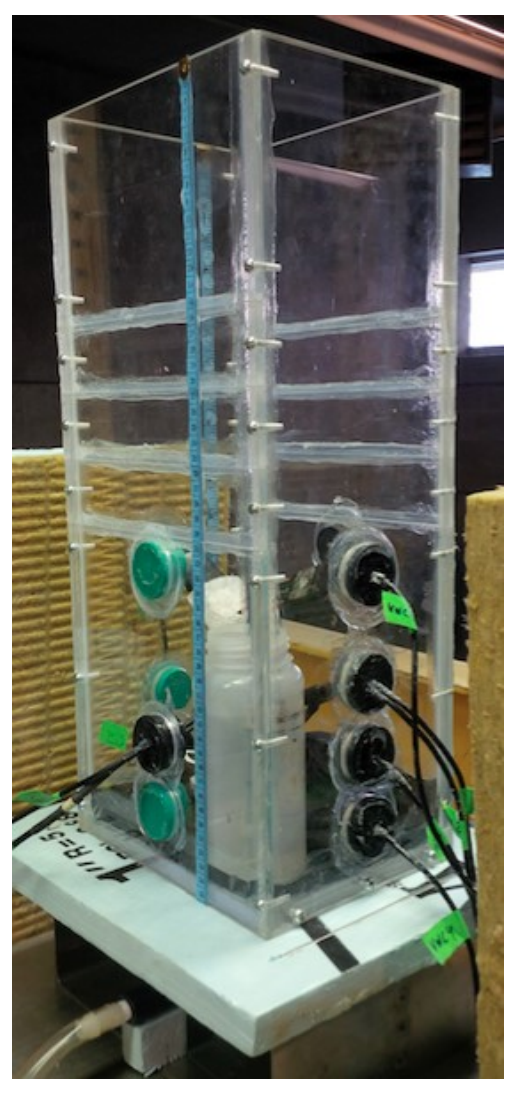

Figure 41. Sensors attached to acrylic column at prior the deposition of tailings.

The column was waterproofed using water-resistant silicone in all the slits and small opening between sections. A sheet of geotextile was place at the bottom of the column to avoid the clogging of the draining system.

Lastly, the entire column set up was placed on an electronic scale to measure daily weight changes. This way, it was possible to measure the amount of water being evaporated and drained away from the MFT. 


\subsubsection{Sensors Used in the Column Tests}

Four different types of sensors were used in the three column tests. These sensors were in charge of measuring volumetric water content, electro-conductivity, temperature, and water potential.

\subsubsection{5TE Water Content, EC, and Temperature Sensor}

The 5TE sensor (Fig. 42) offered by Decagon Devices Inc. is designed to measure water content, electro-conductivity (EC), and temperature in soil. This sensor measures the dielectric permittivity of the soil to determine its water content. Also, small thermistors attached to the sensor measure soil temperature and the two screws located at the surface of the sensor form an electric array to the EC (Decagon Devices Inc., 2013).

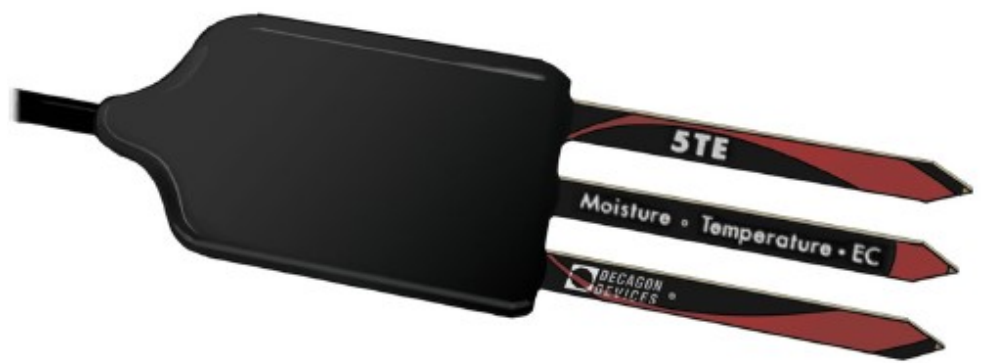

Figure 42. 5TE sensor (Decagon Devices Inc., 2013). 
The 5TE sensor was chosen because of its temperature working range $\left(-40^{\circ} \mathrm{C}\right.$ to $60^{\circ} \mathrm{C}$ ) and its proven reliability in other experiments involving MFT.

\subsubsection{RT-1 Soil Temperature Sensor}

The RT-1 sensor (Fig. 43) is a thermistor type of sensor and it is used to measure soil temperature. It covers a temperature range of $-40{ }^{\circ} \mathrm{C}$ to $80{ }^{\circ} \mathrm{C}$. At temperatures below zero, between $5{ }^{\circ} \mathrm{C}$ and $-40{ }^{\circ} \mathrm{C}$, its temperature accuracy is $\pm 1{ }^{\circ} \mathrm{C}$ (Decagon Device Inc., 2013). They are proven to be weatherproofed and easy to use.

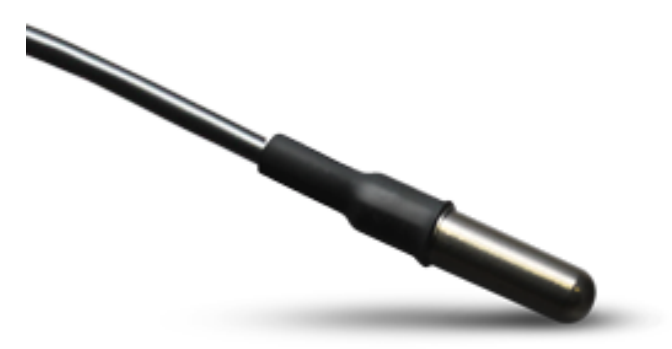

Figure 43. RT-1 temperature sensor.

\subsubsection{T5 Tensiometer}

The $\mathrm{T} 5$ tensiometers are used to measure water potential in soils. Refer to Section 2.6.2.1 for a detailed description of the T5 tensiometers. 


\subsubsection{MPS-6 Water Potential Sensor}

The MPS-6 sensors are also used to measure water potential in soils. Refer to Section 2.6.2.2 for a detailed description of the MPS-6 sensors.

\subsubsection{Data Loggers}

Two different data loggers were used to store the information obtained through the sensors described above: the EM50 Digital data logger and DL2e data logger. The EM50 data logger (Fig. 44) was used to store data from the 5TE, RT-1, and MPS-6 sensors. It has the capability to read up to 5 sensors at the same time and it does not require an external power source since it operates with batteries. On the other hand, the DL2e data logger (Fig. 45) needs an external power source to operate over long periods of time but it can accommodate more sensors. The T5 tensiometers store their data in this data logger. Both data logger required of a software package to program and modify the sensor's settings, as well as the recording time among others.

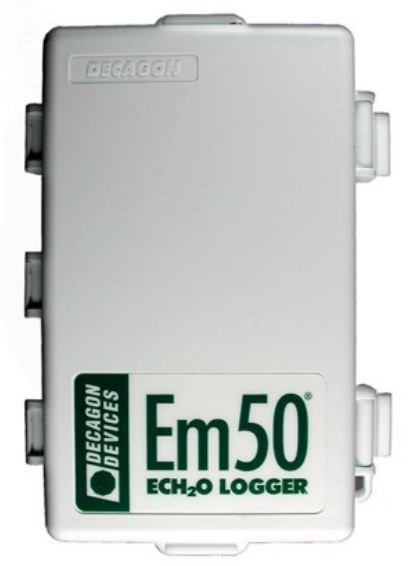

Figure 44. EM50 data logger. 


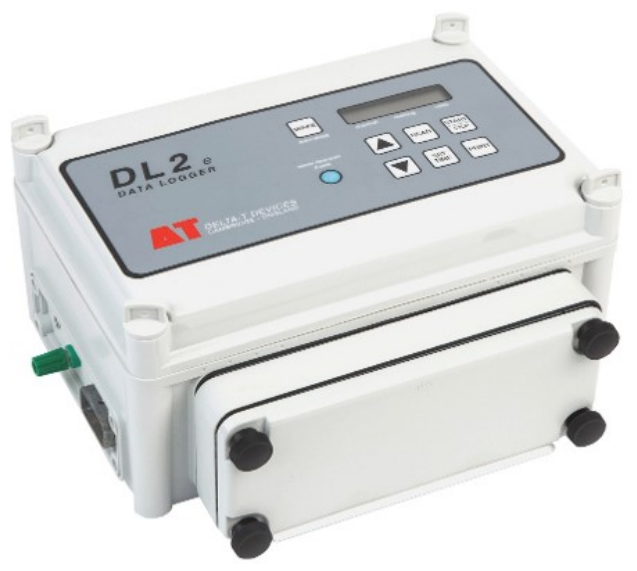

Figure 45. DL2e data logger.

\subsection{Initial Matric Suction Tests}

Five testing experiments were conducted using the MPS-6 dialectric water potential sensors. The purposes of these tests were to assess the performance of said sensors under temperatures below zero and to initially understand the evolution of matric suction during freezing and thawing.

These tests used small sample cylinders (4-by-8-inch) with two holes on its side to accommodate the MPS-6 sensors (Fig. 46). The cylinders were filled with polymer amended MFT and placed inside a freezer. After one day, the cylinders were removed and let to thaw at room temperature. The thawing period also lasted one day. 


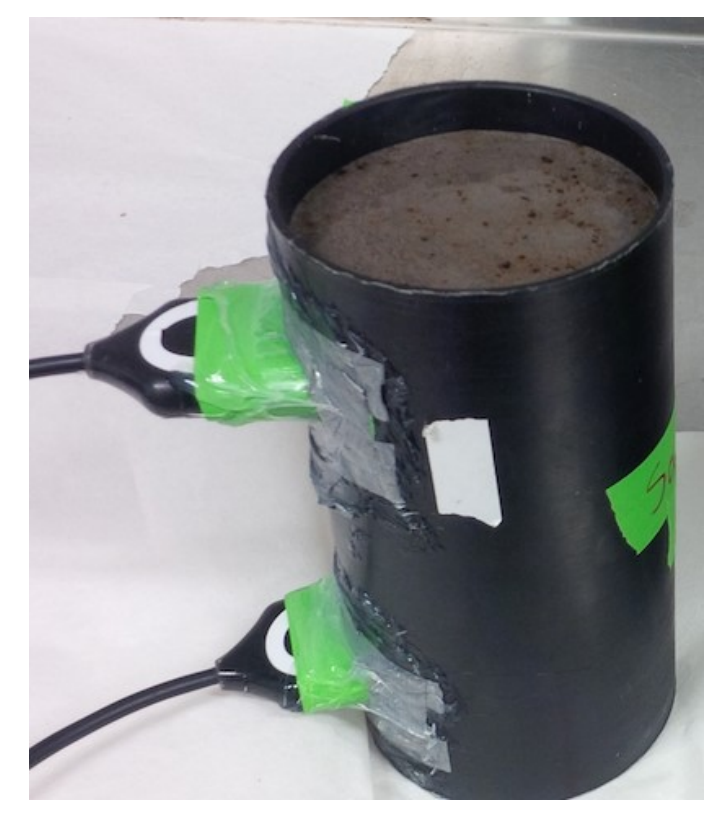

Figure 46. Test set-up for initial matric suction testing.

\subsection{Column Tests}

As mentioned previously, three column tests under different conditions were tested for this research. In the sections below, the details of each experimental set-up are presented.

\subsubsection{Column Test \#1: Self-Weight Consolidation with Ambient Drying and} Freeze-Thaw Cycle

Column test \#1 started on May 7, 2015 and concluded on November 26, 2015. The test lasted a total of 205 days. For a detailed description of different events during column test 1 see Appendix D. Also, Table 13 shows the type and location of sensors present in this test. 
Table 13. Type and sensor location for column test \#1.

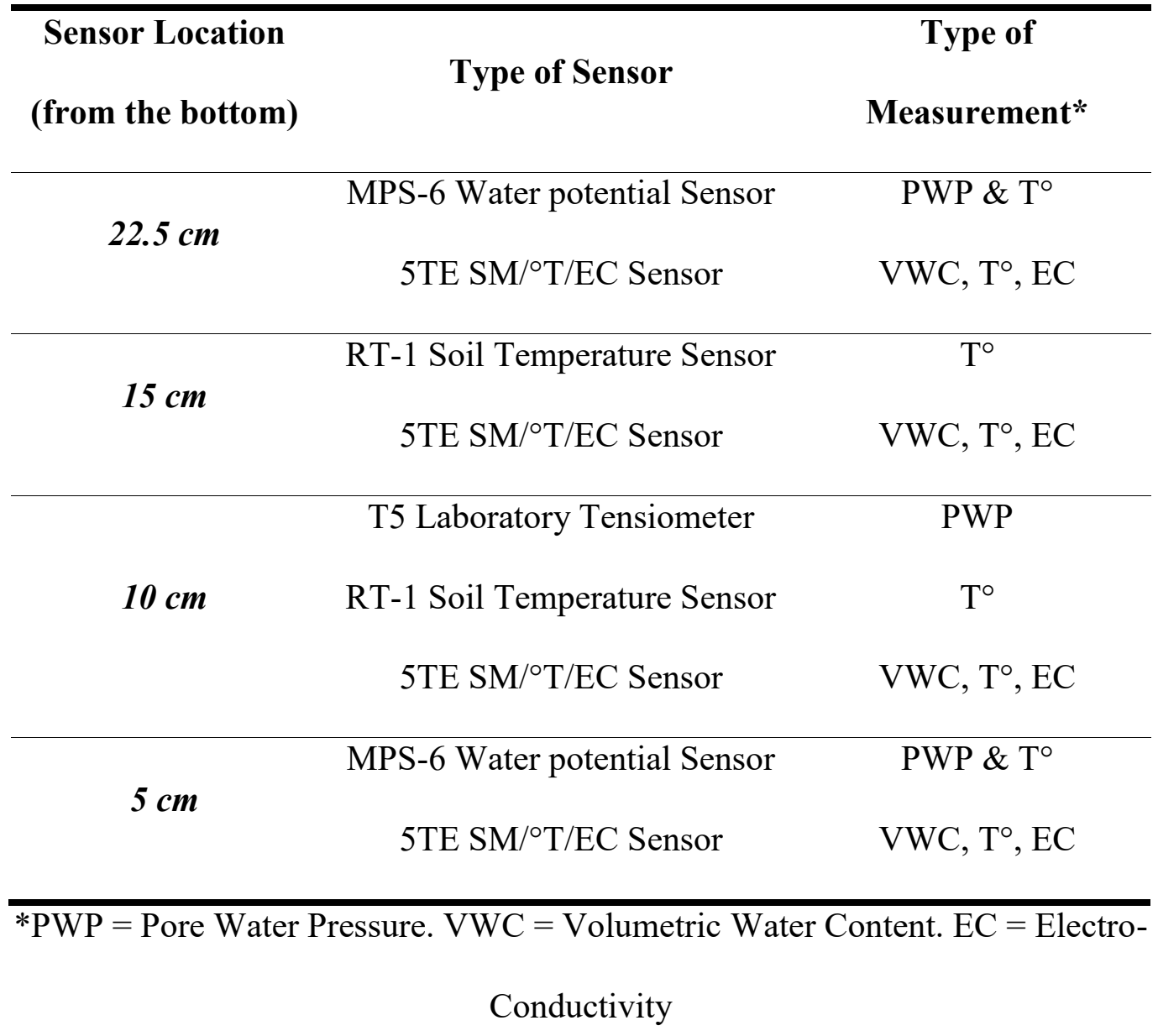

\subsubsection{Deposition}

Prior deposition, MFT was mixed with polymer as explained in Section 3.1. The dosage of polymer per container comprising $3.6 \mathrm{Kg}$ of raw MFT each was $207 \mathrm{~g}$. Six containers of amended MFT were needed to fill up the column at a lift of $0.5 \mathrm{~cm}$. The total weight of the material was $21.6 \mathrm{Kg}$. Also, the MFT's gravimetric water and solids content at the beginning of the test were $188.1 \%$ and $34.7 \%$, respectively. Figure 47 , 
48, and 49 show the experimental set-up prior, during, and post deposition of the amended MFT. Once the material was placed inside the column, the drainage system was open and the MFT was allowed to drain. Drained water was collected using an Erlenmeyer flask. Also, the data loggers used to store the data obtained from the different sensors were turned on and the data recording process began.

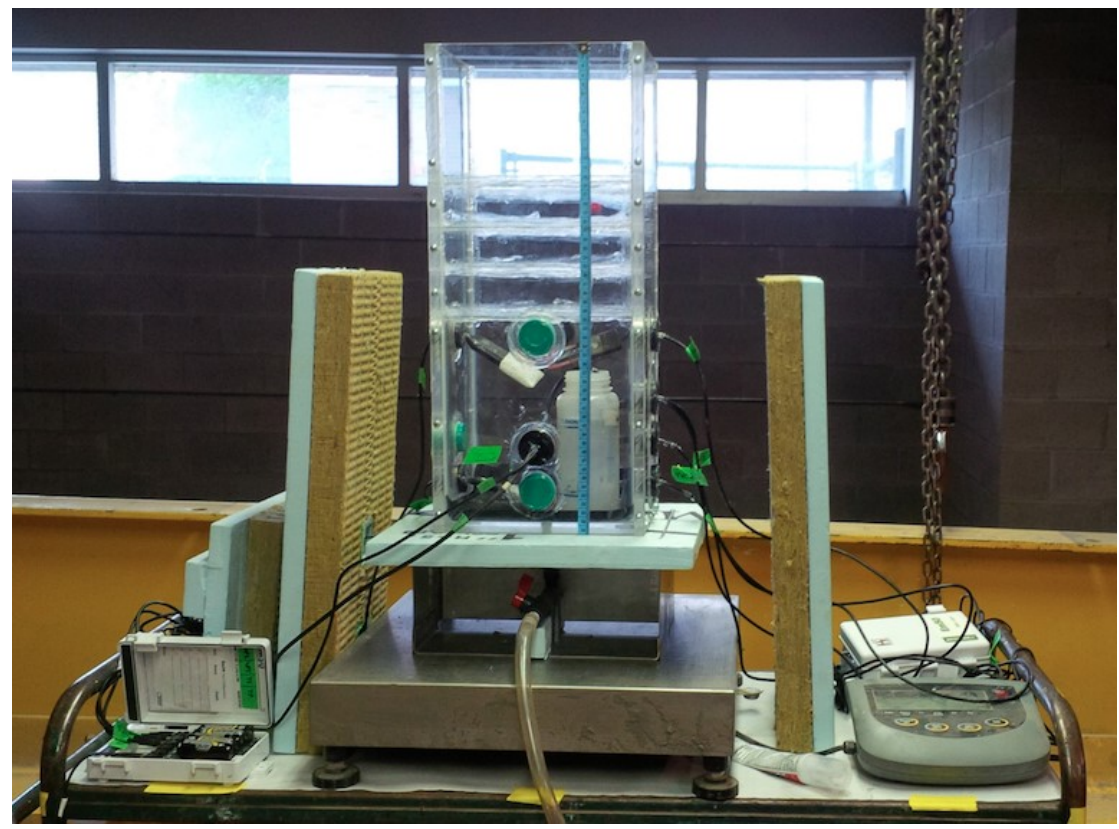

Figure 47. Experimental set-up of column test \#1 prior deposition. 


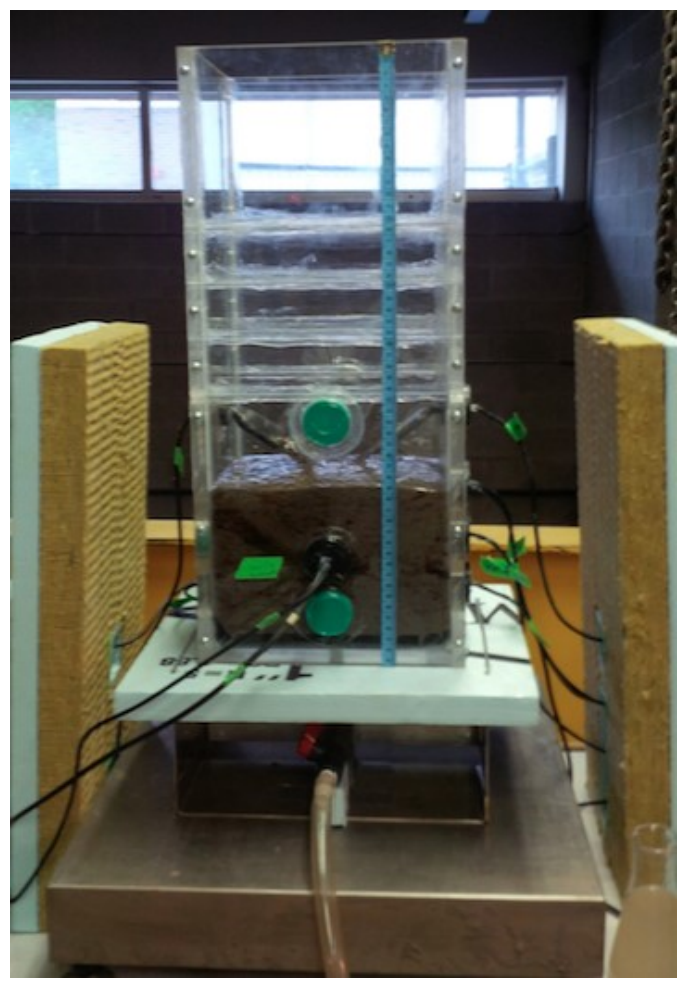

Figure 48. Experimental set-up of column test \#1 during deposition.

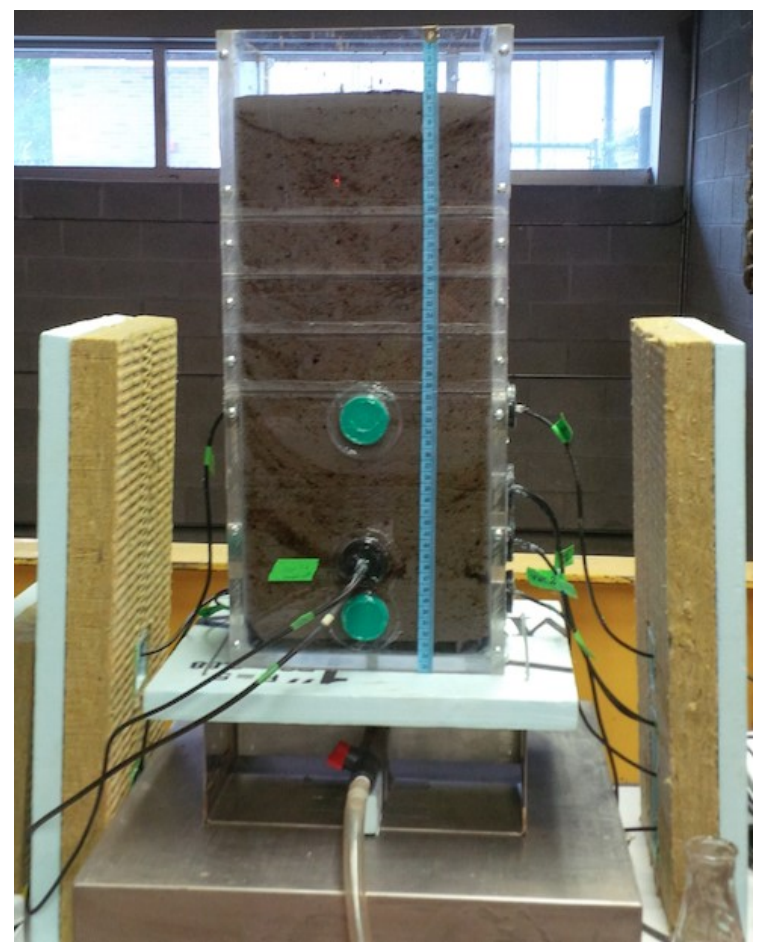

Figure 49. Experimental set-up of column test \#1 post deposition. 
Daily height and weight measurements of the MFT column were taken. The amount of drained water was also recorded daily. The water cover formed on top of the MFT the first few days of the test (Fig. 50) was drained on a daily basis and considered as drained water.

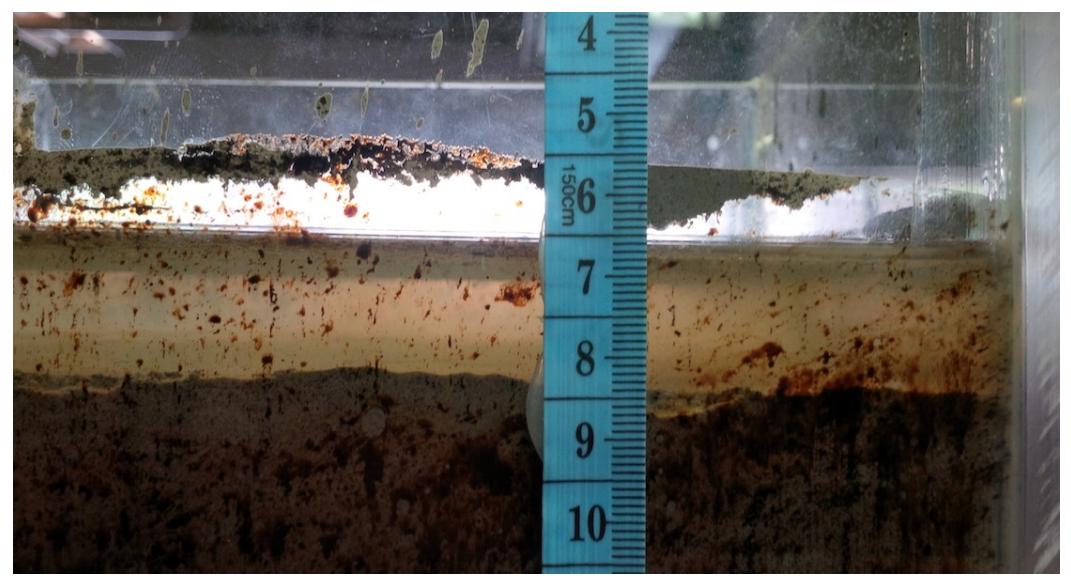

Figure 50. Water cover at the MFT surface.

\subsubsection{Self-weight Consolidation with Ambient Drying Phase}

The MFT was allowed to self-weight consolidate for 51 days. This time was chosen to allow the polymer amended MFT to consolidate $20 \mathrm{~cm}$ from the original 50 $\mathrm{cm}$ before the start of the freezing phase. This would leave $30 \mathrm{~cm}$ of tailings remaining. However, at the end of this period the tailings only consolidated $18.2 \mathrm{~cm}$ (Fig. 51). 


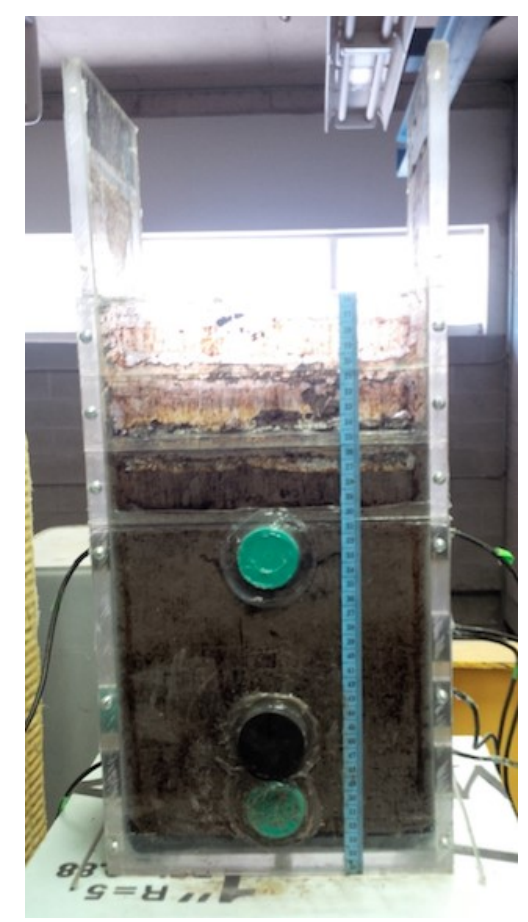

Figure 51. Experimental set-up of column test \#1 at day 51. Height of MFT column $=31.8 \mathrm{~cm}$.

\subsubsection{Freezing Phase}

The freezing phase lasted 143 days. It was decided that the freezing phase would terminate when the sensor located at $5 \mathrm{~cm}$ away from the bottom would reach a temperature of zero degree Celsius. To initiate the freezing phase, the top 3 sections of the acrylic column were removed to allow the cooling plate to be as close as possible to the MFT allowing an efficient one-directional freezing (Fig. 52). The top $1.8 \mathrm{~cm}$ of the MFT column was manually removed to achieve the height of $30 \mathrm{~cm}$, as well as a flat surface to interact with the cooling plate, as seen in Figure 52. This was equivalent to 744 grs of dried MFT. 


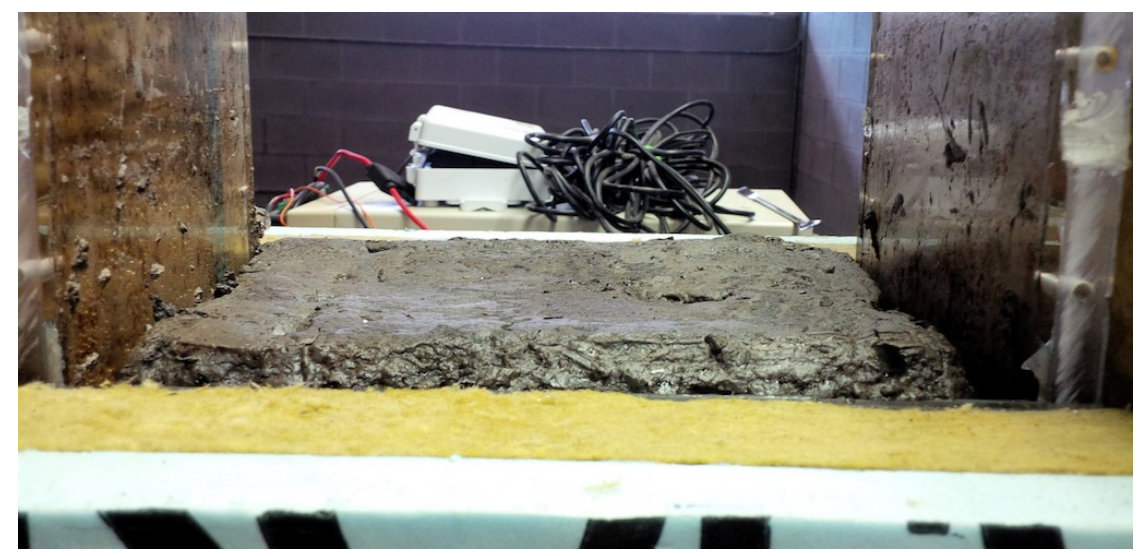

Figure 52. MFT's flat surface at a height of $30 \mathrm{~cm}$.

The freezing phase started by placing the cooling plate in the column as close to the dried MFT as possible. Any gap between the column and the cooling plate was properly insulated using insulating foam. The insulating case was assembled and secured around the acrylic column (Fig. 53). Next, the cooling plate was set to a temperature of $-15^{\circ} \mathrm{C}$ and the freezing phase began.

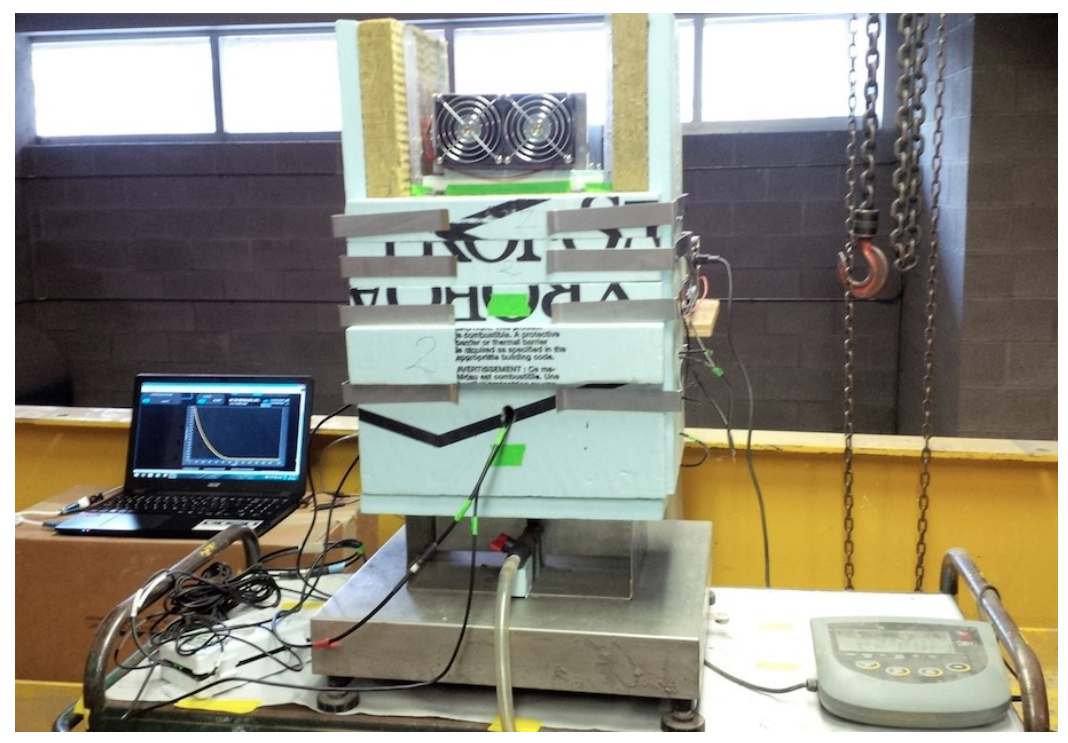

Figure 53. Experimental set-up of column test $\# 1$ at the beginning of the freezing phase. 
As mentioned in Section 3.2.2.3, due to the ice build-up originated from the air moisture in the lab, the entire experimental set up was moved and placed inside a fridge to reduce the air moisture around the column, as seen in Figure 54. This occurred on August $28^{\text {th }}, 2015$ at day 114 from the start of the experiment.

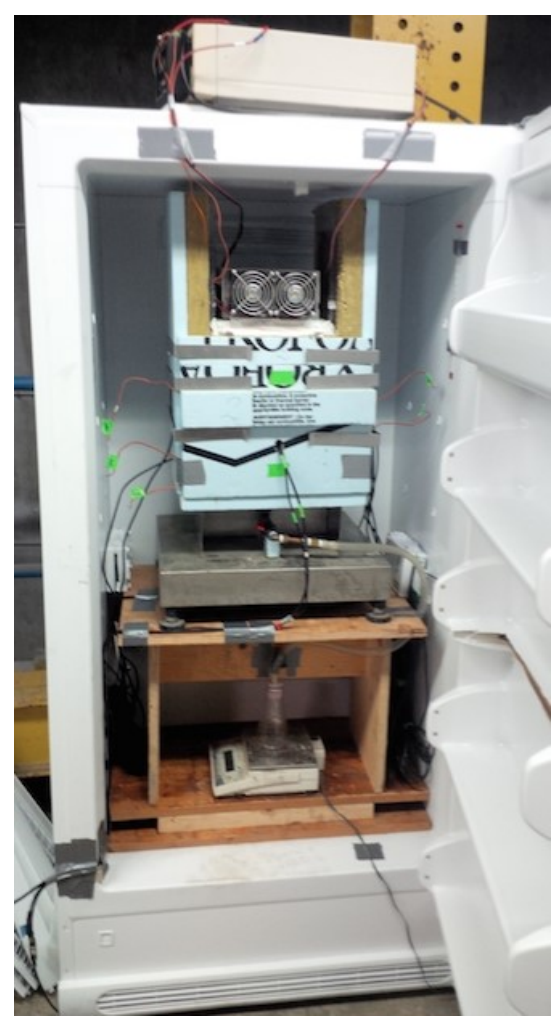

Figure 54. Experimental set-up of column test \#1 inside modified fridge.

The freezing phase was concluded on November $18^{\text {th }}, 2015$ at day 197 from the beginning of the experiment. 


\subsubsection{Thawing Phase and Termination}

The thawing phase lasted 7 days. The cooling plate and the insulating case were removed to allow the tailings to equilibrate with the room temperature $\left(22^{\circ} \mathrm{C}\right)$ and let to thaw (see Figure 55). This thawing temperature was chosen due to the absence of an environmental chamber to control the temperature around the column. Also, surface water from thawing was drained daily and counted as drained water.

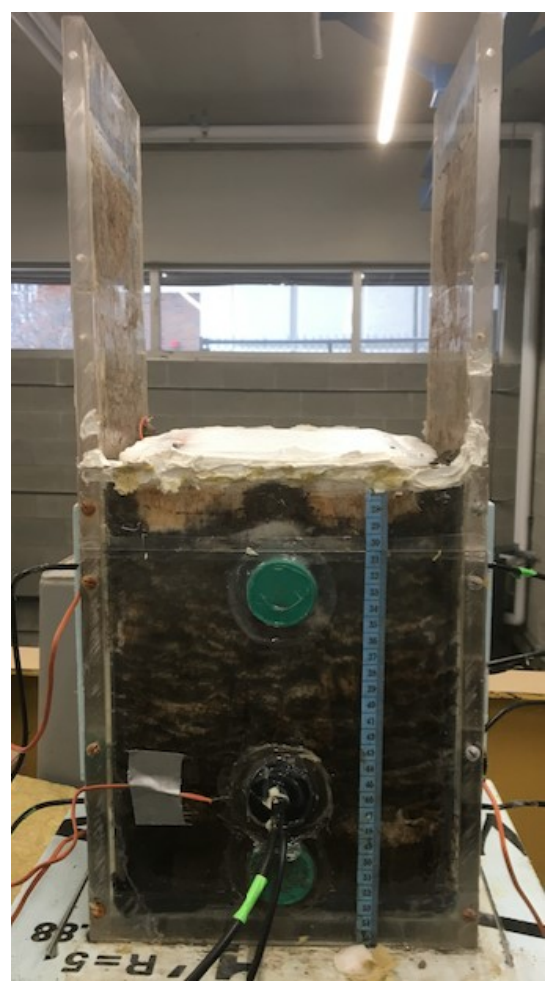

Figure 55. Experimental set-up of column test $\# 2$ at the beginning of the thawing phase.

The experiment was terminated when no further significant $(<1 \mathrm{~mm})$ self-weight consolidation due to thawing was detected. Core samples were taken (Fig.56) from the MFT column to obtain gravimetric water content, solids content, and total suction 
profiles. Also, vane shear and consolidation tests were performed at different depths to measure strength, compressibility, and permeability parameters. See Section 3.5 for further explanation on these tests. Column test \#1 ended on November 26, 2015 after 205 days of testing.

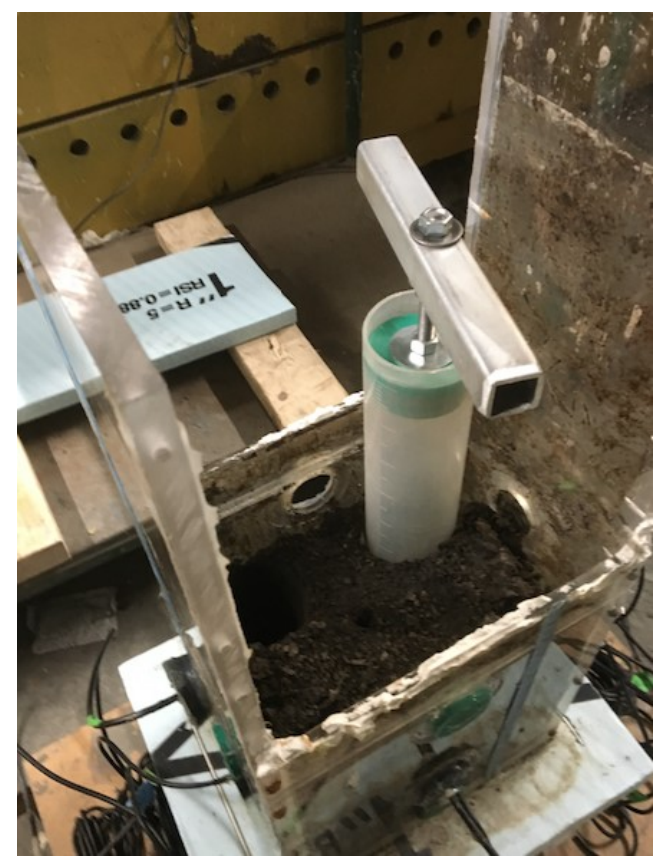

Figure 56. MFT coring post-thawing of column test \#1.

\subsubsection{Column Test \#2: Self-Weight Consolidation with Ambient Drying}

Column test \#2 started on February 20, 2016 and concluded on June 13, 2016. The test lasted a total of 115 days. For this test, a new acrylic column was built with the same dimensions as the column in test \#1. The differences from column test \#1 are the absence of removable parts since this column test does not undergo a freeze-thaw cycle 
and the addition of sensors at the surface of the tailings. This test ran simultaneously with column test \#3.

For a detailed description of different events during column test \#2 see Appendix D. Also, Table 14 shows the type and location of sensors present in this test.

Table 14. Type and sensor location for column test \#2.

\begin{tabular}{|c|c|c|}
\hline $\begin{array}{l}\text { Sensor Location } \\
\text { (from the bottom) }\end{array}$ & Type of Sensor & $\begin{array}{c}\text { Type of } \\
\text { Measurement* }\end{array}$ \\
\hline & MPS-6 Water potential Sensor & PWP \& $\mathrm{T}^{\circ}$ \\
\hline Surface & 5TE SM/ ${ }^{\circ} \mathrm{T} / \mathrm{EC}$ Sensor & $\mathrm{VWC}, \mathrm{T}^{\circ}, \mathrm{EC}$ \\
\hline & RT-1 Soil Temperature Sensor & $\mathrm{T}^{\circ}$ \\
\hline $22.5 \mathrm{~cm}$ & $5 \mathrm{TE} \mathrm{SM} /{ }^{\circ} \mathrm{T} / \mathrm{EC}$ Sensor & $\mathrm{VWC}, \mathrm{T}^{\circ}, \mathrm{EC}$ \\
\hline $15 \mathrm{~cm}$ & $5 \mathrm{TE} \mathrm{SM} /{ }^{\circ} \mathrm{T} / \mathrm{EC}$ Sensor & $\mathrm{VWC}, \mathrm{T}^{\circ}, \mathrm{EC}$ \\
\hline $5 \mathrm{~cm}$ & 5TE SM/ T/EC Sensor & VWC, $\mathrm{T}^{\circ}, \mathrm{EC}$ \\
\hline
\end{tabular}

\subsubsection{Deposition}

Similar to column test \#1, MFT was mixed with polymer as explained in Section 3.1. The dosage of polymer per container comprising $3.6 \mathrm{Kg}$ of raw MFT each was 201 grams. Six and a half containers of amended MFT were needed to fill up the 
column at a lift of $0.5 \mathrm{~cm}$. The total weight of the material was $22.2 \mathrm{Kg}$. Also, the MFT's gravimetric water and solids content at the beginning of the test were $191.7 \%$ and $34.3 \%$, respectively. Figure 57 shows the experimental set-up post deposition of the amended MFT. Once the material was placed inside the column, the drainage system was open and the MFT was allowed to drain. Drained water was collected using an Erlenmeyer flask. Also, the data loggers used to store the data obtained from the different sensors were turned on and the data recording process began.

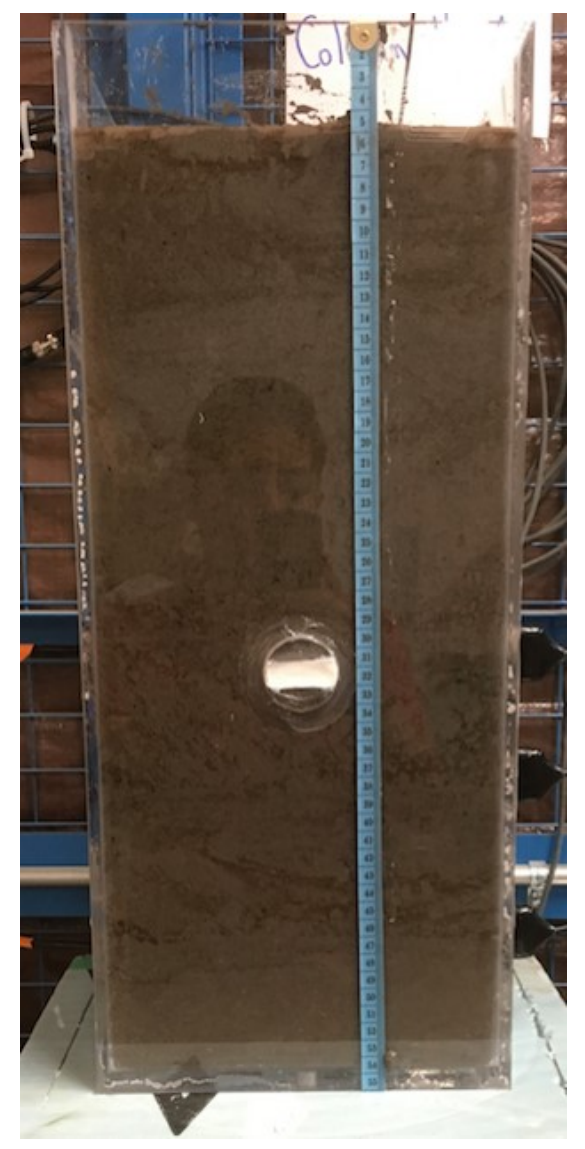

Figure 57. Experimental set-up of column test $\# 2$ right after deposition. 
Daily height and weight measurements of the MFT column were taken. The amount of drained water was also recorded daily. The water cover formed on top of the MFT the first few days of the test was drained on a daily basis and considered as drained water.

\subsubsection{Self-Weight Consolidation with Ambient Drying Phase}

The entirety of this test consisted on self-weight consolidation with ambient drying of polymer amended MFT. The material was allowed to self-weight consolidate for 115 days. Figure 58 shows the experimental set-up at day 115.

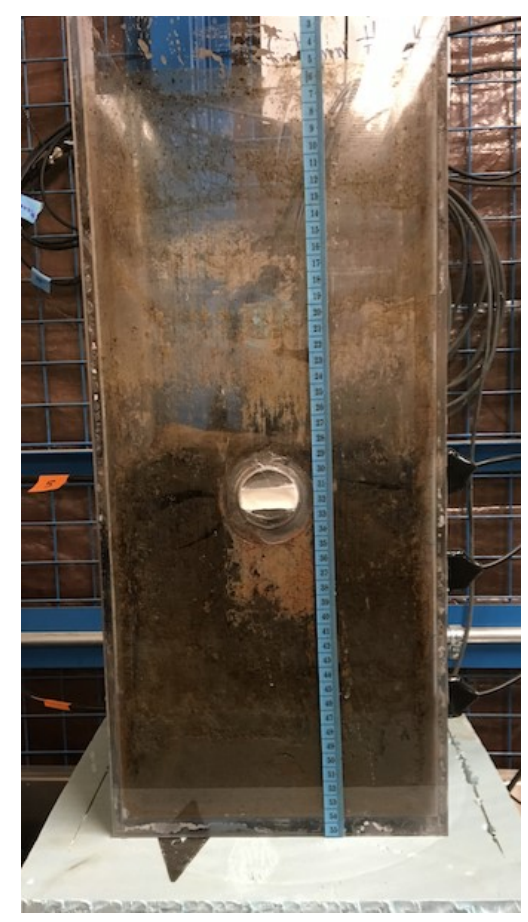

Figure 58. Experimental set-up of column test \#2 at day 115. 
The running time of this test depended solely on the testing time of column test

\#3 since both tests ran at the same time. Similar to column test \#1, after termination, core samples were taken from the MFT column to obtain gravimetric water content, solids content, and total suction profiles. Also, vane shear and consolidation tests were performed at different depths to measure strength, compressibility, and permeability parameters. See Section 3.5 for further explanation on these tests.

\subsubsection{Column Test \#3: Self-Weight Consolidation with Ambient Drying, Accelerated Desiccation, and Freeze-Thaw Cycle}

Column test \#3 started on February 20, 2016 and concluded on June 13, 2016. The test lasted a total of 115 days. This test used the same acrylic column as test \#1. It contains the same removable parts on the front and back of the column to allow the cooling plate to rest on top of the tailings. It also has sensors at its surface. This test ran simultaneously with column test \#2.

For a detailed description of different events during column test \#3 see Appendix D. Also, Table 15 shows the type and location of sensors present in this test. 
Table 15. Type and sensor location for column test \#2.

\begin{tabular}{|c|c|c|}
\hline $\begin{array}{l}\text { Sensor Location } \\
\text { (from the bottom) }\end{array}$ & Type of Sensor & $\begin{array}{c}\text { Type of } \\
\text { Measurement* }\end{array}$ \\
\hline \multirow{2}{*}{ Surface } & $5 \mathrm{TE} \mathrm{SM} /{ }^{\circ} \mathrm{T} / \mathrm{EC}$ Sensor & VWC, $T^{\circ}, \mathrm{EC}$ \\
\hline & RT-1 Soil Temperature Sensor & $\mathrm{T}^{\circ}$ \\
\hline \multirow[b]{2}{*}{$22.5 \mathrm{~cm}$} & $5 \mathrm{TE} \mathrm{SM} /{ }^{\circ} \mathrm{T} / \mathrm{EC}$ Sensor & $\mathrm{VWC}, \mathrm{T}^{\circ}, \mathrm{EC}$ \\
\hline & MPS-6 Water potential Sensor & PWP \& $\mathrm{T}^{\circ}$ \\
\hline \multirow{2}{*}{$15 \mathrm{~cm}$} & $5 \mathrm{TE} \mathrm{SM} /{ }^{\circ} \mathrm{T} / \mathrm{EC}$ Sensor & $\mathrm{VWC}, \mathrm{T}^{\circ}, \mathrm{EC}$ \\
\hline & MPS-6 Water potential Sensor & PWP \& $\mathrm{T}^{\circ}$ \\
\hline \multirow[b]{2}{*}{$5 \mathrm{~cm}$} & $5 \mathrm{TE} \mathrm{SM} /{ }^{\circ} \mathrm{T} / \mathrm{EC}$ Sensor & $\mathrm{VWC}, \mathrm{T}^{\circ}, \mathrm{EC}$ \\
\hline & MPS-6 Water potential Sensor & PWP \& $T^{\circ}$ \\
\hline
\end{tabular}

\subsubsection{Deposition}

As the previous two tests, MFT was mixed with polymer as explained in Section 3.1. The dosage of polymer per container comprising 3.6 Kg of raw MFT each was 189 grams. Six and a half containers of amended MFT were needed to fill up the column at a lift of $0.5 \mathrm{~cm}$. The total weight of the material was $22.0 \mathrm{Kg}$. Also, the MFT's gravimetric water and solids content at the beginning of the test were $208.8 \%$ and $32.4 \%$, respectively. Figure 59 shows the experimental set-up post deposition of the 
amended MFT. Once the material was placed inside the column, the drainage system was open and the MFT was allowed to drain. Drained water was collected using an Erlenmeyer flask. Also, the data loggers used to store the data obtained from the different sensors were turned on and the data recording process began.

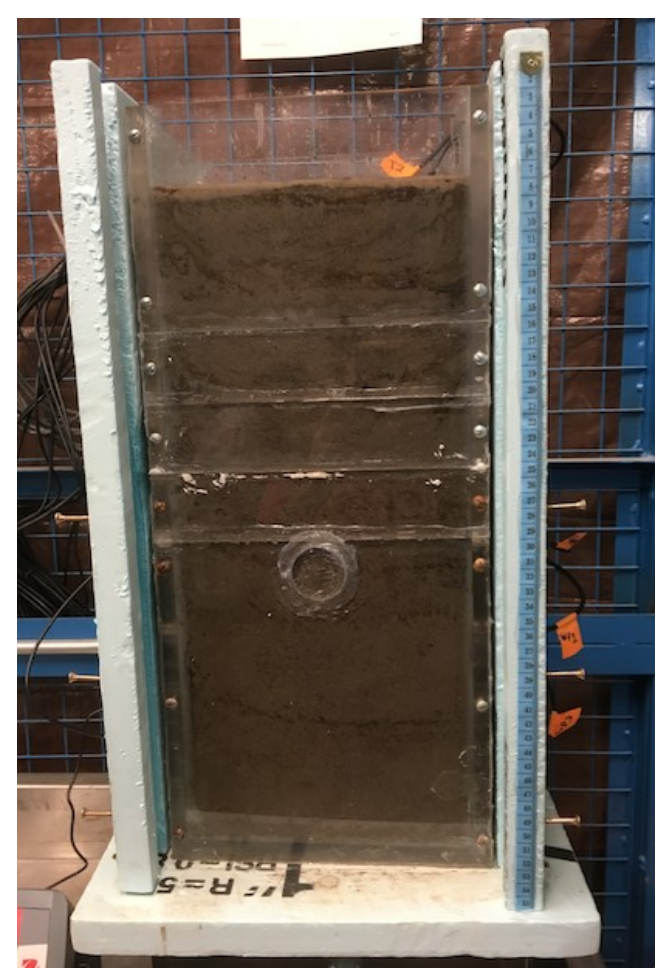

Figure 59. Experimental set-up of column test \#3 right after deposition of the tailings.

\subsubsection{Self-Weight Consolidation with Ambient Drying Phase}

The MFT was allowed to self-weight consolidate for 13 days. It was arbitrarily decided that the self-weight consolidation with ambient drying phase should last 2 weeks before the desiccation phase. The figure below (Fig. 60) shows the experimental set-up at the end of the self-weight consolidation with ambient drying phase. 


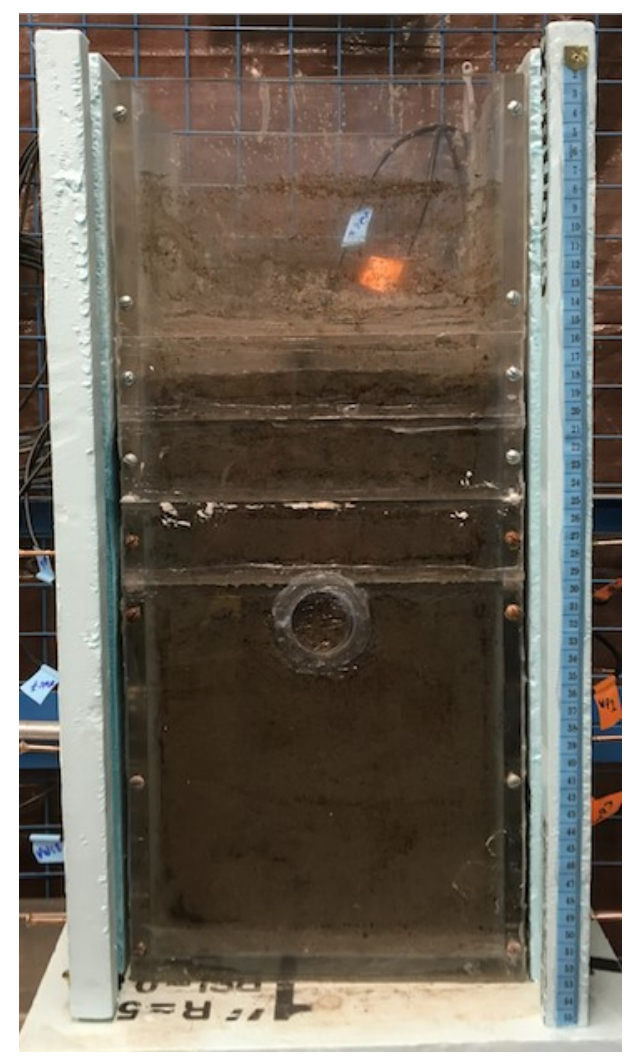

Figure 60. Experimental set-up of column test $\# 3$ at the end of the self-weight consolidation with ambient drying phase.

\subsubsection{Desiccation Phase}

For the desiccation phase, a fan was installed above the tailings (Fig. 61) to promote the circulation of air and, therefore, increase the evaporation rate in the MFT. The fan was set at its minimum setting targeting an evaporation rate of $5-10 \mathrm{~mm} /$ day. However, after many attempts the achieved evaporation rates was approximately 1 $\mathrm{cm} /$ day. It is important to mention that the direction of the wind during the accelerated desiccation phase was vertical, while in the field the direction of the wind is horizontal. The decision to have a vertical wind direction was taken due to the size restrictions of 
the column and the height of the tailings after the self-weight consolidation period. The desiccation phase lasted 14 days.

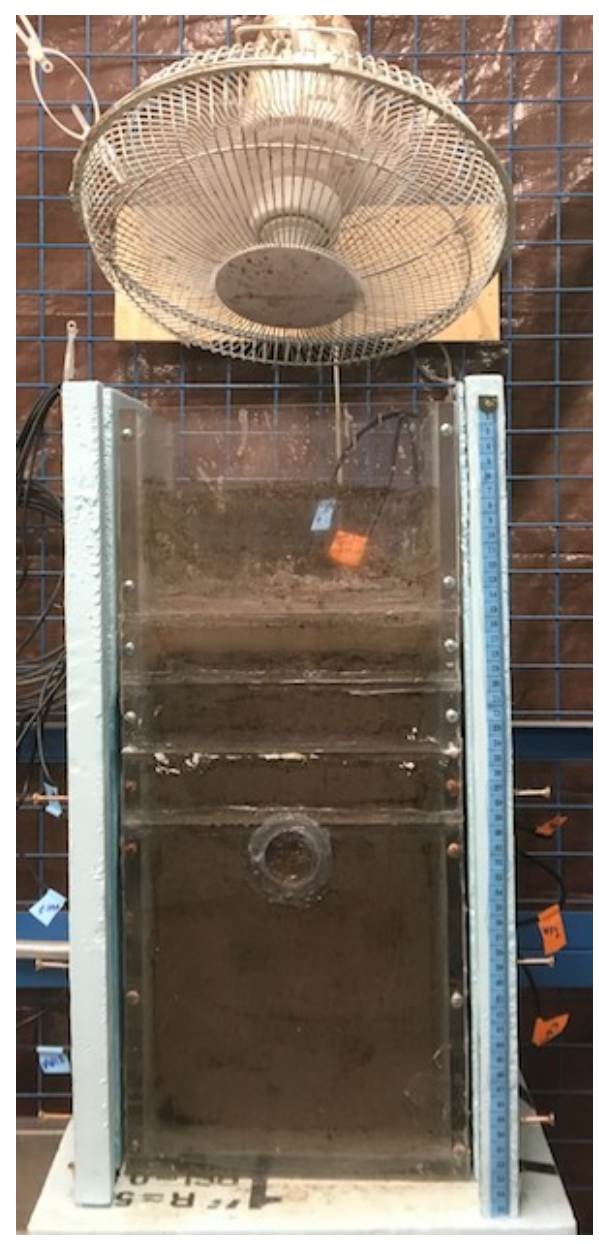

Figure 61. Experimental set-up of test column \#3 during the desiccation phase.

\subsubsection{Freezing Phase}

The freezing phase lasted 171 days. Similar to column test \#1, it was decided that the freezing phase would terminate when the sensor located at $5 \mathrm{~cm}$ away from the bottom would reach a temperature of zero degree Celsius. To initiate the freezing 
phase, the top 3 sections of the acrylic column were removed to allow the cooling plate to be as close as possible to the MFT to allow an efficient one-directional freezing. The top $1.0 \mathrm{~cm}$ of the MFT column was manually removed (412 grs.) to achieve the height of $30 \mathrm{~cm}$, as well as a flat surface to interact with the cooling plate.

The freezing phase started by placing the cooling plate in the column as close to the dried MFT as possible. Any gap between the column and the cooling plate was properly insulated using insulating foam. The insulating case was assembled and secured around the acrylic column. Next, the cooling plate was set to a temperature of $15^{\circ} \mathrm{C}$ and the freezing phase began.

Lastly, the entire set-up was placed inside a fridge to avoid ice build-up at the MFT's surface. Figure 62 shows the insulated column during the freezing phase. 


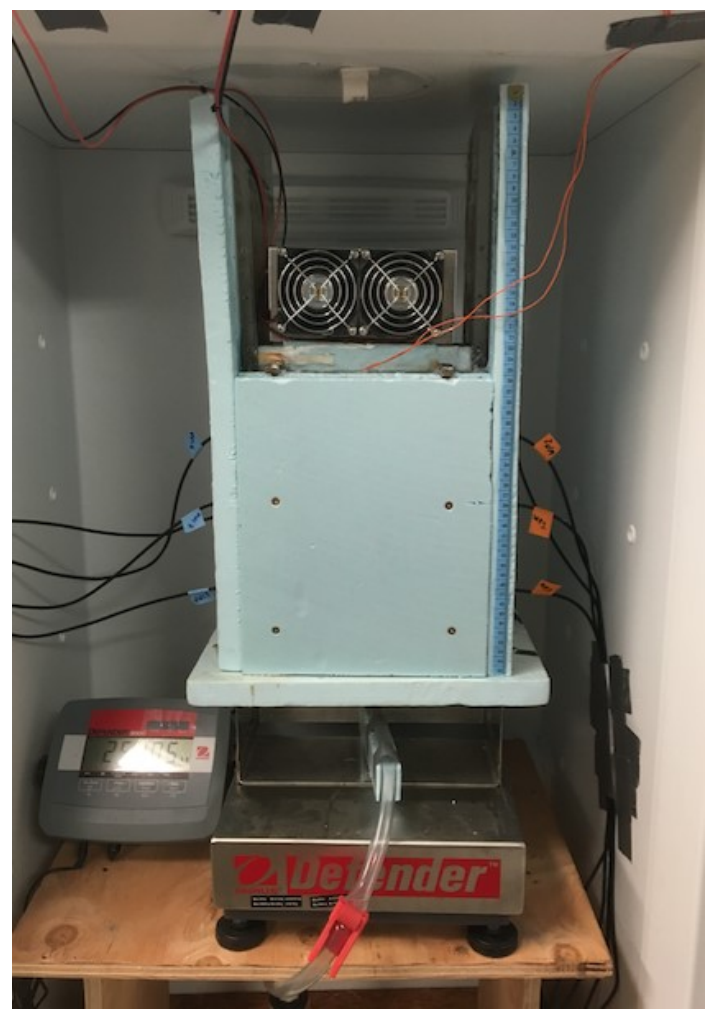

Figure 62. Experimental set-up of column test \#3 during the freezing phase.

\subsubsection{Thawing Phase and Termination}

The thawing phase lasted 11 days. Similar to column test \#1, the cooling plate and the insulating case were removed to allow the tailings to equilibrate with the room temperature and let to thaw (see Figure 63). Also, surface water from thawing was drained daily and counted as drained water. 


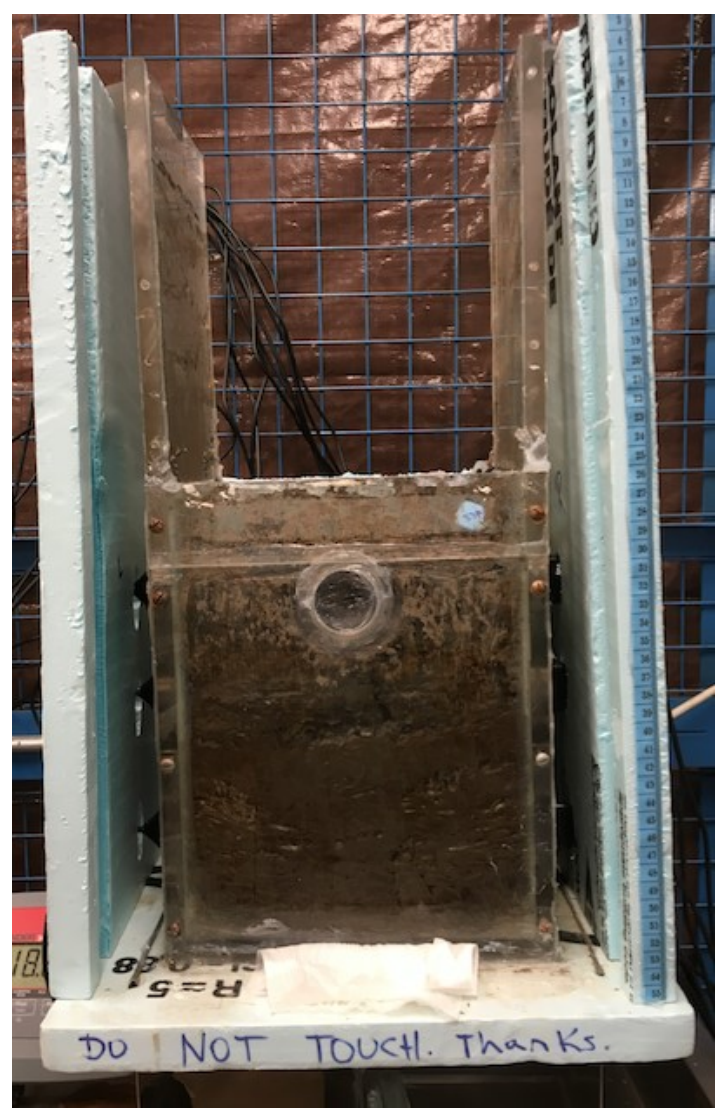

Figure 63. Experimental set-up of column test \#3 during the thawing phase.

The experiment was terminated once there was no further self-weight consolidation due to thawing. Core samples were taken from the MFT column to obtain gravimetric water content, solids content, and total suction profiles. Also, vane shear and consolidation tests were performed at different depths to measure strength, compressibility, and permeability parameters. See Section 3.5 for further explanation on these tests.

Column tests \#2 and \#3 were ended on June 14, 2016 after 115 days of testing. 


\subsection{Post-Termination Tests}

This section outlines the tests that took place after the termination of the three column tests presented above. Core samples were obtained from all the column tests to perform these tests. They include consolidation, gravimetric water content, solids content, and suction tests.

\subsubsection{Core Sampling}

Core samples were needed to obtain solid content, water content, and total suction profiles, as well as samples at different depths for consolidation tests. They were taken from each column test upon their completion.

Since the area available to obtain the core samples was significantly limited due to the size of the acrylic column and the sensors crossing the MFT at different depths, standard core samplers were proven to be either too big or too small (smaller than samples required for consolidation testing) to be utilized in these tests. Due to this limitation, an especially design core sampler was design, as seen in Figure 64. It consists of a plastic graduated cylinder with $5.6 \mathrm{~cm}$ in diameter. Both ends have been cut to obtain just a cylinder. One of its ends was sharpened to facilitate the insertion of the cylinder into the tailings. To create a vacuum inside the cylinder to contain the MFT sample and prevent it from falling, a rubber stopper with a handle system was attached to one end of the cylinder. This 'rubber-stopper-handle' not only provides suction inside the cylinder but also a way to pull out the cylinder and the MFT sample. 


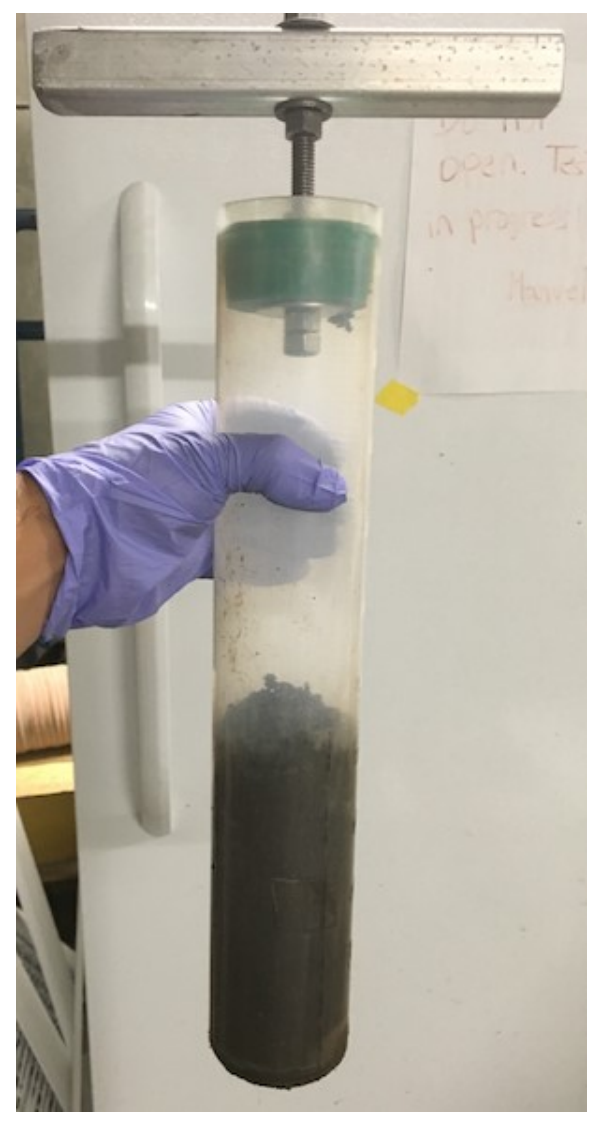

Figure 64. Core Sampler used in this research.

\subsubsection{Consolidation Tests}

Consolidation tests were performed for each column tests upon their termination. The one-dimensional consolidation testing was completed according to ASTM D2435/D2435M-11. Several samples from different depths obtained from coring were tested. The table below details the number and location of the obtained samples from each column. 
Table 16. Consolidation test samples' number and location.

\begin{tabular}{cccc} 
& Column Test \#1 & Column Test \#2 & Column Test \#3 \\
\hline Number of Samples & 4 & 2 & 2 \\
\hline Location of Samples & $3.25 \mathrm{~cm}, 6.75 \mathrm{~cm}$, & & \\
(from bottom)* & $10.25 \mathrm{~cm}$, and & $4.25 \mathrm{~cm}$ and & $6.25 \mathrm{~cm}$ and \\
& $13.75 \mathrm{~cm}$ & $10.75 \mathrm{~cm}$ & $12.75 \mathrm{~cm}$
\end{tabular}

*Sample's locations are measured from the middle of the sample to the bottom of the of the column.

The consolidation test procedure is briefly summarized below:

- Once the MFT sample was removed from the core sampler, smaller samples were obtained at the desired depths.

- The consolidation ring was inserted into the smaller MFT samples (Fig. 65 and 66) and trimmed at the bottom and top to match the volume of consolidation ring.

- Water content measurements were taken from the material around the consolidation ring.

- The mass of the consolidation ring and the sample was recorded.

- The consolidation ring and tailings sample were placed on top of a saturated porous stone, which was inside the consolidometer.

- An upper saturated porous stone was placed on top of the consolidation ring. 
- The top of the consolidotmeter was attached and secured to its base.

- The consolidometer was filled with water up to the upper porous stone.

- Then, the consolidometer was placed on the loading device (Fig. 67).

- The vertical deflection gauge was adjusted to measure the compression of the MFT sample.

- The following loads were applied to the MFT sample: $1,2,4,8,16,32$, and 64 Kg. Each load was left for a period of 24 hours.

- At the end of the test, the mass of the consolidation ring and sample were recorded.

- Water content measurements of the sample were taken.

- Compressibility and permeability calculations were conducted according to ASTM D2435/D2435M-11.

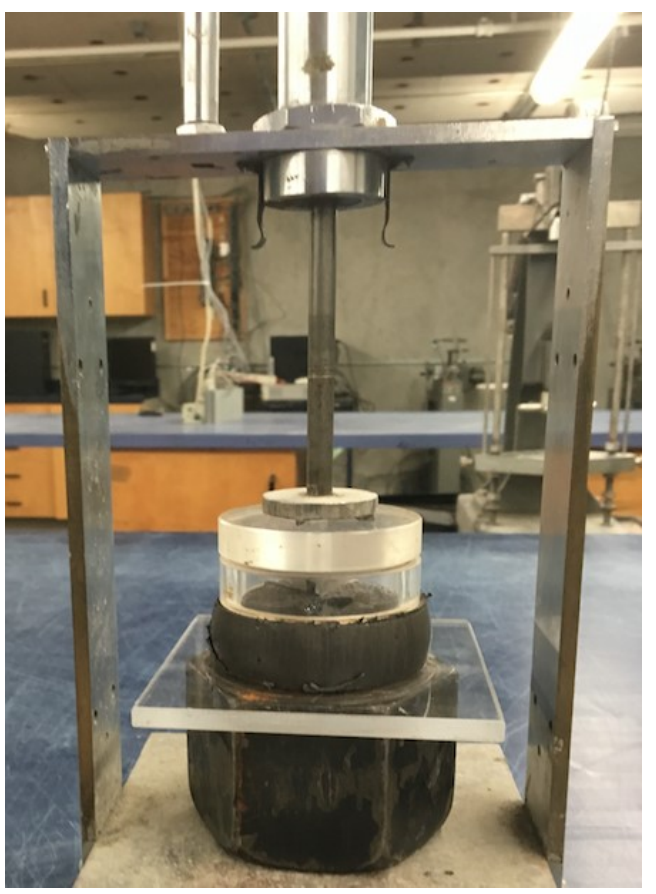


Figure 65. Equipment used to push consolidation ring into MFT sample.

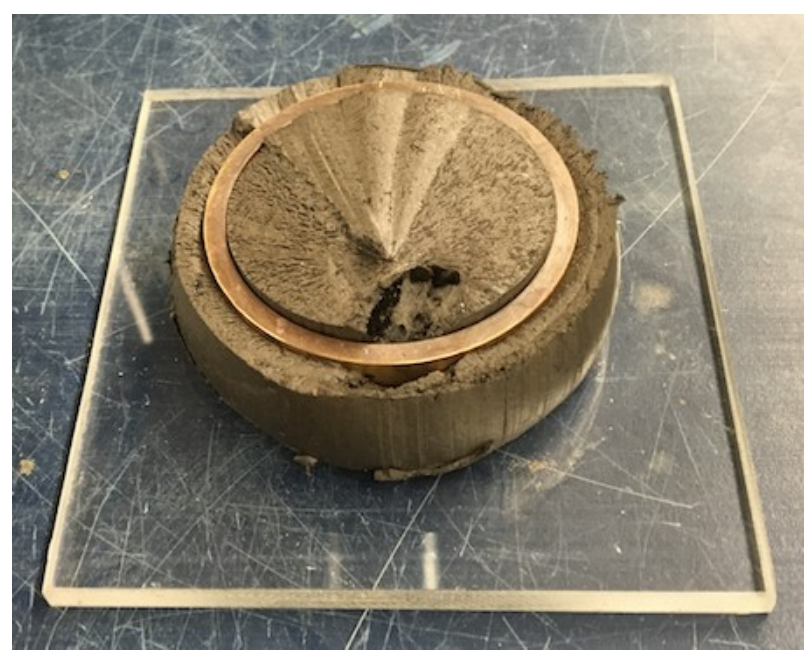

Figure 66. Consolidation ring inside MFT sample.

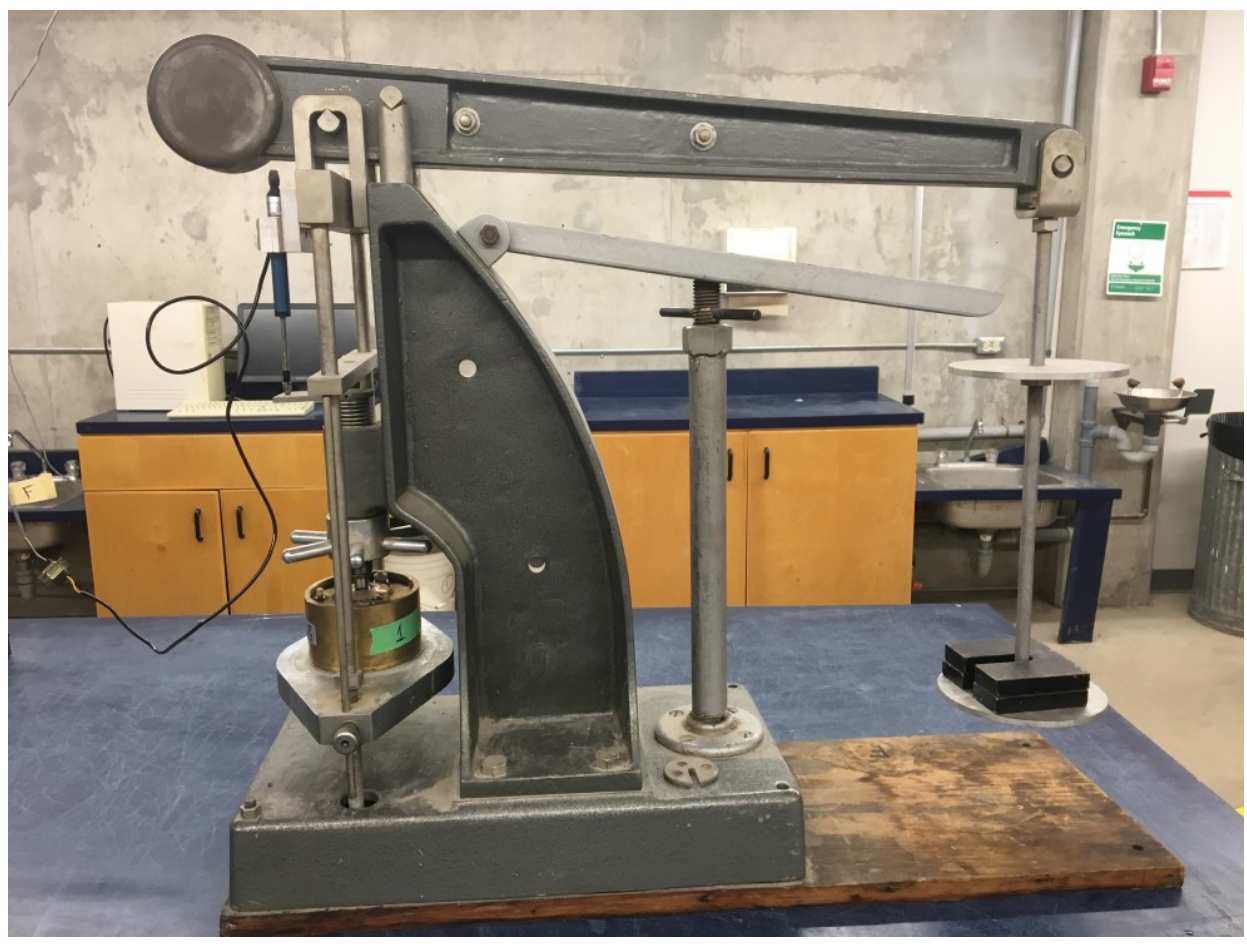

Figure 67. Consolidation test set-up. 


\subsubsection{Water and Solids Content Profiles}

Water and solids content were taken from core samples. Smaller samples of 1 $\mathrm{cm}$ in height each were taken to measure the volumetric water and solids content. The equations used to calculate said parameters are presented in Section 3.7. The following steps were taken for these tests:

- The mass of empty containers was measured.

- Then, the mass of the MFT samples plus the container was measured.

- The samples were put into an over at $105^{\circ} \mathrm{C}$ for 24 hours.

- After 24 hours, the samples were taken from the oven and their mass was measured mas again.

From these measurements, the mass of solids, mass of water, and total mass of the sample were obtained. Then, the volumetric water content and solids content values were calculated.

\subsubsection{Total Suction Profiles}

Similar to the water and solids content procedure, $1 \mathrm{~cm}$ in height samples were obtained from the core samples. Each sample provided material to be analysed in the WP4C Water Potential Meter. This water potential measuring device is explained in detail in Section 2.6.2.3. From this data, total suction profiles were constructed. 


\subsubsection{Vane Shear Test (VST)}

The vane shear test was performed according to ASTM D2573 (1). This in-situ test is used to determine the peak undrained shear strength $\left(S_{\mathrm{u}}\right)$ of soft to medium stiff clays. During the VST, a rectangular shear vane is pushed into the soil and is rotate it from the surface through a handle at a rate of 0.1 degrees per second. A vane of various diameters was inserted into the soil at $5 \mathrm{~cm}$ intervals. Also, specific factors corresponding to different vane sizes were applied to correct the readings. Figure 68 shows the device used. The range of the device is from zero to $260 \mathrm{KPa}$.

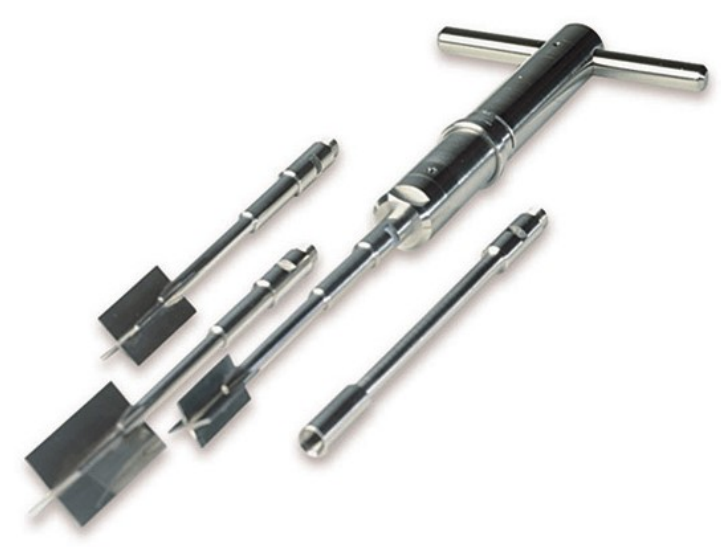

Figure 68. Vane shear test equipment.

\subsection{Soil Water Characteristic Curve (SWCC) Test}

A soil water characteristic curve was constructed for fresh polymer amended tailings. The test lasted 76 days. The device used was a SWC-150 Soil Water Characteristic Cell or Fredlund SWCC device from GCTS Testing Systems, as seen in Figure 69. The steps taken to perform this test are as follow: 
- The raw MFT was mixed with the polymer as described in Section 3.1.

- The polymer amended MFT was placed inside the sample ring and weight measurements were taken.

- Gravimetric water content measurements were taken from leftover sample.

- Prior to be used, the top and bottom sections of the SWCC cell were covered with vacuum grease to avoid air from escaping or entering the cell.

- The sample ring was placed into the SWCC cell and the weight of the entire cell was recorded.

- The pressure tubes were connected to the top of the cell and the pressure cylinder was open. The pressures used in this test were $0,20,40,80,160,400$, 700, 23 357, $167413 \mathrm{KPa}$.

- Daily height measurements of the water volume change indicator were taken to measure the water discharge out of the specimen.

- Lastly, at the end of each pressure interval the SWCC cell weight was recorded. The height and diameter of the specimen were also measure. 


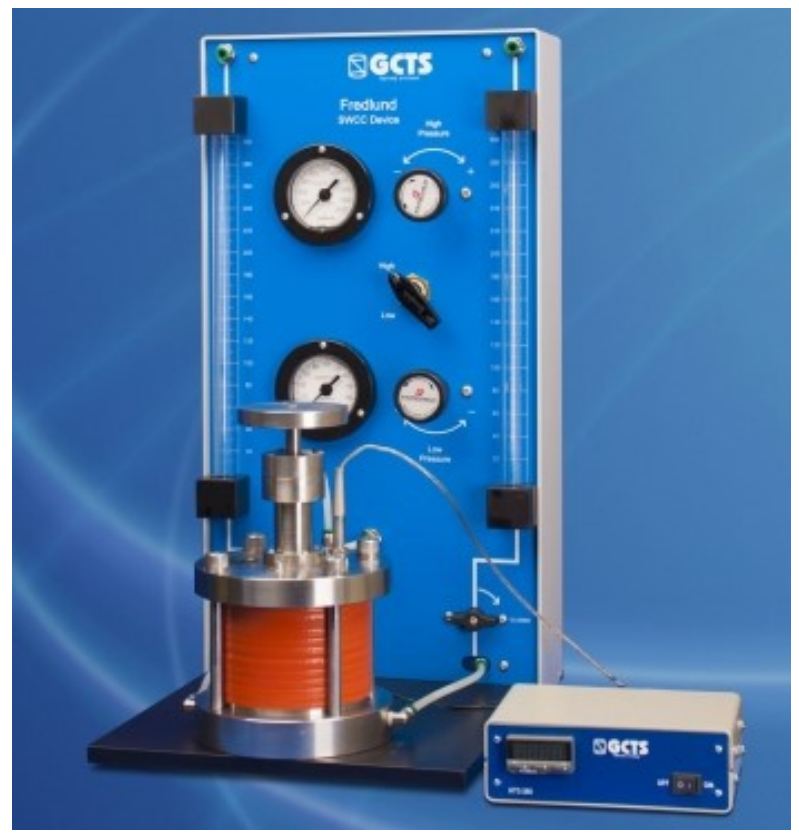

Figure 69. SWCC Fredlund device (GCTS Testing Systems).

\subsection{Properties Calculations}

This section summarizes all the equations used to measure MFT properties, such as solids content, gravimetric water content, unit weight, void ratio, and slump.

\subsubsection{Solids Content (\%)}

In the oil sands terminology, the solids content is defined as the ratio of mass of solids to the total mass of the sample. It is noteworthy to point out that the mass of solids includes fine particles, sands, and bitumen. To determine the solids content, samples were placed in an oven at $105^{\circ} \mathrm{C}$ for 24 hours. The equation used to calculate the solids content is the following: 


$$
C_{S}(\%)=\frac{M_{S}}{M_{T}} \times 100
$$

Where,

$$
\begin{aligned}
& C_{S}=\text { Solids Content }(\%) ; \\
& M_{S}=\text { Mass of Solids; } \\
& M_{T}=\text { Total Mass. }
\end{aligned}
$$

\subsubsection{Gravimetric Water Content (\%)}

For this research, the gravimetric wet water content was used to measure the amount of moisture within a sample. This relationship is defined as the ratio of the mass of water to the total mass of the sample. It is represented by the following expression:

$$
G W C=w(\%)=\frac{M_{w}}{M_{S}} \times 100
$$

Where,

$$
\begin{aligned}
& \text { GWC }=\mathrm{w}(\%)=\text { Gravimetric Water Content }(\%) ; \\
& M_{w}=\text { Mass of Water; } \\
& M_{S}=\text { Dry Mass. }
\end{aligned}
$$




\subsubsection{Unit Weight}

The unit weight is defined as the weight per unit volume of a material. It is expressed as:

$$
\gamma_{b u l k}=\frac{\gamma_{w}(G+S e)}{1+e}
$$

Where,

$$
\begin{aligned}
& \gamma_{b u l k}=\text { Bulk Unit Weight; } \\
& \gamma_{w}=\text { Unit Weight of Water; } \\
& \mathrm{S}=\text { Degree of Saturation; } \\
& \mathrm{e}=\text { void ratio; } \\
& \mathrm{G}=\text { Specific Gravity. }
\end{aligned}
$$

\subsubsection{Void Ratio}

The void ratio is defined as the ratio of the volume of voids to the volume of solids. In a fully saturated soil, the voids are filled with water; while in a partially saturated sample, the voids are filed with air and water. The following relationship was used to calculate the void ratio:

$$
e=\frac{V_{v}}{V_{s}}
$$


Where,

$$
\begin{aligned}
& \mathrm{e}=\text { Void Ratio; } \\
& V_{v}=\text { Volume of Voids. If } \mathrm{S}=1, V_{v}=V_{w} \\
& V_{S}=\text { Volume of Solids. }
\end{aligned}
$$

\subsubsection{Slump Test}

To ensure uniformity in the mixing process of the MFT and flocculant, slump tests were taken at every other mixed $3.6 \mathrm{~kg}$ badge. The slump test follows the procedure described by Pashias et al., (1996). The test consists on pouring the polymer amended MFT into a cylindrical container with a known height. The container has to be completely filled. Then, the cylindrical container is carefully removed and put aside the MFT, as seen in Figure 70. The final height of the MFT is measured. The difference between the initial and final height of the polymer amended MFT is the slump. Consistency in the measured slump ensures the uniformity of the material being mixed.
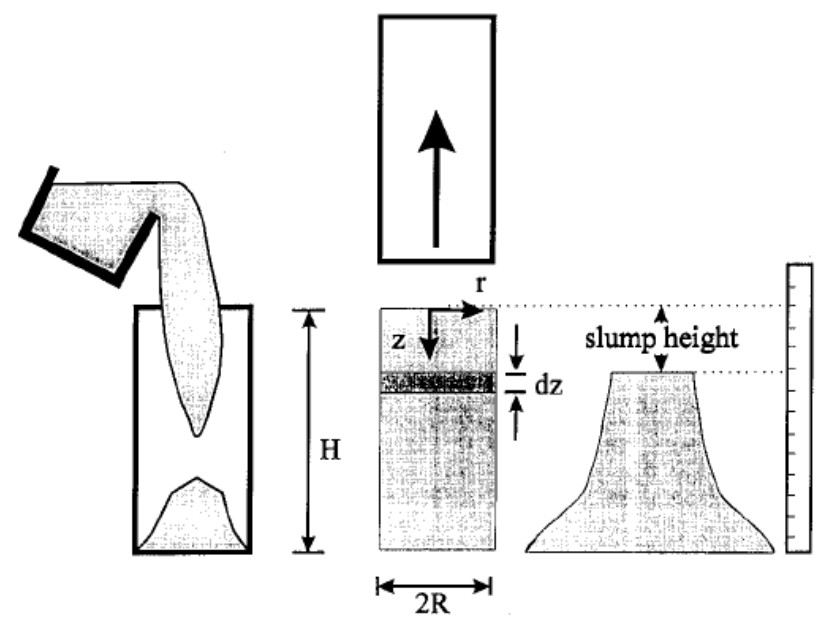

Figure 70. Diagram for slump test (Pashias et al., 1996) 
From the measured slump it is possible to measure the yield stress of the material using the formula given by Pashias et al., (1996). The relationship is as follows:

$$
\tau_{y}=0.5 \rho g h\left(1-\sqrt{S^{\prime}}\right)
$$

Where,

$$
\begin{aligned}
& \tau_{y}=\text { Yield stress }(\mathrm{kPa}) \\
& \rho=\text { Bulk density of sample }\left(\mathrm{kg} / \mathrm{m}^{3}\right) \\
& \mathrm{g}=\text { acceleration of gravity }\left(\mathrm{m} / \mathrm{s}^{2}\right) \\
& \mathrm{h}=\text { Height of the slump cylinder }(\mathrm{m}) \\
& \mathrm{S}^{\prime}=\text { Dimensionless slump }\left(\left(\mathrm{h}-\mathrm{h}_{\mathrm{f}}\right) / \mathrm{h}\right)
\end{aligned}
$$




\subsection{References}

Baker, T. (1976). Transportation, Preparation, and Storage of Freezing Soil Samples for Laboratory Testing. Soil Specimen Preparation for Laboratory Testing, ASTM STP 599, 88-112.

Decagon Device Inc. (2013). RT-1 Soil Temperature Sensor. Retrieved August 2, 2016, from Decagon Devices: https://www.decagon.com/en/soils/volumetric-watercontent-sensors/rt-1-rugged-soil-temperature-sensor/

Decagon Devices Inc. (2013). 5TE water content, EC, and temperature sensor. Pullman, WA: Decagon Devices Inc.

GCTS Testing Systems. (n.d.). Systems: SWC-150 SOIL-WATER CHARACTERISTIC CELL. Retrieved August 02, 2016, from GCTS Testing Systems: http://www.gcts.com/?s=prod_ver\&p=products\&ID=156\#tab-2

Government of Canada. (n.d.). Historical Climate Data. Retrieved July 29, 2016, from Government of Canada - Environmental and Natural Resources: http://climate.weather.gc.ca/

Henry, H. (2007). Soil freeze-thaw cycle experiments: Trends, methodological weaknesses and suggested improvements. Soil Biology and Biochemistry (39), 977-986.

Hobbs, P. (1974). Ice Physics. Oxford, UK: Clarendon Press.

Inc, S. E. (2009). Patent No. US 9068776 B2. Canada. 
Mizani, S., Soleimani, S., \& Simms, P. (2013). Effects of polymer dosage on dewaterability, rheology, and spreadability of polymer-amended mature fine tailings. Sixteenth International Seminar on Paste and Thickened Tailings (Paste13), (pp. 117-31). Belo Horizonte.

Pashias, N., Boger, B., Summers, J., \& Glenister, D. (1996). A fifty cent rheometer for yield stress measurement. Journal of Rheology , 40 (6), 1179-1189.

Soleimani, S., Simms, P., Dunmola, A., Freeman, G., \& Wilson, G. (2014). Desiccation and consolidation in thin-lift deposition of polymer-amended mature fine tailings. Paste 2014 - R.J. Jewell, A.B. Fourie, S. Wells and D. van Zyl (eds) (p. 13). Vancouver: InfoMine Inc.

TE Technology Inc. (n.d.). TE Technology, Inc. Retrieved July 28, 2016, from CP-121: http://tetech.com/product/cp-121/

Williams, P. (1968). Thermoelectric Cooling For Precise Temperature Control Of Frozen And Unfrozen Soils. Canadian Geotechnical Journal , 5 (4), 264-266. 


\section{Chapter: Results}

This chapter presents the results of the preliminary freezing tests, the three column tests, and the soil water characteristic curve test performed for this research. Also, it presents the results from the consolidation tests performed on the MFT after the completion of the column tests. This chapter concludes with the comparison of results from the column tests to single out and identify the effects of one freeze-thaw cycle in the dewatering of tailings.

\subsection{Preliminary Suction Tests}

The following tests were performed to assess the negative pore water (or matric suction) development at room temperatures and at temperatures below zero. They also helped determine the reliability of the suction readings as tailings freeze. MPS-6 sensors were used in all these tests. Lastly, the first two tests did not use polymer amended MFT while the third test did.

\subsubsection{Preliminary Test \#1}

Figure 71 and 72 show the suction development at room temperature and freezing, respectively. The experimental set-up and sensor location for this test is found in Section 3.3. Figure 71 shows an increase of $1.8 \mathrm{kPa}$ in matric suction as the tailings dry. Evaporation was not measured for this test but it is present, especially at the high temperatures the sample was exposed to (i.e. high 20 's ${ }^{\circ} \mathrm{C}$ ). On the other hand, Figure 72 also shows the development of matric suctions as the temperature drops. The sensor does not record matric suction values before the freezing point of water $\left(0{ }^{\circ} \mathrm{C}\right)$. 
However, once temperatures drop below zero, specifically at $-2{ }^{\circ} \mathrm{C}$, suction values develop a fast and steady rate reaching suctions of up to $3500 \mathrm{kPa}$ at $-25^{\circ} \mathrm{C}$.

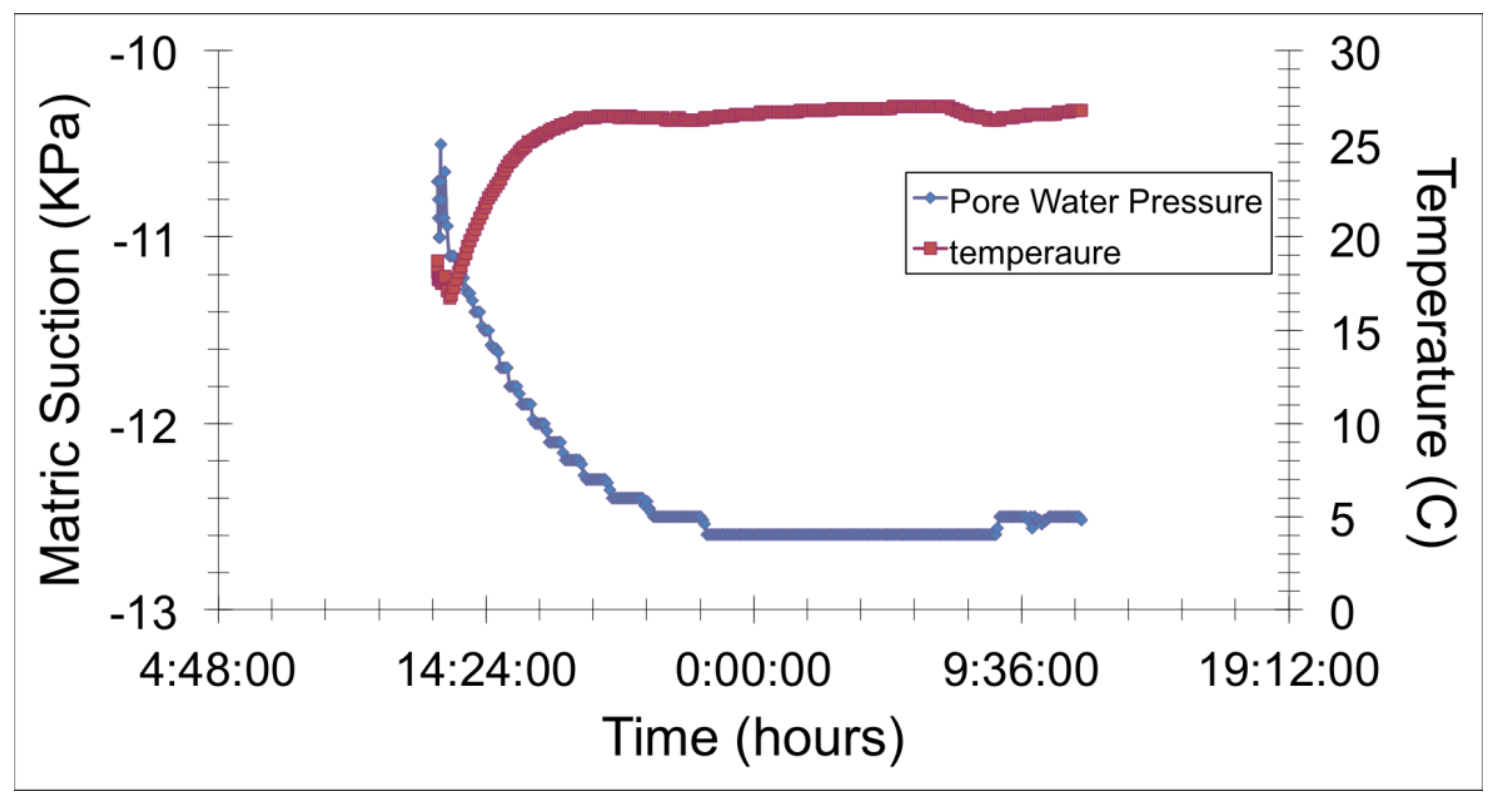

Figure 71. Temperature and Matric Suction results at room temperature.

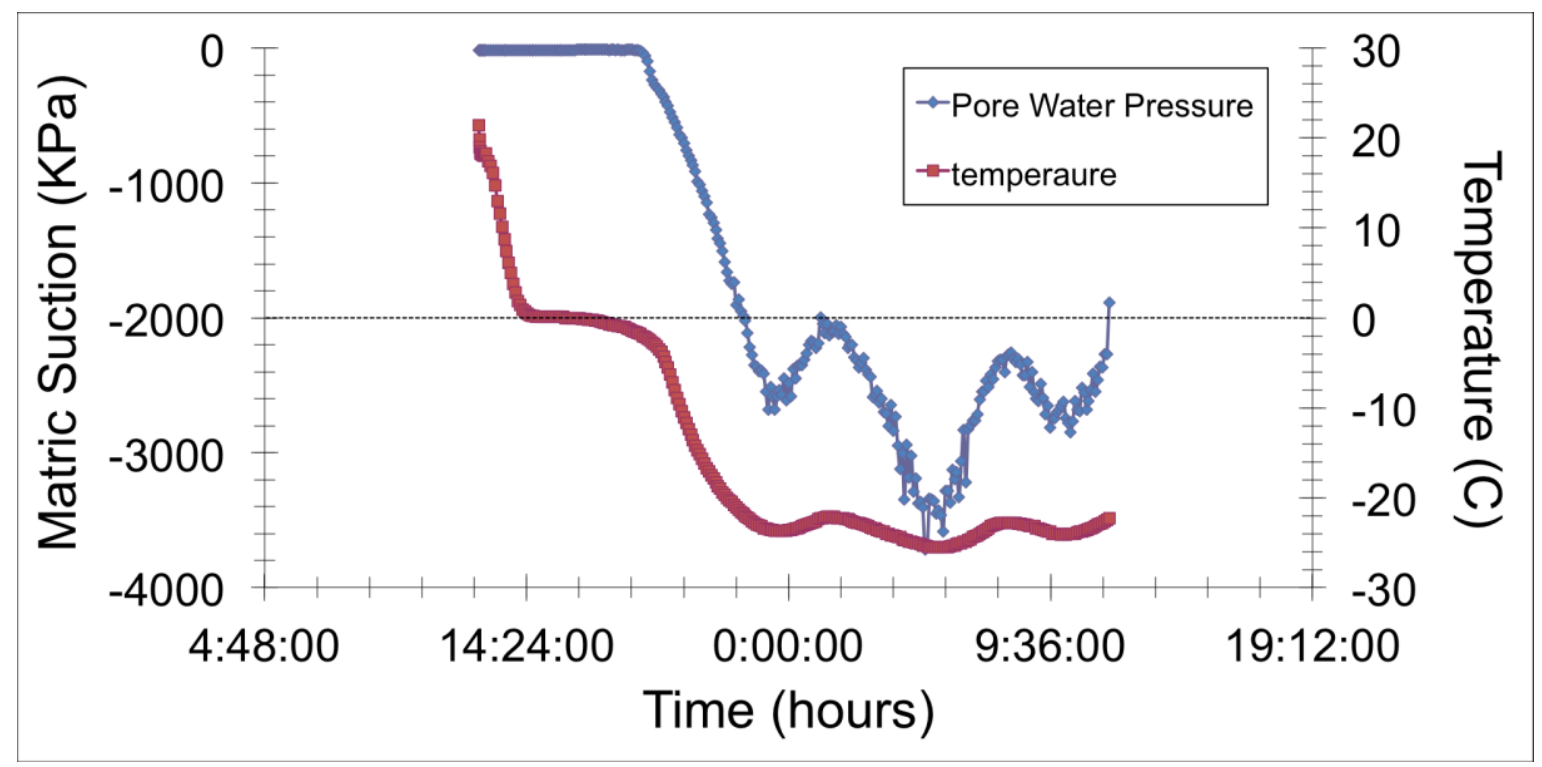

Figure 72. Temperature and Matric Suction results for freezing tailings. 
It is unclear if the suction readings at temperatures below zero are reliable. The MPS-6 sensor measures the electrical permittivity of its ceramic disks after equilibrium was achieved between the sensor and the tailings in order to infer its water content and then its pore water pressure (or matric suction). As the tailings freeze and the water inside the sensors' pores begin to turn into ice, the permittivity readings become unreliable since the permittivity of ice and the ceramic discs are very similar (i.e. $~ 5$ ) leading to inaccurate water content readings and therefore inaccurate matric suction readings (Decagon Devices, 2014).

Also, there seems to be an in-phase response between the temperature and matrix suction readings, as seen in Figure 72. The similar response is due to the freezing of the sensor itself. Temperature readings gradually become more negative while ice starts to form inside the sensor leading to unreliable matric suctions.

Lastly, Figure 73 shows the relationship between temperature and matric suction recorded by the MPS-6 sensor. The measured matric suctions remain unchanged as temperatures drop until the freezing tailings reached $-2{ }^{\circ} \mathrm{C}$. At this temperature, the slope of the curve remained almost flat until it reached approximately $250 \mathrm{kPa}$. As temperatures kept dropping, the rate of increase in matric suction became steeper until around $-3000 \mathrm{kPa}$. The matric suction continued increasing but there was no significant change in temperature as it remained around $-25^{\circ} \mathrm{C}$. As seen from the figure below, the direct relationship between temperature and matric suction becomes apparent. As temperature drops, ice crystals form and matric suctions develop. 


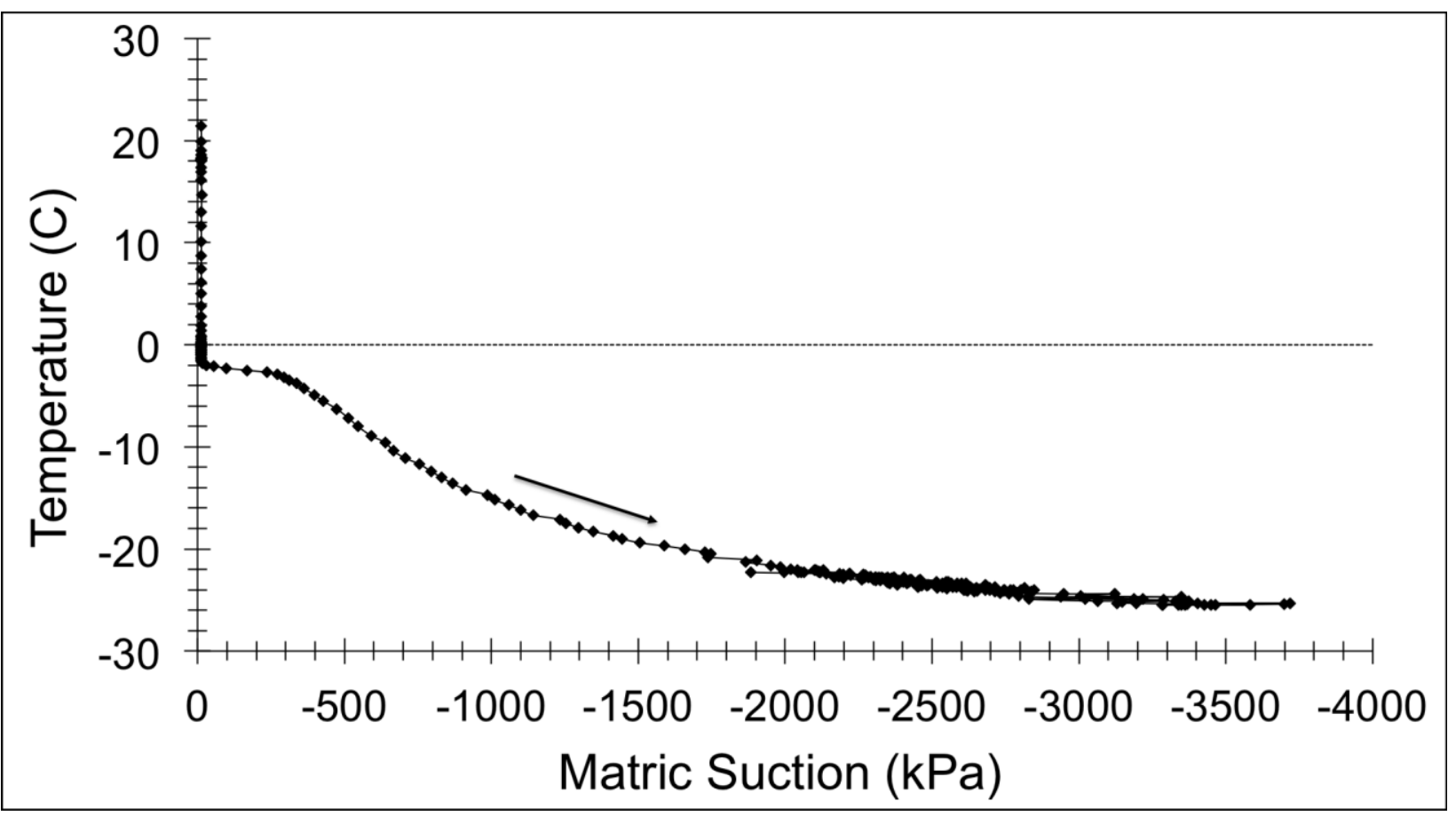

Figure 73. Temperature vs Matric Suction for Preliminary Test \#1.

\subsubsection{Preliminary Test \#2}

Preliminary test \#1 gave indications of the development of matric suctions below the freezing front; thus, for this test two sensors at different depths were tested to measure the progression of freezing-induced suctions. Figure 74 shows the matric suction and temperature for the top sensor and Figure 75 for the bottom sensor. Both sensors are $5 \mathrm{~cm}$ part. The experimental set-up and sensor location for this test is found in Section 3.3. 


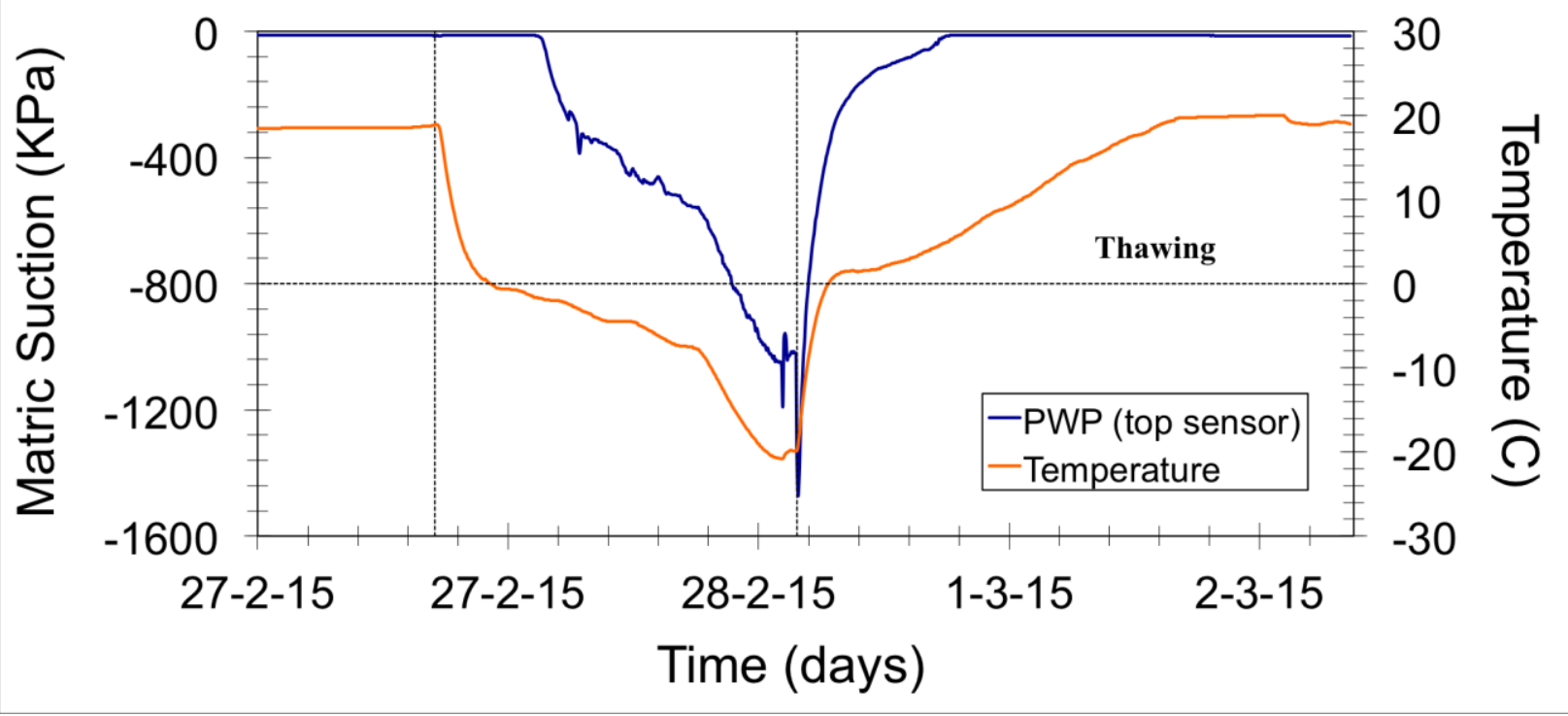

Figure 74. Pore water pressure and temperature over time (top sensor).

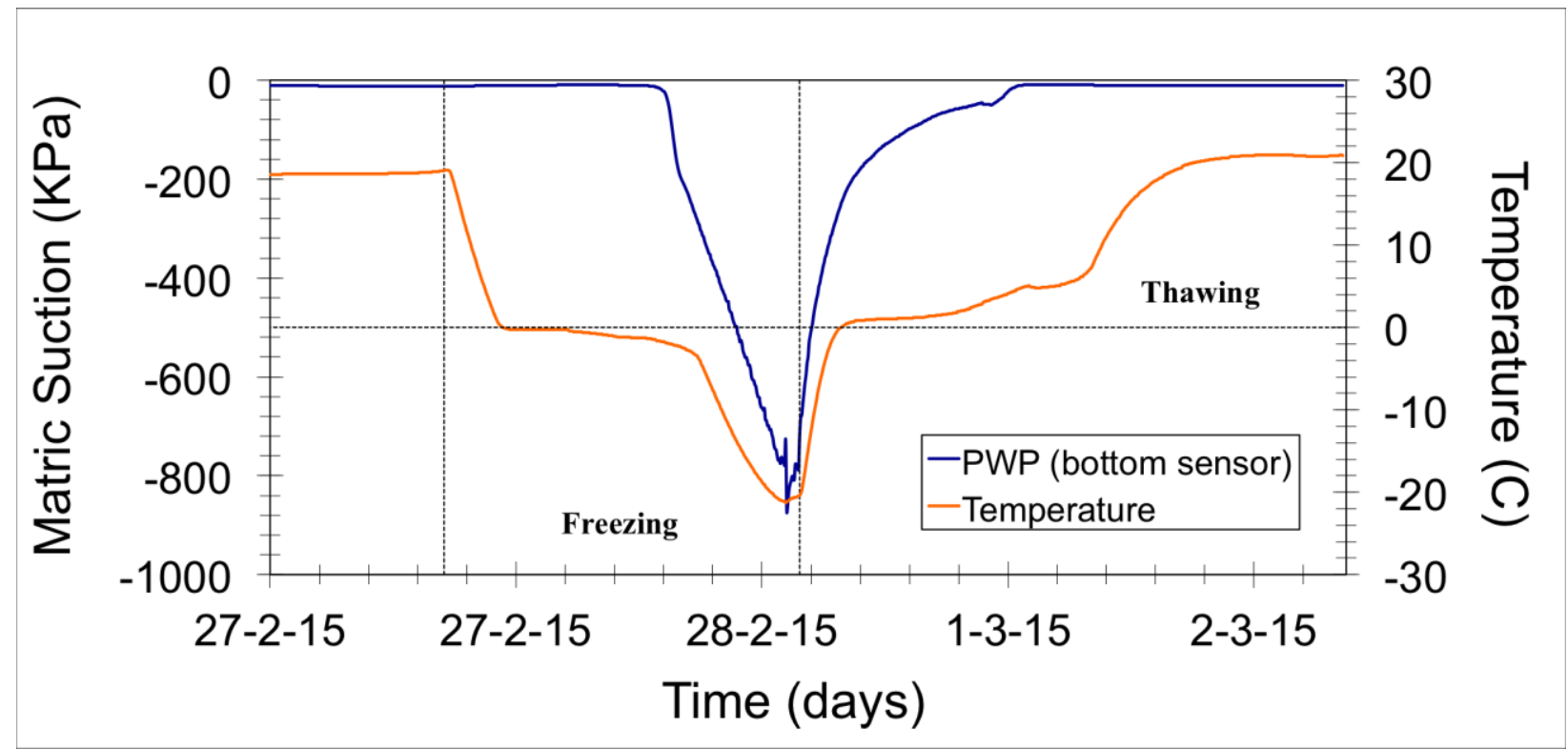

Figure 75. Pore water pressure and temperature over time (bottom sensor). 
After one day of freezing, the temperature at both sensors' location was approximately $-20^{\circ} \mathrm{C}$. However, the suction profiles are different. The highest suction value recorded by the top sensor during freezing was $1470 \mathrm{kPa}$ and the highest suction value recorded at a temperature of $0{ }^{\circ} \mathrm{C}$ was approximately $12.2 \mathrm{kPa}$. For the bottom sensor, the highest value recorded was $870 \mathrm{kPa}$ and the highest suction value at a temperature of $0{ }^{\circ} \mathrm{C}$ was $12.3 \mathrm{kPa}$. Also, the suctions developed below the freezing front are not different. This could be attributed to the size of the sample and the rate of freezing the tailings underwent. Both sensors froze almost at the same making their freezing behaviour very similar. This is expected to be different in the column tests explained in the sections below (i.e. small vs large sample).

Figure 76 and 77 show the relationship between temperature and matric suctions for the freezing and thawing phase of the experiment. As expected, hysteresis-like behaviour occurs in the development of matric suction as temperatures drop (freezing) and increase (thawing). In both figures, the same matric suction value occurs at different temperatures. For example, during the freezing process to achieve a matric suction value of $-800 \mathrm{kPa}$ the temperature needed was $-16^{\circ} \mathrm{C}$, while during the thawing process the same matric suction value occurred at approximately $-10{ }^{\circ} \mathrm{C}$. 


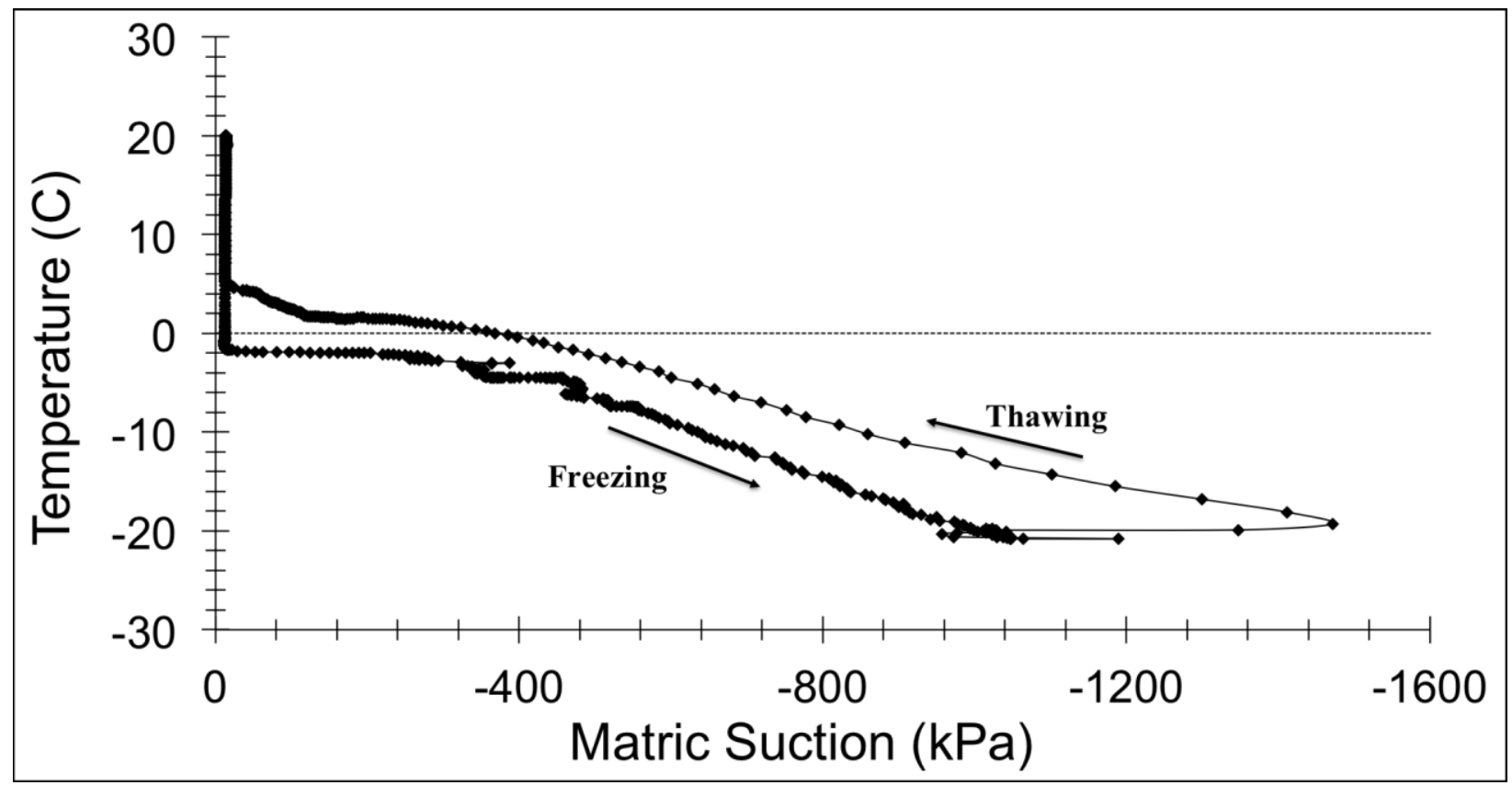

Figure 76. Temperature vs Matric Suction for Preliminary test \#2 (top sensor).

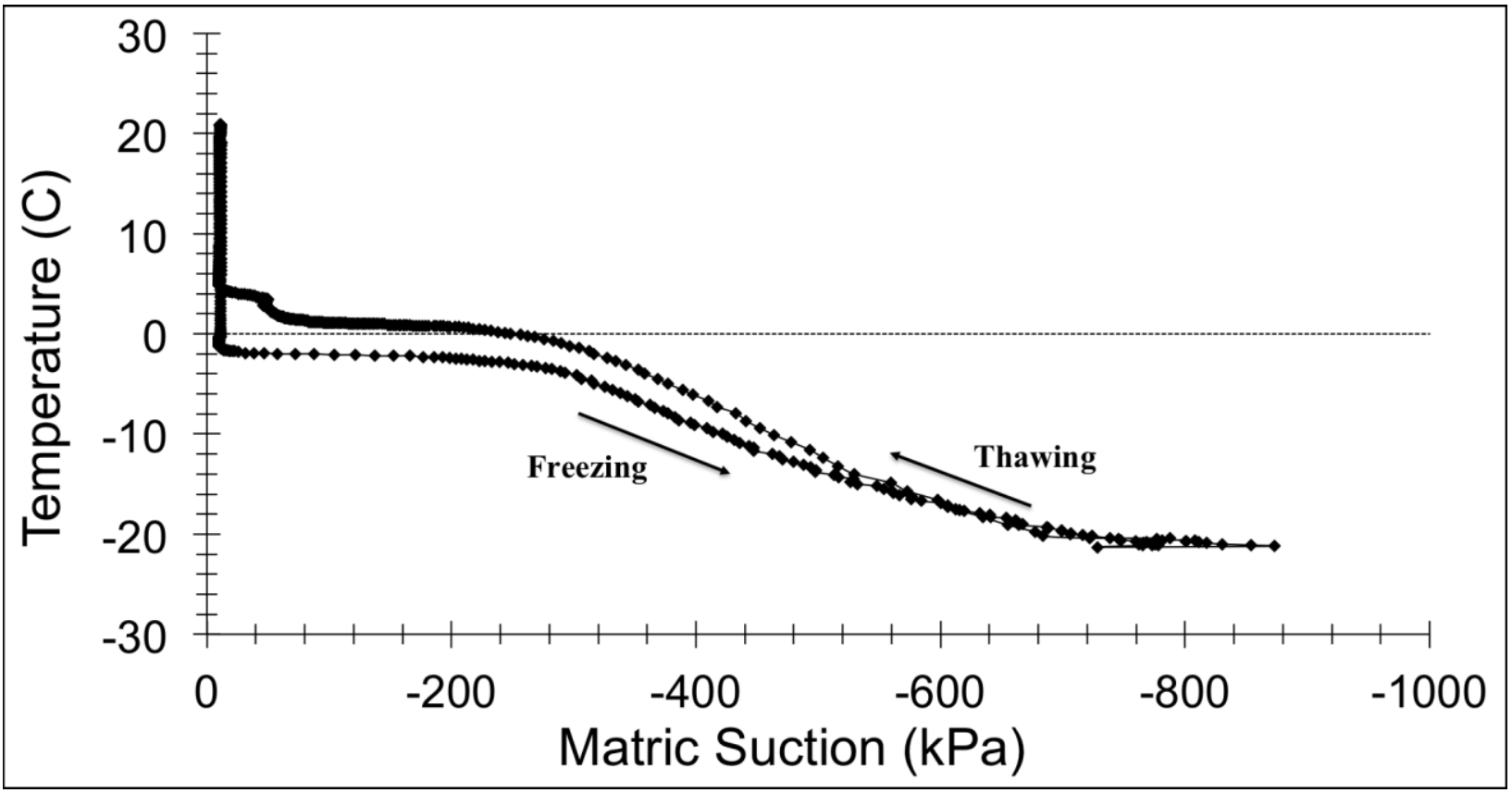

Figure 77. Temperature vs Matric Suction for Preliminary test \#2 (bottom sensor). 
Lastly, in both cases, relatively large matric suctions still occurred at temperature above zero degrees. In the top sensor (Fig. 76), suctions of up to $-320 \mathrm{kPa}$ were recorded at temperature slightly above $0{ }^{\circ} \mathrm{C}$ and in the bottom sensor (Fig. 77) the readings reached approximately $-200 \mathrm{kPa}$. At the end of the thawing phase, both sensor recorded matric suction values between 9 and $12 \mathrm{kPa}$ (air entry value of the sensor).

\subsubsection{Preliminary Test \#3}

The third preliminary test involved the freezing of polymer amended MFT for a period of 14 hours. Figure 78 and 79 show the matric suction and temperature profiles at two different depths within the sample. The experimental set-up and sensor location for this test is found in Section 3.3.

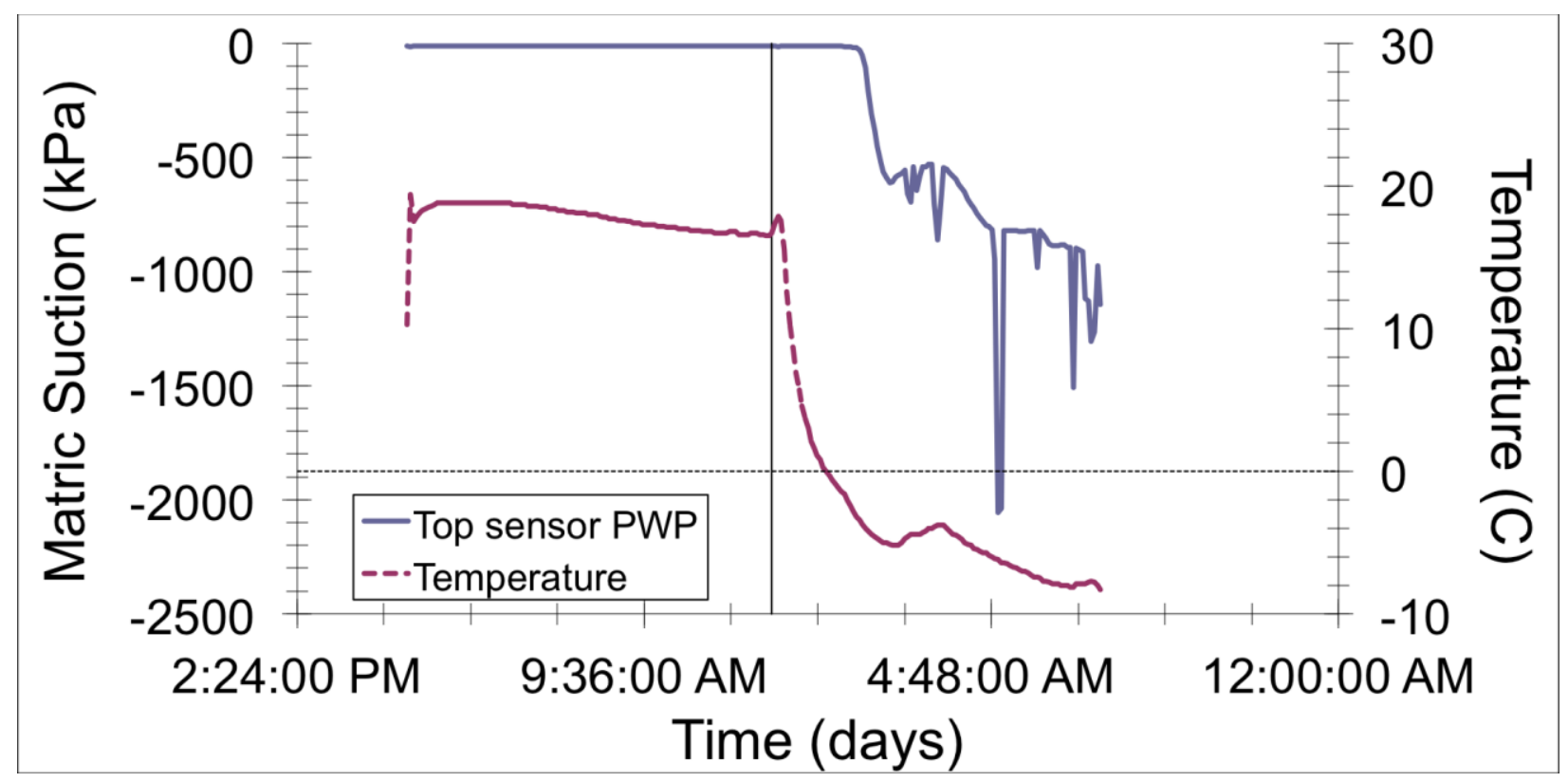

Figure 78. Pore water pressure and temperature profile (top sensor - test \#3). 


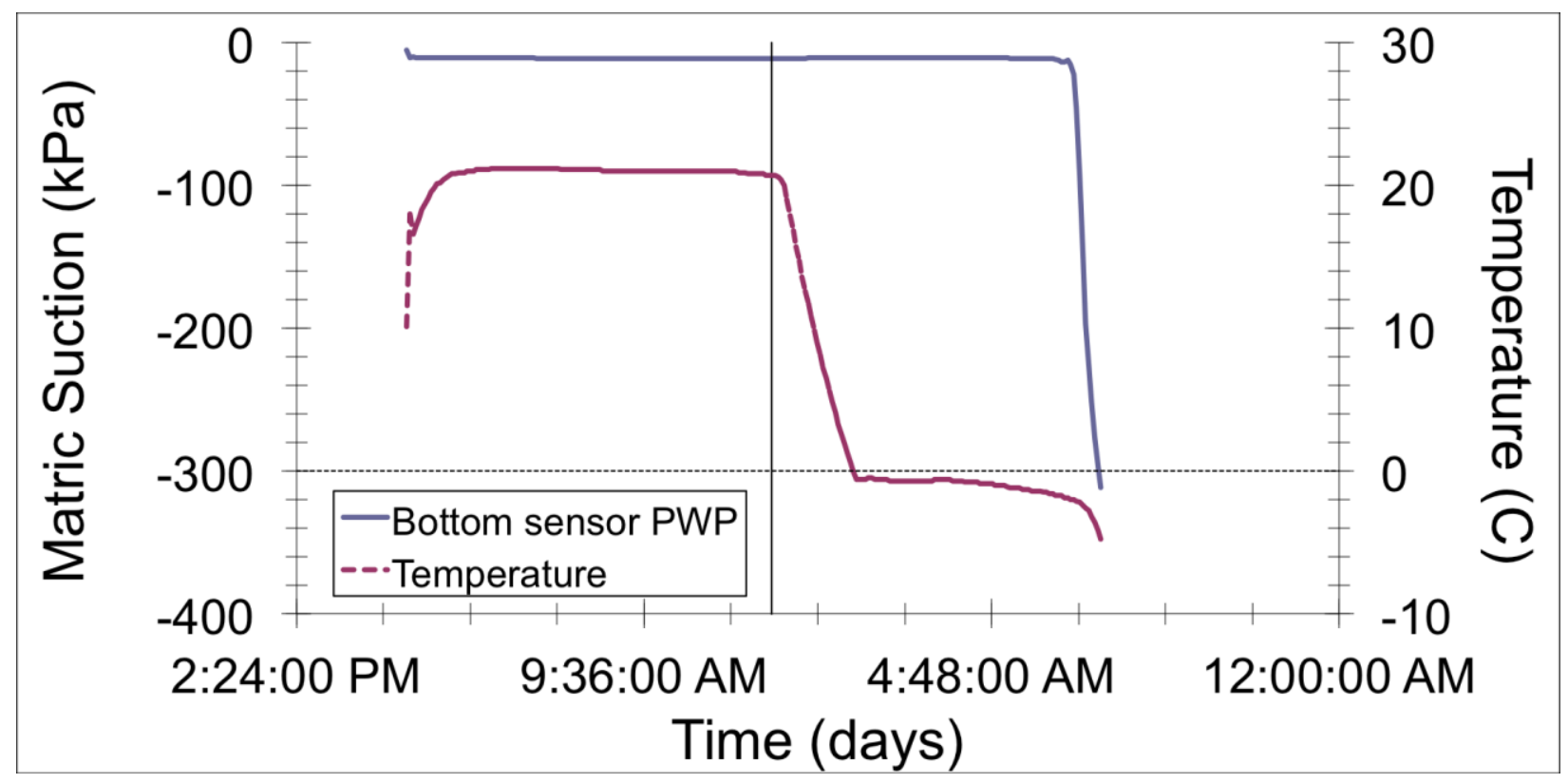

Figure 79. Pore pressure and temperature profile (bottom sensor - test \#3).

In this test, the highest suction value recorded at the top sensor's location is $1140 \mathrm{kPa}$ at a temperature of $-8.3{ }^{\circ} \mathrm{C}$ while the suction at $0{ }^{\circ} \mathrm{C}$ was $12 \mathrm{kPa}$. For the lower sensor the highest suction value recorded was $311 \mathrm{kPa}$ at $-4.8^{\circ} \mathrm{C}$ while the section at $0{ }^{\circ} \mathrm{C}$ was $10.4 \mathrm{kPa}$. The tailings in this experiment showed similar responses the previous two tests.

As explained before, the matric suction readings at temperatures below $0{ }^{\circ} \mathrm{C}$ appeared to be inaccurate due to the fact that liquid water within the sensor's pores freezes. However, the matric suctions developed before temperature reach $0{ }^{\circ} \mathrm{C}$ or, in other words, right below the freezing front are still considered reliable. The sections below explore the development of the matric suction below the freezing front in greater detail. 


\subsection{Column Test \#1: Self-Weight Consolidation with Ambient Drying and Freeze-Thaw Cycle}

\subsubsection{Temperature Profile}

Figure 80 shows the temperature profile of the MFT column at heights (from the bottom of the column) of $5 \mathrm{~cm}, 10 \mathrm{~cm}, 15 \mathrm{~cm}$, and $22.5 \mathrm{~cm}$. The figure presents the temperature changes that MFT column underwent during the self-weight consolidation with Ambient Drying phase, freezing phase, and thawing phase.

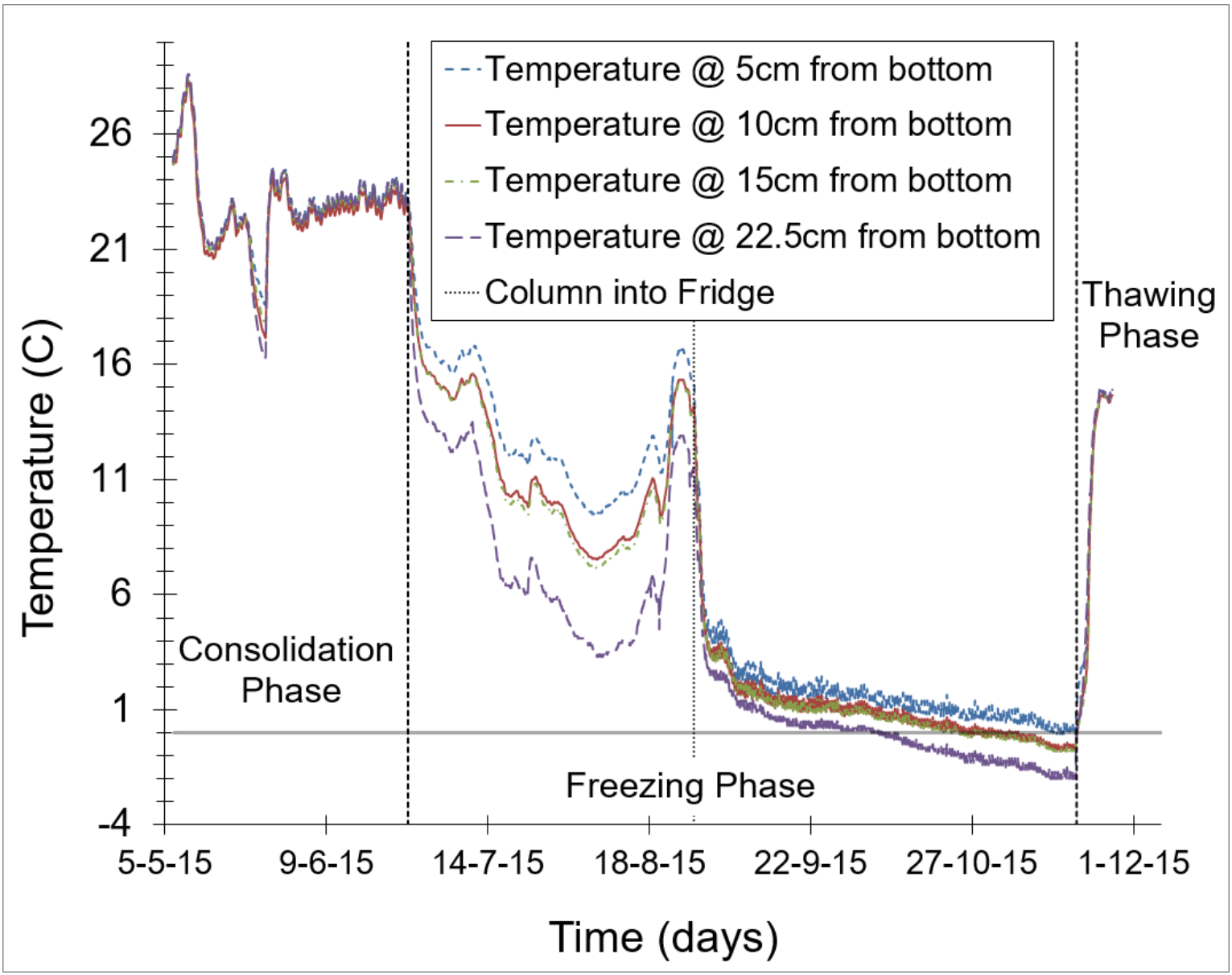

Figure 80. Temperature profile of column test \#1. 
During the self-weight consolidation with ambient drying phase, the temperature of the tailings fluctuated along with the air temperature. The temperatures present during this phase fluctuated within the low $20 \mathrm{~s}{ }^{\circ} \mathrm{C}$ range, having recorded a maximum temperature of $28.6^{\circ} \mathrm{C}$ and a lowest temperature of $16.3^{\circ} \mathrm{C}$.

During the first two months of the freezing phase, the MFT column was enclosed within its insulating case alone. The high temperatures of late summer $\left(24{ }^{\circ} \mathrm{C}\right.$ to $30{ }^{\circ} \mathrm{C}$ ) and the presence of air moisture significantly slowed down the freezing process and triggered ice build up in and around the cooling plate. In this period, the temperature differences at different heights within the MFT column were significant. Even though all the sensors recorded a similar decrease-in-temperature pattern, the sensor closest to the surface $(22.5 \mathrm{~cm})$ recorded the largest temperature change. The lowest temperature recorded by this sensor was $3.4{ }^{\circ} \mathrm{C}$ while the bottommost sensor ( 5 $\mathrm{cm}$ ) recorded a temperature of $5.9^{\circ} \mathrm{C}$. On August $20^{\text {th }}, 2015$ an unexpected power outage occurred and the cooling plate stopped working. This led to an unplanned increase in temperature and partial thaw of the tailings. The sensors' data in Figure 80 does not show the tailings being exposed to temperatures below zero yet, but show the increase in internal temperature. Since the cooling plate was set at $-15^{\circ} \mathrm{C}$, it is safe to assume that the surface of the tailings was frozen, which ended up melting due to the power outage. Eventually, the power was restored and the experiment continued.

Subsequently, in order to control the temperature around the column and reduce the air moisture, the column was placed in a fridge to steadily freeze the column by 
avoiding large temperature fluctuations. From this point onwards, the freezing process became steady. The freezing rate has a steep slope for the first 5 days and a flatter slope afterwards. The 1-Dimensional freezing process itself took several weeks to be achieved. Even though the interface between the MFT and the cooling plate remained at a constant $-15{ }^{\circ} \mathrm{C}$ during the freezing phase, the tailings below the surface did not show a rapid drop in temperature; but on the contrary, they sometimes showed an increase in temperature. Henry (2007) describes these differences in temperature between the surface and the soil below as being representative of the field. While the surface of the soil sample undergoes similar temperatures to the air temperature, the material below the surface does not experience the same temperature. This is in contrast to smaller samples being frozen too quickly that could lead to exaggeration of their freeze-thaw behaviour, which could explain the large variation of results found in the literature. Also, the temperature trend during the freezing process while the column is placed inside the fridge shows an oscillating pattern. This oscillation is attributed to the refrigeration cycle of the fridge. Once the sensors located at a height of $5 \mathrm{~cm}$ recorded a temperature of $0{ }^{\circ} \mathrm{C}$, the freezing phase concluded. It took 84 days to onedimensionally freeze $11,220 \mathrm{~cm}^{3}(30 \mathrm{~cm} \times 22 \mathrm{~cm} \times 17 \mathrm{~cm})$ of polymer amended MFT.

Lastly, during the thawing phase the MFT rapidly equilibrated itself with the air temperature. In a span of 7 days the temperature of the MFT went from $0{ }^{\circ} \mathrm{C}$ to $14.9^{\circ} \mathrm{C}$ at a really fast rate. Similar to the self-weight consolidation with ambient drying phase, the internal temperature of MFT at various heights over time remained constant. At the 
end of the thawing phase, the sensor located at $22.5 \mathrm{~cm}$ was left exposed to the air since the MFT tailings settled to a height of $19 \mathrm{~cm}$.

\subsubsection{Settlement, Water Loss, and MFT Densification}

Figure 81 shows the measured height of the tailings throughout the experiment. These measurements do not account for the supernatant water cover thickness produced by the tailings the first two weeks of the experiment. The change in height is due to self-weight consolidation of the tailings, which is driven by water loss in the form of evaporation and under-drainage.

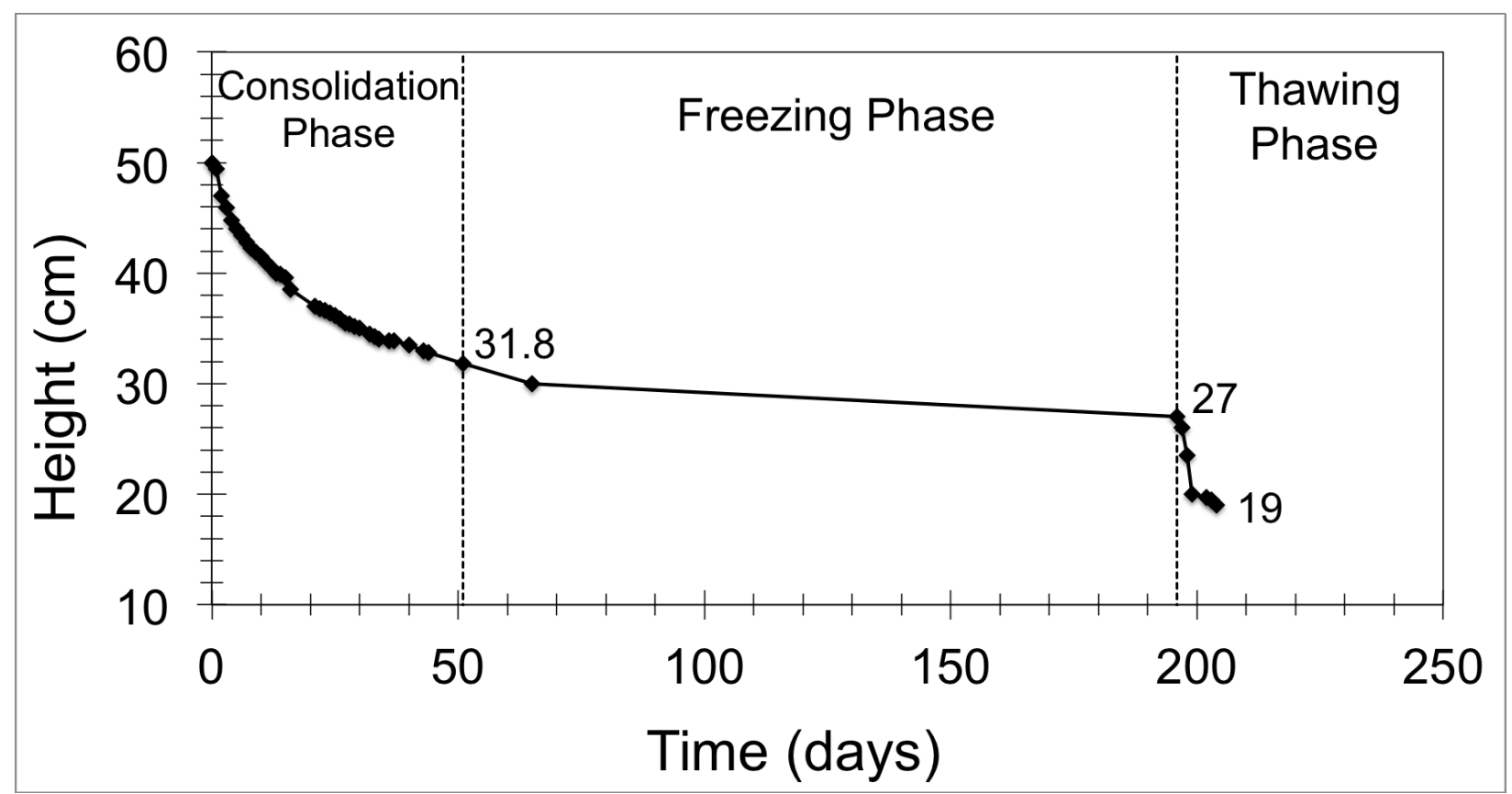

Figure 81. Change in height over time in column test \#1. 
During the self-weight consolidation with ambient drying phase, the tailings settled down on a steady and parabolic-shaped trend. The initial height of the MFT column was $50 \mathrm{~cm}$ and it decreased to a height of $31.8 \mathrm{~cm}$ in 51 days. The major factors for self-weight consolidation at this initial stage are under-drainage, supernatant water from the first two weeks of the experiment, and evaporation. The freezing phase initially started with $31.8 \mathrm{~cm}$ of MFT; however, to properly ensure the contact between the cooling plate and the tailings, the MFT column height was shortened to $30 \mathrm{~cm}$. The tailings froze over 145 days to a final height of $27 \mathrm{~cm}$. The $3 \mathrm{~cm}$ consolidation during this phase is attributed to the formation of and ice layer between the cooling plate and the tailings. The ice acted as overburden pressure on the tailings, which drove the tailings to consolidate $3 \mathrm{~cm}$. During the thawing phase, the ice channels within the tailings melted and promoted further water release. The column's height decreased form $27 \mathrm{~cm}$ to $19 \mathrm{~cm}$. Similarly to the self-weight consolidation with ambient drying phase, under-drainage and evaporation drove the decrease in height throughout this phase.

As mentioned previously, the MFT's total water loss was calculated by measuring the loss of water due to drainage and evaporation. The actual evaporation was calculated by subtracting the drainage water from the total weight loss measured by the electronic scale on a daily basis. Figure 82 shows the contributions of drainage and evaporation to the total water loss throughout all the phases. 


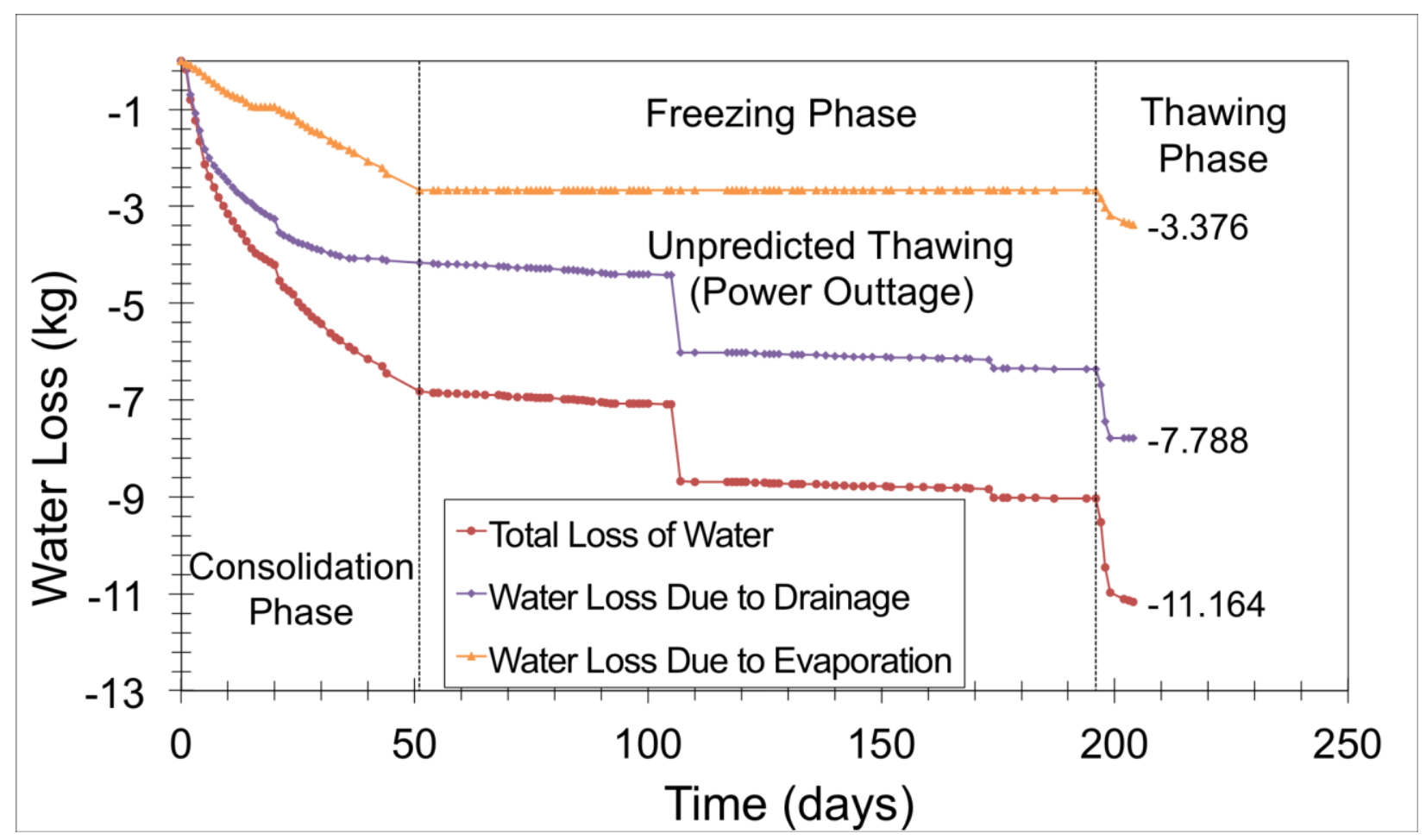

Figure 82. Cumulative water loss measurements for column test \#1.

Approximately $11 \mathrm{~kg}$ of water were released from the MFT, which is roughly $51 \%$ of the total weight. Figure 82 shows steady dewatering from both, drainage and actual evaporation, during the self-weight consolidation with ambient drying phase. The evaporation rate of water from the tailings during the self-weight consolidation with ambient drying phase was relatively constant and it was $52 \mathrm{gr} /$ day. This type of behaviour in MFT dewatering due to self-weight consolidation has also been reported by Rozina et al. (2015). Cracking on the surface did not occur which lead to no noticeable changes in the evaporation behaviour of the MFT. The self-weight consolidation with ambient drying phase was stopped once the drainage was not playing a big part in the dewatering process anymore. At the end of this phase, $6.8 \mathrm{~kg}$ 
of water were released by the MFT. During the freezing phase, drainage became the only dewatering mechanism. Even though the water collected as under-drainage was not abundant, it was constant. This was expected since some water inside the MFT column was likely to be moving up towards the freezing front and not down towards the drainage system. No evaporation occurred since the surface of the tailings was completely covered by the cooling plate. As shown in Figure 82, half way during the freezing phase, an unexpected power outage triggered an early thawing phase. During this event, approximately $1.6 \mathrm{~kg}$ of water was released over a 2 -day period. At the end of the freezing period a planned thawing phase started. During thawing, another $2.1 \mathrm{~kg}$ of water were release in the form drainage and evaporation. The evaporation rate during the first three days of this phase was approximately $173 \mathrm{gr} /$ day. Later on, it decreased to 38 gr/day. These "two" freeze-thaw cycles and under-drainage contributed about 20\% of the total water loss in the MFT.

As a consequence of constant water loss throughout the three phases of this experiment, the solids content changed as well. Densification of the tailings was back calculated using the total change in weight due to water loss and the initial mass of solids, which are assumed to be unchanged throughout the experiment. Figure 83 shows the evolution of the average solids content in the MFT column. 


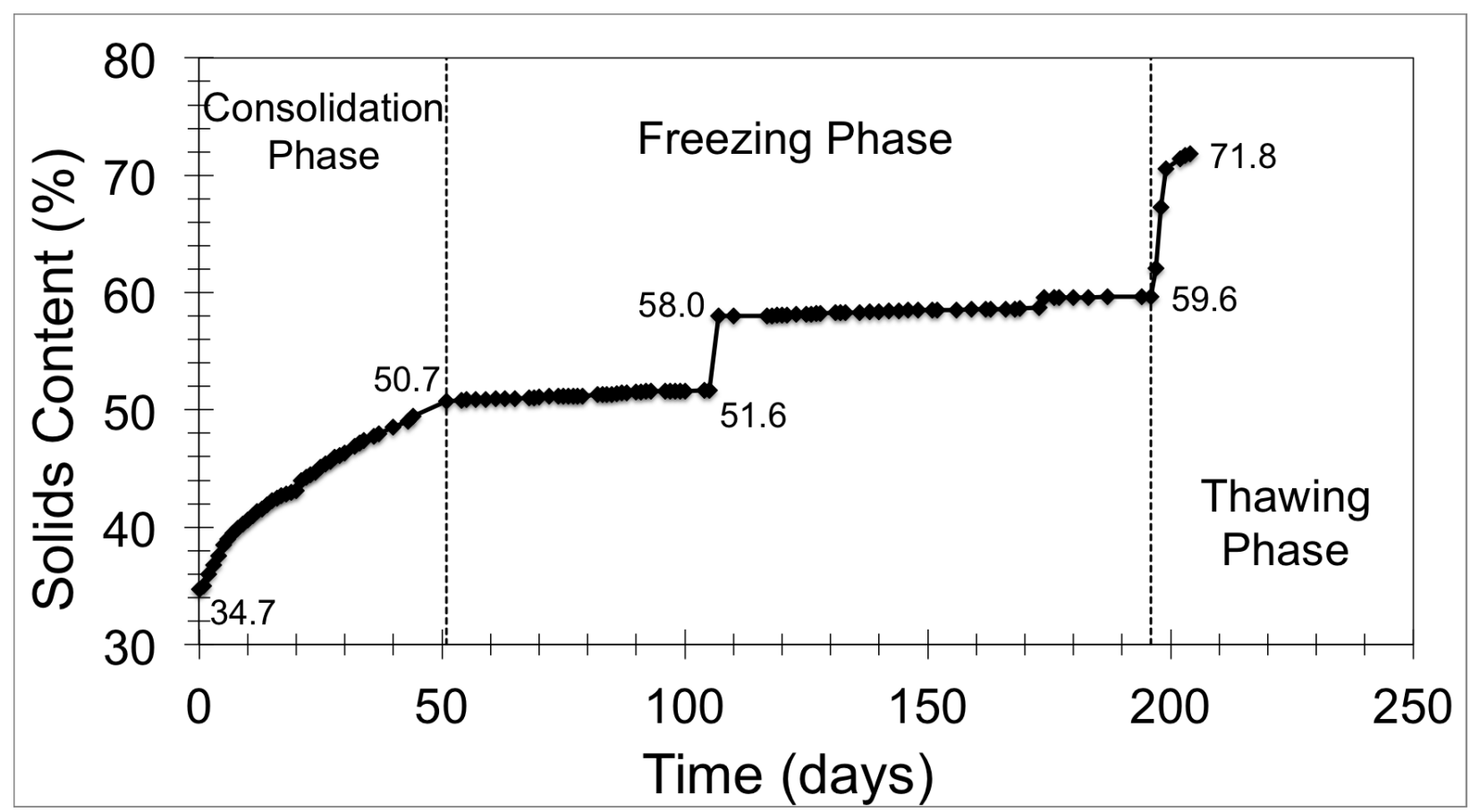

Figure 83. Average solids content development in column test \#1.

The change in solids content shows a similar trend when compared to the change in water loss since they are correlated (Fig. 82). At deposition, the initial solids content was $34.7 \%$ and at the end of the self-weight consolidation with ambient drying phase the solids content increased to $50.7 \%$. Additionally, at the end of the thawing phase, solids content was calculated to be approximately $71.8 \%$. That is an increase of $37.1 \%$ overall, which is reflected as an increase in tailings' strength (discussed in the next sections). The final average solids concentration of the MFT was compared with actual measurements at the termination of the experiment. A profile of solids content was obtained at the termination of the experiment (Figure 84), which yielded an average of $70 \%$ solids content agreeing with the back-calculated value. A sudden increase in solids content, $6.4 \%$, halfway through the freezing process was caused by a 
sudden power outage, which lead to unexpected thawing. This column was put into freezing mode again as soon as power was restored. Lastly, note that the solids content calculation did not take into consideration the formation of ice as part of the solids content.

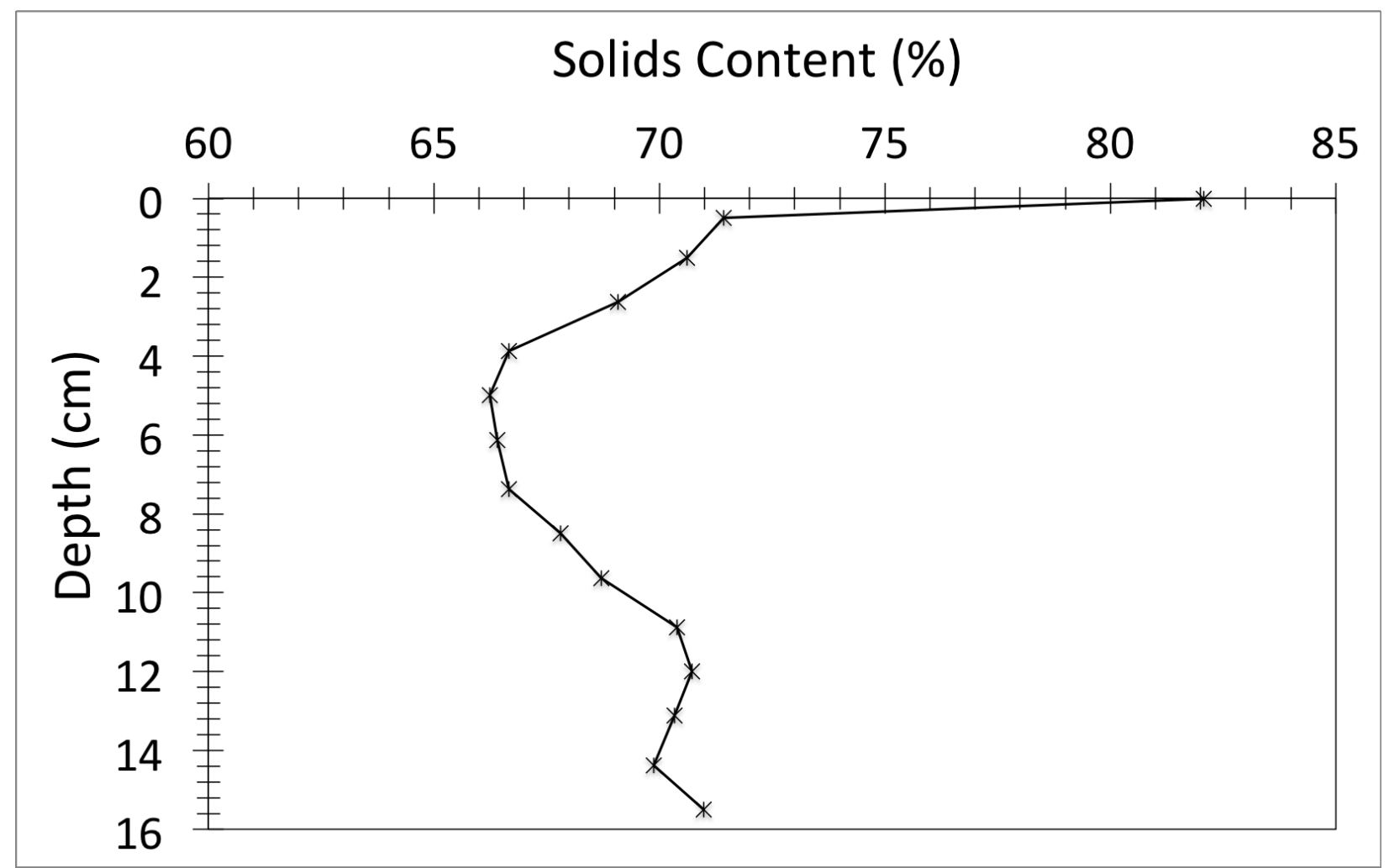

Figure 84. Solids content profile at termination of experiment (Column test \#1).

Figure 85 shows the dewatered state of the tailings' surface pre- and postfreezing. After the thawing phases ended, it is possible to see how the tailings eroded at the surface. Ferrick and Gatto (2005) stated that erosion at the surface is enhanced when water content is high, which is the case of MFT. 

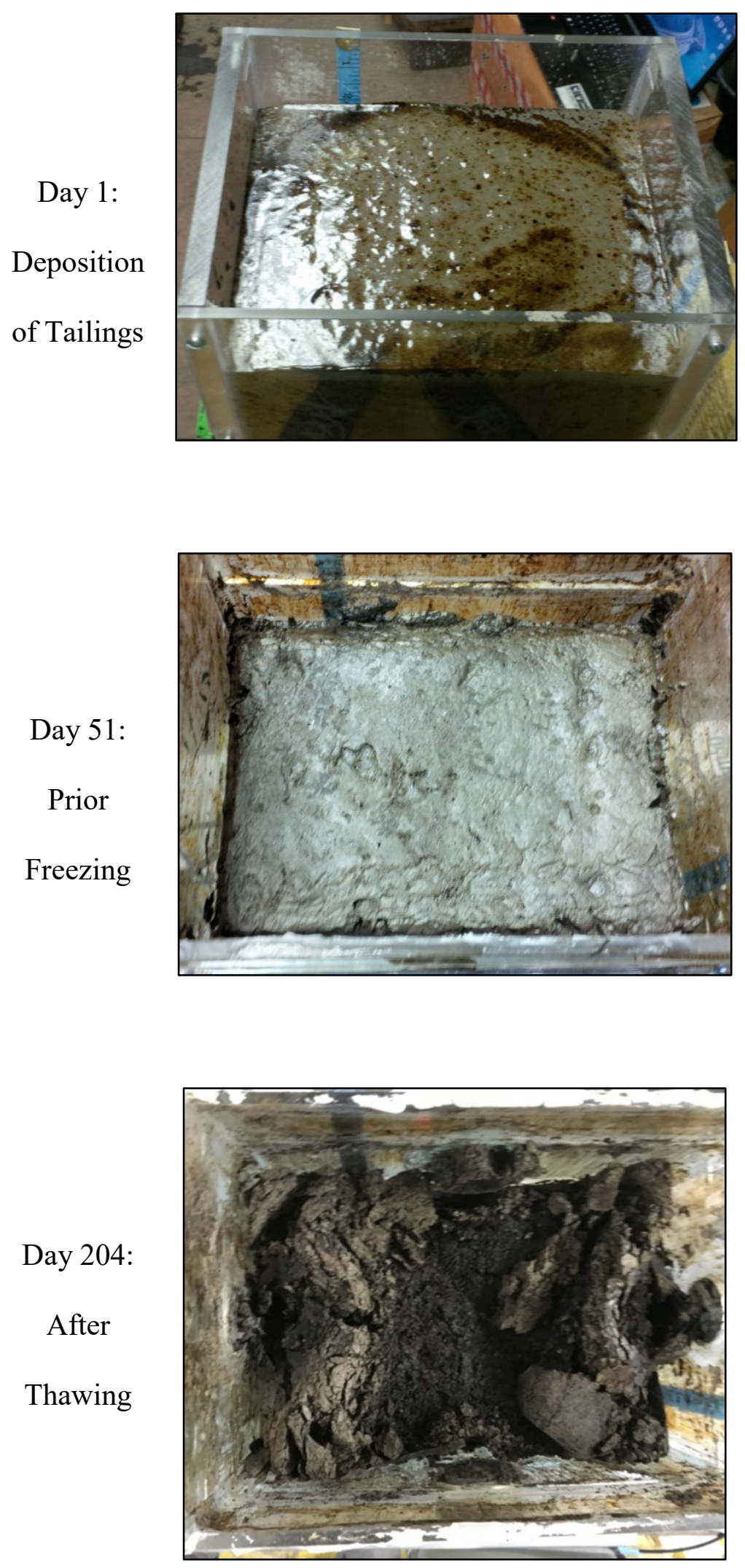

Figure 85. Surface dewatering process in column test \#1. 


\subsubsection{Water Content Profile}

As discussed previously, not only there is water movement due to self-weight consolidation and thawing but there is also water migration during freezing within the tailings. Figure 86 shows the volumetric water content readings recorded during the column test at different heights. Out of the 4 sensors installed to measure moisture content at heights of $5 \mathrm{~cm}, 10 \mathrm{~cm}, 15 \mathrm{~cm}$, and $22.5 \mathrm{~cm}$, only the data from bottom three sensors are graphed in Figure 85. The sensor located at $22.5 \mathrm{~cm}$ malfunction during the freezing phase of the experiment therefore it is not included as part of the results.

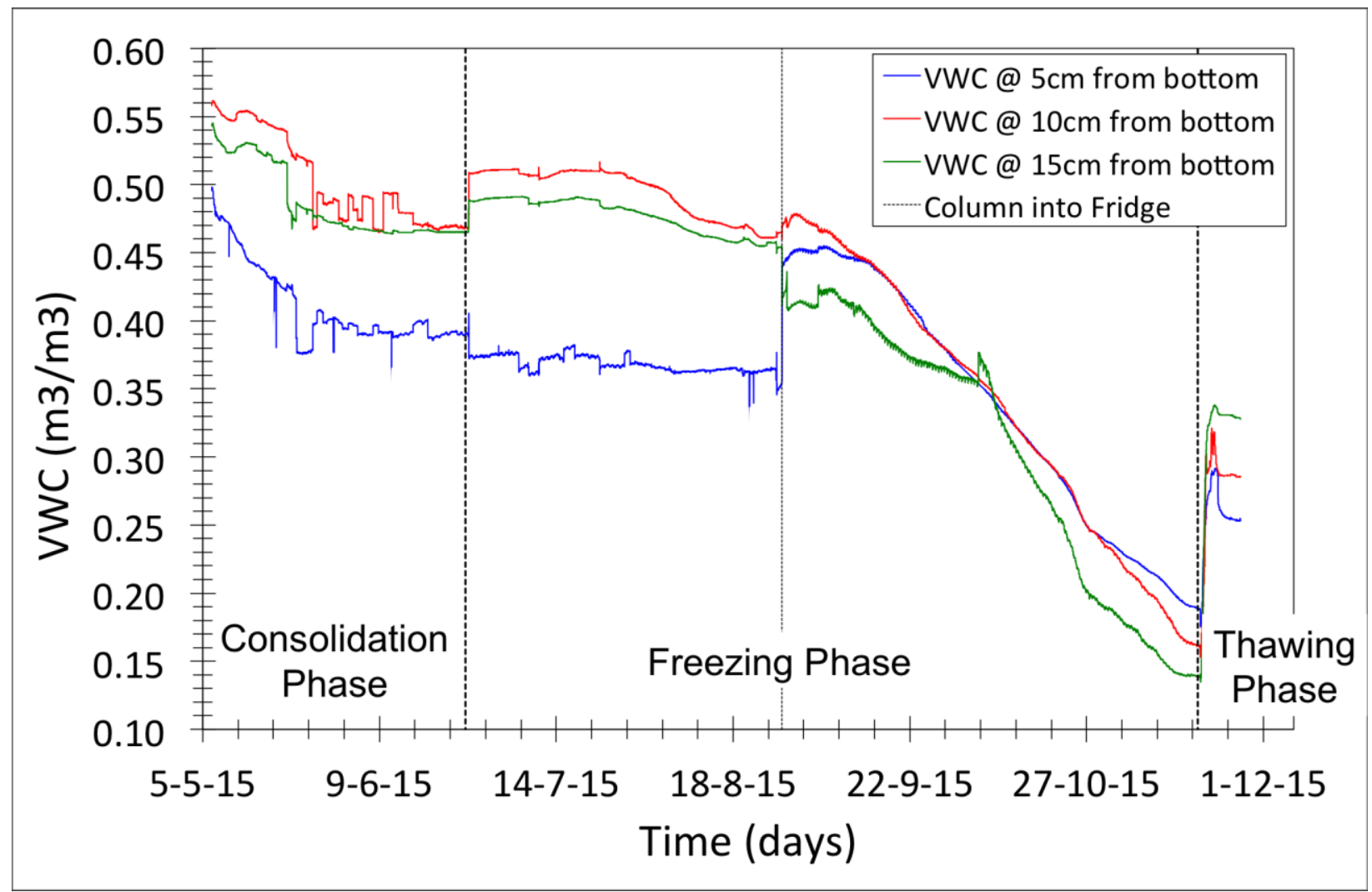

Figure 86. Volumetric water content over time in column test \#1. 
As seen in the figure above, water distribution during the self-weight consolidation with ambient drying phase has a decreasing trend for all the sensors. The sensor located at $5 \mathrm{~cm}$ from the bottom (blue line) shows a steady decrease in water content due to the constant under-drainage the MFT produced during this phase. It records a drop from $0.496 \mathrm{~m}^{3} / \mathrm{m}^{3}$ to $0.390 \mathrm{~m}^{3} / \mathrm{m}^{3}$. The other two sensors, $10 \mathrm{~cm}$ and $15 \mathrm{~cm}$ from the bottom, also show a loss in water content but at a slower rate. The 10 cm sensor records a drop from $0.558 \mathrm{~m}^{3} / \mathrm{m}^{3}$ to $0.469 \mathrm{~m}^{3} / \mathrm{m}^{3}$, while the $15 \mathrm{~cm}$ sensor records a drop from $0.543 \mathrm{~m}^{3} / \mathrm{m}^{3}$ to $0.465 \mathrm{~m}^{3} / \mathrm{m}^{3}$. This behaviour could be due to the migration of water to the surface since the density of water is less compared to the density of the tailings. During the freezing phase and before the introduction of the fridge, the three sensors show a slight change in water content but nothing too significant. The $5 \mathrm{~cm}, 10 \mathrm{~cm}$, and $15 \mathrm{~cm}$ sensors show drops of $0.030 \mathrm{~m}^{3} / \mathrm{m}^{3}, 0.031$ $\mathrm{m}^{3} / \mathrm{m}^{3}$, and $0.044 \mathrm{~m}^{3} / \mathrm{m}^{3}$, respectively. It is possible that the column surface underwent most of the moisture change since it reached temperatures below zero at this point but no record of it was obtained. The second part of the freezing phase shows steady decreased in water content from all the sensors. This period records the most drastic changes in water content having drops of $0.261 \mathrm{~m}^{3} / \mathrm{m}^{3}, 0.309 \mathrm{~m}^{3} / \mathrm{m}^{3}$, and $0.281 \mathrm{~m}^{3} / \mathrm{m}^{3}$ for the $5 \mathrm{~cm}, 10 \mathrm{~cm}$, and $15 \mathrm{~cm}$ sensors, respectively. As the freezing front advances downwards and there is a change in water phase, liquid water can only be found at the lower parts of the MFT column. This can be seen in the data recorded at the end of the freezing phase. The $5 \mathrm{~cm}$ sensor has higher water content $\left(0.190 \mathrm{~m}^{3} / \mathrm{m}^{3}\right)$ than the $10 \mathrm{~cm}$ sensor $\left(0.163 \mathrm{~m}^{3} / \mathrm{m}^{3}\right)$, which in effect has higher water content than the $15 \mathrm{~cm}$ sensor $\left(0.140 \mathrm{~m}^{3} / \mathrm{m}^{3}\right)$. The different in water content could be attributed to the 
change in phase of water from liquid to solid. This distribution of water is reversed during the thawing phase. As ice melts, some water leaves the column in the form of under-drainage and some water is retained by the tailings. The water in the tailings is redistributed within the tailings due to density differences, having larger amounts of water towards the surface than at the bottom. This behaviour can be seen in in the water content data at the end of the thawing phase in Figure 86. The sensor located at $15 \mathrm{~cm}$ from the bottom records higher water content values $\left(0.331 \mathrm{~m}^{3} / \mathrm{m}^{3}\right)$ than the sensor located closest to the bottom $\left(0.254 \mathrm{~m}^{3} / \mathrm{m}^{3}\right)$.

Lastly, a gravimetric water content profile at the termination of the test was obtained (Figure 87). This profile also confirms the sensor readings for water distribution within the tailings. The approximate location of the $15 \mathrm{~cm}$ sensor recorded a water content value of $51 \%$, while the $5 \mathrm{~cm}$ sensor recorded a value of $43 \%$.

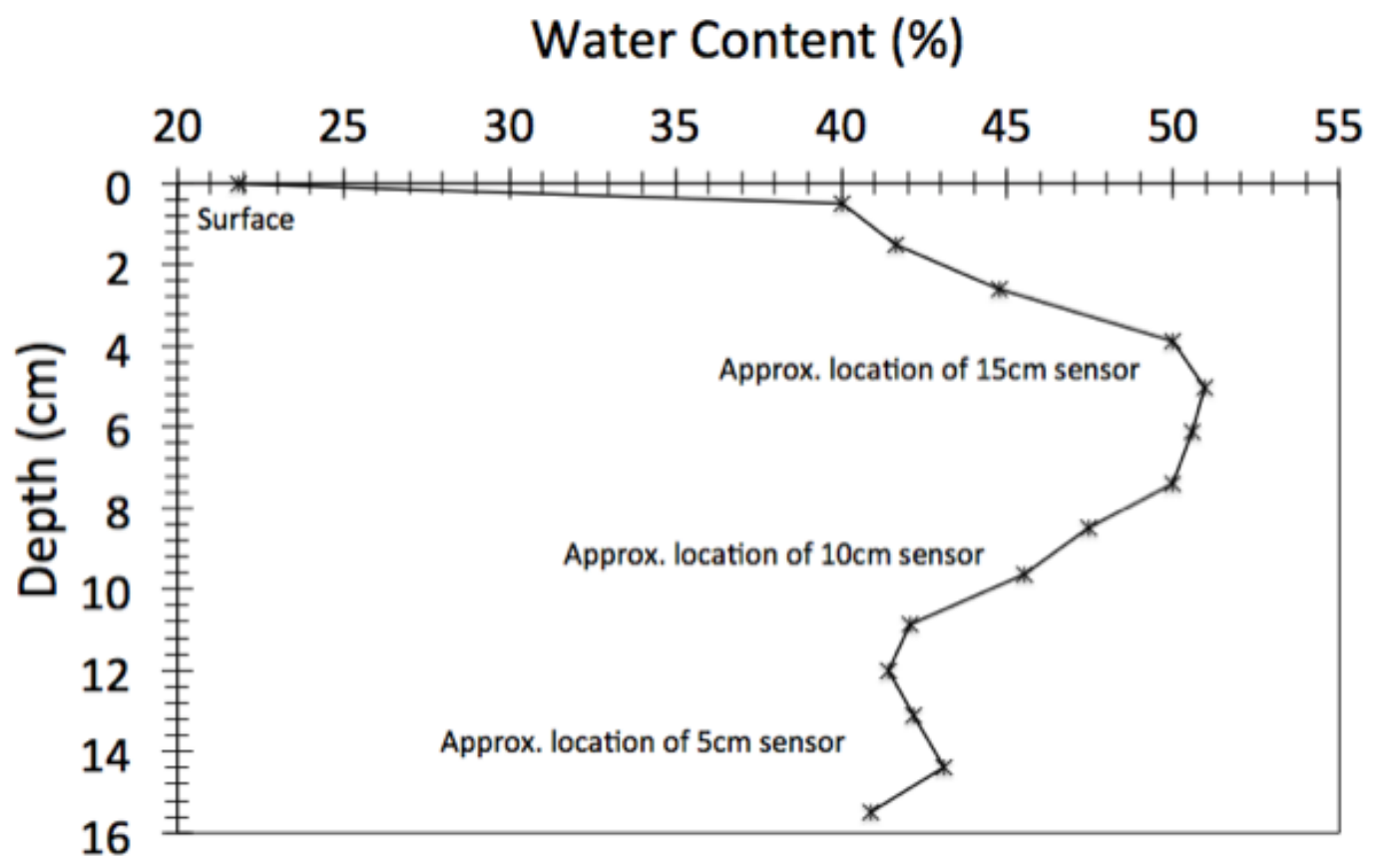

Figure 87. Gravimetric water content profile at termination (Column test \#1). 


\subsubsection{Unfrozen water content and Temperature}

As previously stated (Section 2.7), unfrozen water content is still present in frozen soils because of its lowered freezing point. The presence of matric suctions within the soil particles and the ice lower the energy status of the liquid water, which in effect lowers its freezing point (Egbert et al., 1996). Figure 88 shows the measured unfrozen water content with respect to the soil temperature at different heights.

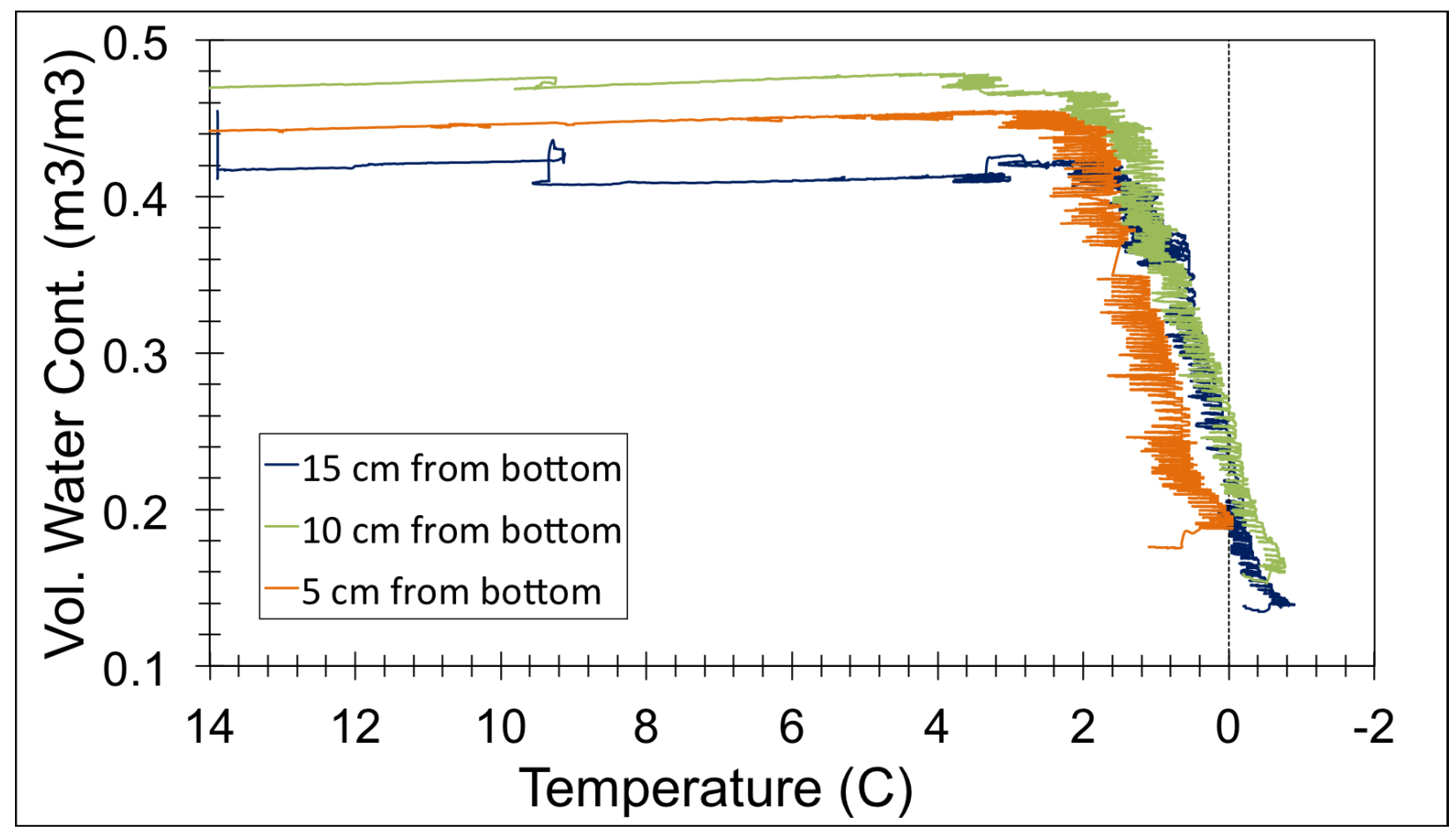

Figure 88. Unfrozen water content with respect to temperature.

The three data sets show a similar pattern in the desaturation of tailings as temperatures decrease. At a temperature of approximately $2.4{ }^{\circ} \mathrm{C}$ the desaturation begins. At a height of $15 \mathrm{~cm}$ from the bottom, the volumetric content decreased from 
$0.42 \mathrm{~m}^{3} / \mathrm{m}^{3}$ to $0.14 \mathrm{~m}^{3} / \mathrm{m}^{3}$ at $-0.9^{\circ} \mathrm{C}$. At a height of $10 \mathrm{~cm}$ from the bottom, the water content decreases from $0.47 \mathrm{~m}^{3} / \mathrm{m}^{3}$ to $0.16 \mathrm{~m}^{3} / \mathrm{m}^{3}$ at a temperature of $-0.8^{\circ} \mathrm{C}$. Lastly, at a height of $5 \mathrm{~cm}$ from the bottom, the decrease ranges from $0.44 \mathrm{~m}^{3} / \mathrm{m}^{3}$ to 0.19 $\mathrm{m}^{3} / \mathrm{m}^{3}$ at $0{ }^{\circ} \mathrm{C}$.

\subsubsection{Ice Content in Frozen Tailings}

Figure 89 and 90 show the volumetric ice content readings at heights of $15 \mathrm{~cm}$ and $10 \mathrm{~cm}$ from the bottom, respectively. The ice content was inferred from the immediate increase in volumetric water content from the difference between the prethaw and post-thaw readings. Also, it has been assumed that consolidation within the tailings does not occur at temperature below zero. Ice content data at a height of 22.5 $\mathrm{cm}$ is not available due to the malfunctioning of the volumetric water sensor.

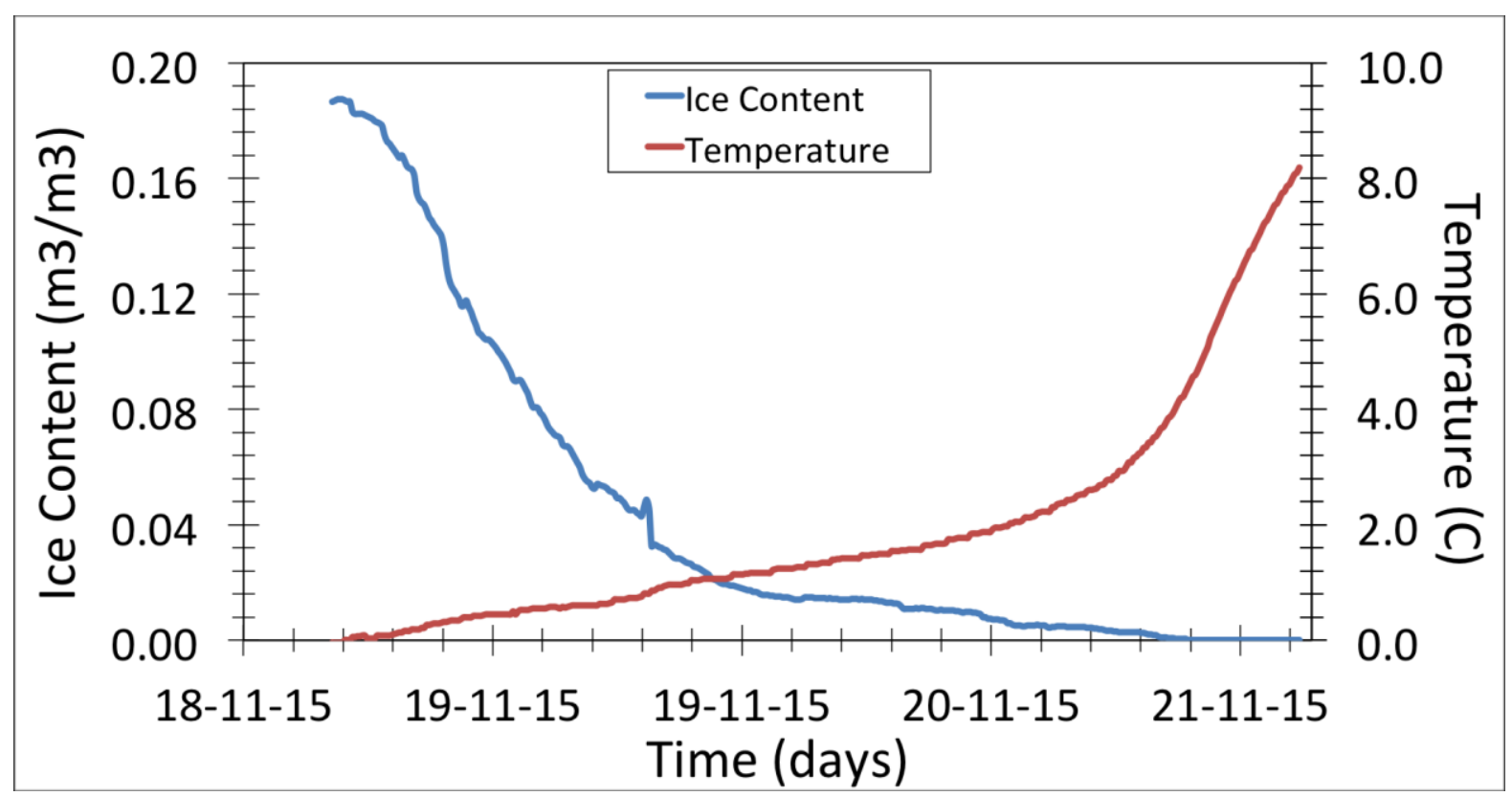

Figure 89. Volumetric ice content during the freezing period at a height of $15 \mathrm{~cm}$. 


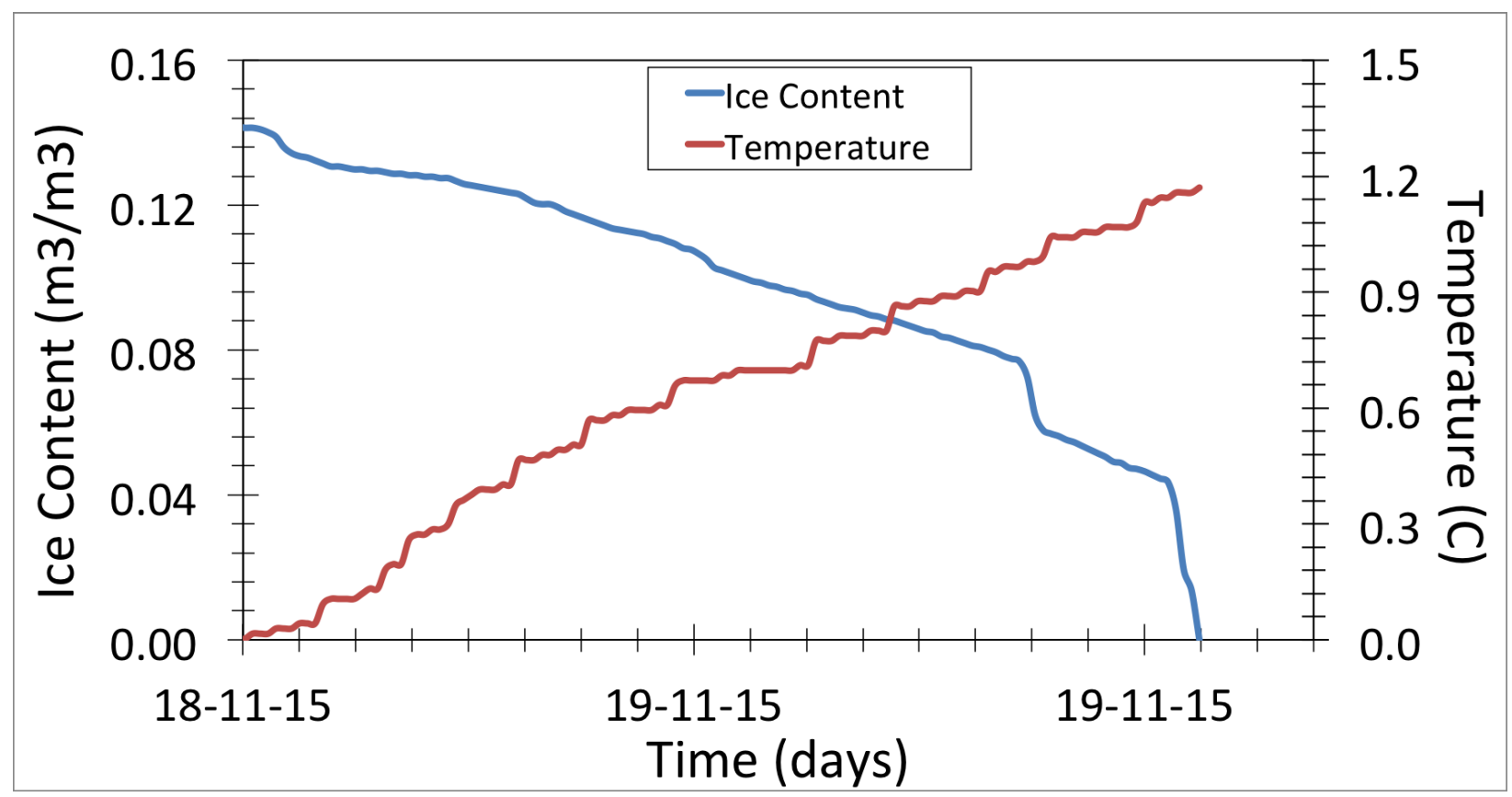

Figure 90. Volumetric ice content during the freezing period at a height of $10 \mathrm{~cm}$.

Figure 89 shows approximately $0.187 \mathrm{~m}^{3} / \mathrm{m}^{3}$ of ice present at a height of $15 \mathrm{~cm}$ right after the freezing phase ends, while Figure 90 shows $0.141 \mathrm{~m}^{3} / \mathrm{m}^{3}$ present at a height of $10 \mathrm{~cm}$. From the volumetric water content profile (Fig. 86), it is possible to observe lower water content at a height of $15 \mathrm{~cm}$ at the end of the freezing phase than at $10 \mathrm{~cm}$. This could mean that the majority of liquid water present at the height of $15 \mathrm{~cm}$ was turned into ice, which can justify the large amount of ice content present at that height.

\subsubsection{Suction and Frozen Tailings}

As discussed in Section 2.7, when fine-grained soils undergo freezing, negative pore water pressures (or suctions) develop within the soil mass. This occurs specifically between the water surrounding the soil particles and the ice filling the voids. In freezing 
soils, suction occurs due to the difference in surface tension between ice and water surrounding soil particles. This difference in pressure causes water to migrate from the unfrozen soil below to migrate towards the growing ice crystals (Dawson et al. 1999).

The development of matric suction can be observed in Figures 91 and 92. The data was obtained at two different heights, $22.5 \mathrm{~cm}$ and $5 \mathrm{~cm}$ from the bottom, from the MPS-6 sensors.

As previously, explained the pore pressure readings at temperatures below zero are considered inaccurate in this research due to the inability of the WPS- 6 sensors to read accurate suctions in frozen soils, or in this case, tailings. Greater attention is paid to the pore pressure readings below the freezing front or when the temperatures at the height of the WPS-6 sensors are greater than zero. 


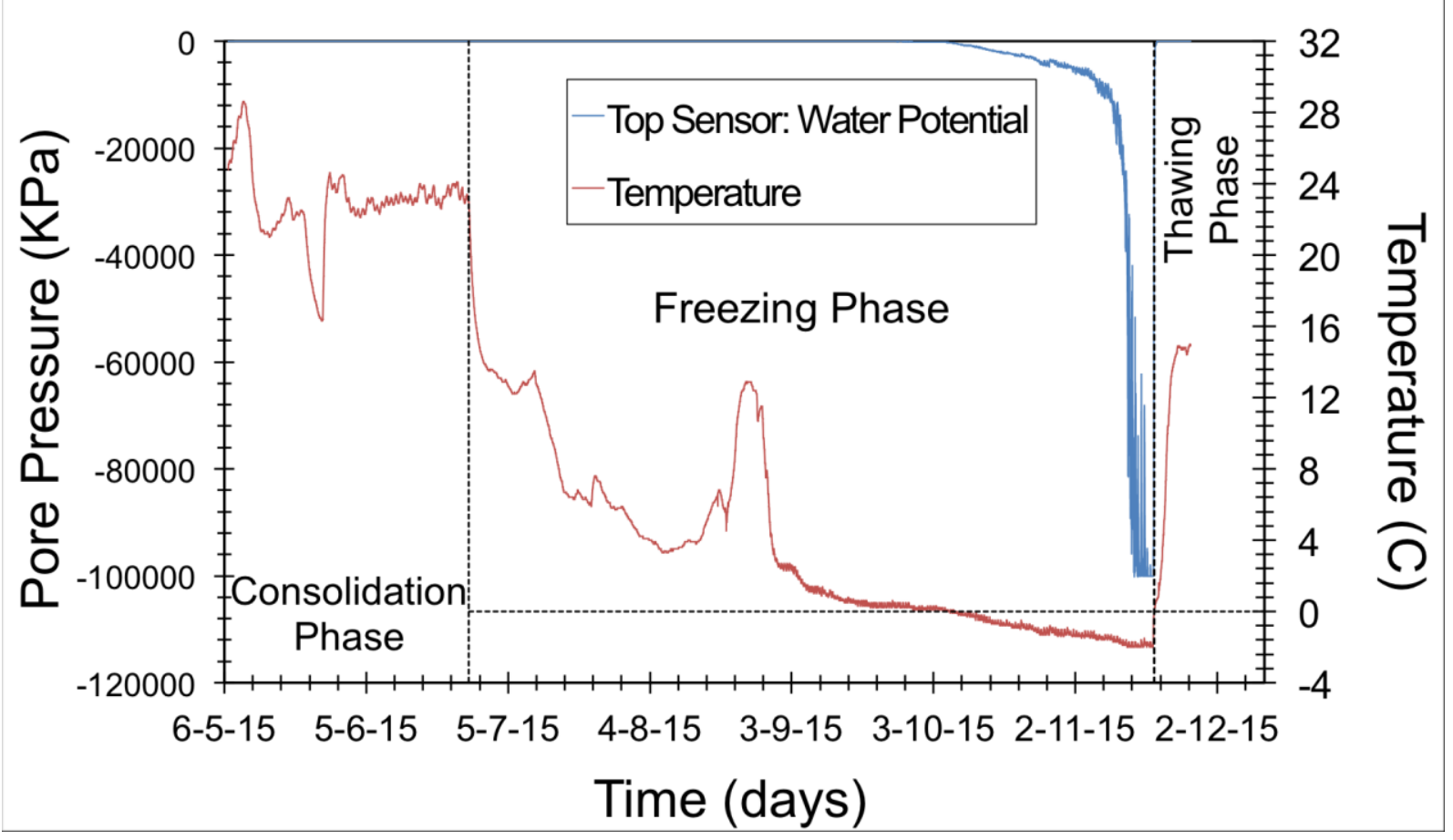

Figure 91. Matric suction from MPS-6 sensor and temperature development over time at a height of $22.5 \mathrm{~cm}$.

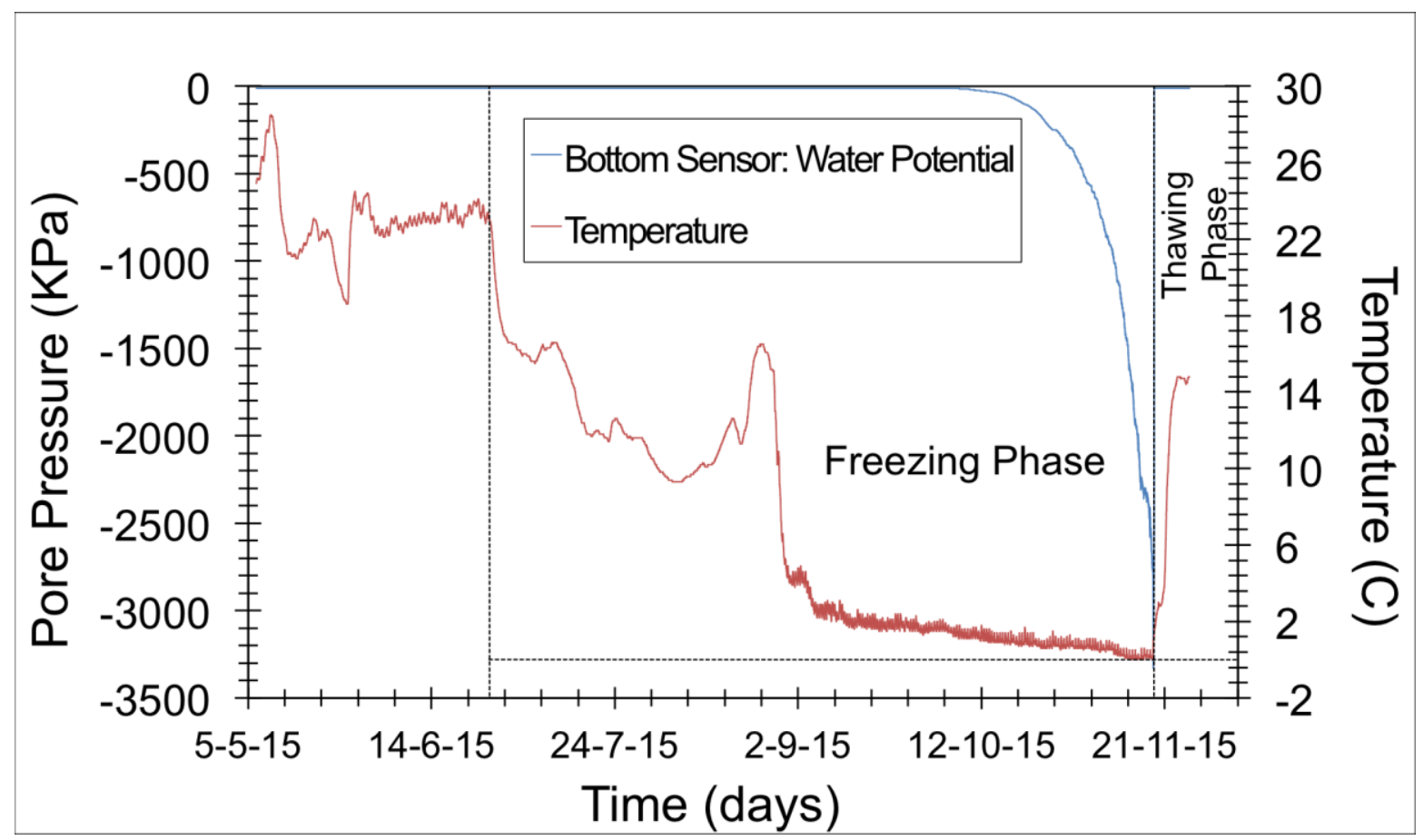

Figure 92. Matric suction measured by MPS-6 sensor and temperature development over time at a height of $5 \mathrm{~cm}$. 
It is important to mention the limitations of the MPS-6 sensors when tailings temperatures are below zero. The sensors cannot accurately read the water potential of the soil once water freezes since the electric properties of water change (i.e. dielectric permittivity). Taking the sensors' limitation into account, Figure 91 displays the matric potential development at a height of $22.5 \mathrm{~cm}$. This sensor is located $7.5 \mathrm{~cm}$ away from the surface. As expected, there is no record of negative pore pressure during the selfweight consolidation with ambient drying phase since the MFT at this height is still considered saturated. Approximately, during the initial 2/3 of the freezing phase there is still no indication of negative pore pressures being developed; however, when the soil temperature at this height reached $0.9^{\circ} \mathrm{C}$, negative pore pressures began to develop. An extract of Figure 91 can be seen the figure below (Fig. 93). Here, the pore pressures are graphed when the tailings temperature are above zero. Figure 93 presents the development of negative pore pressures below the freezing front. The suctions range from $9 \mathrm{KPa}$ to $342 \mathrm{KPa}$ for temperatures between $0.9^{\circ} \mathrm{C}$ and $0{ }^{\circ} \mathrm{C}$. These values can be considered reliable since the presence of ice is not existent. Below $0{ }^{\circ} \mathrm{C}$, negative pore pressures are expected to be much greater than below the freezing front due to the presence of ice. Figure 91 show a continuous increase in negative pore pressures past 0 ${ }^{\circ} \mathrm{C}$. There is a continuous trend approximately up to $12,800 \mathrm{KPa}$ at $-1.5^{\circ} \mathrm{C}$ before suddenly dropping to $-100000 \mathrm{KPa}$, which is the sensor reading limit. It is unclear at which pore pressure value and temperature below zero the readings become unreliable but for this research only the pore pressure values in above zero temperatures will be considered. 


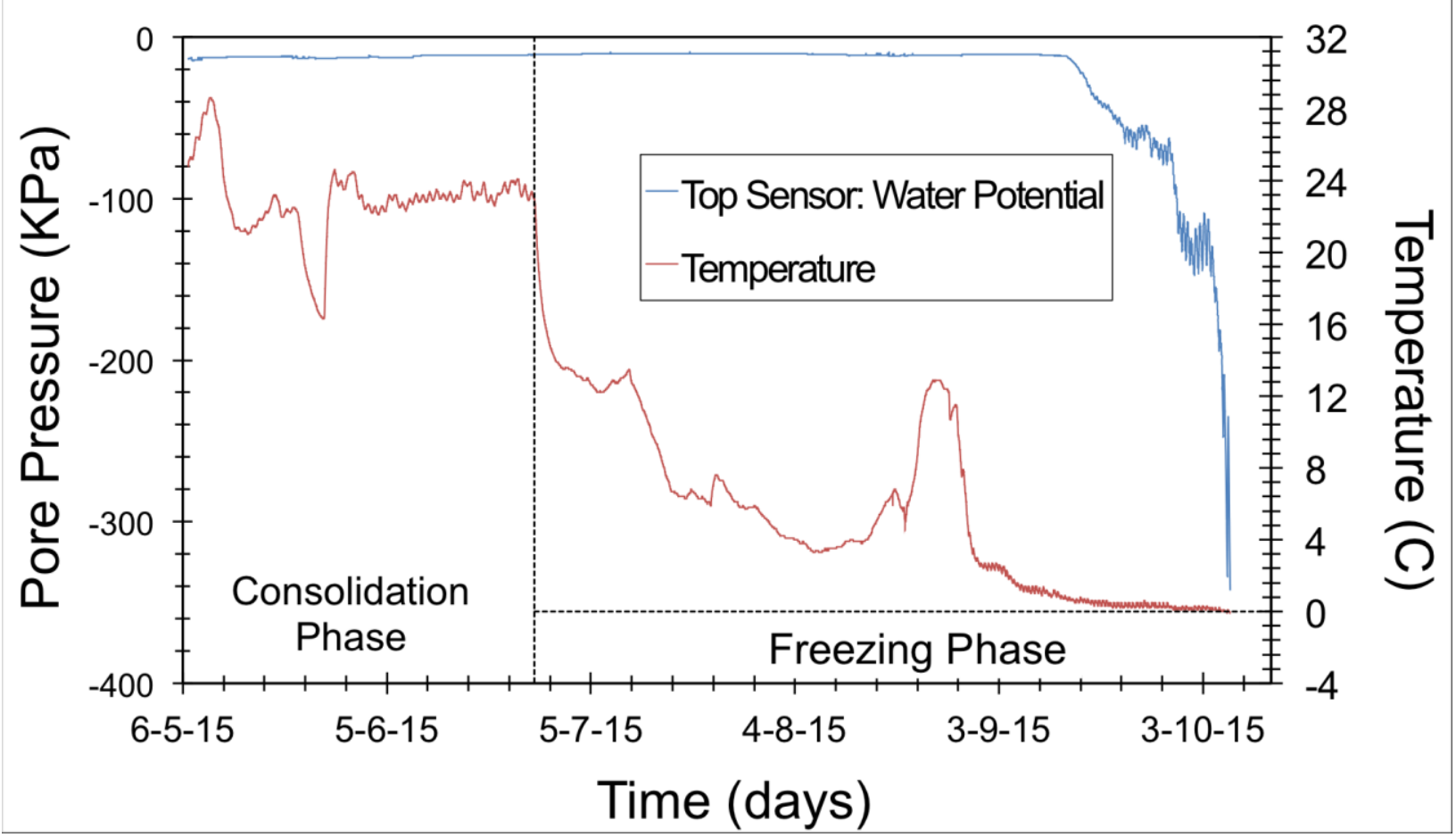

Figure 93. Matric suction (MPS-6) and temperature development over time for temperatures above zero at a height of $22.5 \mathrm{~cm}$.

Figure 92 shows the pore pressure at a height of $5 \mathrm{~cm}$. In this particular case, the entire data set is considered because it occurred when tailings temperatures were above zero only. Similar to the $22.5 \mathrm{~cm}$ sensor data, no negative pore pressures were developed during the self-weight consolidation with ambient drying phase and well into the freezing phase. At a temperature of $1.5^{\circ} \mathrm{C}$, the recorded suction value was $10.5 \mathrm{KPa}$ and it continued to increase at an exponential rate up to $3300 \mathrm{KPa}$ at $0{ }^{\circ} \mathrm{C}$. This pore pressures were also developed below the frozen front and are responsible for the water migration towards the ice lenses. 
Both heights record a starting value for negative pore pressure development between $9 \mathrm{KPa}$ and $11 \mathrm{KPa}$. This is due to the air entry value of the ceramic discs present on the sensors, which is $9 \mathrm{KPa} \pm 2 \mathrm{KPa}$ according to the manufacturer. Even though both readings start at almost the same negative pore pressures, the rate and temperatures at which the pore pressures develop are different. Table 17 summarizes the initial and final negative pore pressures and temperatures recorded for each height during negative pore pressure development.

Table 17. Initial and final values for during negative pore pressure development.

\begin{tabular}{ccccc}
\hline Elevation & Initial & Initial & Final & Final \\
$(\mathrm{cm})$ & PWP & Temp. & PWP & Temp. \\
\hline 5 & $10.5 \mathrm{KPa}$ & $1.5^{\circ} \mathrm{C}$ & $3300 \mathrm{KPa}$ & $0{ }^{\circ} \mathrm{C}$ \\
\hline 22.5 & $9 \mathrm{KPa}$ & $0.9{ }^{\circ} \mathrm{C}$ & $342 \mathrm{KPa}$ & $0{ }^{\circ} \mathrm{C}$ \\
\hline
\end{tabular}

The different in behaviour may be attributed to the amount of ice lenses formed in the freezing front. Since the quantity of ice is proportionally related to the negative pore pressure magnitude, more ice lenses would produce larger negative pore pressures.

Lastly, a total suction profile was obtained at the completion of the test, as seen in Figure 94. It shows higher suction values at the surface and they decrease with depth. It follows a similar trend when compared to the gravimetric water content profile (Figure 87). As the water content increases, the suction values decrease and vice versa. 


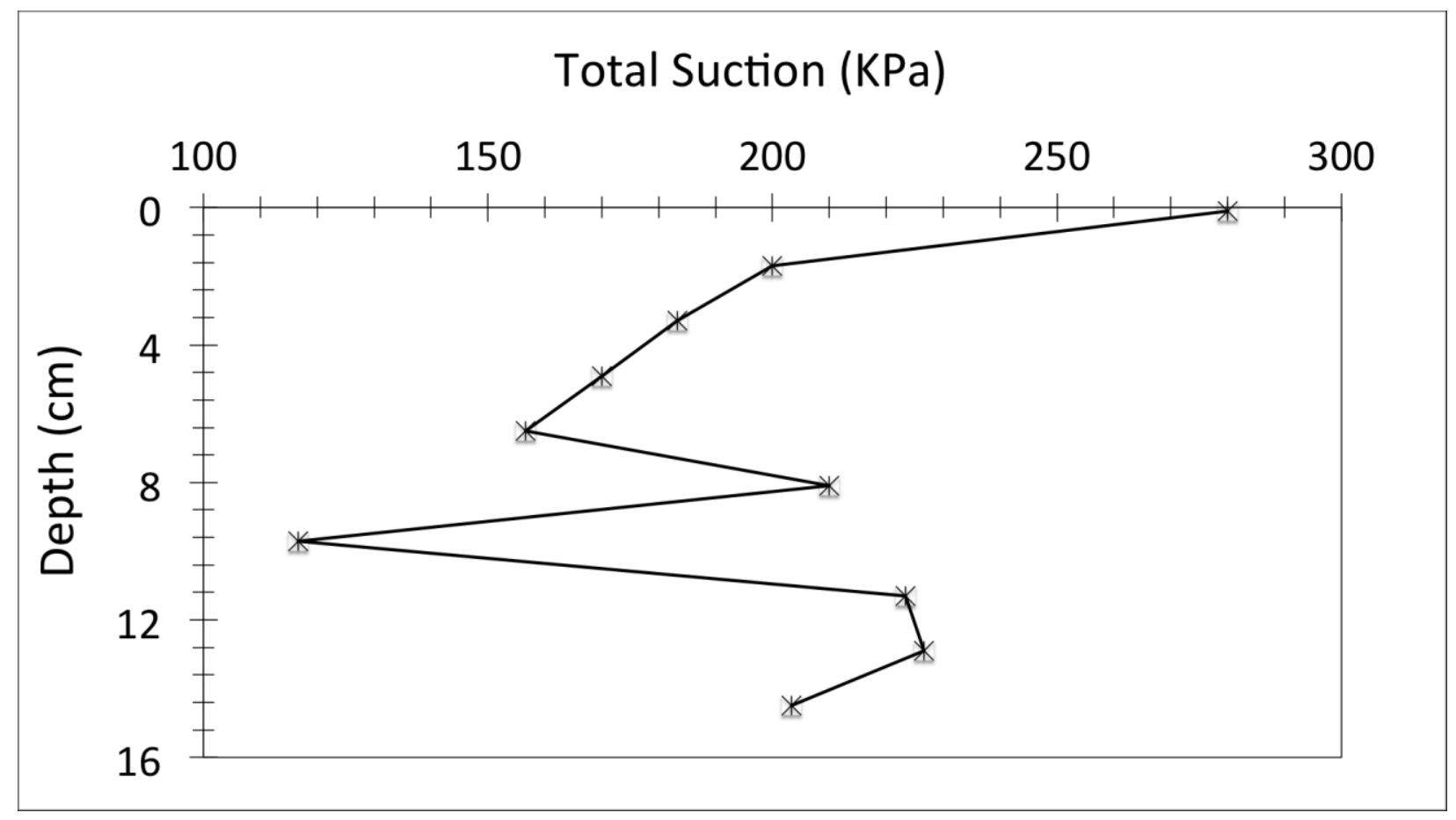

Figure 94. Total suction profile at termination of column test \#1.

\subsubsection{SWCC below the Freezing Front}

Since negative pore pressures, or suctions, and water contents were recorded during the freezing phase, a soil water characteristic curve was constructed to describe the desaturation rate of the MFT right below the freezing front. The values correspond to temperatures greater than zero to ensure that the water present in the tailings and in the sensors is not frozen. Unfortunately, water content data at a height of $22.5 \mathrm{~cm}$ was not recorded due to the sensor malfunctioning so no SWCC for this height was constructed. Furthermore, Figure 95 shows the SWCC right below the freezing front at a height of $5 \mathrm{~cm}$. 


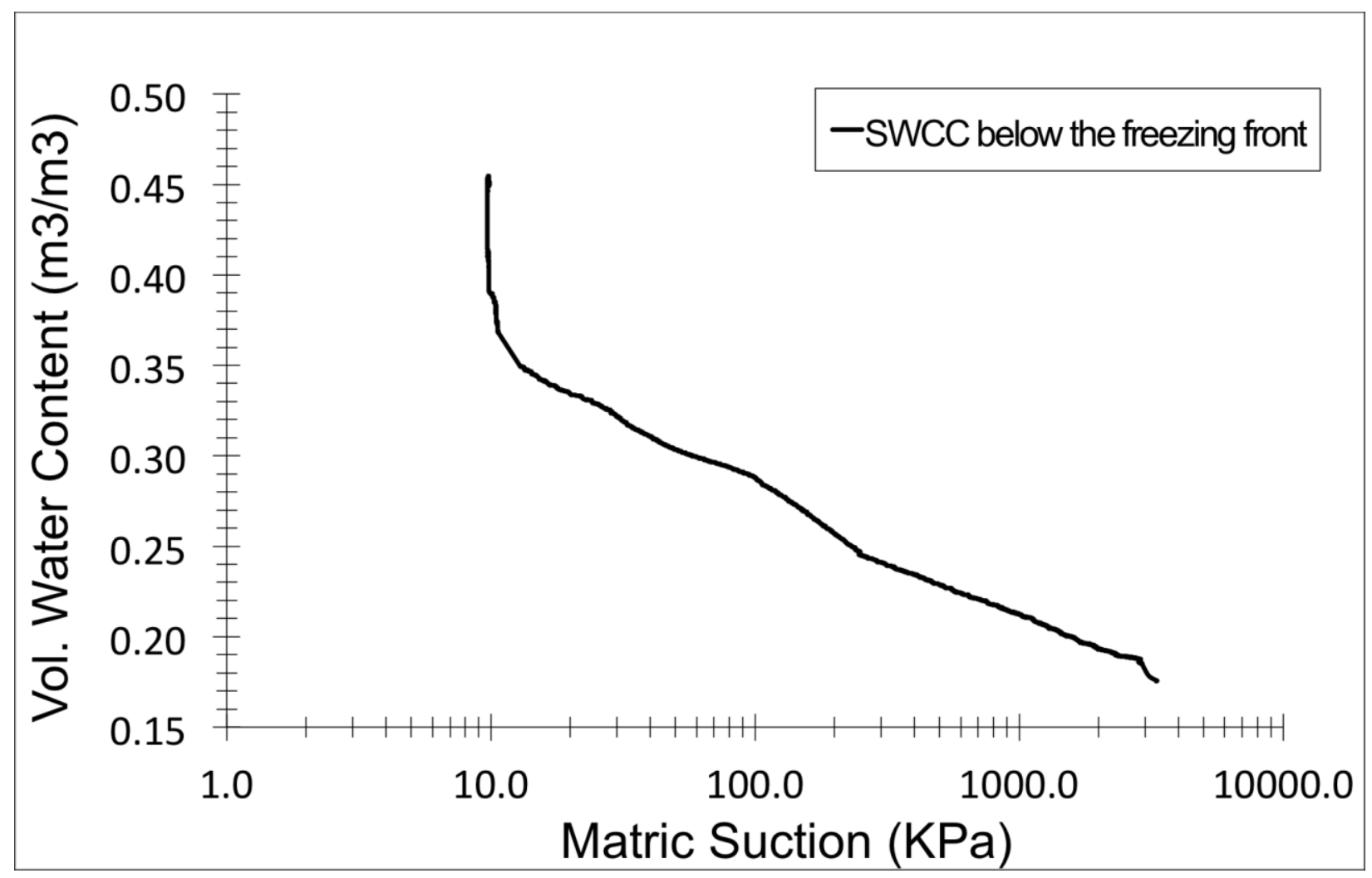

Figure 95. SWCC right below the freezing front at a height of $5 \mathrm{~cm}$ in column tests \#1.

The volumetric water content range of the SWCC ranges from $0.46 \mathrm{~m}^{3} / \mathrm{m}^{3}$ to $0.18 \mathrm{~m}^{3} / \mathrm{m}^{3}$; while the matric suction ranges from $10 \mathrm{KPa}$ (air entry value of the sensor) to approximately $3300 \mathrm{KPa}$.

\subsubsection{Thaw Strain}

Thaw strain is defined as the ratio between change in height due to thawing and initial height of the specimen. The initial height of the MFT column before freezing was $30 \mathrm{~cm}$, while the height at the end of the thawing was $19 \mathrm{~cm}$, as seen in Figure 96. The thaw strain for column test $\# 1$ was found to be 0.37 or $37 \%$. 


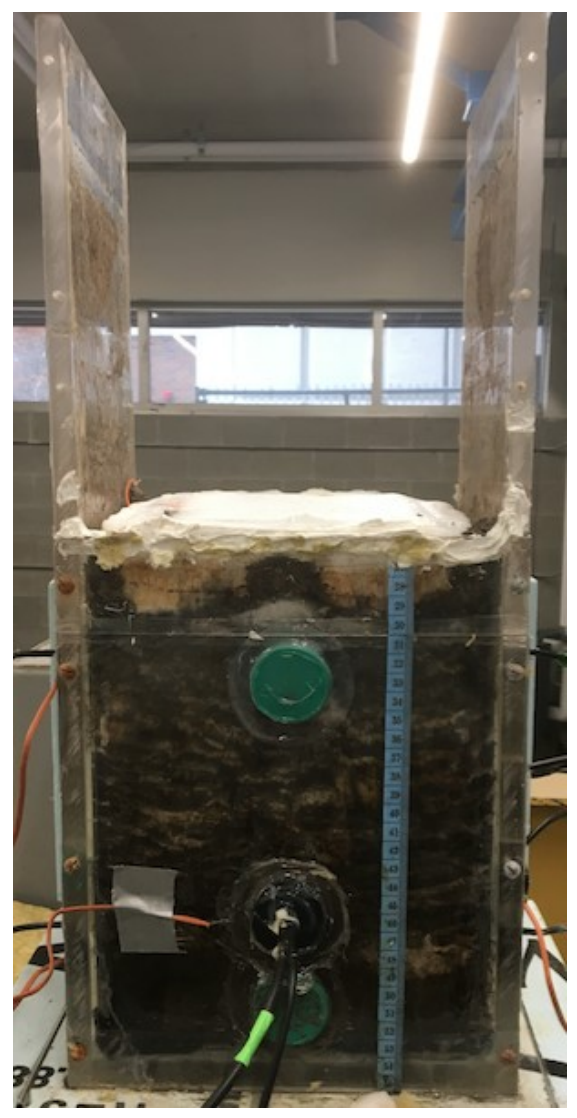

MFT prior thawing

Height $_{\text {average }} \approx 30 \mathrm{~cm}$

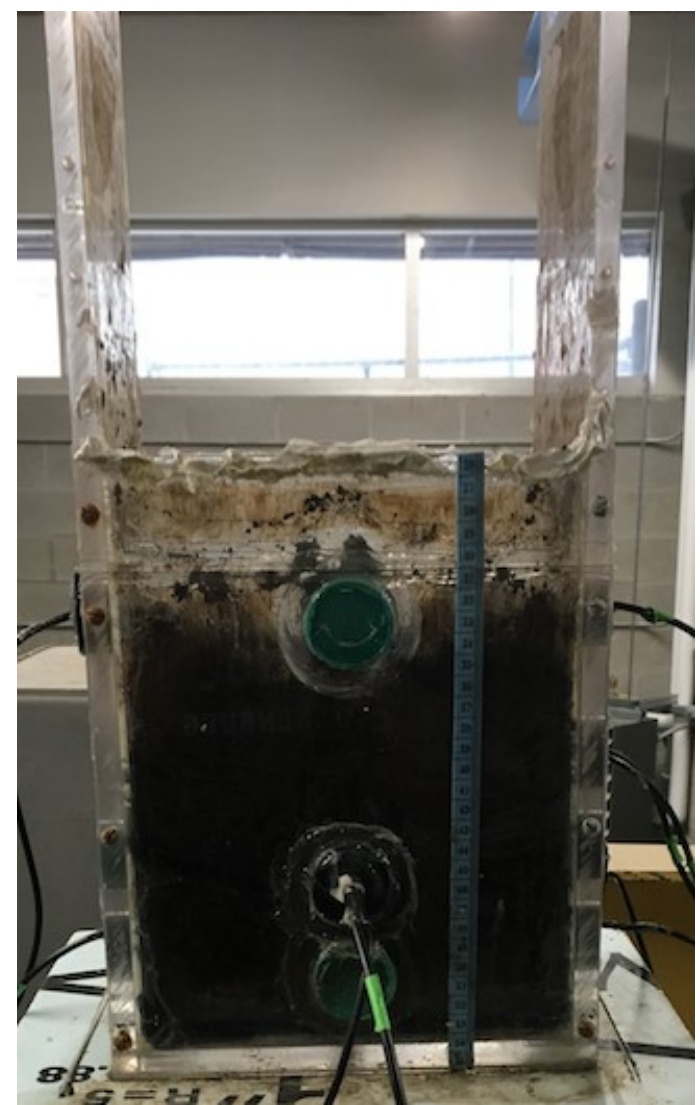

MFT after thawing

Height $_{\text {average }} \approx 19 \mathrm{~cm}$

Figure 96. MFT height before and after the thawing phase.

\subsubsection{Undrained Shear Strength}

A vane shear test was conducted at the end of the thawing phase to determine the undrained shear strength of the thawed tailings. Figure 97 shows the results obtained at intervals of $5 \mathrm{~cm}$. As seen in the figure below, the undrained shear strength increases with depth and decreases at bottom of the column. 


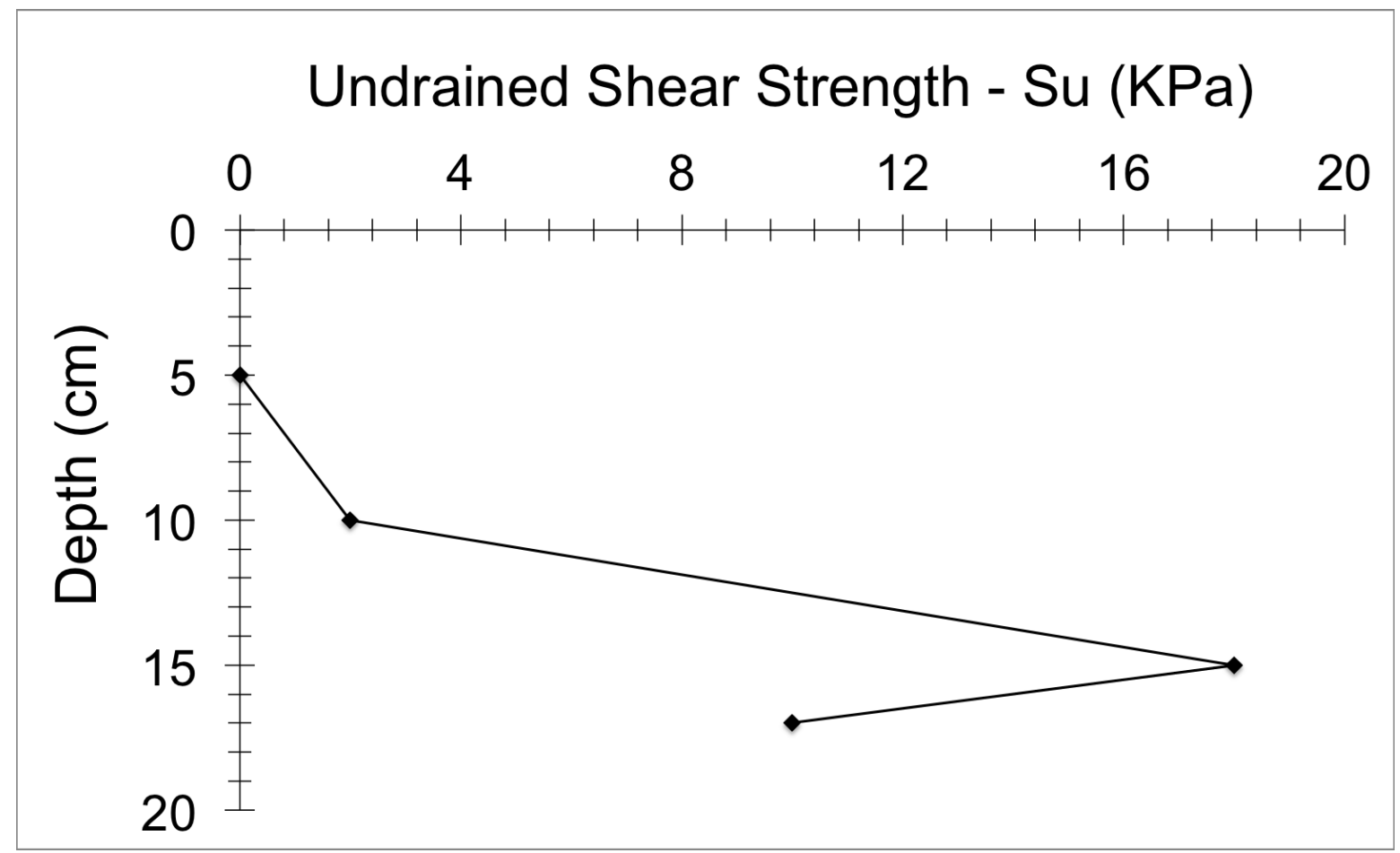

Figure 97. Vane shear test results for column test \#1.

\subsubsection{Consolidation Behaviour and Permeability}

The results of the oedometer tests performed on the MFT after the thawing phase are shown in Figure 98. Four tests were performed at different depths on a $16 \mathrm{~cm}$ core sample. The samples at depths of $3.25 \mathrm{~cm}, 6.75 \mathrm{~cm}$, and $10.25 \mathrm{~cm}$ underwent freeze-thaw meanwhile the sample located at $13.75 \mathrm{~cm}$ did not. As stated before, the freezing phase stopped when the lowest sensor, located at $5 \mathrm{~cm}$ from the bottom, recorded a temperature of zero. This means that $11 \mathrm{~cm}$ out of the $16 \mathrm{~cm}$ core sample were frozen and thawed. The $13.75 \mathrm{~cm}$ sample belongs to the unfrozen part. 


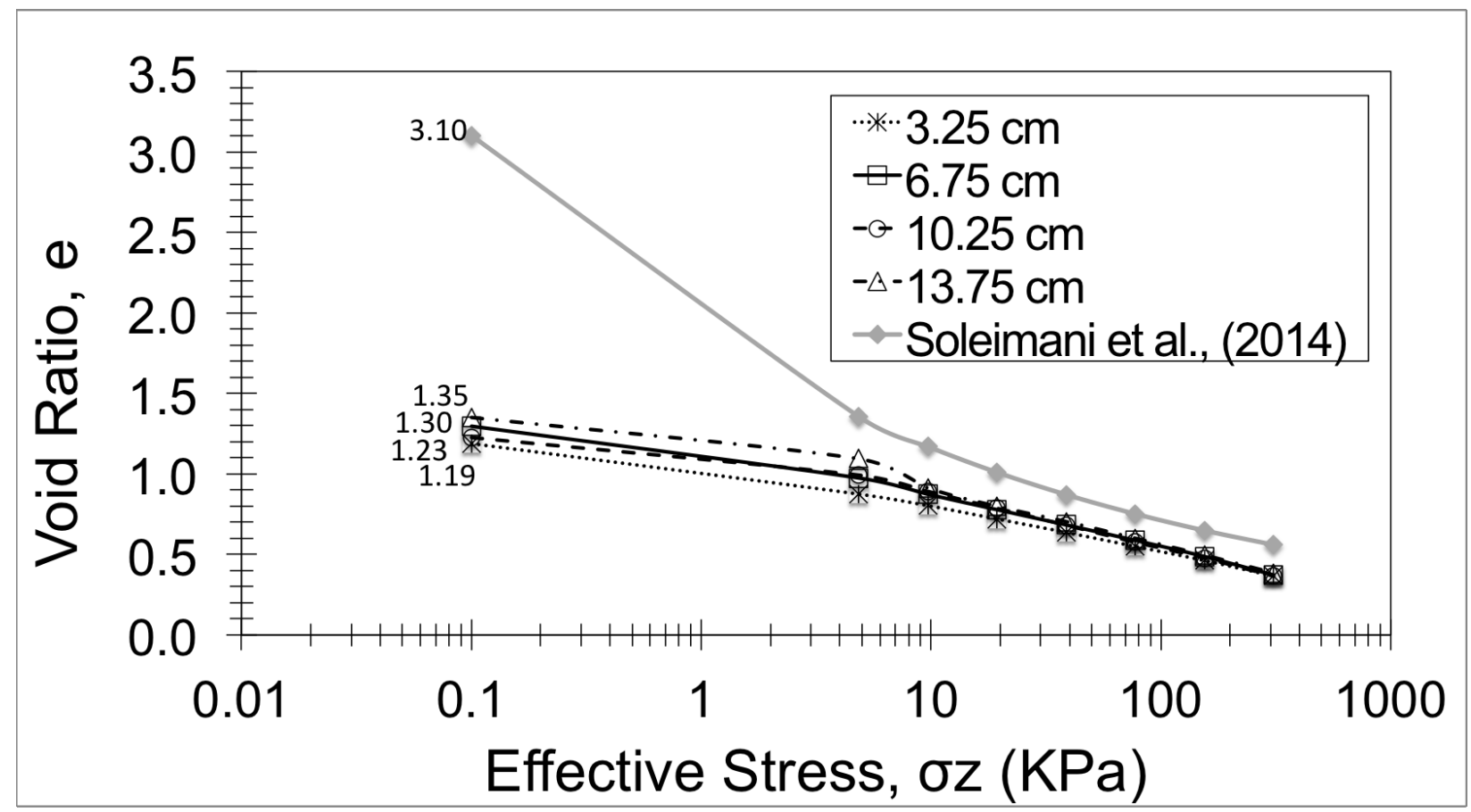

Figure 98. Consolidation test results at different depths for column test \#1.

Even though the four samples were loaded equally, they exhibit slightly different consolidation properties, as seen in Table 18. The four samples show comparable values for initial water content, initial solids content, and initial void ratio. The percentage difference between the highest and lowest values is $16.6 \%, 5.2 \%$, and $12.6 \%$, respectively. The variability of results can be attributed to the different thaw strains that $3.25 \mathrm{~cm}, 6.75 \mathrm{~cm}$, and $10.25 \mathrm{~cm}$ samples underwent and the lack of freezing for the $13.75 \mathrm{~cm}$ sample. Moreover, the bottom three samples concur on a common curve at effective stresses greater than 10KPa showing similar consolidation behaviour. However, the sample corresponding to a depth of $3.25 \mathrm{~cm}$ shows lower void ratio values after the $10 \mathrm{KPa}$ mark. This can be attributed to the fact that the $3.25 \mathrm{~cm}$ sample was subjected to a larger compressive force (i.e. overconsolidation) by the ice build-up 
at the surface of the MFT column. As the top material freezes, the formed ice begins to expand while the column and thermoelectric cooling plate prevent it from doing so. Ice would, therefore, begin to load the MFT to accommodate its natural expansion. Consequently, the effective stress acting on the soil mass increases and the soil starts to compress. As the freezing front advances, the ice loading would drive water from the unfrozen material either towards the bottom drainage or towards the freezing front aiding the production of more ice in the MFT column.

Furthermore, the bottom three samples $(6.75 \mathrm{~cm}, 10.25 \mathrm{~cm}$, and $13.75 \mathrm{~cm})$ show a decreasing trend in their compression index $(\mathrm{Cc})$ as well as a decrease in their initial void ratio values as effective stresses increase. These results are expected since the initial void ratio and the compression index are proportionally related (Nishida, 1956). When compared to data from Soleimani et al., (2014), which only had a self-weight consolidation with ambient drying phase, it is possible to see the immediate impact of a freeze-thaw cycle, which is to reduce the initial void ratio of the MFT sample. Also, it is important to point out that all five samples show similar slopes at effective stresses greater than $10 \mathrm{KPa}$ meaning that they all have similar compressibility rates. The material and experimental setup used by Soleimani et al., (2014) is similar to the one used in this experiment. The polymer dosage was also $650 \mathrm{mg} / \mathrm{Kg}$ and the sample was allowed to drain from the bottom and evaporation was restricted.

Furthermore, Figure 99 shows the hydraulic conductivity of all four samples. They were calculated using Terzaghi's consolidation theory. Most of the permeability 
values are lower than $10^{-9} \mathrm{~m} / \mathrm{s}$, except for the values corresponding to the last load increment. As expected, the hydraulic conductivity of the MFT increases as the void ratio increases in an approximately linear trend.

When comparing the obtained results with Soleimani et al., (2014), it is distinguishable that both sets of data differ in permeability values by two to four orders of magnitude at similar void ratios. The samples that underwent self-weight consolidation with ambient drying and one freeze-thaw cycle show higher hydraulic conductivity values than the sample that was allowed only to consolidate as the void ratio increases. This can be attributed to the impact of freeze-thaw on microstructure of and void ratio of MFT, as discussed below.

Table 18. MFT consolidation properties summary for column test \#1.

\begin{tabular}{|c|c|c|c|c|c|}
\hline Depth (cm) & $\begin{array}{c}\text { Initial Water } \\
\text { Content (\%) }\end{array}$ & $\begin{array}{c}\text { Initial Solids } \\
\text { Content(\%) }\end{array}$ & $\begin{array}{c}\text { Initial Void } \\
\text { Ratio, eo }\end{array}$ & $\begin{array}{c}\text { Recompression } \\
\text { Index, Cr }\end{array}$ & $\begin{array}{c}\text { Compression } \\
\text { index, Cc }\end{array}$ \\
\hline 3.25 & 46.9 & 68.1 & 1.19 & 0.186 & 0.289 \\
\hline 6.75 & 50.1 & 66.6 & 1.30 & 0.191 & 0.333 \\
\hline 10.25 & 45.9 & 68.5 & 1.23 & 0.138 & 0.348 \\
\hline 13.75 & 42.4 & 70.2 & 1.35 & 0.154 & 0.35 \\
\hline
\end{tabular}




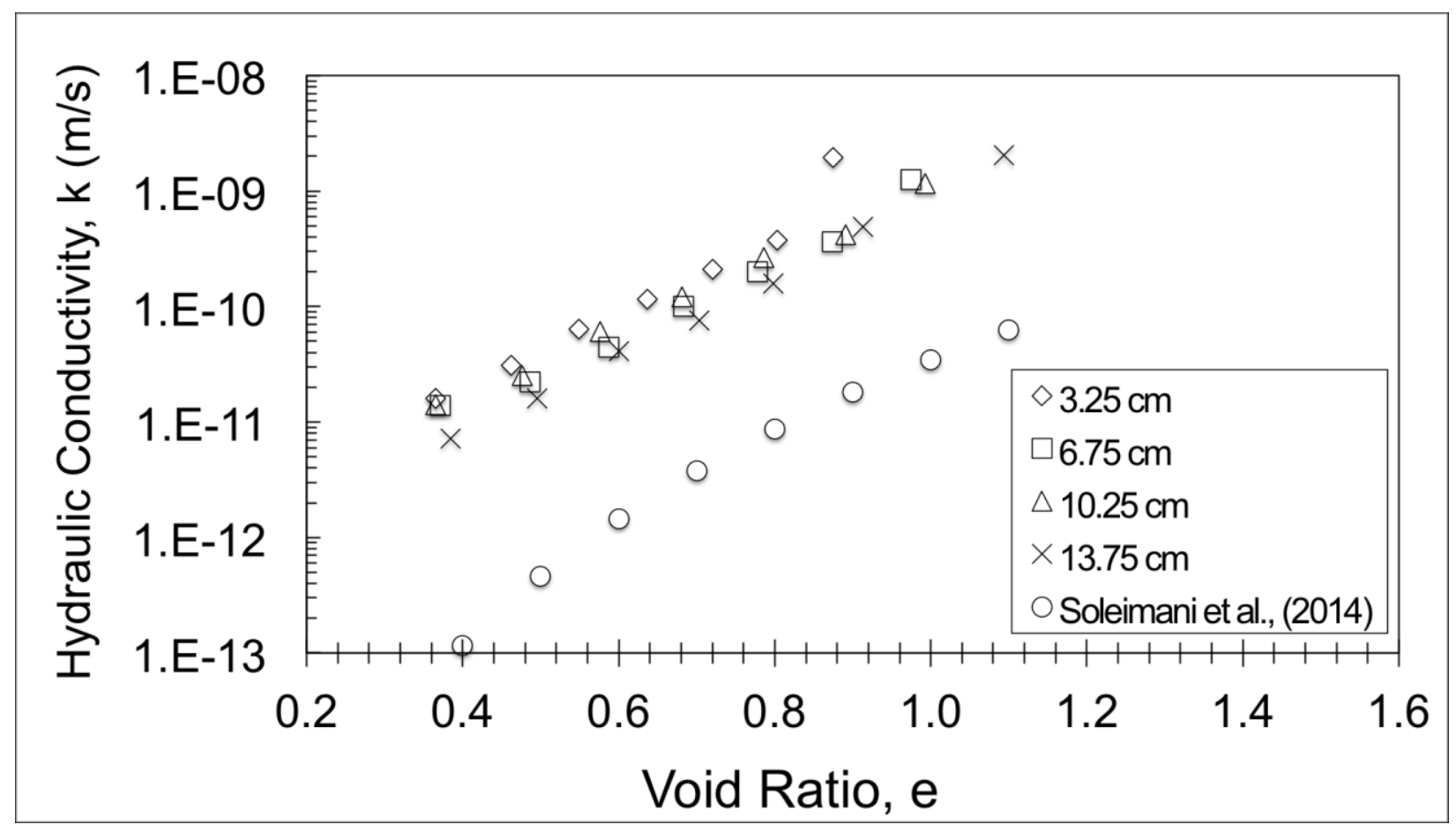

Figure 99. Hydraulic conductivity results for column test \#1.

Chamberlain and Gow (1979) showed that, even though overconsolidation leads to a reduction of hydraulic conductivity in high clay content soils, overconsolidation due to freeze-thaw cycles leads to a visible increase in hydraulic conductivity in the studied samples. They stated that in soils that are comprised of a flocculated clay matrix and where sand and silt grains are not in contact, the compressibility and permeability of the material is dependent on the arrangement of the clay particles. This is the case of the polymer amended oil sands MFT. They continue by explaining that a freeze-thaw cycle will lead to a reduction in void ratio due to the rearrangement of the clay particles to a more dispersed structure. Further scanning electron microscope (SEM) analysis could be done to corroborate this arrangement of particles. Moreover, the increase in permeability can be attributed to the same structural changes that provoke the material 
to shrink as ice crystals start to form. Vertical ice lenses perpendicular to the direction of freezing were found on the MFT column, as seen in Figure 100. The ice lens formation was observed at the same depths from which the first three samples $(3.25 \mathrm{~cm}$, $6.75 \mathrm{~cm}$, and $10.25 \mathrm{~cm}$ ) were obtained. No ice formation occurred at the depth of the $13.75 \mathrm{~cm}$ sample.

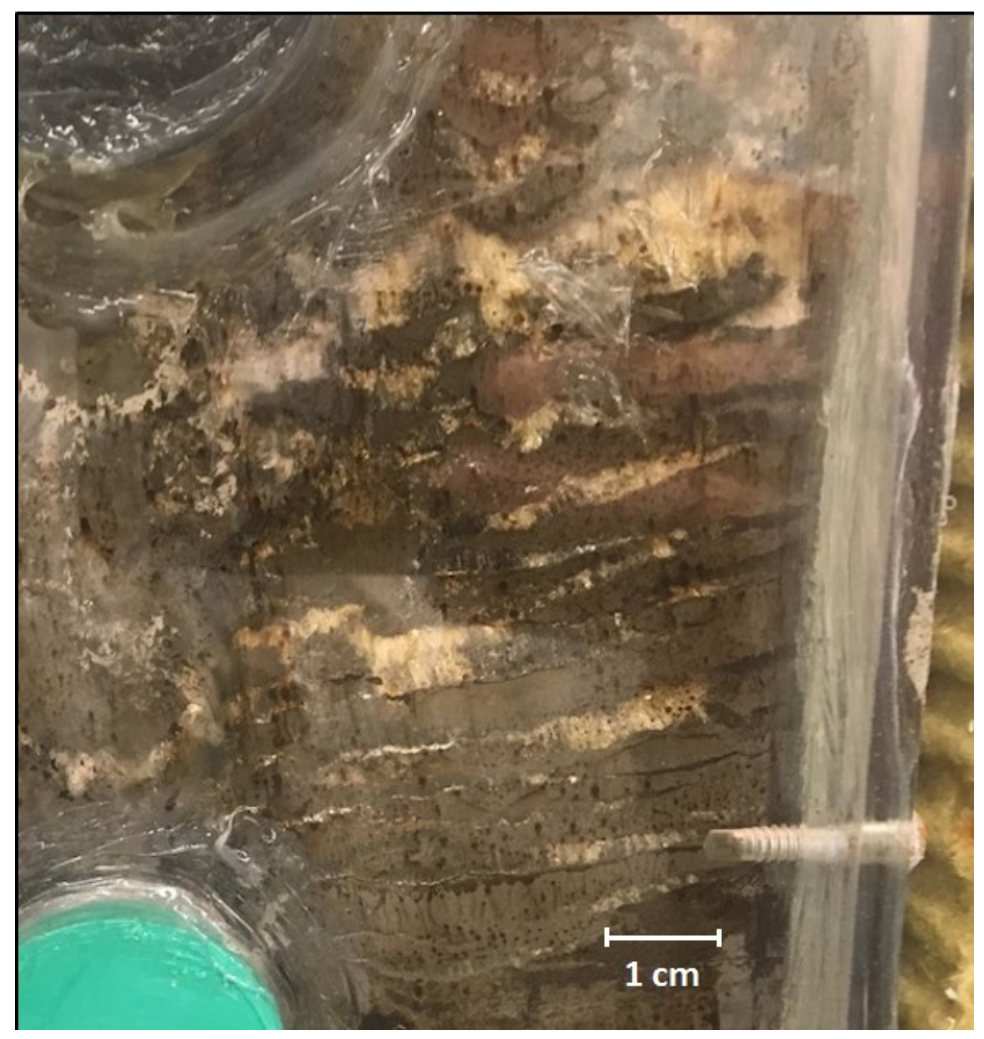

Figure 100. Vertical ice lenses in MFT column (column test \#1).

The complete data set obtained from all the consolidation tests is found on Appendix A. 


\subsection{Column Test \#2: Self-Weight Consolidation with Ambient Drying}

\subsubsection{Temperature Profile}

Figure 101 shows the temperature profile of the MFT column at heights (from the bottom of the column) of $5 \mathrm{~cm}, 15 \mathrm{~cm}, 22.5 \mathrm{~cm}$, and surface. The surface sensor changes height according to the MFT settlement from a height of $50 \mathrm{~cm}$ to $27.5 \mathrm{~cm}$, as shown in the figure below. The temperature data shown corresponds to the self-weight consolidation with ambient drying phase alone since it is the only phase present in this experiment.

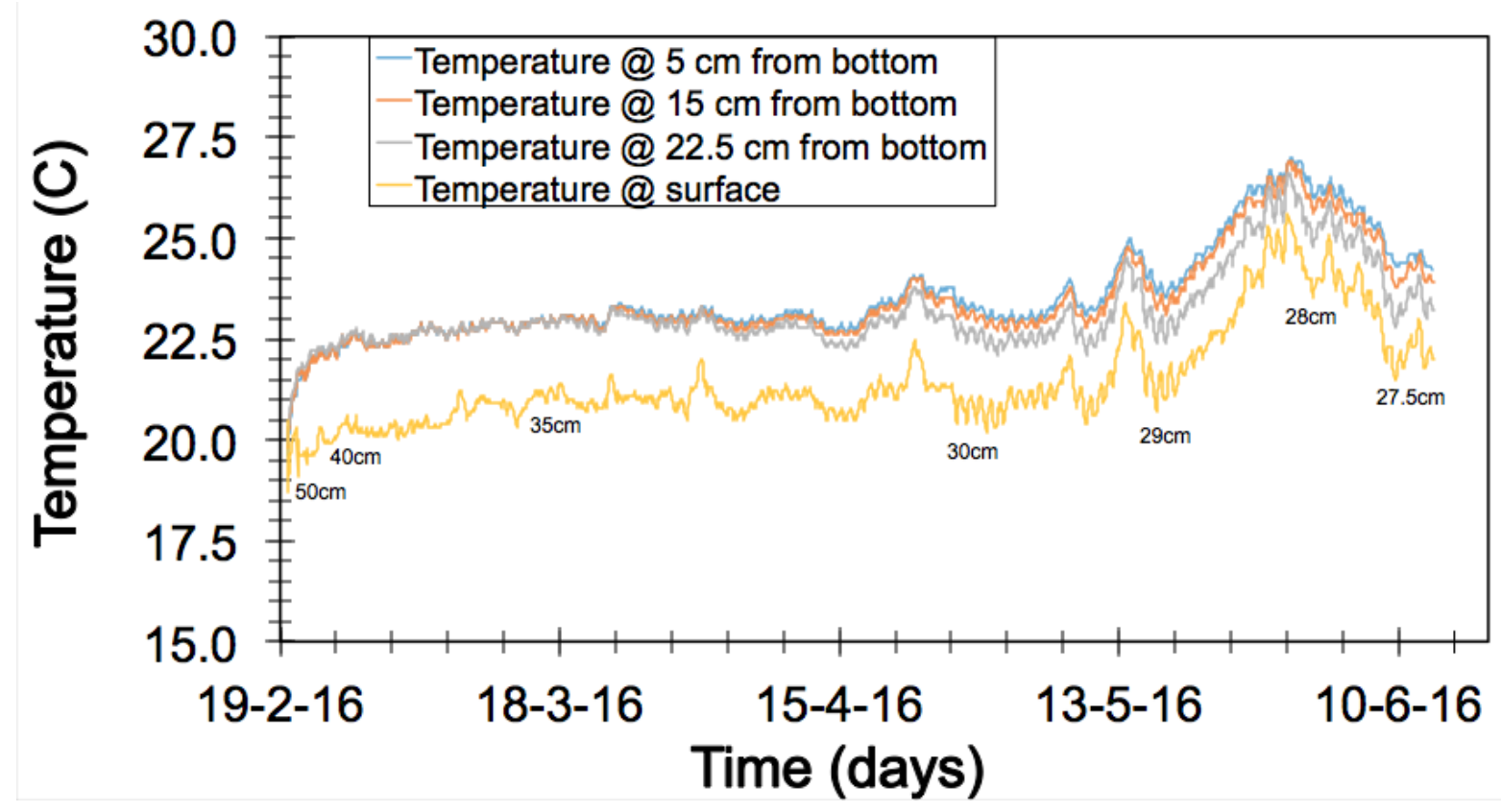

Figure 101. Temperature profile and surface sensor height location in column test \#2. 
Throughout the duration of the experiment, the temperature of the tailings fluctuated along with the air temperature. Unlike column test \#1, the surface temperature was recorded this time and it was noted that the surface temperature varies by a few degrees Celsius when compared to the internal temperature of the tailings. The temperature within the tailings (at height of $5 \mathrm{~cm}, 15 \mathrm{~cm}$, and $22.5 \mathrm{~cm}$ ) remains almost the same throughout the experiment. However, the surface temperature constantly varies by $1.5{ }^{\circ} \mathrm{C}$ from the rest of the MFT column at temperatures between $19{ }^{\circ} \mathrm{C}$ and $23.5{ }^{\circ} \mathrm{C}$. At temperatures greater than $23.5^{\circ} \mathrm{C}$, the difference between surface and internal temperatures decreases to approximately $0.5{ }^{\circ} \mathrm{C}$ or less. The similarity in temperatures the last few weeks of the experiment could be attributed to the surface sensor being located closer to the $22.5 \mathrm{~cm}$ sensor, which would allow similar temperature readings. The difference in temperature can be attributed to the tailings' ability to store energy. This property is also known as volumetric heat capacity and it is dependant on the organic material, water content, and density of the soil. Furthermore, the internal and surface temperatures present during this experiment fluctuated from 20 ${ }^{\circ} \mathrm{C}$ to $27{ }^{\circ} \mathrm{C}$ and $18.8^{\circ} \mathrm{C}$ to $25.4{ }^{\circ} \mathrm{C}$, respectively.

\subsubsection{Settlement, Water Loss, and MFT Densification}

Figure 102 shows the measured height of the tailings throughout the experiment. These measurements do not account for the supernatant water cover thickness produced by the tailings the first two weeks of the experiment. The change in height is due to self-weight consolidation of the tailings, which is driven by water loss in the form of evaporation and under-drainage. 


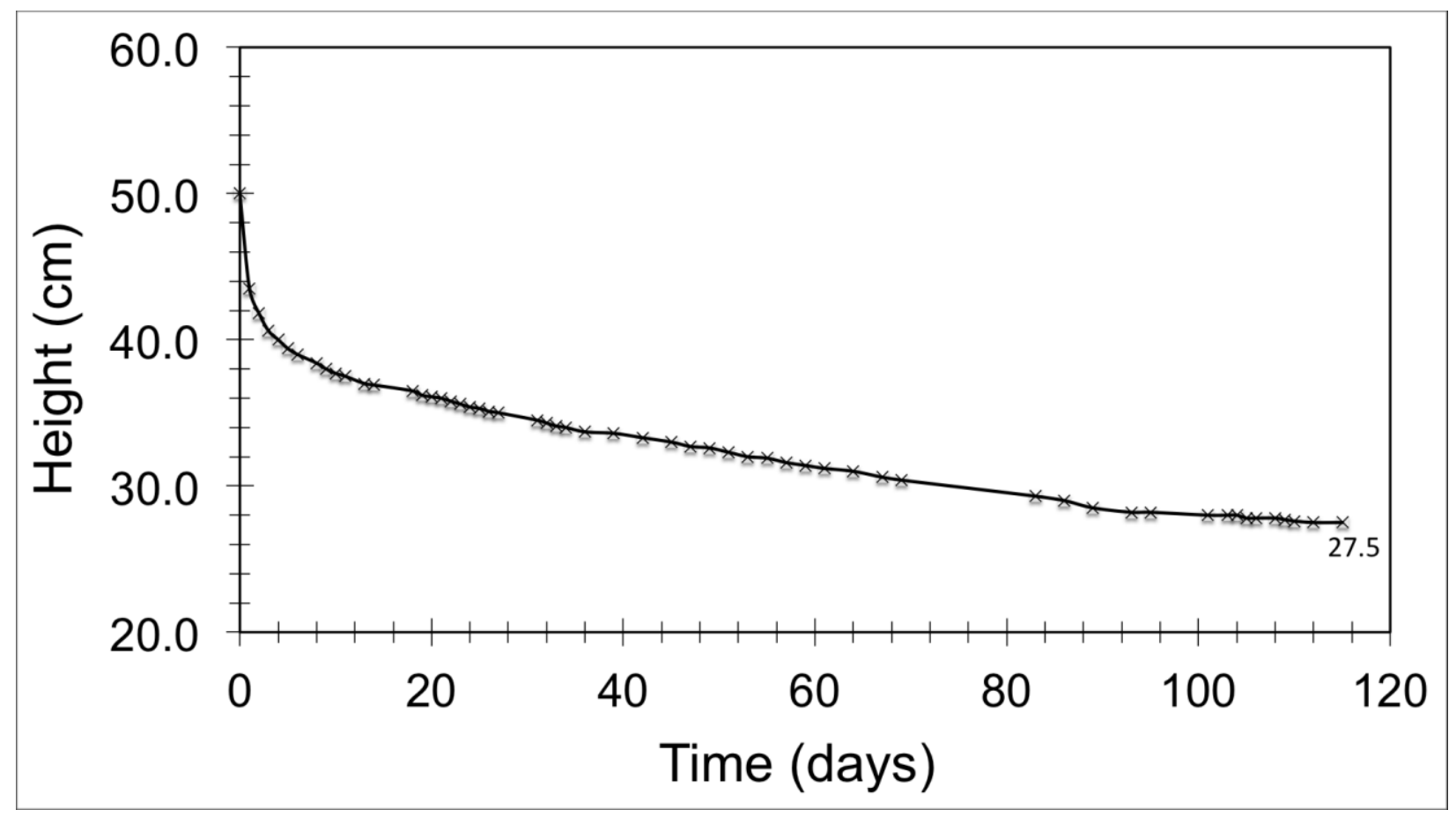

Figure 102. Height change over time in column test \#2.

During the experiment, the tailings settled down on a steady and exponential trend. The initial height of the MFT column was $50 \mathrm{~cm}$ and it decreased to a height of $27.5 \mathrm{~cm}$ in 115 days. The major factors for self-weight consolidation throughout the experiment were under-drainage, supernatant water from the first two weeks of the experiment, and evaporation.

As mentioned previously, the MFT's total water loss was calculated by measuring the loss of water due to drainage and evaporation. The actual evaporation was calculated by subtracting the drainage water from the total weight loss measured by 
the electronic scale on a daily basis. Figure 103 shows the contributions of drainage and evaporation to the total water loss during the experiment.

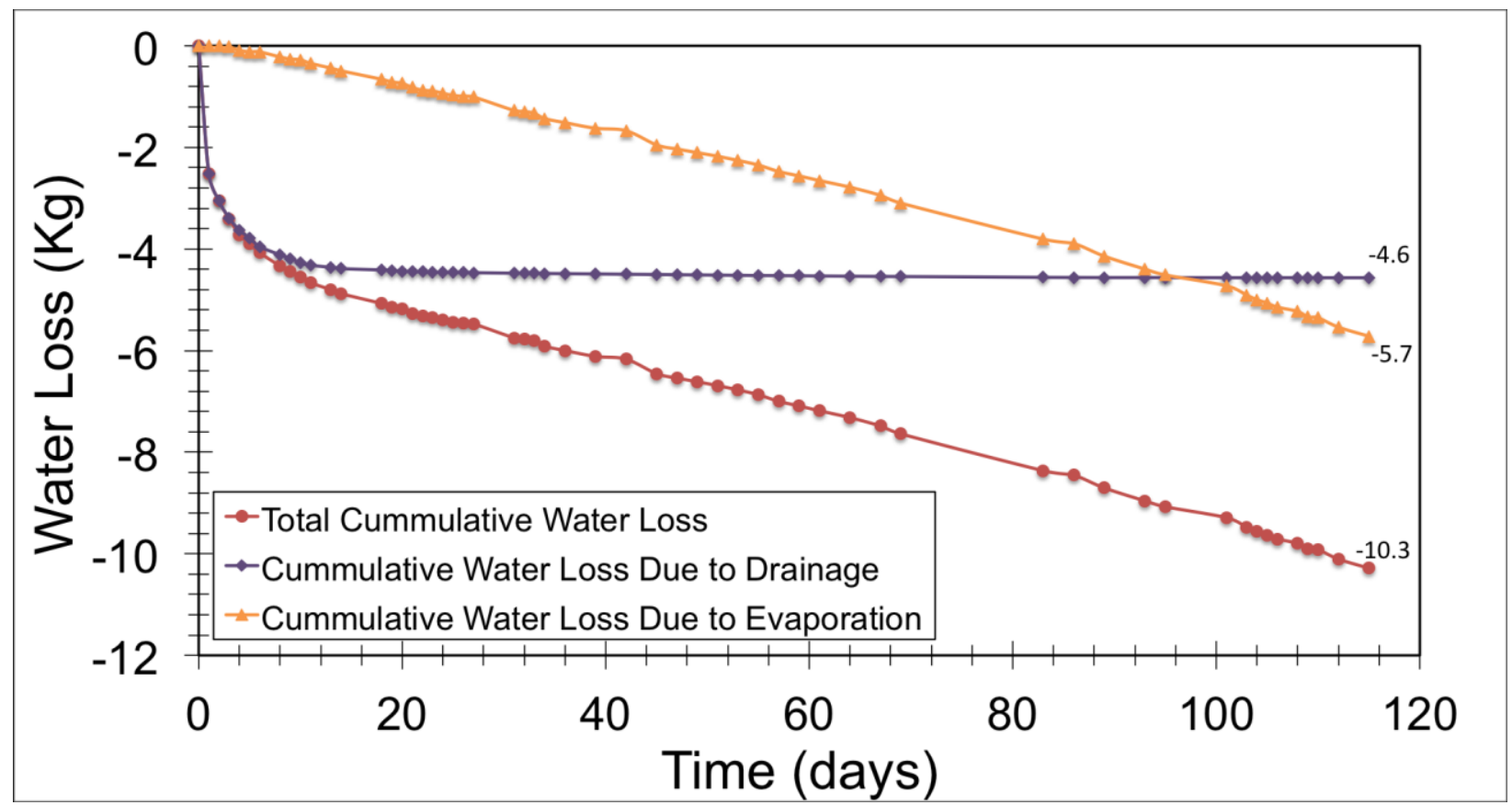

Figure 103. Cumulative water loss due to evaporation and drainage in column test \#2.

Approximately $10.3 \mathrm{~kg}$ of water were released from the MFT, which is roughly $46 \%$ of the total weight. Figure 103 shows steady dewatering from both, drainage and actual evaporation, during the experiment. The evaporation rate throughout the experiment was constant and steady at $49.7 \mathrm{gr} /$ day $(1.33 \mathrm{~mm} /$ day $)$. This type of behaviour in MFT dewatering due to self-weight consolidation has also been reported by Rozina et al. (2015). At day 11 of the experiment, the dewatering contribution due to drainage became almost negligible but the evaporation rate continued unchanged until the end of the experiment. At day 95 of the experiment, the dewatering contribution due 
to evaporation became greater than the contribution due to drainage. At completion of the test, approximately $5.7 \mathrm{~kg}$ of water were evaporated from the tailings and $4.6 \mathrm{~kg}$ were drained. Also, cracking on the surface did not occur; however, shrinkage of the surface as a whole did (Figure 104). Even though, more material was exposed due to the surface shrinking, there was no increase in the evaporation rate.

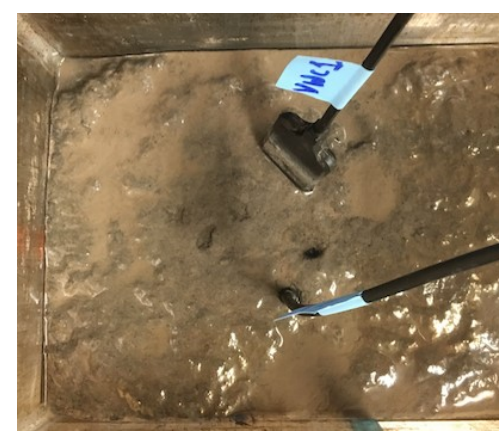

Day 8

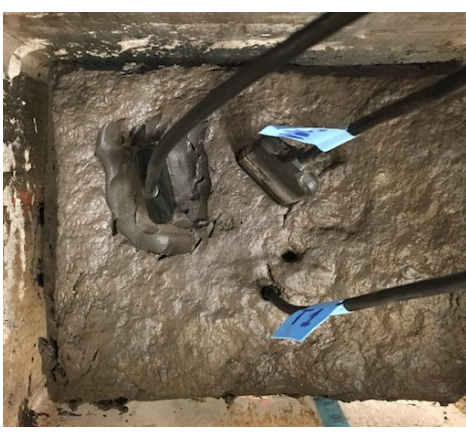

Day 61

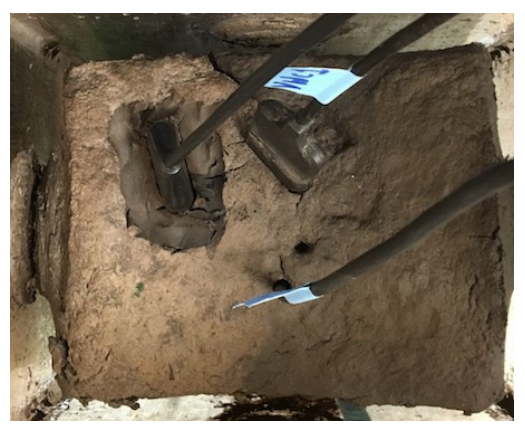

Day 115

Figure 104. Surface shrinkage in column test \#2.

As a consequence of constant water loss throughout the three phases of this experiment, the solids content changed as well. Densification of the tailings was back calculated using the total change in weight due to water loss and the initial mass of solids, which are assumed to be unchanged throughout the experiment. Figure 105 shows the evolution of the average solids content in the MFT column. 


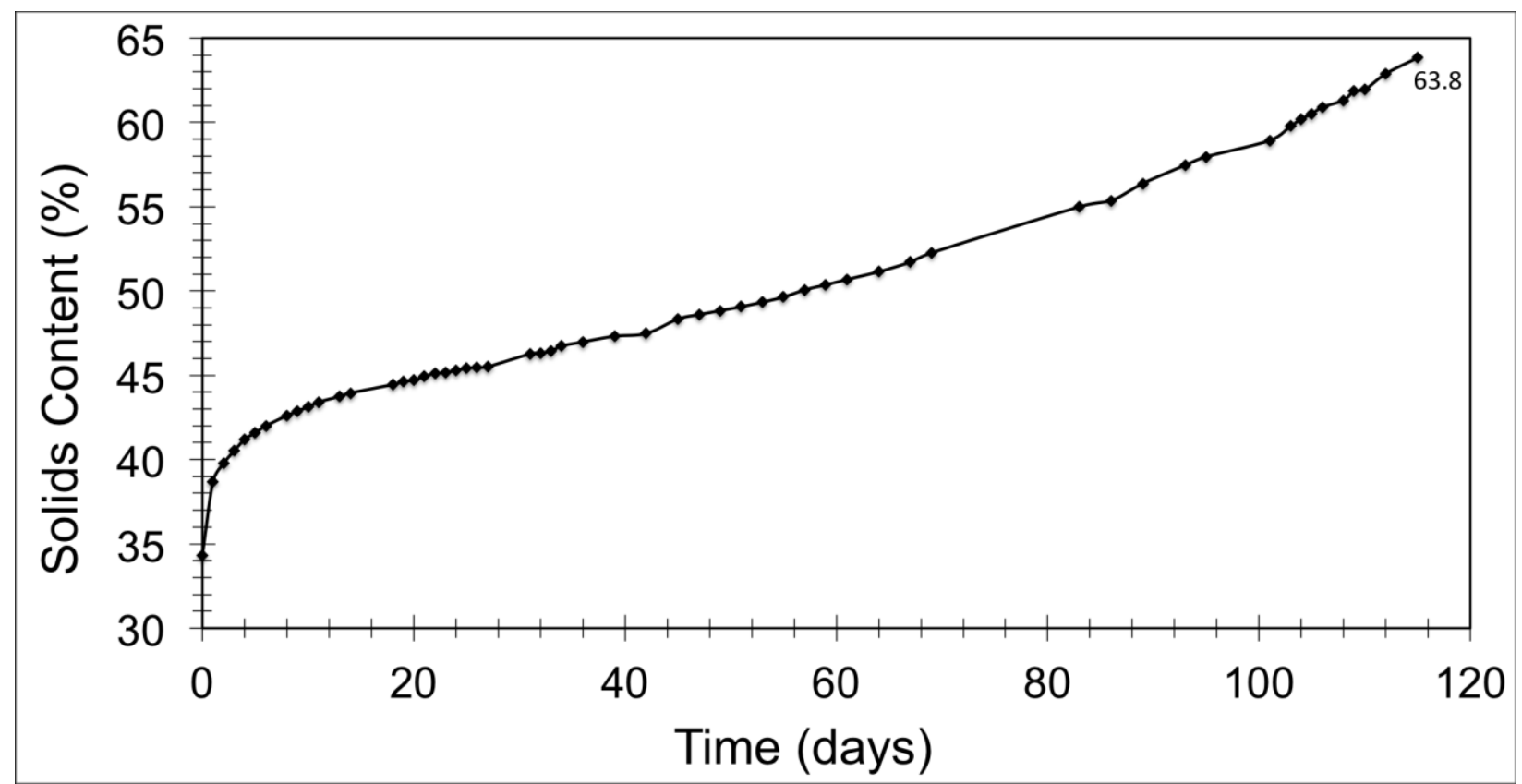

Figure 105. Solids content development over time in column test $\# 2$.

The change in solids content shows a similar trend when compared to the change in water loss since they are correlated (Fig. 103). At deposition, the initial solids content was $34.3 \%$ and at the end of the self-weight consolidation with ambient drying phase the solids content increased to $63.8 \%$. That is an increase of $29.5 \%$ overall. The final average solids concentration of the MFT was compared with actual measurements at the termination of the experiment. A profile of solids content was obtained at the termination of the experiment (Figure 106), which yielded an average of $64.5 \%$ solids content agreeing with the back-calculated value. Samples were taken from two different sections on the surface, A and B. Section A has higher solids content $(87.6 \%)$ than section B (75.1\%). This difference is attributed to the lower water content in section A. As the tailings settled, section A of the surface cracked from the bottom because one of 
the water content sensors was blocking further settlement and more material was exposed for further evaporation. This particular event only occurred on the top $2 \mathrm{~cm}$ from the left part of the surface.

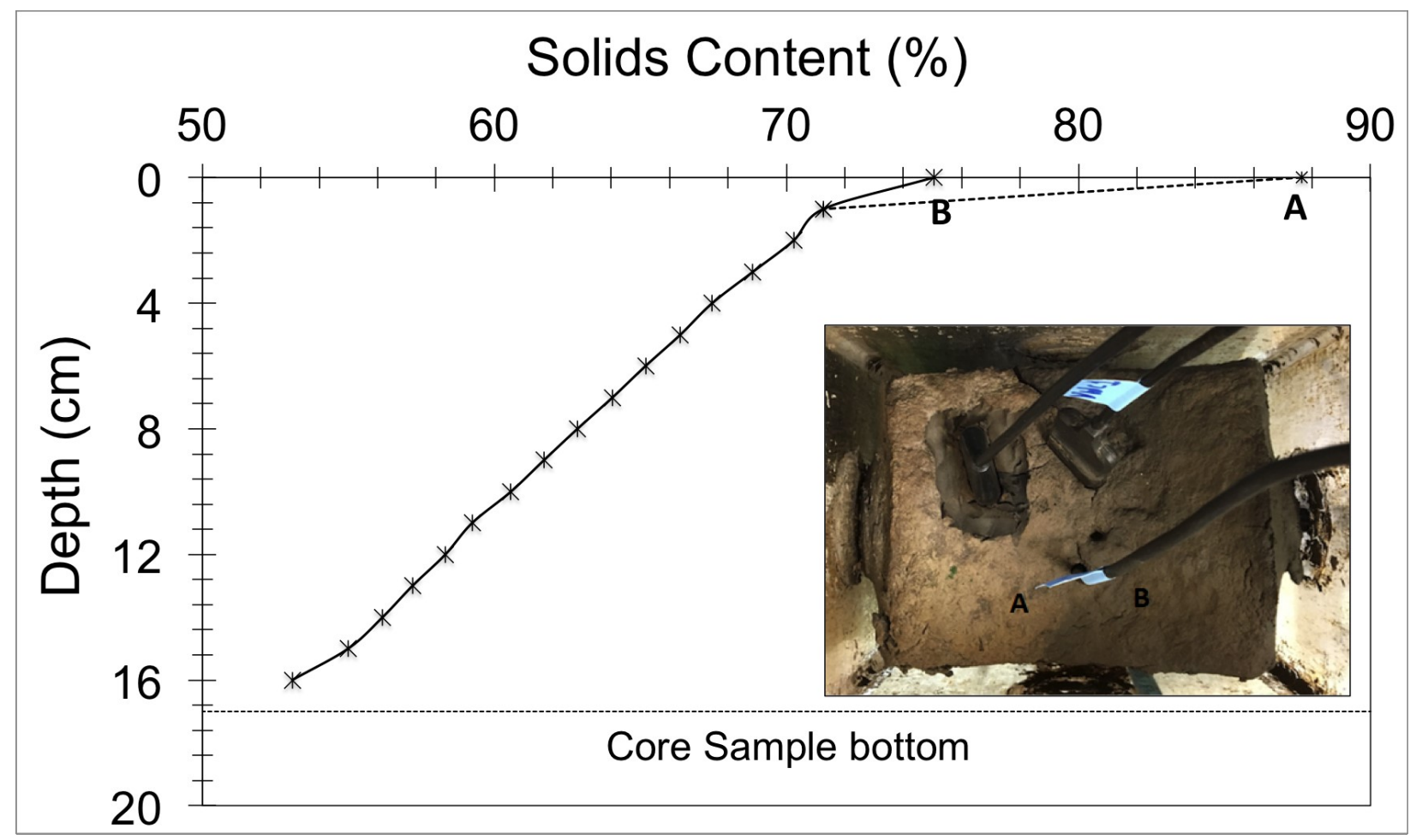

Figure 106. Solids content profile at the end of column test \#2.

\subsubsection{Volumetric Water Content Profile}

Figure 107 shows the volumetric water content readings recorded during the column test at different heights and at the surface. The figure also shows the height at which the surface sensor was located over time. 


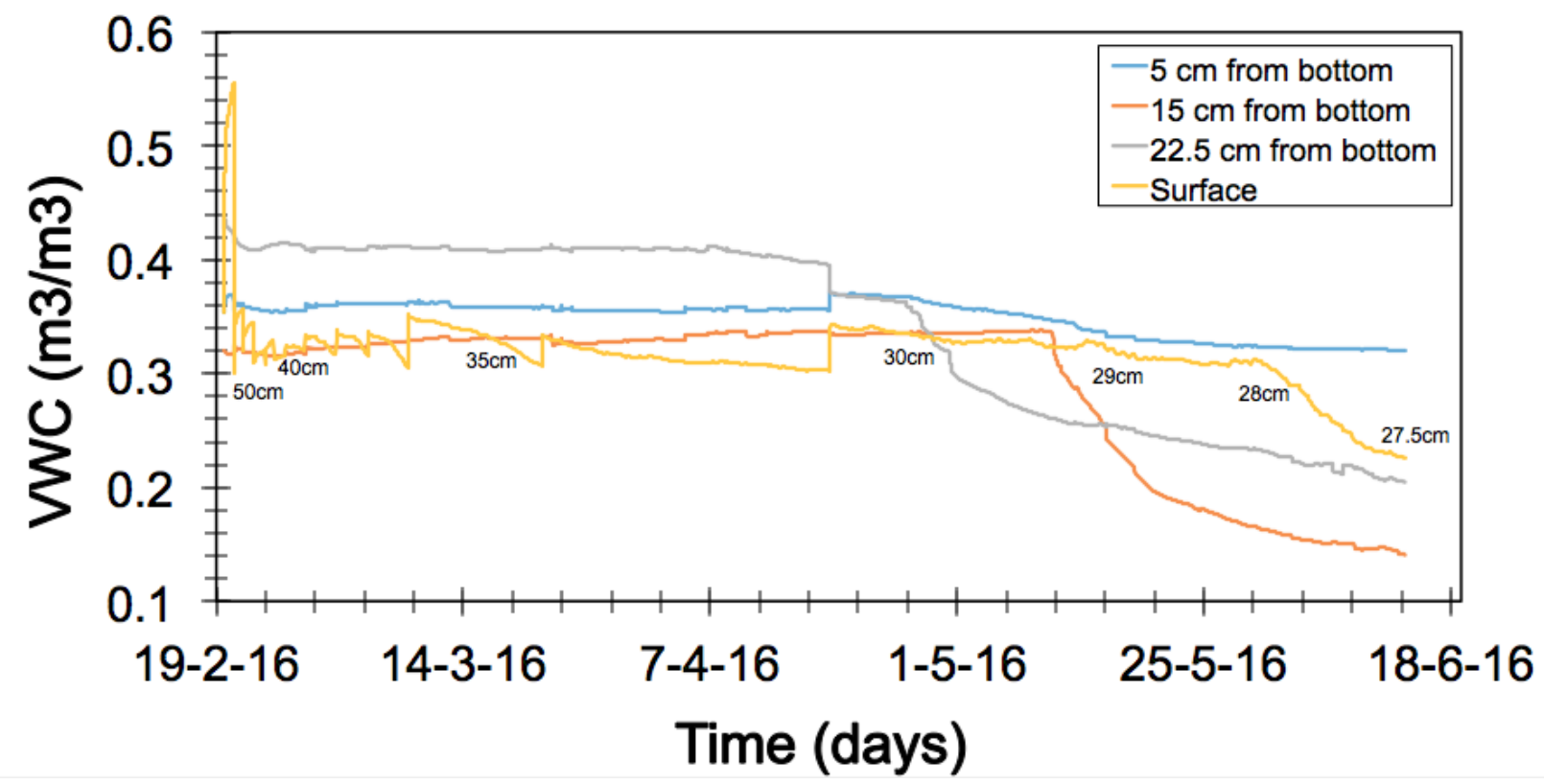

Figure 107. Volumetric water content profile at different heights and surface height location in column test \#2.

As seen in the figure above, the initial water distribution during the experiment has a semi-constant trend for all the sensors. In the latter part of the experiment, all the sensors record a decrease in volumetric water content. During the first 24 days of the experiment, supernatant water was being removed from the surface of the MFT column. As water kept moving to the surface due to self-weight consolidation, the sensor recorded an increase in water content, or 'peak', at the surface followed by a rapid drop due to the daily removal of surface water.

Furthermore, there is a disagreement in the theorized water content distribution within the tailings and the recorded values. In theory, due to density differences, higher water contents should be recorded near the surface while low water contents should be 
recorded at the bottom. As seen in Figure 107, this is not the case. During the first half of the experiment, the $22.5 \mathrm{~cm}$ sensor (gray line) recorded higher values than the surface sensor (yellow line) but this can be attributed to the daily dewatering of the surface and constant evaporation of the material the surface sensor is buried in. The 15 $\mathrm{cm}$ sensor (orange line) recorded similar water contents to the surface sensor, which adds on to the discrepancy in water content distribution. The $5 \mathrm{~cm}$ sensor (blue line) recorded higher values than the surface and $15 \mathrm{~cm}$ sensor, and lower values than the $22.5 \mathrm{~cm}$ sensor. During the second half of the experiment, the distribution of water shifted completely. As the tailings started drying and the top portion of the MFT column shrunk, the volumetric water content readings from all the sensors dropped. The $15 \mathrm{~cm}$ sensor recorded the lowest water content readings while the $5 \mathrm{~cm}$ sensor recorded the higher. From a visual stance, it was possible to observe the accumulation of water at the bottom of the MFT column as the top portion of the tailings was shrinking, as seen in Figure 108. This could explain the higher water content readings from the $5 \mathrm{~cm}$ sensor. 


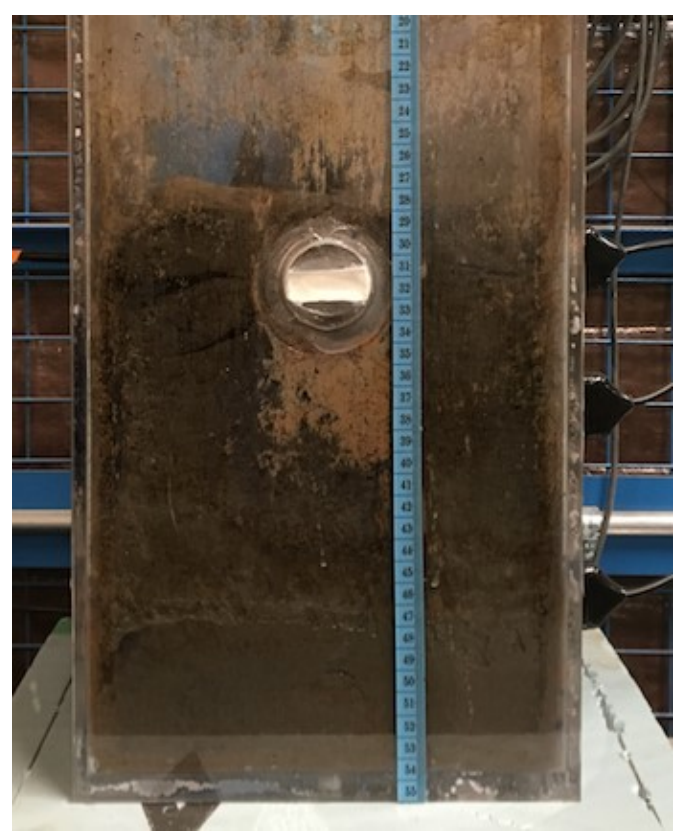

Figure 108. Water accumulation at the bottom of the column.

The inconsistency and unreliability of the readings from the volumetric water content sensors in this experiment can be attributed to the following factors: possible air pockets could have formed under the sensor as the tailings settled, which could have affected the readings; as well as the possibility of the sensors malfunctioning. The latter is less likely since the sensors used were band new. The sensor data could also have been compromised by the shrinkage of the MFT column. As the top portion of the material shrunk, the evaporation and drainage was not one-dimensional anymore but it became three-dimensional. This way, the MFT column at different heights underwent water content changes that would not normally undergo under one-dimensional conditions.

Lastly, a gravimetric water content profile at the termination of the test was obtained, as seen in Figure 109. This profile confirms the visual report from Figure 108 
for water distribution within the tailings: the bottom of the column has higher water content than the surface. Similar to the solids content data, the surface was divided into two visible areas, A and B. Gravimetric water content measurements were taken from both areas. The difference in water content between area A and B is $19 \%$.

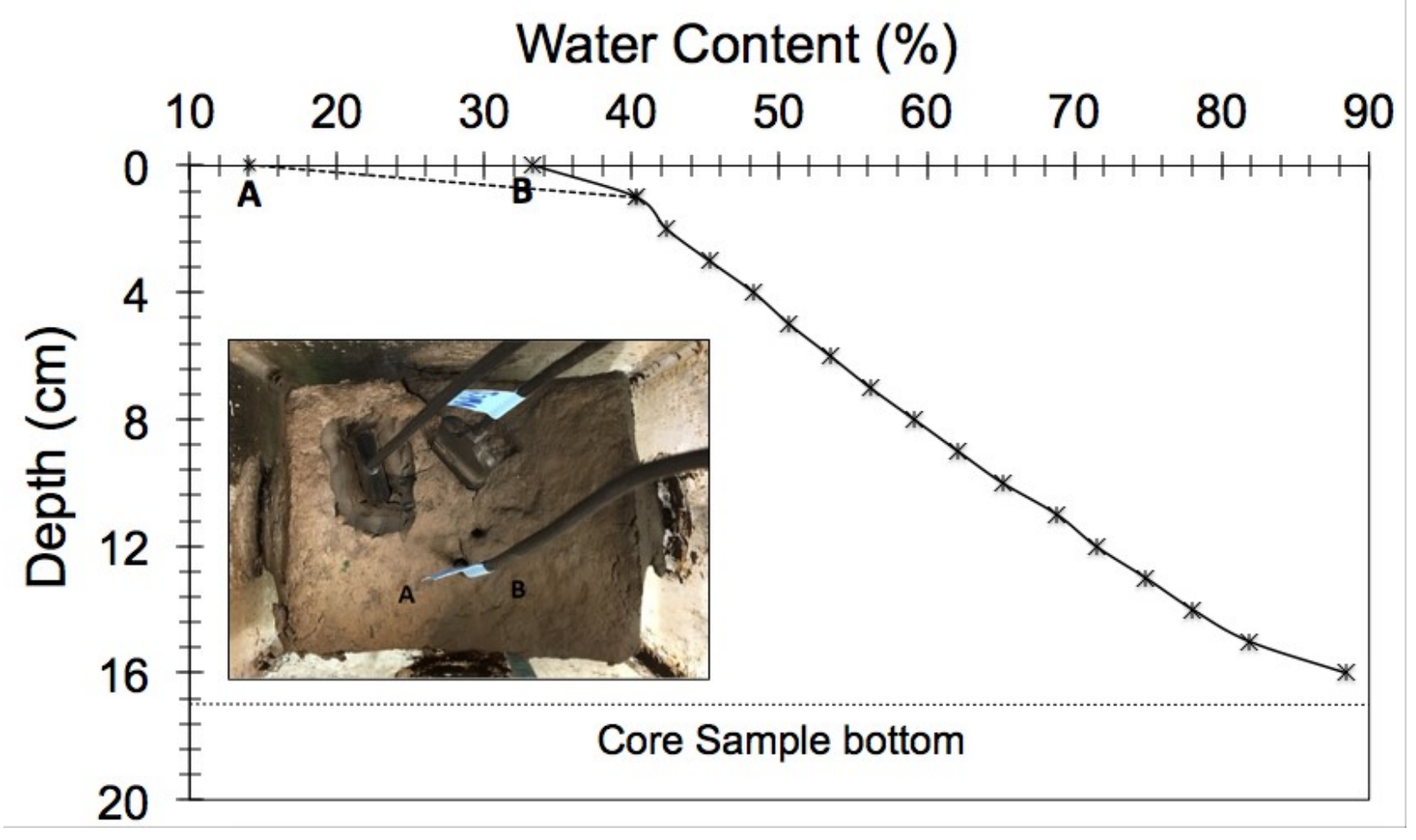

Figure 109. Gravimetric water content at termination of column test $\# 2$.

\subsubsection{Pore Water Pressure Development}

The data obtained from two tensiometers located at heights of $5 \mathrm{~cm}$ and $22.5 \mathrm{~cm}$ from the bottom of the column are presented in Figure 110 and Figure 111. 
Figure 110 shows the pore pressure ranging from $3.6 \mathrm{KPa}$ to $-100 \mathrm{KPa}$ at a height of $22.5 \mathrm{~cm}$. The figure shows the pore pressure data going further than $-100 \mathrm{KPa}$ (solid and dotted blue line); however, the sensor range is only $-100 \mathrm{KPa}$ if the water within the sensor is not de-aired. The temporary range of the sensor extends up to the $\mathrm{AEV}$, as the data shows. Figure 111 shows the pore pressure values greater than zero as the tailings desaturate. The data from the first four days shows a large reduction in pore pressure. This is due to the daily removal of supernatant water form the surface. On the following days, the pore water dissipation remains almost constant on the positive range. Once negative pore pressures, or suctions, started to develop, the dissipation rate accelerated from $0 \mathrm{KPa}$ to $-100 \mathrm{KPa}$ in 41 days. Negative pore pressures continued to increase beyond $-100 \mathrm{KPa}$ until the tensiometer cavitated at $270 \mathrm{kPa}$, close to the $\mathrm{AEV}$ of the ceramic tip (dotted blue line on Figure 111).

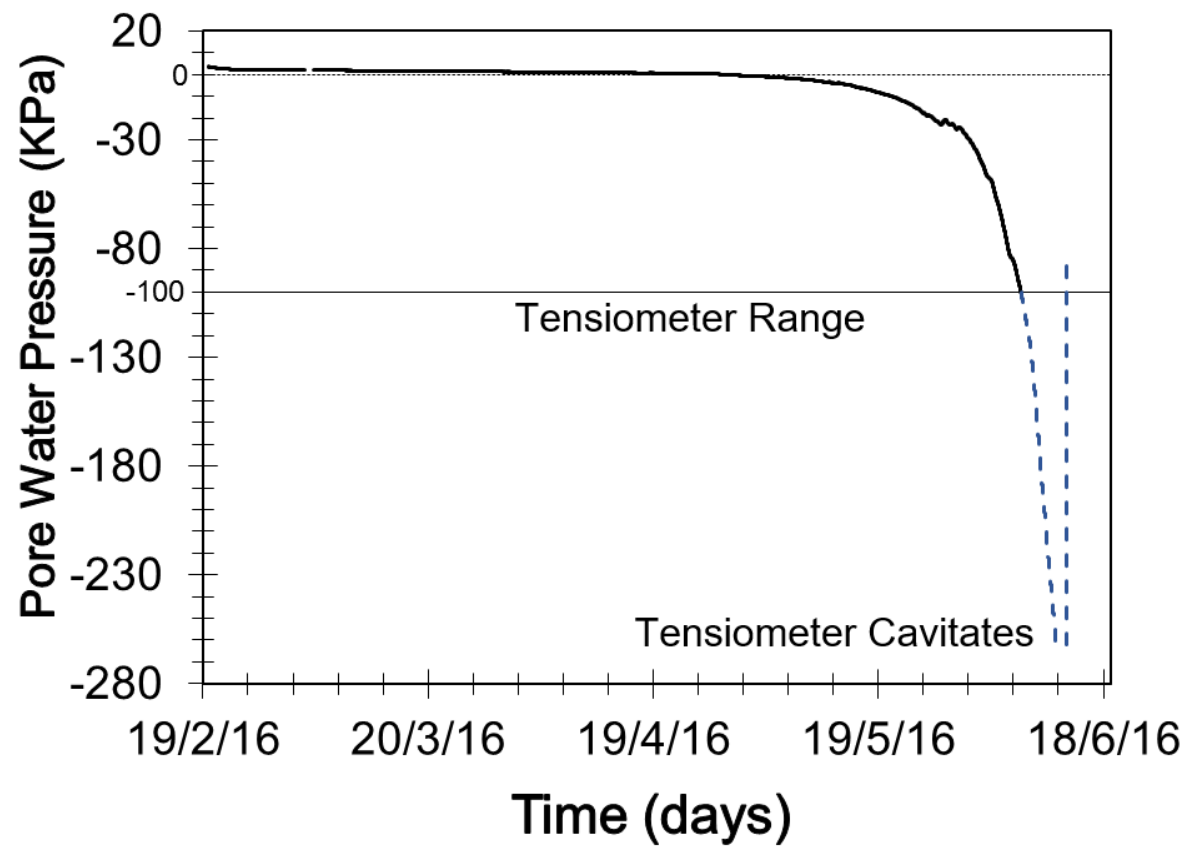

Figure 110. Tensiometer data at a height of $22.5 \mathrm{~cm}$ from the bottom. 


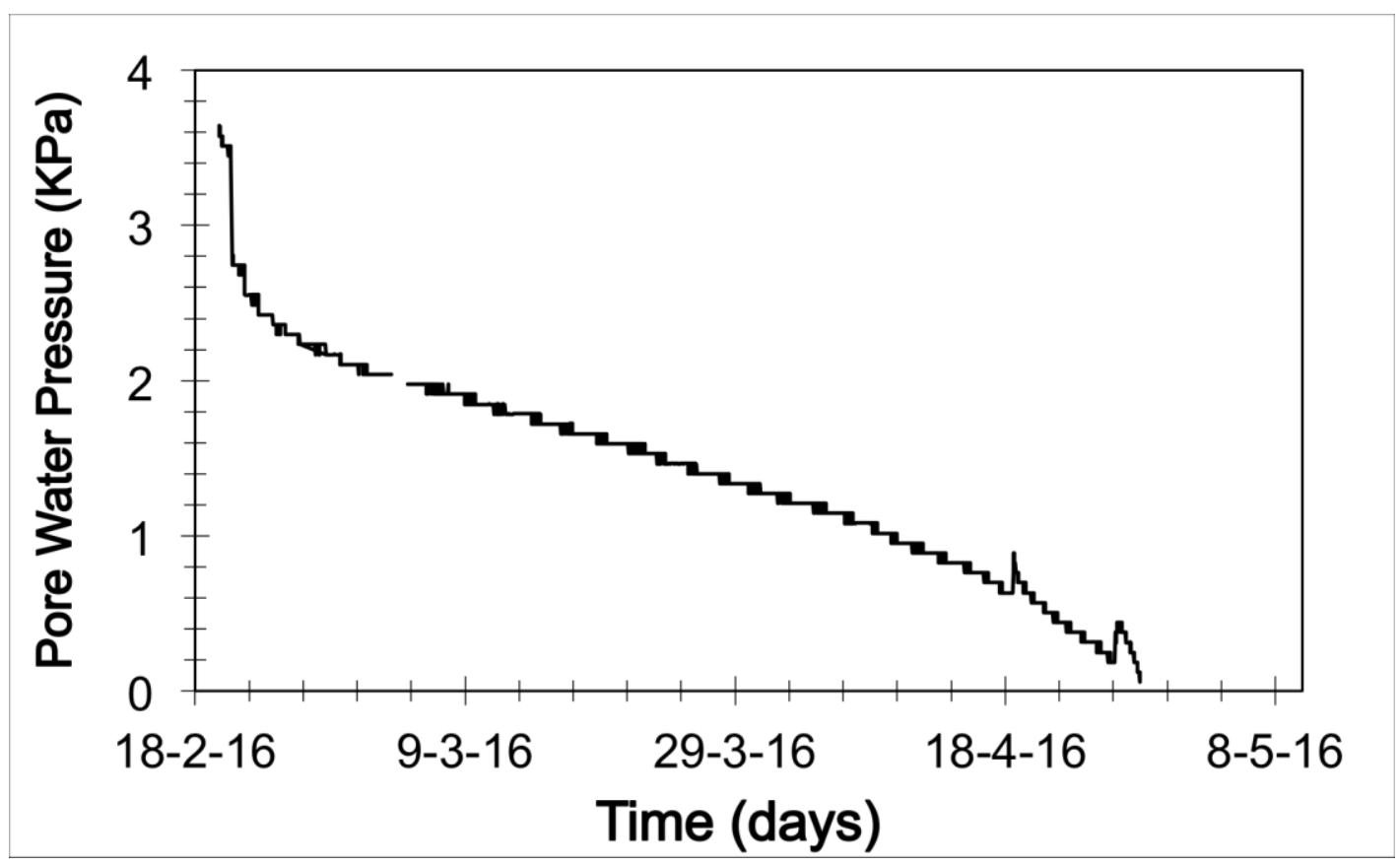

Figure 111. Tensiometer data for the $22.5 \mathrm{~cm}$ sensor during the first 36 days of the experiment.

Figure 112 shows pore water dissipation at a height of $5 \mathrm{~cm}$. Similar to the previous data set, there is a rapid dissipation of pore water pressure during the first 4 days of the experiment. The following days show an almost linear trend in pore water dissipation. As previously mentioned, the bottom part of the MFT column accumulated water and remained saturated due to the shrinkage of the top portion of the material. The presence of water in the tailings at this height $(5 \mathrm{~cm})$ slowed down the pore water dissipation of the tailings. Negative pore pressures developed almost at the end of the experiment reaching a magnitude of $-0.7 \mathrm{KPa}$. 


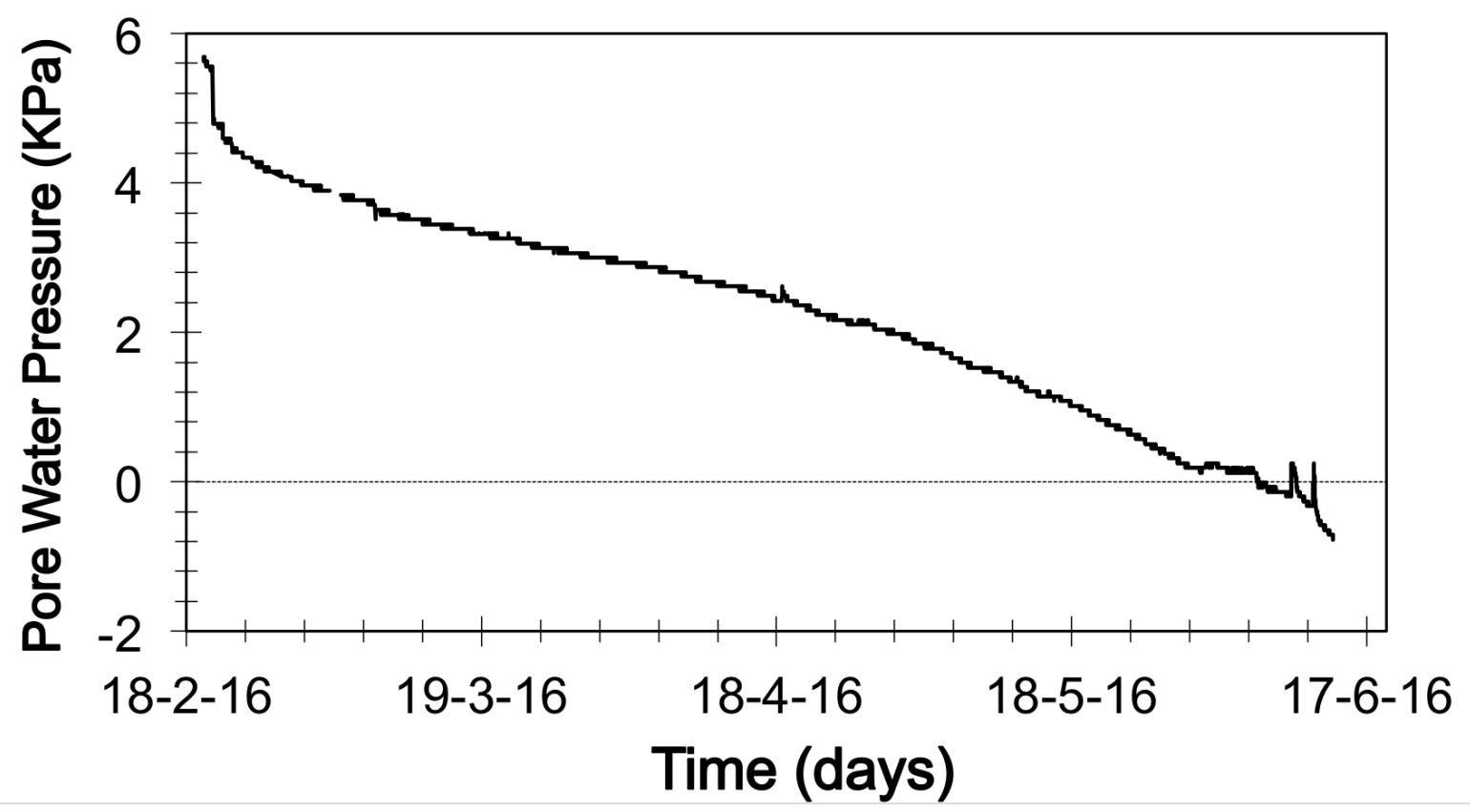

Figure 112. Tensiometer data at a height of $5 \mathrm{~cm}$ from the bottom.

Lastly, a total suction profile was obtained at the completion of the test, as seen in Figure 113. It shows higher suction values at the surface and they decrease with depth. 


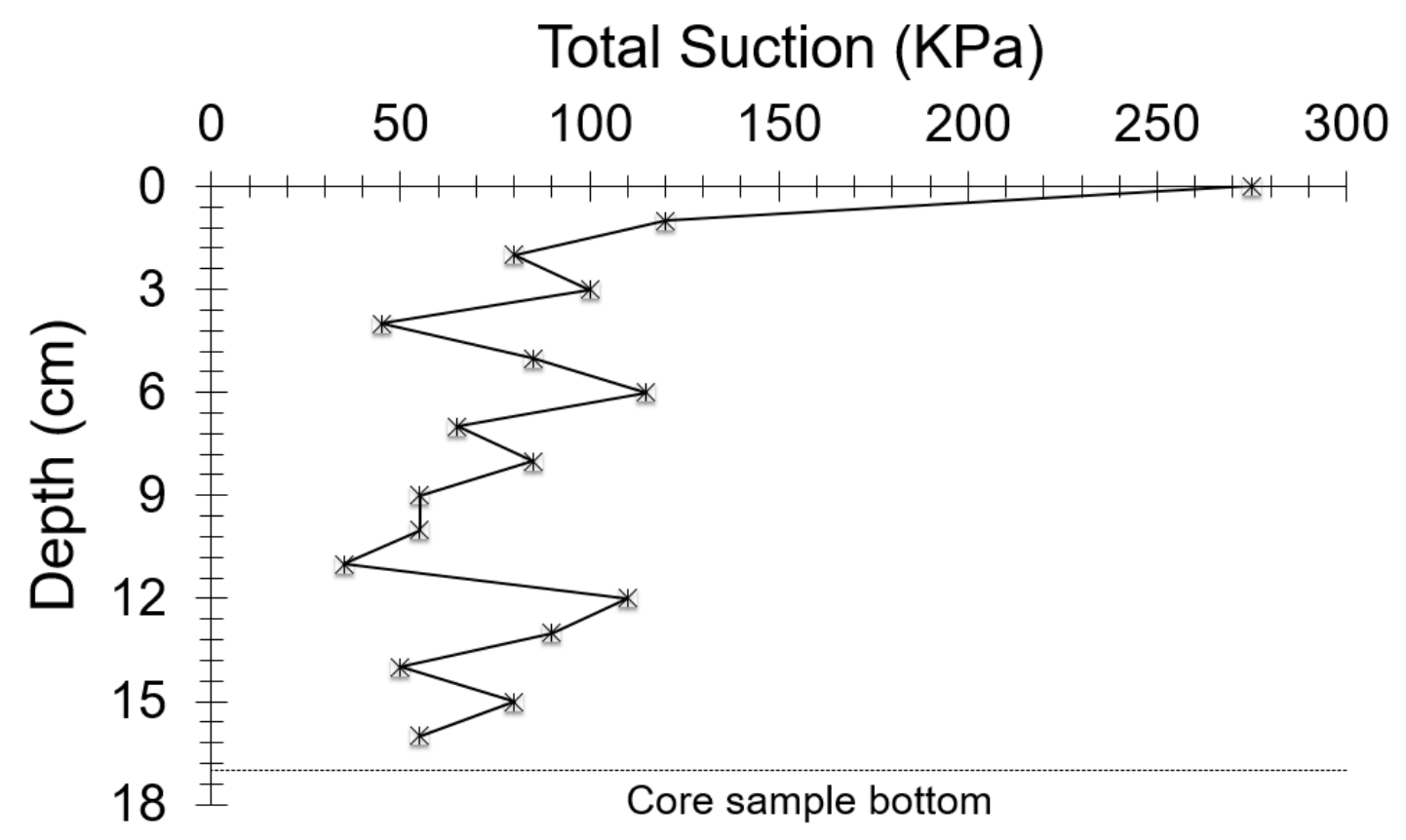

Figure 113. Total suction profile at completion of Column Test 2.

\subsubsection{Undrained Shear Strength}

A vane shear test was conducted at the end of the thawing phase to determine the undrained shear strength of the thawed tailings. Figure 114 shows the results obtained at intervals of $5 \mathrm{~cm}$. As seen in the figure below, the undrained shear strength decreases with depth. The material near the surface has been shown to have the biggest strength. 


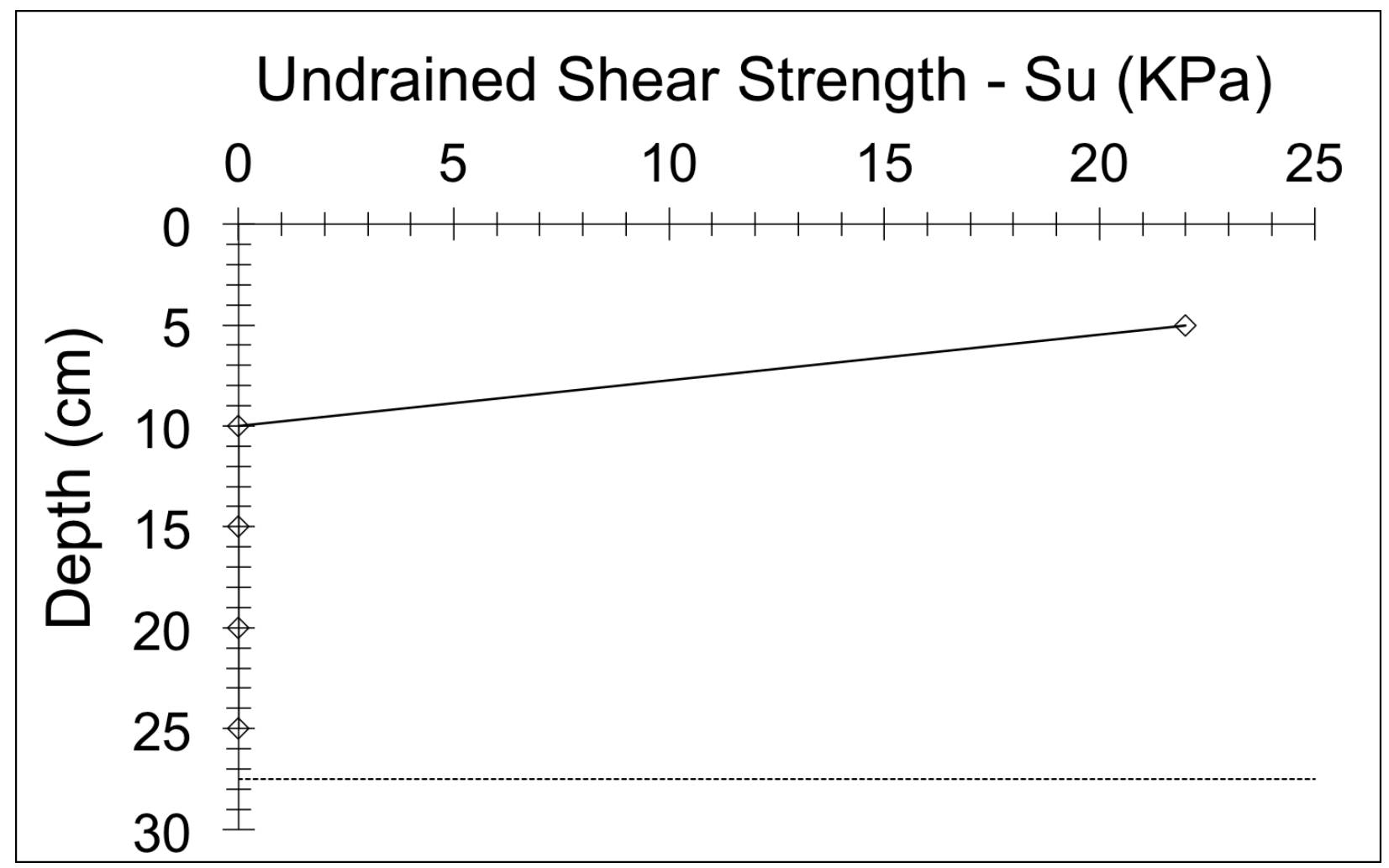

Figure 114. Vane shear test result for column test \#2.

\subsubsection{Consolidation Behaviour and Permeability}

The results of the oedometer tests performed on the MFT after the thawing phase are shown in Figure 115. Two tests were performed at different depths on a 17 cm core sample. The two samples at depths of $4.25 \mathrm{~cm}$ and $10.75 \mathrm{~cm}$ underwent selfweight consolidation only. 


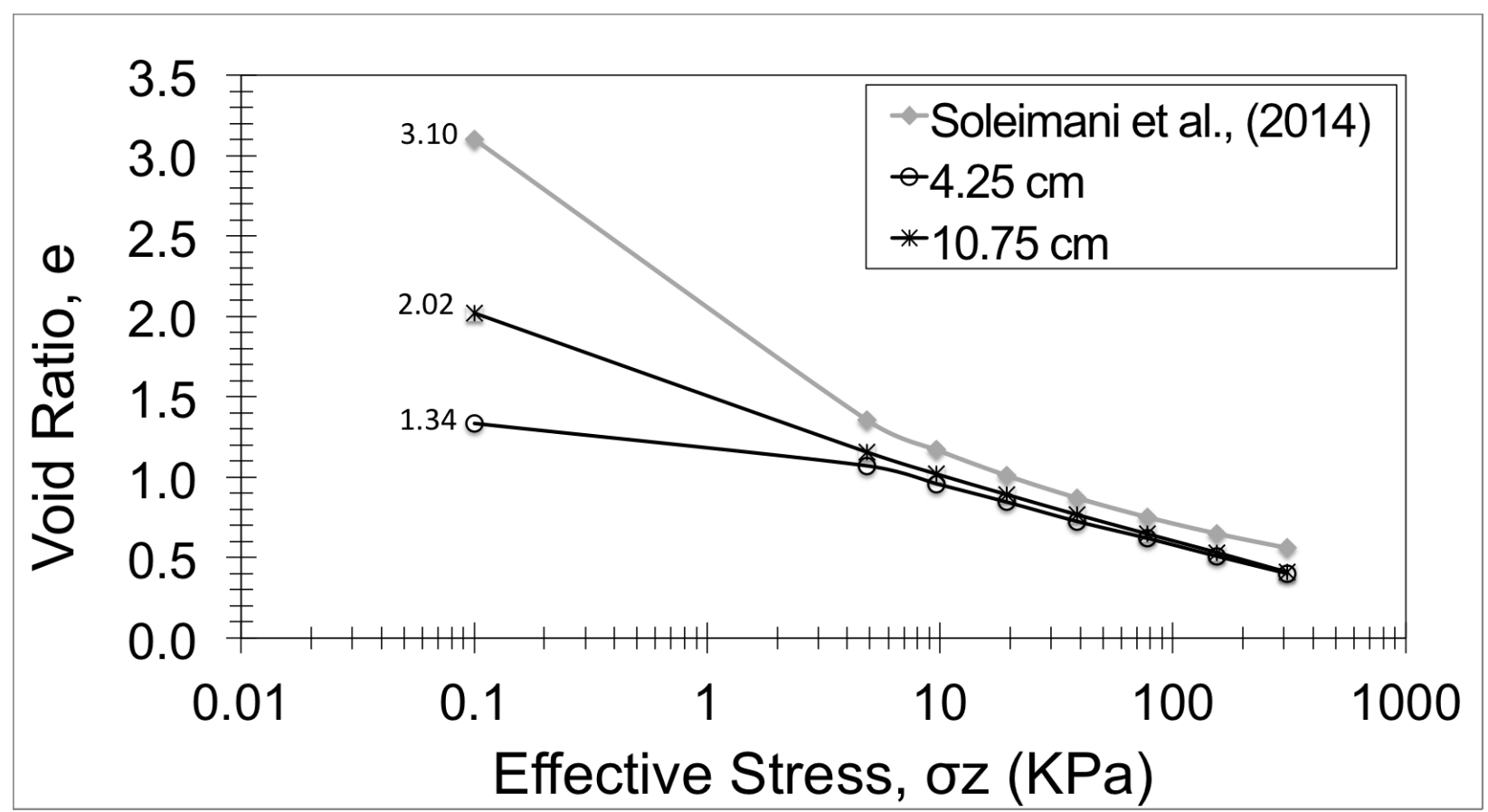

Figure 115. Void ratio vs effective stress for column test $\# 2$.

Even though the two samples were loaded equally, they exhibit slightly different consolidation properties, as seen in Table 19. The two samples show different values for initial water content, initial solids content, and initial void ratio. The percentage difference between these properties is $24.6 \%, 9.0 \%$, and $40.5 \%$, respectively. The variability of results can be attributed to the different thaw strains that both samples underwent and the degree of desaturation provoked by the shrinkage of the top portion of the MFT column. Moreover, both samples show similar void ratios at effective stresses greater than $10 \mathrm{KPa}$ demonstrating similar consolidation behaviour.

Furthermore, both samples show a decreasing trend in their compression index $(\mathrm{Cc})$ as well as a decrease in their initial void ratio values as effective stresses increase. 
These results are expected since the initial void ratio and the compression index are proportionally related (Nishida, 1956). When compared to data from Soleimani et al. (2014), which only had a self-weight consolidation with ambient drying phase as well, it is possible to see differences in the consolidation behaviour. Even though the material, polymer dosage $(650 \mathrm{mg} / \mathrm{Kg})$, and lift height $(0.5 \mathrm{~m})$ used by Soleimani et al. (2014) are similar to the one used in this experiment, there are differences in the evaporation and desiccation parameters that could account for the difference in results. The experiment by Sahar et al. (2014) lasted 35 days and it included a desiccation phase at the second half of the experiment, while column test \#2 lasted 115 days and evaporation was allowed. The longer self-weight consolidation period in column test \#2 allowed more water to leave the MFT column, which decreased the average void ratio and change the consolidation behaviour of the material. Also, it is important to point out that all the trends show parallel slopes at effective stresses greater than $10 \mathrm{KPa}$ meaning that they have similar compressibility rates.

Furthermore, Figure 116 shows the hydraulic conductivity of both samples. They were calculated using Terzaghi's consolidation theory. Most of the permeability values are lower than $10^{-9} \mathrm{~m} / \mathrm{s}$, except for the values corresponding to the last load increment. As expected, the hydraulic conductivity of the MFT increases as the void ratio increases in an approximate linear trend. The $10.75 \mathrm{~cm}$ sample shows similar hydraulic conductivity values to the $4.25 \mathrm{~cm}$ sample, except at the highest effective stresses the samples underwent where there seems to be a magnitude-of-10 difference between results. 
When comparing the obtained results with Soleimani et al., (2014), it is distinguishable that both sets of data differ in permeability values by two to four orders of magnitude at similar void ratios.

Table 19. Consolidation properties for column test \#2.

\begin{tabular}{|c|c|c|c|c|c|}
\hline Depth (cm) & $\begin{array}{c}\text { Initial Water } \\
\text { Content (\%) }\end{array}$ & $\begin{array}{c}\text { Initial Solids } \\
\text { Content(\%) }\end{array}$ & $\begin{array}{c}\text { Initial Void } \\
\text { Ratio, e。 }\end{array}$ & $\begin{array}{c}\text { Recompression } \\
\text { Index, Cr }\end{array}$ & $\begin{array}{c}\text { Compression } \\
\text { index, Cc }\end{array}$ \\
\hline 4.25 & 51.3 & 66.1 & 1.34 & 0.157 & 0.369 \\
\hline 10.75 & 65.7 & 60.4 & 2.02 & 0.514 & 0.407 \\
\hline
\end{tabular}

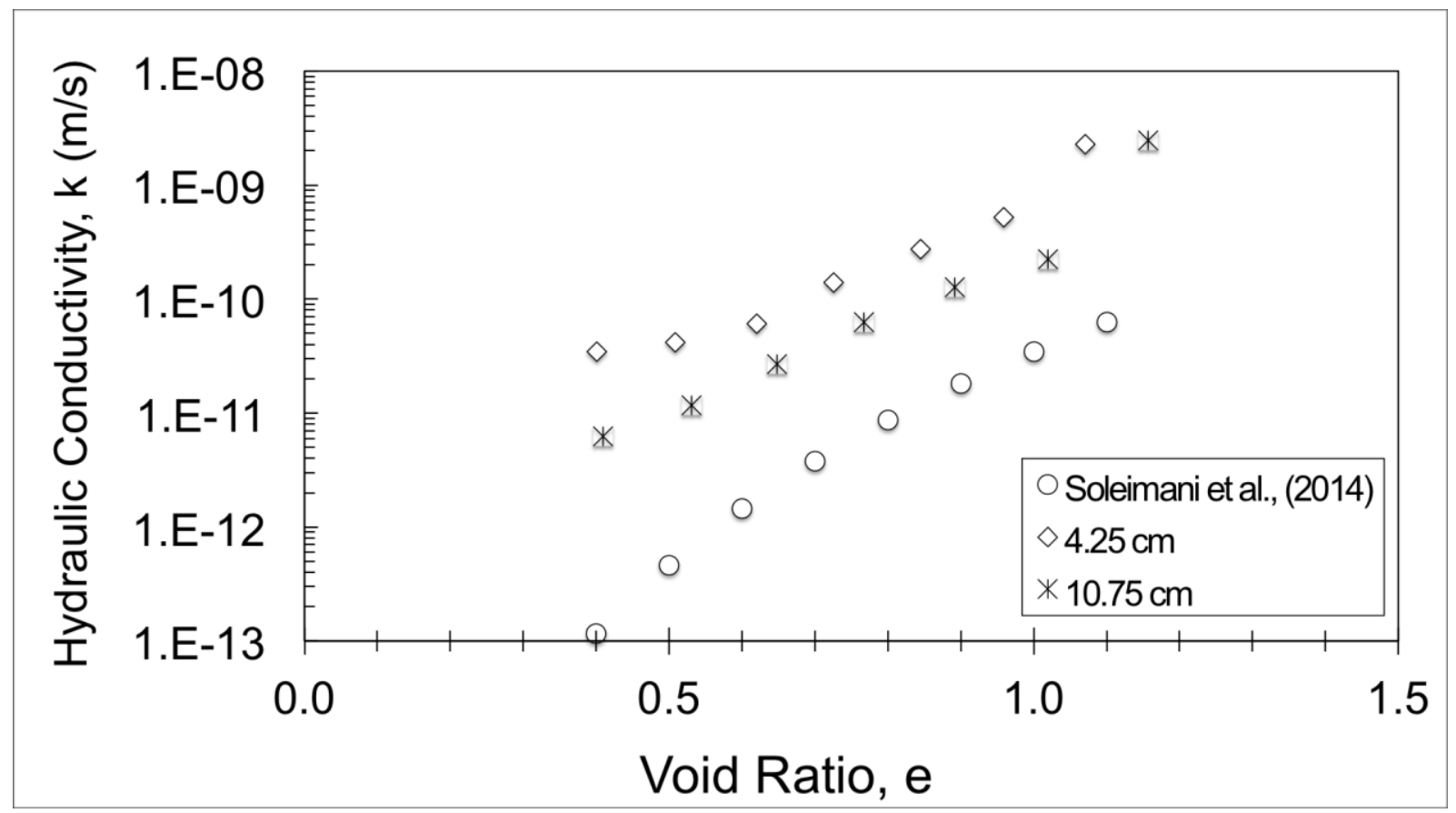

Figure 116. Permeability vs void ration for column test \#2. 
The complete data set obtained from all the consolidation tests is found on Appendix B.

\subsection{Column Test \#3: Self-Weight Consolidation with Ambient Drying, Accelerated Desiccation, and Freeze-Thaw Cycle}

\subsubsection{Temperature Profile}

Figure 117 shows the temperature profile of the MFT column at heights (from the bottom of the column) of $5 \mathrm{~cm}, 15 \mathrm{~cm}, 22.5 \mathrm{~cm}$ and at the surface. It also shows the locations of the surface sensor (yellow line) as the tailings consolidated. The figure presents the temperature changes that MFT column underwent during the self-weight consolidation with ambient drying phase, desiccation phase, freezing phase, and thawing phase.

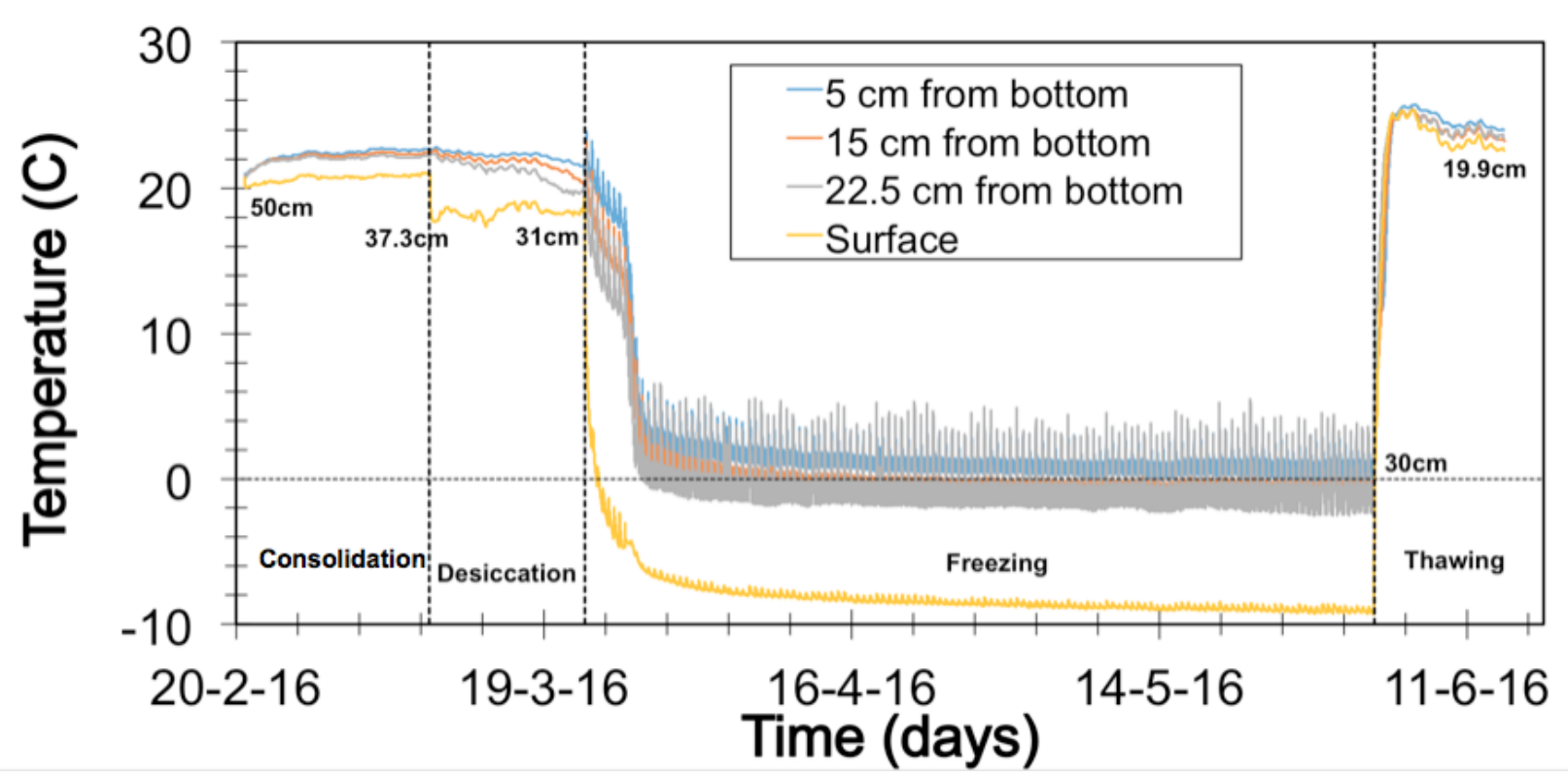

Figure 117. Temperature profile and surface sensor location for column test \#3. 
During the self-weight consolidation with ambient drying phase, the temperature of the tailings fluctuated along with the air temperature and remained relatively constant. As seen in column test $\# 2$, the surface temperature varies by a few degrees Celsius when compared to the internal temperature of the tailings. The temperature within the tailings (at height of $5 \mathrm{~cm}, 15 \mathrm{~cm}$, and $22.5 \mathrm{~cm}$ ) remains almost the same throughout the experiment. However, the surface temperature constantly varies by $1.5^{\circ} \mathrm{C}-2{ }^{\circ} \mathrm{C}$ from the rest of the MFT column. The difference in temperature can be attributed to the volumetric heat capacity of the tailings. Furthermore, the temperatures present during this phase fluctuated within the low $20 \mathrm{~s}{ }^{\circ} \mathrm{C}$ range, having recorded a maximum temperature of $22.7^{\circ} \mathrm{C}$ and a lowest temperature of $20.5^{\circ} \mathrm{C}$.

The next phase, desiccation, is highlighted by the decrease in temperature due to the introduction of a fan to accelerate the evaporation rate. The drop in temperature is attributed to the increase in the evaporation rate. As water vapour keeps leaving the system, the net radiation in the form of heat is consumed by the evaporation process itself leading to a drop in surface temperature (Qiu and Ben-Asher, 2010), as seen in Figure 117. The surface temperature decreases almost instantly at the introduction of the fan, while the temperature at other heights took longer time to respond. Surface temperature dropped from $20.9{ }^{\circ} \mathrm{C}$ to $18.4{ }^{\circ} \mathrm{C}$. It was during this period where the top portion of the tailings shrunk significantly (Figure 118) due to the accelerated evaporation. 


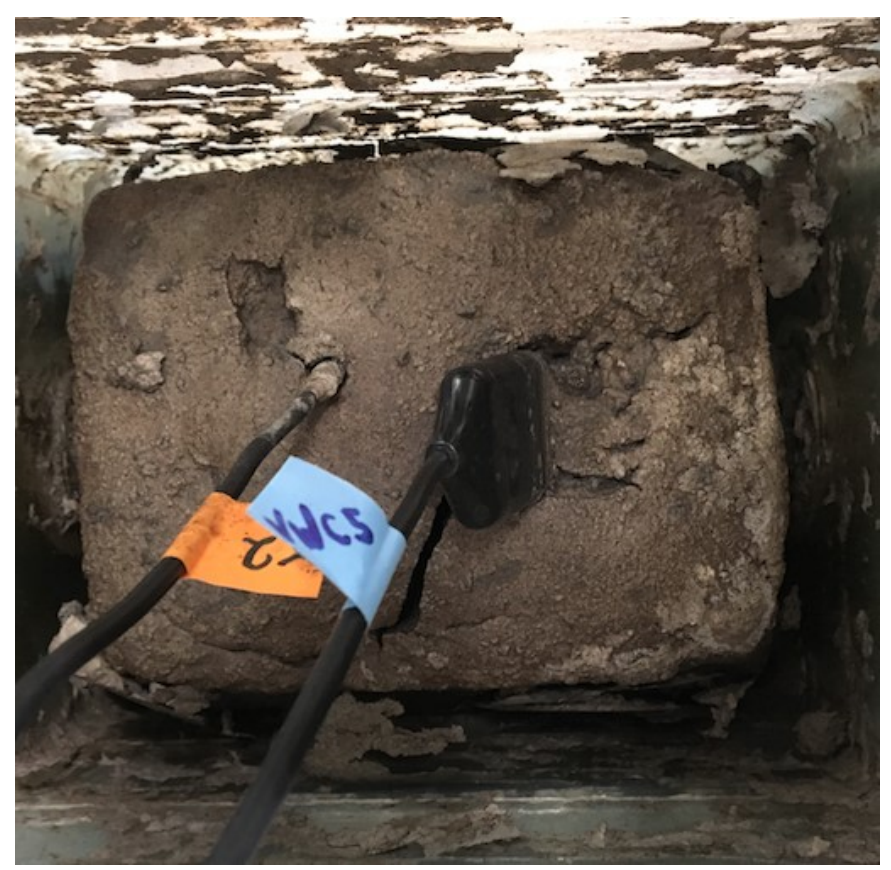

Figure 118. Top portion of the MFT column at the end of the desiccation phase (column test \#3).

During the freezing phase the MFT column was enclosed within its insulating case and placed inside the fridge. The freezing process was steady and large fluctuations were not recorded as in the case of column test \#1 prior the introduction of the fridge. The freezing rate has a steep slope for the first 10 days and a flatter slope afterwards. Similar to column test \#1, the one-dimensional freezing process itself took several weeks to be achieved. Even though the interface between the MFT and the cooling plate remained at a constant $-15{ }^{\circ} \mathrm{C}$ during the freezing phase, the tailings below the surface did not show a rapid drop in temperature. Henry (2007) describes these differences in temperature between the surface and the soil below as being representative of the field. While the surface of the soil sample undergoes similar temperatures to the air temperature, the material below the surface does not experience 
the same temperature. This is in contrast to smaller samples being frozen too quickly and experience drastic temperature changes that could lead to exaggeration of their freeze-thaw behaviour. This could explain the large variation of results found in the literature. Also, the oscillating pattern in the temperature trend was observed again during the freezing phase. This oscillation is attributed to the refrigeration cycle of the fridge. Once the sensor located at a height of $5 \mathrm{~cm}$ recorded a temperature of $0{ }^{\circ} \mathrm{C}$, the freezing phase concluded. It took 71 days to one-dimensionally freeze $11,220 \mathrm{~cm}^{3}(30$ $\mathrm{cm} \times 22 \mathrm{~cm} \times 17 \mathrm{~cm}$ ) of polymer amended MFT.

Lastly, during the thawing phase the MFT rapidly equilibrated itself with the air temperature. In a span of 11 days the temperature of the MFT went from below $0{ }^{\circ} \mathrm{C}$ to low $20 \mathrm{~s}{ }^{\circ} \mathrm{C}$ at a fast rate. At the end of the thawing phase, the sensor located at $22.5 \mathrm{~cm}$ was left exposed to the air since the MFT tailings settled to a height of $19.9 \mathrm{~cm}$.

\subsubsection{Settlement, Water Loss, and MFT Densification}

Figure 119 shows the measured height of the tailings throughout the experiment. These measurements do not account for the supernatant water cover thickness produced by the tailings the first two weeks of the experiment. Similarly to the two previous column tests, the change in height is due to self-weight consolidation of the tailings, which is driven by water loss in the form of evaporation and underdrainage. 


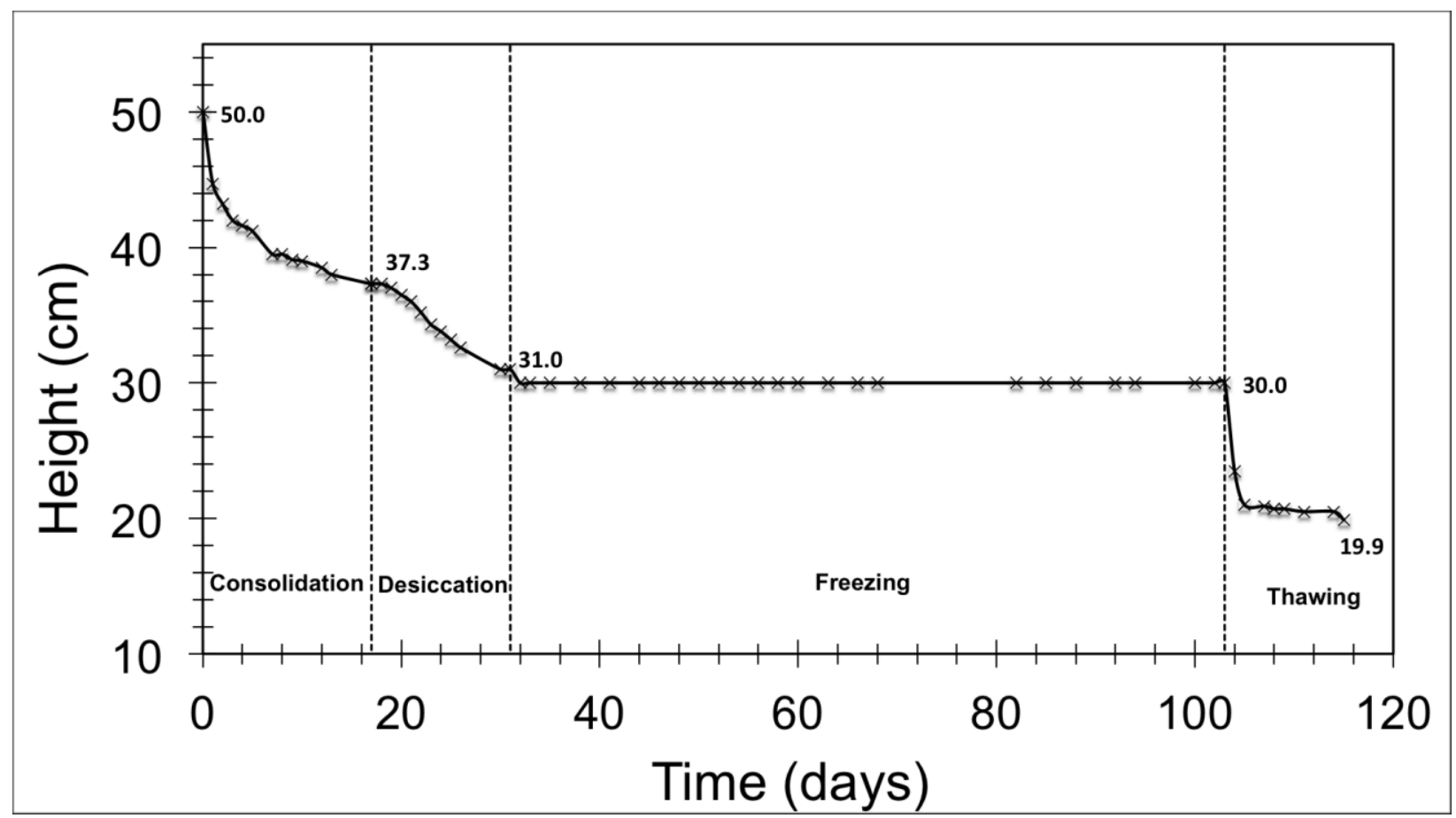

Figure 119. Height changes over time in column test \#3.

During the self-weight consolidation with ambient drying phase, the tailings settled down on an almost steady and parabolic-shaped trend. The initial height of the MFT column was $50 \mathrm{~cm}$ and it decreased to a height of $37.3 \mathrm{~cm}$ in 13 days. The major factors for self-weight consolidation at this initial stage are under-drainage, supernatant water from the first two weeks of the experiment, and evaporation. During the desiccation phase, the tailings settled in an almost linear fashion. The change in height went from $37.3 \mathrm{~cm}$ to $31 \mathrm{~cm}$ on a 14-day period. Consequently, prior to the freezing phase, the tailings initially started with $31 \mathrm{~cm}$ of MFT; however, to properly ensure the contact between the cooling plate and the tailings, the MFT column height was shortened to $30 \mathrm{~cm}$. The tailings froze over 71 days and no change in height was measured. Ice build-up was encountered but it did not reduce the height of the tailings 
since it was mostly found around the surface, as seen in Figure 120. During the thawing phase, the ice channels within the tailings melted and promoted further water release. The column's height decreased form $30 \mathrm{~cm}$ to $19.9 \mathrm{~cm}$. Similarly to the self-weight consolidation with ambient drying phase, under-drainage and evaporation drove the decrease in height throughout this phase.

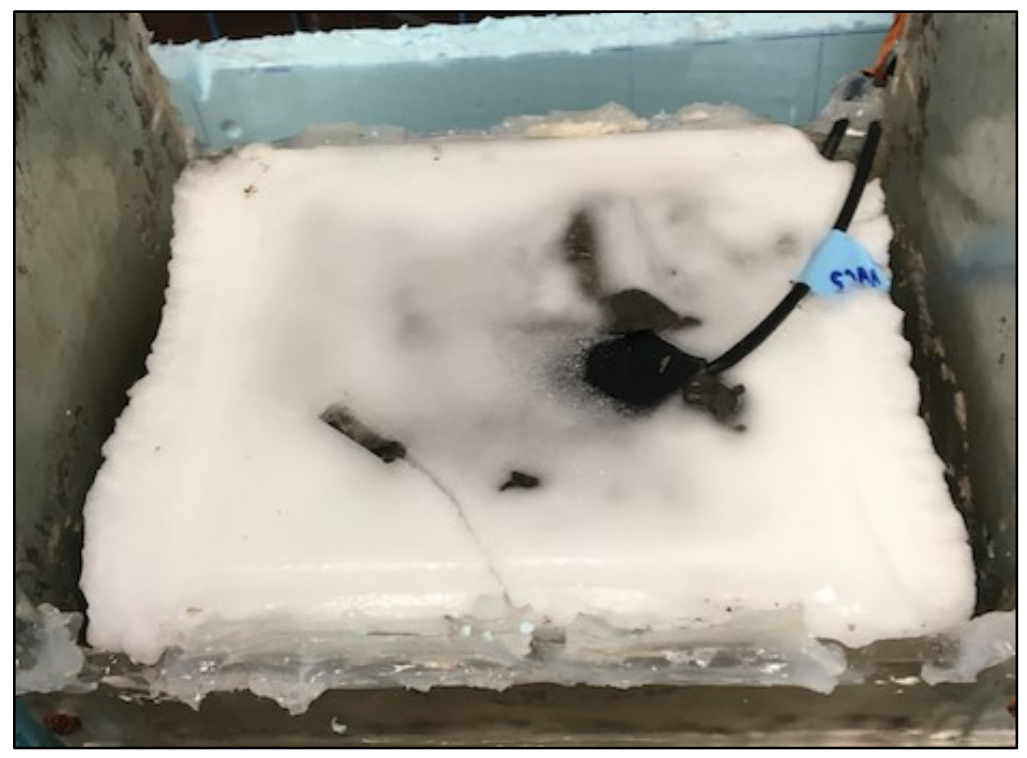

Figure 120. Ice build-up on and around MFT column (column test \#3).

Furthermore, the MFT's total water loss was calculated by measuring the loss of water due to drainage and evaporation. The actual evaporation was calculated by subtracting the drainage water from the total weight loss measured by an electronic scale on a daily basis. Figure 121 shows the contributions of drainage and evaporation to the total water loss throughout all the phases. 


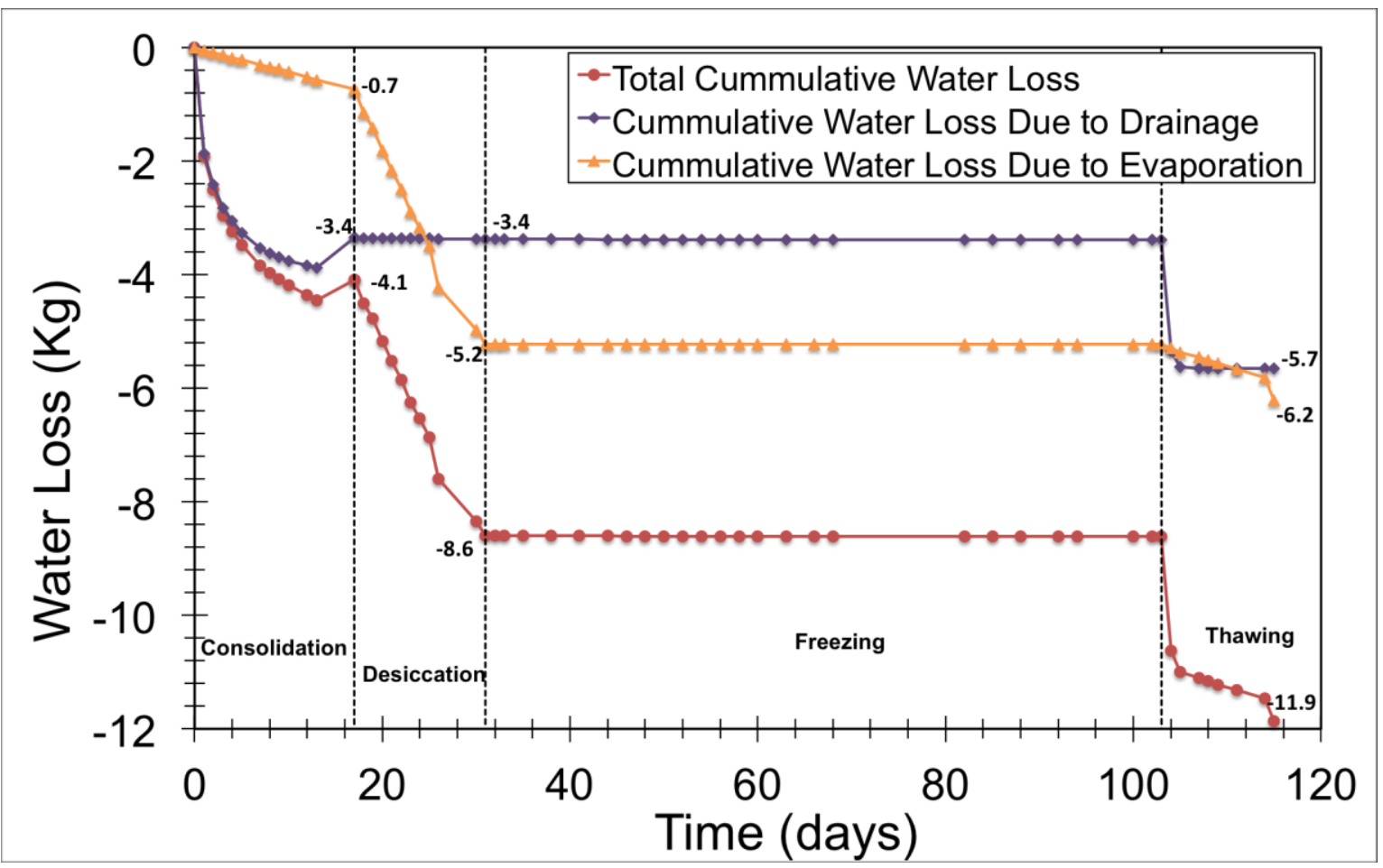

Figure 121. Water loss due to drainage and evaporation over time (column test \#3).

Approximately $12 \mathrm{~kg}$ of water were released from the MFT, which is roughly $54 \%$ of the initial weight of the MFT column. Figure 121 shows steady dewatering from both, drainage and actual evaporation, during the self-weight consolidation with ambient drying phase. This type of behaviour in polymer-amended MFT in dewatering due to self-weight consolidation has also been reported by Rozina et al. (2015). Drainage is the dominant dewatering process during this phase since evaporation only contributed to $0.7 \mathrm{~kg}$ out of the total $3.4 \mathrm{~kg}$ of dewatered water. The rate of evaporation at during the self-weight consolidation was $43.5 \mathrm{gr} / \mathrm{day}$. At the end of the self-weight consolidation with ambient drying phase there is a decrease in the "water loss due to drainage' trend. This occurred because supernatant water was added to the system to 
measure the actual evaporation rate prior the desiccation phase. The self-weight consolidation with ambient drying phase was stopped after two weeks. As seen in Figure 121, evaporation was the dominant, if not only, dewatering process during the desiccation phase. Approximately, $4.5 \mathrm{~kg}$ of water were removed from the system due to evaporation. The evaporation rate during the desiccation phase was $320 \mathrm{gr} /$ day. Drainage at the bottom did not occurred during this phase. Once again, cracking at the surface did not occur but the top section of the MFT column shrunk noticeably (Figure 118). Consequently, during the freezing phase, drainage became the only dewatering mechanism. However, only 14 grams of water were drained. This type of behaviour was expected since large amounts of water were evaporated away from the system during the desiccation phase and the remainder water inside the MFT column was likely to be moving up towards the freezing front and not down towards the drainage system. No evaporation occurred since the surface of the tailings was completely covered by the cooling plate. Lastly, during the thawing phase, drainage and evaporation were present as dewatering mechanism. The evaporation rate during this phase was $53.6 \mathrm{gr} /$ day. Approximately $2.3 \mathrm{~kg}$ of water were drained and $1 \mathrm{~kg}$ of water evaporated during thus phase.

As a consequence of constant dewatering throughout the four phases of this experiment, the solids content changed as well. Densification of the tailings was back calculated using the total change in weight due to water loss and the initial mass of solids, which are assumed to be unchanged throughout the experiment. Figure 122 shows the evolution of the average solids content in the MFT column. 


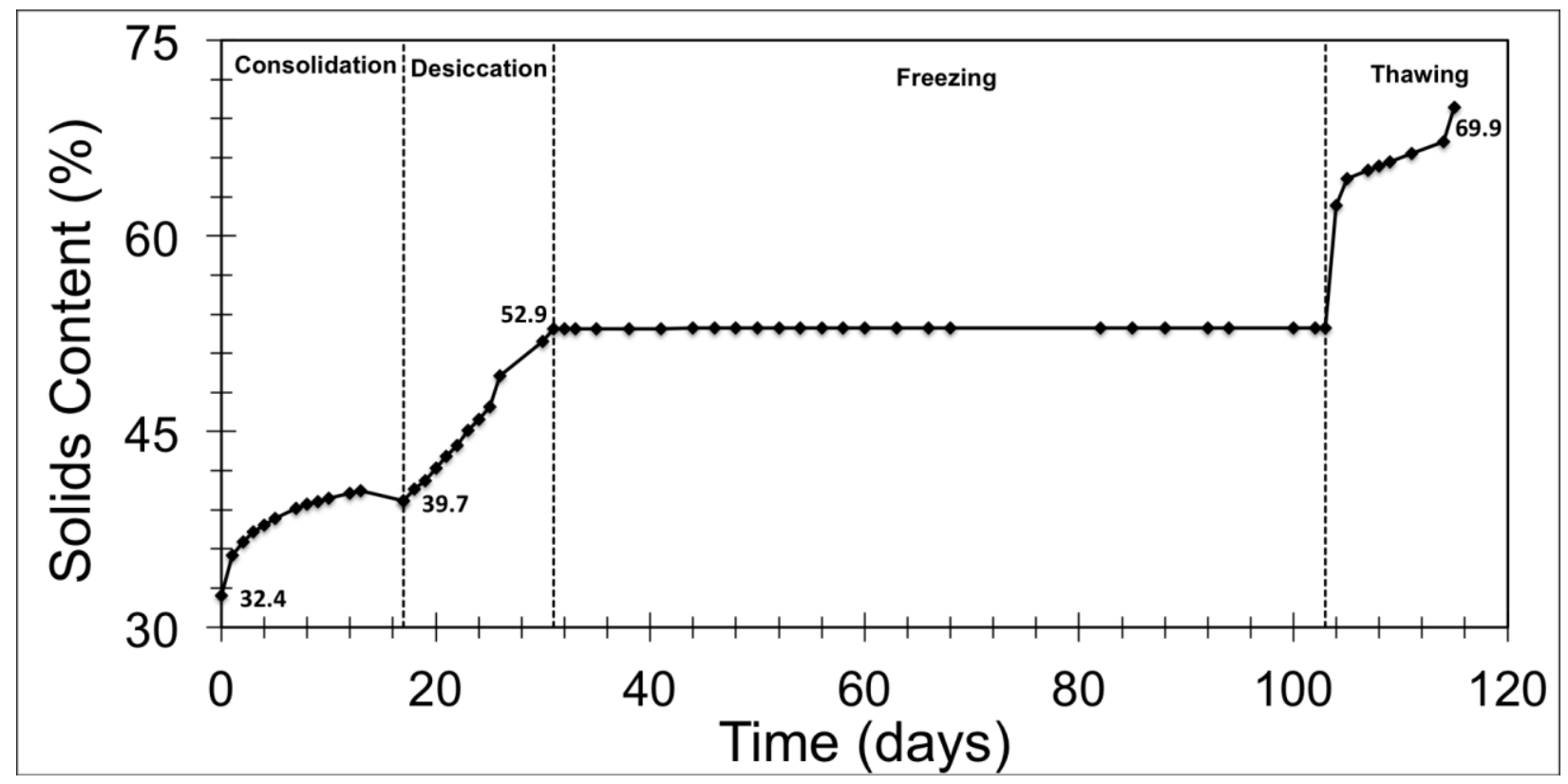

Figure 122. Solids content development over time for column test \#3.

The change in solids content shows a similar trend when compared to the change in water loss since they are correlated (Fig. 121). At deposition, the initial solids content was $32.4 \%$ and at the end of the consolidation and desiccation phase the solids content increased to $39.7 \%$ and $52.9 \%$, respectively. Additionally, at the end of the thawing phase, solids content was calculated to be approximately $69.9 \%$. That is an increase of $37.5 \%$ overall, which is reflected as an increase in tailings' strength (discussed in Section 4.6.6). Furthermore, the final average solids concentration of the MFT was compared with actual measurements at the termination of the experiment. A profile of solids content was obtained at the termination of the experiment (Figure 123), which yielded an average of $70.6 \%$ solids content agreeing with the back-calculated value. Also, two solids content values were taken from the surface, A and B. Sample A 
belonged to a dry surface tailings $(\mathrm{SC}=90.6 \%)$ and sample $\mathrm{B}$ to moister tailings $(\mathrm{SC}=$ $78.3 \%)$

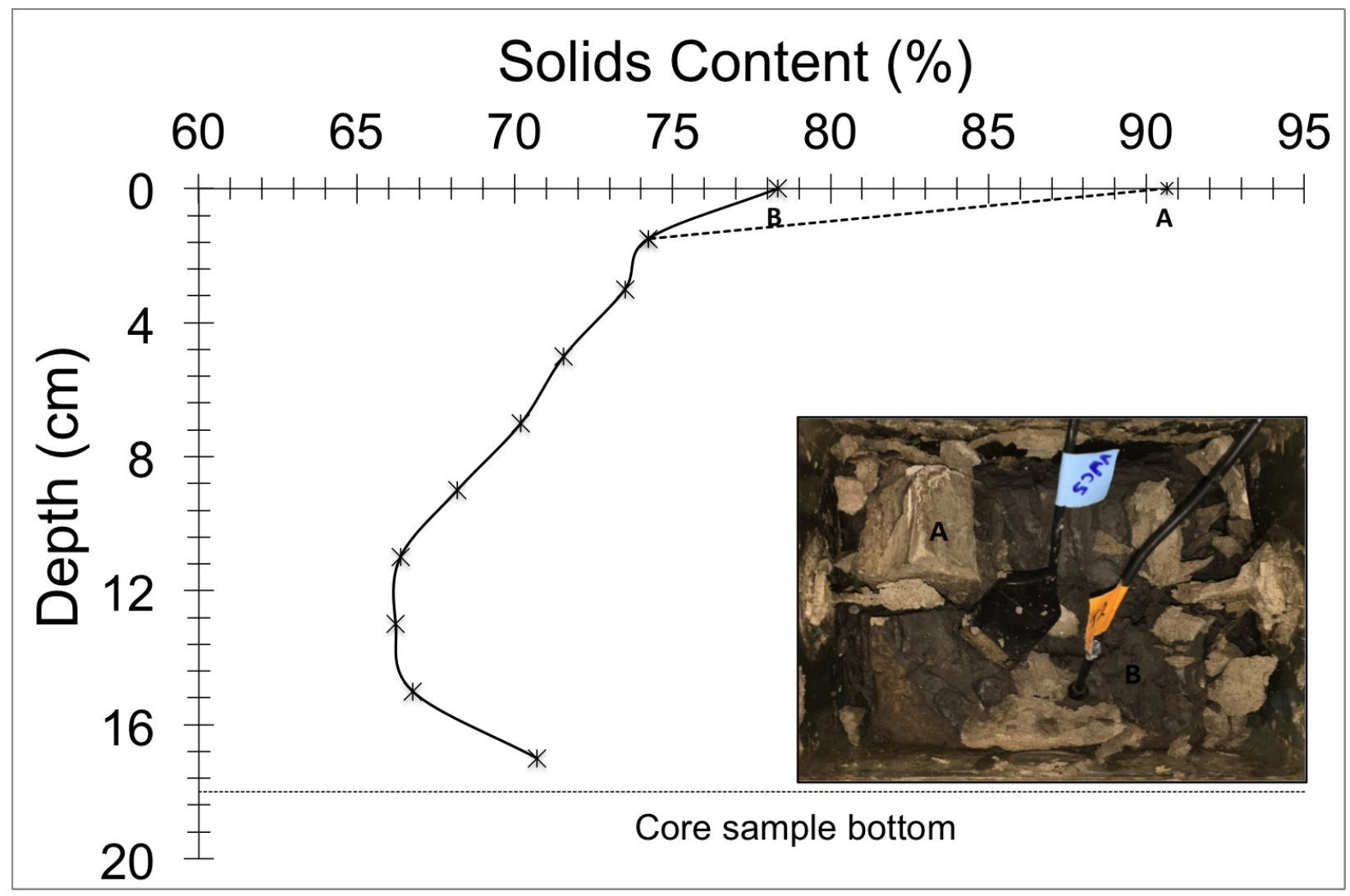

Figure 123. Solids content profile at the end of column test \#3.

Figure 124 shows the dewatered state of the tailings' surface during all the phases. After the thawing phases ended, it is possible to see how the tailings eroded at the surface. Ferrick and Gatto (2005) stated that erosion at the surface is enhanced when water content is high, which is the case of MFT. 

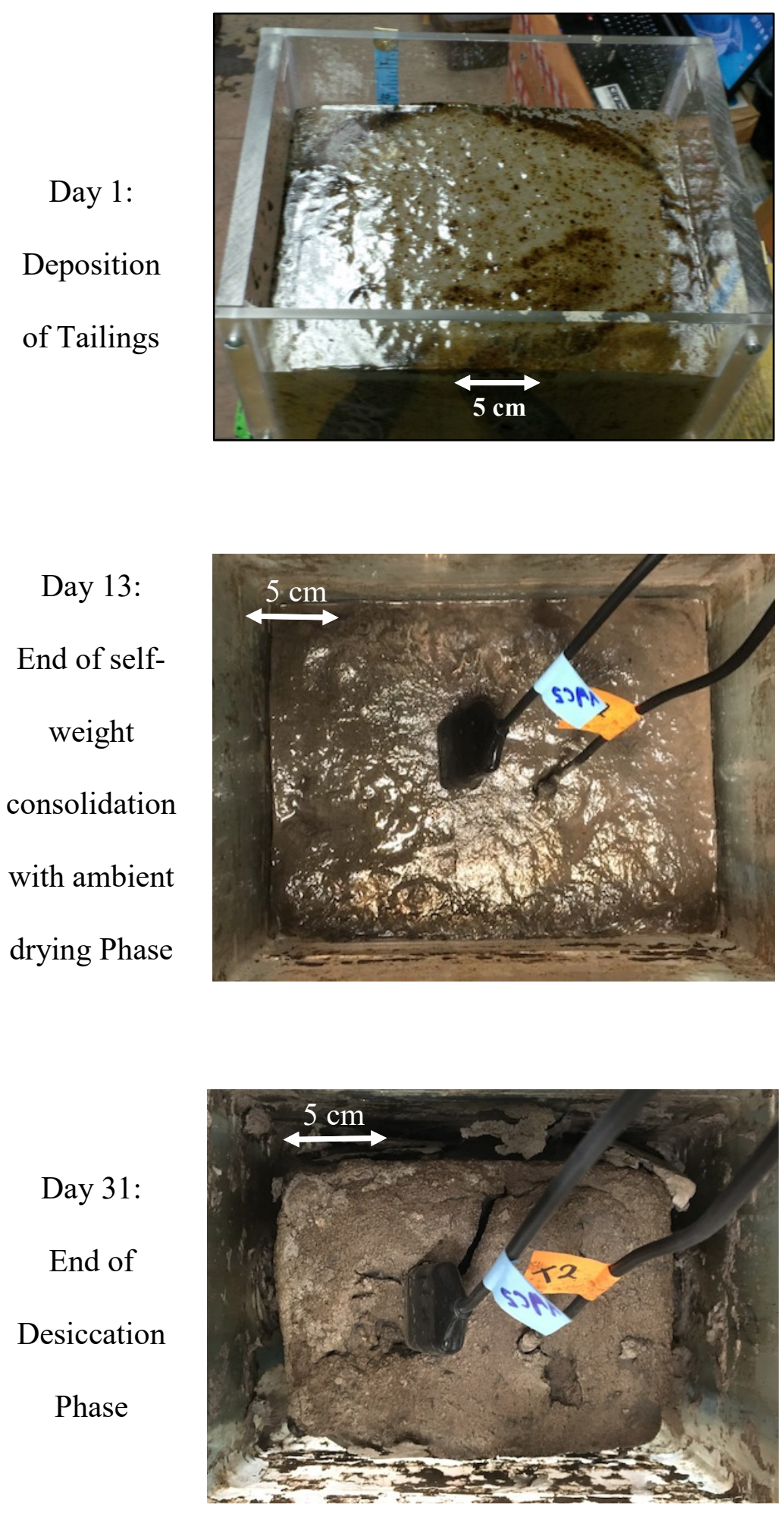

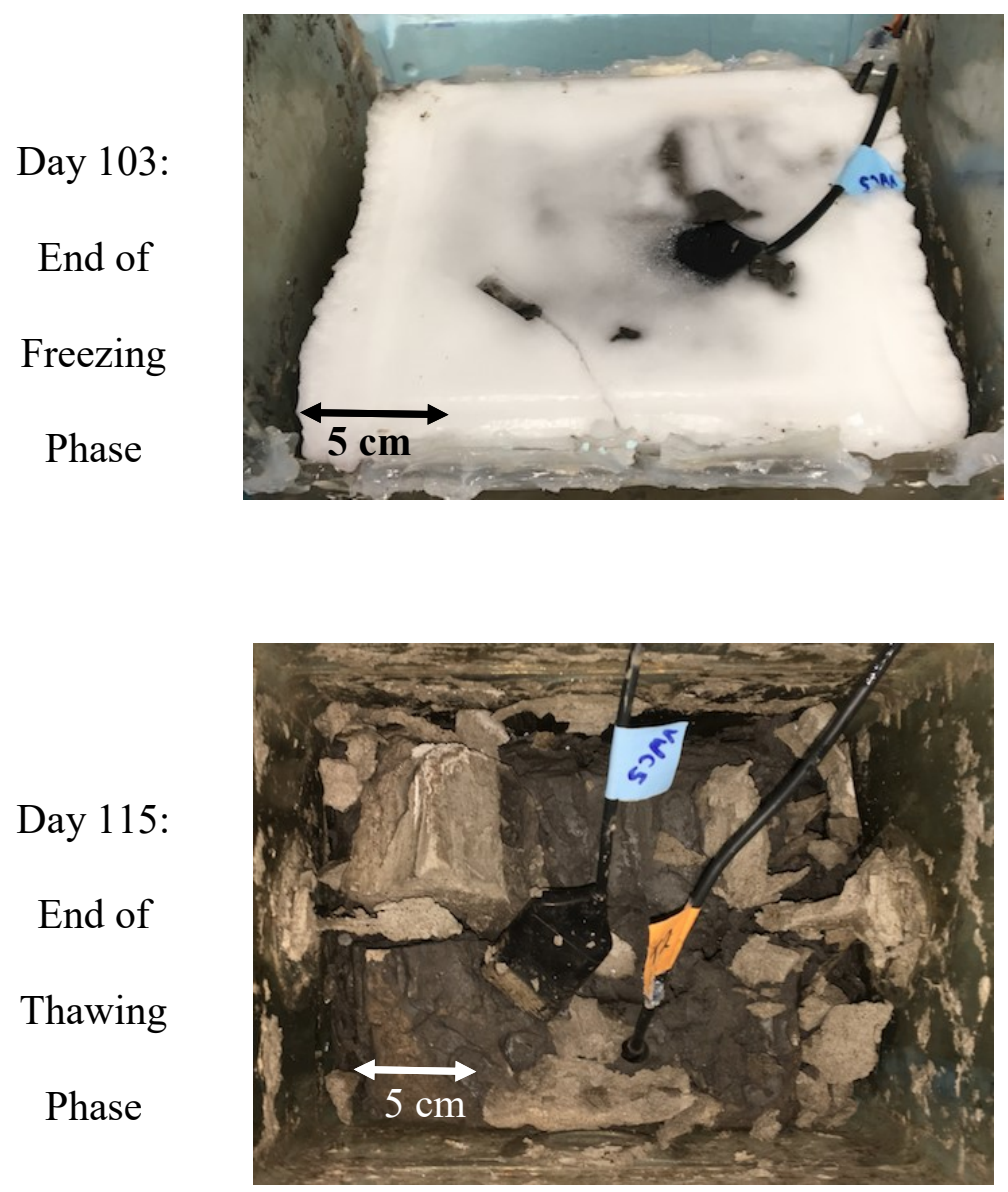

Figure 124. Surface changes at different phases in column test \#3.

\subsubsection{Water Content Profile}

As discussed in Chapter 3, not only there is water movement due to self-weight consolidation and thawing but there is also water migration during freezing within the tailings. Figure 125 shows the volumetric water content readings recorded during the column test at height of $5 \mathrm{~cm}, 15 \mathrm{~cm}, 22.5 \mathrm{~cm}$, and at the surface. The surface sensor's height throughout column test \#3 is also recorded in Figure 125. 


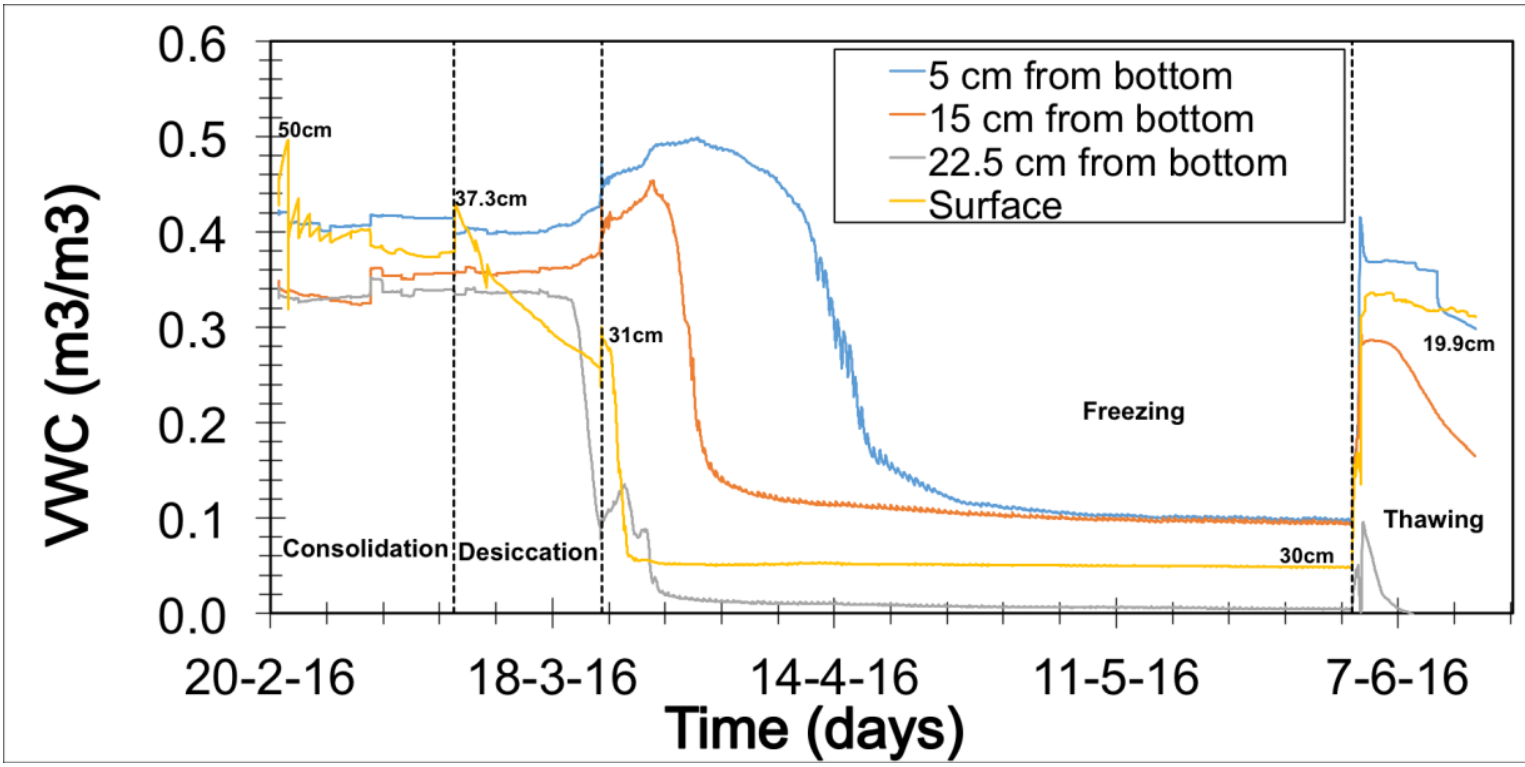

Figure 125. Volumetric water content profile and surface height location during column test \#3.

As seen in the figure above, the volumetric water content readings have a decreasing trend for all the sensors during the first half of the self-weight consolidation with ambient drying phase. During the second half, the sensors located at $5 \mathrm{~cm}, 15 \mathrm{~cm}$ and $22.5 \mathrm{~cm}$ from the bottom show a slight increase in water content, while the water content at the surface continues decreasing as the surface is constantly evaporating. During the desiccation phase, the water content readings at the surface drop significantly from $0.428 \mathrm{~m}^{3} / \mathrm{m}^{3}$ to $0.269 \mathrm{~m}^{3} / \mathrm{m}^{3}$. The water content at a height of 22.5 $\mathrm{cm}$ drops during the last few days of this phase from $0.329 \mathrm{~m}^{3} / \mathrm{m}^{3}$ to $0.104 \mathrm{~m}^{3} / \mathrm{m}^{3}$. This drastic reduction in water content could be attributed to the drying of the tailings as the evaporation rate was increased but since the drop is higher than the surface water content drop it is possible that the readings might have been misleading. As the top portion of the MFT column shrunk, a section of the $22.5 \mathrm{~cm}$ sensor was exposed to air, 
which could exaggerate the drop in water content. On the other hand, the bottom two sensors $(5 \mathrm{~cm}$ and $15 \mathrm{~cm})$ recorded an increase in volumetric water content during the desiccation phase. Since the top portion of the MFT reduced its volume significantly due to drying, water started to accumulate at the bottom of the column. The accumulated water could account for the increase in water content. During the freezing phase, water content at the surface had a steep drop since phase change of water from liquid to solid was occurred. Initially, water content at a height of $22.5 \mathrm{~cm}$ increased to $0.128 \mathrm{~m}^{3} / \mathrm{m}^{3}$. This could be due to the migration of water from the lower section of the column towards the freezing front. Eventually, water content at this height dropped to $0.007 \mathrm{~m}^{3} / \mathrm{m}^{3}$ due to liquid water turning into ice. The same can be said about the bottom two sensors $(5 \mathrm{~cm}$ and $15 \mathrm{~cm})$. Both showed an increase in water content $(0.496$ $\mathrm{m}^{3} / \mathrm{m}^{3}$ and $0.446 \mathrm{~m}^{3} / \mathrm{m}^{3}$, respectively) followed by a drop $\left(0.094 \mathrm{~m}^{3} / \mathrm{m}^{3}\right)$ as the freezing front advanced. The distribution of water is reversed during the thawing phase. As ice melts, some water leaves the column in the form of under-drainage and some water is retained by the tailings. The pore water is redistributed within the tailings but unlike column test $\# 1$, more water is found at the bottom of the column. At a height of $5 \mathrm{~cm}$ the water content value is the highest $\left(0.369 \mathrm{~m}^{3} / \mathrm{m}^{3}\right)$. At this point the $22.5 \mathrm{~cm}$ sensor is completely exposed to the air since the tailings settled past this height making its readings inaccurate. The same can be said about the $15 \mathrm{~cm}$ sensor. A portion of the sensor was exposed to air, which exaggerates the water content readings. The surface water content at the end of the thawing phase slowly decreased to $0.317 \mathrm{~m}^{3} / \mathrm{m}^{3}$ from $0.333 \mathrm{~m}^{3} / \mathrm{m}^{3}$ as water evaporated. 
Lastly, a gravimetric water content profile at the termination of the test was obtained (Figure 126). This profile also confirms the sensor readings for water distribution within the tailings having the lower section of the column with higher water contents than the surface.

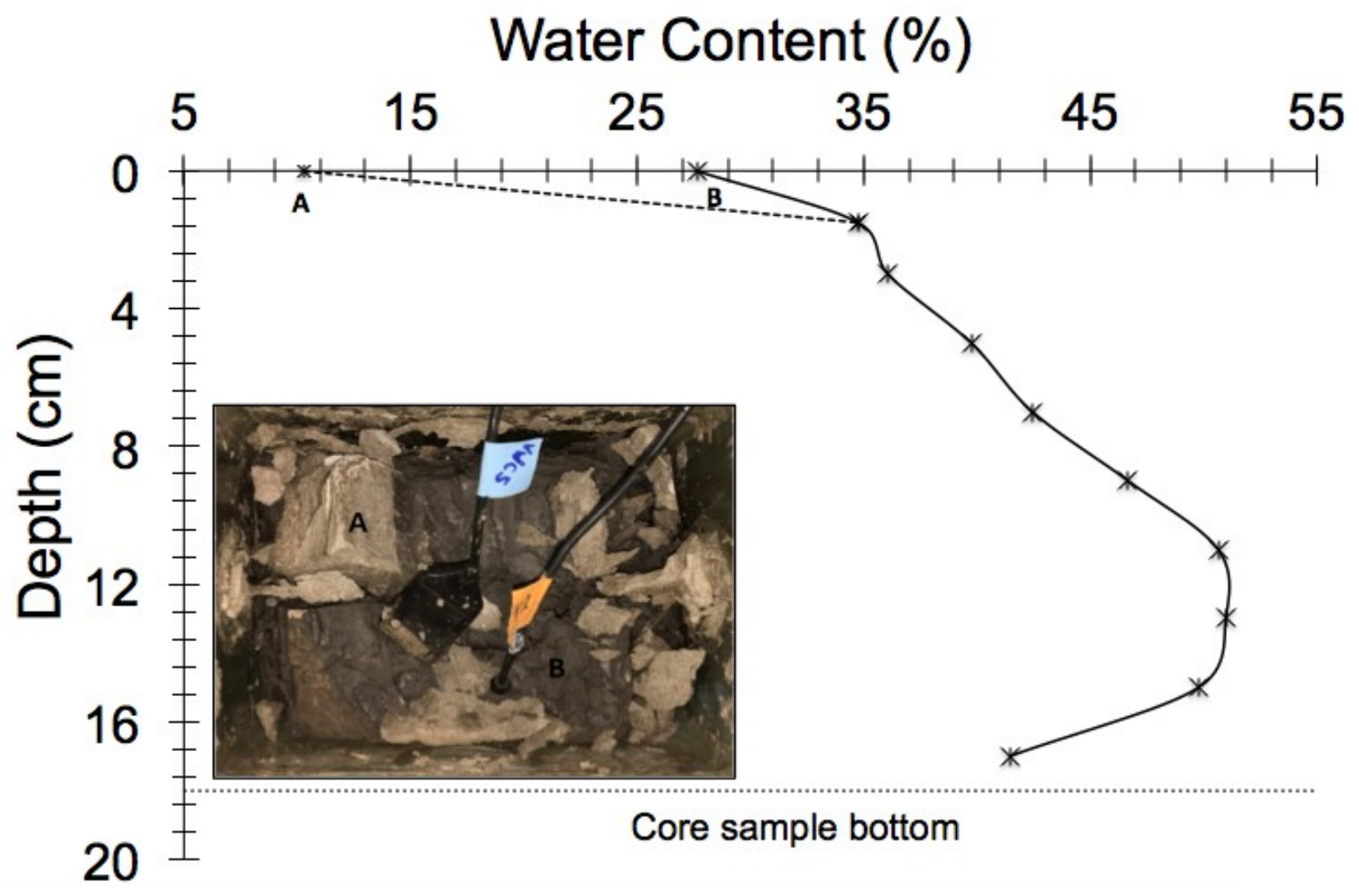

Figure 126. Gravimetric water content profile obtained at the end of the thawing phase (column test \#3).

\subsubsection{Unfrozen Water Content and Temperature}

As previously stated (Section 2.7), unfrozen water content is still present in frozen soils because of its lowered freezing point. The presence of matric suctions 
within the soil particles and the ice lower the energy status of the liquid water, which in effect lowers its freezing point (Egbert et al., 1996). Figure 127 shows the measured unfrozen water content with respect to the soil temperature at different heights.

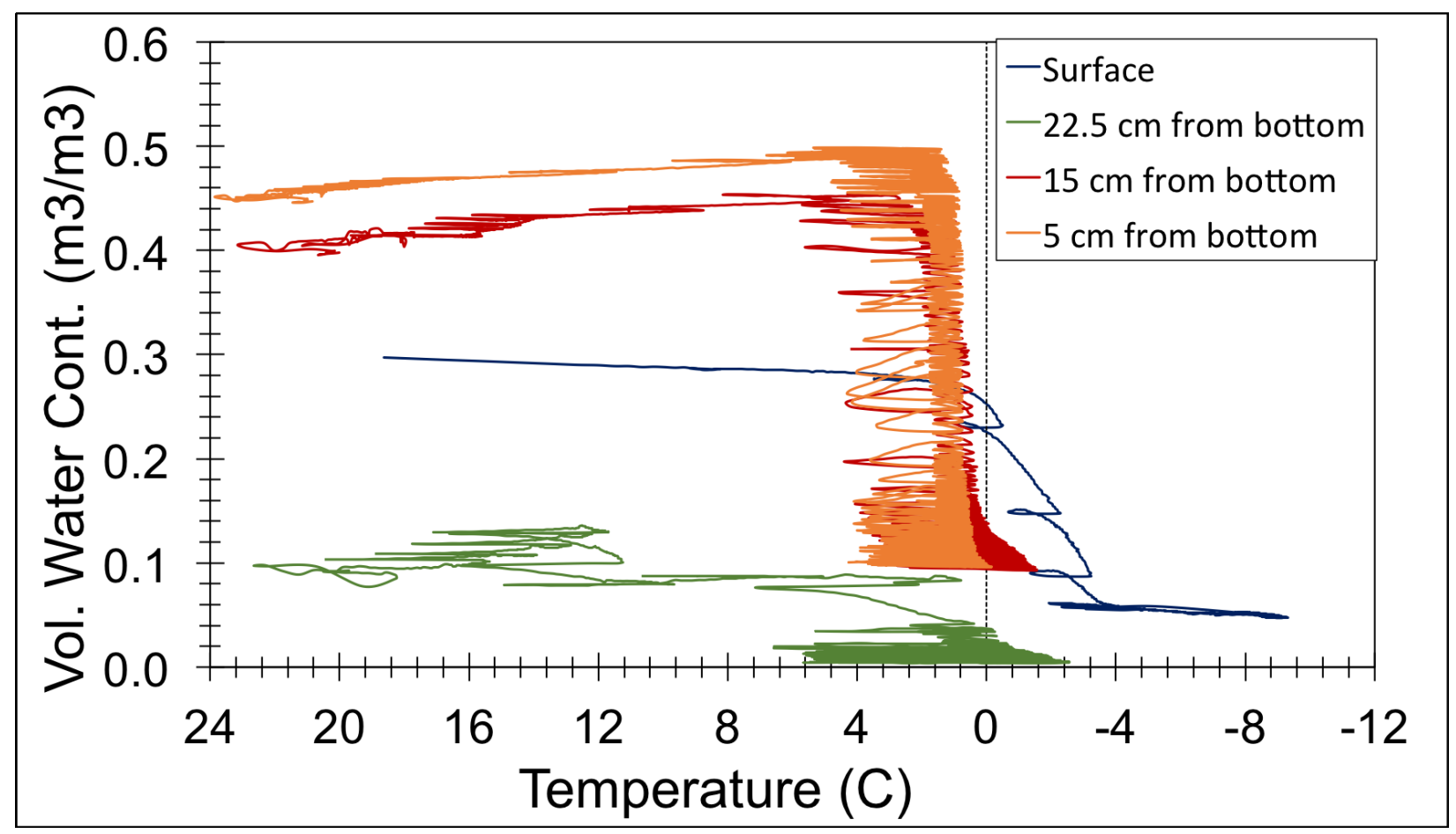

Figure 127. Unfrozen water content with respect to temperature.

The four data sets show a decreasing pattern in the desaturation of tailings as temperatures approach negative values. At a temperature of approximately $2.5^{\circ} \mathrm{C}$ the desaturation begins. At the surface, the volumetric content decreased from $0.28 \mathrm{~m}^{3} / \mathrm{m}^{3}$ to $0.05 \mathrm{~m}^{3} / \mathrm{m}^{3}$ at $-10{ }^{\circ} \mathrm{C}$. At a height of $22.5 \mathrm{~cm}$ from the bottom, the water content decreases from $0.09 \mathrm{~m}^{3} / \mathrm{m}^{3}$ to $0.005 \mathrm{~m}^{3} / \mathrm{m}^{3}$ at a temperature of $-2.5^{\circ} \mathrm{C}$. At a height of $15 \mathrm{~cm}$ from the bottom, the water content decreases from $0.45 \mathrm{~m}^{3} / \mathrm{m}^{3}$ to $0.09 \mathrm{~m}^{3} / \mathrm{m}^{3}$ 
at a temperature of $-1.5^{\circ} \mathrm{C}$. Lastly, at a height of $5 \mathrm{~cm}$ from the bottom, the decrease ranges from $0.49 \mathrm{~m}^{3} / \mathrm{m}^{3}$ to $0.09 \mathrm{~m}^{3} / \mathrm{m}^{3}$ at $0{ }^{\circ} \mathrm{C}$.

\subsubsection{Ice Content in Frozen Polymer Amended MFT}

Figure 128, 129, and 130 show the volumetric ice content readings at the surface, at a height of $22.5 \mathrm{~cm}$, and $15 \mathrm{~cm}$, respectively. The ice content was inferred from the immediate increase in volumetric water content from the difference between the pre-thaw and post-thaw readings. Also, it has been assumed that consolidation within the tailings does not occur at temperature below zero.

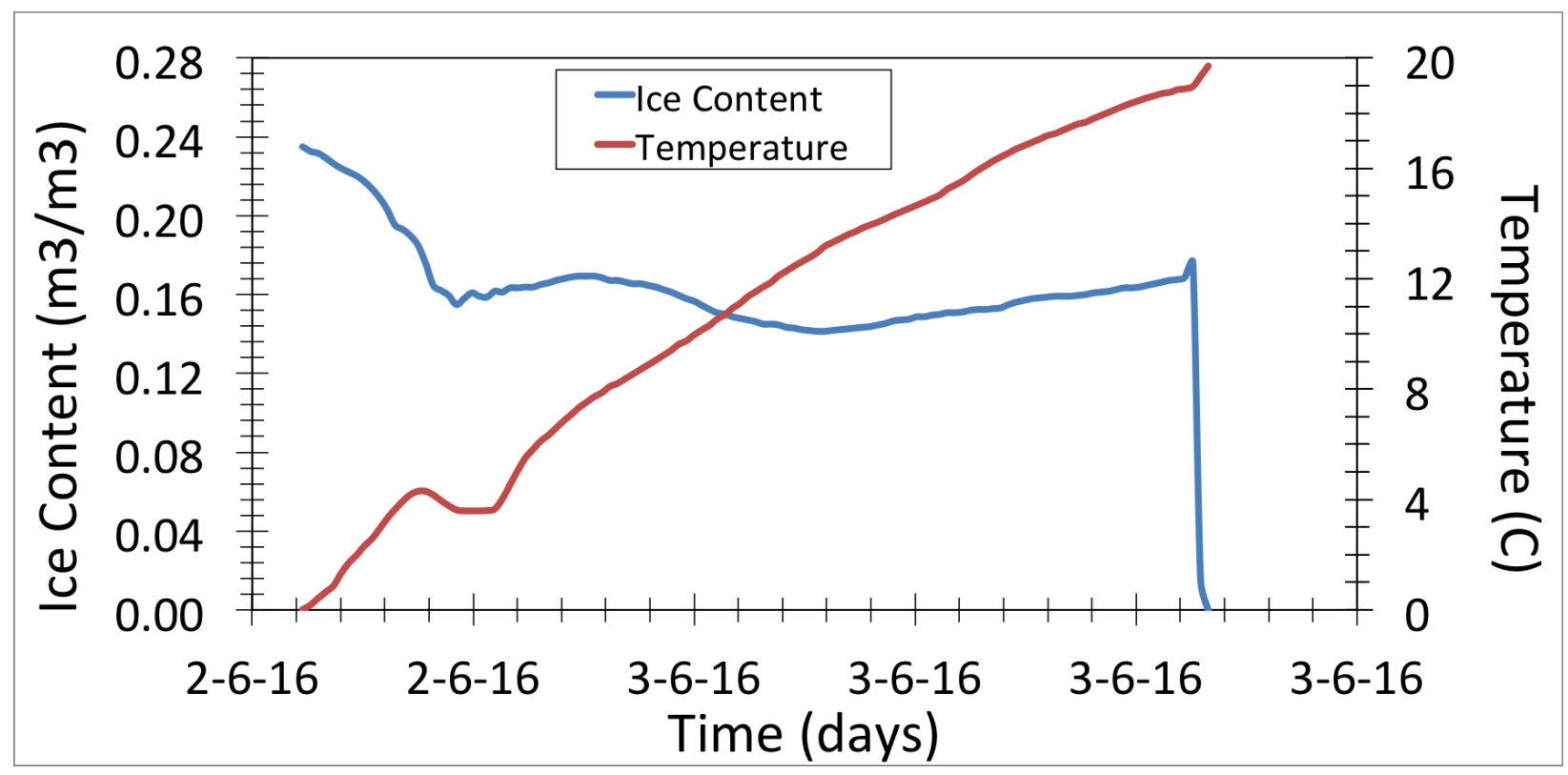

Figure 128. Ice content at the surface during the freezing phase. 


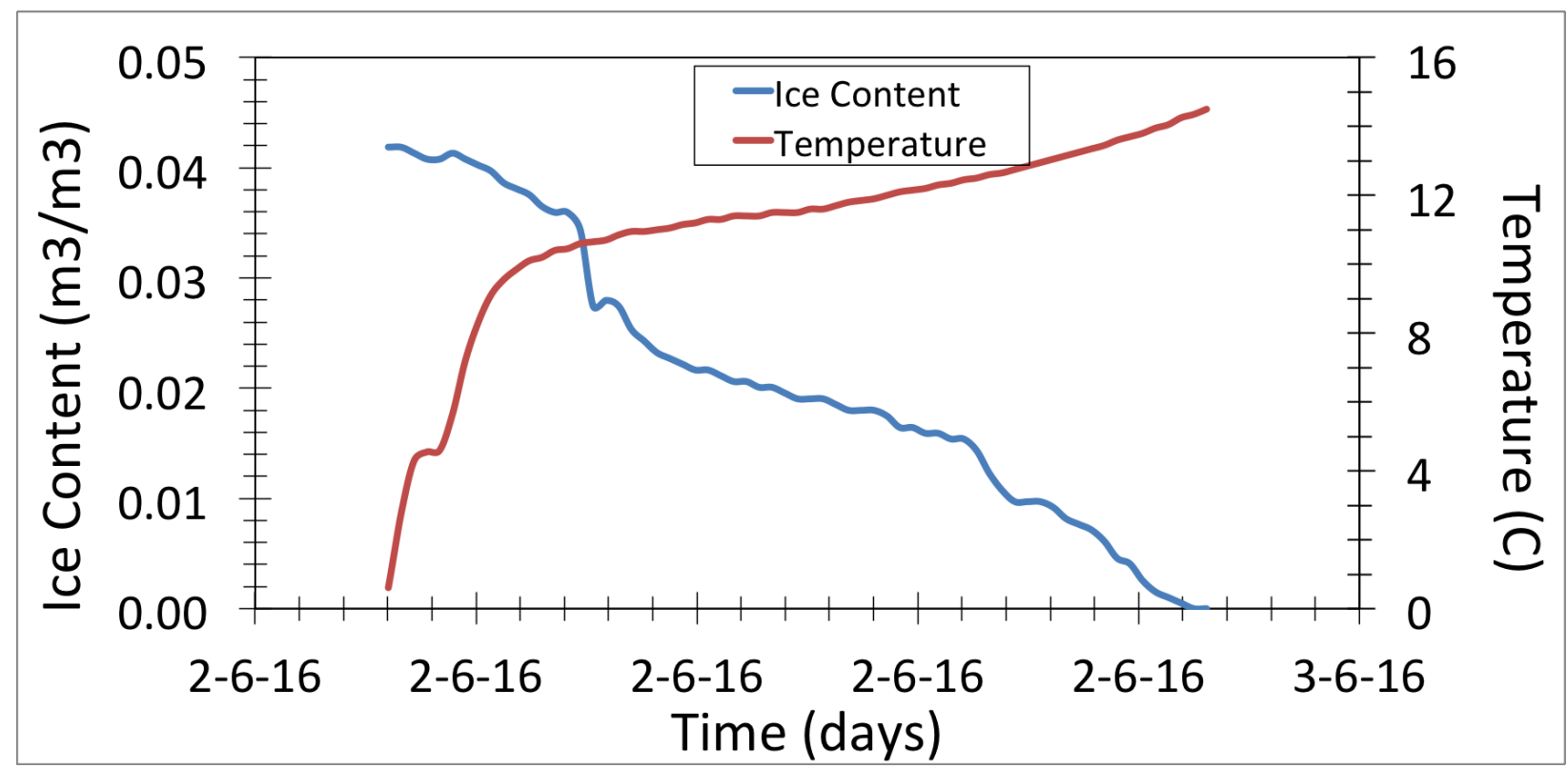

Figure 129. Ice content at a height of $22.5 \mathrm{~cm}$ during the freezing phase.

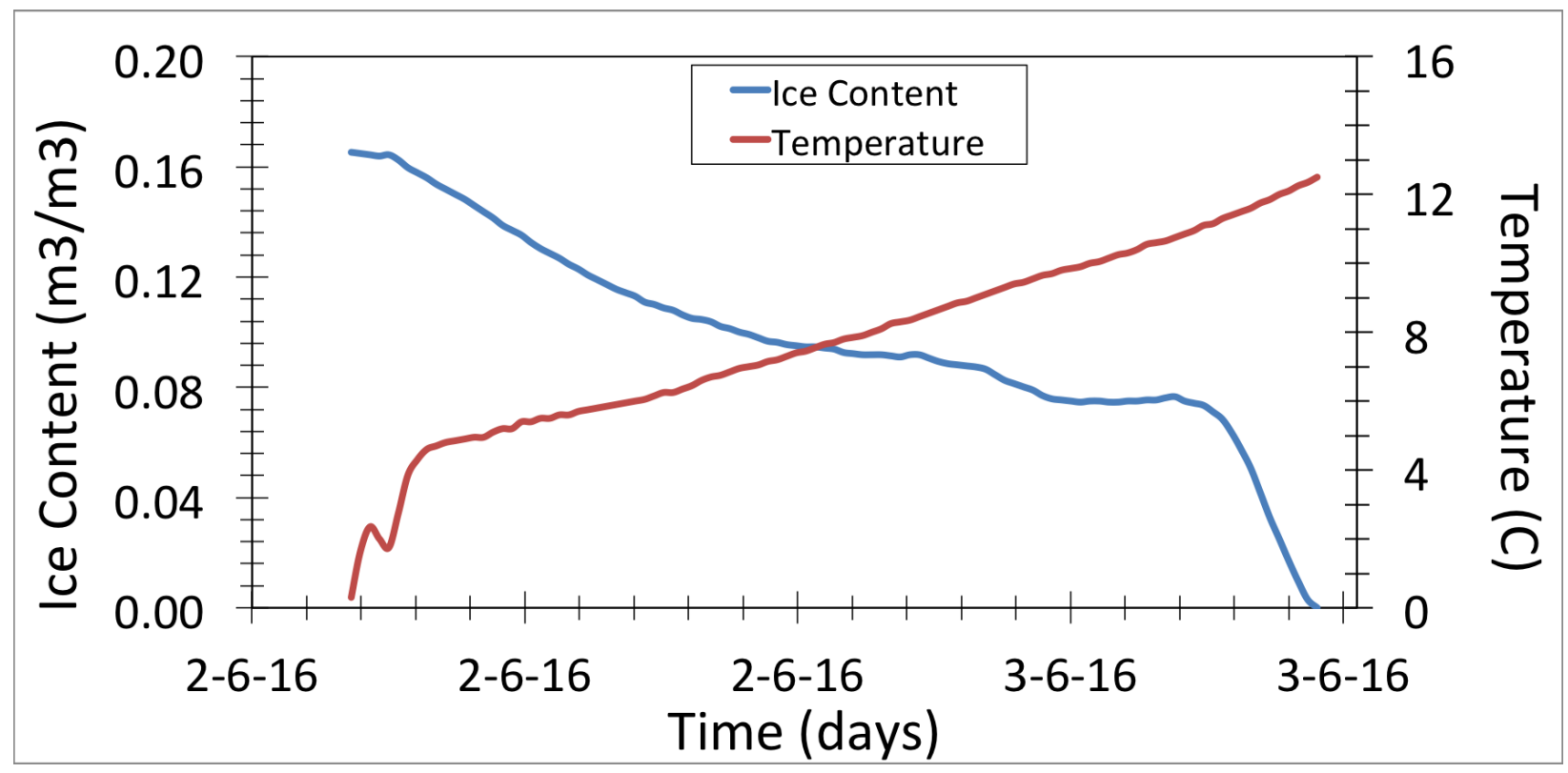

Figure 130. Ice content at a height of $15 \mathrm{~cm}$ during the freezing phase. 
Figure 128 shows approximately $0.235 \mathrm{~m}^{3} / \mathrm{m}^{3}$ of ice present at the surface right before the thawing phase, while Figure 129 shows $0.042 \mathrm{~m}^{3} / \mathrm{m}^{3}$ present at a height of $22.5 \mathrm{~cm}$. Lastly, Figure 129 shows $0.165 \mathrm{~m}^{3} / \mathrm{m}^{3}$ of ice present at a height of $15 \mathrm{~cm}$.

\subsubsection{Pore Water Pressure Development}

The development of positive and negative pore water pressures can be observed in the figures below. The data was obtained at three different heights from the bottom: $22.5 \mathrm{~cm}, 15 \mathrm{~cm}$, and $5 \mathrm{~cm}$. The data was obtained using MPS-6 sensors and tensiometers.

Figure 131 and 132 show the pore water pressures throughout the experiment at a height of $22.5 \mathrm{~cm}$. As discussed in the previous sections, it is important to mention the limitations of the MPS-6 sensors when tailings temperatures are below zero. The sensors cannot accurately read the pore water pressure of the tailings once water freezes since the electric properties of water change (i.e. dielectric permittivity) due to phase change. Taking the sensors' limitation into account, Figure 131 displays the matric suction development at a height of $22.5 \mathrm{~cm}$. This sensor is located $7.5 \mathrm{~cm}$ away from the surface. As expected, there is no record of negative pore pressure during the selfweight consolidation with ambient drying phase since the MFT at this depth is still considered fully saturated and positive pore pressures are present. Suction commences to develop towards the end of the desiccation phase as the tailings start to dry. The highest suction recorded was $56 \mathrm{kPa}$ (not visible in Figure 131 due to the scaling of the y-axis but shown in Figure 133 instead). At the beginning of the freezing phase, suction 
values started to develop instantaneously. This behaviour was not encountered in Column Test \#1 in which suctions developed well into the freezing phase. Once the temperature at this depth reached a value of $0{ }^{\circ} \mathrm{C}$ the sensor had already reached its maximum possible reading at $100,000 \mathrm{kPa}$. This suggests that the sensor was exposed to the air before water starting to freeze. Since the tailings started to drastically shrink in the desiccation phase, a portion of the MPS- 6 sensor might have been exposed to the air leading to misleading readings.

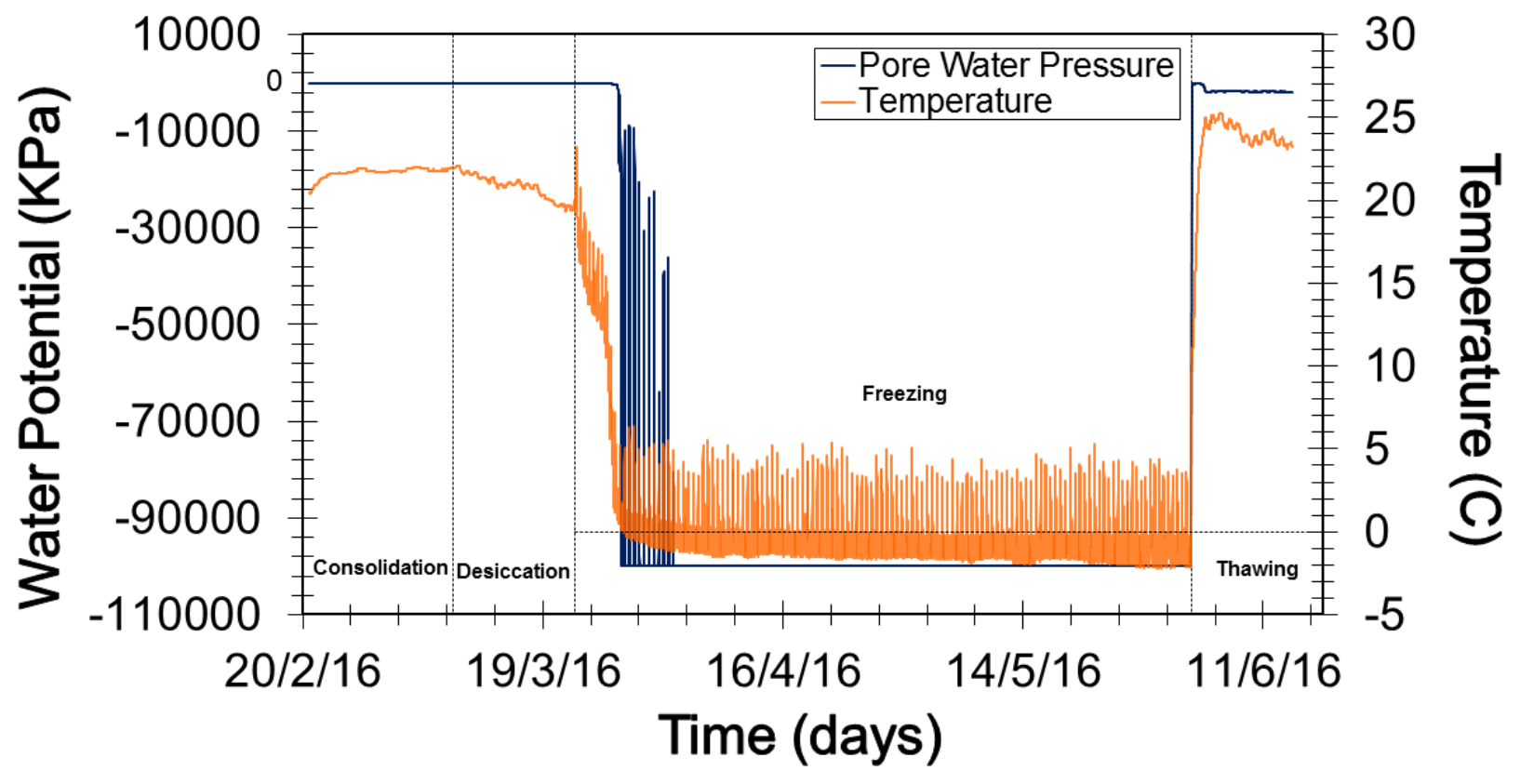

Figure 131. Matric suction throughout the experiment obtained by the MPS-6 sensor at a height of $22.5 \mathrm{~cm}$. 


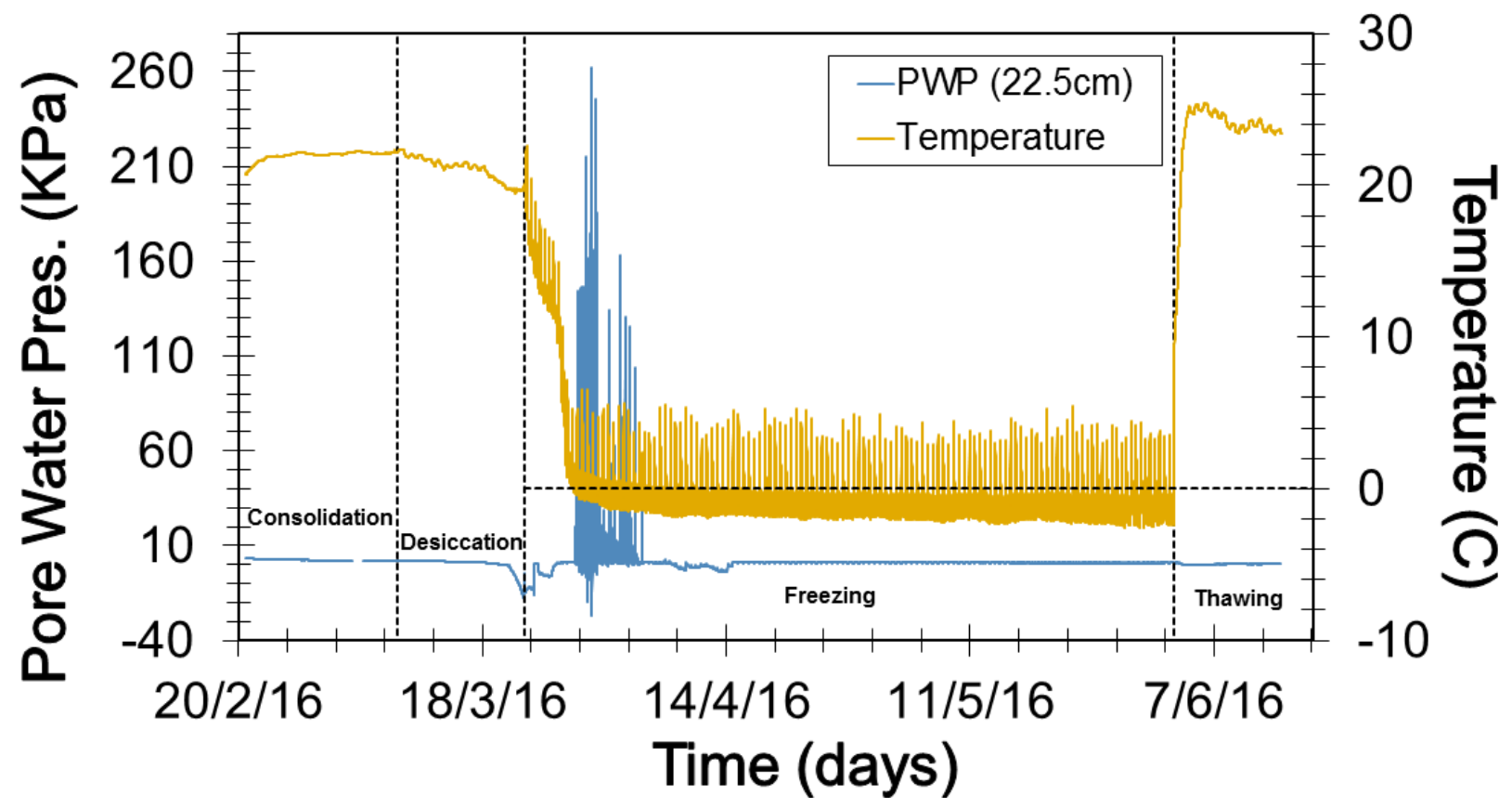

Figure 132. Pore water pressures throughout the experiment obtained by a tensiometer at a height of $22.5 \mathrm{~cm}$.

Figure 132 shows the pore water pressures recorded by the tensiometer during the experiment at a height of $22.5 \mathrm{~cm}$. During the self-weight consolidation with ambient drying phase, positive pore water pressures starting from $3.6 \mathrm{kPa}$ at the beginning of the phase and $2.1 \mathrm{kPa}$ at the end were recorded. Pore water pressures became negative during the desiccation phase as the tailings were drying. The suction recorded at the end of this phase was $17.5 \mathrm{kPa}$. Shortly after the start of the freezing phase, the tip of the tensiometer broke because of the ice pressure exerted on the tip as ice lenses started to form. 
The comparison of both sets of pore water pressure data for a height of $22.5 \mathrm{~cm}$ is shown in Figure 133. The figure shows the pore water pressure from the beginning of the self-weight consolidation with ambient drying phase up to the tensiometer-breaking event.

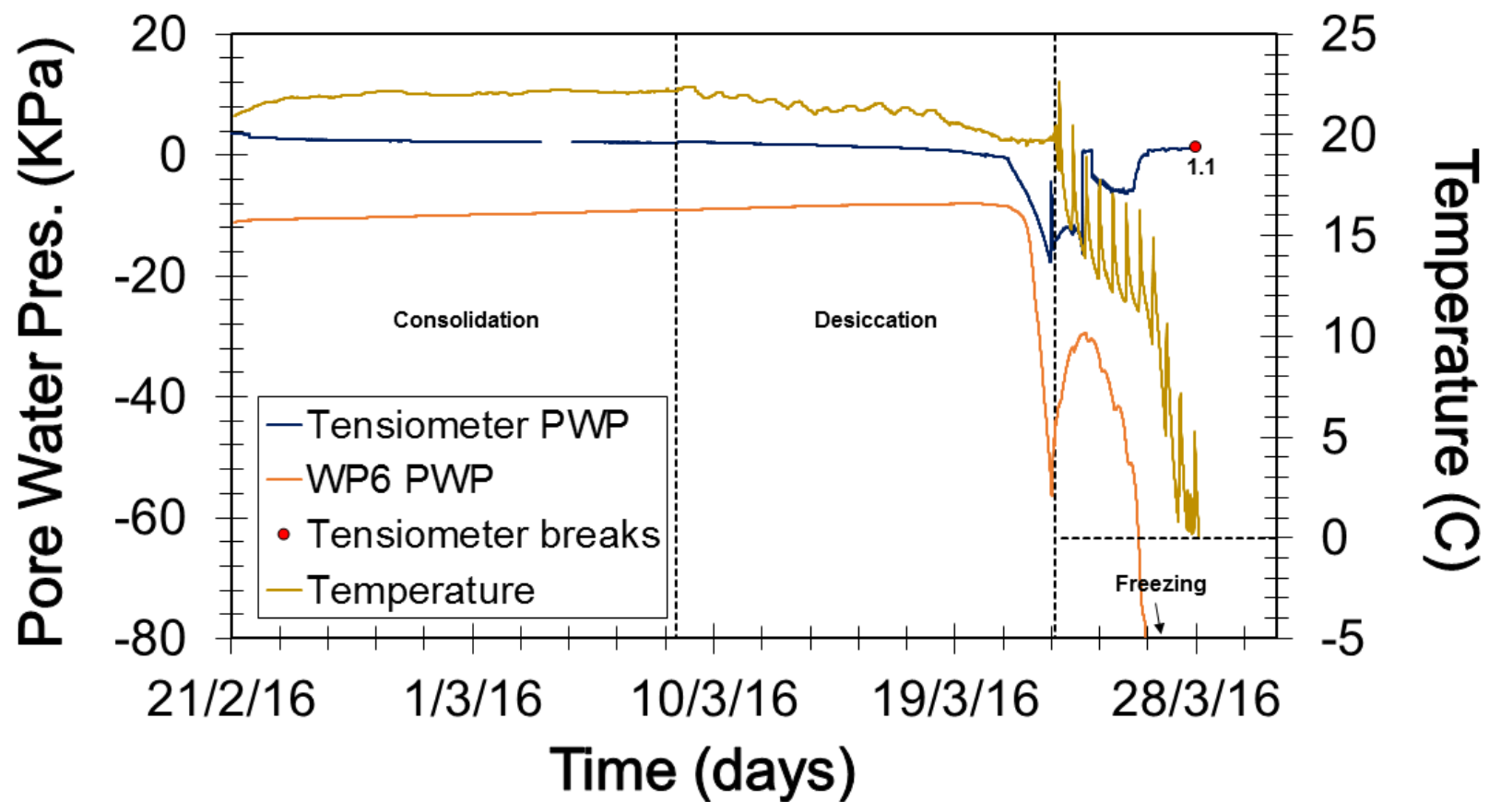

Figure 133. Comparison between data obtained from a MPS-6 sensor and a tensiometer at a height of $22.5 \mathrm{~cm}$.

Both sets of data show similar trends during self-weight consolidation, desiccation and at the start of the freezing phase. During the self-weight consolidation with ambient drying phase, there is not a response to positive pore water pressure changes from the MPS-6 sensor, as expected, while the tensiometer recorded the changes. The same can be said for the desiccation phase; however, both sensors 
recorded the pore water pressure changes as the tailings at this height begin to dry at the end of this phase. Both sensors record the changes at different magnitudes. The MPS-6 recorded a suction changes from $8 \mathrm{kPa}$ to $54 \mathrm{kPa}$, while the tensiometer recorded changes from $0.1 \mathrm{kPa}$ to $17 \mathrm{kPa}$. As freezing starts, there is an increase in pore water pressure value recorded by both sensors. The trend continues until the tensiometer breaks and data obtained from then on is considered erroneous. The MPS- 6 sensor data shows an increase in suction afterwards.

Figure 134 shows the pore pressure at a height of $15 \mathrm{~cm}$ form the MPS- 6 sensor. No tensiometer was placed at this height. Similar to the $22.5 \mathrm{~cm}$ sensor data, negative pore pressures were not developed during the self-weight consolidation, desiccation phase, and at the beginning of the freezing phase. At a temperature of $1.2{ }^{\circ} \mathrm{C}$, the recorded suction value was $9 \mathrm{KPa}$ and it continued to increase at an accelerated rate up to $206 \mathrm{KPa}$ at $0{ }^{\circ} \mathrm{C}$. These suctions were developed below the frozen front and are responsible for water migration towards the forming ice lenses. As mentioned before, suction values below $0{ }^{\circ} \mathrm{C}$ are considered unreliable for this research. Furthermore, during the thawing phase, recorded pore water pressure values go back up to the positive range but as the tailings started to desaturate by evaporation and drainage, suctions began to develop again up to $76 \mathrm{kPa}$ at the end of the test. 


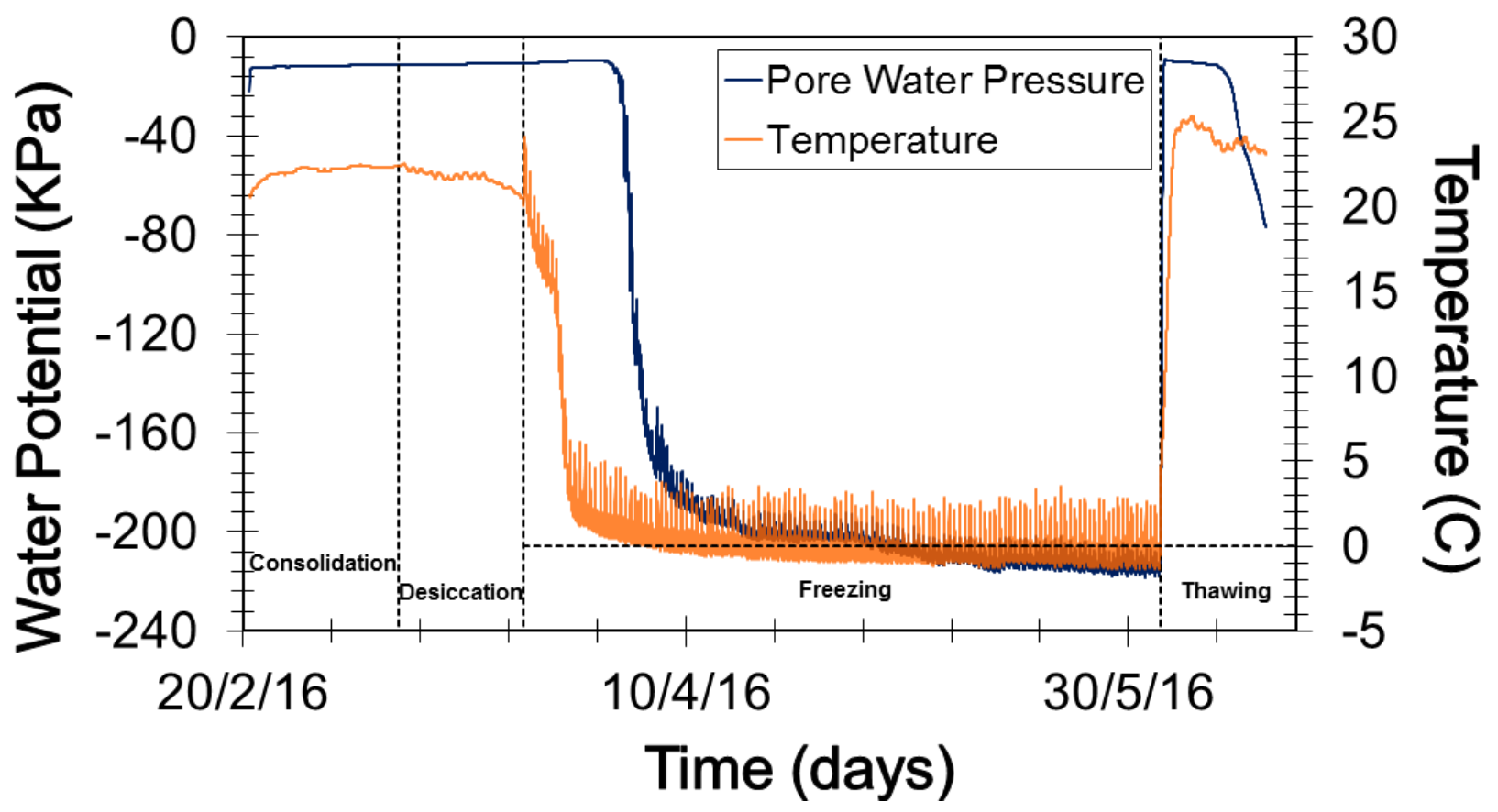

Figure 134. Matric suction obtained by a MPS-6 sensor at a height of $15 \mathrm{~cm}$.

Figure 135 and 136 show the pore water pressures at a height of $5 \mathrm{~cm}$ form the bottom of the column obtained from the MPS- 6 sensor and a tensiometer. Taking the MPS-6 sensors' limitation into account, Figure 135 displays the suction development at a height of $5 \mathrm{~cm}$. Similar to the other sensor data, negative pore pressures did not developed during the self -weight consolidation, desiccation phase, and during the first half of the freezing phase. At a temperature of $3.4{ }^{\circ} \mathrm{C}$, the recorded suction value was 7.5 $\mathrm{KPa}$ and it continued to increase at an accelerated rate up to $1,550 \mathrm{KPa}$ at $0{ }^{\circ} \mathrm{C}$. Suction fluctuations were recorded as they change along with temperature fluctuations. The freezing phase was stopped at this point $\left(\mathrm{T}^{\circ}=0{ }^{\circ} \mathrm{C}\right)$. These suctions were developed below the frozen front and are responsible for water migration towards the forming ice lenses. Suction values below zero degrees were not present. Furthermore, 
during the thawing phase, recorded pore water pressure values go back up to the positive range producing no response on the sensor.

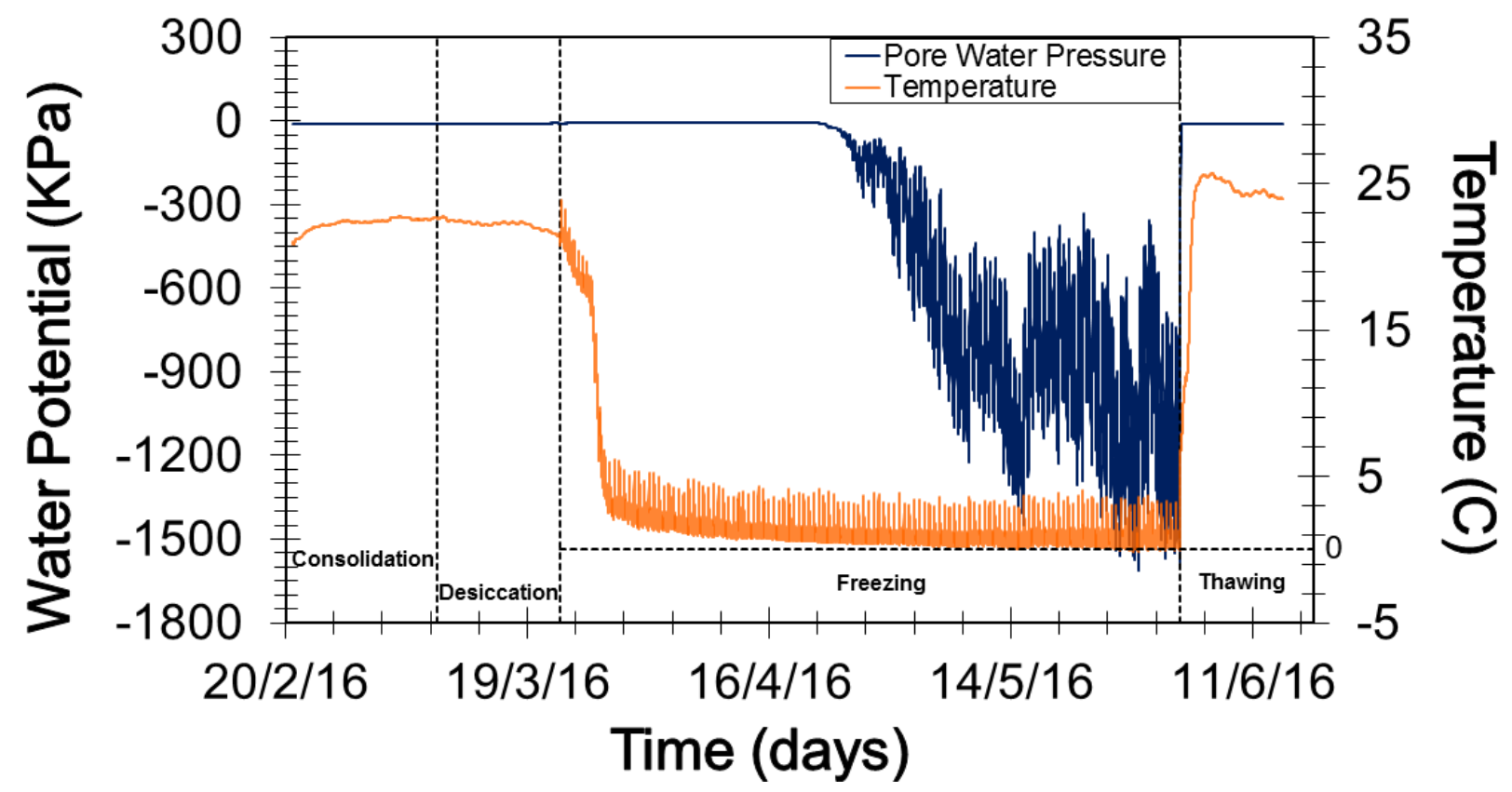

Figure 135. Matric suction throughout the experiment obtained by a MPS-6 sensor at a height of 5 cm. 


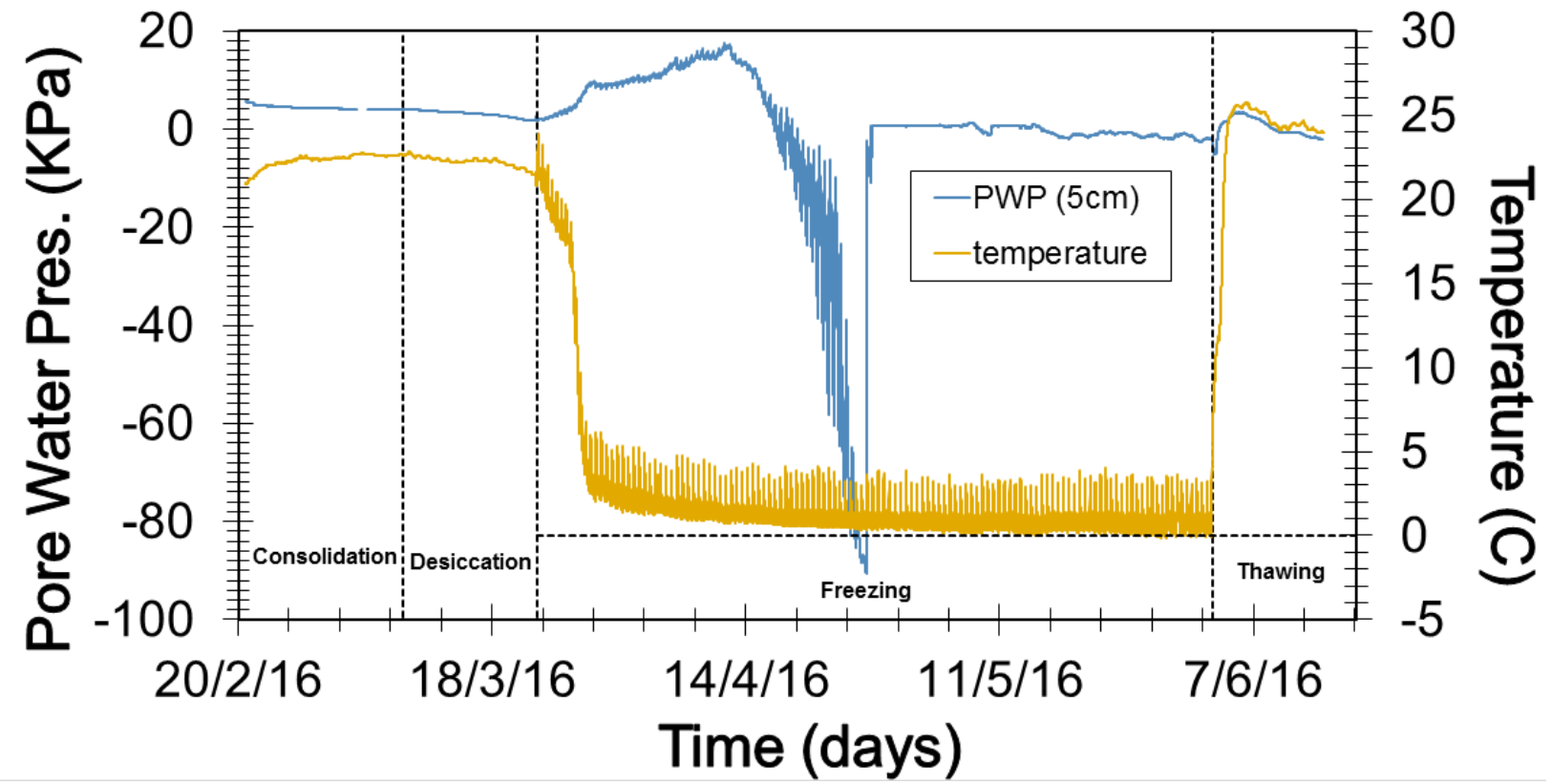

Figure 136. Pore water pressures throughout the experiment obtained by a tensiometer at a height of $5 \mathrm{~cm}$.

Figure 136 shows the pore water pressures recorded by the tensiometer during the experiment at a height of $5 \mathrm{~cm}$. During the self-weight consolidation with ambient drying phase, positive pore water pressures starting from $5.6 \mathrm{kPa}$ at the beginning of the phase and $3.9 \mathrm{kPa}$ at the end were recorded. Pore water pressures continued to decrease during the desiccation phase as the tailings were drying. The pore water pressure recorded at the end of this phase was $2 \mathrm{kPa}$. Shortly after the start of the freezing phase, pore water pressures increase noticeably to $16.8 \mathrm{kPa}$. This can be attributed to the pressure ice exerts on the unfrozen water below the freezing front. Consequently, as temperatures approach zero, positive pore water pressures decrease rapidly turning into suctions below the freezing front. The tensiometer recorded a maximum suction value of $88.6 \mathrm{kPa}$ before breaking. 
The comparison of both sets of pore water pressures data for a height of $5 \mathrm{~cm}$ is shown in Figure 137. The figure shows the pore water pressure from the beginning of the freezing phase up to the tensiometer-breaking event.

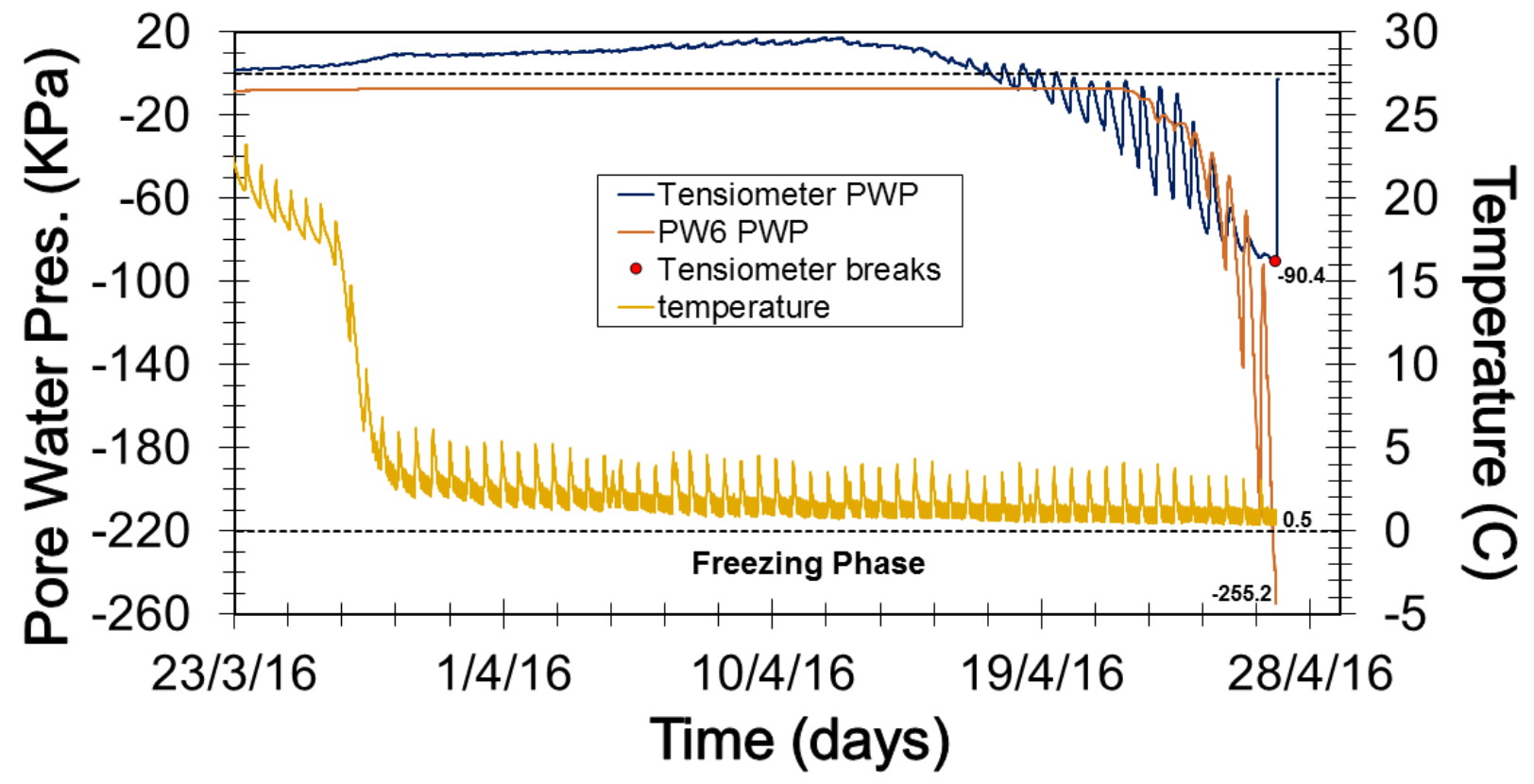

Figure 137. Comparison between data obtained by a MPS-6 sensor and a tensiometer at a height of $5 \mathrm{~cm}$.

Both sets of data show similar trends during the freezing phase. As temperatures drop, there is an increase in pore water pressure value recorded by tensionmeter, while the MPS-6 sensor records no change since the values are outside of its range. Later on, both sensors record the development of suctions as temperatures drop to zero. Unlike the pore water pressures recorded at a height of $22.5 \mathrm{~cm}$, both sensors at a height of 5 $\mathrm{cm}$ recorded similar suction values up to approximately $85 \mathrm{kPa}$. After this point, the 
fluctuations in the MPS-6 sensor became larger and the tensiometer broke. The last suction value the tensiometer recorded was $90.4 \mathrm{kPa}$ while the MPS-6 sensor recorded $255.2 \mathrm{kPa}$ at the same time.

Lastly, a total suction profile was obtained at the completion of the test, as seen in Figure 138. It shows higher suction values at the surface and they decrease with depth. It follows a similar trend when compared to the gravimetric water content profile (Figure 126). As the water content increases, the suction values decrease and vice versa.

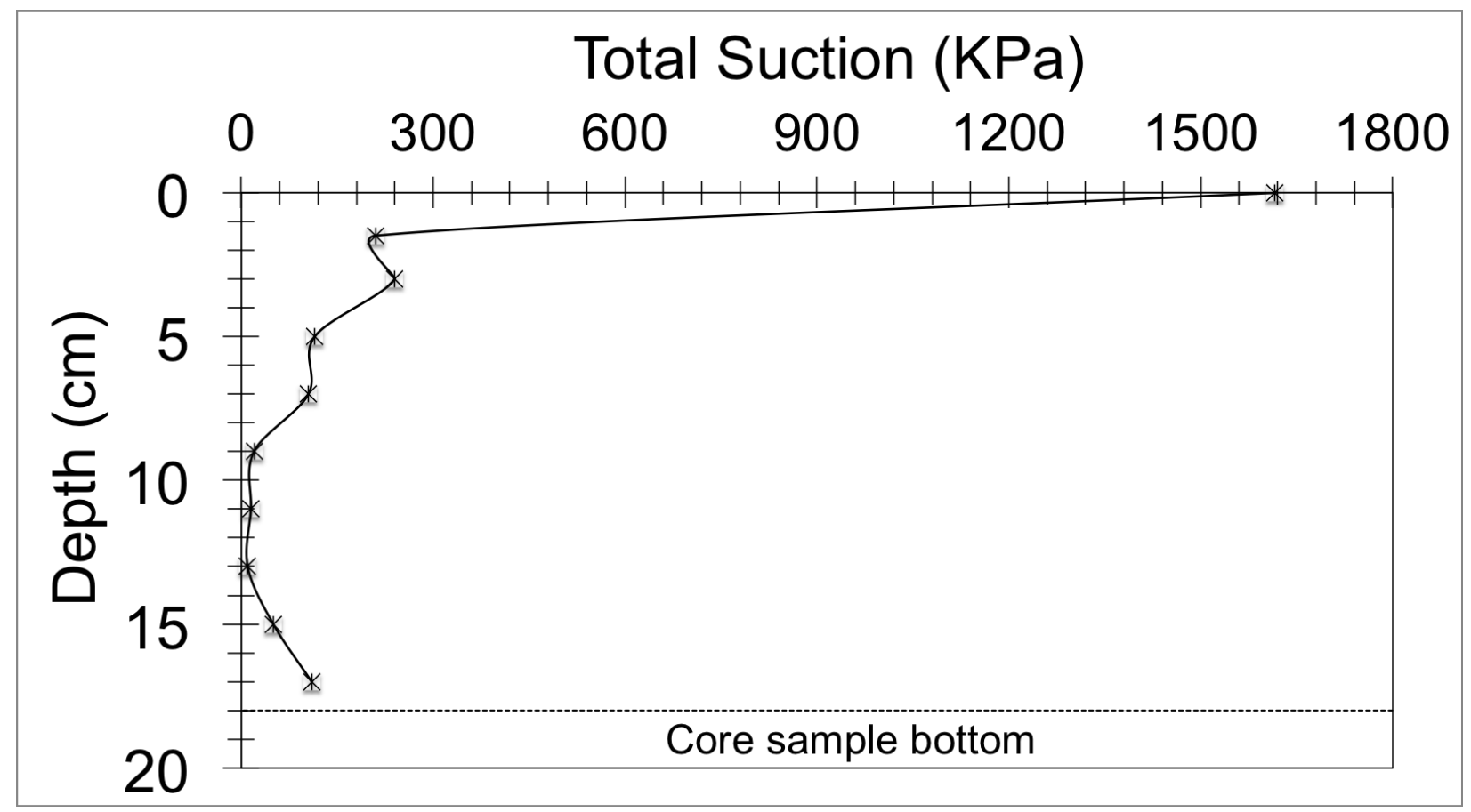

Figure 138. Total suction profile obtained at completion of column test $\# 3$. 


\subsubsection{SWCC During Desiccation}

Since water pore pressures, or suctions, and water contents were recorded during the self-weight consolidation with ambient drying phase, a soil water characteristic curve was constructed to describe the desaturation rate of the MFT as the tailings settle down and dry. Figure 139 shows the SWCC at a height of $22.5 \mathrm{~cm}$ constructed from the tensiometer data.

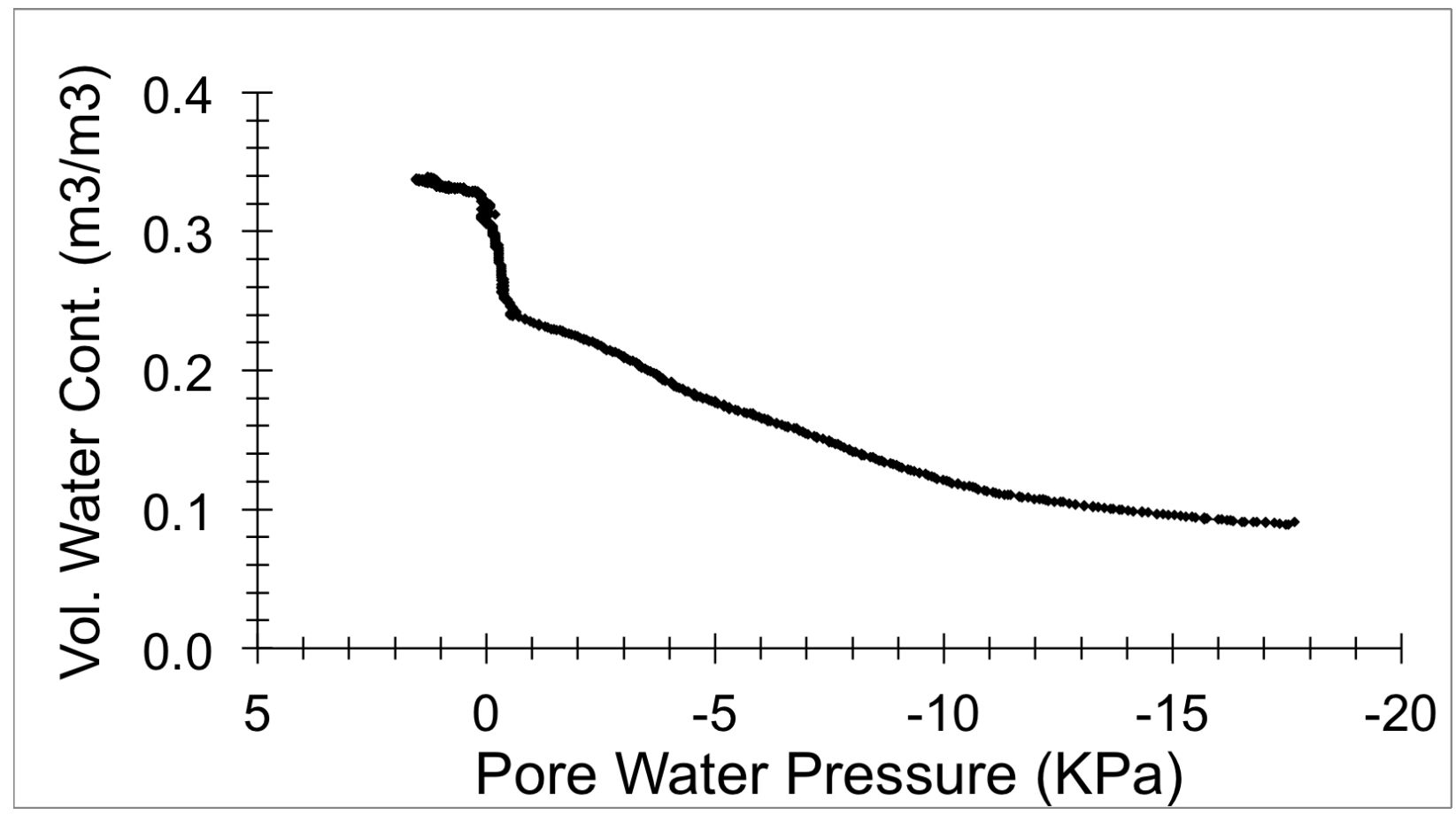

Figure 139. SWCC at a height of $22.5 \mathrm{~cm}$ during the desiccation phase.

The volumetric water content range of the SWCC ranges from $0.34 \mathrm{~m}^{3} / \mathrm{m}^{3}$ to $0.09 \mathrm{~m}^{3} / \mathrm{m}^{3}$, while the pore water pressures range from $1.5 \mathrm{KPa}$ to approximately -17.5 KPa. 


\subsubsection{SWCC Below the Freezing Front}

Since negative pore pressures, or suctions, and volumetric water contents were recorded during the freezing phase, a soil water characteristic curve was constructed to describe the desaturation rate of the MFT right below the freezing front. The values correspond to temperatures greater than zero to ensure that the water present in the tailings and in the sensors is not frozen. Figure 140 and 141 show the SWCC right below the freezing front at heights of $15 \mathrm{~cm}$ and $5 \mathrm{~cm}$ from the bottom of the column. The negative pore pressure was obtained using the MPS-6 sensors.

The volumetric water content range of the SWCC in Figure 140 ranges from $0.44 \mathrm{~m}^{3} / \mathrm{m}^{3}$ to $0.14 \mathrm{~m}^{3} / \mathrm{m}^{3}$, while the matric suction ranges from $10 \mathrm{KPa}$ (air entry value of the sensor) to approximately $46 \mathrm{KPa}$.

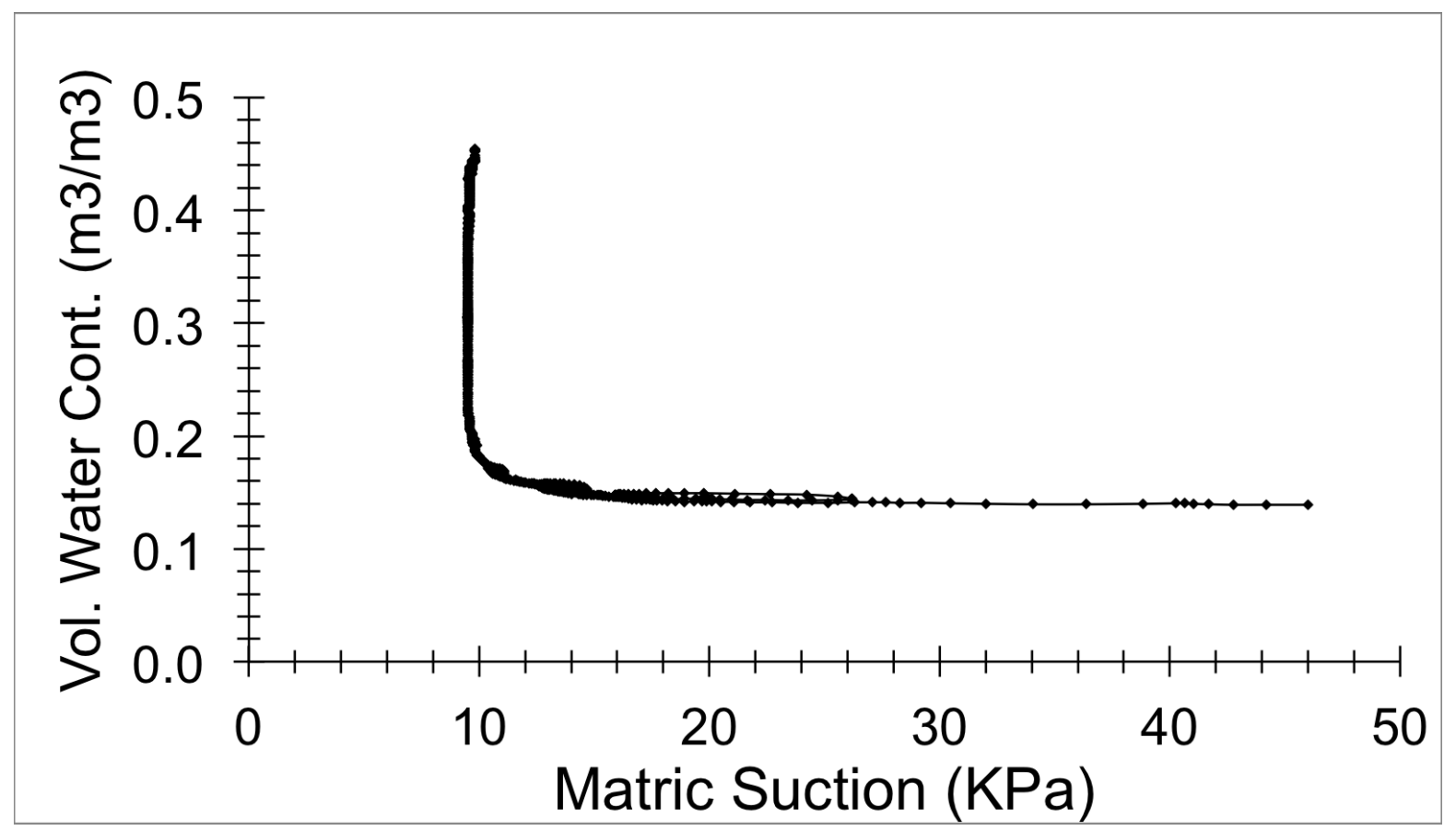

Figure 140. SWCC right below the freezing front at a height of $15 \mathrm{~cm}$ in column tests \#3. 


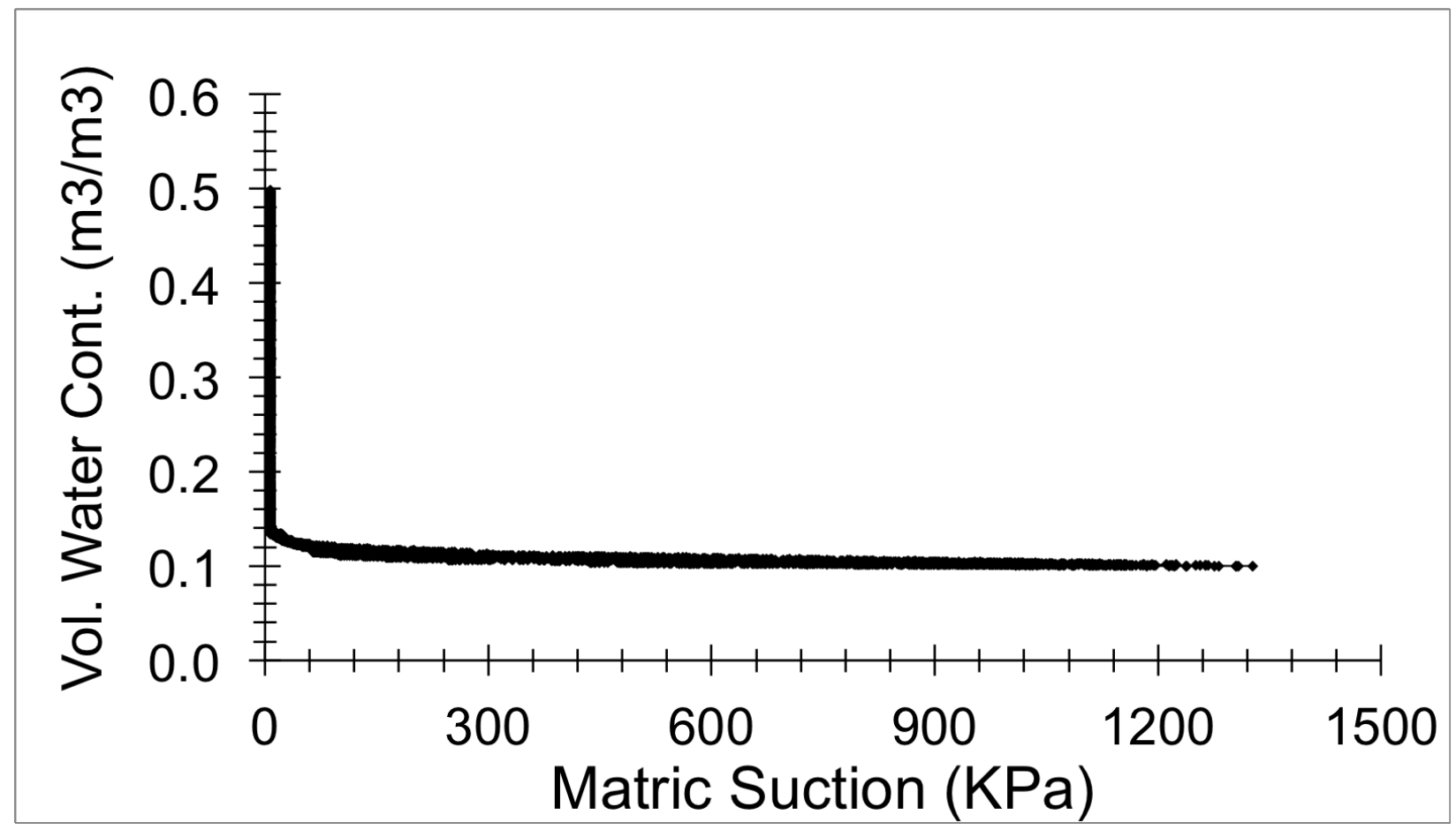

Figure 141. SWCC right below the freezing front at a height of $5 \mathrm{~cm}$ in column tests \#3.

The volumetric water content range of the SWCC in Figure 141 ranges from $0.50 \mathrm{~m}^{3} / \mathrm{m}^{3}$ to $0.10 \mathrm{~m}^{3} / \mathrm{m}^{3}$, while the matric suction ranges from $10 \mathrm{KPa}$ (air entry value of the sensor) to approximately $1326 \mathrm{KPa}$. Further analysis and comparison of the SWCC below the freezing front is presented in Section 4.6.4.

\subsubsection{Thaw Strain}

Thaw strain is defined as the ratio between change in height due to thawing and initial height of the specimen. The initial height of the MFT column before freezing was $30 \mathrm{~cm}$, while the height at the end of the thawing was $19.9 \mathrm{~cm}$, as seen in Figure 142. The thaw strain for column test \#3 was found to be 0.34 or $34 \%$. 


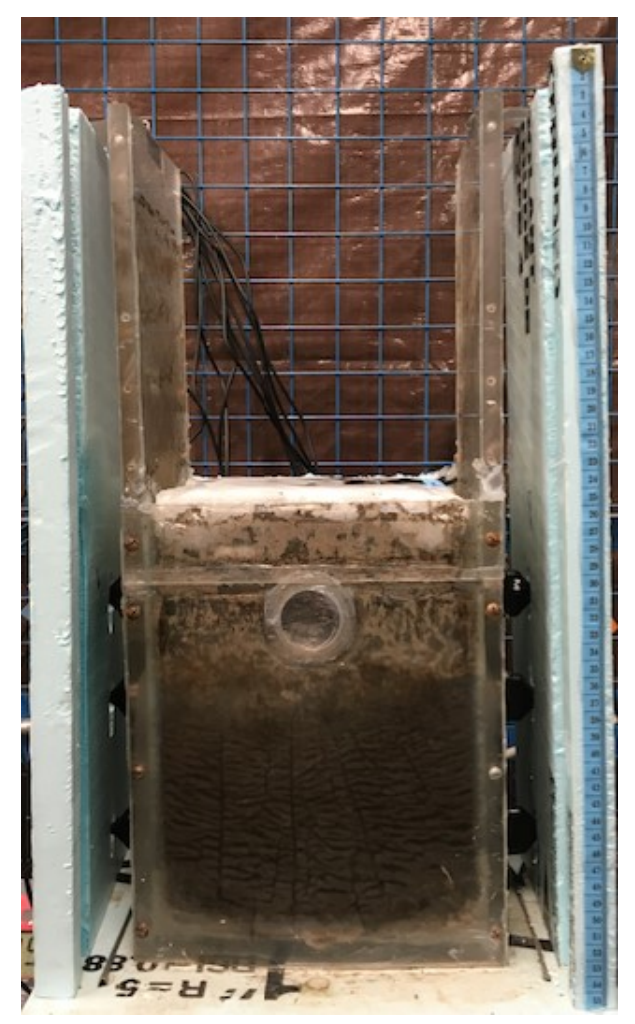

MFT prior thaiwng

Height $_{\text {average }} \approx 30 \mathrm{~cm}$

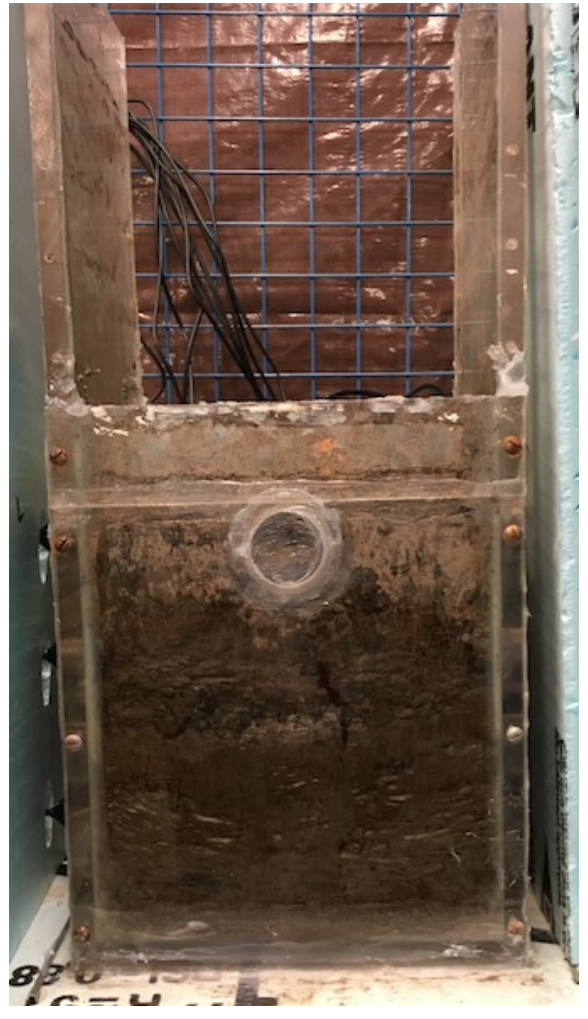

MFT after thawing

Height $_{\text {average }} \approx 19.9 \mathrm{~cm}$

Figure 142. MFT column before and after the thawing phase.

\subsubsection{Undrained Shear Strength}

A vane shear test was conducted at the end of the thawing phase to determine the undrained shear strength of the thawed tailings. Figure 143 shows the results obtained at intervals of $5 \mathrm{~cm}$. As seen in the figure below, the undrained shear strength increases with depth and decreases at bottom of the column. 


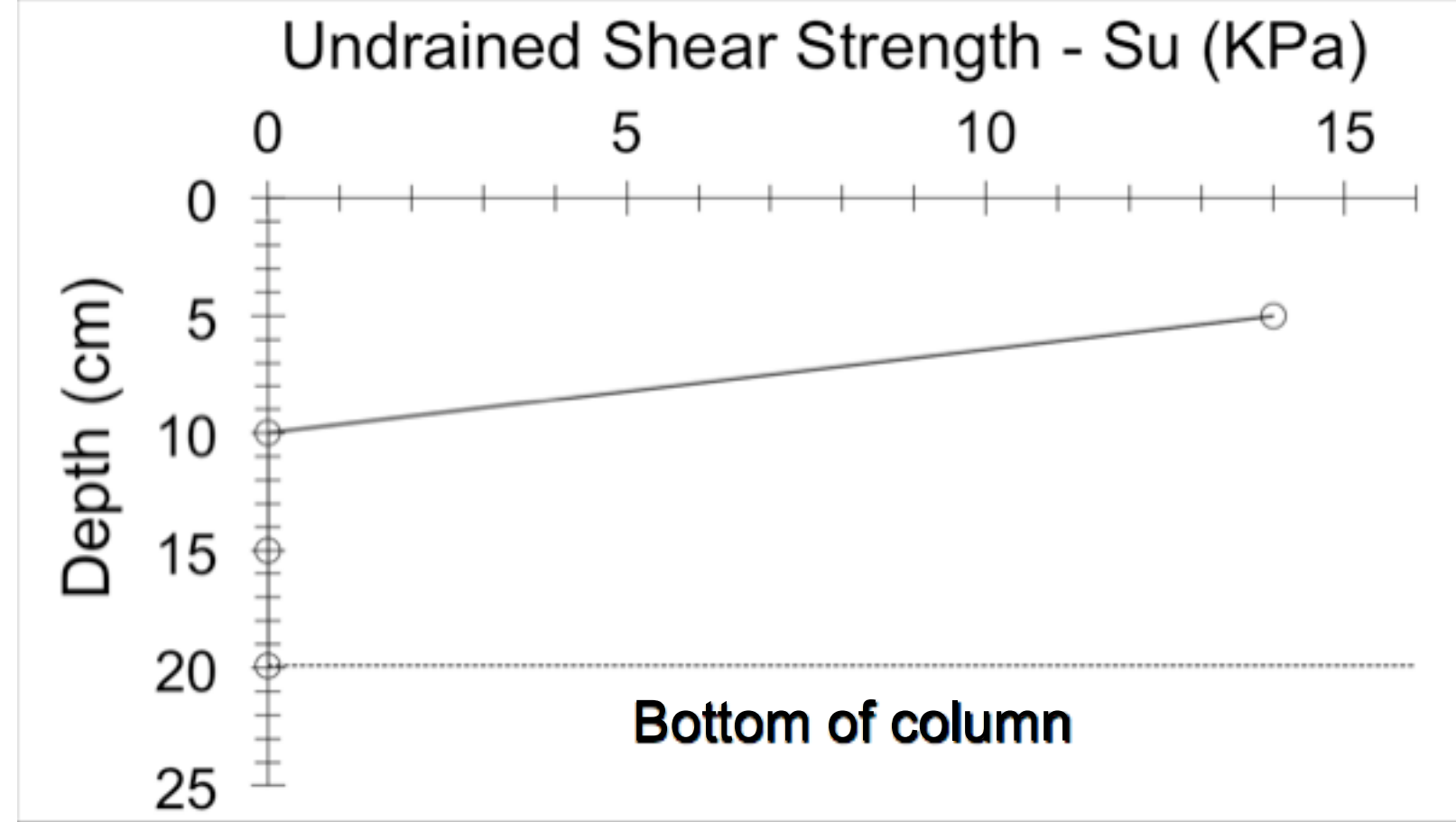

Figure 143. Vane shear test results for column test \#3.

\subsubsection{Consolidation Behaviour and Permeability}

The results of the oedometer tests performed on the MFT after the thawing phase are shown in Figure 144. Two tests were performed at different depths on a 19 $\mathrm{cm}$ core sample. The samples were obtained at depths of $6.25 \mathrm{~cm}$ and $12.75 \mathrm{~cm}$. Also, both samples underwent one freeze-thaw cycle. 


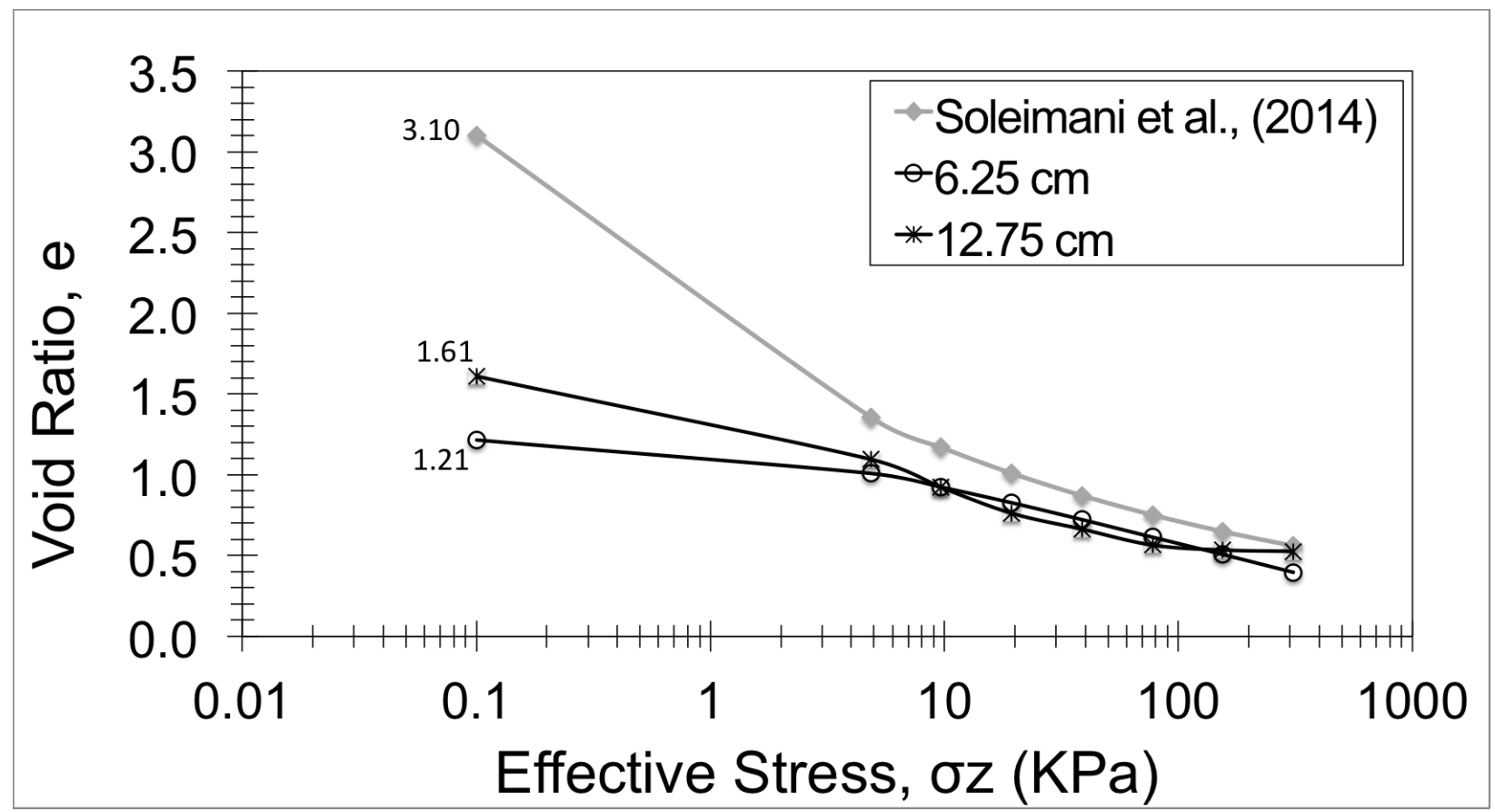

Figure 144. Void ratio vs effective stress (column test $\# 3$ ).

Even though the two samples were loaded equally, they exhibit slightly different consolidation properties, as seen in Table 20. Both samples show comparable values for initial water content, initial solids content, and initial void ratio. The percentage difference between values is $7.0 \%, 2.2 \%$, and $28.4 \%$, respectively. The variability of results can be attributed to the different thaw strains that both samples underwent. Both samples show similar curves at effective stresses greater than $10 \mathrm{KPa}$ showing different consolidation behaviour.

Furthermore, both samples show a decreasing trend in their compression index (Cc) as well as a decrease in their initial void ratio values as effective stresses increase. These results are expected since the initial void ratio and the compression index are 
proportionally related (Nishida, 1956). When compared to data from Soleimani et al. (2014), which only had a self-weight consolidation with ambient drying phase as well, it is possible to see differences in the consolidation behaviour. Even though the material, polymer dosage $(650 \mathrm{mg} / \mathrm{Kg})$, and lift height $(0.5 \mathrm{~m})$ used by Soleimani et al. (2014) are similar to the one used in this experiment, there are differences in the evaporation and desiccation parameters that could account for the difference in results. The experiment by Sahar et al. (2014) lasted 35 days and it included a desiccation phase at the second half of the experiment, while column test \#3 lasted 115 days and evaporation was allowed. The longer self-weight consolidation period in column test \#3 allowed more water to leave the MFT column, which decreased the average void ratio and change the consolidation behaviour of the material. Unlike column test \#1 and \#2, both trends do not show parallel slopes at effective stresses greater than 10KPa. The $12.75 \mathrm{~cm}$ sample shows a flat slope at effective stress greater than $100 \mathrm{KPa}$, while the $6.25 \mathrm{~cm}$ samples presents and continually decreasing trend. The dissimilarity in results shows that both samples have different compressibility rates.

Furthermore, Figure 145 shows the hydraulic conductivity of both samples. They were calculated using Terzaghi's consolidation theory. Most of the permeability values are lower than $10^{-9} \mathrm{~m} / \mathrm{s}$, except for the values corresponding to the last load increment. As expected, the hydraulic conductivity of the MFT increases as the void ratio increases in an approximate linear trend. However, the $12.75 \mathrm{~cm}$ sample shows different hydraulic conductivity values than the $6.25 \mathrm{~cm}$ sample. Both samples differ 
from their permeability properties by approximately one order of magnitude at similar void ratios.

When comparing the obtained results with Soleimani et al., (2014), it is distinguishable that both sets of data differ in permeability values as well. The difference ranges from two to four orders of magnitude at similar void ratios.

Table 20. Consolidation properties (column test \#3).

\begin{tabular}{|c|c|c|c|c|c|}
\hline Depth (cm) & $\begin{array}{c}\text { Initial Water } \\
\text { Content (\%) }\end{array}$ & $\begin{array}{c}\text { Initial Solids } \\
\text { Content(\%) }\end{array}$ & $\begin{array}{c}\text { Initial Void } \\
\text { Ratio, eo }\end{array}$ & $\begin{array}{c}\text { Recompression } \\
\text { Index, Cr }\end{array}$ & $\begin{array}{c}\text { Compression } \\
\text { index, Cc }\end{array}$ \\
\hline 6.25 & 47.9 & 67.6 & 1.21 & 0.121 & 0.350 \\
\hline 12.75 & 51.4 & 66.1 & 1.61 & 0.304 & 0.262 \\
\hline
\end{tabular}

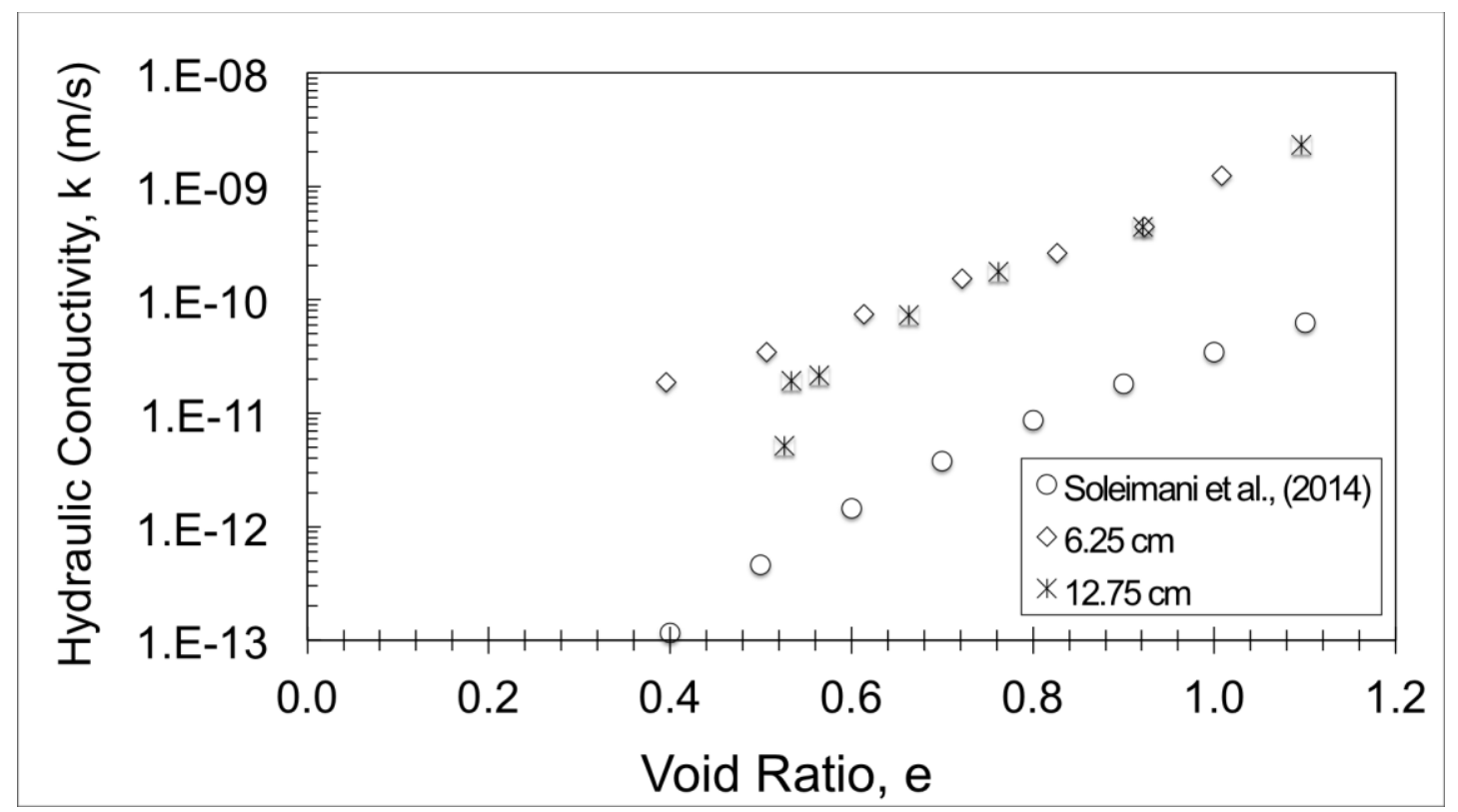

Figure 145. Hydraulic conductivity vs void ratio (column test \#3). 
Chamberlain and Gow (1979) showed that, even though overconsolidation leads to a reduction of hydraulic conductivity in high clay content soils, overconsolidation due to freeze-thaw cycles leads to a visible increase in hydraulic conductivity in the studied samples. They stated that in soils that are comprised of a flocculated clay matrix and where sand and silt grains are not in contact, the compressibility and permeability of the material is dependent on the arrangement of the clay particles. This is the case of the polymer-amended MFT. They continue by explaining that a freeze-thaw cycle will lead to a reduction in void ration due to the rearrangement of the clay particles to a more dispersed structure. Moreover, the increase in permeability can be attributed to the same structural changes that provoked the material to shrink as ice crystals start to form. Similar to column test $\# 1$, vertical ice lenses perpendicular to the direction of freezing were found on the MFT column, as seen in Figure 146. The ice lens formation was observed at the depths the samples were obtained from. 


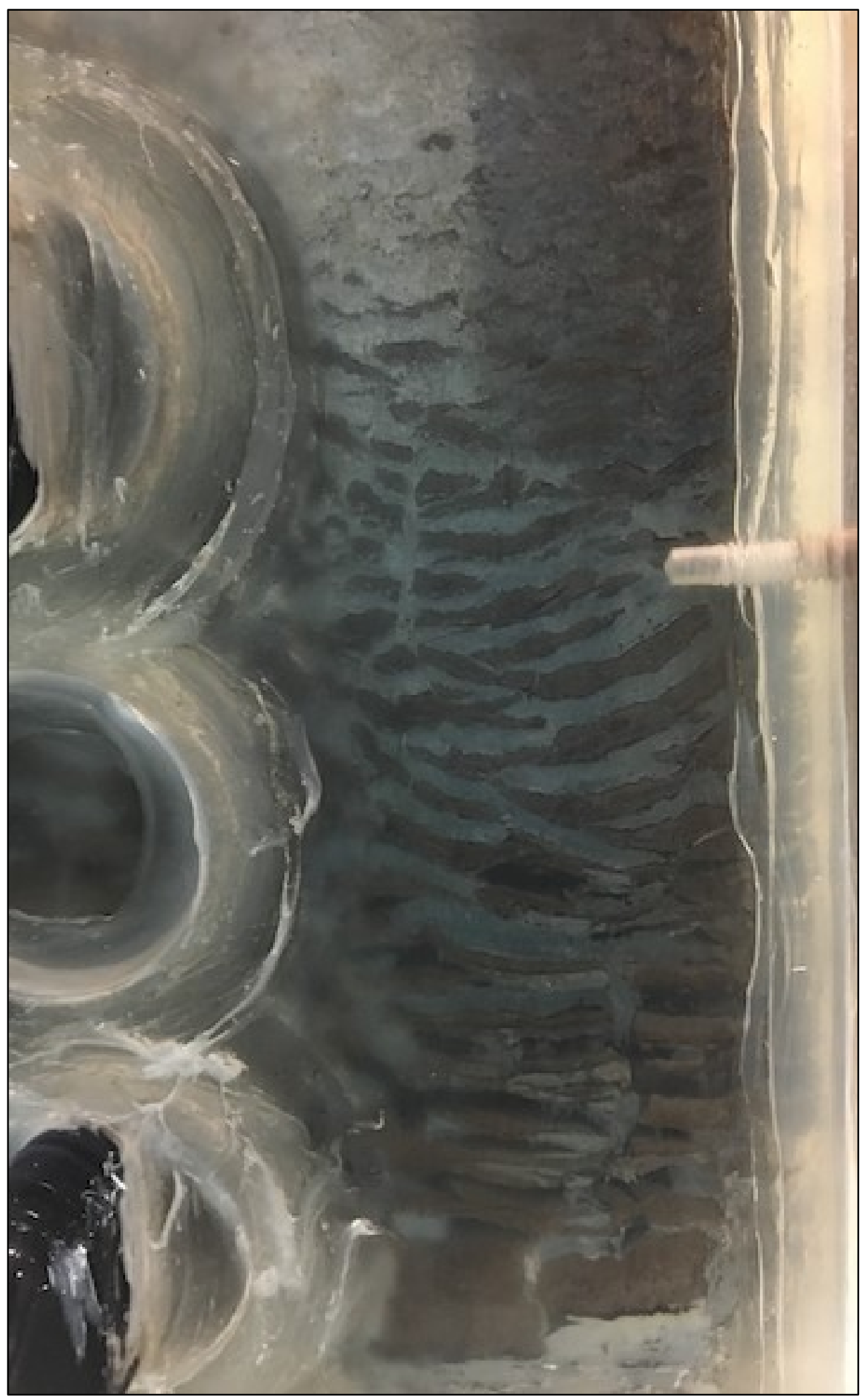

Figure 146. Ice formations perpendicular to the direction of freezing in column test \#3. 
The complete data set obtained from all the consolidation tests is found on Appendix C.

\subsection{Soil Water Characteristic Curve (SWCC) Test}

A soil water characteristic curve was constructed for fresh polymer amended tailings using the same dosage as the column tests. Figure 147 shows the results for the SWCC test.

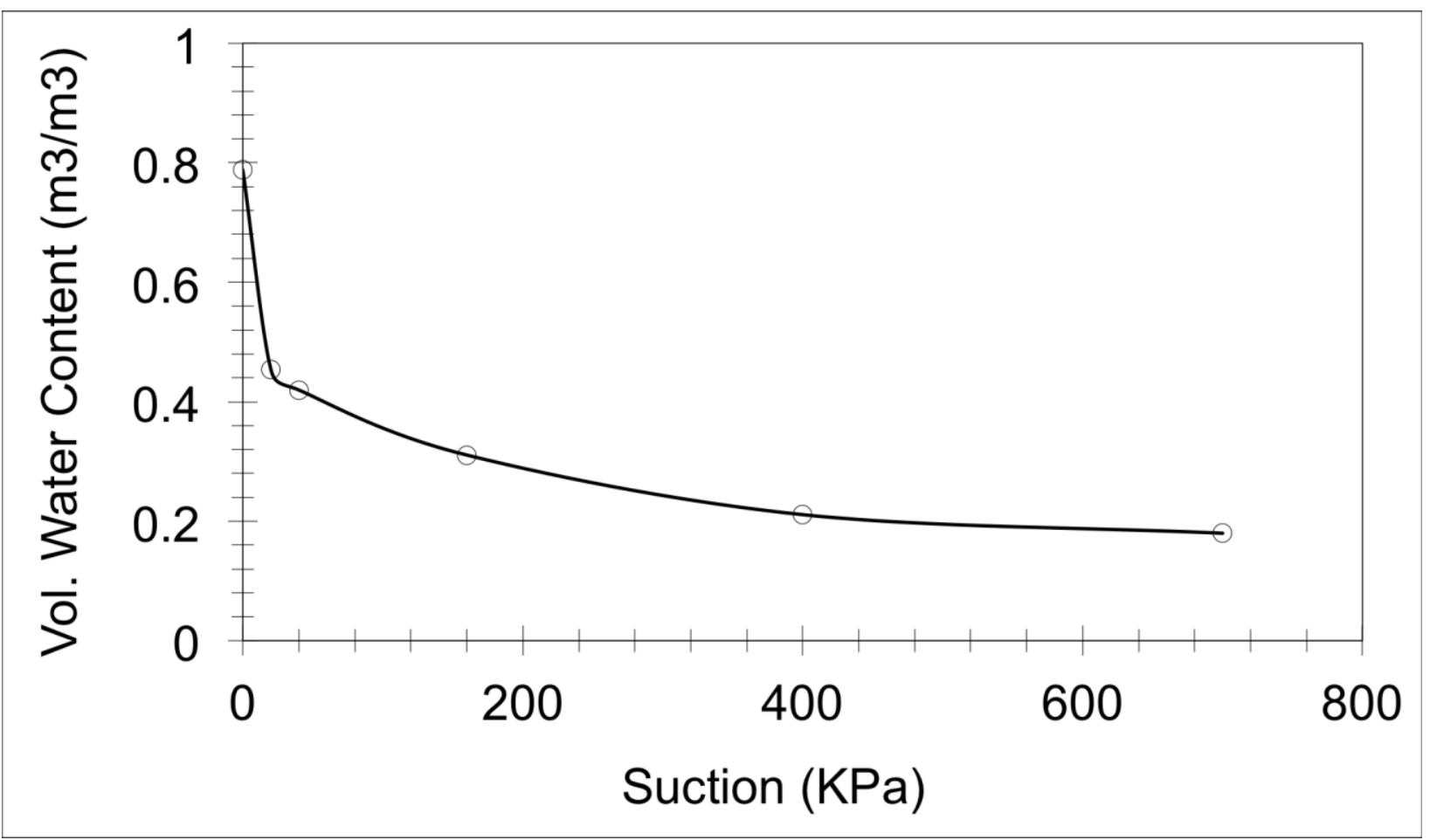

Figure 147. SWCC for freshly made polymer-amended MFT.

The volumetric water content array for the SWCC ranges from $0.79 \mathrm{~m}^{3} / \mathrm{m}^{3}$ to $0.18 \mathrm{~m}^{3} / \mathrm{m}^{3}$, while the matric suction ranges from $0 \mathrm{KPa}$ to $700 \mathrm{KPa}$. 


\subsection{Comparison of Results}

This section presents the comparison between the three column tests performed in this research. Comparisons between column test \#2 and column test \#3 are presented for all their individual results since the testing duration of both columns occurred simultaneously. Comparisons between the two afore mentioned column tests and column test \#1 are drawn where possible since the testing time for column test \#1 was longer than the other two.

\subsubsection{Settlement}

Figure 148 shows the change in height over time for column test \#2 and \#3. For both column tests, during the self-weight consolidation with ambient drying phase, the degree of settlement is very similar being $36.4 \mathrm{~cm}$ and $37.3 \mathrm{~cm}$, respectively. This would indicate that the material in both columns is similar due to their comparable consolidation properties. This agrees with the fact that column test \#2 and \#3 were deposited at the same time using the material. During column test \#3's desiccation phase, the settlement rate is accelerated and the final height at this phase is $31 \mathrm{~cm}$. Meanwhile, column test \#2 continued settling at a constant rate throughout the experiment since it only consisted on one phase, self-weight consolidation. The recorded height at a similar time to the end of the desiccation phase in column test \#2 was $34.3 \mathrm{~cm}$. By comparing both sets of data it is possible to see the immediate effect

of desiccation through evaporation on the MFT. At this point, approximately $1,234 \mathrm{~cm}^{3}$ more of water was removed from column test \#3 than column test \#2. During column test \#3's freezing phase, there was no change in height, as it remained $30 \mathrm{~cm}$ 
throughout the entire phase. Even though an increase in height in the form of frost heave is usually expected, it did not occur due to the placement of the cooling plate at the top of the MFT column. Instead, as liquid water turned into ice and it increased its volume, the tailings were compressed to accommodate the ice volumetric expansion. This may have lead to further consolidation of the tailings during the freezing phase. Column test \#2 continued to settle at a constant rate surpassing the settlement rate of column test \#3 at the end of the freezing phase with a height of $28 \mathrm{~cm}$. During the last phase, thawing, column test \#3 settled the most. The tailings' height decreased approximately by $10.1 \mathrm{~cm}$ at the end of this phase as all ice lenses turned into liquid water and were drained away from the column. The final height for column test \#3 was $19.9 \mathrm{~cm}$ while the final height for column test \#2 was $27.5 \mathrm{~cm}$. The difference in height between both columns is $7.6 \mathrm{~cm}$ or a percentage difference of $32.1 \%$.

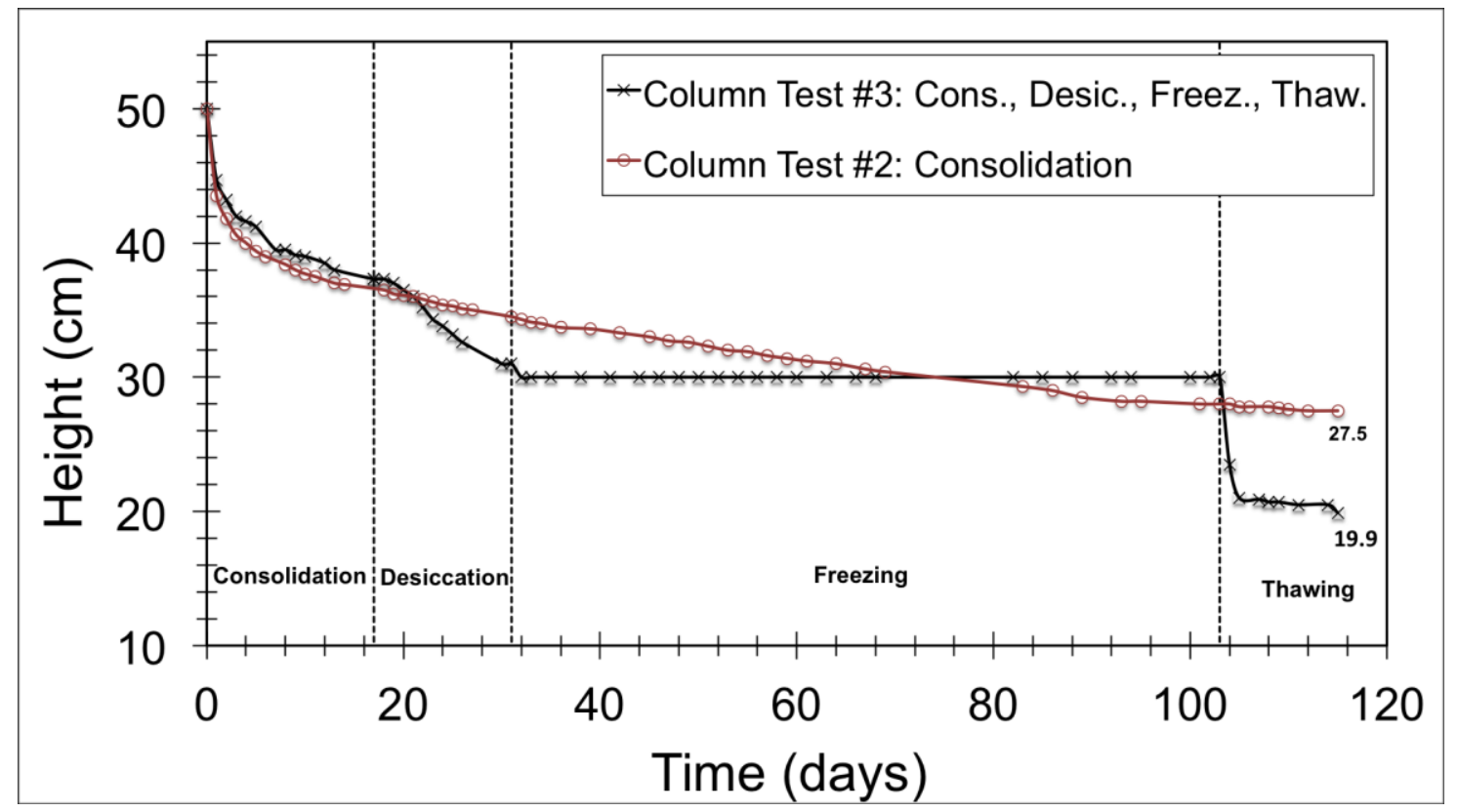

Figure 148. Comparison of height change over time between column test \#2 and column test \#3. 
Figure 149 shows the change in height over time for the self-weight consolidation with ambient drying phase of column test \#1, also the first 51 days of consolidation of column test \#2, and finally the self-weight consolidation and desiccation phases of column test \#3. The settlement rate between column \#2 and \#3 is very similar as determined before. However, the settlement rate of column test \#1 is slower compared to the other two. From the slump tests in Appendix D it is possible to determine the different material properties between column test \#1 and column test \#2 and \#3. Column test \#1 has higher slump test values when compared to the other two column tests. This means that column test \#1 has lower yield stresses at the time of deposition. Also, the difference in consolidation behaviour could be attributed to the different environmental settings the column tests underwent. Column test \#1 took place during the summer months in a room where temperature was not controlled and humidity levels were high. Column test \#2 and \#3 took place during the winter months in a room where the temperature remained almost constant throughout the experiment and humidity levels were low. Also, the different rate of consolidations could be attributed to the fact that the tailings used in Column test \#1 were different than the tailings in Column test \#2 and \#3. They were obtained from different containers that were transported at different times from the field. The material properties between Column test \#1 and Column test \#2 and \#3 could be slightly different. Again, it is possible to see the effect desiccation has on the dewatering of tailings in the data from column test \#3. After the desiccation phase the height of column test \#3 was $31 \mathrm{~cm}$, while the height of column test $\# 1$ and $\# 2$ was $34.5 \mathrm{~cm}$ and $34.7 \mathrm{~cm}$, respectively. The percentage differences between these two values and the height at the end of the self- 
weight consolidation with ambient drying phase in column test \#3 are $10.7 \%$ and $11.3 \%$, respectively. Since the self-weight consolidation with ambient drying phase for column test \#1 and \#2 lasted longer than for column test \#3, further comparisons can be made between the two. After 40 days of self-weight consolidation the heights for both columns converge at $33.5 \mathrm{~cm}$. Both trends continue to decrease until day 51 in which the difference between the two is $0.5 \mathrm{~cm}$. The differences between the consolidation behaviour of Column test \#1 from Column test \#2 and \#3 would indicate that the material (i.e. MFT) used in the three tests was slightly different. Column test \#2 and \#3 show similar consolidation properties, which would indicate the repeatability of the tests.

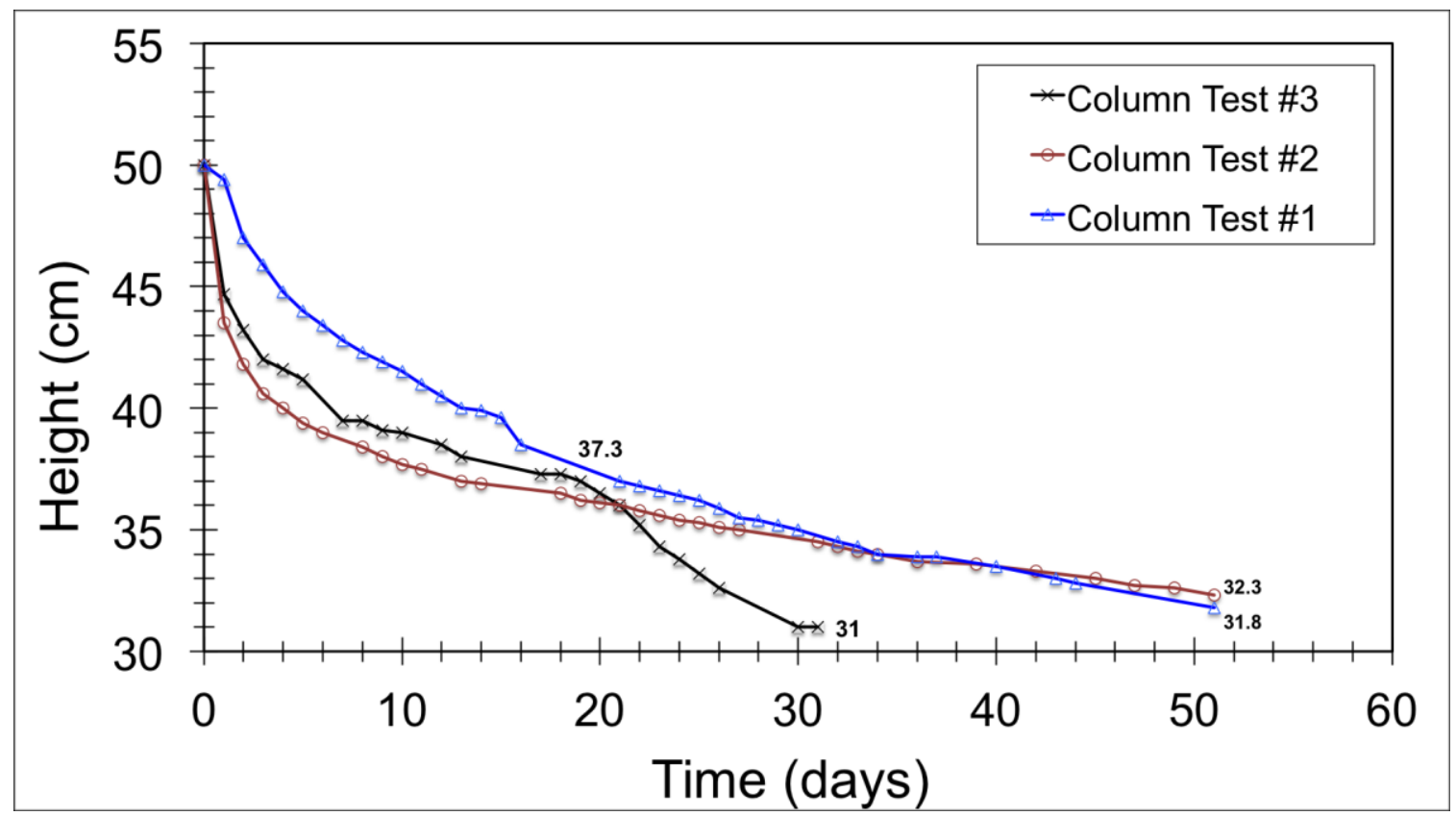

Figure 149. Height change over time comparison between self-weight consolidation with ambient drying phase of column test \#1, column test \#2, and self-weight consolidation with ambient drying \& desiccation phase of column test \#3. 
Furthermore, Figure 150 shows the change in height of column test \#1 and \#3 during the thawing phase. During the same time frame, 8 days, tailings in column test $\# 1$ settled $8 \mathrm{~cm}$, while tailings in column test $\# 3$ settled $9.5 \mathrm{~cm}$. The difference in settlement between the two columns is $1.5 \mathrm{~cm}$ and it could be attributed to the tailings in column test \#3's ability to settle, not only downwards, but sideways since some room was created after the shrinkage of top portion of the tailings allowing further settlement.

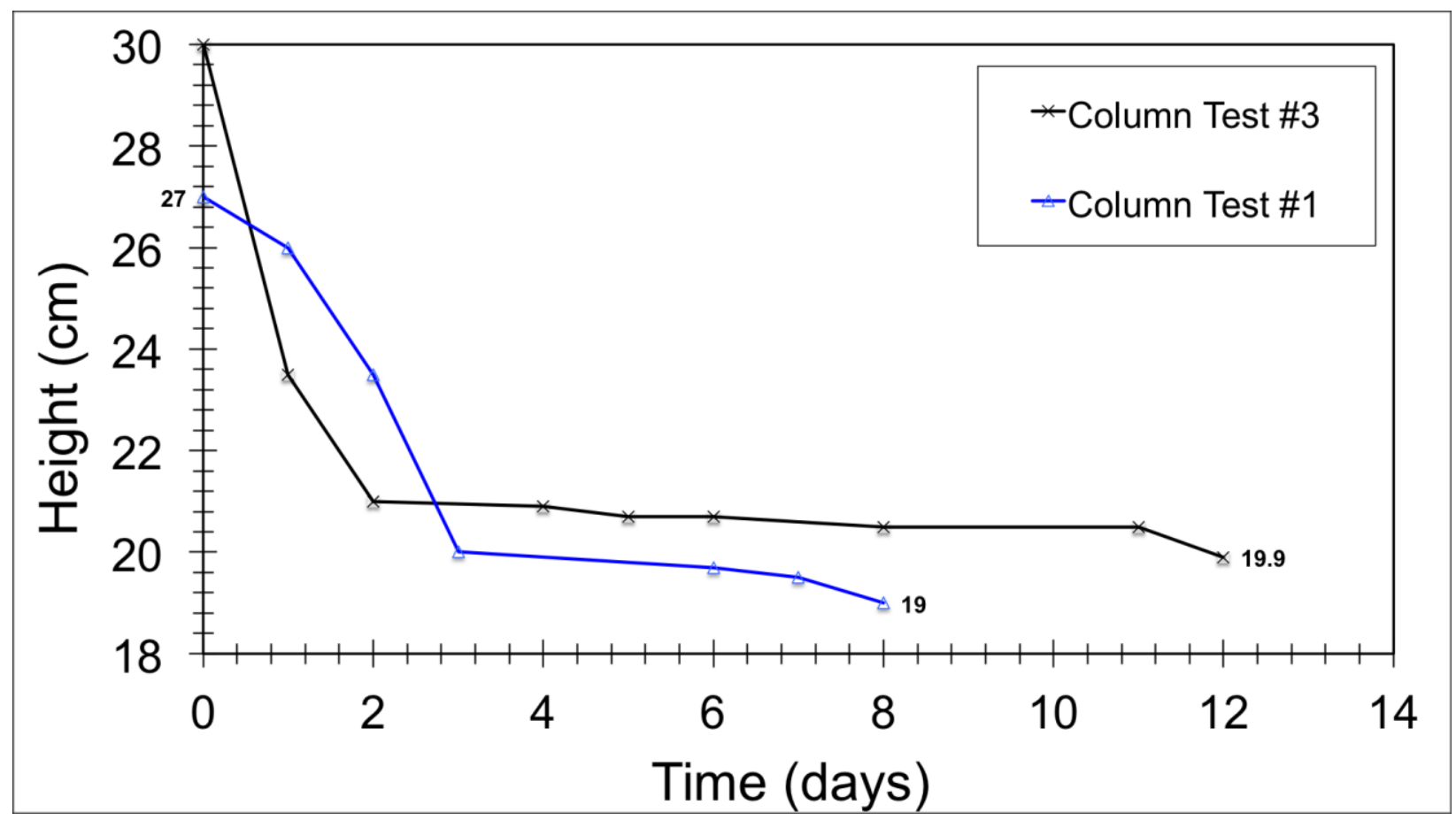

Figure 150. Height change over time comparison between thawing phases of column test \#1 and column test \#3.

Lastly, it is important to note that the difference in height between two columns does not necessarily represent the difference in the amount of water that has been removed from both samples. For example, the lessening in the water mass of the 
tailings in column test \#3 was not longer one-directional after the desiccation phase, but three-directional since the top portion of the tailings started to shrink on all sides. In other words, the reduction in height of column test \#3 from $50 \mathrm{~cm}$ to $19.9 \mathrm{~cm}$ does not mean that $30.1 \mathrm{~cm}$ of water were removed at the end of the test because that measurement only takes into account the change in mass in one direction (i.e. vertical) and not in three directions (i.e. volumetric) as it is the case of the MFT for this particular test. A set of data that better represents the amount of water removed from an MFT column and highlights the impact of a freeze-thaw cycle is the change in weight over time.

\subsubsection{Water Loss}

Figure 151 shows the water loss rate at different times for column test \#2 and column test \#3. As expected, during the self-weight consolidation with ambient drying phase the water loss between the columns is very similar since they are both exposed to the same evaporative conditions and were prepared in a similar manner. The percentage difference in water loss right before the end of the self-weight consolidation with ambient drying phase (day 13 ) is only $7.4 \%$, which is further proof of the similarity in dewatering rates. During the desiccation phase, column test \#3 lost approximately $4 \mathrm{~kg}$ of water, while column test \#2 lost $0.68 \mathrm{~kg}$ of water. The increased evaporation in column test \#3 during this phase is responsible for a water loss difference of $3.32 \mathrm{~kg}$ between the two columns. Also, the $4 \mathrm{~kg}$ of water lost in column test $\# 3$ are responsible for the shrinkage of the top portion of the MFT column. As the freezing phase started, no water loss occurred in column test \#3 since evaporation was not present and under- 
drainage was nearly 0 grams. On the other hand, the water loss rate in column test \#2 remained constant through the entire experiment. The amount of water loss in column \#2 during the same time the freezing phase took in column test \#3 was $3.73 \mathrm{~kg}$. Lastly, during the thawing phase, column test \#3 lost $3.3 \mathrm{~kg}$ of water, while column test \#2 only lost $0.9 \mathrm{~kg}$.

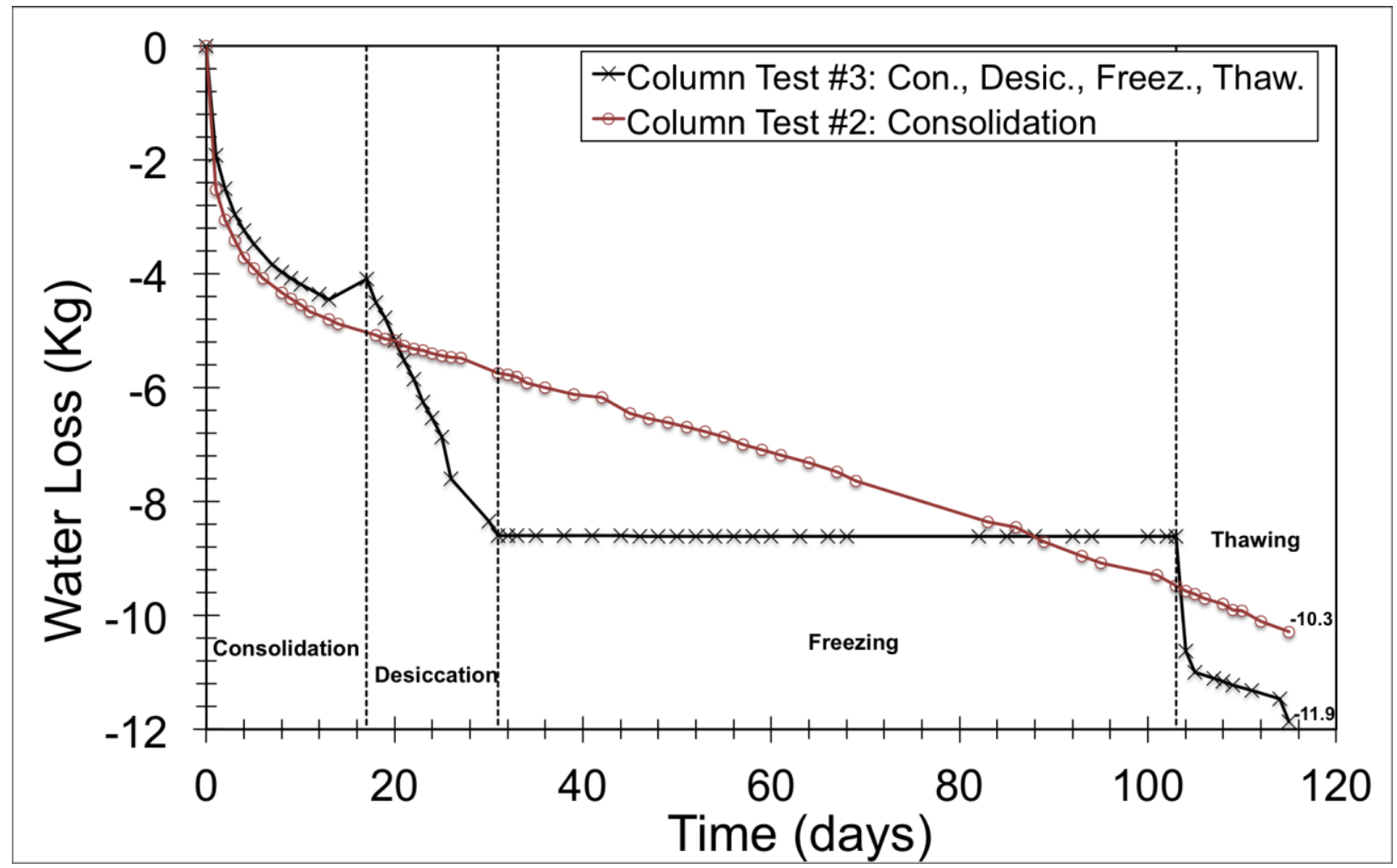

Figure 151. Water loss comparison between column test \#3 and column test \#2.

To sum up, column test \#3 lost a total of $11.9 \mathrm{~kg}$ of water during the entire experiment: $34.3 \%$ was lost during the self-weight consolidation with ambient drying phase, $38 \%$ during the desiccation phase, nearly $0 \%$ during the freezing phase, and $27.7 \%$ during the thawing phase. During the same period of time, column test \#2 lost a 
total of $10.3 \mathrm{~kg}$ of water: $49.5 \%$ during the first 17 days of the experiment (column test \#3's self-weight consolidation with ambient drying phase) and 50.5\% during the rest of the experiment. The dewatering rate during this period remained constant at a loss of 53 grs of water per day. Lastly, as seen in Figure 51, the introduction of desiccation and one freeze-thaw cycle allowed the tailings to dewater $1.6 \mathrm{~kg}$ of water when compared to tailings that only undergo self-weight consolidation. The percentage difference in water loss is $14.4 \%$.

The next figure (Fig. 152) compares the self-weight consolidation with ambient drying phases of column test \#1 (first 51 days) and \#3, and the self-weight consolidation with ambient drying and desiccation phases of column test \#2. Similar dewatering properties are present in column test \#2 and \#3, while column test \#1 shows a slower dewatering rate. The increasing water loss trend during desiccation for column test \#3 is noticeable when compared to the other two. For column test \#1 and \#2, the amount of water lost at the end of column test \#1's self-weight consolidation with ambient drying phase is very similar and just varies by $0.1 \mathrm{~kg}$. 


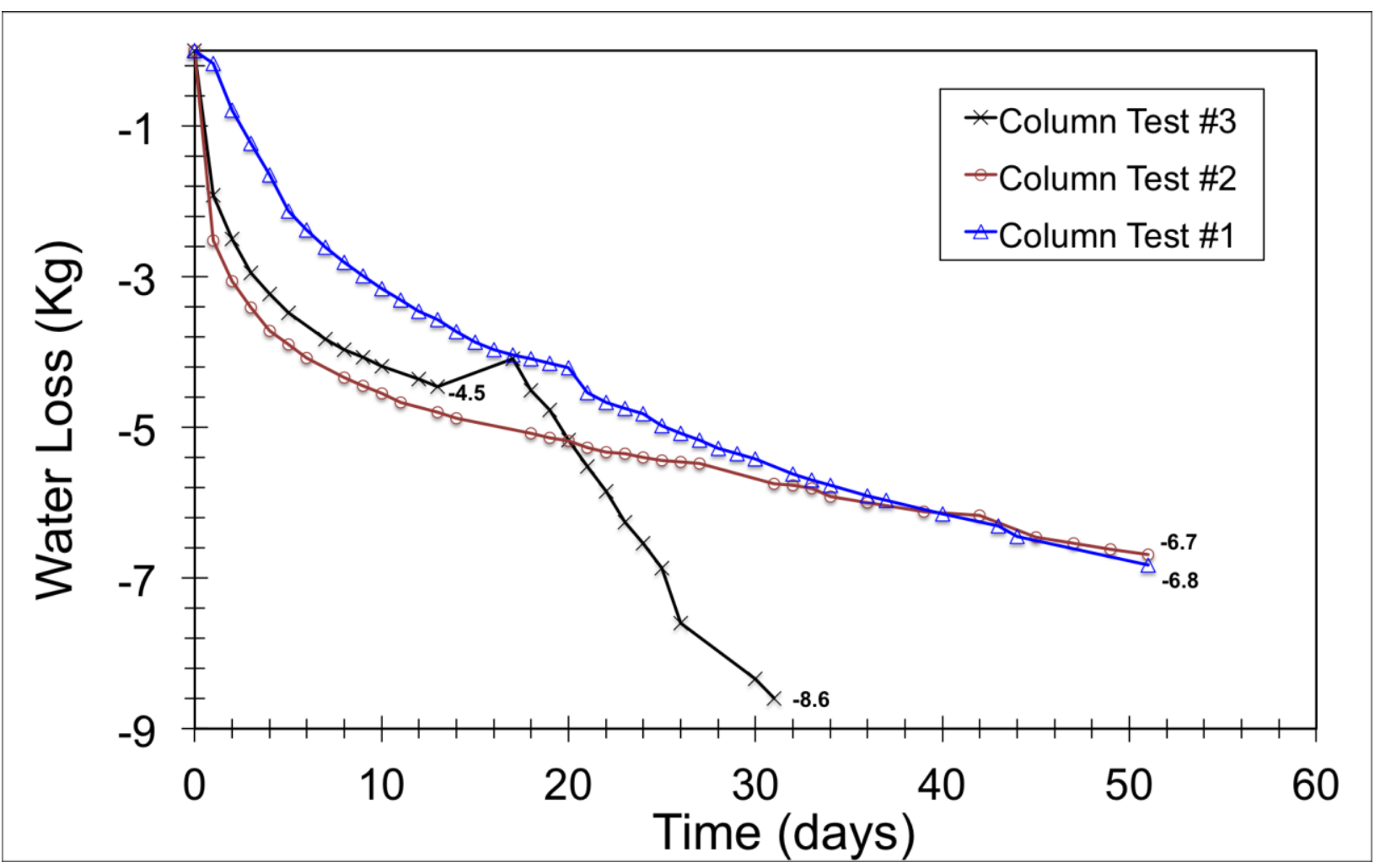

Figure 152. Water loss during the self-weight consolidation with ambient drying phase comparison between column test \#1, \#2, and \#3.

Figure 153 and 154 explore the different contributions of evaporation and under-drainage during the self-weight consolidation with ambient drying phases of the three column tests. Figure 153 shows the constant dewatering rate due to evaporation for three column tests during their respective self-weight consolidation with ambient drying phase. For column test $\# 3$, the evaporation rate changes dramatically due to the introduction of a fan to accelerate the actual evaporation of the tailings. The initial evaporation rate during the self-weight consolidation with ambient drying phase was 43.5 grs of water per day and during the desiccation phase the rate increased to 321.4 grs per day. That is an increase of 277.9 grams per day. The evaporation rate during the 
desiccation phase is clearly over-exaggerated, which amplifies the effects of desiccation in tailings. For column test $\# 1$ and $\# 2$, the evaporation rate remained constant during the self-weight consolidation with ambient drying phase at rates of 53 grams/day and 43 grams/ day, respectively.

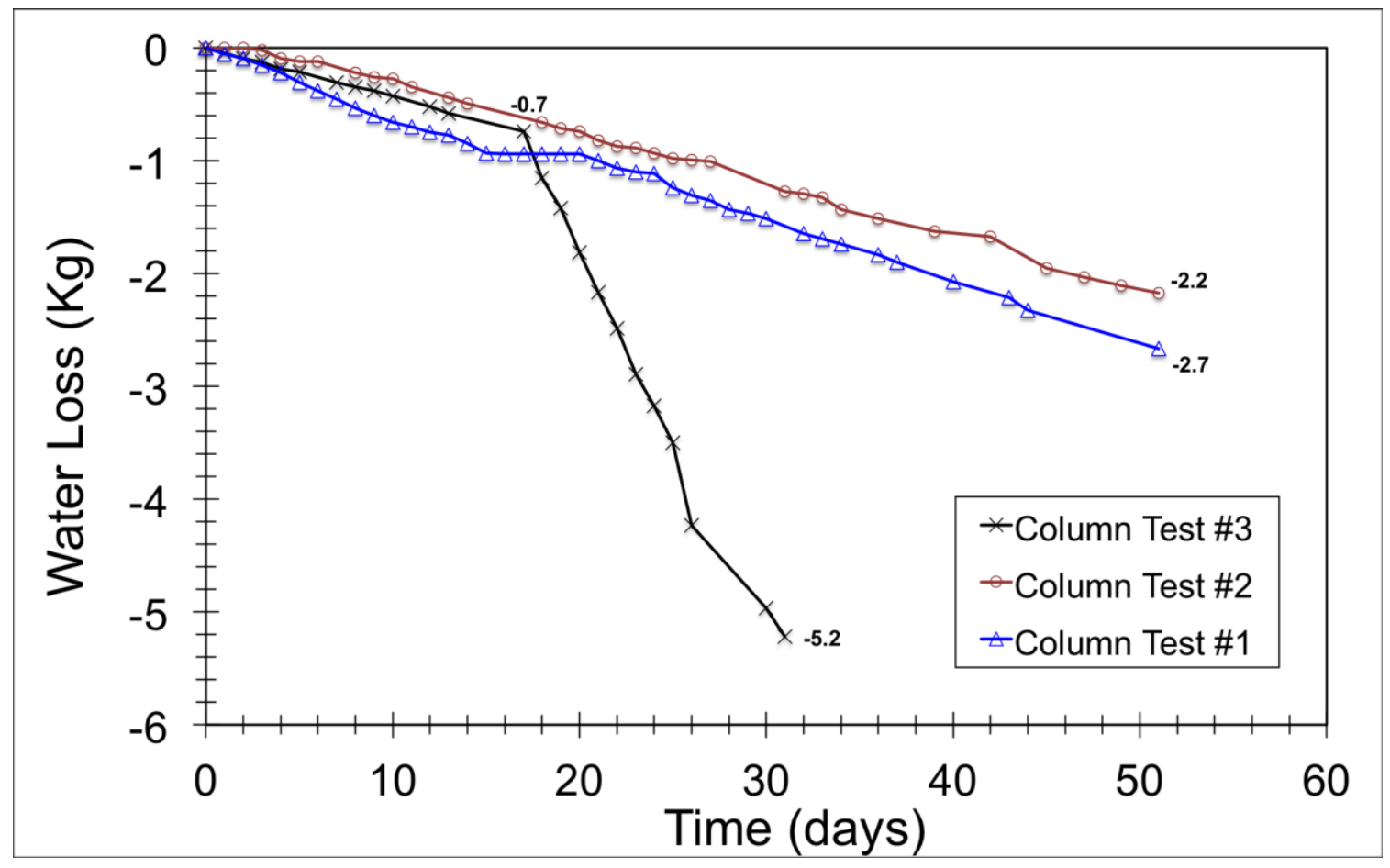

Figure 153. Evaporation contribution to total water loss during the self-weight consolidation with ambient drying phase between column test \#1, \#2 (first 51 days), and \#3.

The next figure (Fig. 154) presents the contribution of under-drainage to water loss during the self-weight consolidation with ambient drying phase of the three column tests. In column test $\# 1$, there is constant under-drainage during the first 36 days of its self-weight consolidation with ambient drying phase. Afterwards, water draining from the bottom of the column stops at a total of $4.2 \mathrm{~kg}$. In column test $\# 2$ and \#3, the underdrainage contribution stops after 18 days at $4.5 \mathrm{~kg}$ and $3.4 \mathrm{~kg}$, respectively. As it has 
been shown, under-drainage only plays a role in the dewatering of polymer amended MFT during the first 3-5 weeks after deposition. As expected, evaporation appears to be present throughout the entire length of the experiment, as it has been presented by evaporation data from column test \#2.

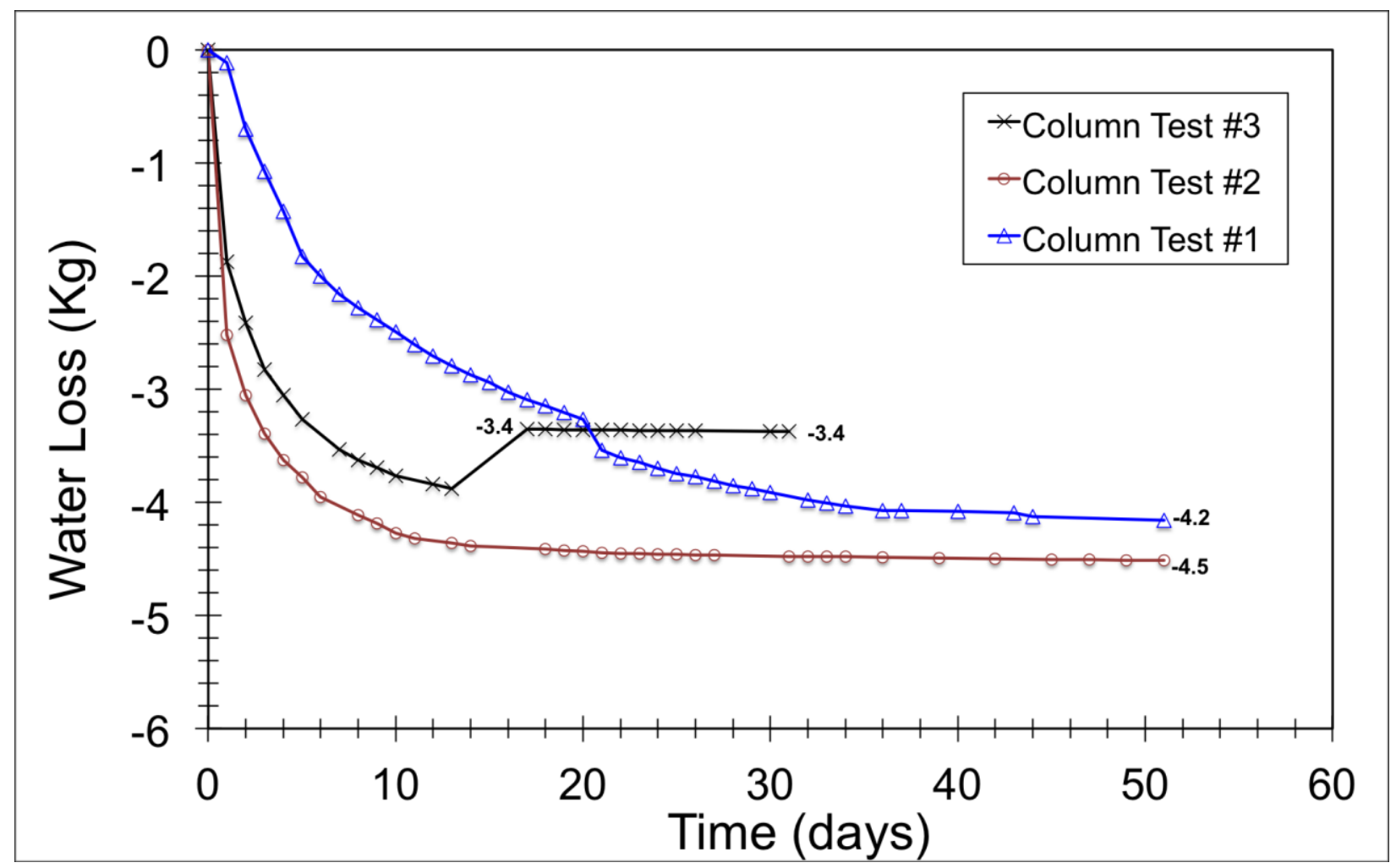

Figure 154. Under-drainage contribution to total water loss during the self-weight consolidation with ambient drying phase comparison between column test \#1, \#2, and \#3.

The last comparison involving water loss corresponds to the thawing period. Figure 155 presents the water loss during the thawing phase for column test \#1 and \#3. During the thawing phase, column test \#1 lost $2.2 \mathrm{~kg}$ of water. Approximately $32 \%$ was lost through evaporation and $68 \%$ was lost through under-drainage. Similarly, column 
test \#3 lost $3.3 \mathrm{~kg}$ of water during the thawing phase: $30.3 \%$ through evaporation and 69.7\% through under-drainage. See Figure 156 and 157 for evaporation and underdrainage contributions to water loss during the thawing phase. In the same way as the self-weight consolidation with ambient drying phase, under-drainage is the dominant dewatering method during the first 2-3 days. Once the ice lenses have all melted, evaporation takes over as the main dewatering method.

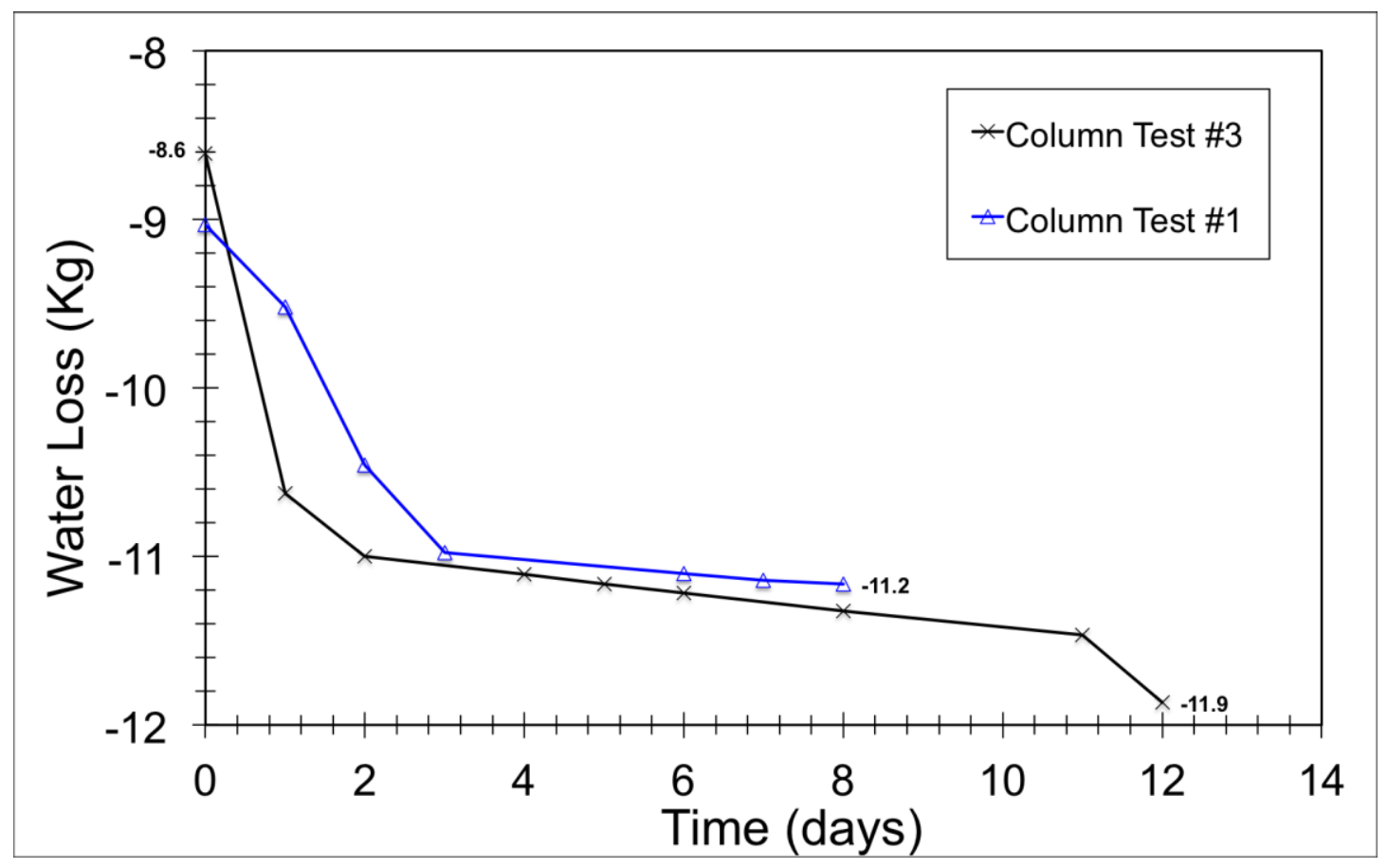

Figure 155. Water loss during the thawing phase comparison between column test \#1 and \#3. 


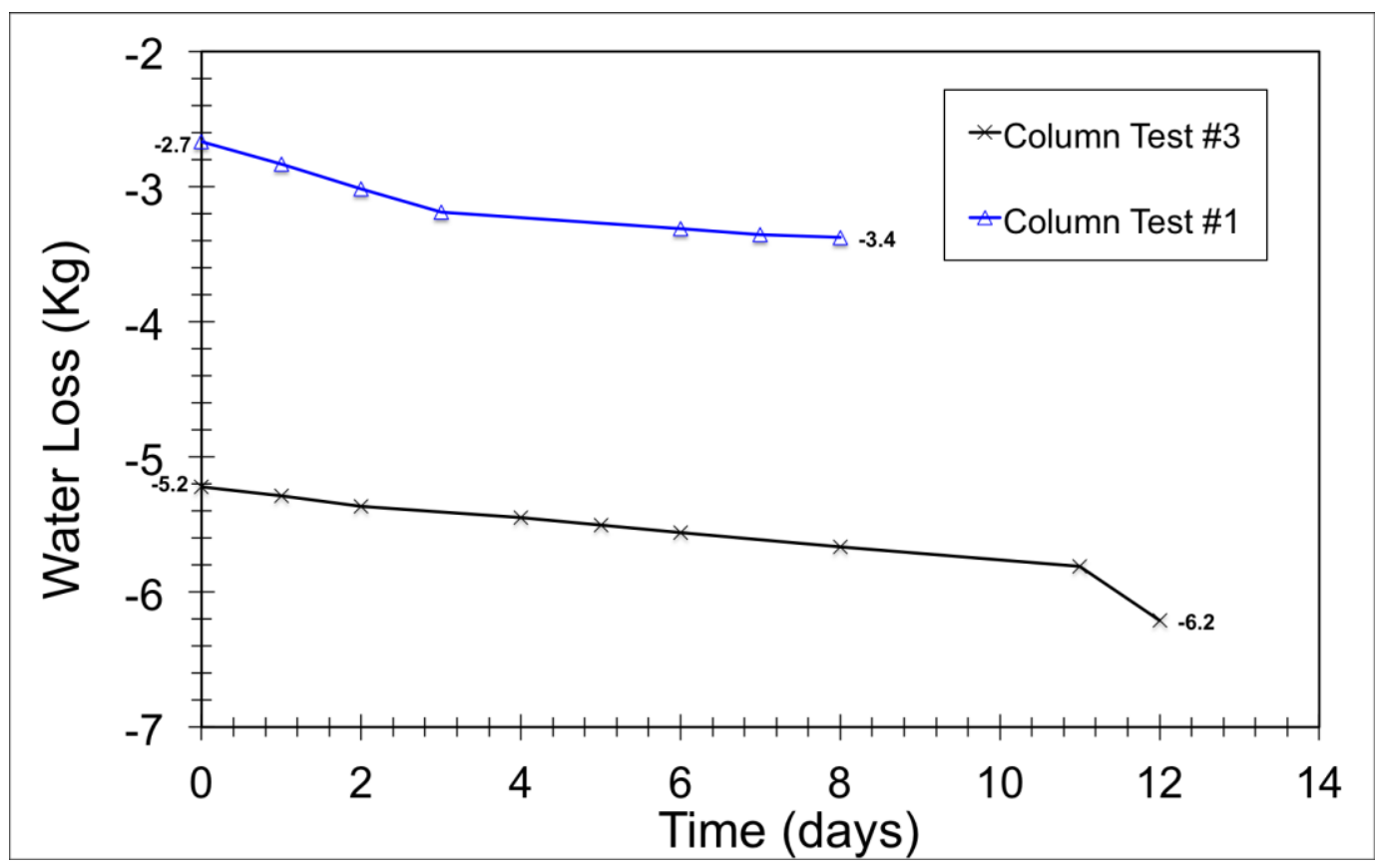

Figure 156. Evaporation contribution to total water loss during the thawing phase comparison between column test \#1 and \#3.

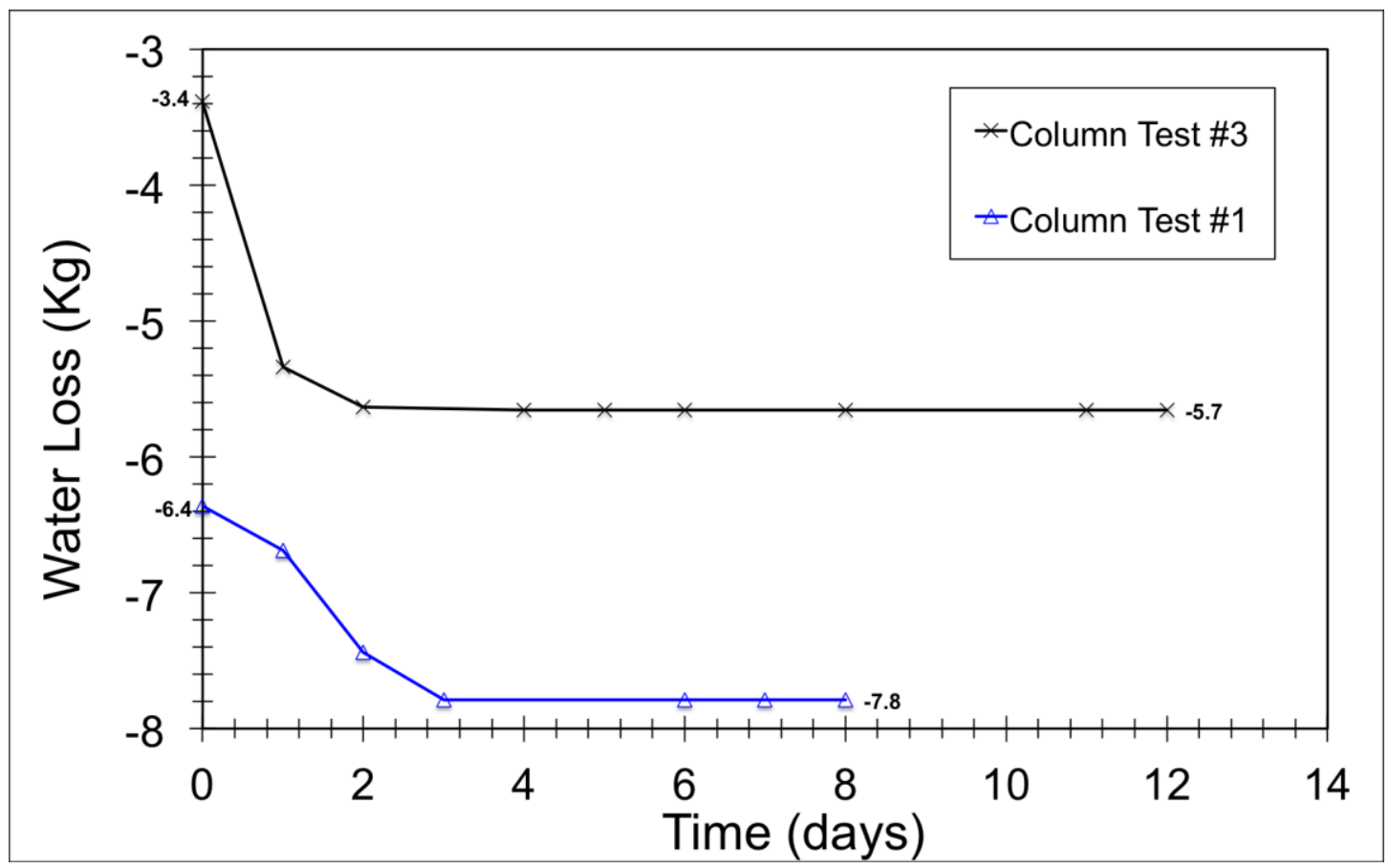

Figure 157. Under-drainage contribution to total water loss during the thawing phase comparison between column test \#1 and \#3. 


\subsubsection{MFT Densification}

As tailings dewater, their average solids content increases. Figure 158 shows the average solids content development of column test \#2 and column test \#3. The solids content trends for both column tests follow the pattern as the water loss since they are both correlated. As expected, column test \#3 shows the bigger changes in solids content during the desiccation and thawing phase. The solids content increased by $13.2 \%$ and $17 \%$, respectively. On the other hand, the average solids content in column test \#2 increased gradually throughout the test to a final solids content of $63.8 \%$. The difference in the average solids content at the end of both tests is $6.1 \%$.

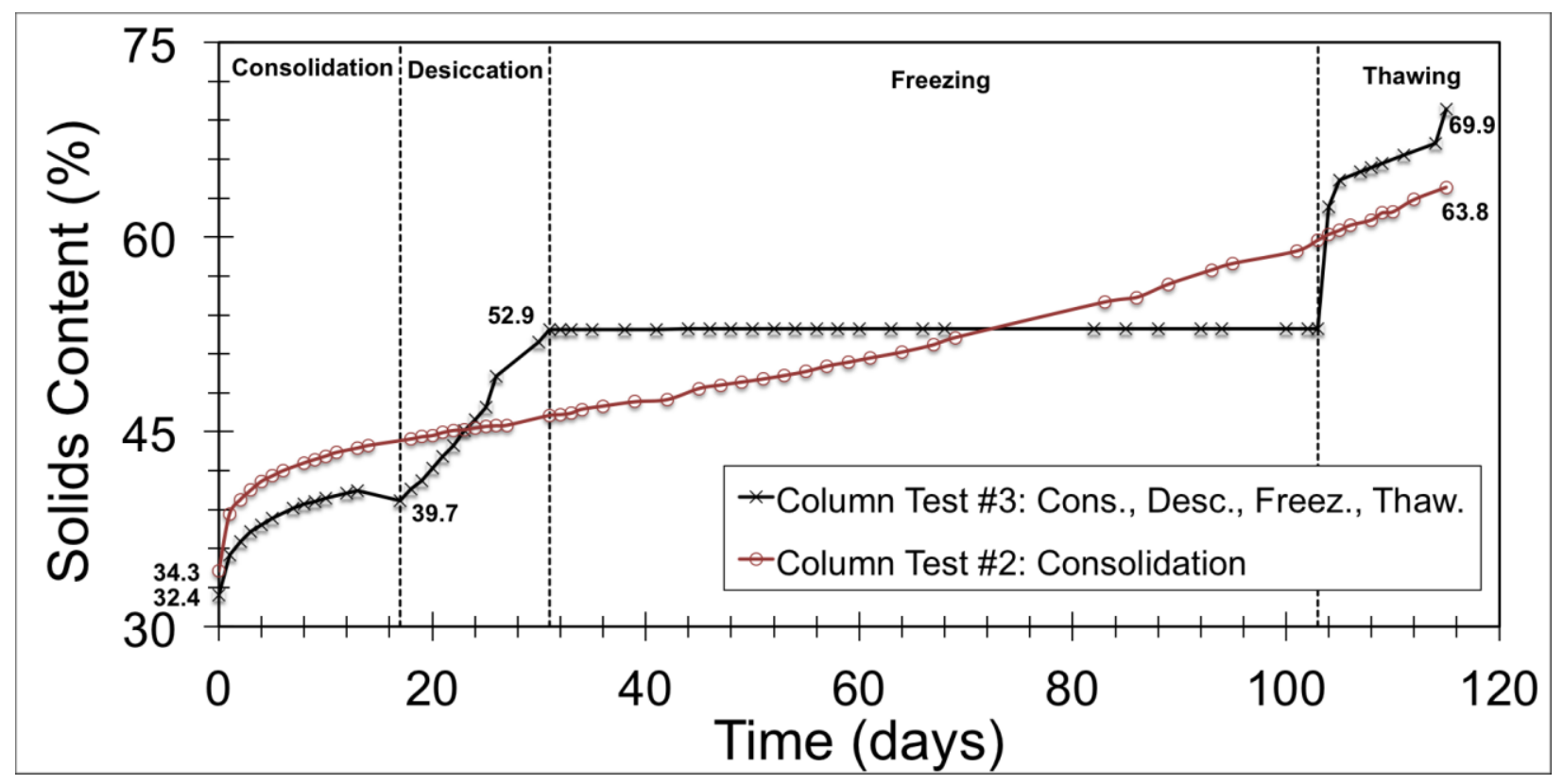

Figure 158. Solids content development comparison between column test \#2 and column test \#3.

Figure 159 shows the development of the average solids content during the selfweight consolidation with ambient drying phase of column test \#1 and \#2, and the self- 
weight consolidation with ambient drying and desiccation phases of column test \#3. During the first 10 days of the experiment the average solids content of column test \#1 and \#3 is almost identical. The trend for column test \#2 presents the same patter as the other two but it contains higher values. As the experiment progressed, the average solids content of column test \#1 and \#2 started to converge at day 34 and continued in a semi-parallel way until the end of the self-weight consolidation with ambient drying phase for column test \#1. The difference in solids content at day 51 was only $1.6 \%$. For column test \#3, the impact of desiccation on solids content is visible as it increases the solids content by $13.2 \%$.

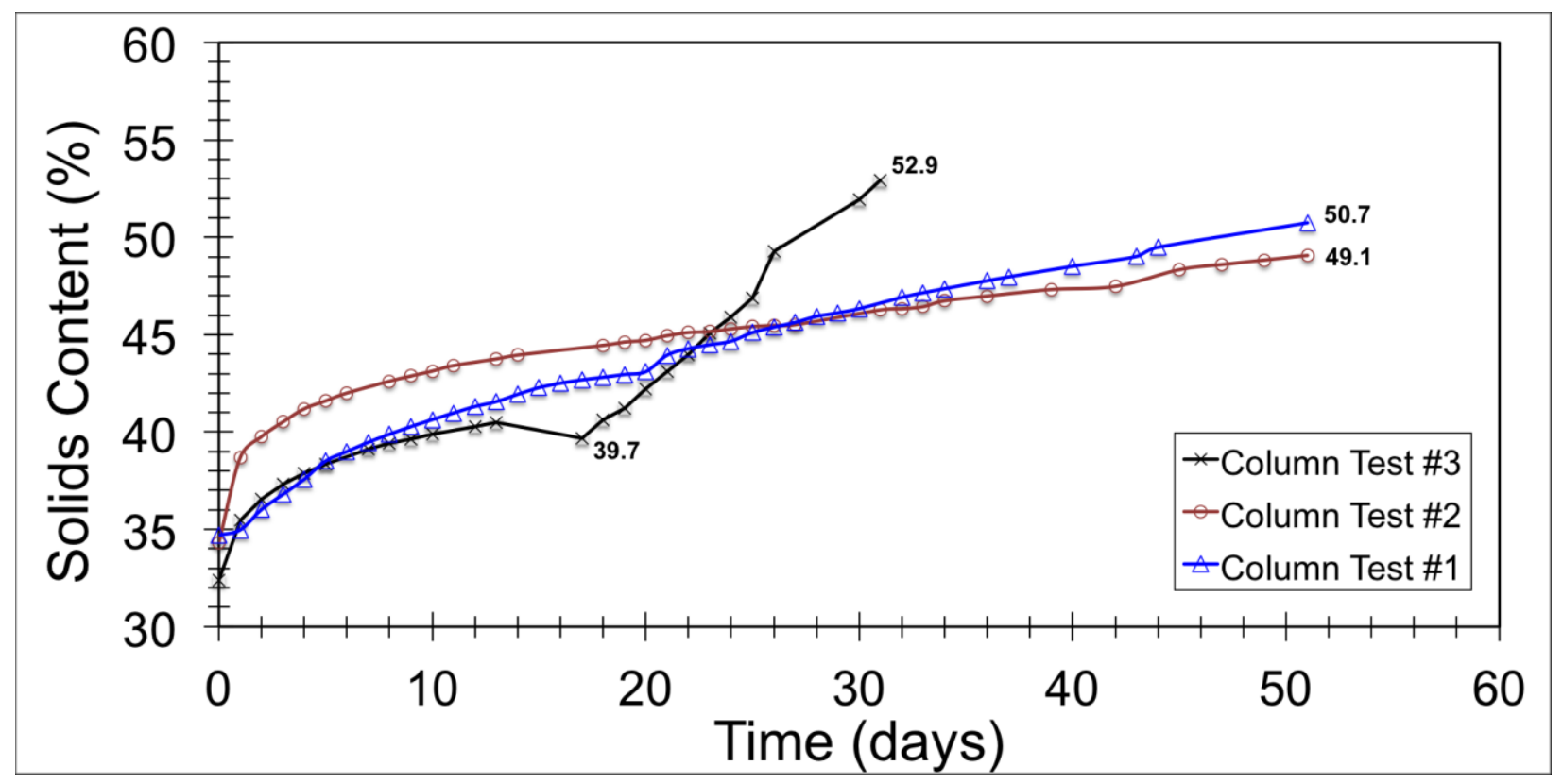

Figure 159. Solids content development comparison between self-weight consolidation with ambient drying phases of column test \#1 \& \#2, and self-weight consolidation with ambient drying and desiccation phases of column test \#3. 
The figure below (Fig. 160) presents the evolution of solids contents during the thawing phase for column test \#1 and \#3. Column test \#1 increased its average solids content by $12.2 \%$, while column test \#3 increased it by $13.3 \%$ over the same amount of time ( 8 days).

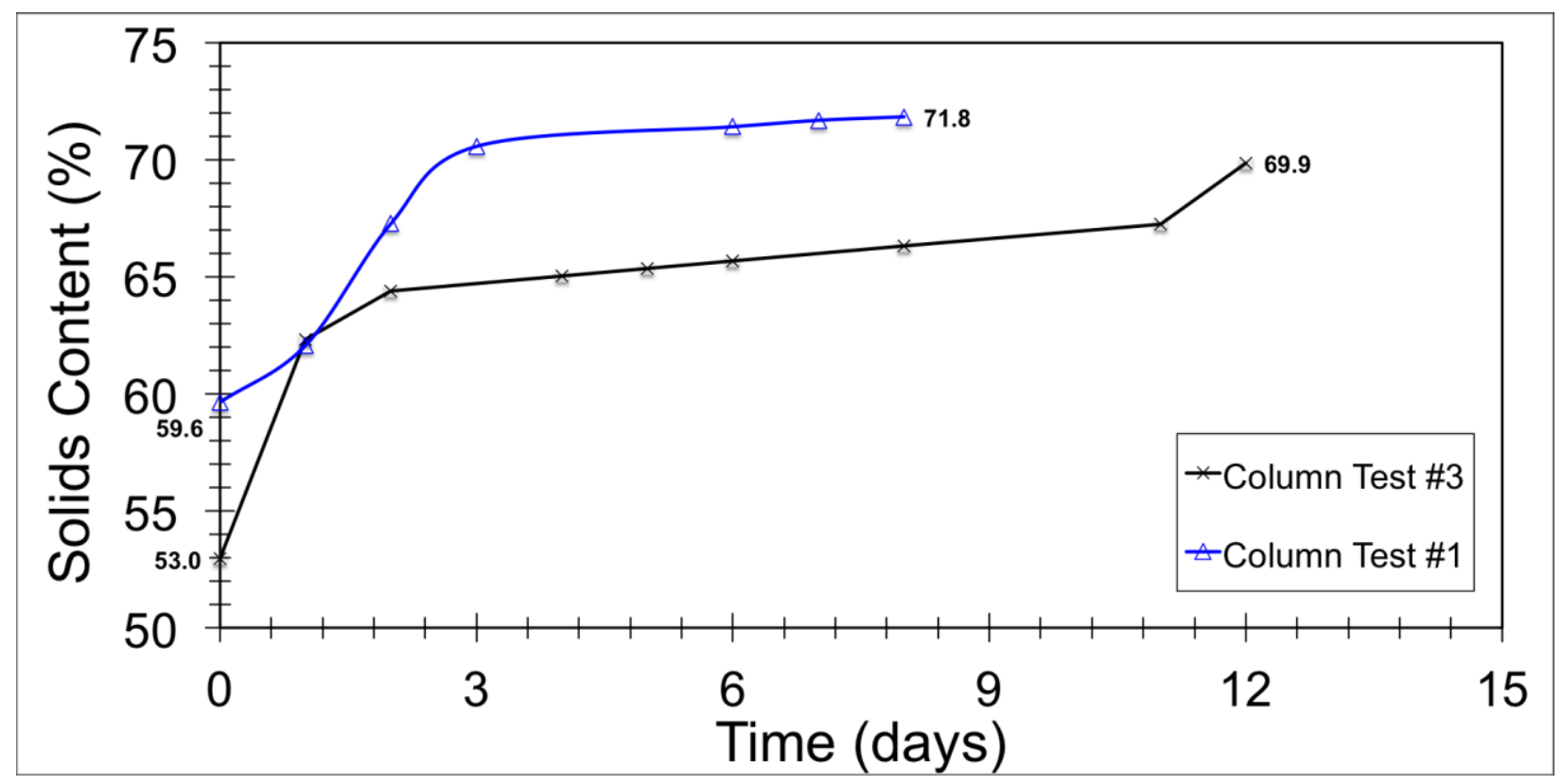

Figure 160. Solids content development during the thawing phase comparison between column test \#1 and column test \#3.

Lastly, Figure 161 presents the solids content profile at the end of the test for all three columns. Column test \#1 had higher solids content towards the surface than at the bottom. The solids content at the surface was $82 \% \mathrm{SC}$ and it decreased at a depth of 5 $\mathrm{cm}$ to $66 \% \mathrm{SC}$. At a depth of $16 \mathrm{~cm}$, the solids content increased again to $71 \% \mathrm{SC}$. Column test \#2 showed a decreasing trend in solids content from $75 \% \mathrm{SC}$ at the surface to $53 \% \mathrm{SC}$ at a depth of $16 \mathrm{~cm}$. Lastly, column test $\# 3$ presented $78 \% \mathrm{SC}$ at the surface 
and it decrease to $66 \% \mathrm{SC}$ at a depth of $5 \mathrm{~cm}$ to increase once more to $71 \% \mathrm{SC}$ at a depth of $16 \mathrm{~cm}$.

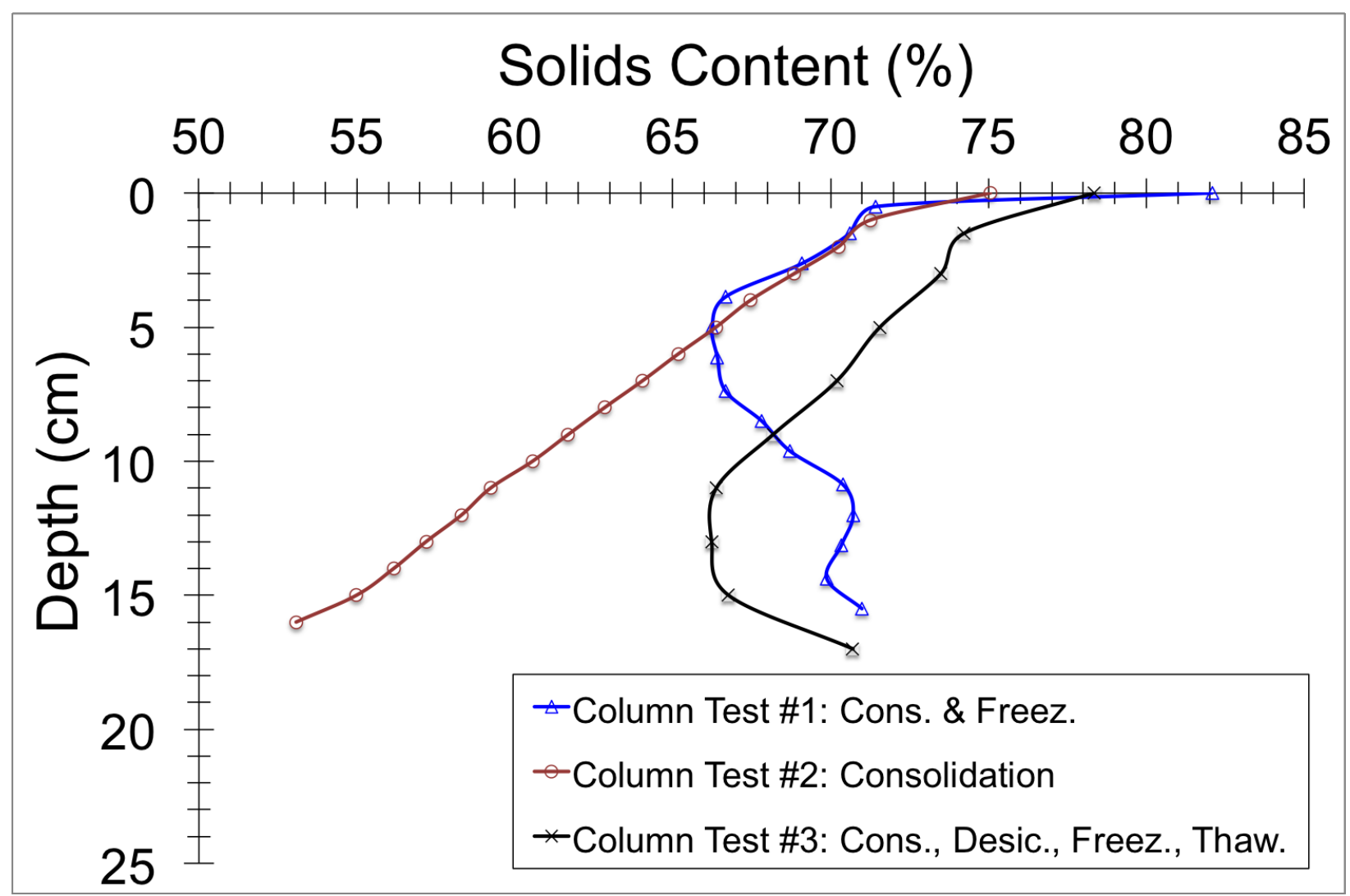

Figure 161. Solids content profile at completion of test comparison between column test $\# 1, \# 2$, and \#3.

\subsubsection{Measured SWCC and SFCC in Different Stages of Dewatering During the}

\section{Freezing Stage}

Figure 162 contains the recorded (MPS-6 sensor) and calculated (Equation $10-$ Section 2.6.4) pore water pressures developed at a height of $22.5 \mathrm{~cm}$ within Column Test \#3 with respect to unfrozen water content (5TE sensor). The calculated pore water 
pressure data was used to construct Soil Freezing Characteristic Curves, or SFCCs, at different heights for Column Test \#1 and \#3. The readings shown below were taken when temperatures were below zero degrees Celsius during the freezing stage alone. Both graphs show a cyclic pattern for the negative and positive pore water pressures due to the constant fluctuation of temperature inside the fridge, which affected the soil temperature as well.

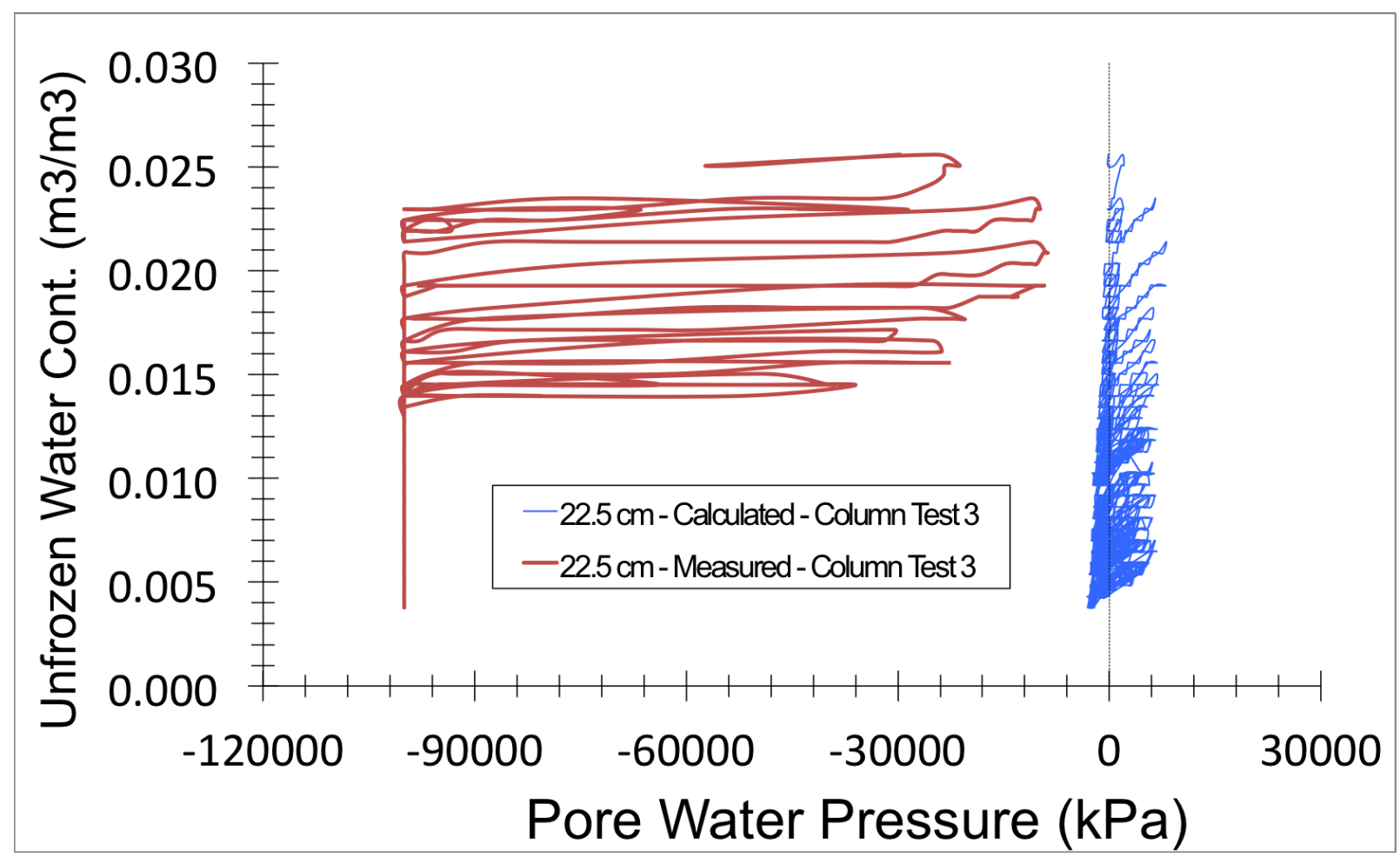

Figure 162. Measured and calculated soil freezing characteristic curve (SFCC) at a height of 22.5 cm for Column Test 3.

The measured data (red line) in Figure 162 shows the development of negative pore pressure, or matric suctions, starting from $-56730 \mathrm{kPa}$ to $-100000 \mathrm{kPa}$ (sensor's reading limit) for unfrozen water contents of $0.025 \mathrm{~m}^{3} / \mathrm{m}^{3}$ to $0.003 \mathrm{~m}^{3} / \mathrm{m}^{3}$, 
respectively. As discussed previously, this shows that this data is indicative of freezing in the sensor's body, not the tailings.

The equation used to calculate the pore water pressure (blue line) from temperature data is found in Section 2.6.4. Figure 163 shows a zoomed version of the calculated data highlighting only the negative pore pressures developed. The matric suctions developed start from $0 \mathrm{kPa}$ to $-3043 \mathrm{kPa}$ for unfrozen water contents of 0.025 $\mathrm{m}^{3} / \mathrm{m}^{3}$ to $0.003 \mathrm{~m}^{3} / \mathrm{m}^{3}$, respectively. The cyclic pattern is also shown since the calculated suctions are linked to temperature variations. A red line going through the highest data points for each cycle was graphed to highlight the trend between unfrozen water content and suction.

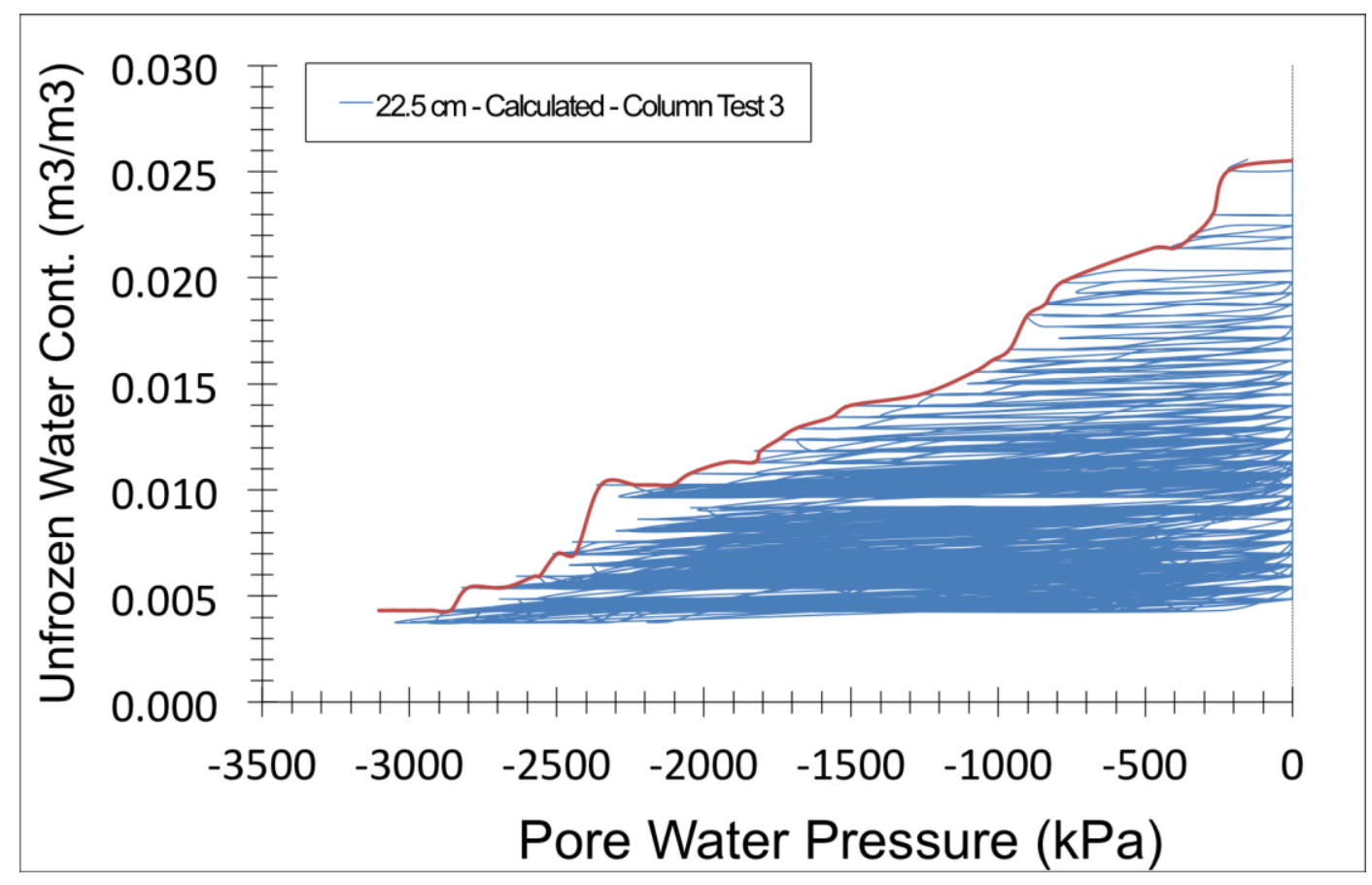

Figure 163. Trend line (red) show the increasing negative pore water pressures in the SFCC at a height of $22.5 \mathrm{~cm}$ in Column Test 3. 
The same graphing procedure to construct SFCCs was followed for other heights from Column Test $\# 1$ and \#3 where data was available. These graphs can be found in Appendix D4. The following figure (Fig. 164) shows a compilation of all the constructed SFCCs from Colum Test \#1 and \#3. The theoretical calculations for the SFCCs show that as initial unfrozen water content decreases (due to previous consolidation and / or desiccation), the slope of the SFCC becomes flatter. This means that there is a large change in matric suction as the variation in unfrozen water content becomes minimal. Figure 164 shows that approximately from an initial unfrozen water content of $0.14 \mathrm{~m}^{3} / \mathrm{m}^{3}$ and under, the slope of the SWCC flattens. For example, the SFCC at a height of $10 \mathrm{~cm}$ in Column Test \#1 has an initial unfrozen water content of $26 \mathrm{~m}^{3} / \mathrm{m}^{3}$ and a final unfrozen water content of $16 \mathrm{~m}^{3} / \mathrm{m}^{3}$. The suction developed during the desaturation process was around $900 \mathrm{kPa}$ at a semi-exponential rate. On the other hand, the SFCC at a height of $22.5 \mathrm{~cm}$ in Column Test 3 has an initial unfrozen water content of $0.025 \mathrm{~m}^{3} / \mathrm{m}^{3}$ and a final unfrozen water content of $0.004 \mathrm{~m}^{3} / \mathrm{m}^{3}$. The suction developed during the desaturation process was around $3100 \mathrm{kPa}$ at a linearalmost-flat rate. 


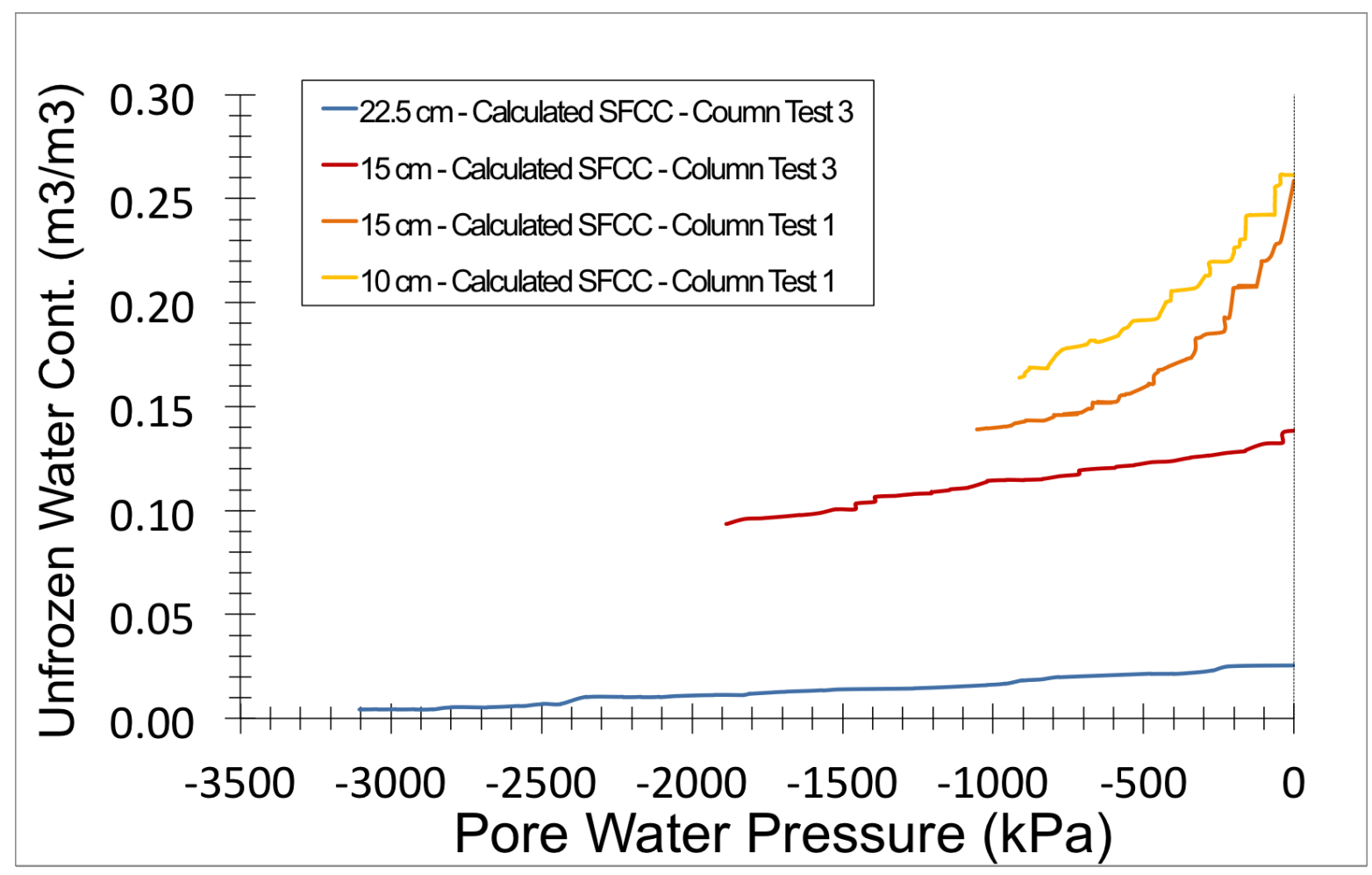

Figure 164. Summary of theoretical SFCCs for Column Test 1 and 3.

Furthermore, all the SFCCs described above are compared to SWCCs measured below the freezing front in Figure 165. The SWCCs shown are further described in Sections 4.2.3.1 and 4.4.3.2. The negative pore water pressure values from the SFCC in Figure 164 were changed to positive values and described as positive suction in a logarithmic scale for better range visualization. Also, the scale in the $\mathrm{x}$-axis in Figure 165 starts at $10 \mathrm{kPa}$ since that is the approximate air-entry-value (AEV) of the ceramic stones in the MPS-6 sensors.

The data corresponding to the height of $22.5 \mathrm{~cm}$ in Column Test \#3 show the SWCC below the freezing front measured by the MPS6 sensor (solid red line) and 
tensiometer (solid orange line) as well as the theoretical SFCC (dotted green line) after the freezing front has passed. The tailings at this height prior freezing have undergone self-weight consolidation with ambient drying and accelerated desiccation. The consolidation of tailings is demonstrated by the change in volume and pore water dissipation over time (see Sections 4.4.2 and 4.4.3). At the end of the accelerated desiccation period, the volumetric water content was reduced to approximately $0.1 \mathrm{~m}^{3 /}$ $\mathrm{m}^{3}$ from the initial $0.34 \mathrm{~m}^{3} / \mathrm{m}^{3}$ at the beginning of the test. Once freezing started, the data recorded by the MPS6 sensor (solid red line) suggests that further desiccation due to freezing occurs prior the arrival of the freezing front. Hence, the relatively small variation in unfrozen water content and the presence of negative pore pressure only. Figure 134 in Section 4.4.3 corroborates the presence of suctions alone at this particular height $(22.5 \mathrm{~cm})$ measured by the MPS6 sensor and tensiometer. The desiccation of the tailings due to freezing continues until the arrival of the freezing front. The suctions developed during this period reached magnitudes of up to $100000 \mathrm{kPa}$ suggesting that the MPS6 sensor might be over-exaggerating the range of desiccation due to freezing below the freezing front. Unfortunately, the data from the tensiometer (solid orange line) is very limited due to breaking of the tensiometer, which does not allow further comparisons with the MPS6 sensor data. Once the freezing front arrives, the theoretical SFCC (dotted green line) shows further desiccation due to freezing at similar unfrozen water contents $\left(\sim 0.02-0.04 \mathrm{~m}^{3} / \mathrm{m}^{3}\right)$, reaching suctions of approximately $3000 \mathrm{kPa}$.

The data corresponding to the height of $15 \mathrm{~cm}$ show the SWCC below the freezing front measured by the MPS6 sensor (solid yellow line) and the theoretical 
SFCC (dotted yellow line) after the freezing front has passed for Column Test \#3. It also shows the theoretical SFCC (dotted black line) for Column Test \#1. The tailings at this height prior freezing in Column Test \#3 have also undergone self-weight consolidation with ambient drying and accelerated desiccation. The consolidation of tailings is assumed to have happened by the change of volume over time. Unfortunately, no tensiometer data is available for further confirmation. At the end of the accelerated desiccation period the volumetric water content was increased to approximately $0.37 \mathrm{~m}^{3} / \mathrm{m}^{3}$ due to the shrinkage of the top portion of the tailings and the accumulation of water at the bottom half of the column (see Section 4.4.2.1). At the beginning of the freezing phase, the data recorded by the MPS6 sensor (solid yellow line) suggests that further consolidation due to freezing occurs prior the arrival of the freezing front. This is backed by the absence of negative pore pressures or suctions during the initial stages of the freezing period (Fig. 135). Right before the freezing front arrives at this height $(15 \mathrm{~cm})$, suctions begin to develop leading to desiccation due to freezing. Simultaneously, desaturation occurs from $0.18 \mathrm{~m}^{3} / \mathrm{m}^{3}$ to $0.14 \mathrm{~m}^{3} / \mathrm{m}^{3}$ and suctions develop up to $200 \mathrm{kPa}$, as seen in Figure 165. Once the freezing front arrives, the theoretical SFCC (dotted yellow line) shows further desiccation due to freezing at similar unfrozen water contents $\left(\sim 0.14 \mathrm{~m}^{3} / \mathrm{m}^{3}\right)$, reaching suctions of approximately $2000 \mathrm{kPa}$. At this height, $15 \mathrm{~cm}$, the SWCC before the freezing front and the SFCC seems to compare well. The data from Column Test \#1 shows similar shape to the data from Column Test \#3 even though it did not undergo an accelerated desiccation phase. The tailings for the SFCC in Column Test \#1 only underwent a self-weight consolidation with ambient drying phase leading to a volumetric water content of 
approximately $0.45 \mathrm{~m}^{3} / \mathrm{m}^{3}$ (see Fig. 87) prior freezing. Since no direct pore water measurements were taken at this height, the evolution of positive pore water pressures and suctions can only be speculated over time during the freezing phase. As expected, during the initial stages of the freezing phase, consolidation due to freezing may have occurred prior the arrival of the freezing front. Desiccation due to freezing may or may have not happened without confirmation from direct measurements. After the freezing front has arrived, desiccation due to freezing is present according to the SFCC (dotted black line). The desaturation occurred from $0.24 \mathrm{~m}^{3} / \mathrm{m}^{3}$ to $0.14 \mathrm{~m}^{3} / \mathrm{m}^{3}$ for a theoretical suction of around $2000 \mathrm{kPa}$.

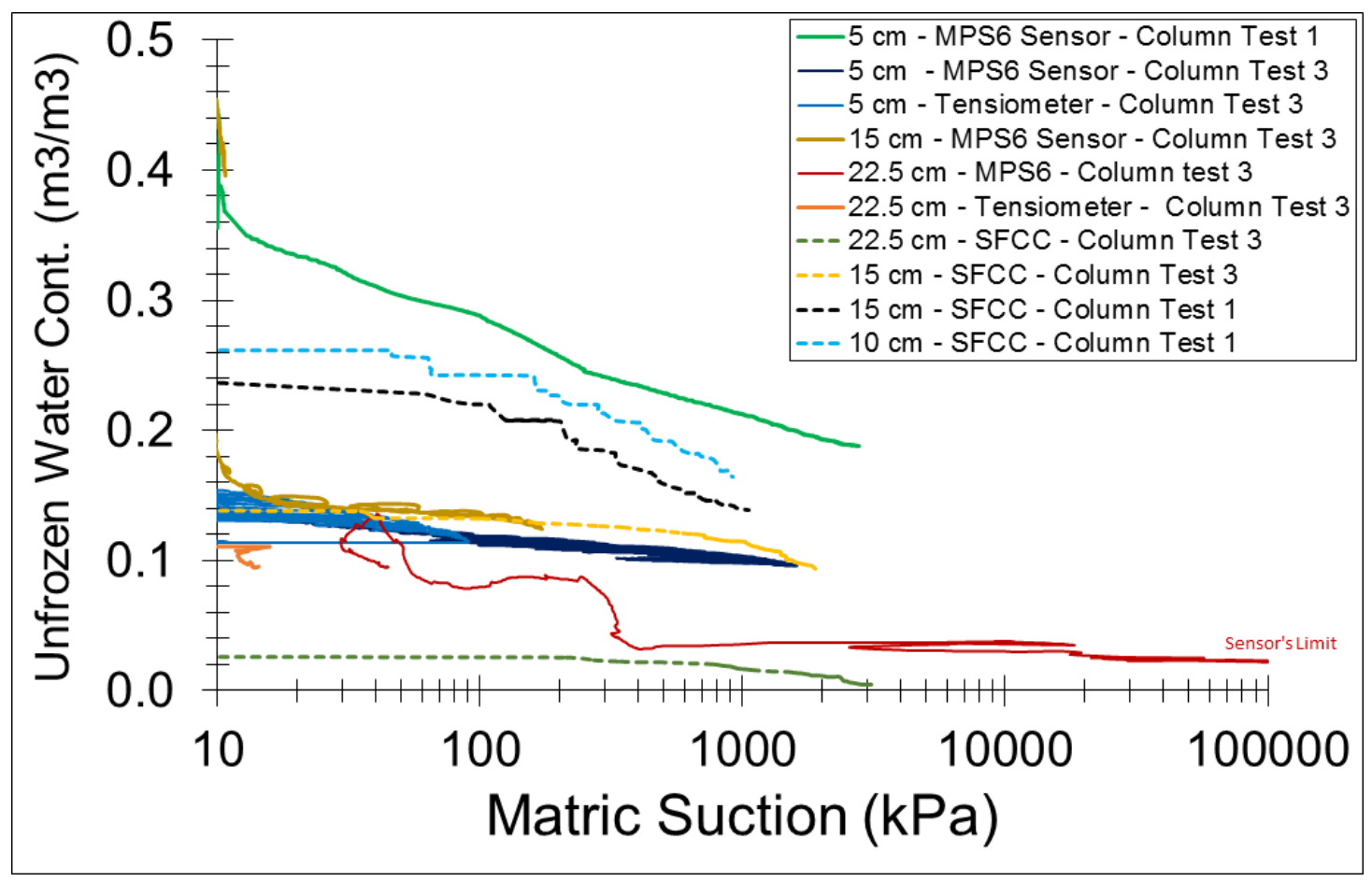

Figure 165. Comparison between soil water characteristic curves (SWCCs) below the freezing front and soil freezing characteristic curves (SFCCs) for Column Test 1 and 3. 
The data corresponding to the height of $10 \mathrm{~cm}$ show the theoretical SFCC (dotted cyan line) after the freezing front has passed for Column Test \#1. The tailings for the SFCC in Column Test \#1 only underwent a self-weight consolidation with ambient drying phase leading to a volumetric water content of approximately $0.47 \mathrm{~m}^{3} /$ $\mathrm{m}^{3}$ (see Fig. 87) prior freezing. Since no direct pore water measurements were taken at this height, the evolution of positive pore water pressures and suctions can only be speculated over time during the freezing phase. As expected, during the initial stages of the freezing phase, consolidation due to desiccation may have occurred prior the arrival of the freezing front. Desiccation due to freezing may or may have not happened without confirmation from direct measurements. After the freezing front has arrived, desiccation due to freezing is present according to the SFCC (dotted cyan line). The desaturation occurred from $0.26 \mathrm{~m}^{3} / \mathrm{m}^{3}$ to $0.18 \mathrm{~m}^{3} / \mathrm{m}^{3}$ for a theoretical suction of around $2000 \mathrm{kPa}$. The SFCCs at heights of $15 \mathrm{~cm}$ and $10 \mathrm{~cm}$ in Column Test \#1 show remarkable similarities in its trends. Both tailings samples desaturated at almost the same rate, reaching similar suctions leading to desiccation due to freezing. It is also an indication of the homogeneity of the material and ice formation at different heights during the freezing phase in Column Test \#1.

Lastly, the data corresponding to the height of $5 \mathrm{~cm}$ show the SWCC below the freezing front measured by the MPS6 sensor (solid dark blue line) and tensiometer (solid light blue line) after the freezing front has passed for Column Test \#3. It also shows the SWCC (solid green line) for the same height in Column Test \#1. The tailings at this height prior freezing in Column Test 3 underwent self-weight consolidation and 
accelerated desiccation. The consolidation of tailings is demonstrated by the change in volume and pore water dissipation over time at this particular height (see Sections 4.4.2 and 4.4.3). Similar to the $15 \mathrm{~cm}$ height data, at the end of the accelerated desiccation period the volumetric water content was increased to approximately $0.42 \mathrm{~m}^{3} / \mathrm{m}^{3}$ due to the shrinkage of the top portion of the tailings and the accumulation of water at the bottom half of the column (see Section 4.4.2.1). At the beginning of the freezing phase and prior to the arrival of the freezing front, the data recorded by the tensiometer (Fig. 138 in Section 4.4.3) shows an increase in positive pore water pressure. This can be attributed to the formation of ice crystals at the top portion of the column, which exerts extra pressure to the lower sections through the soil skeleton and pore water. Approximately mid-way through the freezing phase, positive pore water dissipation occurs suggesting that further consolidation due to freezing is happening. Once negative pore water pressures, or suctions, start to develop, desiccation due to freezing is believed to take place. The SWCC for this height $(5 \mathrm{~cm})$ in Column Test \#3 seems to agree by the readings from the MPS6 sensor and tensiometer. The initial unfrozen water content for both SWCCs starts at approximately below $0.16 \mathrm{~m}^{3} / \mathrm{m}^{3}$ and continues down up to $0.1 \mathrm{~m}^{3} / \mathrm{m}^{3}$. The tensiometer data stops before the MPS6 data because of the tensiometer breaking due to overloading. The SWCC reached a suction value of almost $2000 \mathrm{kPa}$ at the end of the freezing period. There is not data for a SFCC since the freezing phase ended when the temperature at this height was zero degrees Celsius, which means that the freezing front never passed through this height. The tailings for the SWCC in Column Test 1 (solid green line) only underwent a self-weight consolidation with ambient drying phase leading to a volumetric water content of 
approximately $0.35 \mathrm{~m}^{3} / \mathrm{m}^{3}$ (see Fig. 87) prior freezing. Since no direct positive pore water measurements were taken at this height, the evolution of positive pore water pressures can only be speculated over time during the freezing phase. During the initial stages of the freezing phase, consolidation due to freezing may have occurred prior the arrival of the freezing front. Desiccation due to freezing in recorded by the MPS6 sensor, however. The desaturation occurred from $0.4 \mathrm{~m}^{3} / \mathrm{m}^{3}$ to $0.2 \mathrm{~m}^{3} / \mathrm{m}^{3}$ for a suction of around $3000 \mathrm{kPa}$.

Overall, the data suggests that the SWCC before the freezing front and the SFCC after the freezing has arrived seem to agree well for the height of $15 \mathrm{~cm}$ and 22.5 $\mathrm{cm}$. For the other heights no comparable data was obtained. Also, both, the SWCC and SFCC data, show that as their initial water content decreases, the slope of the curve becomes flatter.

\subsubsection{Total Suction at Completion of Test}

Total suction profiles for the three column tests are presented in Figure 166. Column test \#1 shows a total suction value at the surface of $275 \mathrm{kPa}$. Total suction values continued to decrease up to a depth of $10 \mathrm{~cm}$ where the total suction value was $116 \mathrm{kPa}$. Further deep down, the suction values increased to $200 \mathrm{kPa}$ at a depth of 16 $\mathrm{cm}$. Column test \#2 presents a total suction value at the surface of also $275 \mathrm{kPa}$ and it continues to fluctuate until a depth of $16 \mathrm{~cm}$ where the recorded suction was $55 \mathrm{kPa}$. Lastly, column test \#3 presents a high total suction value at the surface of $1615 \mathrm{kPa}$. The total suction decreased with depth reaching $10 \mathrm{kPa}$ at $13 \mathrm{~cm}$. The recorded suction 
value at a depth of $17 \mathrm{~cm}$ was $110 \mathrm{kPa}$. The total suction values for the three columns follow a similar patter to that of the solids content profile in Figure 161. As a general observation, the higher the solids content value, the higher the total suction value and vice versa.

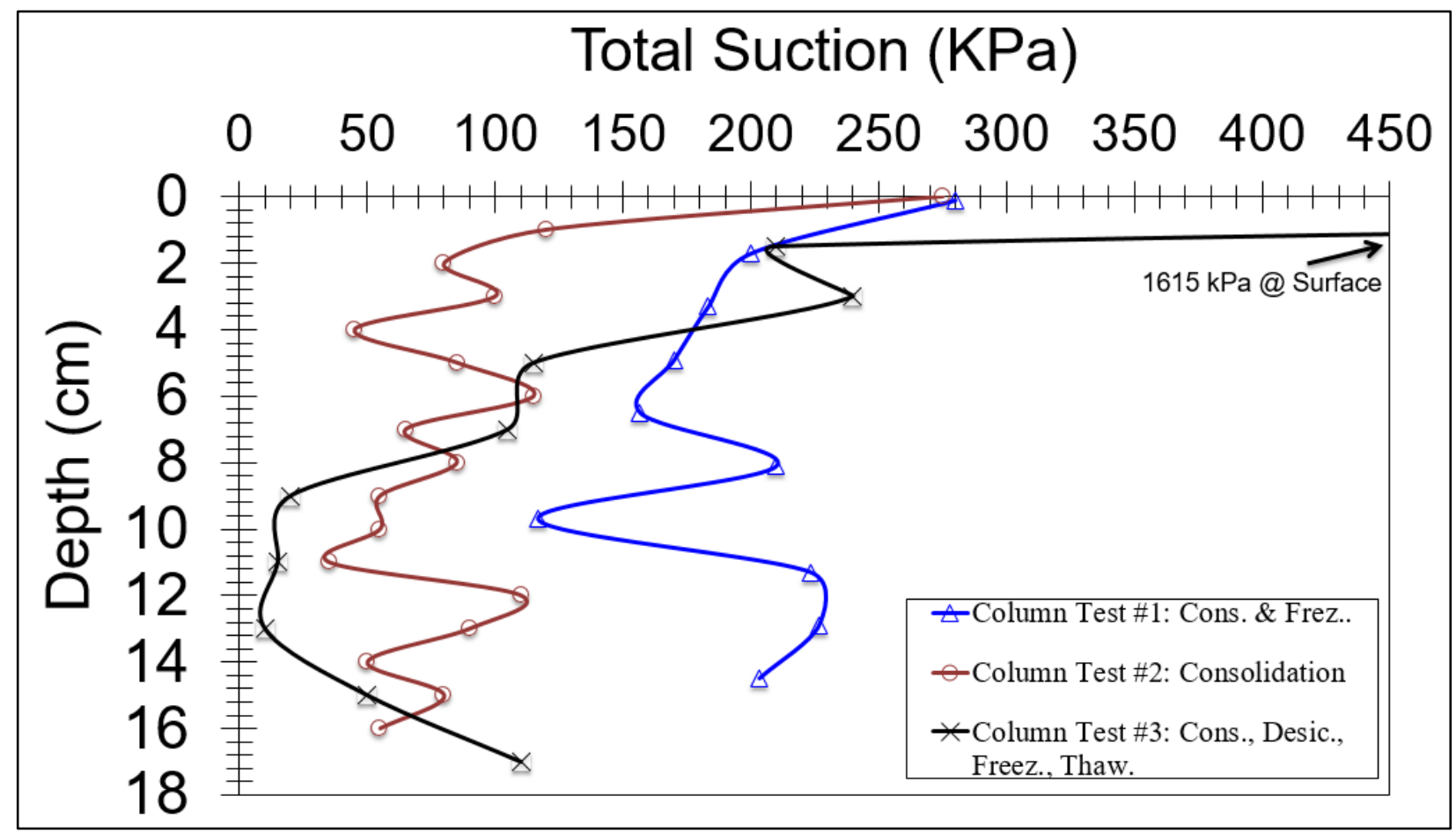

Figure 166. Total suction profile at completion of test for column test \#1, \#2, and \#3. 


\subsubsection{Thaw Strain}

The thaw strain of column test \#1 and \#3 is presented in the table below (Table 21):

Table 21. Thaw strains for column test \#1 and \#3.

Column Test \#1 Column Test \#3

\begin{tabular}{ccc}
\hline Initial height prior thawing & $30 \mathrm{~cm}$ & $27 \mathrm{~cm}$ \\
\hline Final height post thawing & $19.9 \mathrm{~cm}$ & $19 \mathrm{~cm}$ \\
\hline Thaw strain & $\mathbf{3 3 . 7 \%}$ & $\mathbf{3 0 \%}$ \\
\hline
\end{tabular}

Even though both column tests had different phases, testing times, and evaporative conditions, they present similar thaw strains. Both columns lost the similar amounts of water prior freezing. Column test \#1 lost $9 \mathrm{~kg}$, while column test \#3 lost 8.6 $\mathrm{kg}$. It is possible that the water remaining in the system available for freeze-thawing and the similar freezing rate both columns underwent could account for the similar thaw strains.

\subsubsection{Undrained Shear Strength}

Figure 167 shows the undrained shear strength profile for the three column tests obtained from vane shear tests. Column test \#1 presents and increasing trend in undrained shear strength with depth. It shows zero strength a depth of $5 \mathrm{~cm}$. At this depth, the MFT column has the lowest solids content recorded (66\% SC) and a total suction value of $170 \mathrm{kPa}$, which could be reflected in low to non-existing shear strength. At a depth of $15 \mathrm{~cm}$ the undrained shear strength is recorded to be $18 \mathrm{kPa}$. The 
solids content at this depth is $70 \% \mathrm{SC}$, while the total suction value $203 \mathrm{kPa}$. The last data point is at a depth of $17 \mathrm{~cm}$ and the shear strength is reduced to $10 \mathrm{kPa}$. The reduction in strength at this depth is expected since the vane shear test at a depth of 15 $\mathrm{cm}$ disturbed the tailings when placing the vane at the depth of $17 \mathrm{~cm}$. Column test $\# 2$ and \#3 show shear strength values of $22 \mathrm{kPa}$ and $14 \mathrm{kPa}$ at a depth of $5 \mathrm{~cm}$. The solids contents at this depth are $66 \% \mathrm{SC}$ and $71 \% \mathrm{SC}$, respectively. At other depths, the undrained shear strength was recorded to be zero. Column test $\# 2$ and \#3 underwent shrinkage at the top portion of the tailings at different times during the experiment. This event led to the accumulation of water at the bottom of the columns, as explained in Section 4.3. This accumulation of water would increase the pore water pressure of the tailings at depths of $10 \mathrm{~cm}$ and lower decreasing their effective stress and therefore decreasing the undrained shear strength of the tailings.

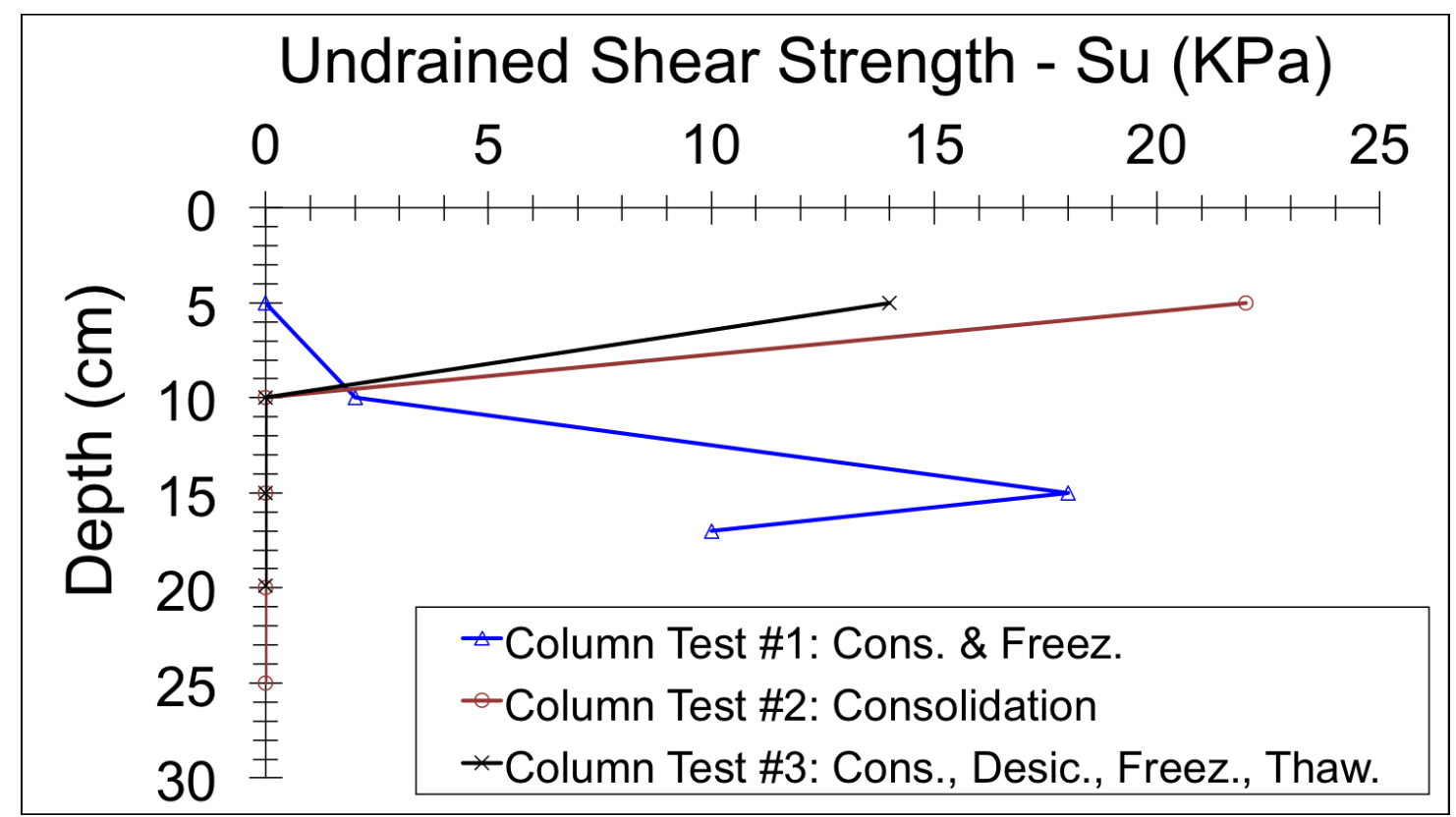

Figure 167. Undrained shear strength profile at completion of test for column test \#1, \#2, and \#3. 


\subsubsection{Consolidation Behaviour and Permeability}

Figure 168 presents the compilation of all the compressibility results obtained from the three column tests at different depths. The gathered data is compared to Soleimani et al., (2014)'s consolidation data from a similar column test in which free bottom drainage occurred but no evaporation was allowed.

When compared to Soleimani et al., (2014)'s data, it is possible to see the immediate impact of a freeze-thaw cycle for column test \#1 (green lines) and \#3 (blue lines), which is to reduce the initial void ratio of the MFT sample. The initial void ratio for all those samples is in between 1.6 and 1.2, while the initial void ratio in Soleimani et al., (2014) is 3. Also, the samples from column test \#2 show a different behaviour. The sample at $10.75 \mathrm{~cm}$ has higher initial void ratio than the sample nearest to the surface $(4.35 \mathrm{~cm})$. This could be attributed to the shrinking of the top portion of the MFT column, which led to accumulation of water at the bottom of the column. The water content at the depth of the $4.25 \mathrm{~cm}$ samples was $48 \%$ while the water content near the $10.75 \mathrm{~cm}$ sample was $75 \%$. When compared to data from Salam (2016), all the data points from the three column tests show higher void ratios at effective stresses of $10 \mathrm{kPa}$. However, at effective stresses lower than $10 \mathrm{kPa}$, Salam (2016)'s data ranges between void ratios of 0.9 and 1.1, which falls in between data from column test \#1

(green). The material used by Salam (2016) was left to self-weight consolidate for 4 weeks allowing drainage and preventing evaporation. The polymer dosage was 600 $\mathrm{mg} / \mathrm{kg}$. 


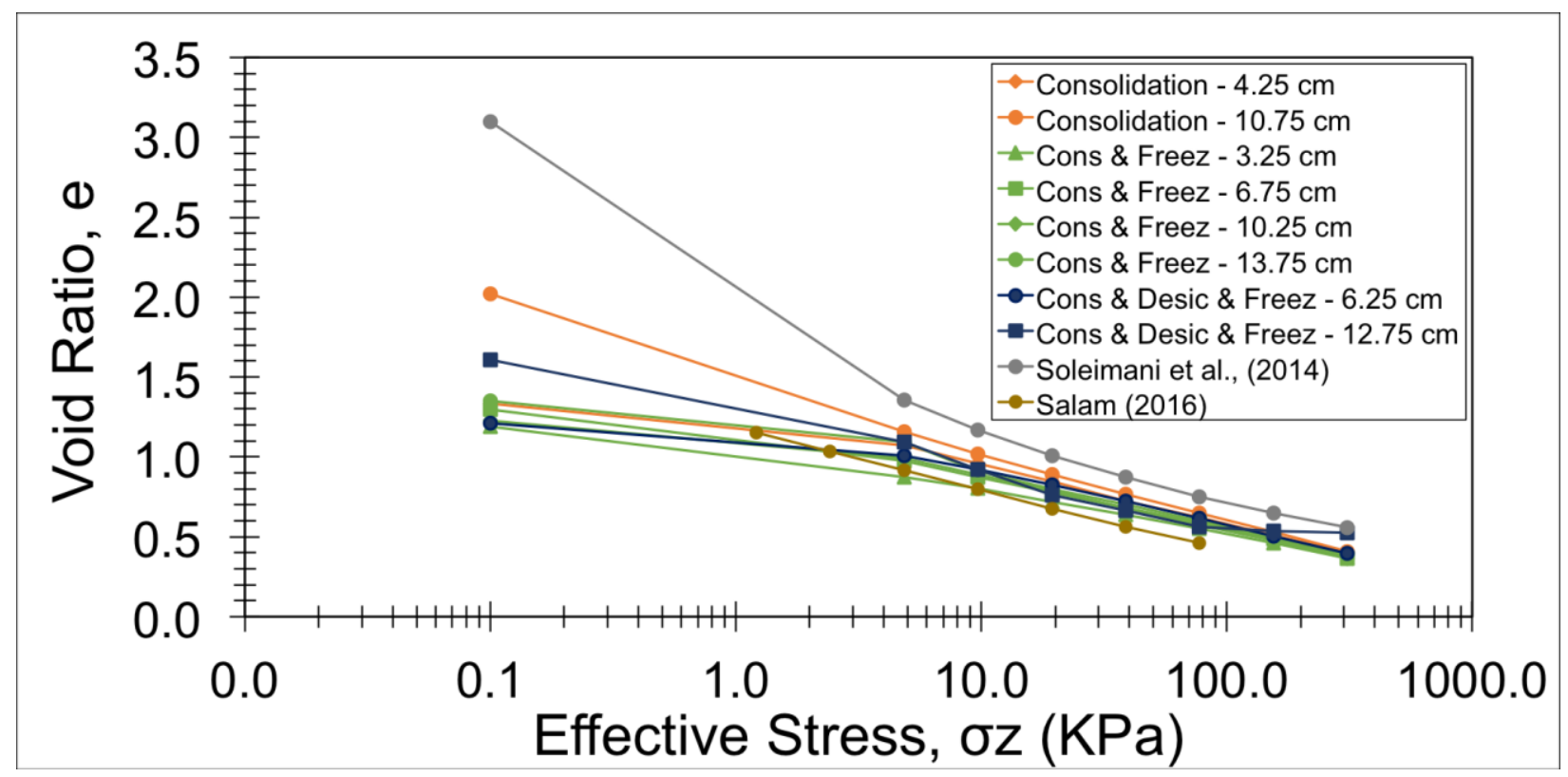

Figure 168. Void ratio vs. effective stress data from all column tests.

Figure 169 shows the hydraulic conductivity data from all the three columns. They were calculated using Terzaghi's consolidation theory. It is possible to see that all data points fall within the same band. Most of the permeability values are lower than $10^{-9} \mathrm{~m} / \mathrm{s}$, except for the values corresponding to the last load increment. As expected, the hydraulic conductivity of the MFT increases as the void ratio increases in an approximate linear trend. Furthermore, the sample at a height of $3.25 \mathrm{~cm}$ from column test \#1 shows the highest permeability values when compared to the other samples. The results from column test \#1 (green) and \#3 (blue) lay in between or at higher values than the samples from column test \#2 (orange). In other words, the 'only-consolidation' column (column test \#2) shows lower permeability values than the column test \#1, and \#3. This type of behaviour was expected. 


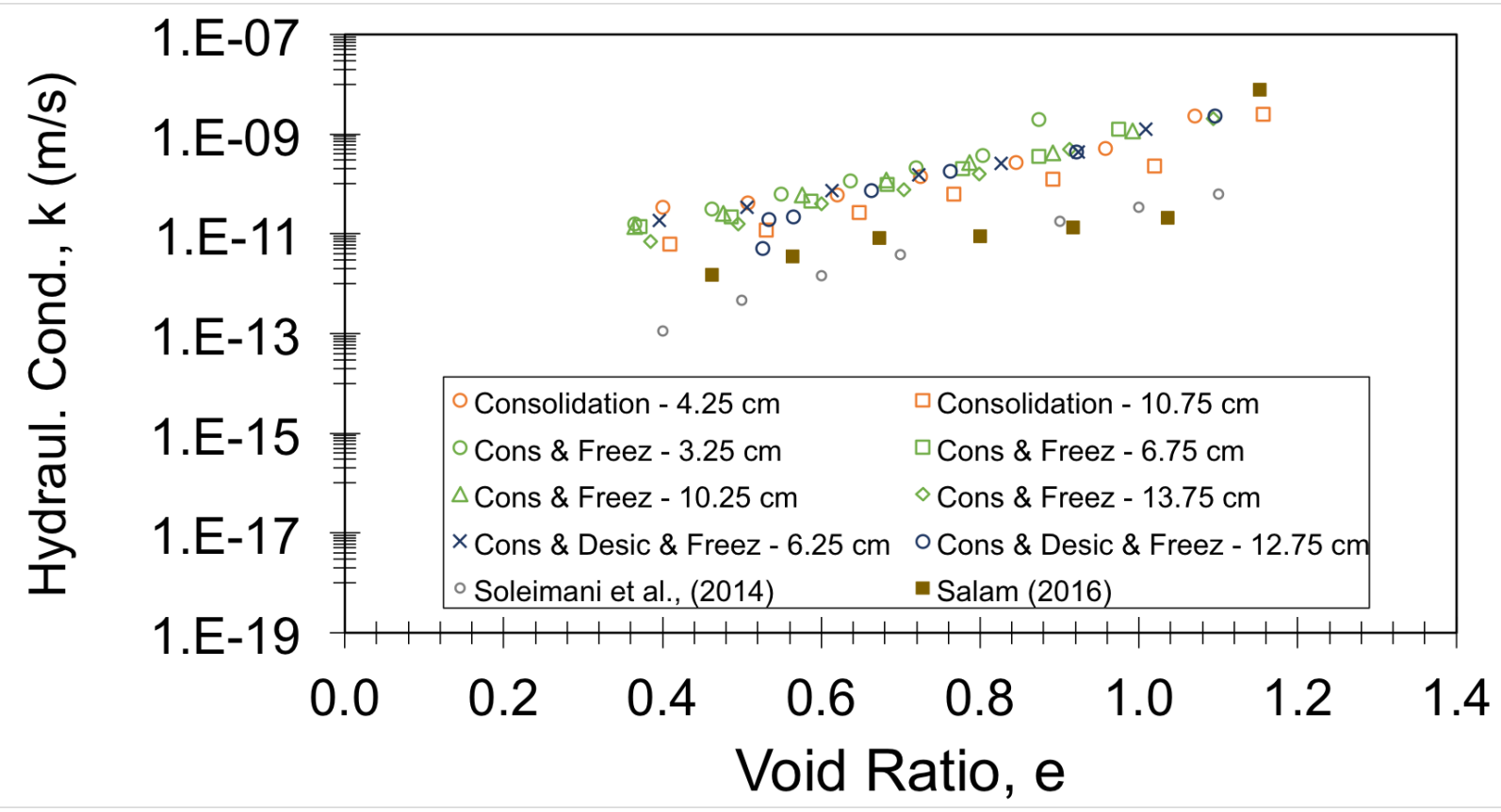

Figure 169. Hydraulic conductivity vs. void ratio data from all column tests.

\subsection{Qualitative Observations During One Freeze-thaw Cycle}

This section presents visual observations of the freezing and thawing phases of column test \#1 and \#3. It aims to highlight the adequate methodology for the freezing of MFT or any type of soil.

Figure 170, 171, and 172 show the ice lens formation in column test \#1. The pictures were taken right before the start of the thawing phase. As seen in the pictures, large amounts of ice were formed at the top of the tailings. The ice layer varied from 1 to $3 \mathrm{~cm}$ in depth at different points in the surface. It was estimated that the ice formed from water drawn away from the tailings and initially from air moisture that underwent condensation at the contact with the cooling plate. Placing the experimental setup inside 
a fridge later solved this problem. The three pictures show vertical layers of ice formed at different depths within the tailings. The ice lenses vary in size from a few millimetres to almost one centimeter. It is believed that during the first unexpected freeze-thaw cycle internal gaps were formed as water thawed. Later, these gaps were filled with leftover water and turned into ice layers during the second planned freeze-thaw cycle. The same can be said about the ice in the surface. Once ice melts away, the surface is left in an eroded state containing many holes and gaps. These openings allowed water and then ice to accumulate and form large round ice collections. 


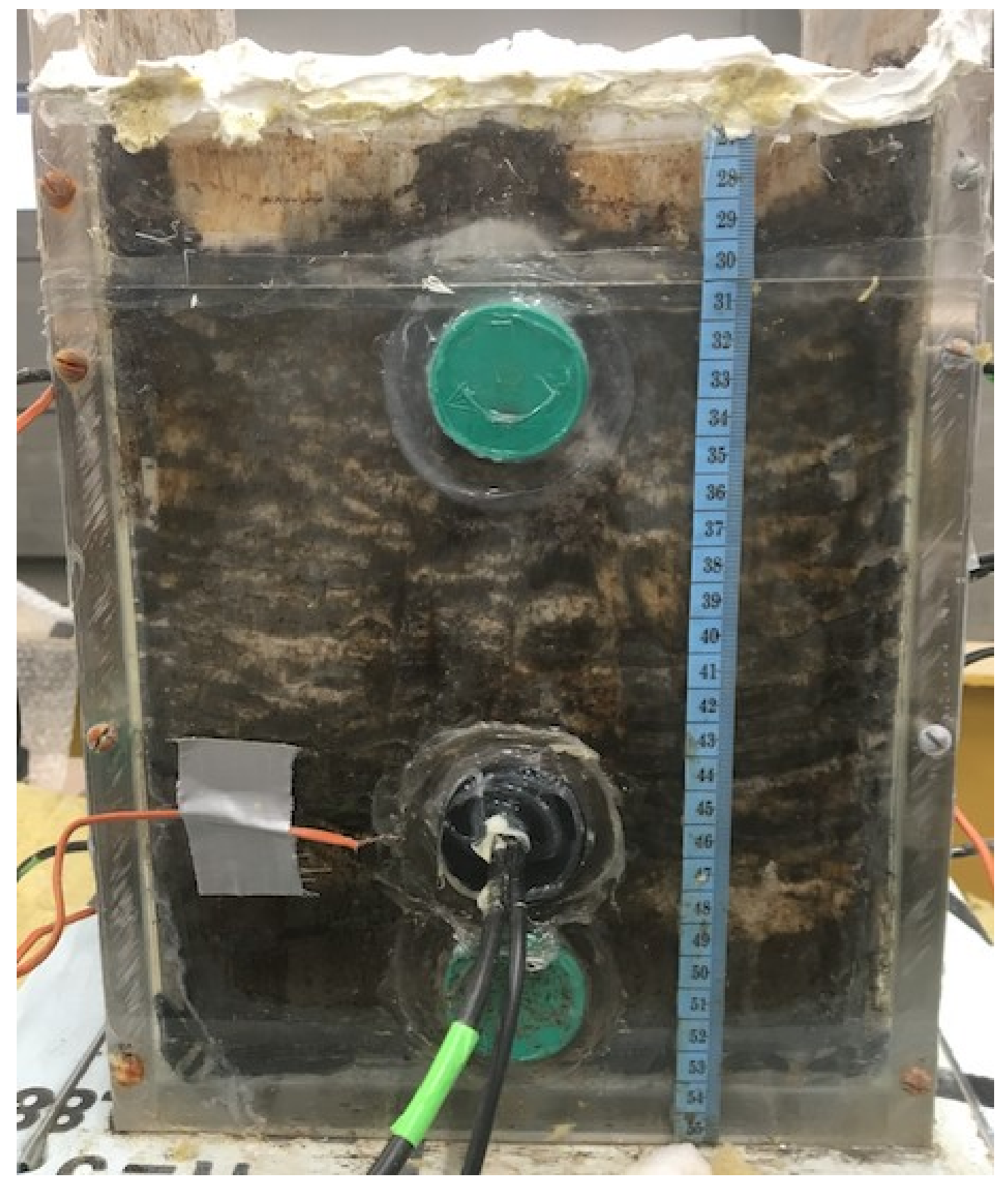

Figure 170. Ice lens formation in column test \#1 (front side). 


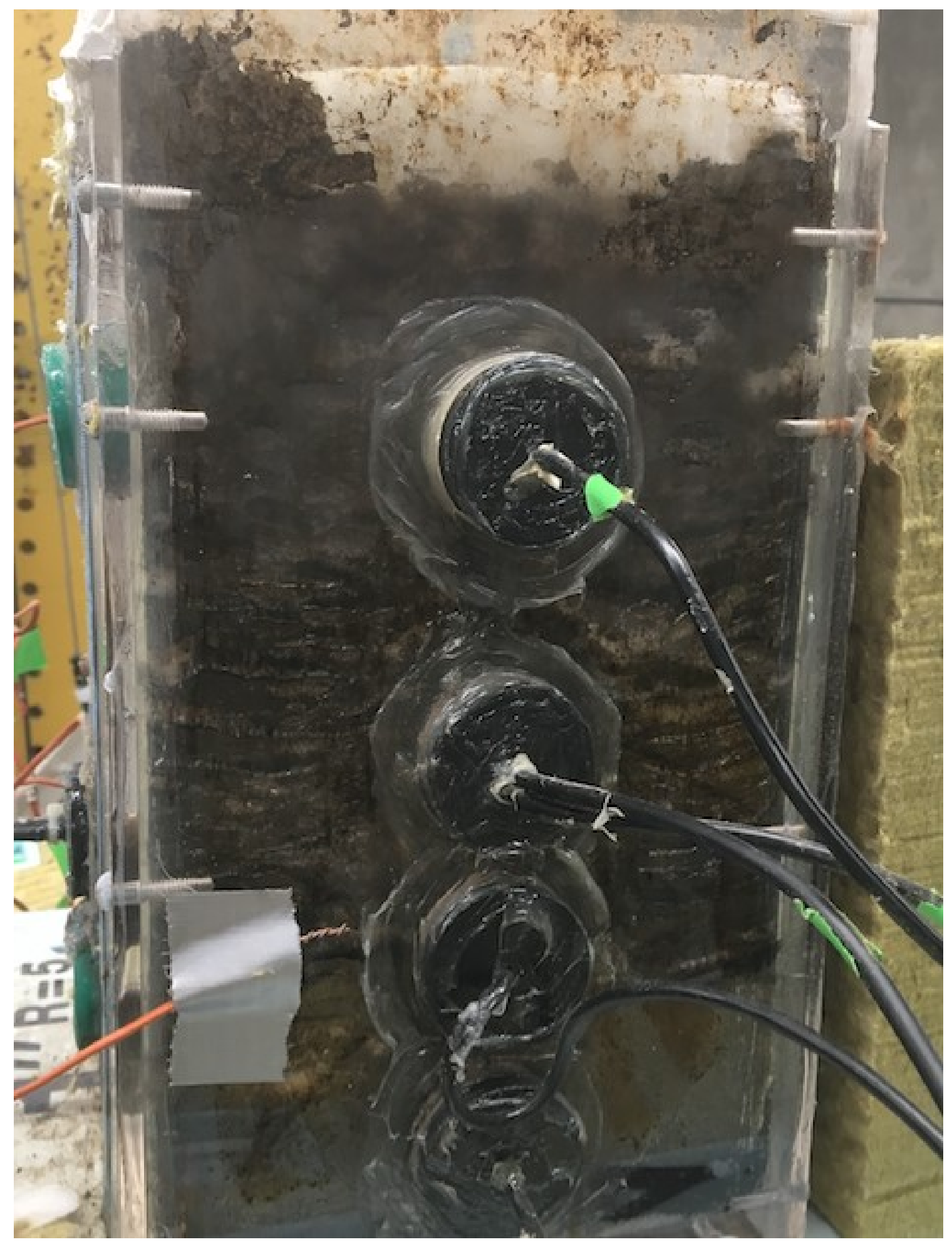

Figure 171. Ice lens formation in column test \#1 (right side). 


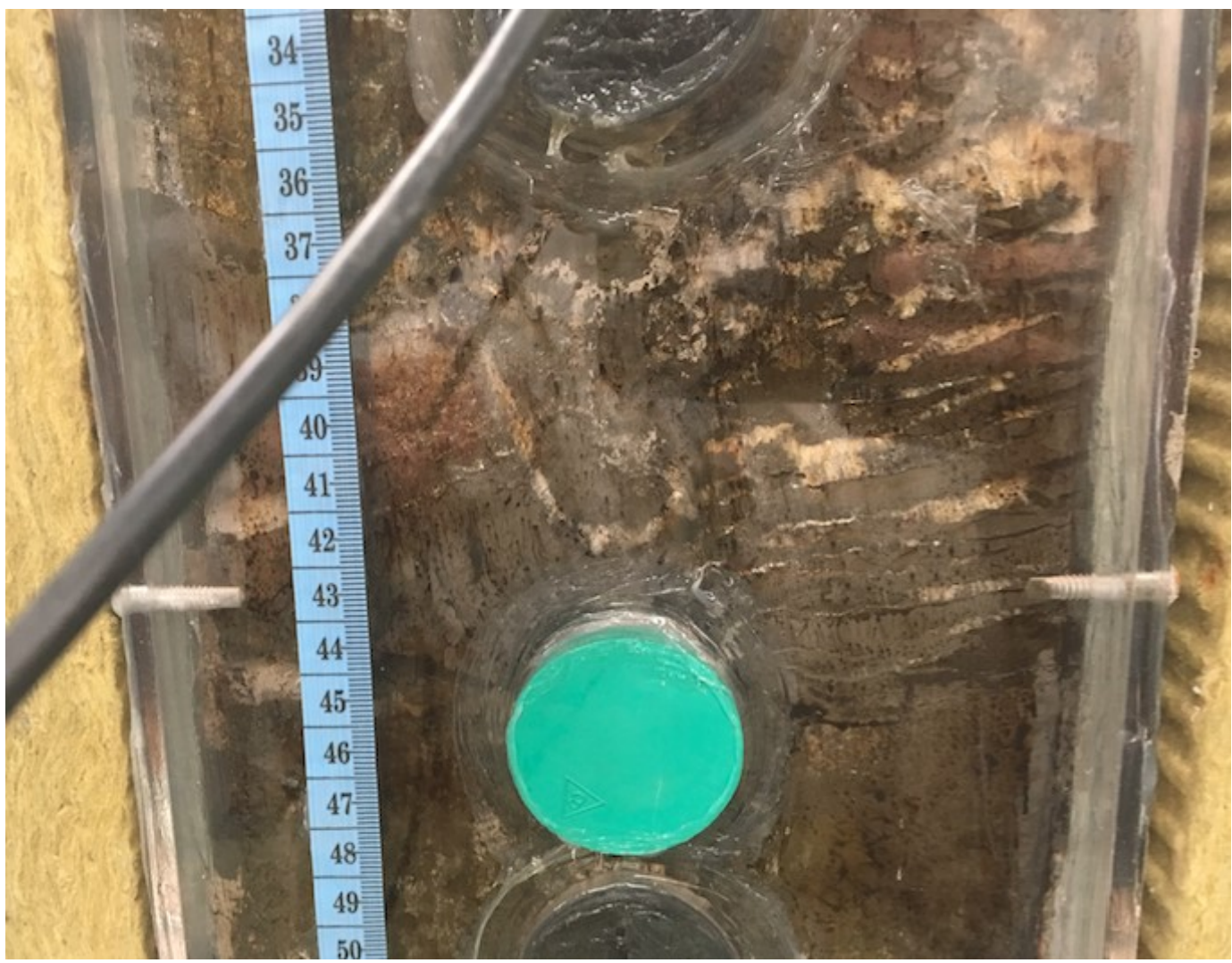

Figure 172. Ice lens formation in column test \#1 (left side).

Furthermore, Figure 173, 174, and 175 show ice lens formations in column test \#3, which underwent only one freeze-thaw cycle. The pictures were taken right before the start of the thawing phase. The ice lens formation in this test indicates that the freezing process was similar to the one on field conditions. In this case, vertical and horizontal ice lenses were formed in a reticulated manner. The width of the ice lenses is constant throughout the column and different depths, which suggest that the freezing rate occurred in a constant fashion (i.e. no major interruptions occurred). The ice accumulations at the top are not as large as is the case in column test \#1. In this test, there is a thin layer of ice at the surface and bigger ice formation around the surface. 
These formations took place in the gap between the surface of the tailings and the acrylic column. The ice lens formations in the first few centimeters from the top (not visible in Figure 172) are almost not visible due to their small size. At a depth of approximately $8 \mathrm{~cm}$, bigger ice lenses are visible until the bottom of the column. Another important point to note is the presence of these channels in the lowest $5 \mathrm{~cm}$ of the column. This portion of the MFT column was not frozen and the disturbance of the tailings in this manner was not expected. However, the existence of said channels could be attributed to the movement of water towards the freezing front.

Consequently, it has been shown that ice formation varies with depth. Surface and near-surface ice formations are different in size and quantity than ice formations found at lower sections of the column. This finding supports the idea that large samples are needed to accurately measure the property changes of soil in freeze-thaw experiments. 


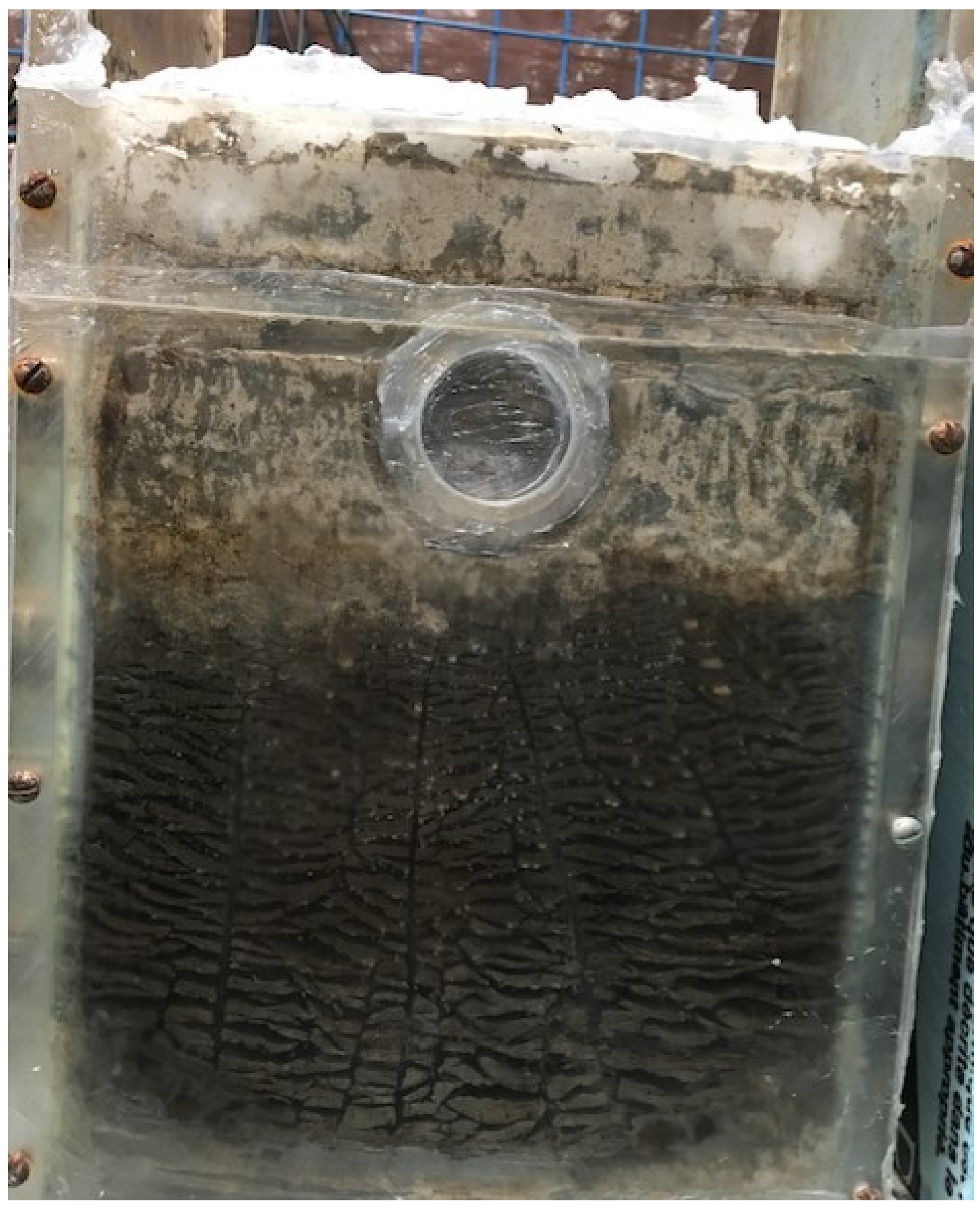

Figure 173. Ice lens formations in column test \#3 (front side). 


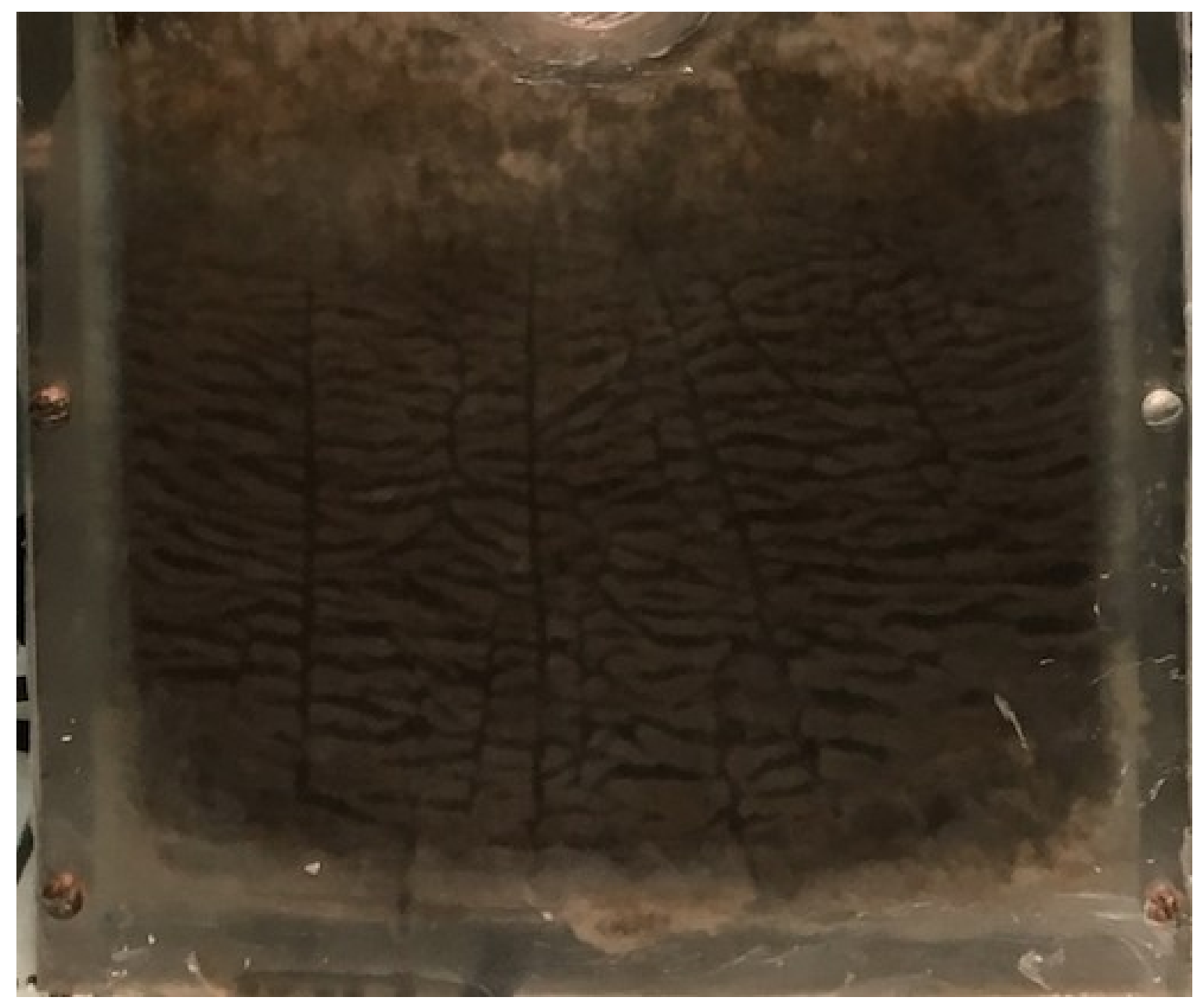

Figure 174. Ice lens formation in column test \#3 (lower front side). 


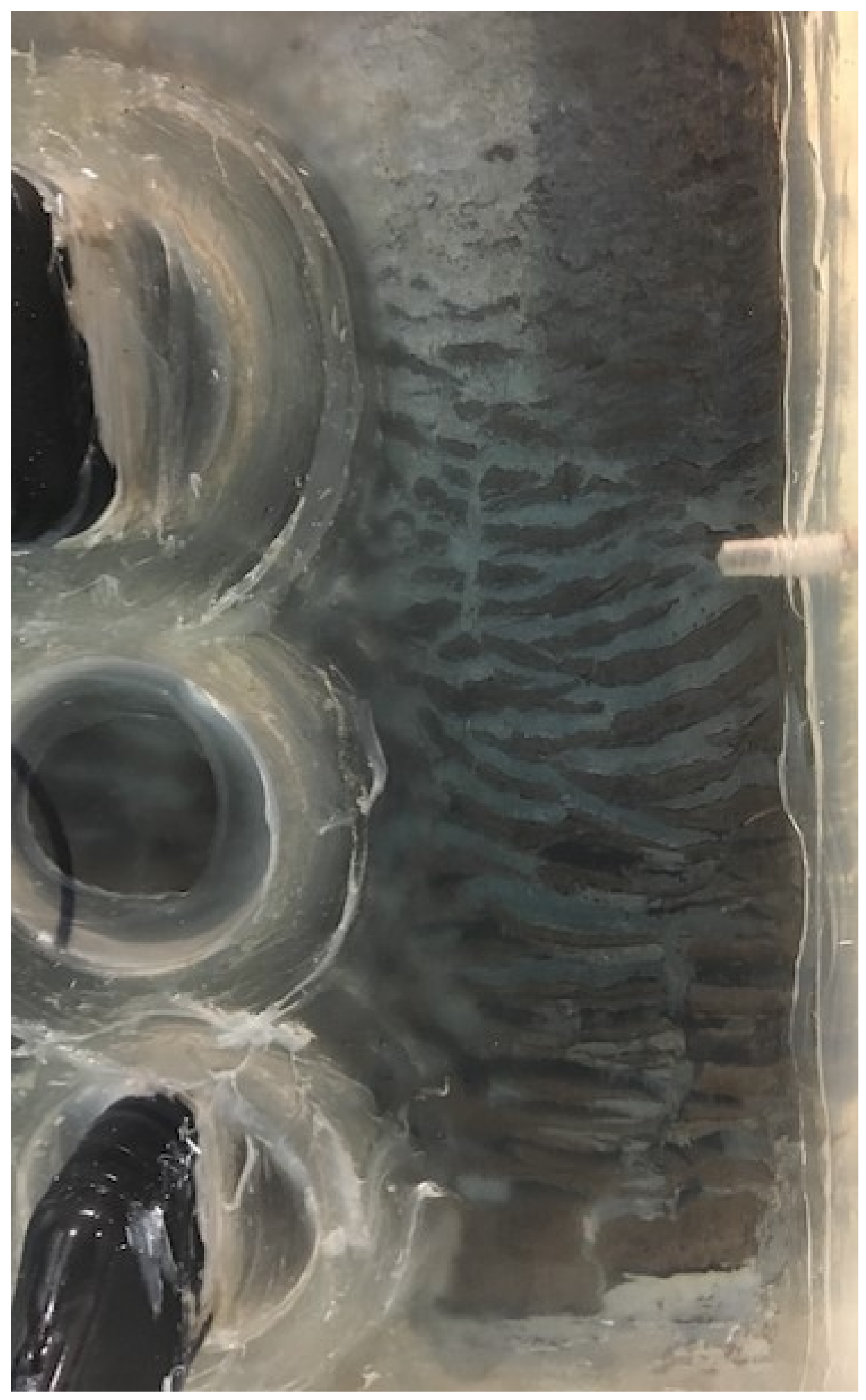

Figure 175. Ice lens formation in column test \#3 (left side). 
Lastly, Figure 176 and 177 show the surface condition after the thawing phase. As explained in the Literature Review chapter (Ch. 2), the surface of thawed soils undergoes erosion. In column test $\# 1$ the bulk of the column decreased its size as the ice melted. The sides around the surface were held back by the sensors attached to the column and were not allowed to settle along with the rest of the tailings. This caused the surface to look as if it imploded inwards.

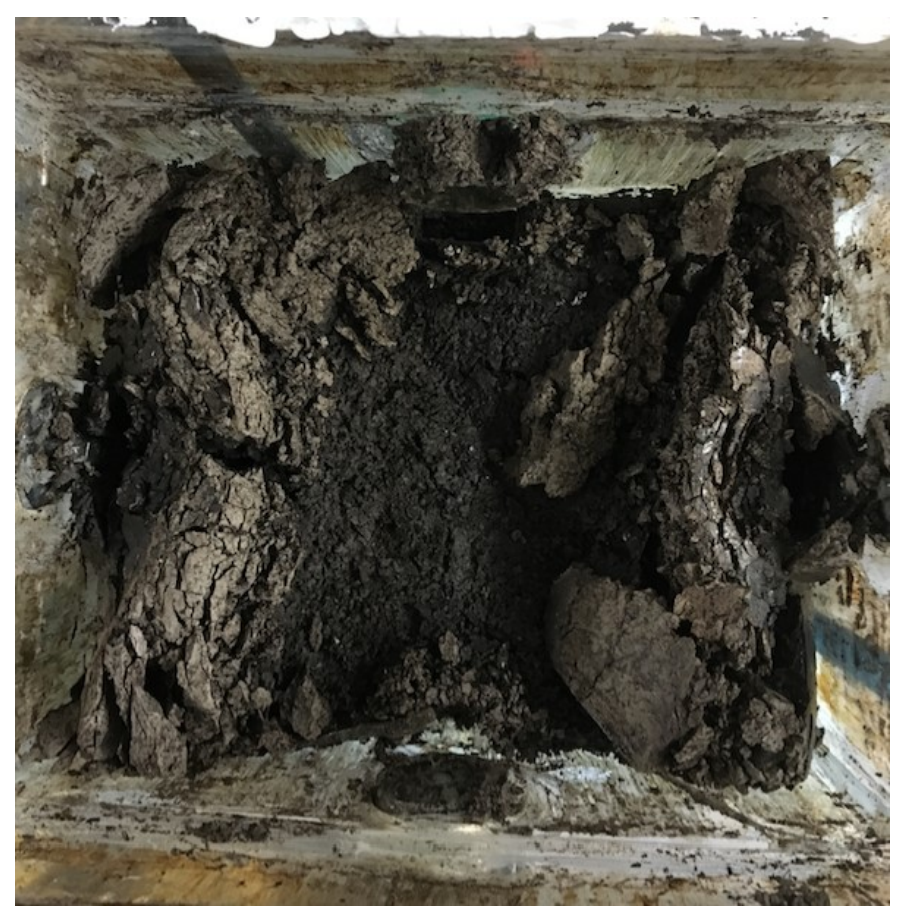

Figure 176. Eroded surface condition of column test $\# 1$ at the end of the thawing phase. 


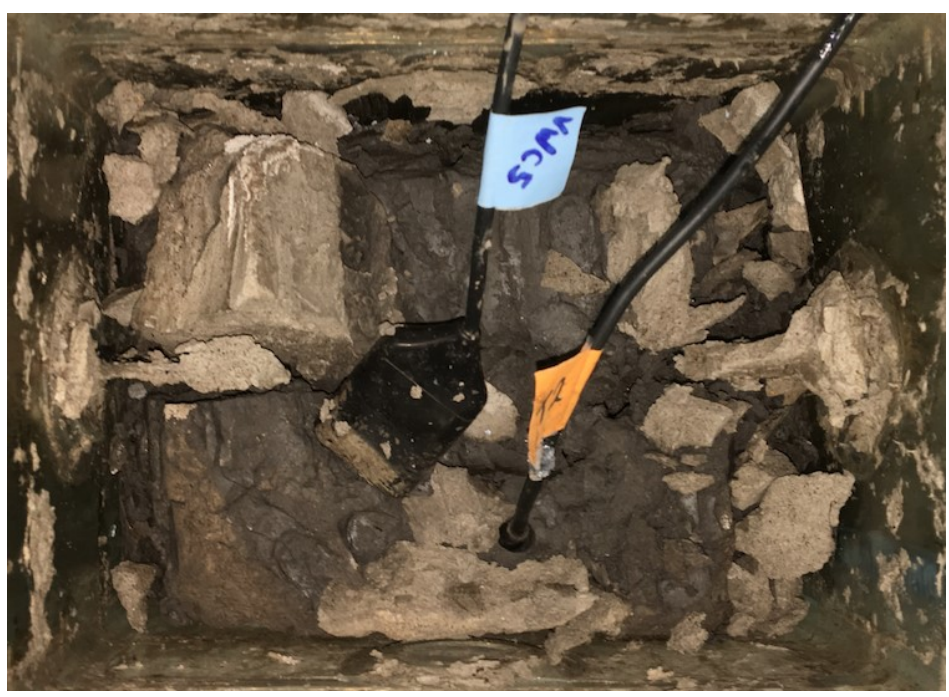

Figure 177. Eroded surface condition of column test $\# 3$ at the end of the thawing phase

In column test \#3, something similar occurred but the sensors did not hold back the surface sides as they did in column test \#1. Since the top portion of the tailings shrunk in the desiccation phase, the surface sides were not in contact with the sensors located at height of $22.5 \mathrm{~cm}$ and therefore they were not held back. The sensors were exposed to air as the bulk of the MFT column settled. 


\subsection{References}

Chamberlain, E., \& Gow, A. (1979). Effects of Freezing and Thawing on the permeability and structure of soils. Engineering Geology (13), 73-92.

Dawson, R., Sego, D., \& Pollock, G. (1999). Freeze-thaw dewatering of oil sands fine tails. Canadian Geotechnical Journal (36), 587-598.

Decagon Devices. (2014, December 04). MPS-2 \& MPS-6 Dialectric Water Potential Sensors. Decangon Devices Inc.

Egbert, J. A., Spaans, A., \& Baker, J. M. (1996). The Soil Freezing Characteristic: It's Measurement and Similarity to the Soil Moisture Characteristic. Soil Sci. Soc. Am. Journal (60), 13-19.

Ferrick, M., \& Gatto, L. (2005). Quantifying the effects of freeze-soil cycle on soil erosion: laboratory experiments. Earth Surface Processes and Landforms (30), 1305-1326.

Henry, H. (2007). Soil freeze-thaw cycle experiments: Trends, methodological weaknesses and suggested improvements. Soil Biology and Biochemistry (39), 977-986. 
Nishida, Y. (1956). A Brief Note on Compression Index of Soils. Journal of Soil Mechanics and Foundations Division, SM3 (82), 1027-1-1027-14.

Qiu, G., \& Ben-Asher, J. (2010). Experimental Determination of Soil Evaporation Stages with Soil Surface Temperature. Soil Sci. Soc. Am. J. , 74 (1), 13-22.

Rozina, E. (2015). Bearing Capacity of Multilayer-deposited In-line Flocculated Oil Sands Tailings. Carleton University, Civil and Environmental Engineering. Ottawa, ON: Carleton University.

Salam, M. (2016). Consolidation Data for MFT. Ottawa, Ontario, Canada.

Soleimani, S., Simms, P., Dunmola, A., Freeman, G., \& Wilson, G. (2014). Desiccation and consolidation in thin-lift deposition of polymer-amended mature fine tailings. Paste 2014 - R.J. Jewell, A.B. Fourie, S. Wells and D. van Zyl (eds) (p. 13). Vancouver: InfoMine Inc. 


\section{Chapter: Summary, Conclusions and Recommendations}

\subsection{Summary and Conclusions}

One of the oil sands industry's important challenges is the long-term management of tailings due to poor natural dewatering rates. Therefore, optimal dewatering is necessary to increase the strength of the tailings as it facilitates the reclamation and trafficability of the land used in the mining process. Natural dewatering processes such as evaporation, self-weight consolidation, thixotropy, and natural freeze-thaw cycles are a cost-effective alternative to manage and reduce the water content in tailings. The objectives of this research were to gain in-depth understanding of dewatering through freeze-thaw cycles of polymer amended MFT, to study the consolidation properties of these tailings post thawing, and to determine an adequate methodological approach to freeze-thaw MFT in a laboratory setting.

To meet the proposed objectives, the following experimental procedures were followed: polymer amended MFT was generated in a lab setting that emulates field samples and three column tests $(0.5 \mathrm{~m}$ lifts $)$ were performed. Each column test had different testing phases. Column test \#1 involved self-weight consolidation with ambient drying of the tailings and one freeze-thaw cycle; column test \#2 involved selfweight consolidation with limited desiccation near the surface; and column test \#3 involved self-weight consolidation with ambient drying, accelerated desiccation, and one freeze-thaw cycle. The main goal of the three column tests was to determine the 
effects of one freeze-thaw cycle in the dewatering process of MFT by reporting the difference in dewatering behaviour between the different phases in each column. Also, core samples were extracted at the end of each test to analyze the final water content, solids content, undrain shear strength, and suction profiles. Samples at different depths were also obtained at the completion of each test to analyze the consolidation properties of MFT. The freezing methodology of tailings was assessed and visual observations of ice lens formation patterns were compared to field patterns.

Column test \#1 results showed that after allowing the polymer-amended tailings to self-weight consolidate and exposing them to one freeze-thaw cycle the final solids content increased from $34.7 \%$ to $72 \%$. The change in solids content is reflected on the $31 \mathrm{~cm}$ settlement the tailings underwent by the expulsion of a total of $11.1 \mathrm{~kg}$ of water at the end of the thawing phase. The test lasted 205 days. Ice content calculations during the freezing phase showed that at heights of $10 \mathrm{~cm}$ and $15 \mathrm{~cm}$, the amount of ice present in the form of ice layers was similar $\left(0.05-0.07 \mathrm{~m}^{3} / \mathrm{m}^{3}\right)$. Suction values were measured below the freezing front and it was observed that higher suction values were present at lower depths $(\approx 3000 \mathrm{kPa})$ than near the surface $(\approx 300 \mathrm{kPa})$. The undrained shear strength was found to increase with depth reaching $18 \mathrm{kPa}$ at a depth of $15 \mathrm{~cm}$. Lastly, compressibility results showed the significant decrease in void ratio after one freeze-thaw cycle when compared to Soleimani et al., (2014)'s data. At effective stresses greater than $10 \mathrm{kPa}$, all the tested samples showed to have similar consolidation behavior as they converged in a common trend. 
Column test $\# 2$ results showed that after allowing the polymer-amended tailings to self-weight consolidate and lightly desiccate for a period of 115 days, the final solids content increased from $34 \%$ to $63.8 \%$. The change in solids content is reflected on the $22.5 \mathrm{~cm}$ settlement the tailings underwent by the release of a total of $10.3 \mathrm{~kg}$ of water at the end of the self-weight consolidation with ambient drying phase. Pore water pressure values were measured at heights of $5 \mathrm{~cm}$ and $22.5 \mathrm{~cm}$. As tailings settled and pore water evaporated, negative pore pressure, or suctions, reached a value of at least 100 $\mathrm{kPa}$ near the surface, while negative pore water pressures at the bottom reached only 1 $\mathrm{kPa}$. The undrained shear strength was found to decrease with depth reaching $22 \mathrm{kPa}$ at the surface and $0 \mathrm{kPa}$ at other depths. Lastly, compressibility results showed the significant decrease in void ratio after a long consolidation period when compared to Soleimani et al., (2014)'s data. The drier sample near the surface showed to have lower initial void ratio than the lower moist sample from the bottom. At effective stresses greater than $10 \mathrm{kPa}$, both samples showed the have the similar consolidation properties as they developed in parallel lines. Permeability results showed an increase between two to four orders of magnitude when compared to samples that underwent a short period of self-weight consolidation while evaporation was not allowed.

Column test \#3 results showed that after allowing the polymer-amended tailings to self-weight consolidate, desiccate, and then exposing them to one freeze-thaw cycle the final solids content increased from $32.4 \%$ to $70 \%$. The change in solids content is reflected on the $30.1 \mathrm{~cm}$ settlement the tailings underwent by the expulsion of a total of $11.9 \mathrm{~kg}$ of water at the end of the thawing phase. The test lasted 115 days. During the 
desiccation alone, the solids content increased by $13.2 \%$ and enhanced evaporation was the main mechanism for water removal. Ice content calculations during the freezing phase showed that the surface contained the largest amount of ice recorded $(0.178$ $\left.\mathrm{m}^{3} / \mathrm{m}^{3}\right)$, while at a height of $22.5 \mathrm{~cm}$ the ice content was lowest $\left(0.007 \mathrm{~m}^{3} / \mathrm{m}^{3}\right)$. At a height of $15 \mathrm{~cm}$ the ice content increased $\left(0.013 \mathrm{~m}^{3} / \mathrm{m}^{3}\right)$ compared to the previous height. Also, suction values were measured below the freezing front and it was observed that higher suction values were present at lower depths $\approx \approx 1500 \mathrm{kPa}$ at a height of $5 \mathrm{~cm})$ than near the surface $(\approx 200 \mathrm{kPa}$ at a height of $15 \mathrm{~cm})$. The undrained shear strength was found to decrease with depth reaching $14 \mathrm{kPa}$ at the surface and 0 $\mathrm{kPa}$ at other depths. Large water accumulations at the bottom of the column due to the shrinkage of the top portion of the tailings during the desiccation phase were found to be responsible for this behavior. Lastly, compressibility results showed the significant decrease in void ratio after desiccation and one freeze-thaw cycle when compared to Soleimani et al., (2014)'s data. Both samples start at similar void ratios and at effective stresses greater than $10 \mathrm{kPa}$, they showed to have similar consolidation properties as they develop similar slopes. Permeability results from the oedometer tests showed higher permeability (up to an order of magnitude) for samples at the bottom, compared to surface samples.

Results from the three columns were compared and the following conclusions were drawn: 1) desiccation and one freeze-thaw cycle enhanced the dewatering process and increased the average solids content of the tailings by $6 \%$ when compared to MFT that only underwent self-weight consolidation. 2) The self-weight consolidation with 
ambient drying phases of the three tests were compared and they showed to be similar in terms of dewatering rate and settlement. Even though the self-weight consolidation with ambient drying phase in column test $\# 1$ showed different settlement and solids content values, the overall trend seemed to be similar to the other two tests. 3) The change in height and solids content over time during the thawing phase in column test $\# 1$ and \#3 were shown to be similar. 4) The data suggests that the SWCC below the freezing front and the SFCC seem to agree well for the height of $15 \mathrm{~cm}$ and $22.5 \mathrm{~cm}$. For the other heights, no comparable data was obtained. Also, the SWCC and SFCC data show that as their initial water content decreases, the slope of the curve becomes flatter. 5) When comparing the self-weight consolidation with ambient drying phase and desiccation phase for the three column tests, it was found that desiccation increases the efficiency of the freezing process. 6) The undrained shear strength profiles for each test seem to contradict each other; however, this was explained by the shrinkage of the top portion of the MFT column. 7) No significant differences in compressibility and permeability properties were found between tailings that underwent just self-weight consolidation with ambient drying, tailings that underwent self-weight consolidation with ambient drying and one freeze-thaw cycle, and tailings that underwent self-weight consolidation with ambient drying, accelerated desiccation and one freeze-thaw cycle.

Furthermore, it was found that desiccation before freezing lowered the time to achieve a given solids concentration for tailings with different solids content at the beginning of the freezing phase. For example, Column Test \#1 had an average solids content of $58 \%$ and a gravimetric water content of $72 \%$ (i.e. $5.4 \mathrm{~kg}$ of water reaming in 
the tailings) at the beginning of the freezing phase, which lasted 82 days. Meanwhile, Column Test \#3 had an average solids content of $52.9 \%$ and a gravimetric water content of $89 \%$ (i.e. $5.9 \mathrm{~kg}$ of water remaining in the tailings) at the beginning of the freezing phase, which lasted 72 days. The freezing time was reduced by 10 days; however, the water contents were different at the beginning of freezing. Column Test \#3 had approximately $0.5 \mathrm{~kg}$ of water more than Column Test \#1 right before freezing. This suggest that Column test \#3 required a higher amount of energy to convert pore water into ice. Yet, its freezing time was less than Column Test \#1. This shows that accelerated desiccation sped up the freezing process. The presence of desiccation cracks allowed cold air to reach deeper sections of the tailings speeding up the freezing process.

In addition, SFCCs and SWCCs were very similar, and both showed variation in slope and AEV dependency on initial void ratio typical of soft soils. This finding is promising in terms of feasibility of modelling coupled freeze-thaw desiccation behavior in these types of tailings.

From a practical point of view, modelling parameters such as thaw strain, solids content evolution after freezing, SWCC under the freezing front, and SFCC can be implemented in constitutive models to predict overall changes in water content and therefore volume change of polymer amended MFT after one freeze-thaw cycle. This knowledge is of great importance in the design of disposal areas for MFT, as well as for optimal deposition plans to properly manage tailings. 
Lastly, it has been shown that ice formation varies with depth. Surface and nearsurface ice formations are different in size and quantity than ice formations found at lower sections of the column. This finding supports the idea that large samples (i.e. bigger than an oedometer cell) are needed to accurately measure the property changes of soil after freeze-thaw cycles.

\subsection{Recommendations}

- To facilitate the generalization of results, numerical simulations of the three column tests presented in this thesis should be developed along with the conduction of sensitivity analysis.

- A numerical analysis of the heat transfer of the system during the freezing phase should be conducted to verify the efficiency of the insulating case.

- Other column tests could be conducted with varying parameters such as evaporation rate, polymer dosage, and freezing surface temperatures.

- Field investigations should be performed in tailings ponds to see if similar behavior occurs in the field during the winter months.

- The introduction of pore water pressure measuring devices within the frozen tailings should be introduced, such as a filter-less rigid piezometer, to corroborate the theoretical negative pore water pressures developed. 
Several suggestions to improve the methodology of the columns tests are presented in the following section.

\subsubsection{Recommendations on Experimental Methodology}

The drainage system should be better designed to emulate field conditions. The area in which water is allowed to drain is really small and it is covered by geotextile. This could cause the drainage system to clog preventing further dewatering. Ideally, several holes at the bottom of the acrylic column should be used to facilitate drainage.

The surface area of the MFT sample should be bigger for desiccation purposes. A larger surface area would facilitate crack initiation during the self-weight consolidation with ambient drying phase and desiccation phase. This way, the effect of cracks on freeze-thaw could be studied. Possibly, a fourth column should be introduced that does not allow cracking to be able to single out the effects of cracking and freezethaw in dewatering of MFT.

The rigid placement of the sensors within the column (i.e. sensors glued to the acrylic column) should be avoided. It creates a 'reinforcement effect' by partially preventing the self-weight consolidation of the tailings and by creating voids underneath the sensors as the tailings settle. This should be specially noted in tests where the surface area of the column is not large. Instead, larger containers should be 
used to allow the relative free movement of the sensors along with the self-weight consolidating tailings.

Even though a cooling plate is recommended as the best way to freeze soil, this may only be applicable for small size samples. The surface area of the cooling plate limits the surface area of the tailings. If using a bigger column, or box, freezing should occur in an environmental room where temperature and air moisture is better controlled and the surface area is exposed allowing better observations of the freezing process.

The efficiency of the insulation system should be increased for larger tests to ensure one-dimensional freezing at all times. The use of acrylic material for the construction of the column allows better observations of ice lens formation but it does not add insulation to the tailings in any way.

Lastly, a large-strain consolidation test apparatus should be used to analyze the compressibility and permeability properties of tailings even after freeze-thaw consolidation. The large void ratios and strains are not always well measured by standard oedometers. 


\section{Appendices}

\section{Appendix A : Consolidation Data for Column Test \#1}

\section{A.1 Consolidation Test Calculations}

Table 22. Calculations prior test - Column Test \#1

\begin{tabular}{|c|c|c|c|c|c|c|c|c|}
\cline { 3 - 9 } & \multicolumn{2}{|c|}{} & \multicolumn{6}{|c|}{ Before Consolidation } \\
\hline $\begin{array}{c}\text { Sample } \\
\#\end{array}$ & $\begin{array}{c}\text { Station } \\
\text { Number }\end{array}$ & $\begin{array}{c}\text { Depth } \\
(\mathbf{c m})\end{array}$ & $\begin{array}{c}\text { Mass of the } \\
\text { Consolidation } \\
\text { Ring (gr) }\end{array}$ & $\begin{array}{c}\text { Mass of the } \\
\text { Consolidation } \\
\text { Ring + } \\
\text { Sample (gr) }\end{array}$ & $\begin{array}{c}\text { Initial } \\
\text { Height of } \\
\text { the Sample } \\
\text { Ho (cm) }\end{array}$ & $\begin{array}{c}\text { Inner } \\
\text { Diameter } \\
\text { of the Ring } \\
\text { (cm) }\end{array}$ & $\begin{array}{c}\text { Wet Mass } \\
\text { of } \\
\text { Specimen } \\
\text { (gr): Mto }\end{array}$ & $\begin{array}{c}\text { Initial } \\
\text { Volume of } \\
\text { the specimen } \\
\text { (cm3): Vo }\end{array}$ \\
\hline $\mathbf{1}$ & F & 13.75 & 69.77 & 129.70 & 2.00 & 5.08 & 59.93 & 40.54 \\
\hline $\mathbf{2}$ & A & 10.25 & 64.83 & 124.66 & 2.00 & 5.08 & 59.83 & 40.54 \\
\hline $\mathbf{3}$ & C & 6.75 & 68.53 & 127.46 & 2.00 & 5.08 & 58.93 & 40.54 \\
\hline $\mathbf{4}$ & B & 3.25 & 65.18 & 124.54 & 2.00 & 5.08 & 59.36 & 40.54 \\
\hline
\end{tabular}

Table 23. Calculations post test (a) - Column Test \#1

\begin{tabular}{|c|c|c|c|c|c|}
\hline & & & \multicolumn{3}{|c|}{ After Consolidation } \\
\hline $\begin{array}{c}\text { Sample } \\
\#\end{array}$ & $\begin{array}{c}\text { Station } \\
\text { Number }\end{array}$ & $\begin{array}{c}\text { Depth } \\
(\mathbf{c m})\end{array}$ & $\begin{array}{c}\text { Mass of the } \\
\text { Consolidation } \\
\text { Ring + Sample } \\
\text { (gr) }\end{array}$ & $\begin{array}{c}\text { Moist Mass of } \\
\text { Total } \\
\text { Specimen }(\mathbf{g r}): \\
\text { Mtf }\end{array}$ & $\begin{array}{c}\text { Final Height } \\
\text { of Sample } \\
\text { (cm):Hf }\end{array}$ \\
\hline $\mathbf{1}$ & F & 13.75 & 119.47 & 49.70 & 1.08 \\
\hline $\mathbf{2}$ & A & 10.25 & 111.92 & 47.09 & 1.21 \\
\hline $\mathbf{3}$ & C & 6.75 & 114.35 & 45.82 & 1.19 \\
\hline $\mathbf{4}$ & B & 3.25 & 112.79 & 47.61 & 1.25 \\
\hline
\end{tabular}

Table 24. Calculations post test (b) - Column Test \#1

\begin{tabular}{|c|c|c|c|c|c|c|c|c|c|c|c|c|}
\hline \multirow[b]{2}{*}{$\begin{array}{c}\text { Sample } \\
\#\end{array}$} & \multirow[b]{2}{*}{$\begin{array}{l}\text { Station } \\
\text { Number }\end{array}$} & \multirow[b]{2}{*}{$\begin{array}{c}\text { Depth } \\
(\mathrm{cm})\end{array}$} & \multicolumn{10}{|c|}{ Calculations } \\
\hline & & & $\begin{array}{l}\text { Dry Mass } \\
\text { (gr): Md }\end{array}$ & $\begin{array}{l}\text { Initial } \\
\text { water } \\
\text { content } \\
\text { (\%): Wo }\end{array}$ & $\begin{array}{c}\text { Final } \\
\text { water } \\
\text { content } \\
\text { (\%): Wf }\end{array}$ & \begin{tabular}{|c|} 
Initial Dry \\
Density \\
(g/cm3): \\
pd
\end{tabular} & $\begin{array}{c}\text { Dry Unit } \\
\text { Weight } \\
\text { (KN/m3): } \\
\text { rd }\end{array}$ & $\begin{array}{c}\text { Volume of } \\
\text { Solids } \\
(\mathrm{cm} 3): \text { Vs }\end{array}$ & $\begin{array}{c}\text { Equivalent } \\
\text { Height of } \\
\text { Solids }(\mathrm{cm}): \\
\text { Hs }\end{array}$ & $\begin{array}{c}\text { Initial } \\
\text { Void } \\
\text { Ratio: eo }\end{array}$ & $\begin{array}{c}\text { Final } \\
\text { Void } \\
\text { Ratio: ef }\end{array}$ & \begin{tabular}{|c|} 
Initial \\
Degree of \\
Saturation \\
(\%): So
\end{tabular} \\
\hline 1 & $\mathrm{~F}$ & 13.75 & 42.31 & 41.6 & 17.5 & 1.04 & 10.23 & 19.23 & 0.95 & 1.11 & 0.14 & 82.69 \\
\hline 2 & A & 10.25 & 40.39 & 48.1 & 16.6 & 1.00 & 9.76 & 18.36 & 0.91 & 1.21 & 0.34 & 87.67 \\
\hline 3 & C & 6.75 & 39.19 & 50.4 & 16.9 & 0.97 & 9.47 & 17.81 & 0.88 & 1.28 & 0.35 & 86.88 \\
\hline 4 & B & 3.25 & 40.82 & 45.4 & 16.6 & 1.01 & 9.87 & 18.56 & 0.92 & 1.18 & 0.36 & 84.34 \\
\hline
\end{tabular}




\section{A.2 Depth of $3.25 \mathrm{~cm}-$ B sample}

Table 25. Compressibility data at depth of $3.25 \mathrm{~cm}$ - Column Test \#1

\begin{tabular}{|c|c|c|c|c|c|c|c|}
\hline Weight & Load Increment & $5 \mathrm{H} / \mathrm{mm}$ & $\mathrm{H}$ & e & $\mathrm{Cv}$ & av & K \\
\hline$(\mathrm{Kg})$ & or ov (Кра) & | & $(\mathrm{Ho}-\Delta \mathrm{H})(\mathrm{mm})$ & $(\mathrm{H}-\mathrm{Hs}) / \mathrm{Hs}$ & $(\mathrm{mm} 2 / \mathrm{s})$ & (m2/KN) & $(\mathrm{m} / \mathrm{s})$ \\
\hline - & 0.1 & 0.0000 & 20.0363 & 1.1889 & - & - & + \\
\hline 1 & 4.8 & 2.8776 & 17.1587 & 0.8745 & 0.0109 & 0.0401 & $1.96 \mathrm{E}-09$ \\
\hline 2 & 9.7 & 3.5319 & 16.5044 & 0.8030 & 0.0064 & 0.0131 & $3.76 \mathrm{E}-10$ \\
\hline 4 & 19.4 & 4.2923 & 15.7440 & 0.7200 & 0.0076 & 0.0061 & $2.09 \mathrm{E}-10$ \\
\hline 8 & 38.7 & 5.0543 & 14.9820 & 0.6367 & 0.0080 & 0.0032 & $1.15 \mathrm{E}-10$ \\
\hline 16 & 77.4 & 5.8533 & 14.1830 & 0.5494 & 0.0087 & 0.0016 & $6.33 \mathrm{E}-11$ \\
\hline 32 & 154.9 & 6.6555 & 13.3808 & 0.4618 & 0.0070 & 0.0010 & $3.10 \mathrm{E}-11$ \\
\hline 64 & 309.8 & 7.5396 & 12.4966 & 0.3652 & 0.0059 & 0.0006 & $1.60 \mathrm{E}-11$ \\
\hline
\end{tabular}

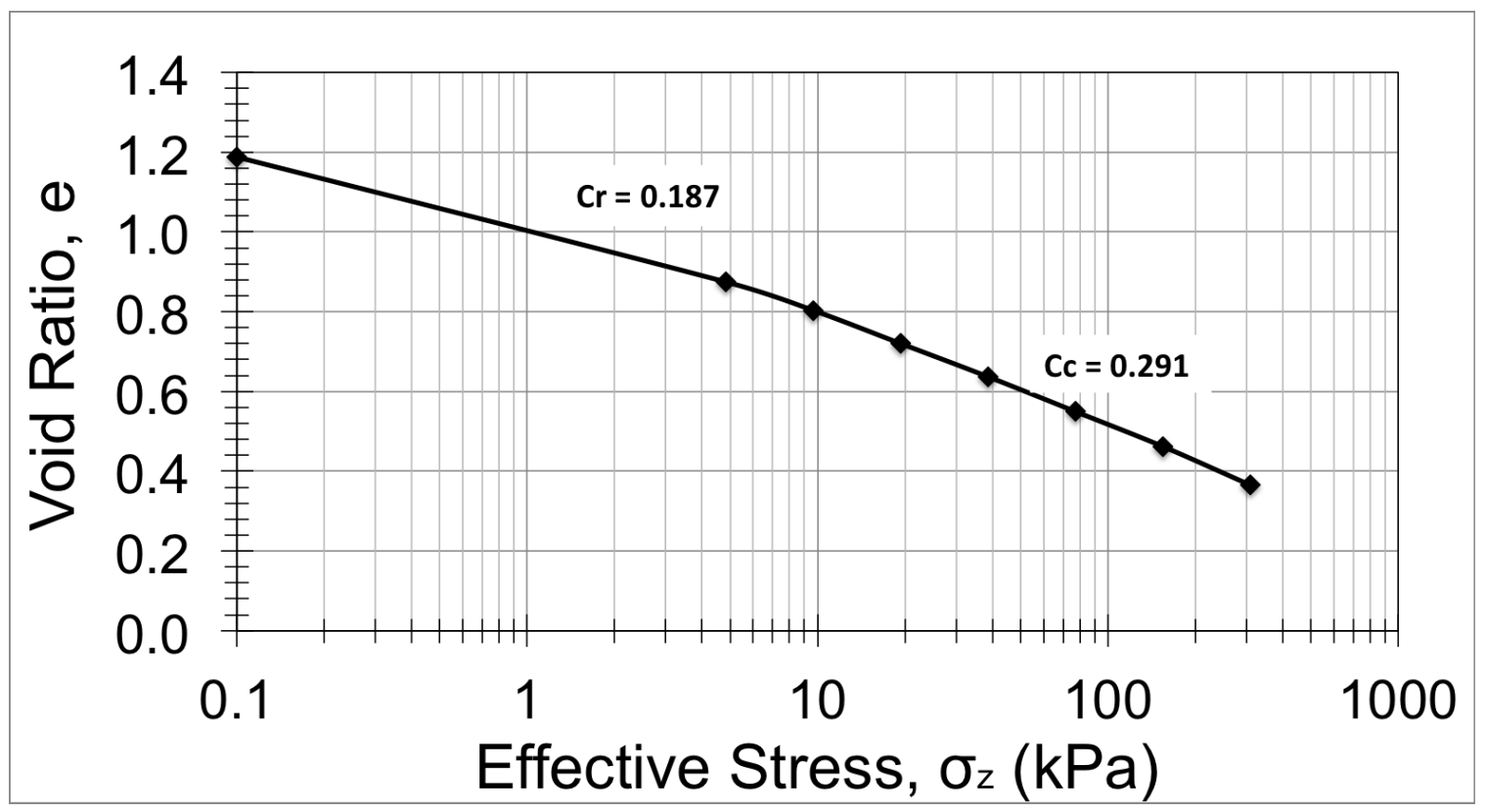

Figure 178. Void ratio vs Effective stress (depth of $3.25 \mathrm{~cm}$ ) - Column Test \#1 


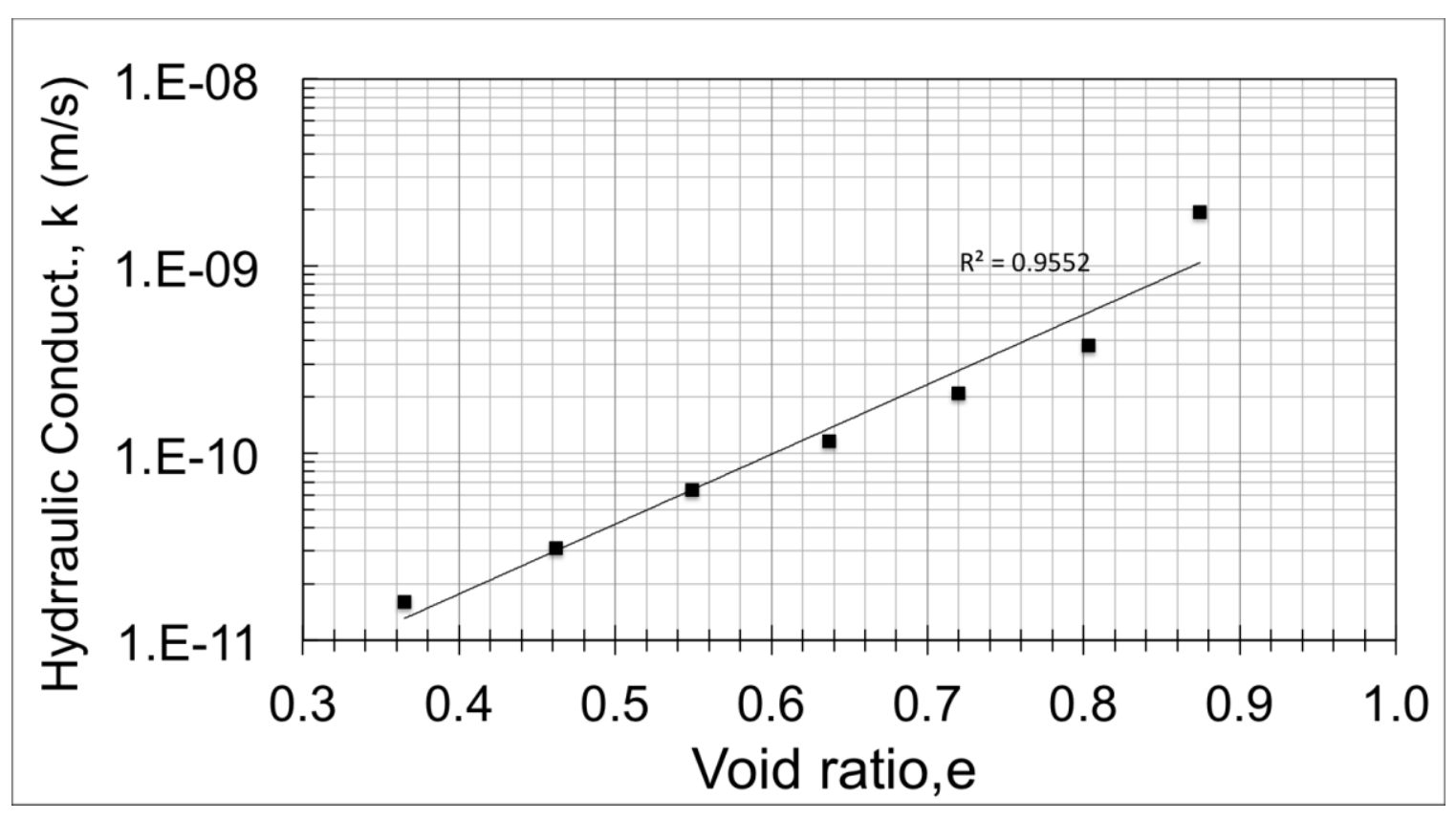

Figure 179. Permeability results (depth of $3.25 \mathrm{~cm}$ ) - Column Test \#1

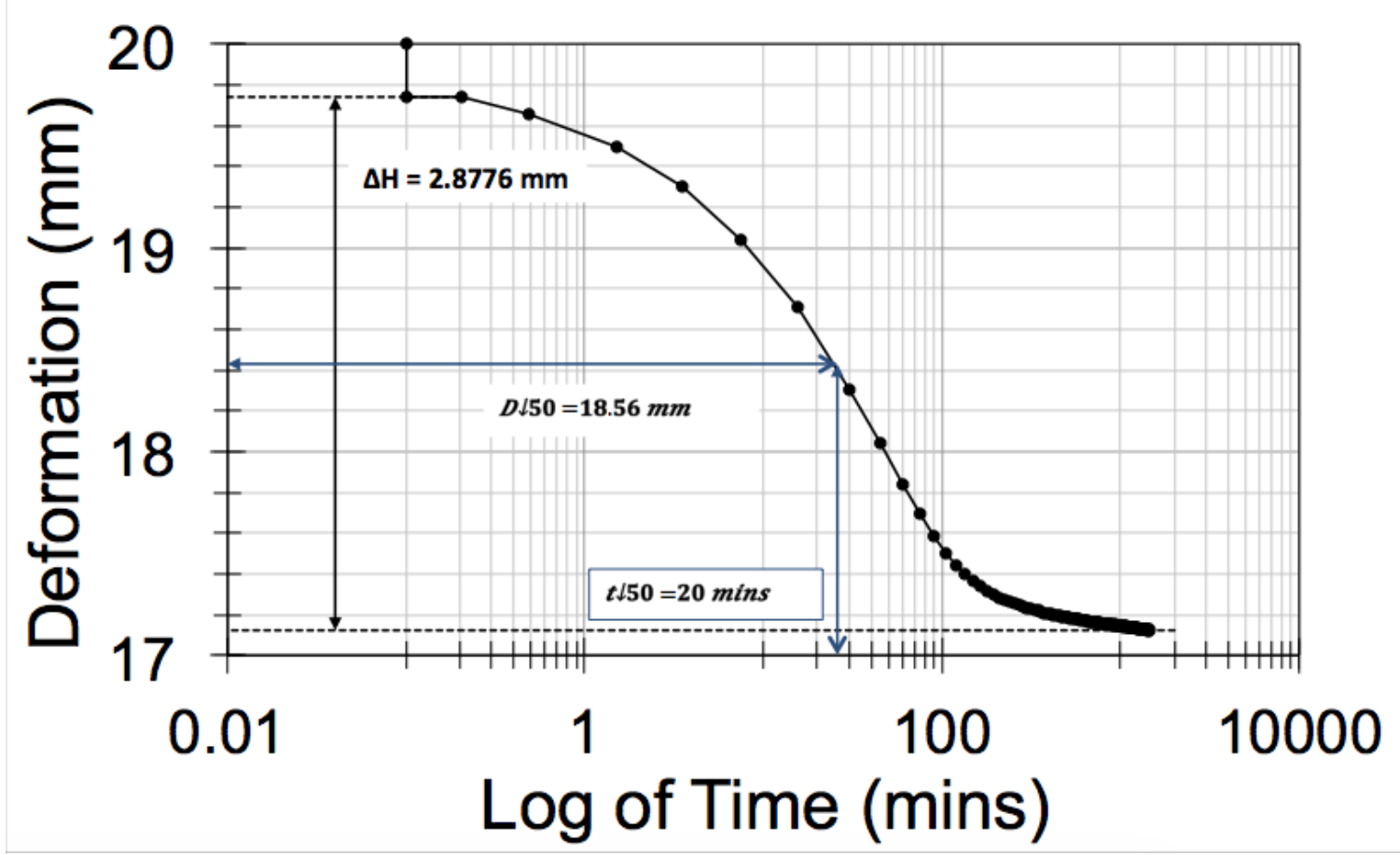

Figure 180. Casagrande analysis for $1 \mathrm{~kg}$ - Column Test \#1. 


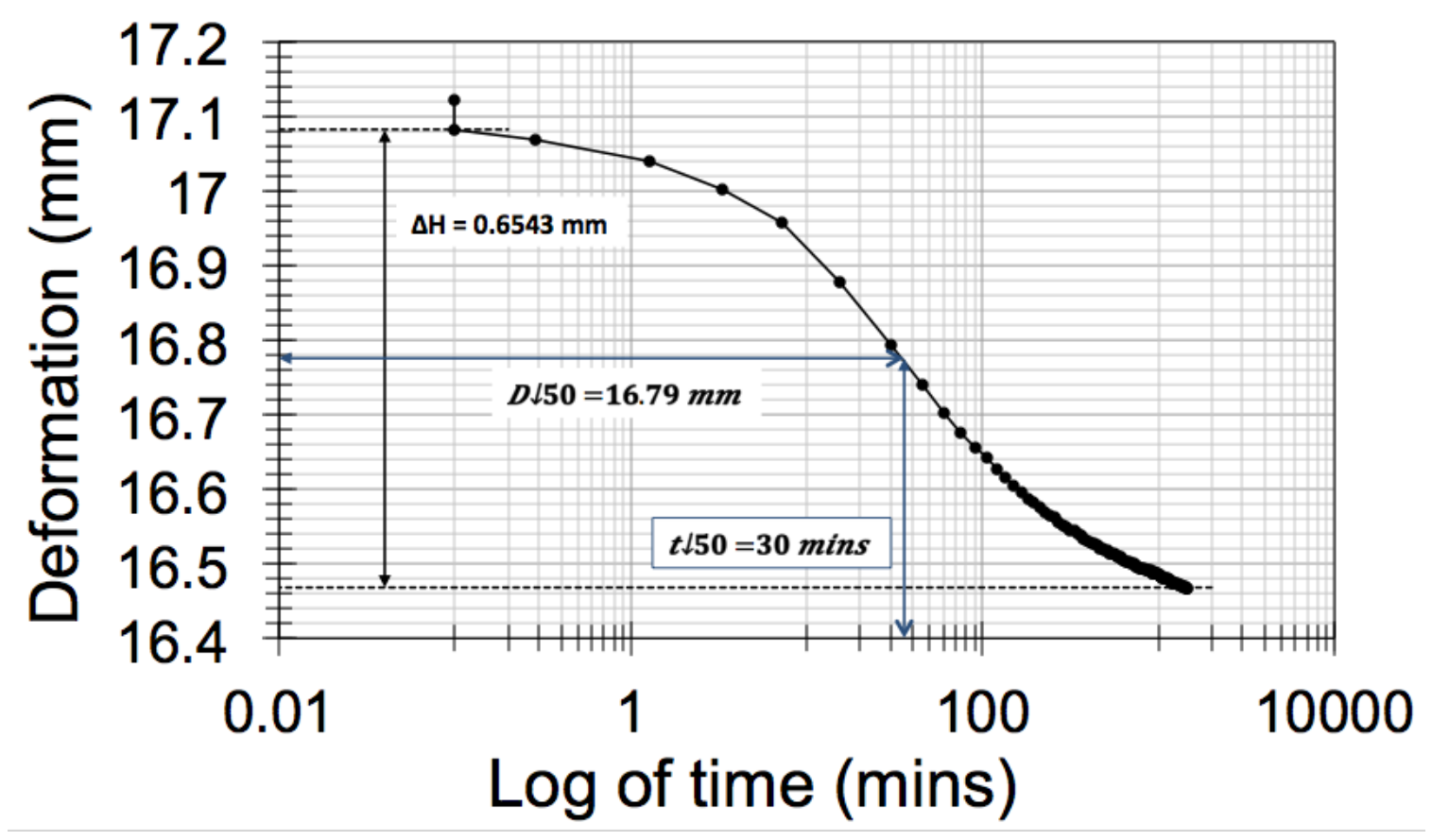

Figure 181. Casagrande analysis for $2 \mathrm{~kg}-$ Column Test \#1.

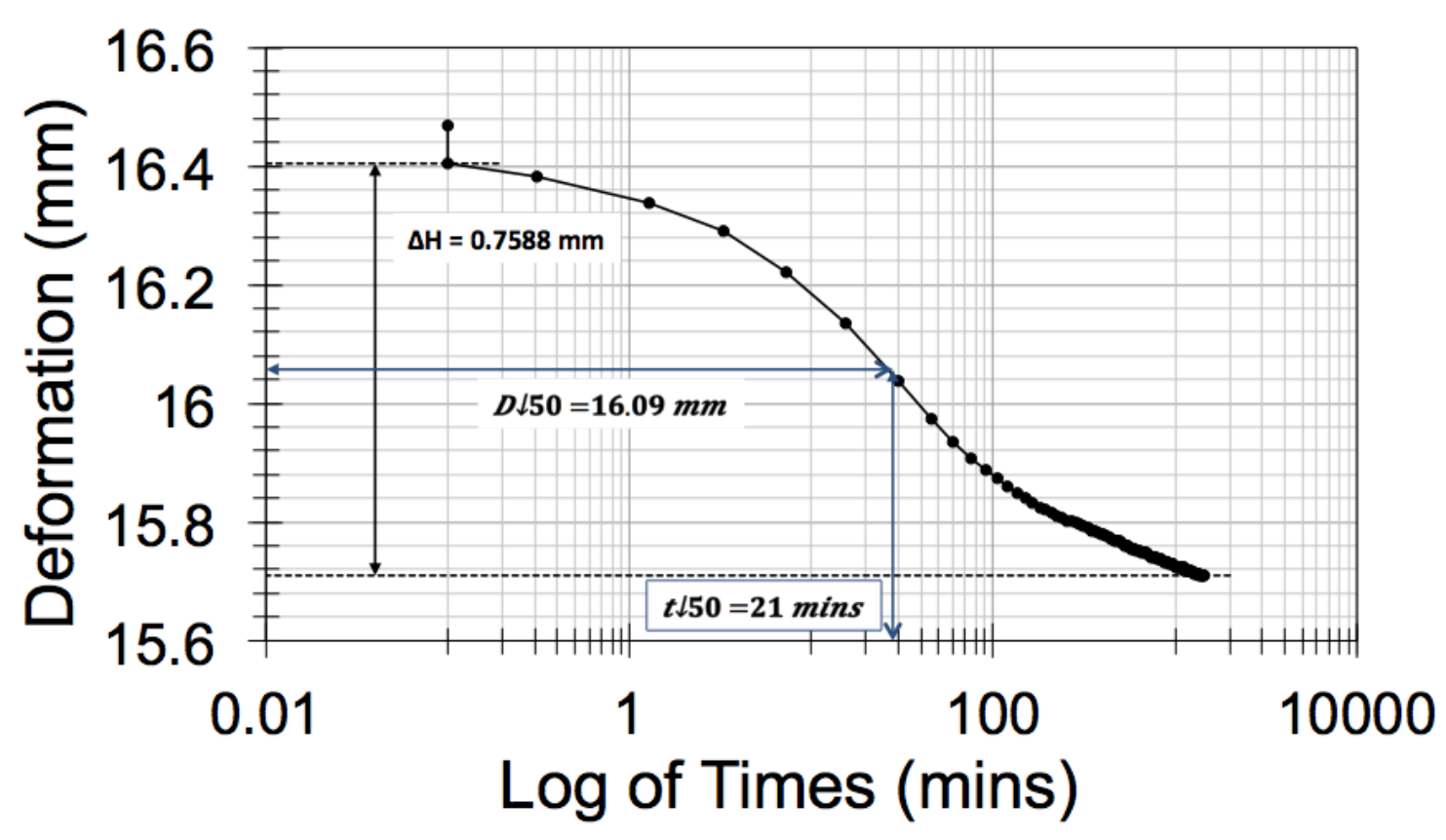

Figure 182. Casagrande analysis for $4 \mathrm{~kg}$ - Column Test \#1. 


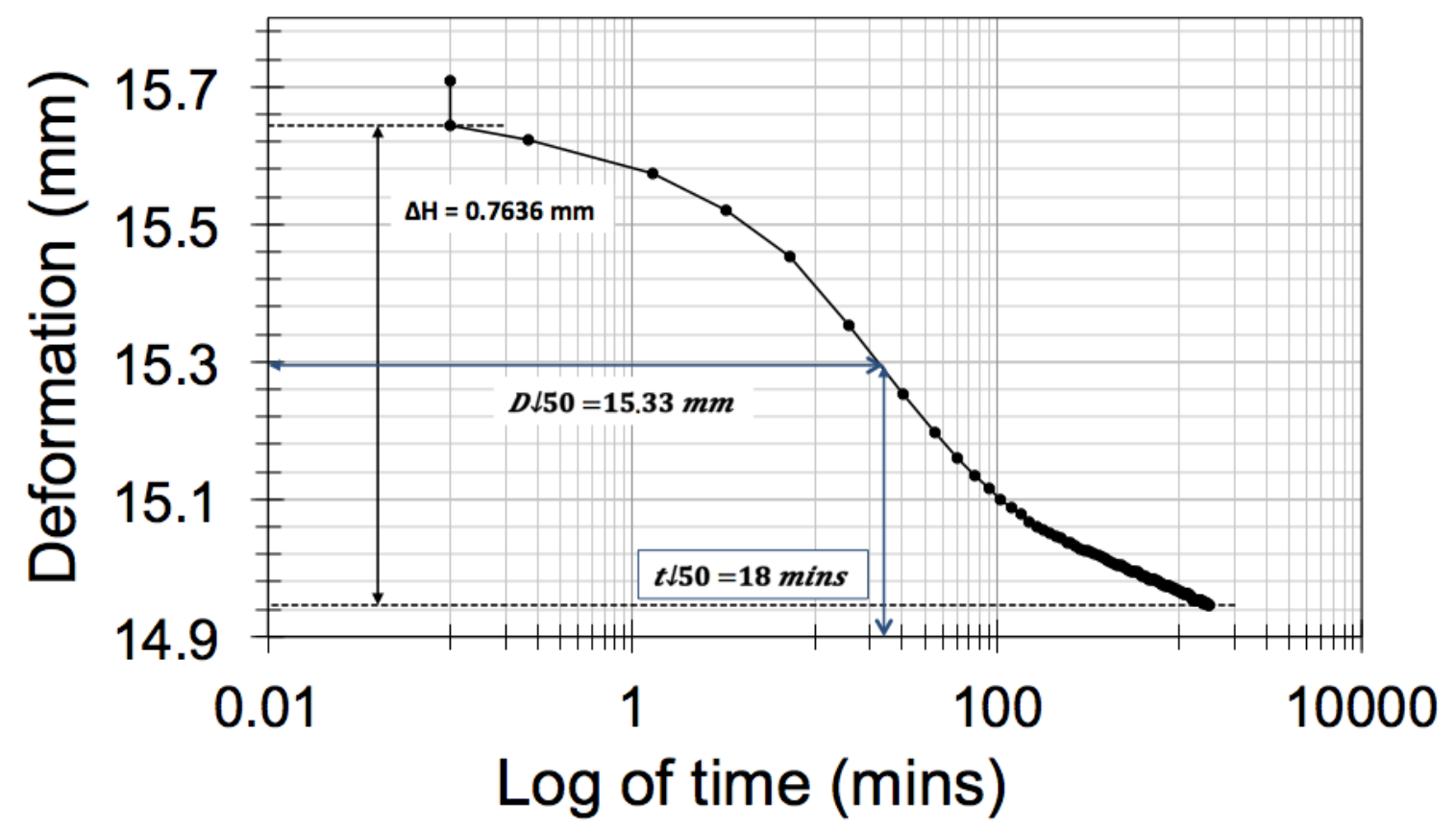

Figure 183. Casagrande analysis for $8 \mathrm{~kg}$ - Column Test \#1.

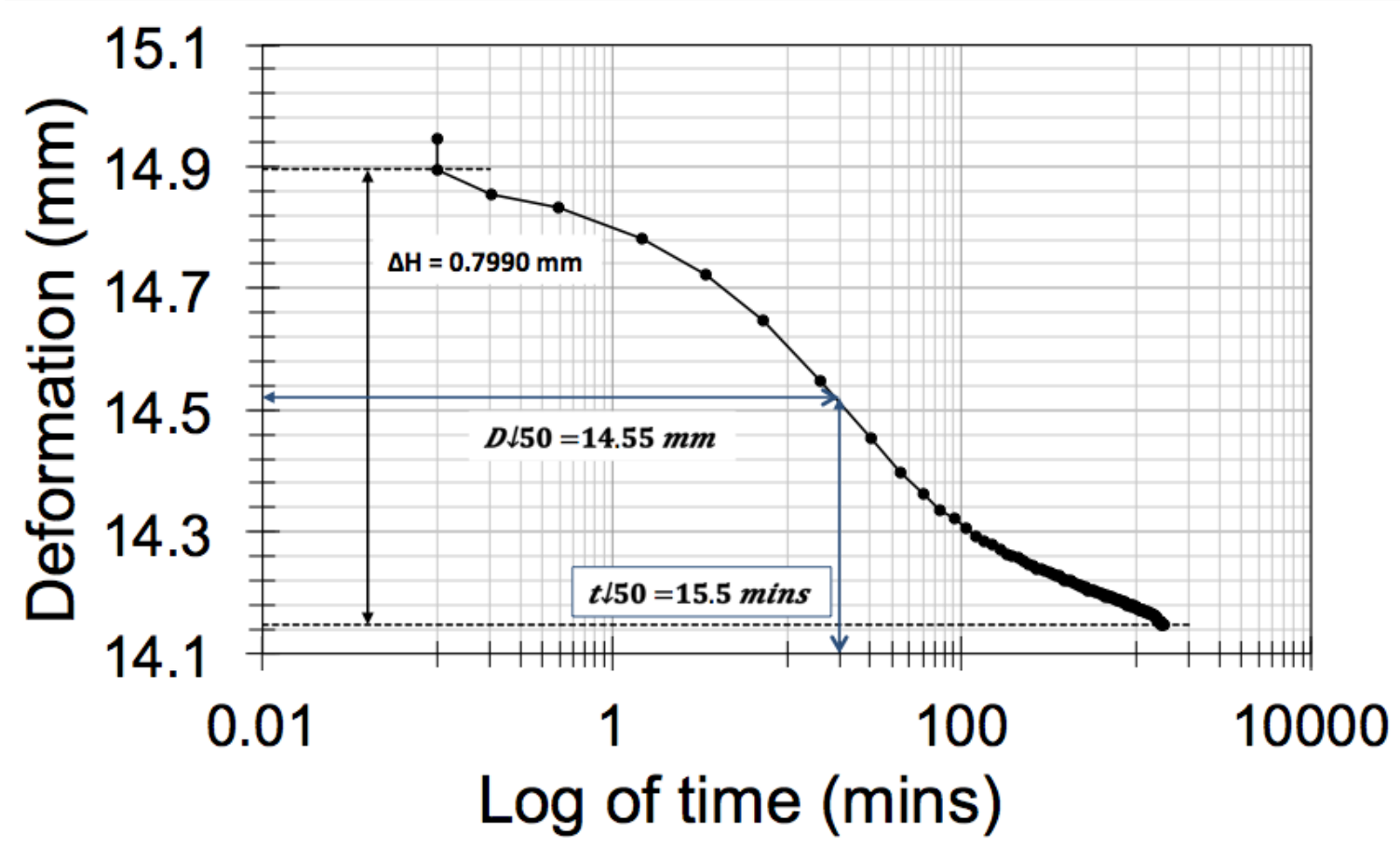

Figure 184. Casagrande analysis for $16 \mathrm{~kg}$ - Column Test \#1. 


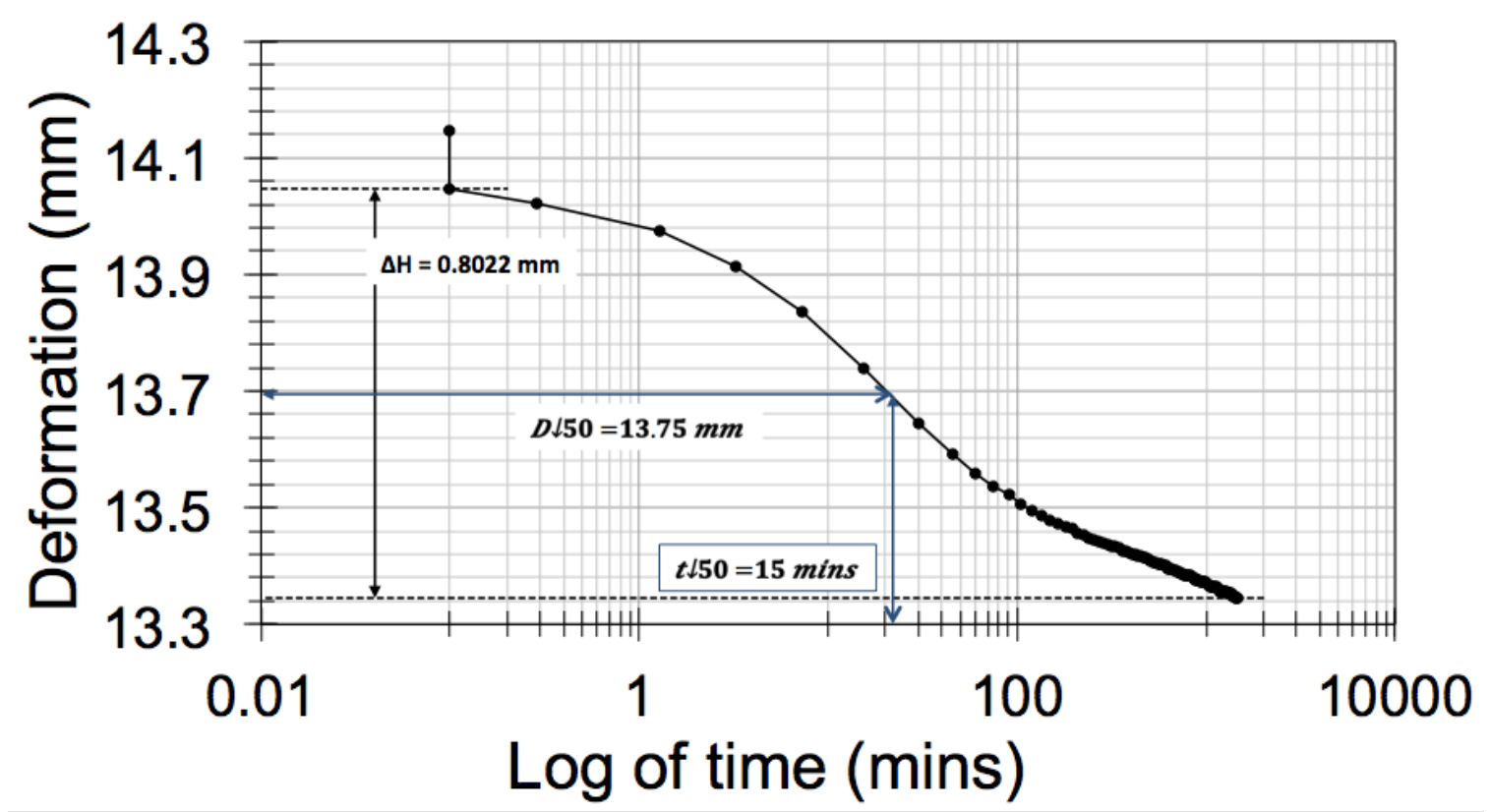

Figure 185. Casagrande analysis for $32 \mathrm{~kg}$ - Column Test \#1.

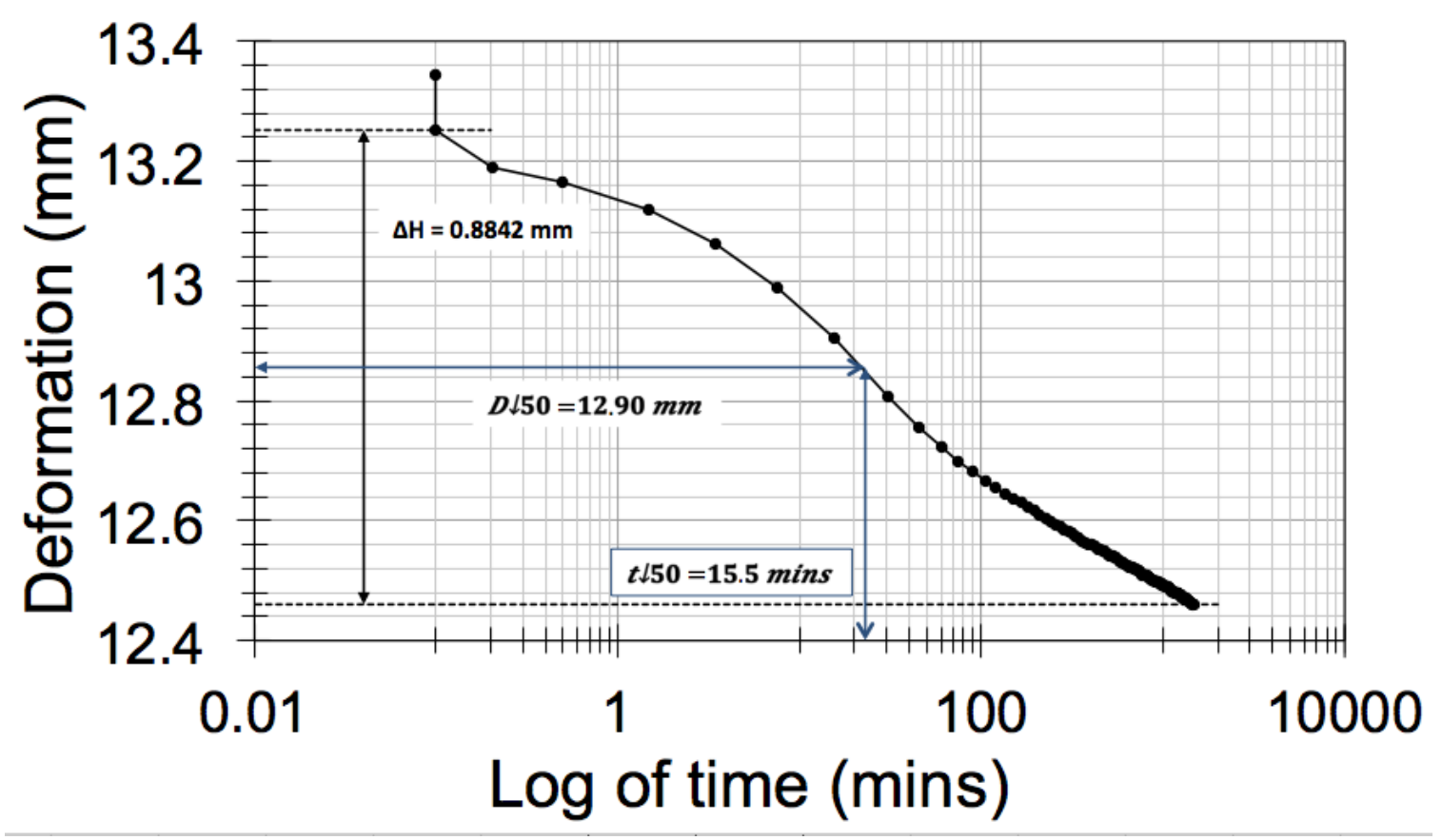

Figure 186. Casagrande analysis for $64 \mathrm{~kg}$ - Column Test \#1. 


\section{A.3 Depth of $6.75 \mathrm{~cm}-\mathrm{C}$ sample}

Table 26. Compressibility data at depth of $6.75 \mathrm{~cm}$ - Column Test \#1

\begin{tabular}{|c|c|c|c|c|c|c|c|}
\hline $\begin{array}{l}\text { Weight } \\
(\mathrm{Kg})\end{array}$ & Load Increment & $\Sigma \Delta H(\mathrm{~mm})$ & $\begin{array}{c}\mathrm{H} \\
(\mathrm{Ho}-\Delta \mathrm{H})(\mathrm{mm})\end{array}$ & \begin{tabular}{|c|} 
e \\
$(\mathrm{H}-\mathrm{Hs}) / \mathrm{Hs}$
\end{tabular} & $\frac{\mathrm{Cv}}{(\mathrm{mm} / \mathrm{s})}$ & \begin{tabular}{|c|} 
av \\
(m)/KN)
\end{tabular} & $\frac{K}{(\mathrm{~m} / \mathrm{s})}$ \\
\hline- & 0.1 & 0.0000 & 20.1917 & 1.2976 & - & - & - \\
\hline 1 & 4.8 & 2.8374 & 17.3543 & 0.9747 & 0.0066 & 0.0449 & $1.26 \mathrm{E}-09$ \\
\hline 2 & 9.7 & 3.7264 & 16.4653 & 0.8736 & 0.0052 & 0.0164 & $3.65 \mathrm{E}-10$ \\
\hline 4 & 19.4 & 4.5672 & 15.6245 & 0.7779 & 0.0067 & 0.0071 & $2.01 \mathrm{E}-10$ \\
\hline 8 & 38.7 & 5.3999 & 14.7918 & 0.6831 & 0.0066 & 0.0035 & $9.99 \mathrm{E}-11$ \\
\hline 16 & 77.4 & 6.2439 & 13.9478 & 0.5871 & 0.0057 & 0.0018 & $4.45 \mathrm{E}-11$ \\
\hline 32 & 154.9 & 7.1265 & 13.0652 & 0.4867 & 0.0052 & 0.0010 & $2.22 \mathrm{E}-11$ \\
\hline 64 & 309.8 & 8.1361 & 12.0556 & 0.3718 & 0.0047 & 0.0007 & $1.39 \mathrm{E}-11$ \\
\hline
\end{tabular}

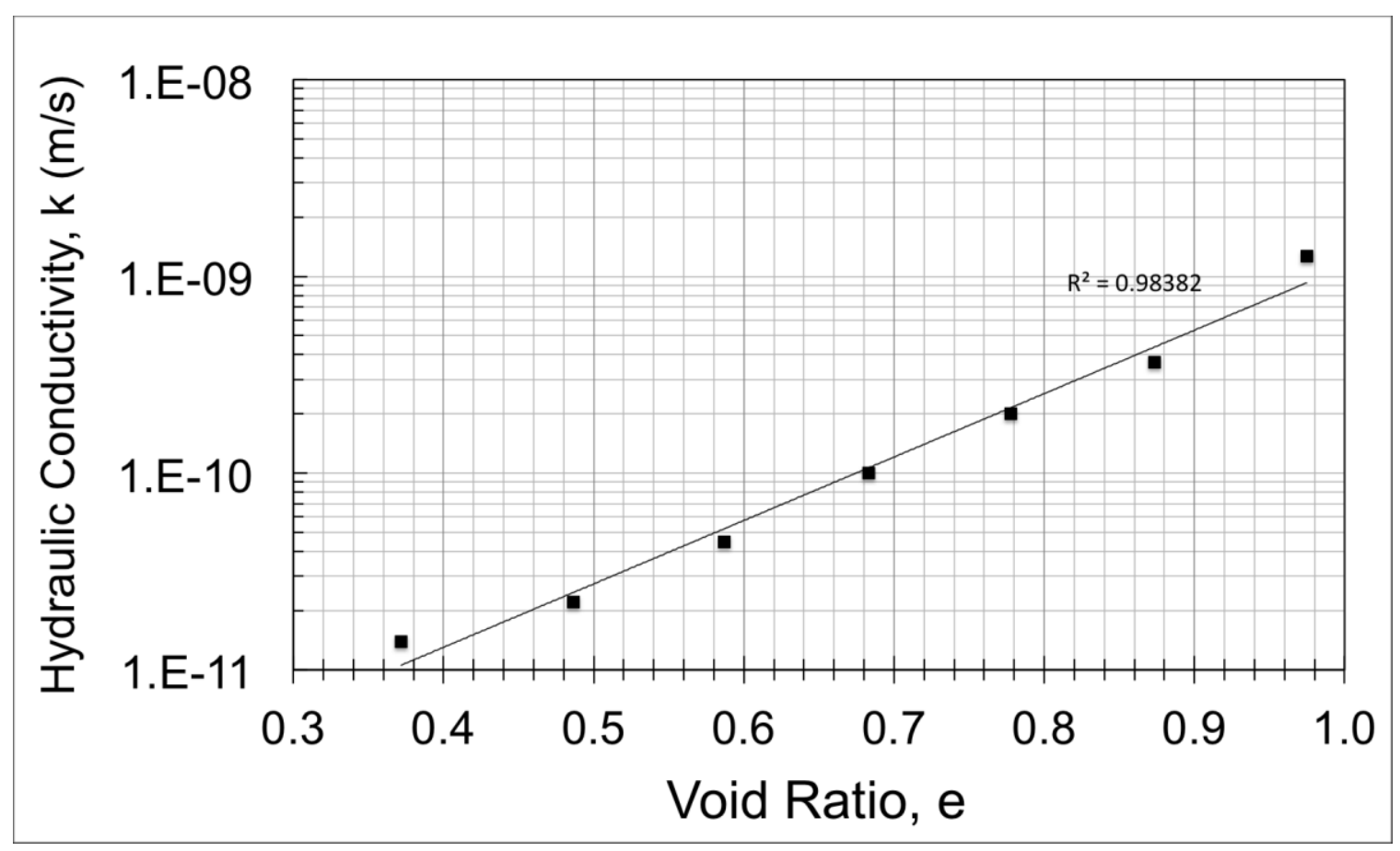

Figure 187. Permeability results (depth of $6.75 \mathrm{~cm}$ ) - Column Test \#1 


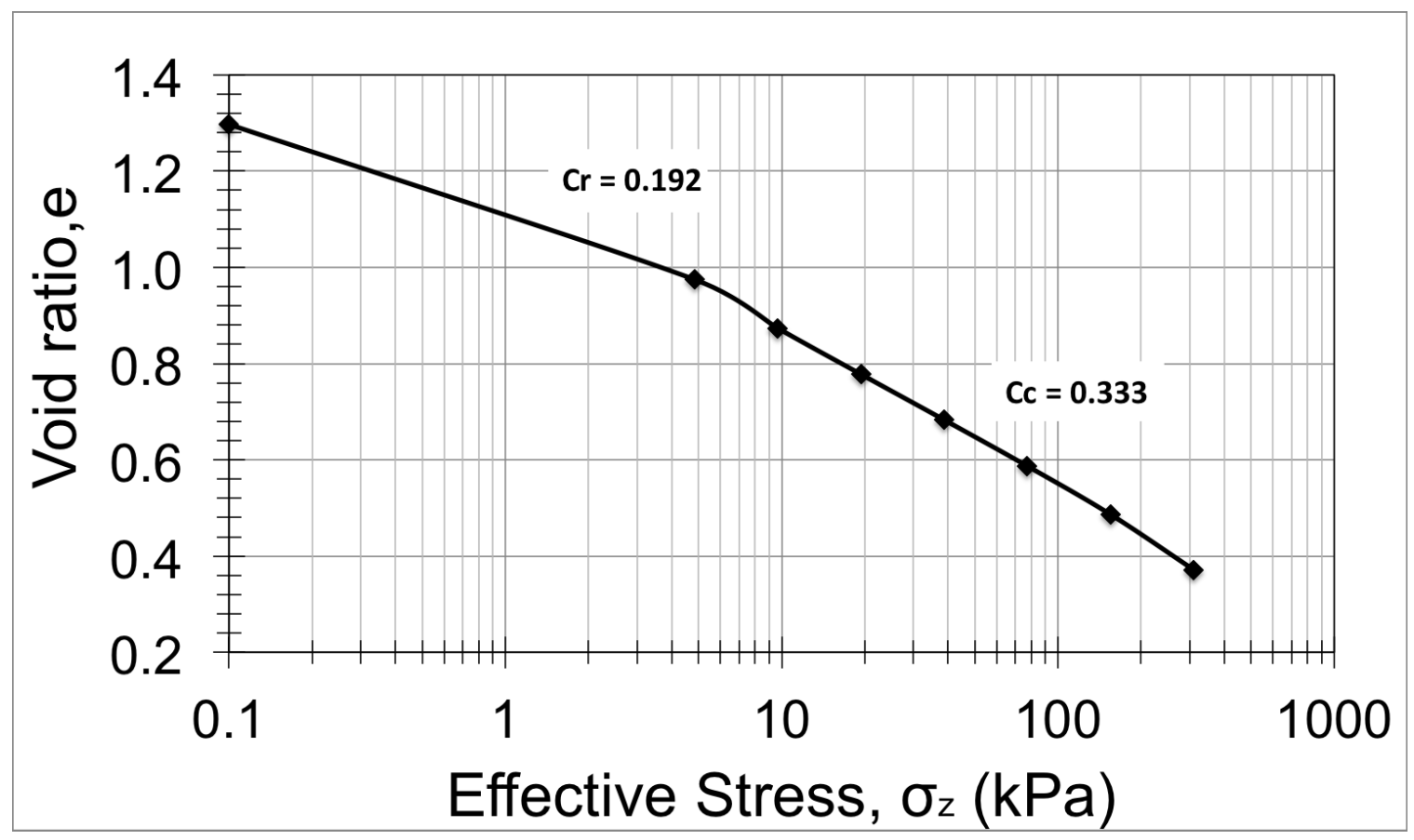

Figure 188. Void ratio vs Effective stress (depth of $6.75 \mathrm{~cm}$ ) - Column Test \#1

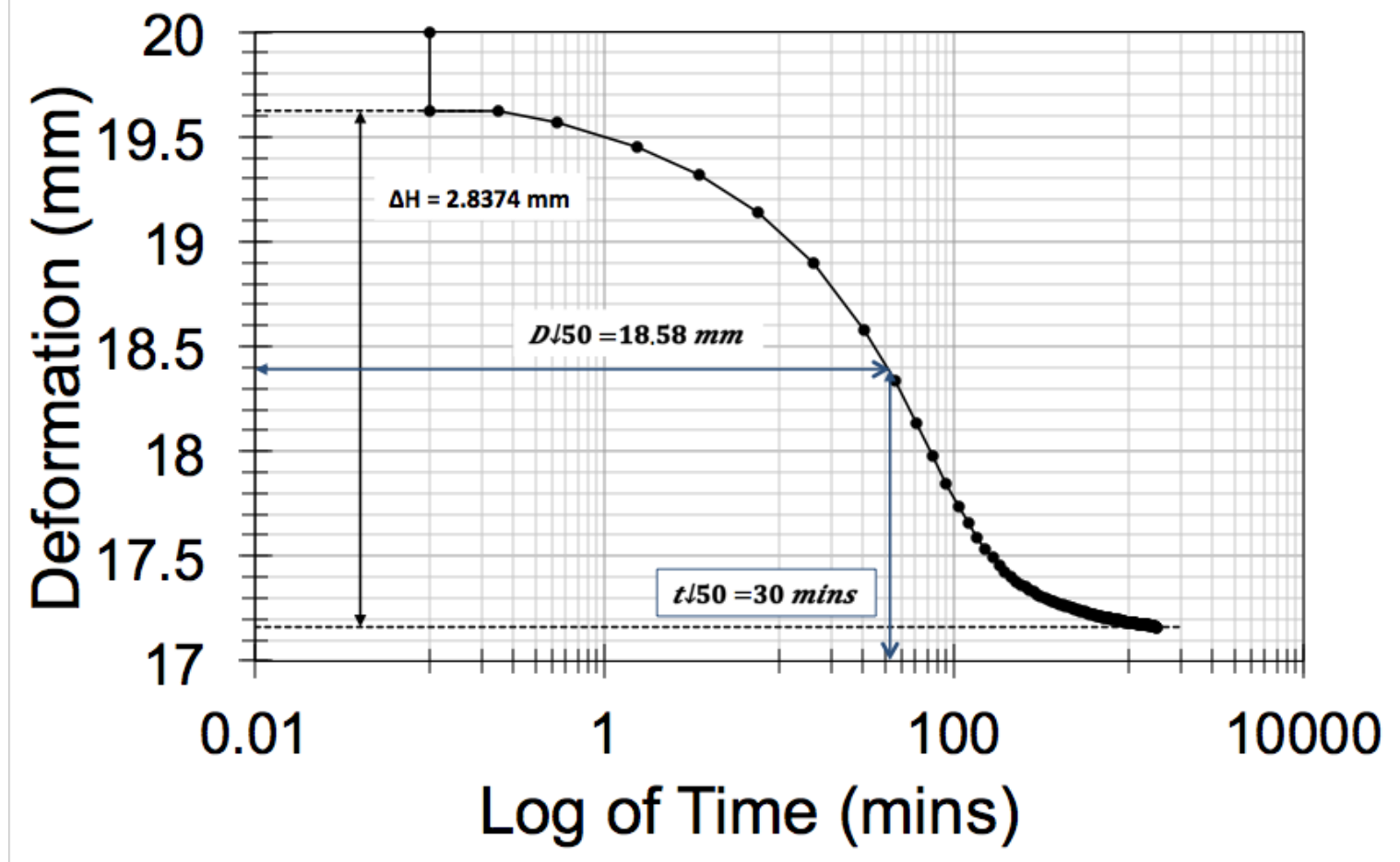

Figure 189. Casagrande analysis for $1 \mathrm{~kg}$ - Column Test \#1. 


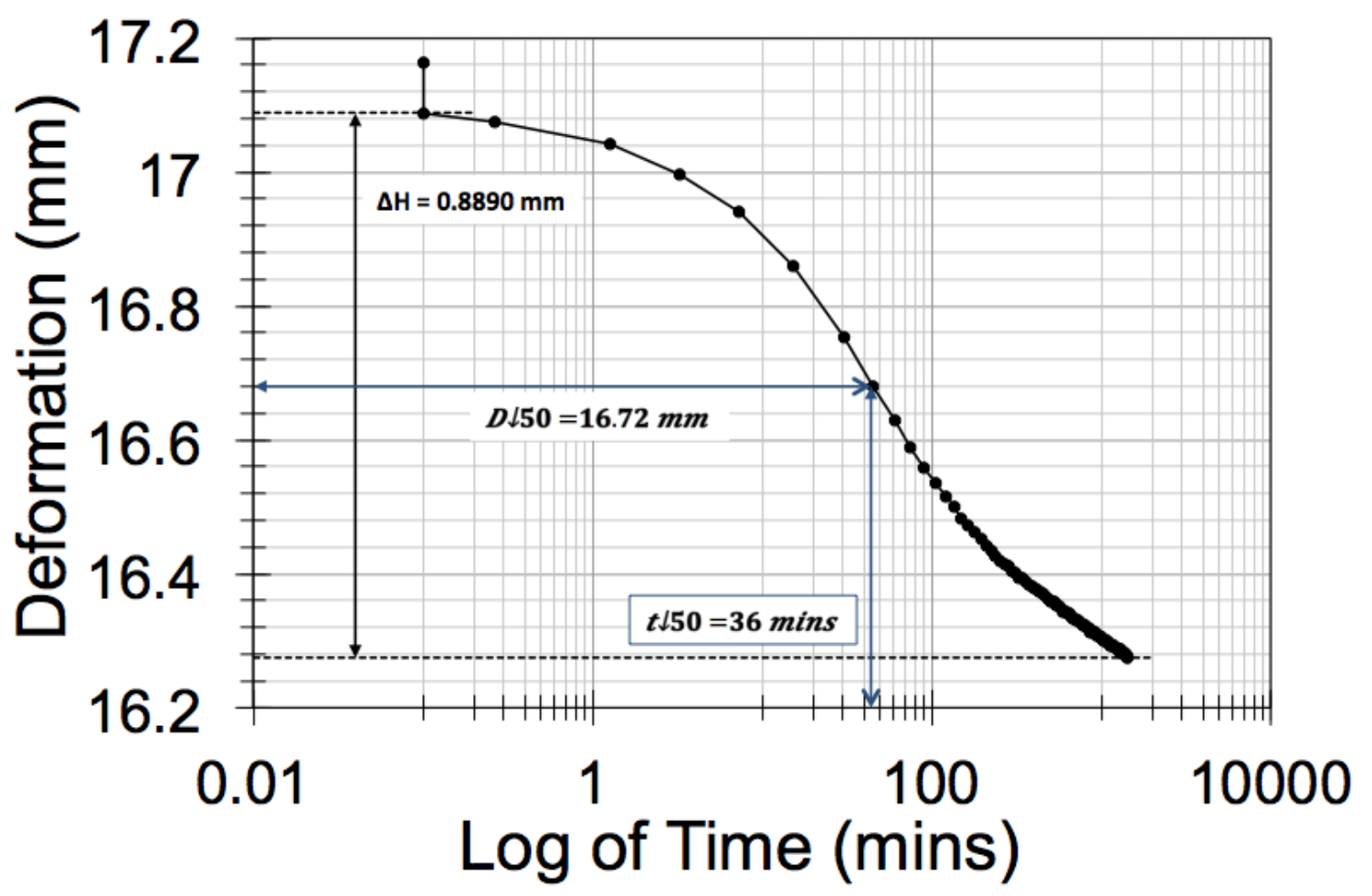

Figure 190. Casagrande analysis for $2 \mathrm{~kg}$ - Column Test \#1.

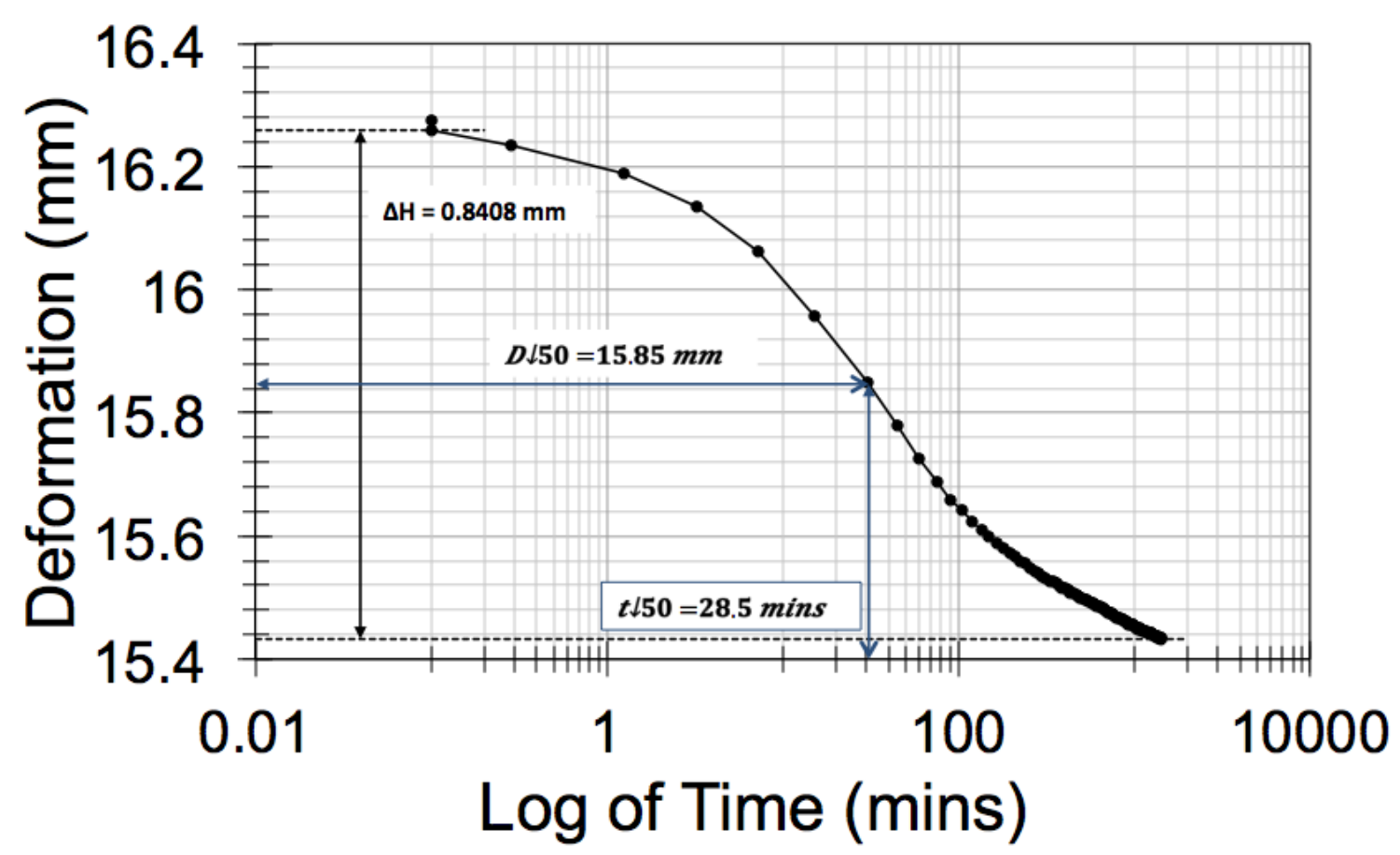

Figure 191. Casagrande analysis for $4 \mathrm{~kg}$ - Column Test \#1. 


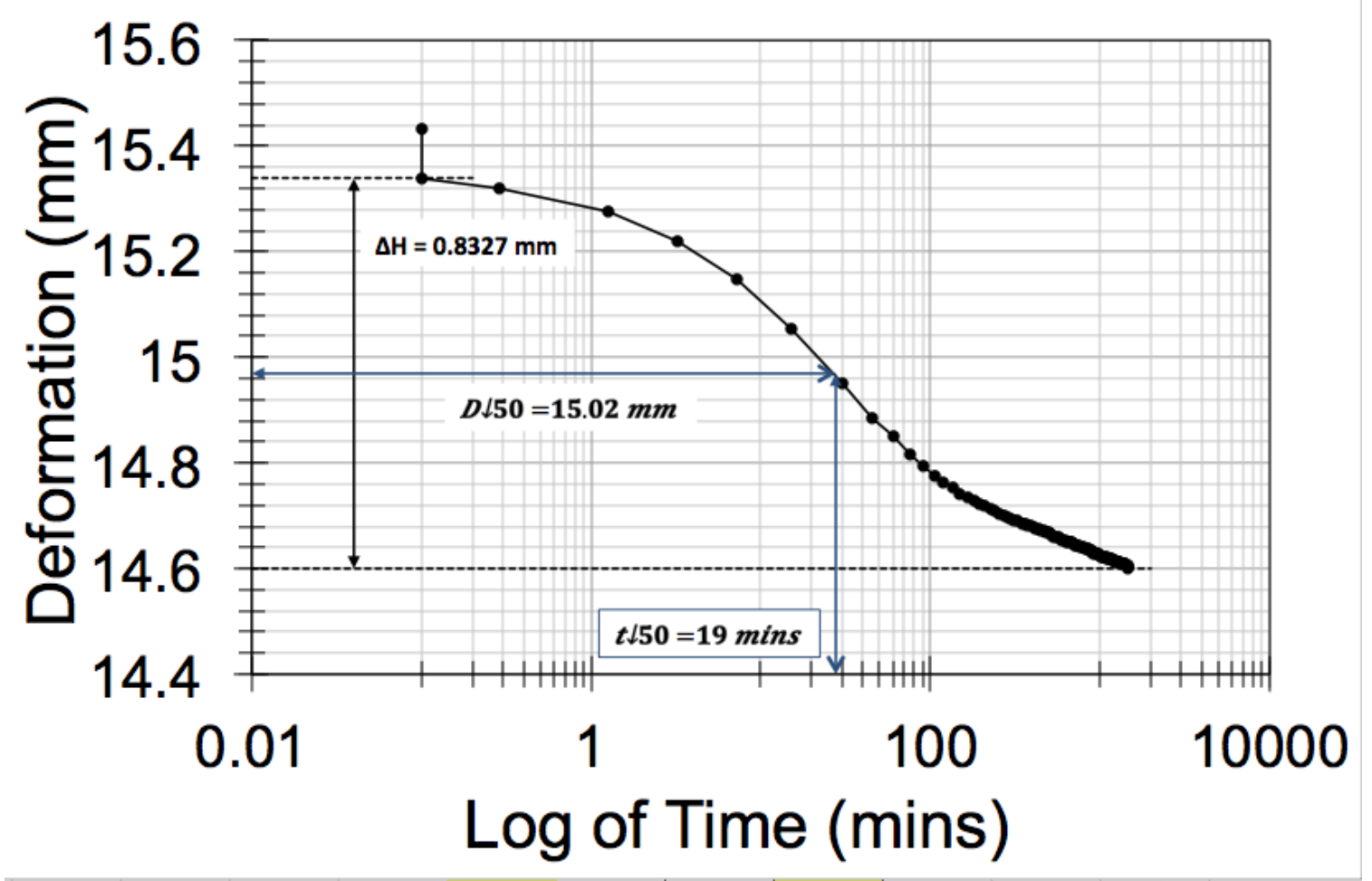

Figure 192. Casagrande analysis for $8 \mathrm{~kg}$ - Column Test \#1.

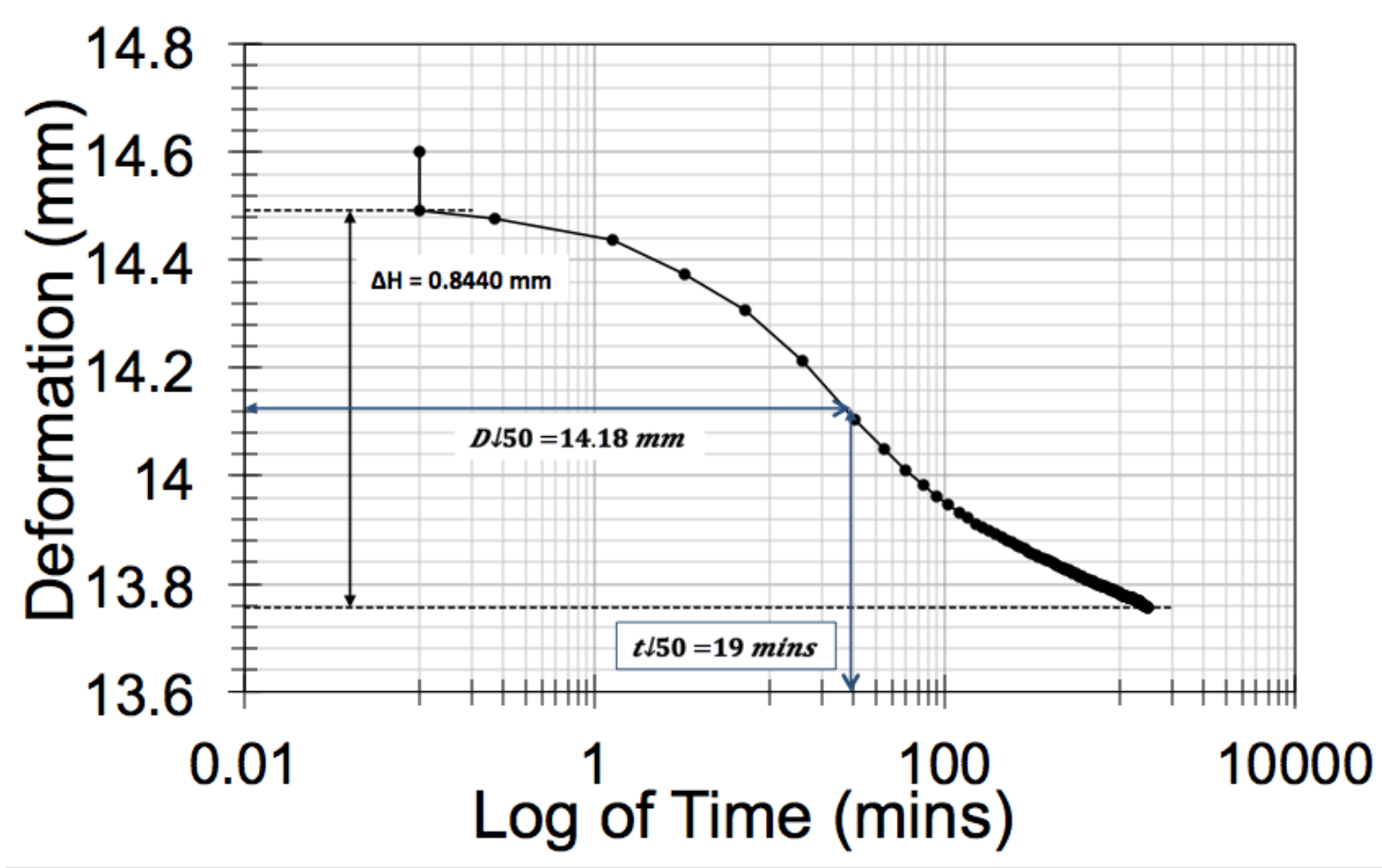

Figure 193. Casagrande analysis for $16 \mathrm{~kg}$ - Column Test \#1. 


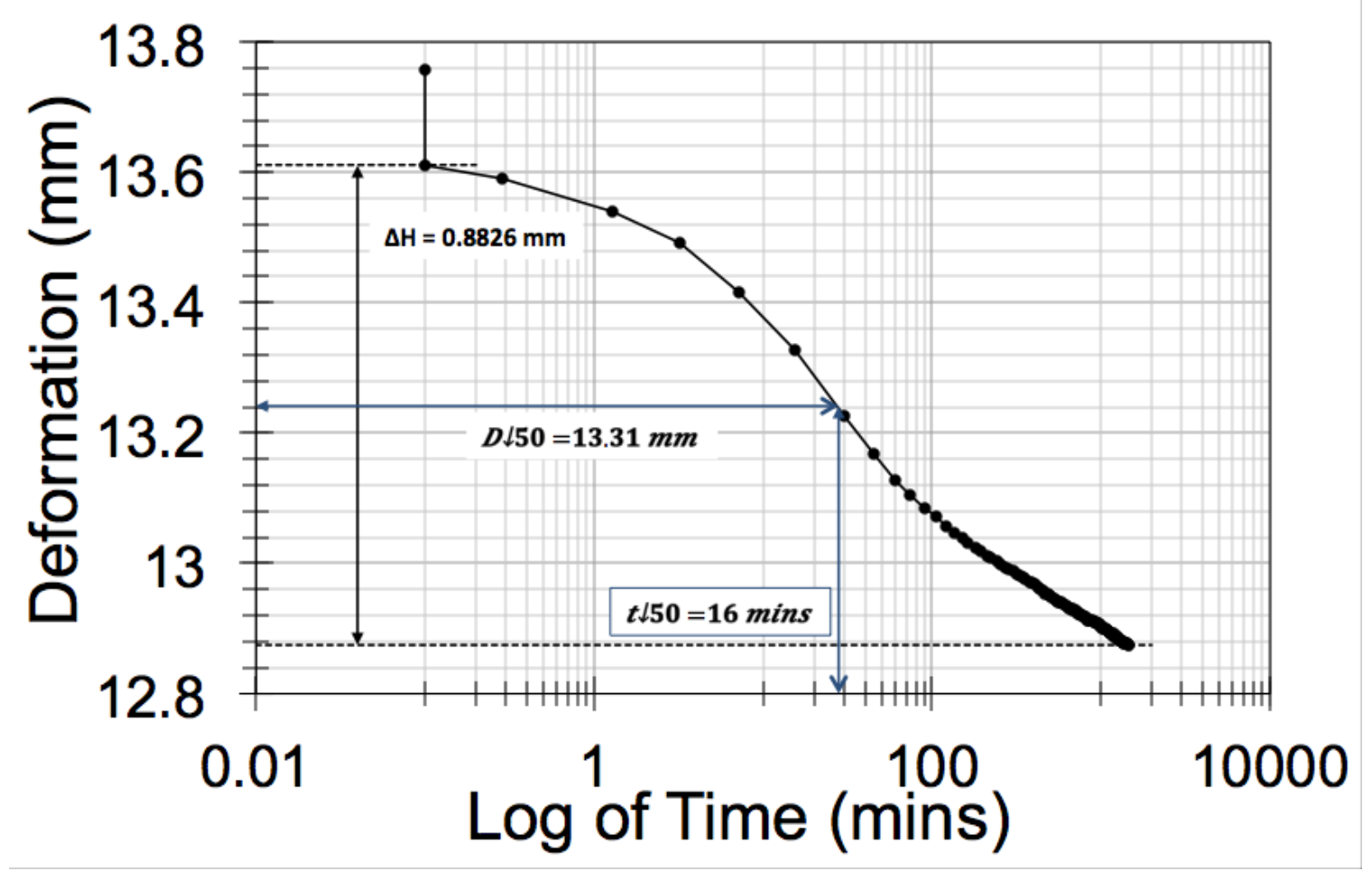

Figure 194. Casagrande analysis for $32 \mathrm{~kg}$ - Column Test \#1.

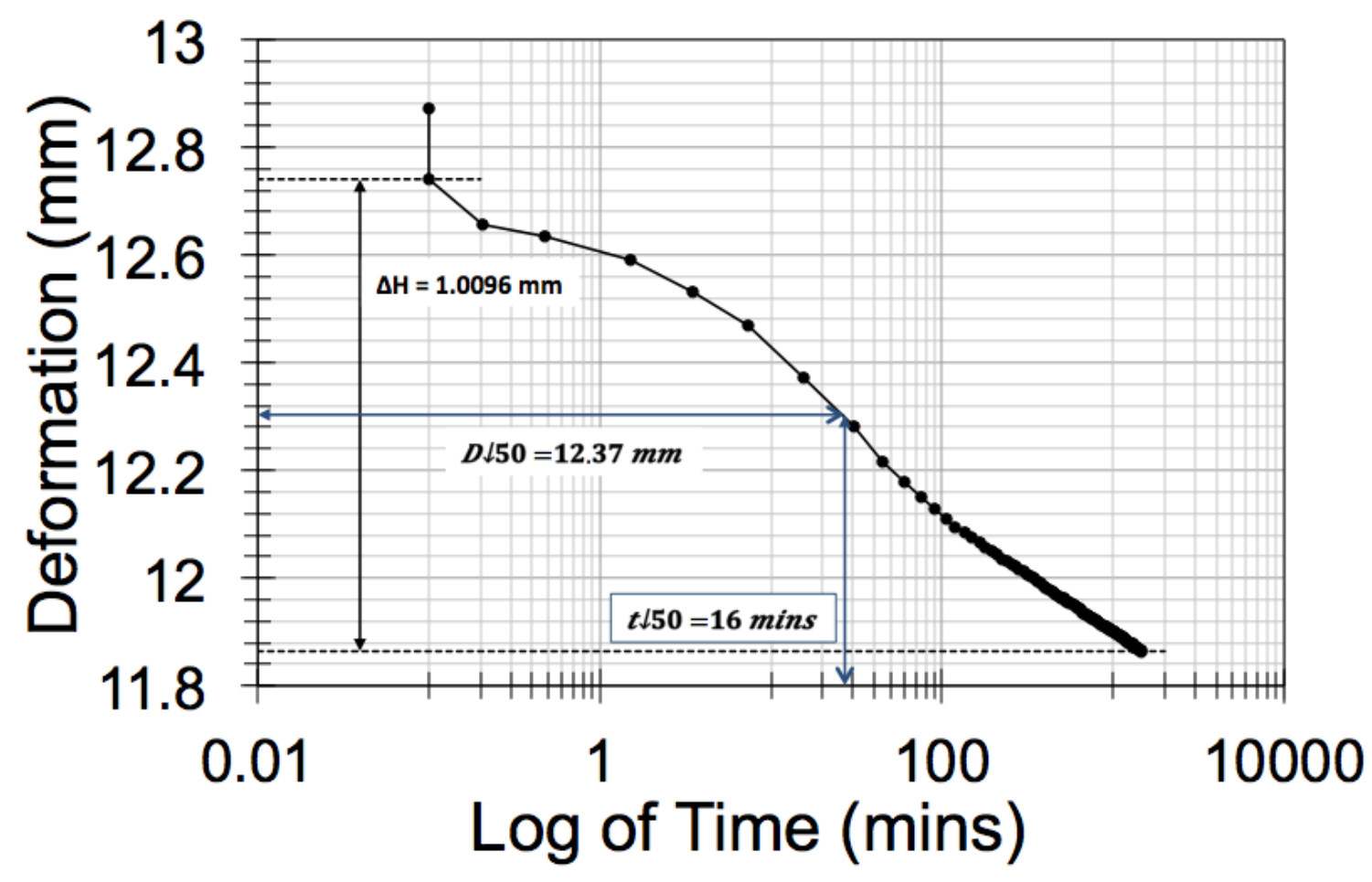

Figure 195. Casagrande analysis for $64 \mathrm{~kg}$ - Column Test \#1. 


\section{A.4 Depth of $10.25 \mathrm{~cm}-$ A sample}

Table 27. Compressibility data at depth of $10.25 \mathrm{~cm}$ - Column Test \#1

\begin{tabular}{|c|c|c|c|c|c|c|c|}
\hline $\begin{array}{c}\text { Weight } \\
(\mathbf{K g})\end{array}$ & $\begin{array}{c}\text { Load Increment } \\
\text { or ov (Kpa) }\end{array}$ & $\mathbf{\Sigma} \Delta \mathbf{H}(\mathbf{m m})$ & $\mathbf{H}$ & $\mathbf{e}$ & $\mathbf{C v}$ & av & $\mathbf{K}$ \\
\hline- & 0.1 & 0.0000 & 20.1602 & 1.2259 & - & - & - \\
\hline 1 & 4.8 & 2.1140 & 18.0462 & 0.9925 & 0.0074 & 0.0355 & $1.15 \mathrm{E}-09$ \\
\hline 2 & 9.7 & 3.0303 & 17.1299 & 0.8913 & 0.0062 & 0.0153 & $4.20 \mathrm{E}-10$ \\
\hline 4 & 19.4 & 3.9804 & 16.1798 & 0.7864 & 0.0077 & 0.0078 & $2.65 \mathrm{E}-10$ \\
\hline 8 & 38.7 & 4.9305 & 15.2297 & 0.6815 & 0.0071 & 0.0039 & $1.22 \mathrm{E}-10$ \\
\hline 16 & 77.4 & 5.8886 & 14.2716 & 0.5757 & 0.0073 & 0.0019 & $6.09 \mathrm{E}-11$ \\
\hline 32 & 154.9 & 6.7857 & 13.3746 & 0.4767 & 0.0059 & 0.0010 & $2.53 \mathrm{E}-11$ \\
\hline 64 & 309.8 & 7.7953 & 12.3650 & 0.3652 & 0.0046 & 0.0007 & $1.41 \mathrm{E}-11$ \\
\hline
\end{tabular}

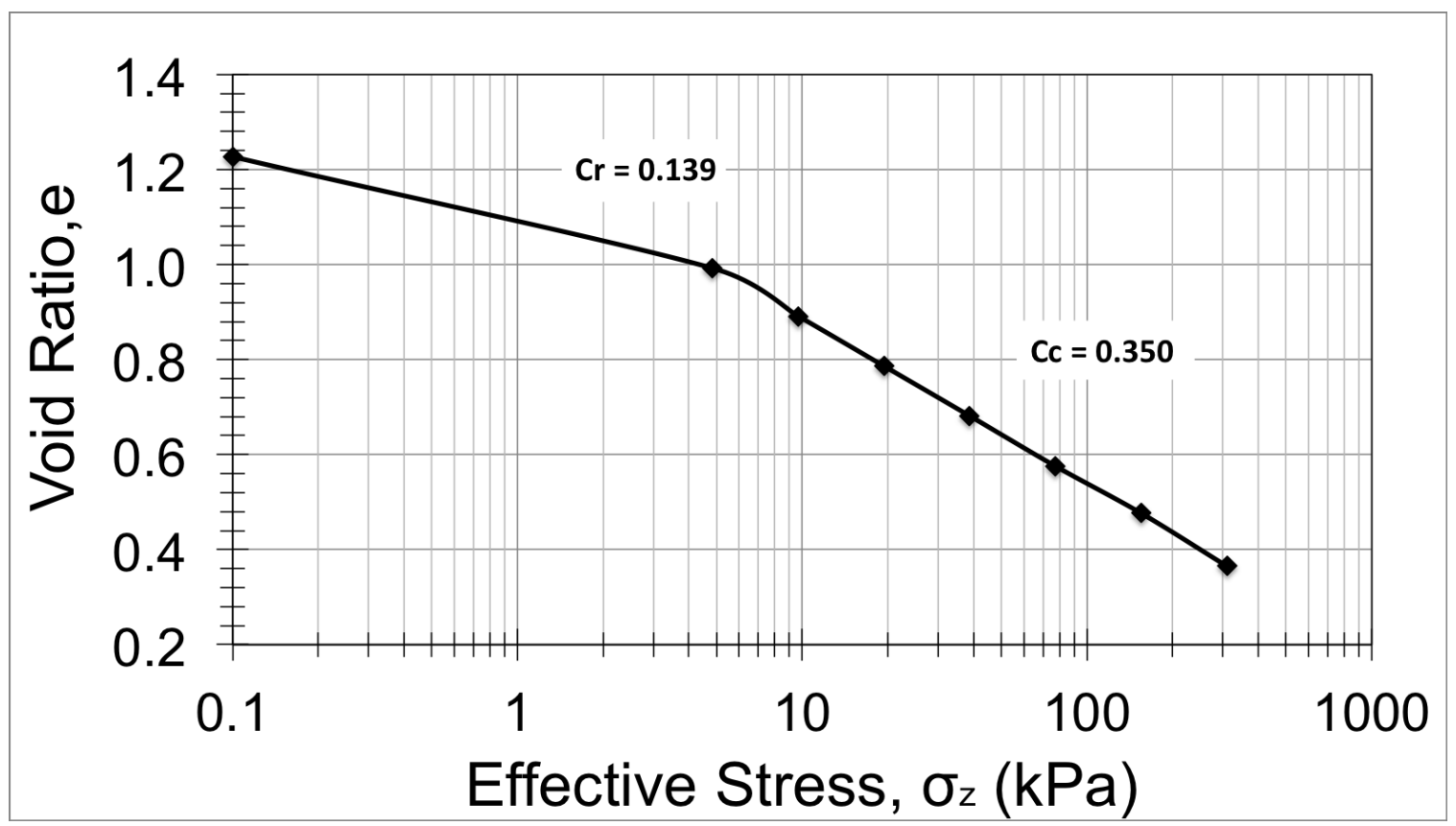

Figure 196. Void ratio vs Effective stress (depth of $10.25 \mathrm{~cm}$ ) - Column Test \#1 


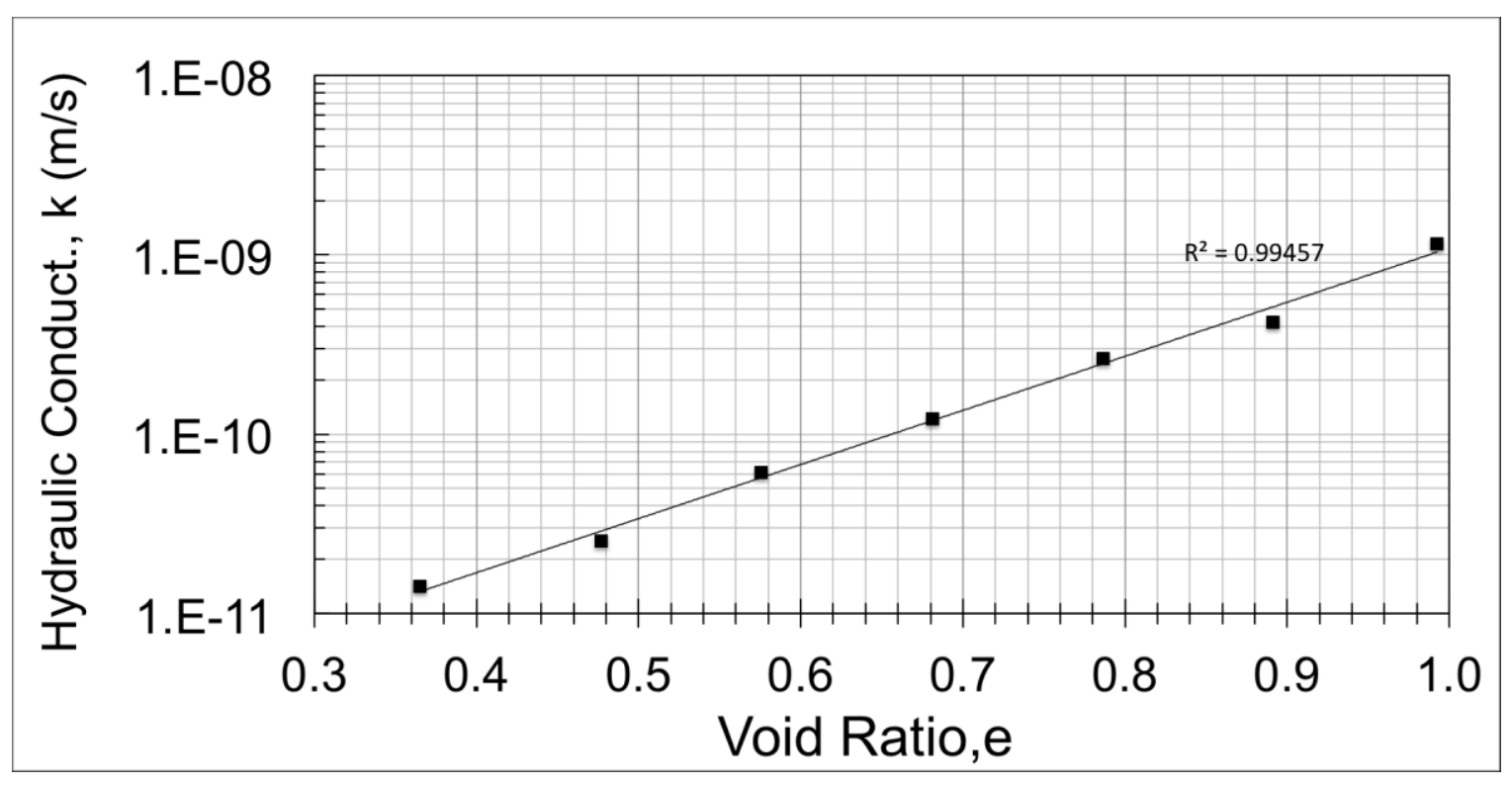

Figure 197. Permeability results (depth of $10.25 \mathrm{~cm})$ - Column Test \#1

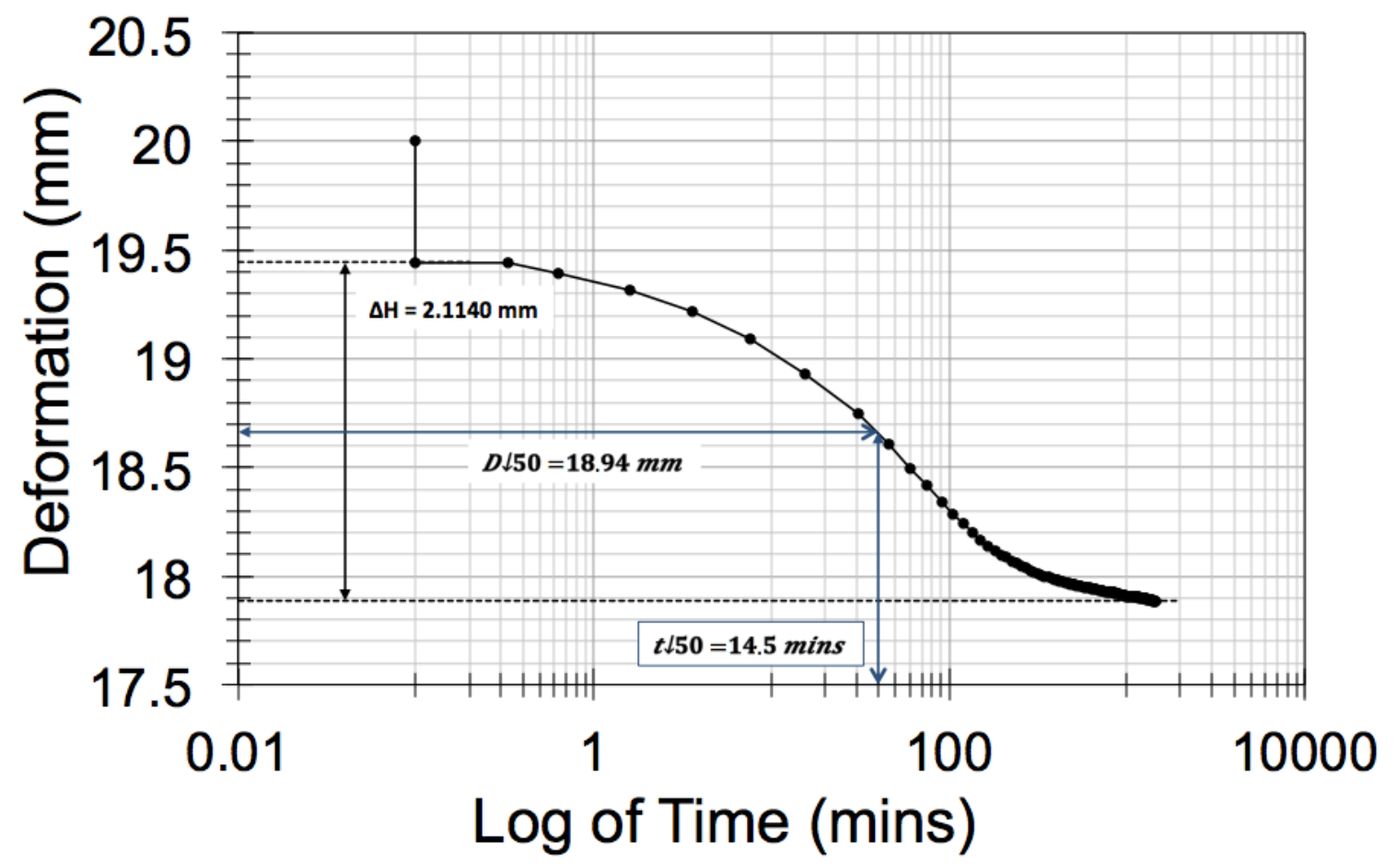

Figure 198. Casagrande analysis for $1 \mathrm{~kg}$ - Column Test \#1. 


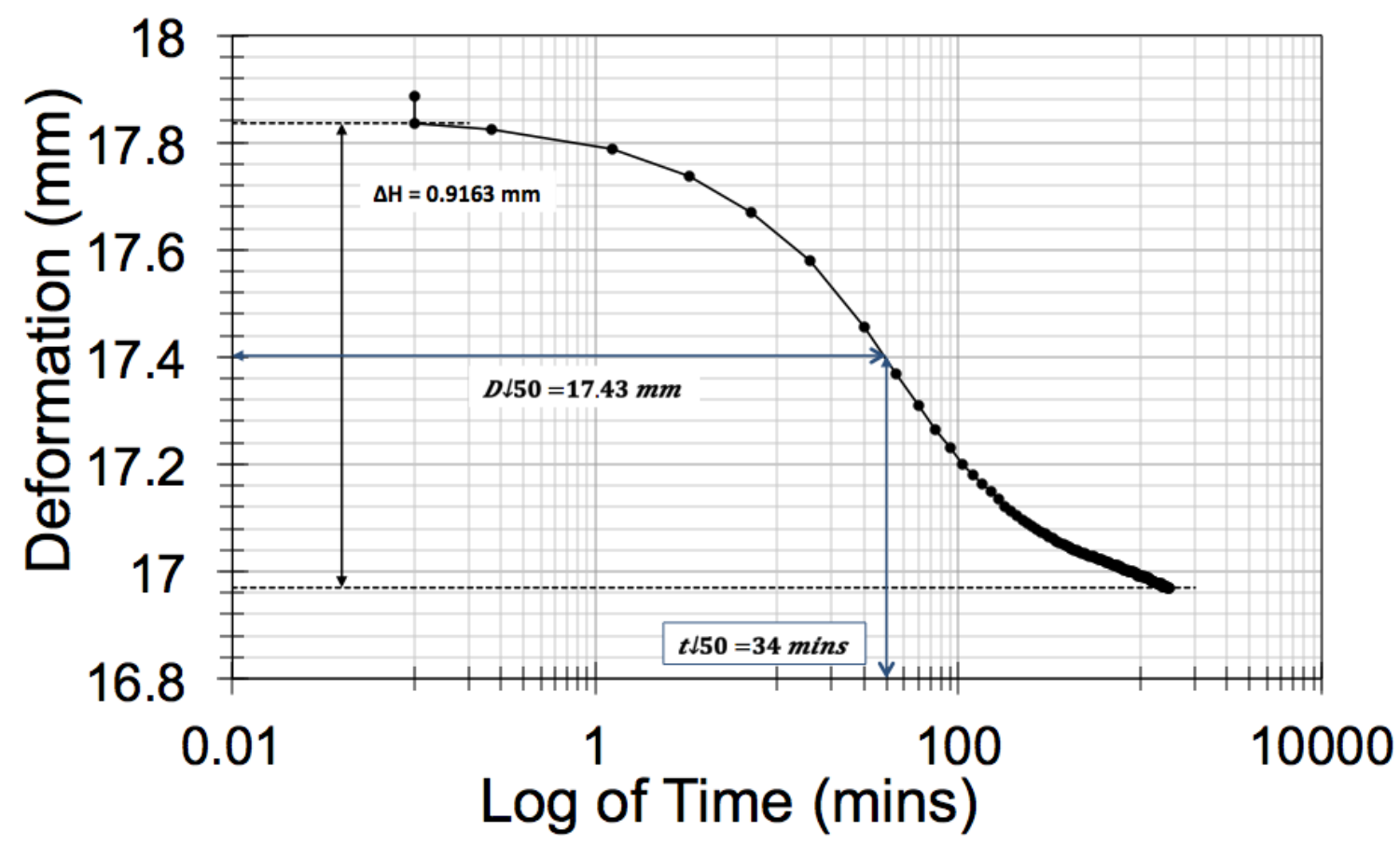

Figure 199. Casagrande analysis for $2 \mathrm{~kg}-$ Column Test \#1.

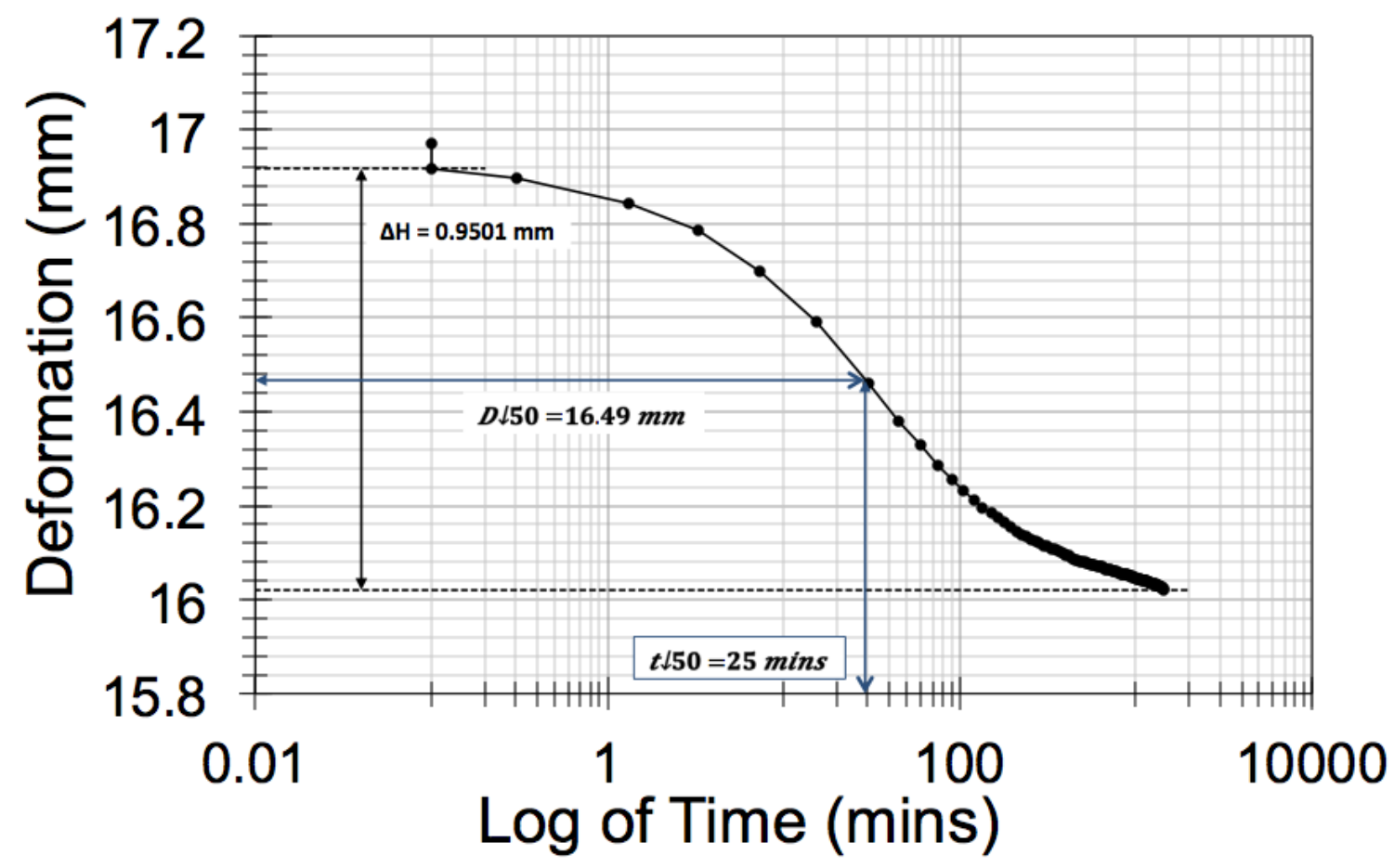

Figure 200. Casagrande analysis for $4 \mathrm{~kg}$ - Column Test \#1. 


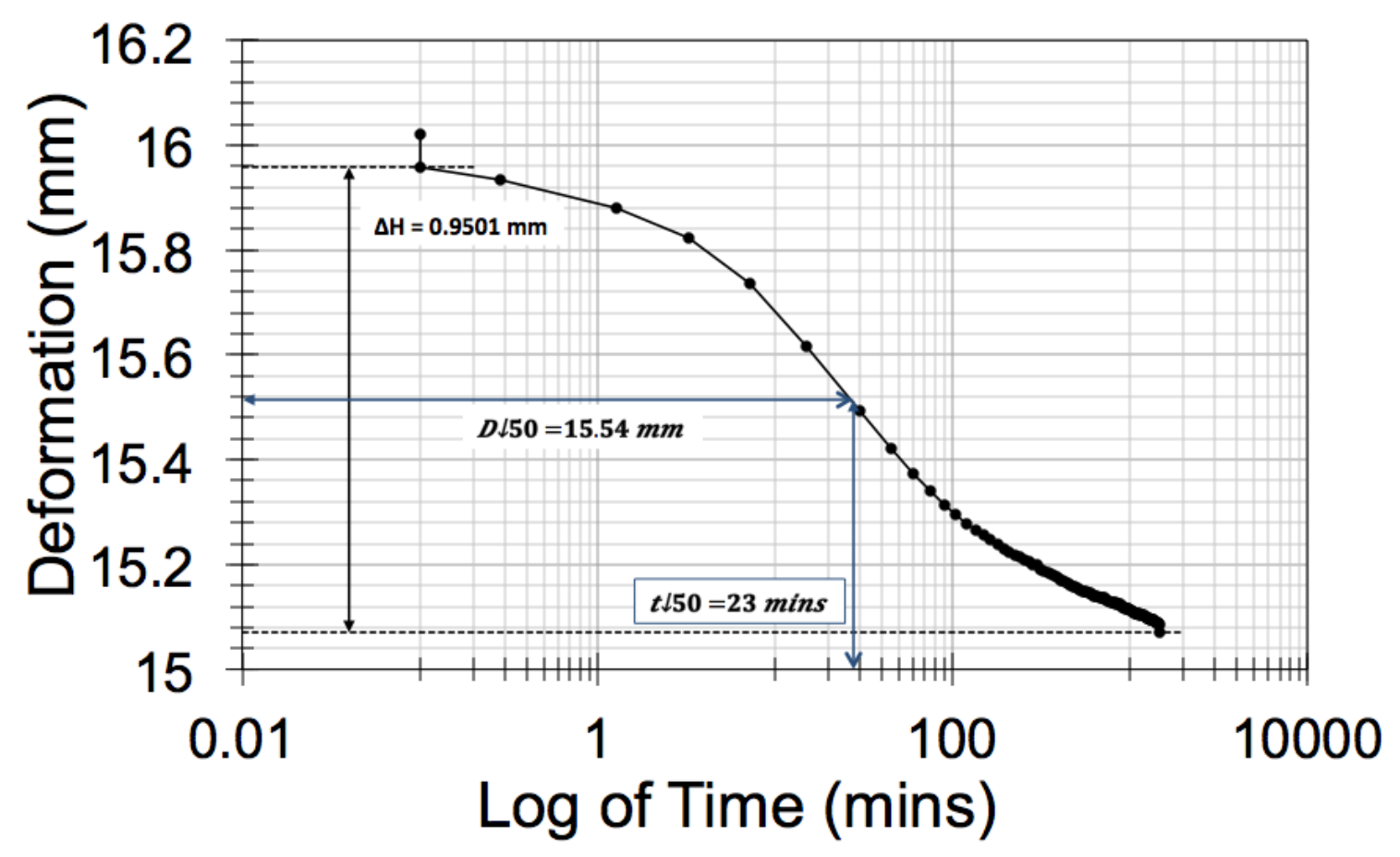

Figure 201. Casagrande analysis for $8 \mathrm{~kg}$ - Column Test \#1.

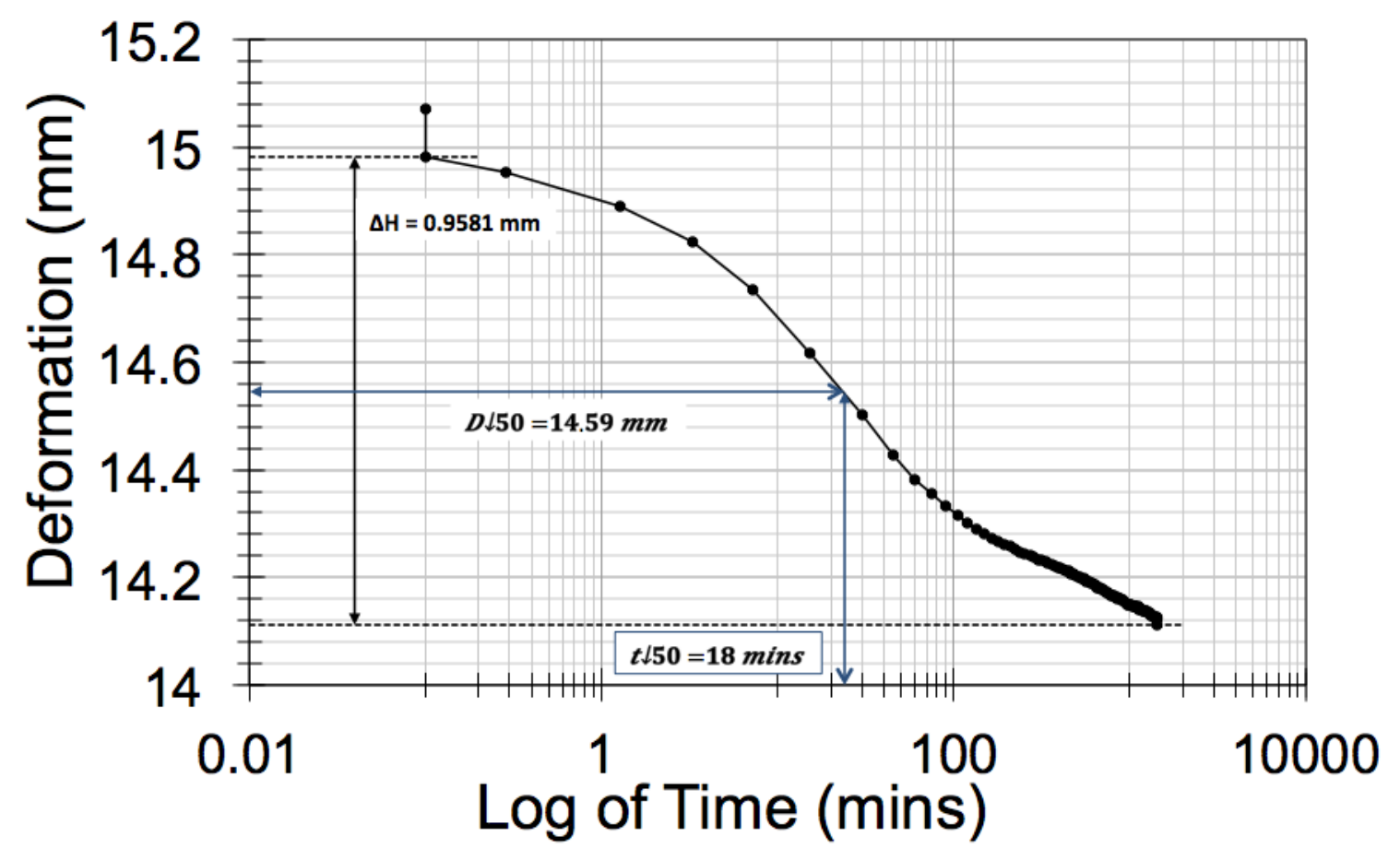

Figure 202. Casagrande analysis for $16 \mathrm{~kg}$ - Column Test \#1. 


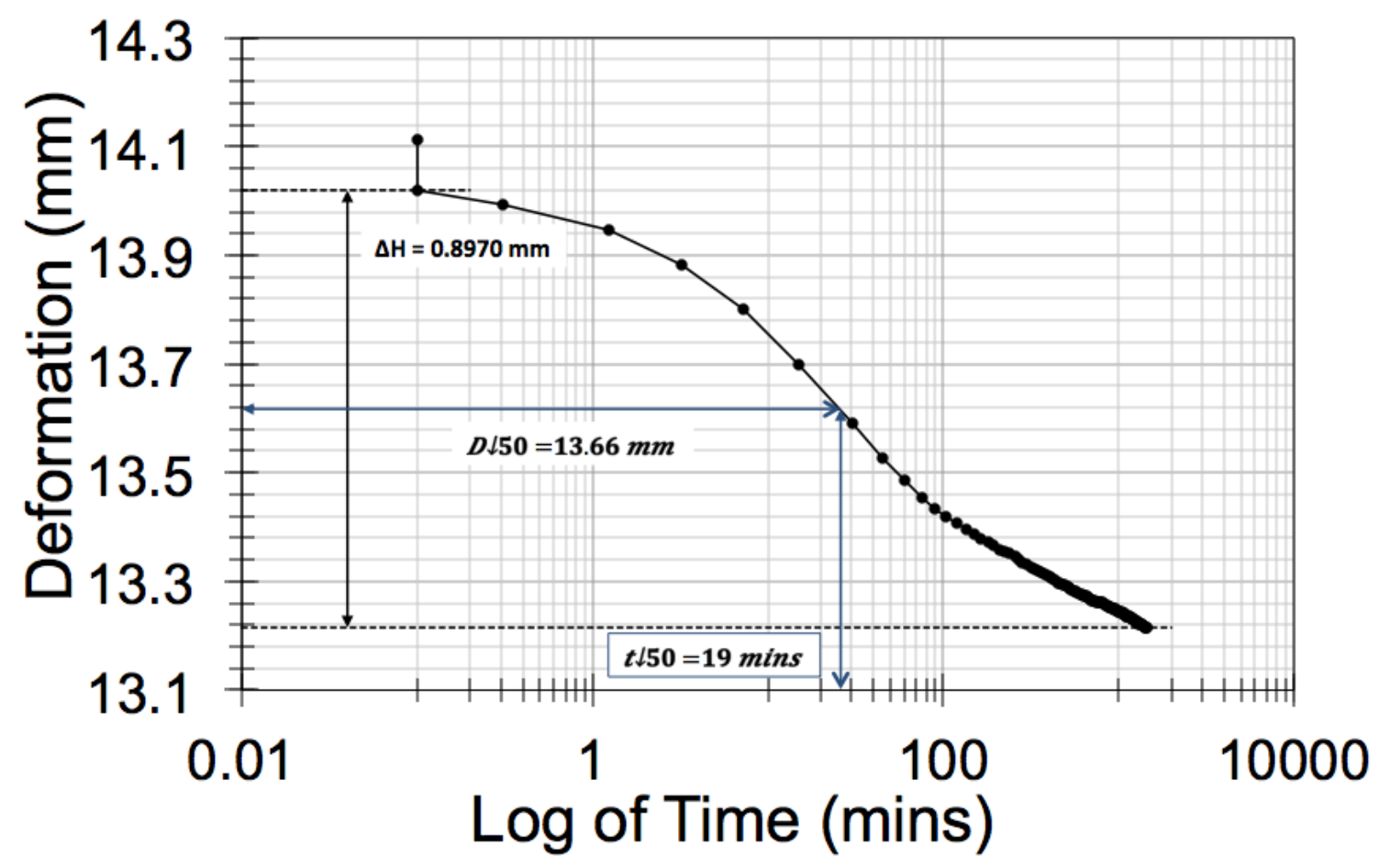

Figure 203. Casagrande analysis for $32 \mathrm{~kg}$ - Column Test \#1.

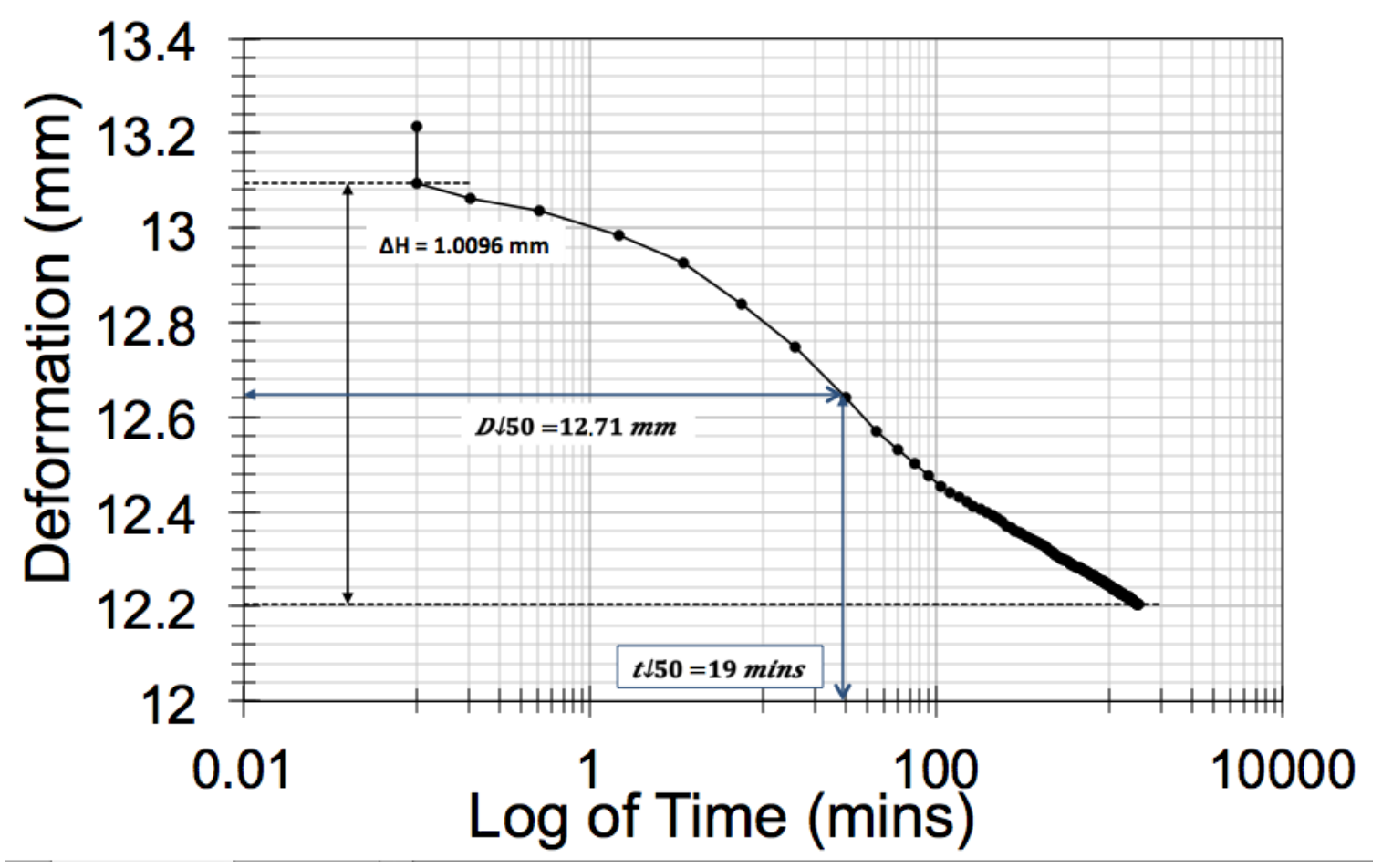

Figure 204. Casagrande analysis for $64 \mathrm{~kg}$ - Column Test \#1. 


\section{A.5 Depth of $13.75 \mathrm{~cm}$ - F sample}

Table 28. Compressibility data at depth of $13.75 \mathrm{~cm}$ - Column Test \#1

\begin{tabular}{|c|c|c|c|c|c|c|c|}
\hline $\begin{array}{c}\text { Weight } \\
(\mathbf{K g})\end{array}$ & $\begin{array}{c}\text { Load Increment } \\
\text { or ov (Kpa) }\end{array}$ & $\boldsymbol{\Sigma} \mathbf{\Delta H}(\mathbf{m m})$ & $\mathbf{H}$ & $\mathbf{e}$ & $\mathbf{C v}$ & av & $\mathbf{K}$ \\
\hline- & 0.1 & 0.0000 & 22.3232 & 1.3528 & - & - & - \\
\hline 1 & 4.8 & 2.4580 & 19.8652 & 1.0938 & 0.0107 & 0.0461 & $2.06 \mathrm{E}-09$ \\
\hline 2 & 9.7 & 4.1765 & 18.1467 & 0.9126 & 0.0054 & 0.0216 & $4.90 \mathrm{E}-10$ \\
\hline 4 & 19.4 & 5.2585 & 17.0648 & 0.7986 & 0.0049 & 0.0077 & $1.58 \mathrm{E}-10$ \\
\hline 8 & 38.7 & 6.1587 & 16.1645 & 0.7037 & 0.0049 & 0.0037 & $7.59 \mathrm{E}-11$ \\
\hline 16 & 77.4 & 7.1394 & 15.1839 & 0.6004 & 0.0051 & 0.0019 & $4.08 \mathrm{E}-11$ \\
\hline 32 & 154.9 & 8.1345 & 14.1888 & 0.4955 & 0.0038 & 0.0010 & $1.59 \mathrm{E}-11$ \\
\hline 64 & 309.8 & 9.1826 & 13.1406 & 0.3850 & 0.0025 & 0.0007 & $7.17 \mathrm{E}-12$ \\
\hline
\end{tabular}

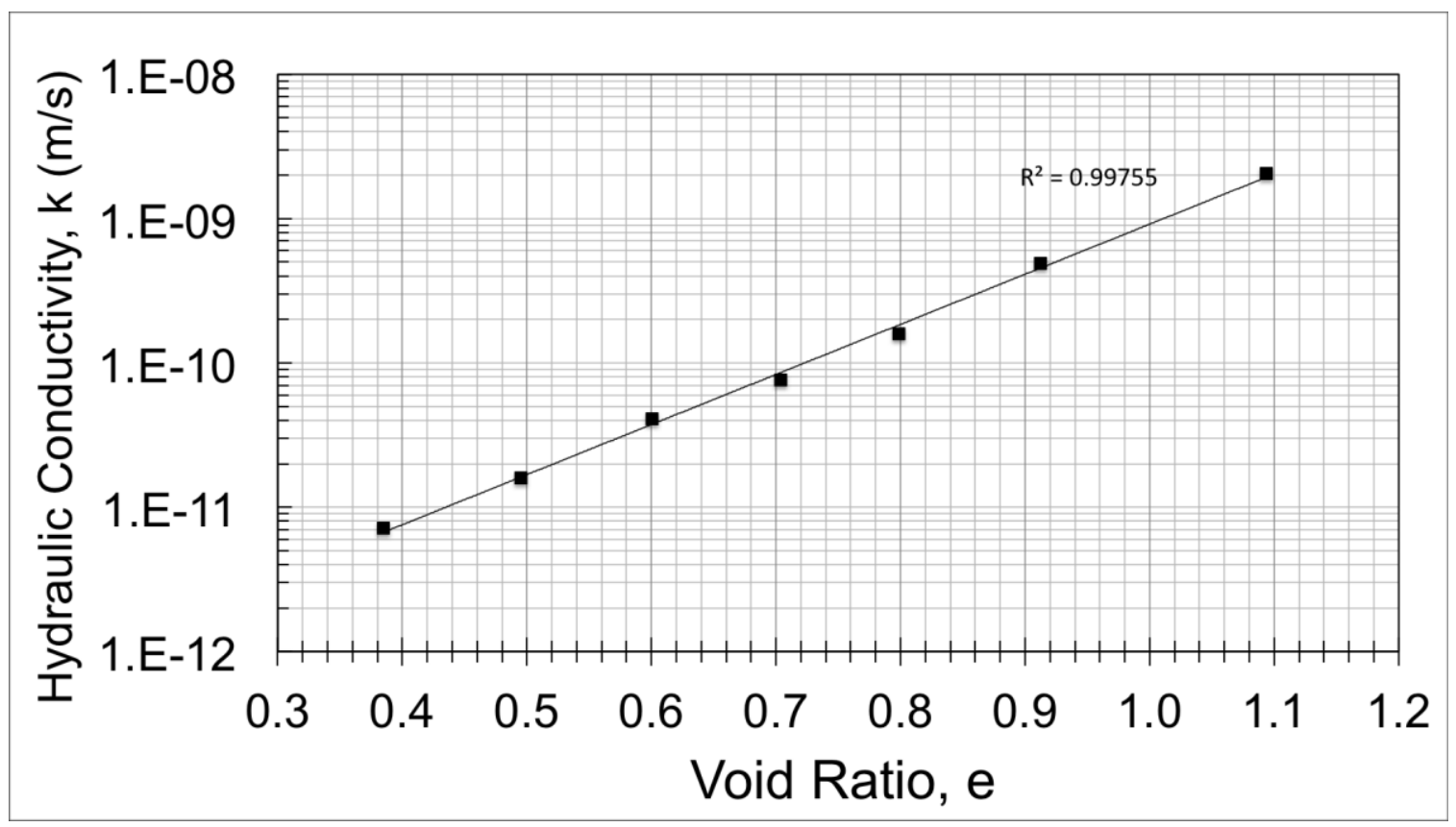

Figure 205. Permeability results (depth of $13.75 \mathrm{~cm}$ ) - Column Test \#1 


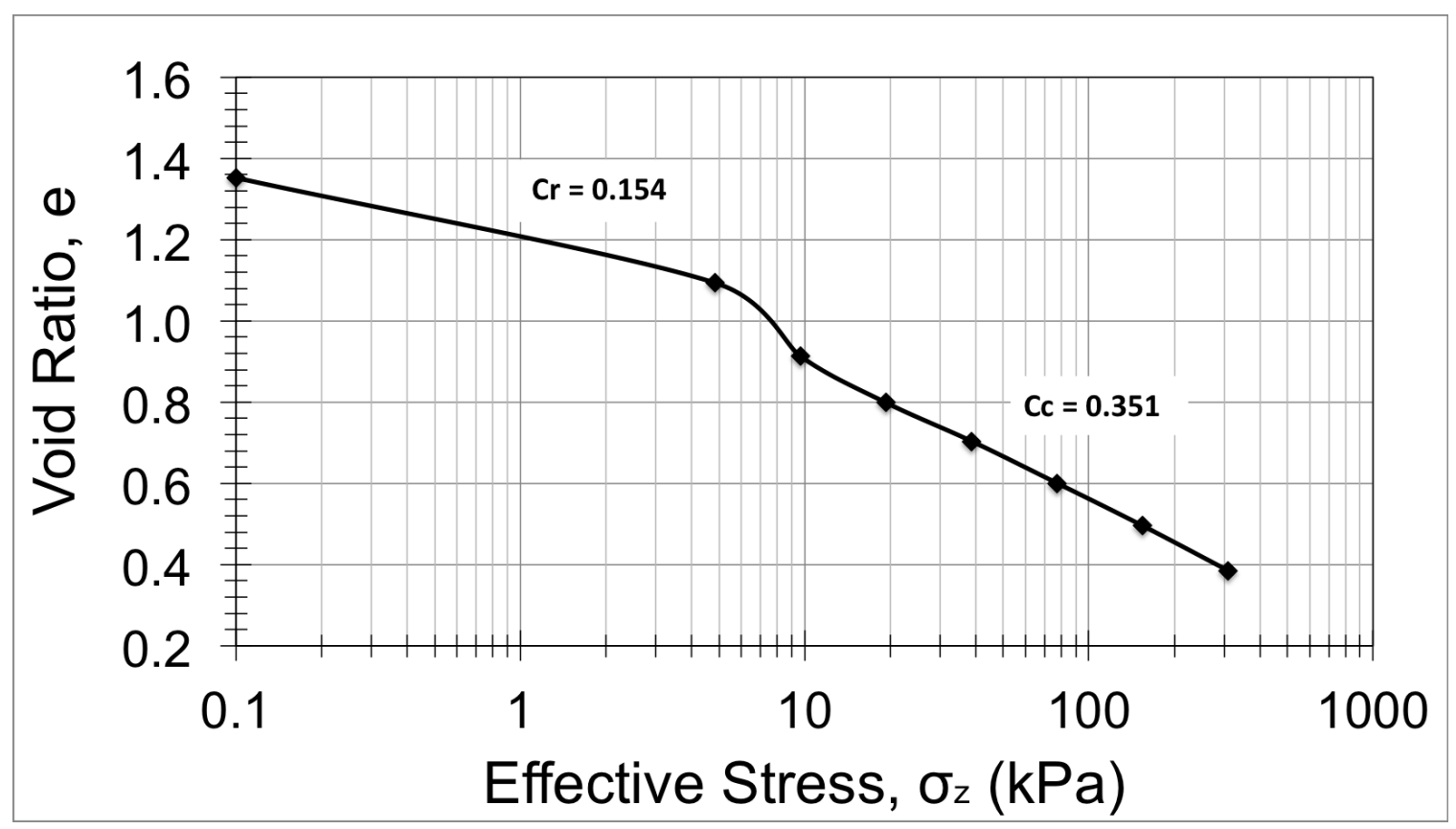

Figure 206. Void ratio vs Effective stress (depth of $13.75 \mathrm{~cm}$ ) - Column Test \#1

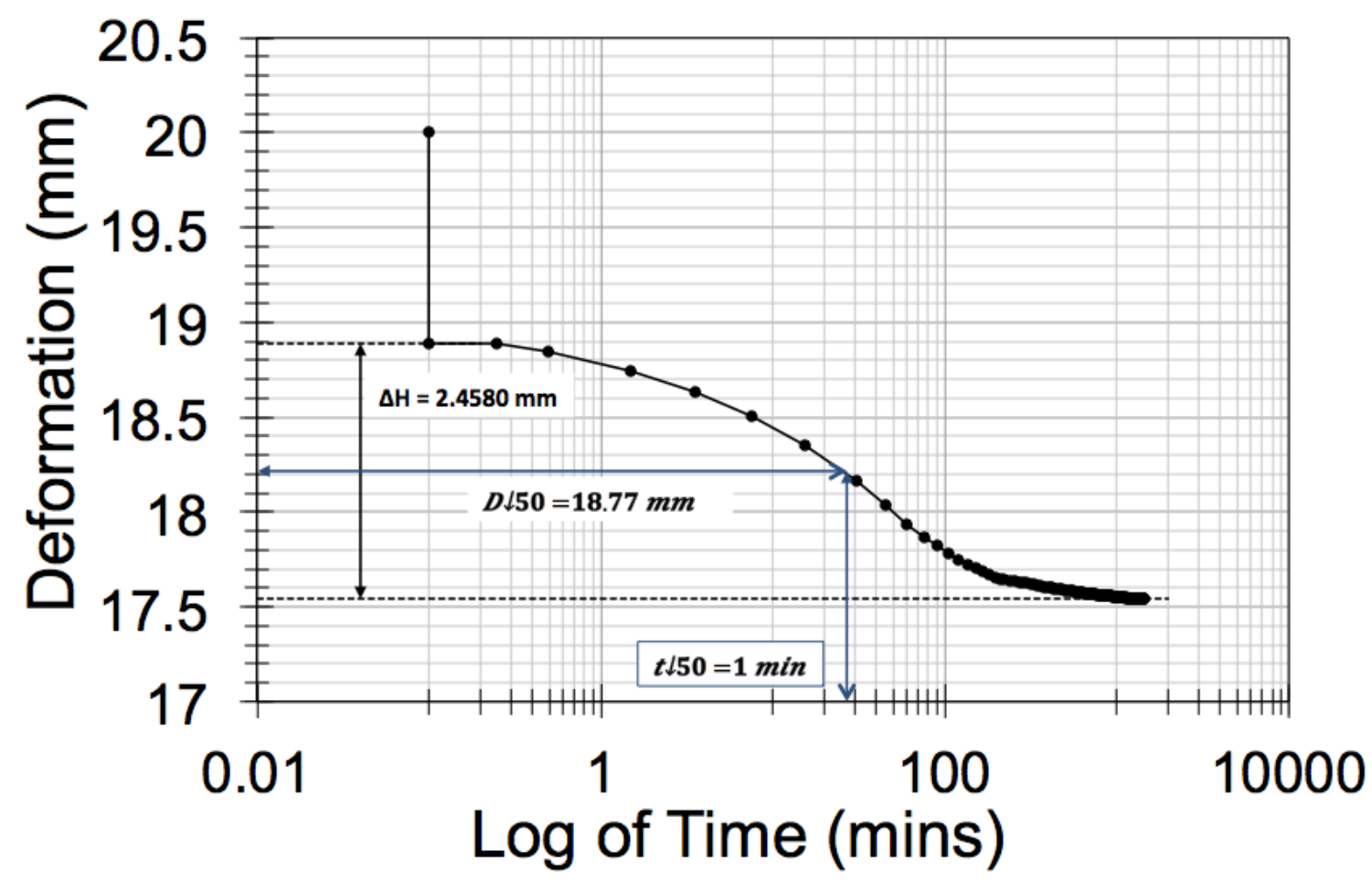

Figure 207. Casagrande analysis for $1 \mathrm{~kg}$ - Column Test \#1. 


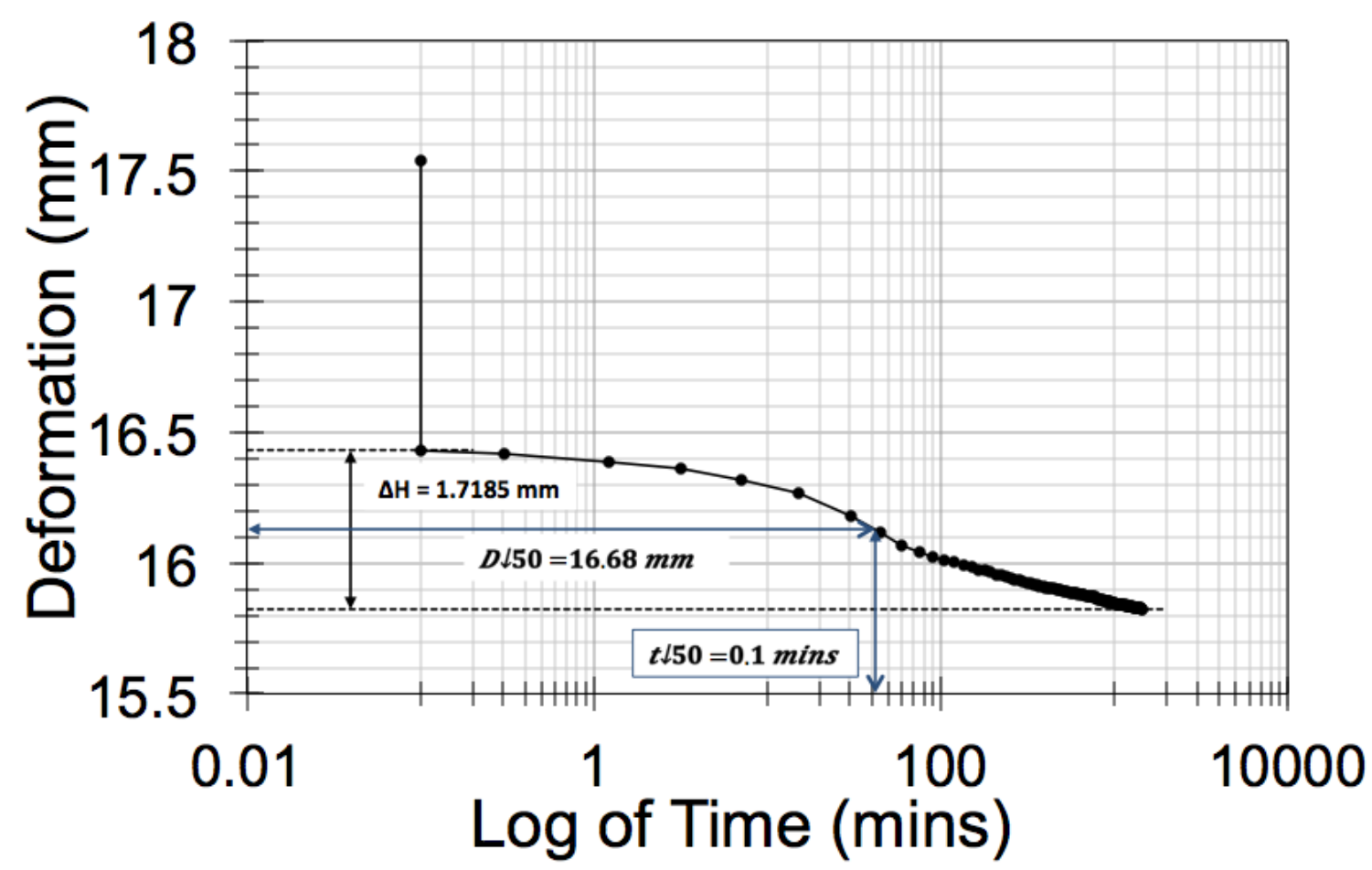

Figure 208. Casagrande analysis for $2 \mathrm{~kg}-$ Column Test \#1.

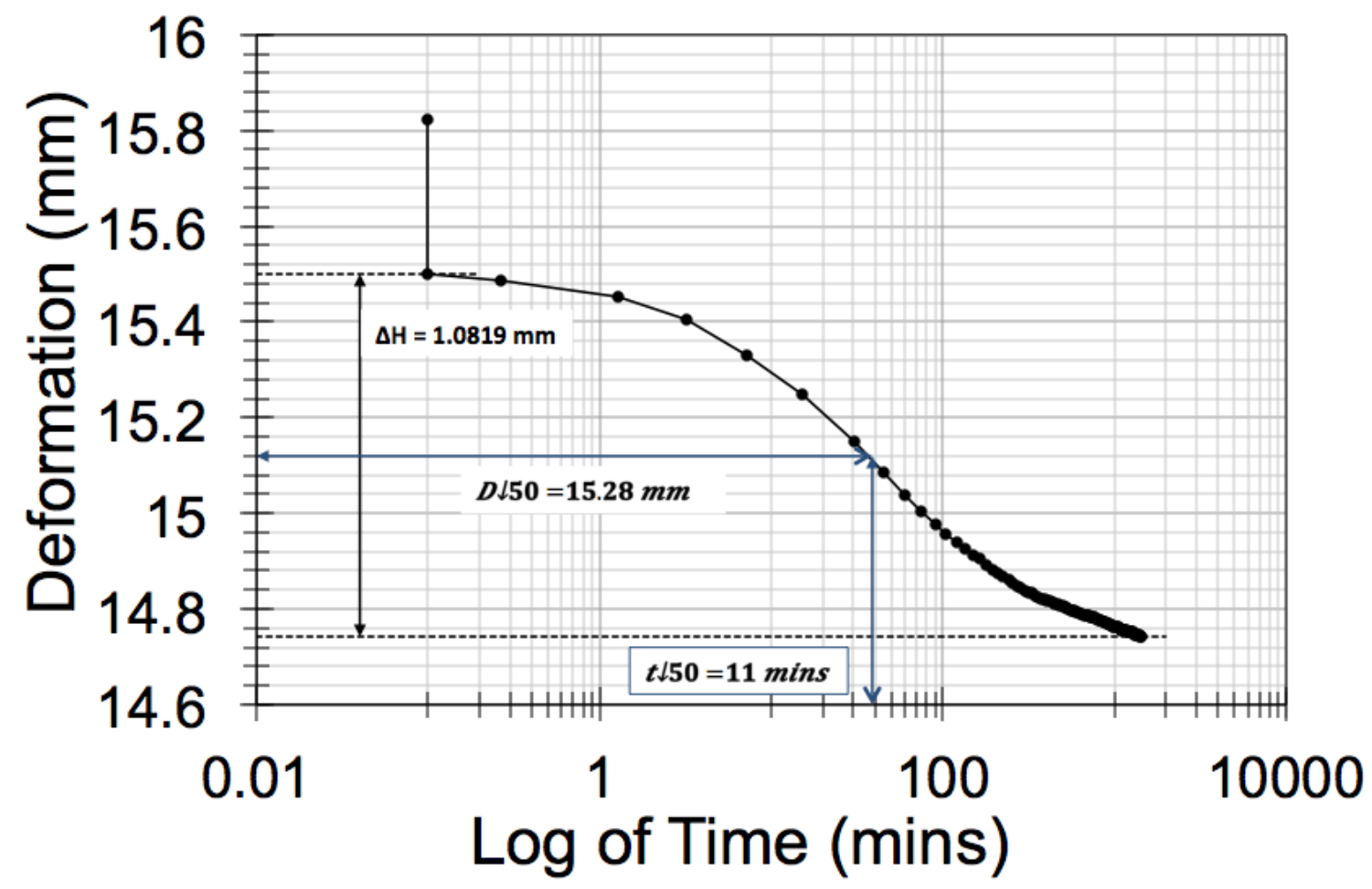

Figure 209. Casagrande analysis for $4 \mathrm{~kg}$ - Column Test \#1. 


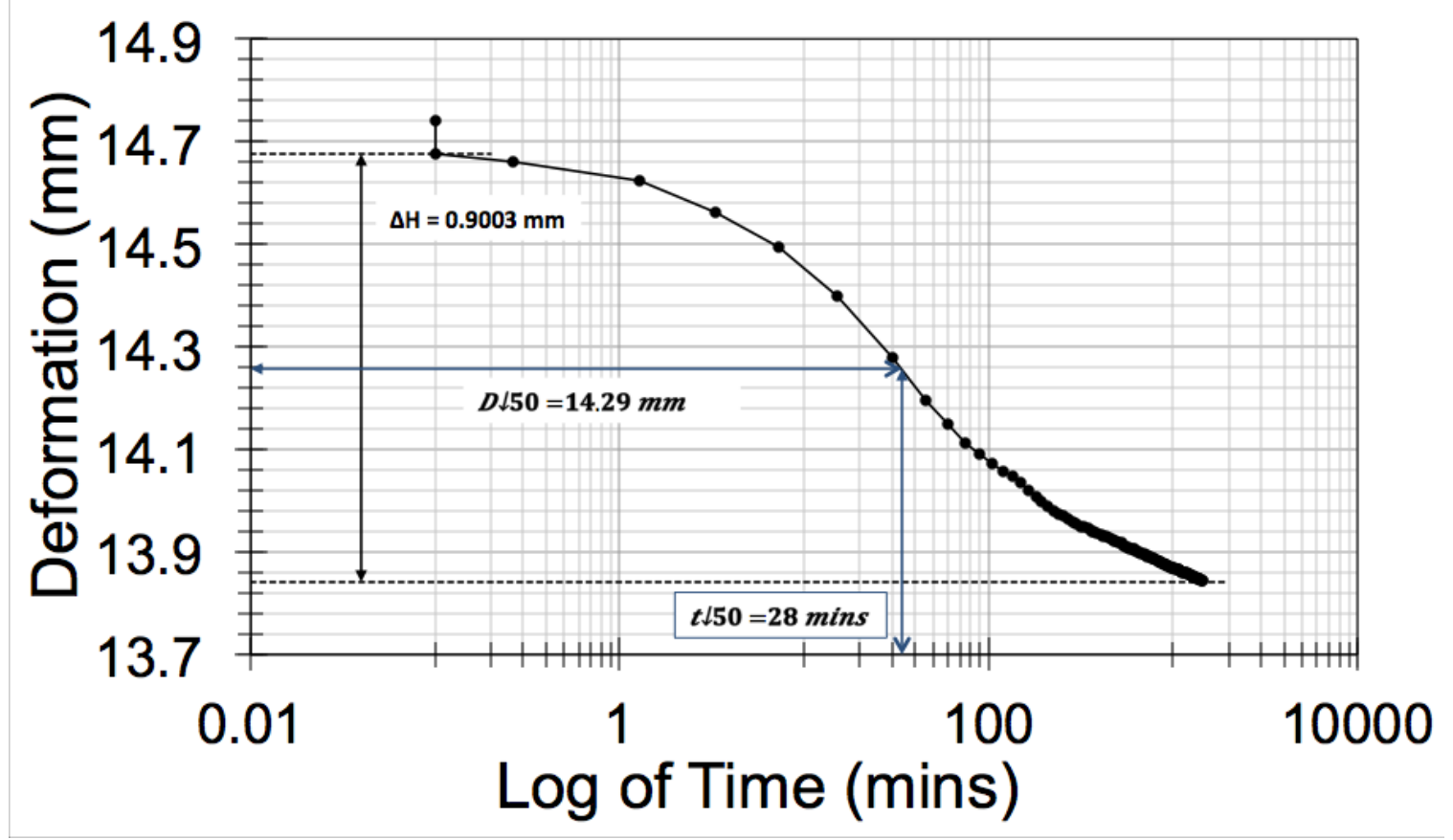

Figure 210. Casagrande analysis for $8 \mathrm{~kg}$ - Column Test \#1.

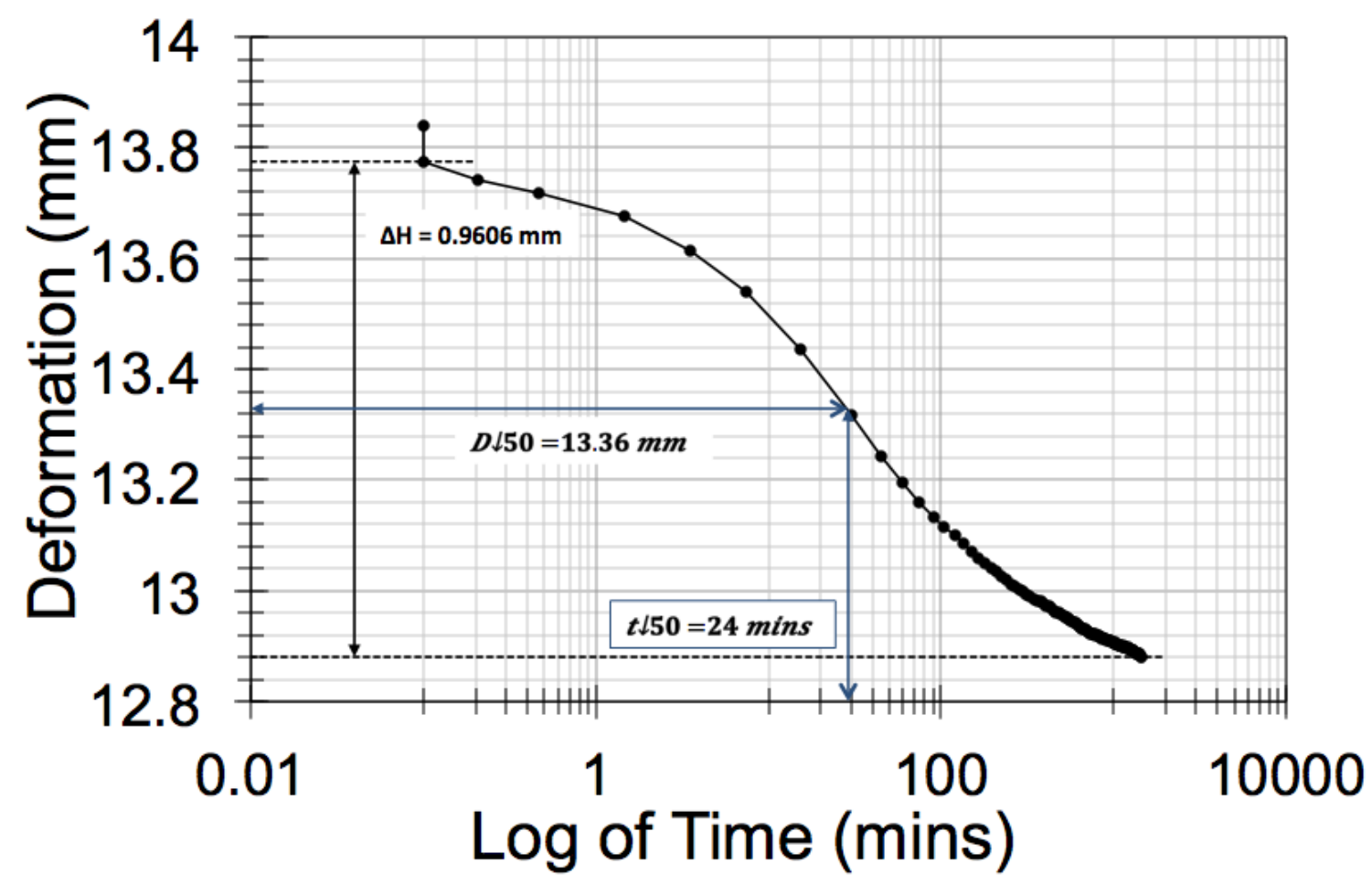

Figure 211. Casagrande analysis for $16 \mathrm{~kg}$ - Column Test \#1. 


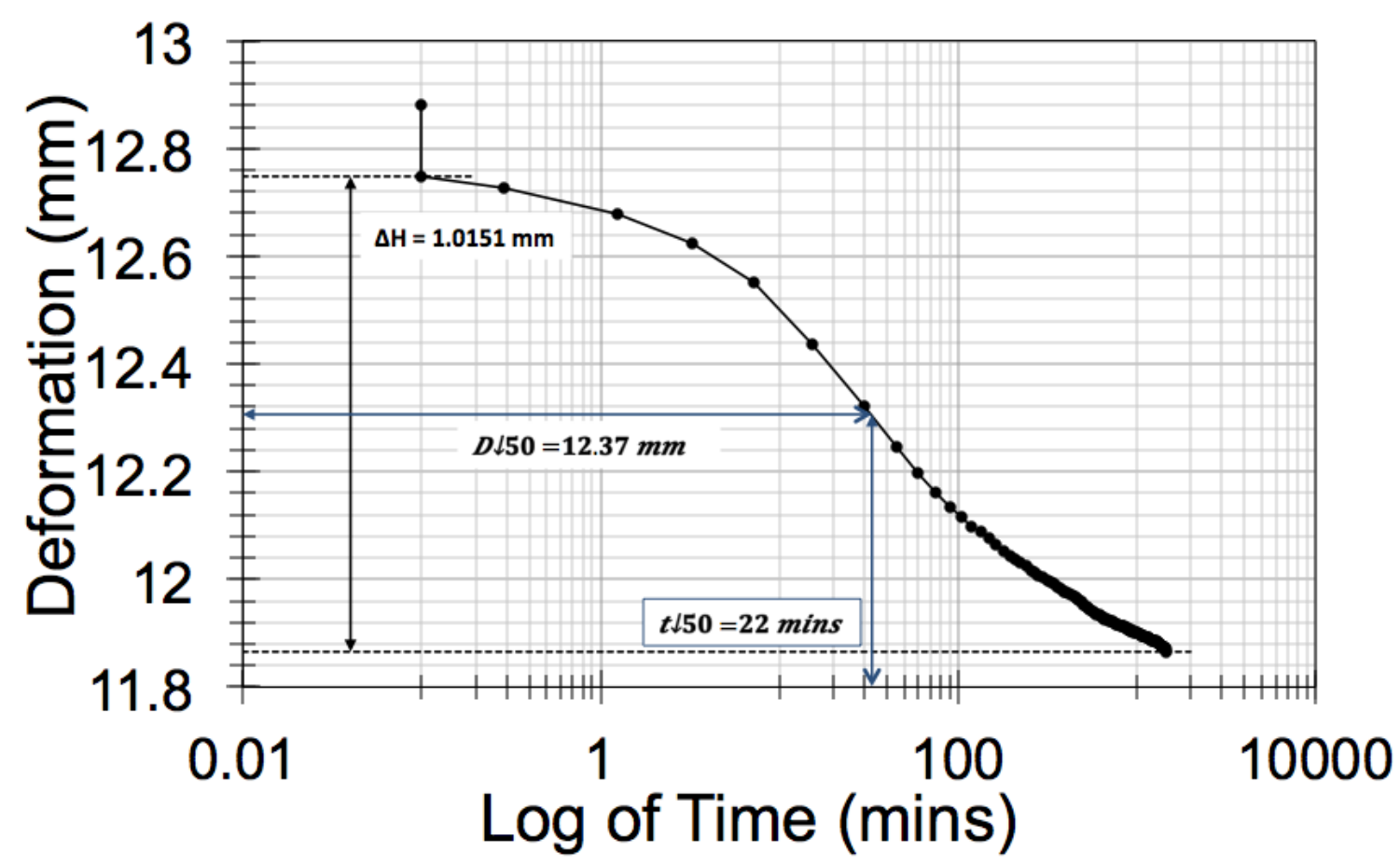

Figure 212. Casagrande analysis for $32 \mathrm{~kg}$ - Column Test \#1.

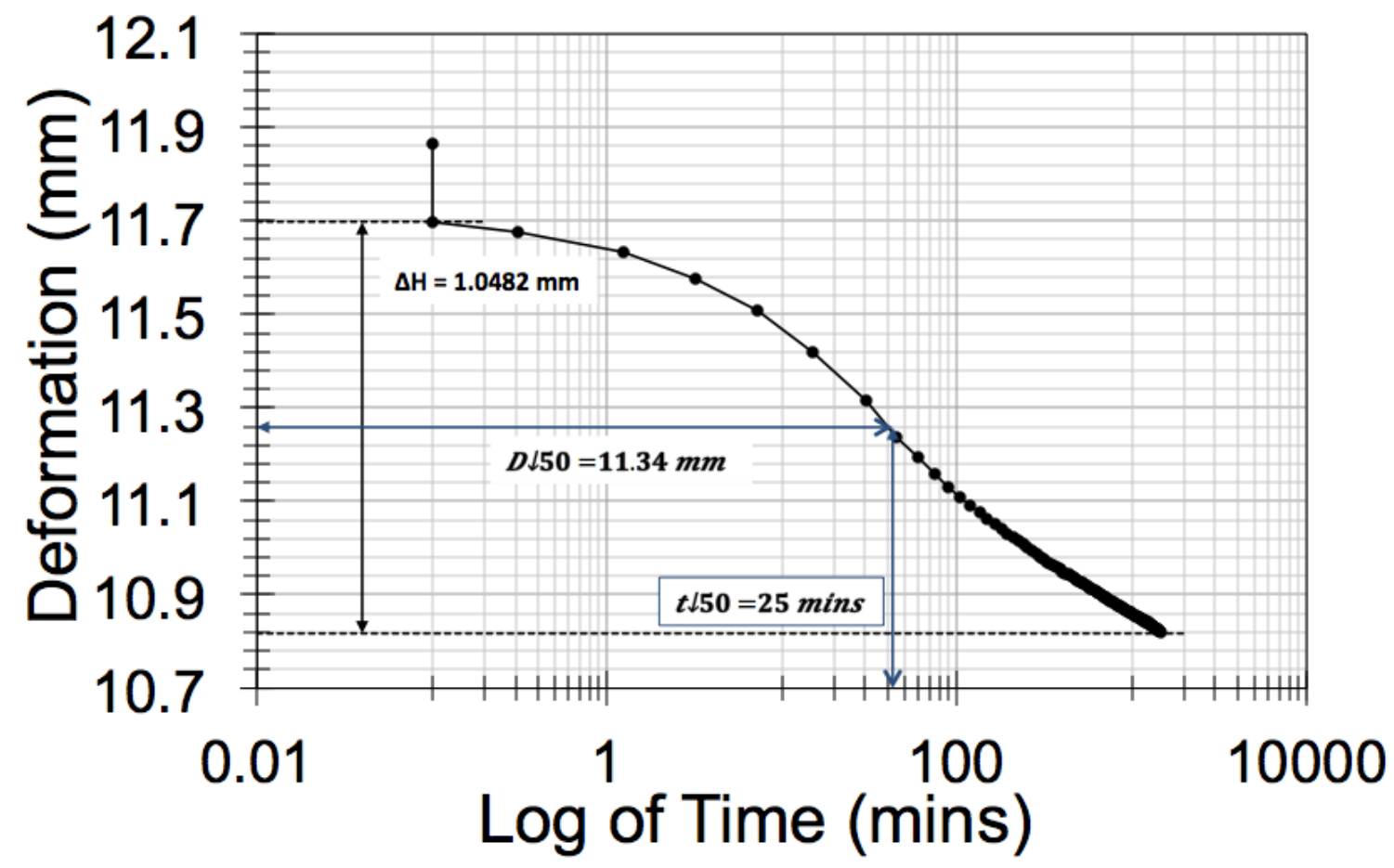

Figure 213. Casagrande analysis for $64 \mathrm{~kg}$ - Column Test \#1. 


\section{Appendix B : Consolidation Data for Column Test \#2}

\section{B.1 Consolidation Test Calculations}

Table 29. Calculations prior test - Column Test \#2

\begin{tabular}{|c|c|c|c|c|c|c|c|c|}
\hline \multirow[b]{2}{*}{$\begin{array}{c}\text { Sample } \\
\#\end{array}$} & \multirow[b]{2}{*}{$\begin{array}{l}\text { Station } \\
\text { Number }\end{array}$} & \multirow[b]{2}{*}{$\begin{array}{c}\text { Depth } \\
\text { (cm) }\end{array}$} & \multicolumn{6}{|c|}{ Before Consolidation } \\
\hline & & & $\begin{array}{c}\text { Mass of the } \\
\text { Consolidation } \\
\text { Ring (gr) }\end{array}$ & \begin{tabular}{|c|} 
Mass of the \\
Consolidation \\
Ring + Sample \\
(gr)
\end{tabular} & $\begin{array}{c}\text { Initial } \\
\text { Height of } \\
\text { the Sample } \\
\text { Ho }(\mathrm{cm})\end{array}$ & \begin{tabular}{|c|} 
Inner \\
Diameter \\
of the Ring \\
(cm)
\end{tabular} & $\begin{array}{l}\begin{array}{c}\text { Wet Mass } \\
\text { of } \\
\text { Specimen } \\
\text { (gr): Mto }\end{array} \\
\end{array}$ & $\begin{array}{c}\text { Initial } \\
\text { Volume of } \\
\text { the specimen } \\
\text { (cm3): Vo }\end{array}$ \\
\hline 1 & $E$ & 10.75 & 69.76 & 126.09 & 2.00 & 5.08 & 56.33 & 40.54 \\
\hline 2 & $\mathrm{D}$ & 4.25 & 64.84 & 126.67 & 2.00 & 5.08 & 61.83 & 40.54 \\
\hline
\end{tabular}

Table 30. Calculations post test (a) - Column Test \#2

\begin{tabular}{|c|c|c|c|c|c|}
\hline & & & \multicolumn{3}{|c|}{ After Consolidation } \\
\hline $\begin{array}{c}\text { Sample } \\
\#\end{array}$ & $\begin{array}{c}\text { Station } \\
\text { Number }\end{array}$ & $\begin{array}{c}\text { Depth } \\
(\mathbf{c m})\end{array}$ & $\begin{array}{c}\text { Mass of the } \\
\text { Consolidation } \\
\text { Ring + Sample } \\
\text { (gr) }\end{array}$ & $\begin{array}{c}\text { Moist Mass of } \\
\text { Total } \\
\text { Specimen }(\mathrm{gr}): \\
\text { Mtf }\end{array}$ & $\begin{array}{c}\text { Final Height } \\
\text { of Sample } \\
\text { (cm):Hf }\end{array}$ \\
\hline $\mathbf{1}$ & E & 10.75 & 110.09 & 40.33 & 0.77 \\
\hline $\mathbf{2}$ & D & 4.25 & 113.13 & 48.29 & 1.14 \\
\hline
\end{tabular}

Table 31. Calculations post test (b) - Column Test \#2

\begin{tabular}{|c|c|c|c|c|c|c|c|c|c|c|c|c|}
\hline \multirow[b]{2}{*}{$\begin{array}{c}\text { Sample } \\
\#\end{array}$} & \multirow[b]{2}{*}{$\begin{array}{c}\text { Station } \\
\text { Number }\end{array}$} & \multirow[b]{2}{*}{$\begin{array}{l}\text { Depth } \\
\text { (cm) }\end{array}$} & \multicolumn{10}{|c|}{ Calculations } \\
\hline & & & $\begin{array}{l}\text { Dry Mass } \\
\text { (gr): Md }\end{array}$ & $\begin{array}{c}\text { Initial } \\
\text { water } \\
\text { content } \\
\text { (\%): Wo }\end{array}$ & $\begin{array}{c}\text { Final } \\
\text { water } \\
\text { content } \\
\text { (\%): Wf }\end{array}$ & \begin{tabular}{|c} 
Initial Dry \\
Density \\
(g/cm3): \\
pd
\end{tabular} & $\begin{array}{c}\text { Dry Unit } \\
\text { Weight } \\
\text { (KN/m3): } \\
\text { rd }\end{array}$ & $\begin{array}{l}\text { Volume } \\
\text { of Solids } \\
\text { (cm3): Vs }\end{array}$ & $\begin{array}{l}\text { Equivalent } \\
\text { Height of } \\
\text { Solids } \\
\text { (cm): Hs }\end{array}$ & $\begin{array}{c}\text { Initial } \\
\text { Void } \\
\text { Ratio: eo }\end{array}$ & $\begin{array}{c}\text { Final Void } \\
\text { Ratio: ef }\end{array}$ & \begin{tabular}{|c|} 
Initial \\
Degree of \\
Saturation \\
(\%): So
\end{tabular} \\
\hline 1 & $E$ & 10.75 & 34.00 & 65.7 & 18.6 & 0.84 & 8.22 & 15.46 & 0.76 & 1.62 & 0.01 & 89.02 \\
\hline 2 & $\mathrm{D}$ & 4.25 & 40.85 & 51.3 & 18.2 & 1.01 & 9.88 & 18.57 & 0.92 & 1.18 & 0.24 & 95.49 \\
\hline
\end{tabular}




\section{B.2 Depth of $4.25 \mathrm{~cm}-$ D sample}

Table 32. Compressibility data at depth of $4.25 \mathrm{~cm}$ - Column Test \#2

\begin{tabular}{|c|c|c|c|c|c|c|c|}
\hline Weight & Load Increment & $\Sigma \Delta \mathrm{H} / \mathrm{mm}$ & $\mathrm{H}$ & e & $\mathrm{Cv}$ & av & K \\
\hline$(\mathrm{Kg})$ & or ov (Кра) & |रिम & $(\mathrm{Ho}-\Delta \mathrm{H})(\mathrm{mm})$ & $(\mathrm{H}-\mathrm{Hs}) / \mathrm{Hs}$ & $(\mathrm{mm} 2 / \mathrm{s})$ & (m2/KN) & $(\mathrm{m} / \mathrm{s})$ \\
\hline - & 0.1 & 0.0000 & 21.4009 & 1.3362 & - & - & + \\
\hline 1 & 4.8 & 2.4307 & 18.9702 & 1.0709 & 0.0138 & 0.0396 & $2.29 \mathrm{E}-09$ \\
\hline 2 & 9.7 & 3.4612 & 17.9398 & 0.9584 & 0.0065 & 0.0191 & $5.18 \mathrm{E}-10$ \\
\hline 4 & 19.4 & 4.4981 & 16.9029 & 0.8452 & 0.0075 & 0.0086 & $2.73 \mathrm{E}-10$ \\
\hline 8 & 38.7 & 5.5961 & 15.8049 & 0.7253 & 0.0080 & 0.0042 & $1.40 \mathrm{E}-10$ \\
\hline 16 & 77.4 & 6.5583 & 14.8426 & 0.6203 & 0.0072 & 0.0020 & $6.12 \mathrm{E}-11$ \\
\hline 32 & 154.9 & 7.5872 & 13.8137 & 0.5080 & 0.0098 & 0.0010 & $4.20 \mathrm{E}-11$ \\
\hline 64 & 309.8 & 8.5727 & 12.8283 & 0.4004 & 0.0117 & 0.0007 & $3.44 \mathrm{E}-11$ \\
\hline
\end{tabular}

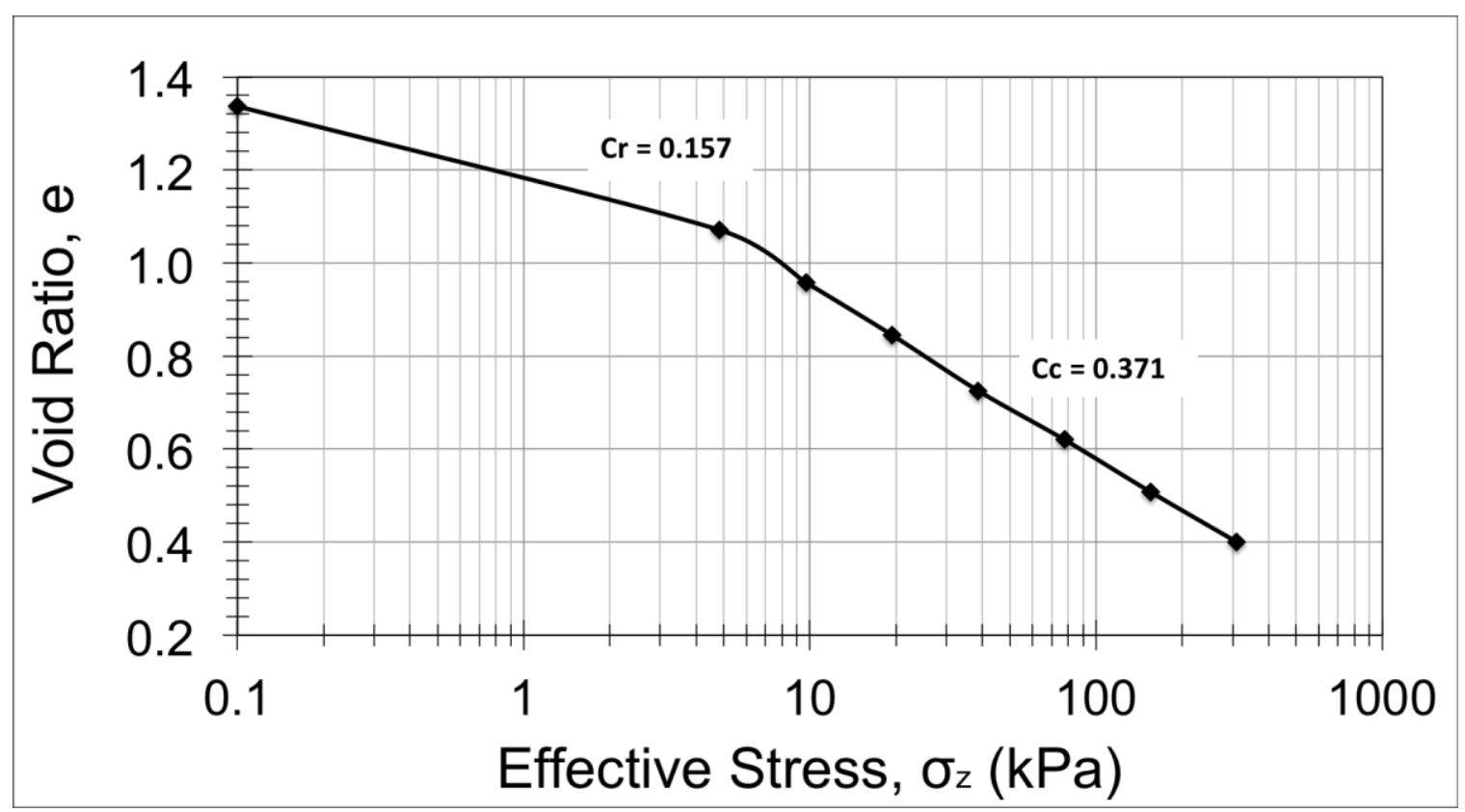

Figure 214. Void ratio vs Effective stress (depth of $4.25 \mathrm{~cm}$ ) - Column Test \#2 


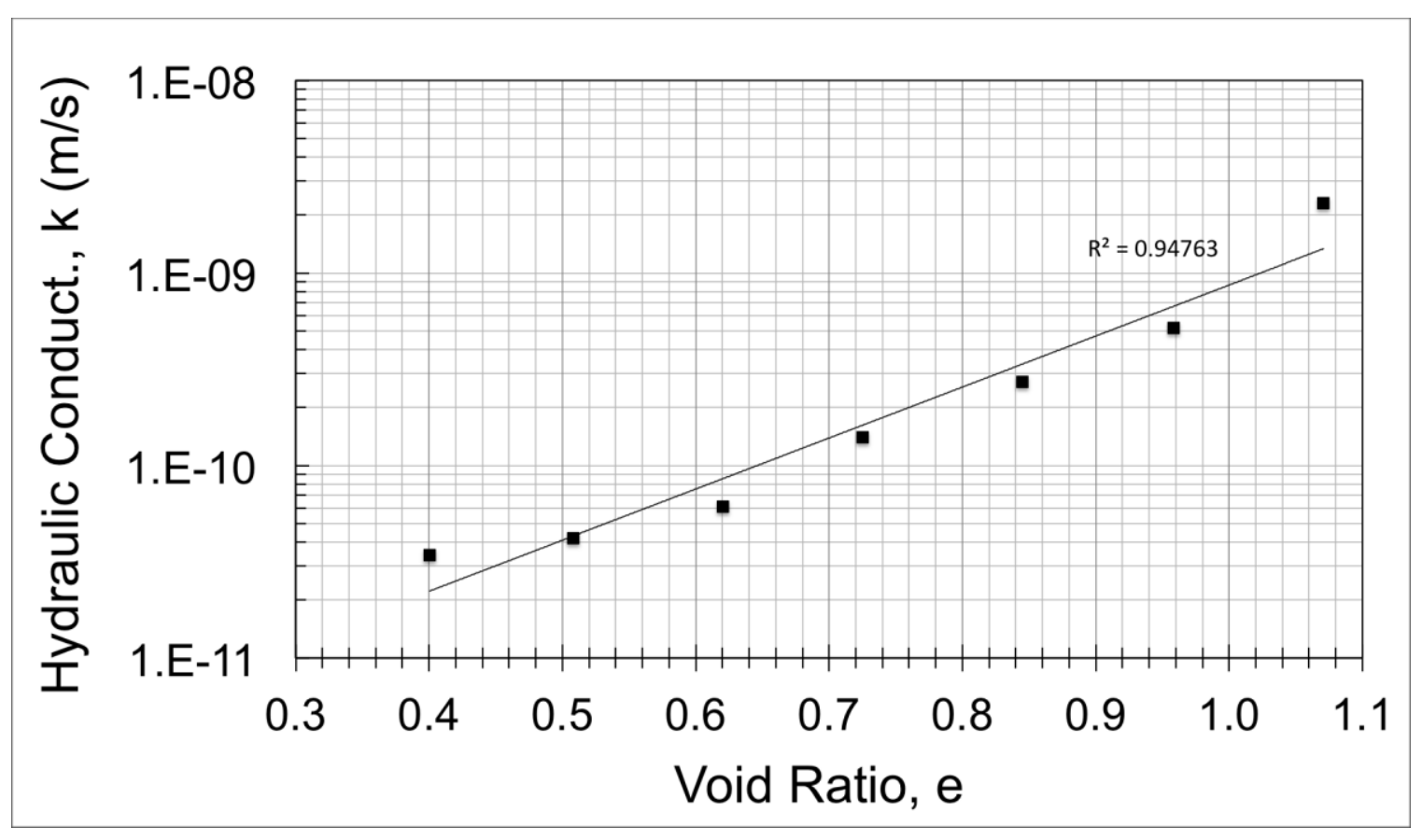

Figure 215. Permeability results (depth of $4.25 \mathrm{~cm}$ ) - Column Test \#2

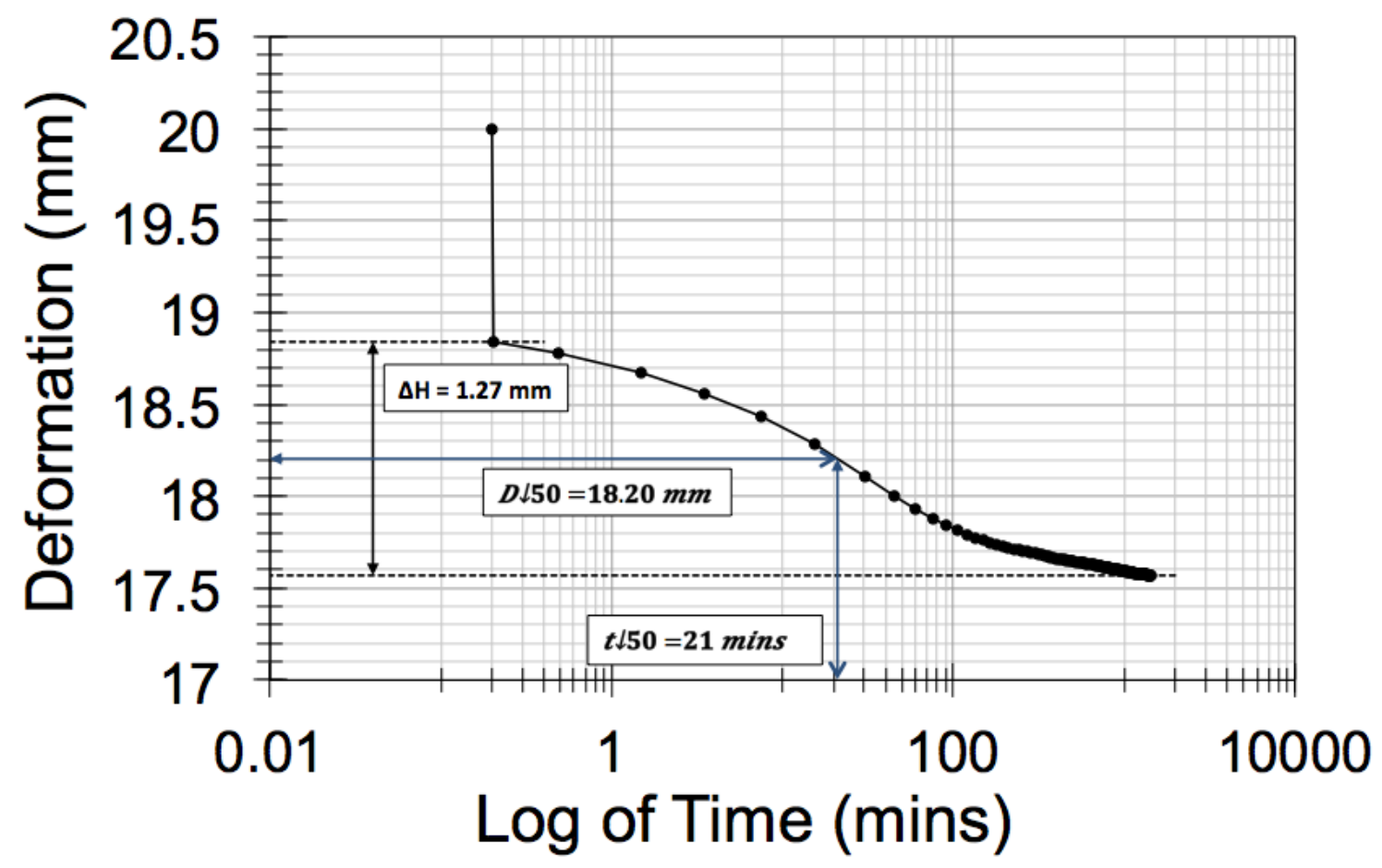

Figure 216. Casagrande analysis for $1 \mathrm{~kg}$ - Column Test \#2. 


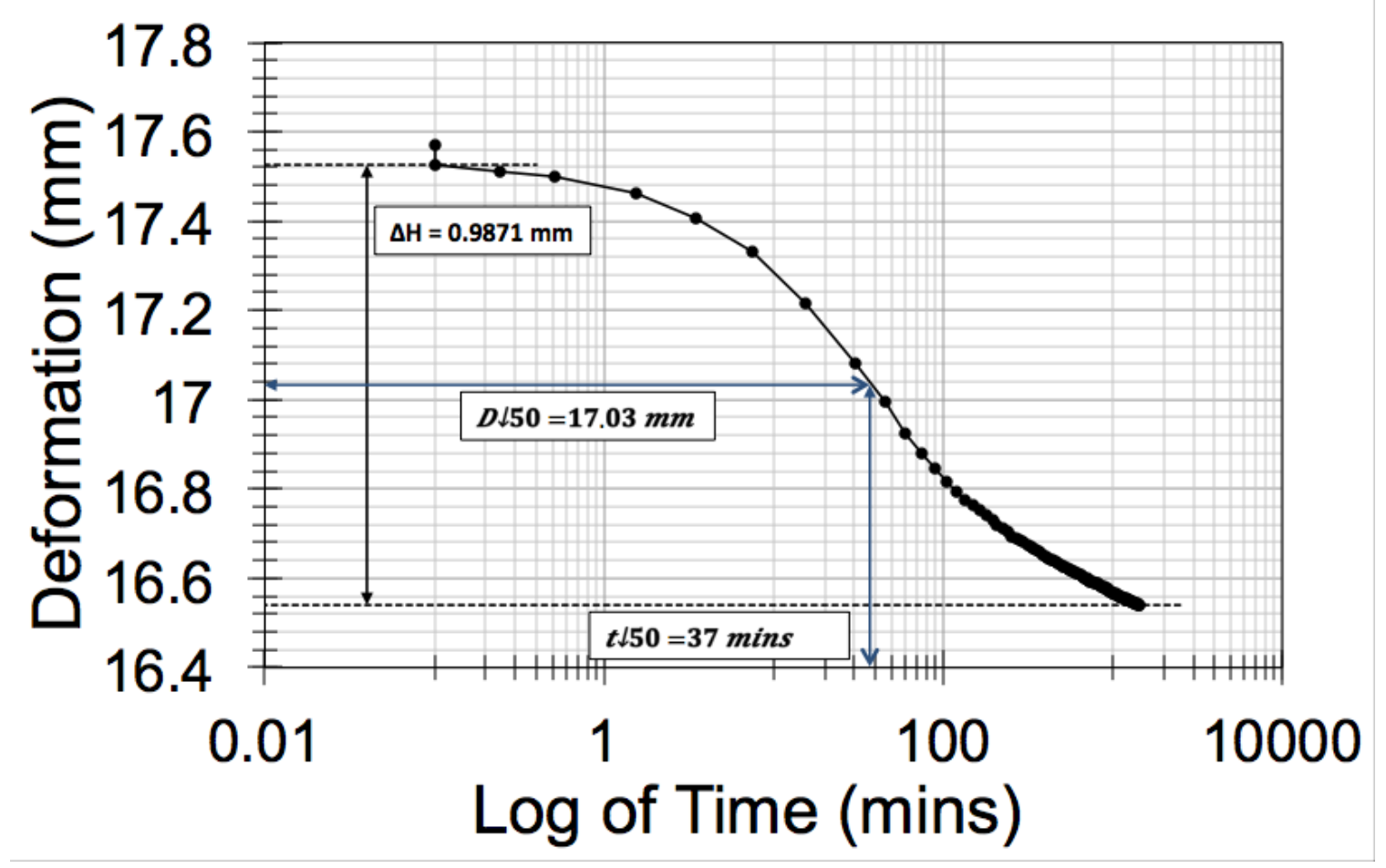

Figure 217. Casagrande analysis for $2 \mathbf{k g}$ - Column Test \#2.

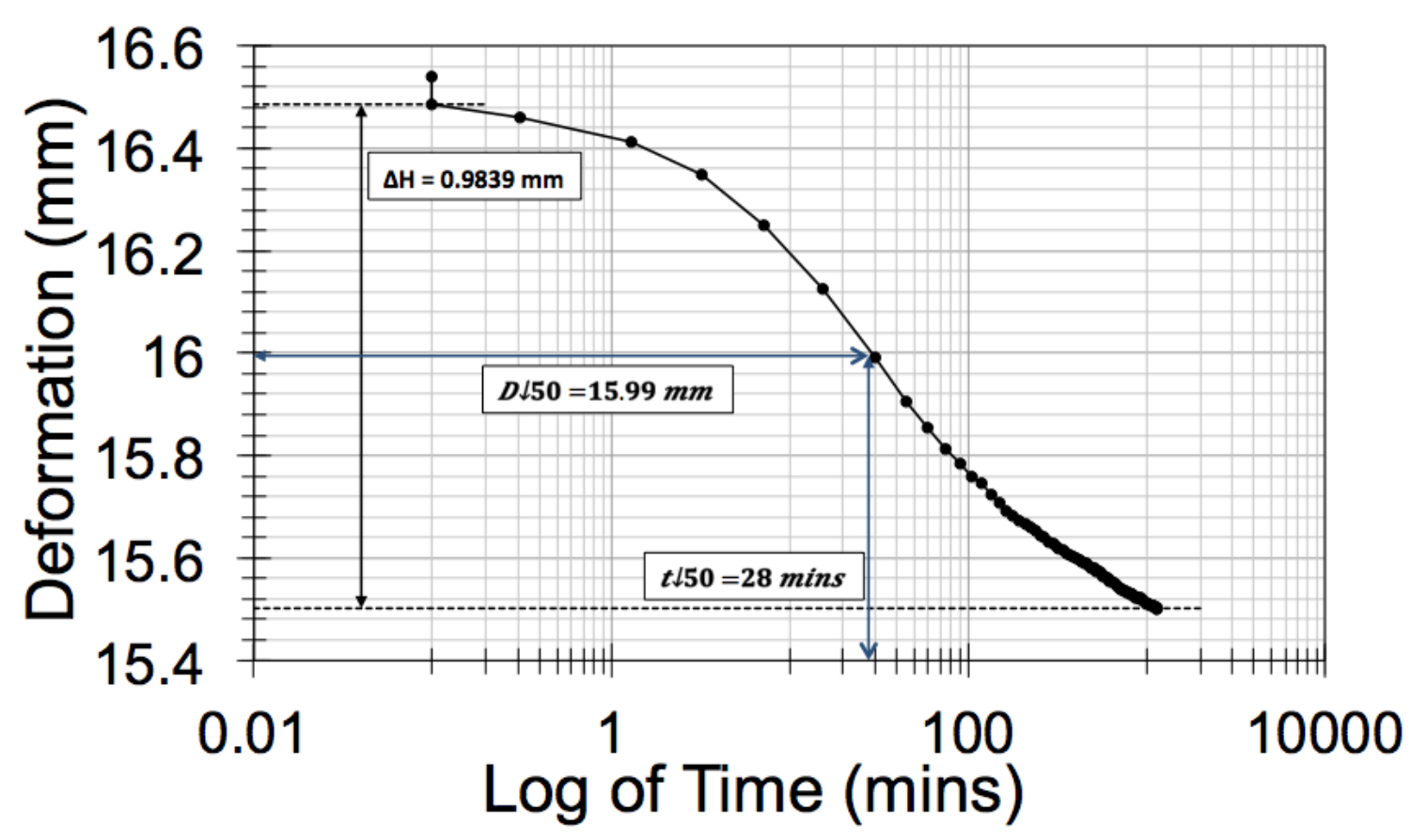

Figure 218. Casagrande analysis for $4 \mathrm{~kg}$ - Column Test \#2. 


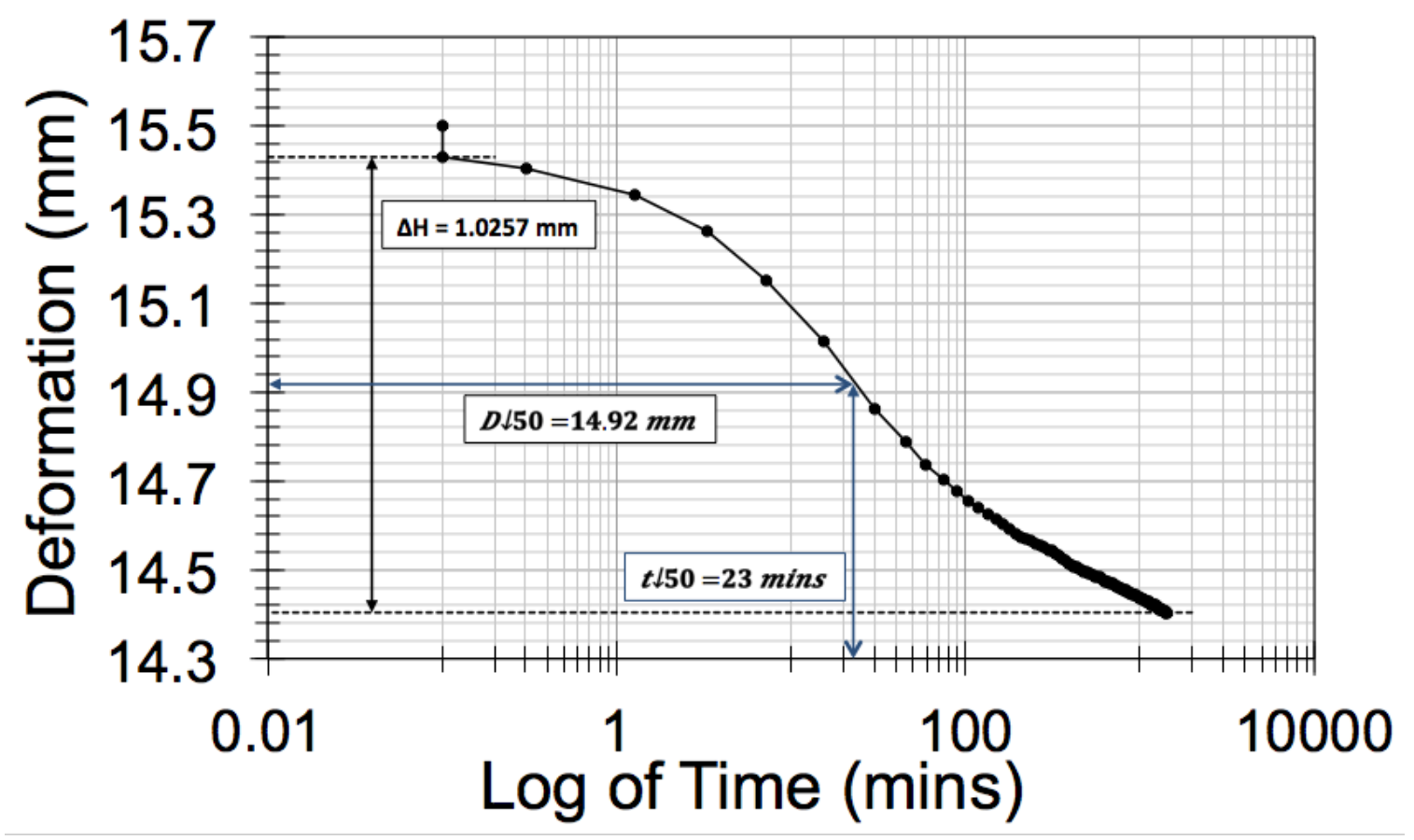

Figure 219. Casagrande analysis for $8 \mathrm{~kg}$ - Column Test \#2.

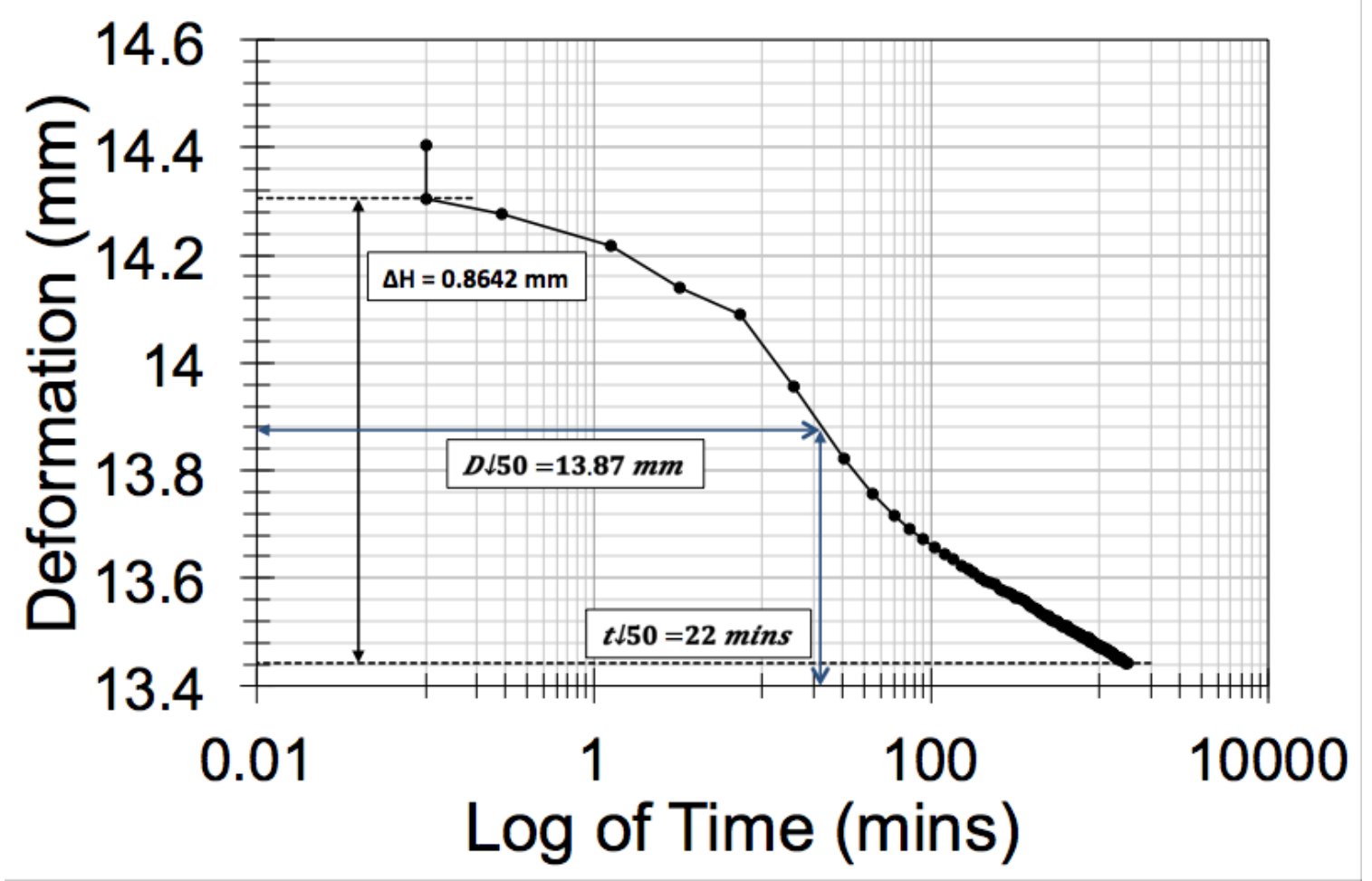

Figure 220. Casagrande analysis for $16 \mathrm{~kg}$ - Column Test \#2. 


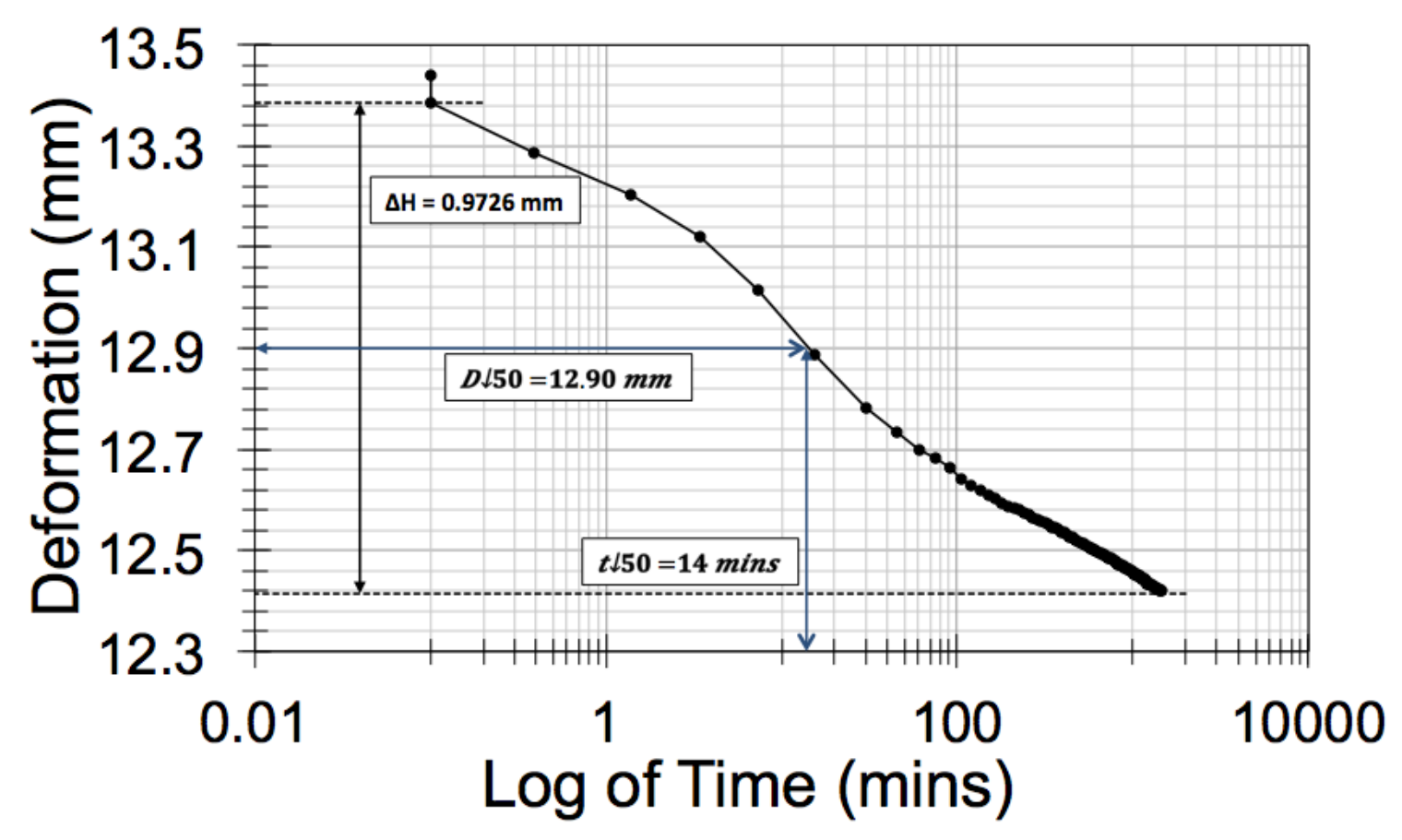

Figure 221. Casagrande analysis for $32 \mathrm{~kg}$ - Column Test \#2.

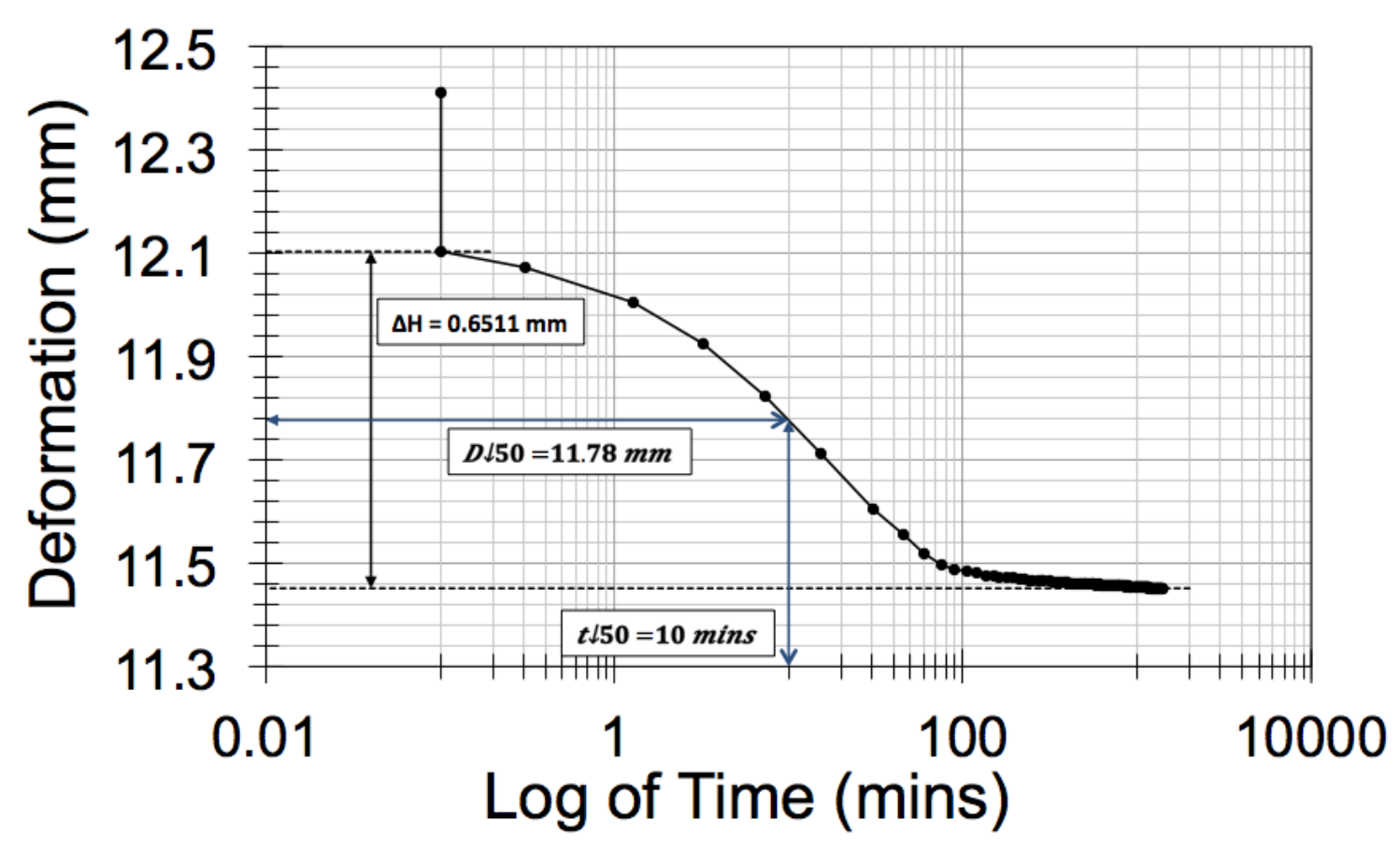

Figure 222. Casagrande analysis for $64 \mathrm{~kg}$ - Column Test \#2. 


\section{B.3 Depth of $10.75 \mathrm{~cm}-$ E sample}

Table 33. Compressibility data at depth of $10.75 \mathrm{~cm}$ - Column Test \#2

\begin{tabular}{|c|c|c|c|c|c|c|c|}
\hline \multirow{2}{*}{$\begin{array}{l}\text { Weight } \\
\text { (Kg) }\end{array}$} & \multirow{2}{*}{$\begin{array}{c}\text { Load Increment } \\
\text { or ov (Кра) }\end{array}$} & \multirow{2}{*}{$\Sigma \Delta \mathrm{H}(\mathrm{mm})$} & $\mathrm{H}$ & e & $\mathrm{Cv}$ & av & $K$ \\
\hline & & & $(\mathrm{Ho}-\Delta \mathrm{H})(\mathrm{mm})$ & $(\mathrm{H}-\mathrm{Hs}) / \mathrm{Hs}$ & $(\mathrm{mm} 2 / \mathrm{s})$ & (m2/KN) & $(\mathrm{m} / \mathrm{s})$ \\
\hline- & 0.1 & 0.0000 & 23.0311 & 2.0207 & - & - & - \\
\hline 1 & 4.8 & 6.5879 & 16.4432 & 1.1567 & 0.0072 & 0.1066 & $2.48 \mathrm{E}-09$ \\
\hline 2 & 9.7 & 7.6329 & 15.3982 & 1.0196 & 0.0035 & 0.0198 & $2.25 \mathrm{E}-10$ \\
\hline 4 & 19.4 & 8.6087 & 14.4224 & 0.8916 & 0.0041 & 0.0095 & $1.27 \mathrm{E}-10$ \\
\hline 8 & 38.7 & 9.5588 & 13.4723 & 0.7670 & 0.0043 & 0.0045 & $6.27 \mathrm{E}-11$ \\
\hline 16 & 77.4 & 10.4671 & 12.5640 & 0.6479 & 0.0037 & 0.0022 & $2.67 \mathrm{E}-11$ \\
\hline 32 & 154.9 & 11.3593 & 11.6718 & 0.5309 & 0.0032 & 0.0011 & $1.17 \mathrm{E}-11$ \\
\hline 64 & 309.8 & 12.2869 & 10.7442 & 0.4092 & 0.0024 & 0.0008 & $6.20 \mathrm{E}-12$ \\
\hline
\end{tabular}

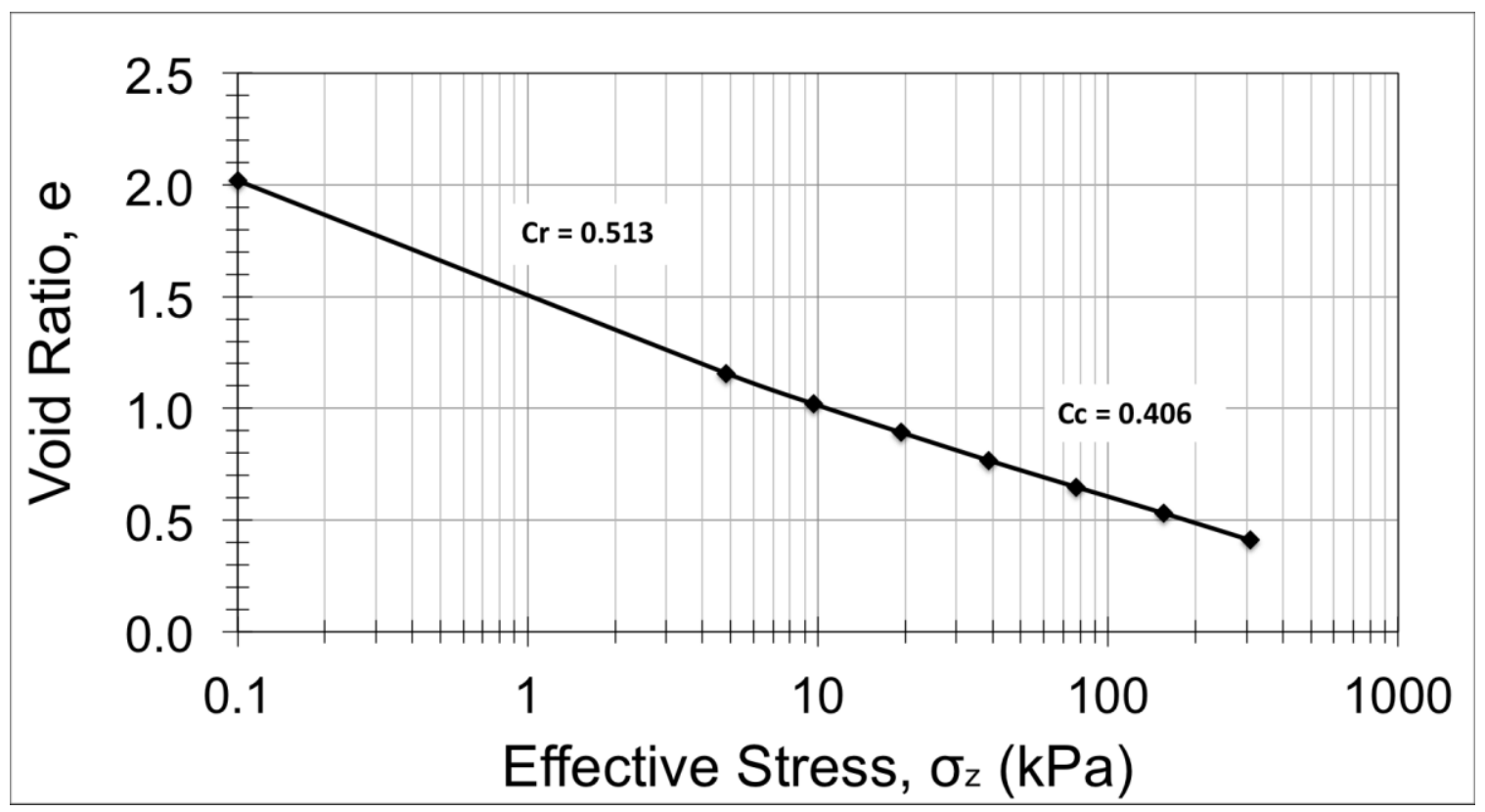

Figure 223. Void ratio vs Effective stress (depth of $10.75 \mathrm{~cm}$ ) - Column Test \#2 


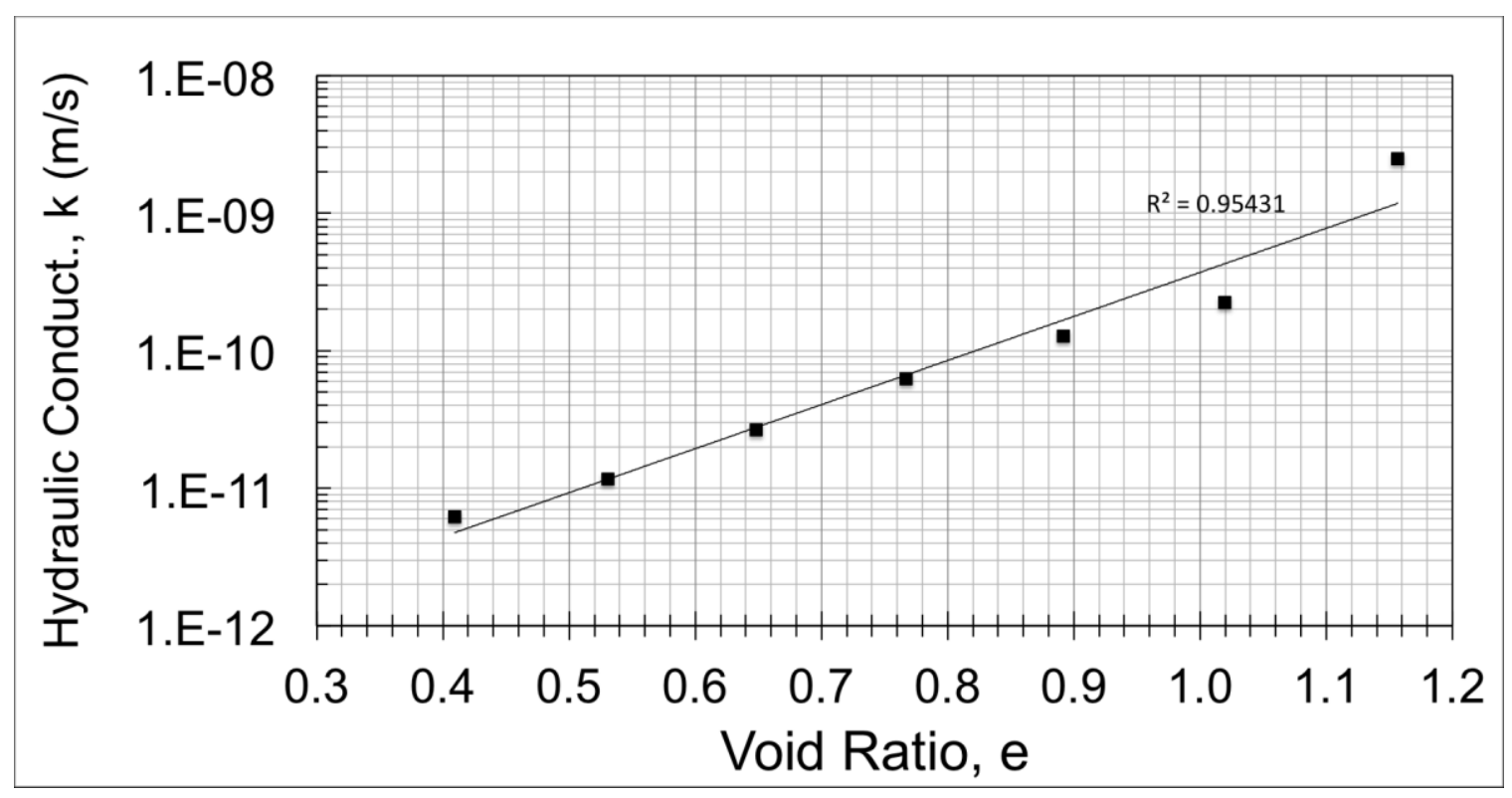

Figure 224. Permeability results (depth of $10.75 \mathrm{~cm})$ - Column Test \#2

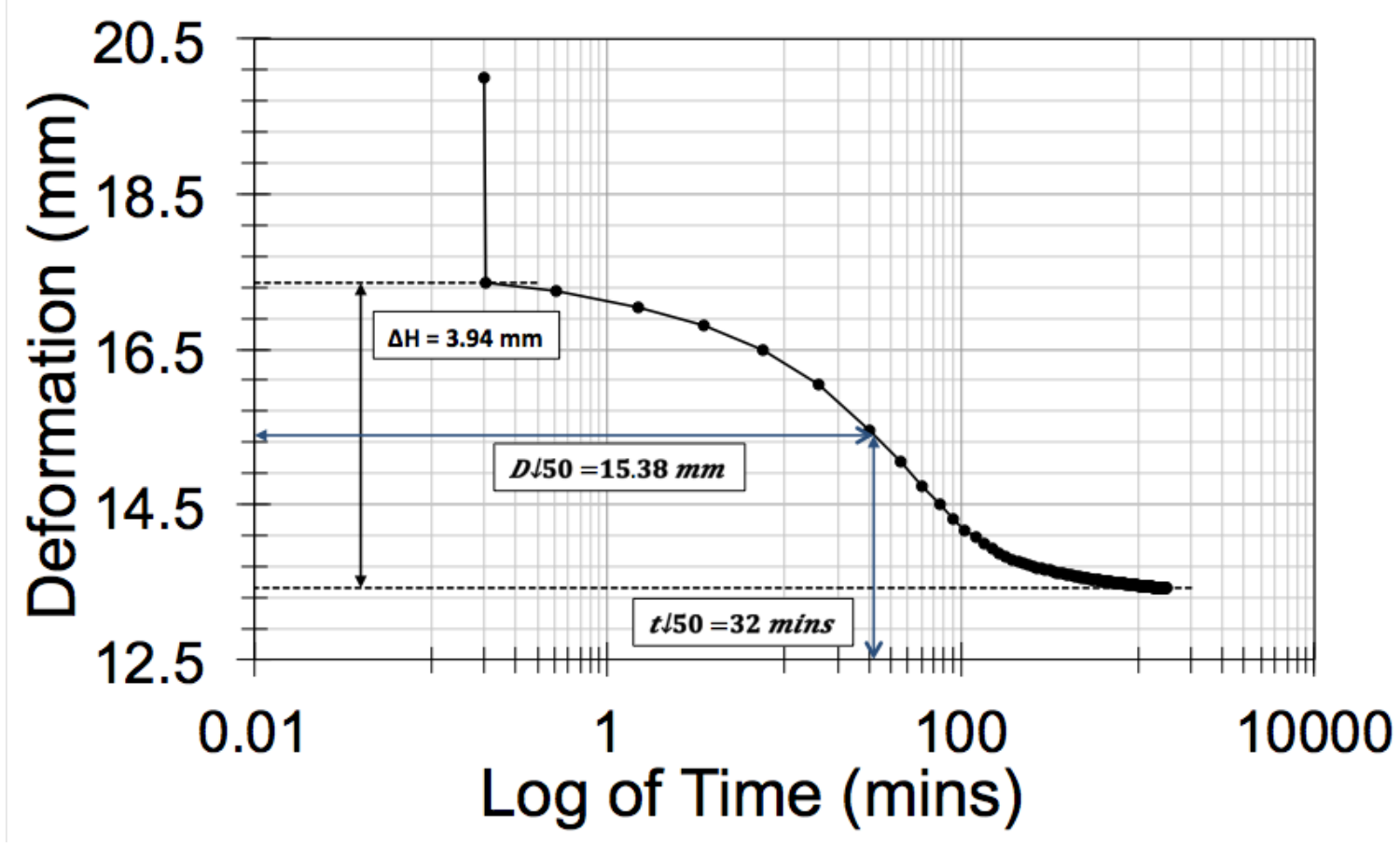

Figure 225. Casagrande analysis for $1 \mathrm{~kg}$ - Column Test \#2. 


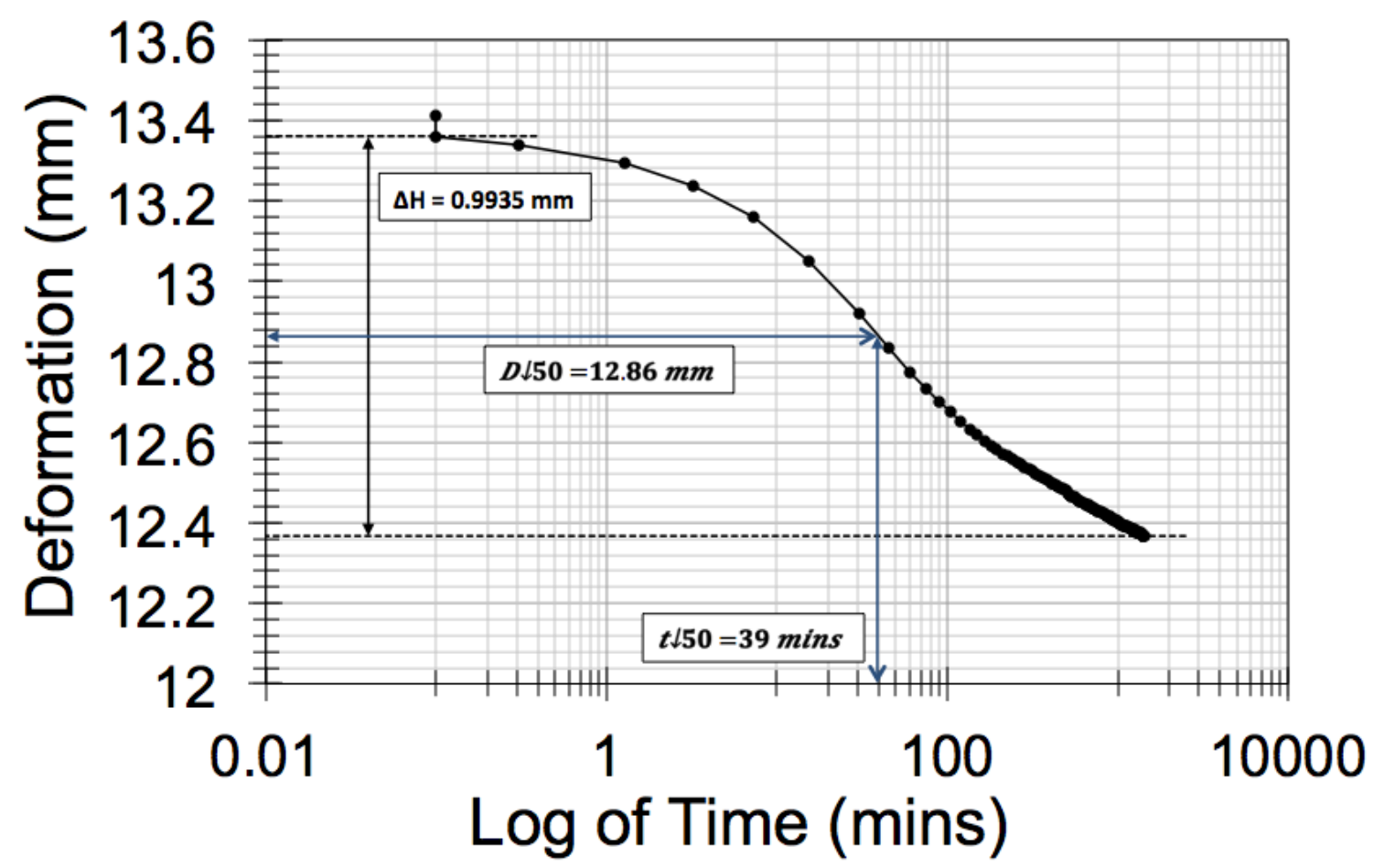

Figure 226. Casagrande analysis for $2 \mathrm{~kg}$ - Column Test \#2.

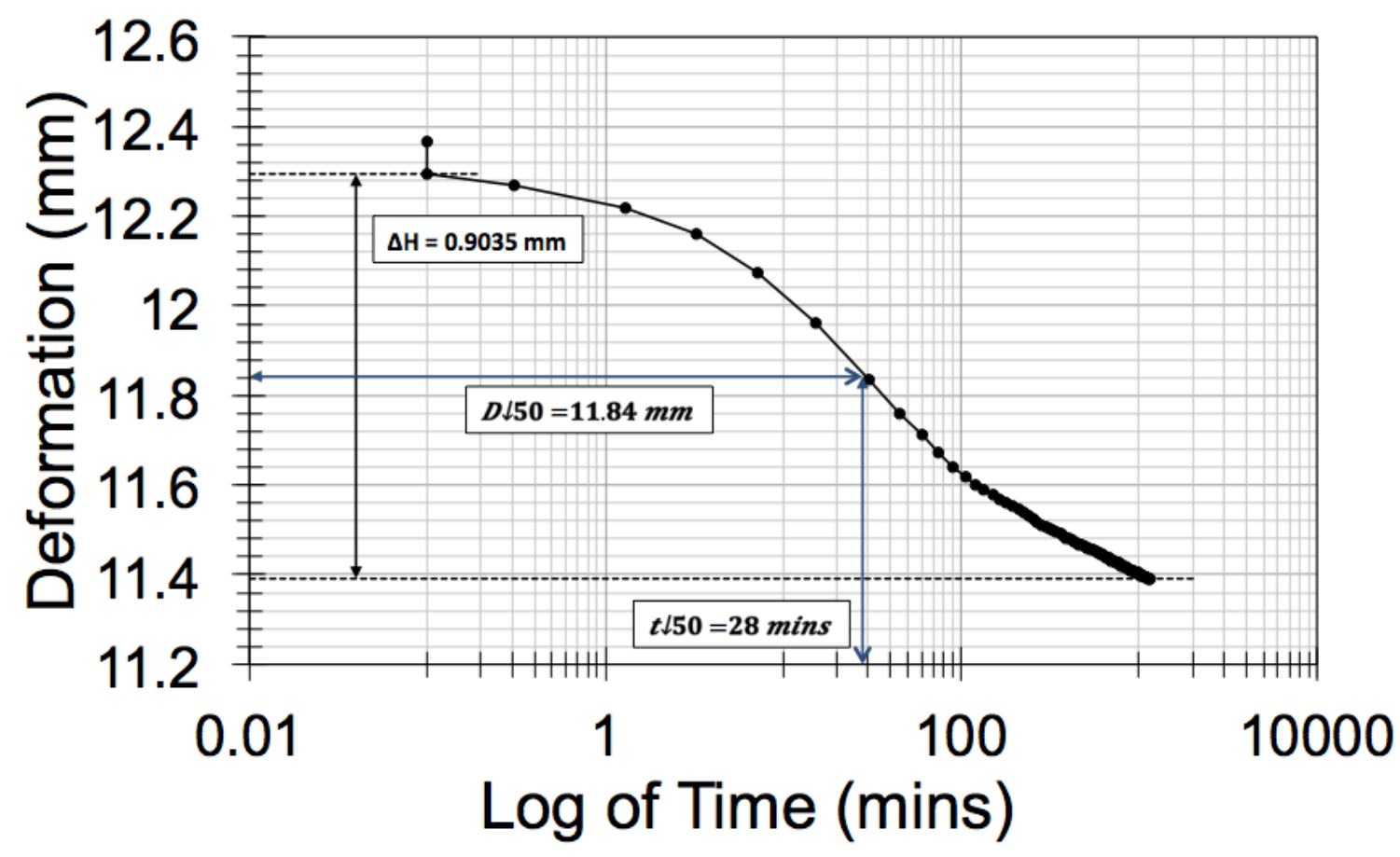

Figure 227. Casagrande analysis for $4 \mathrm{~kg}$ - Column Test \#2. 


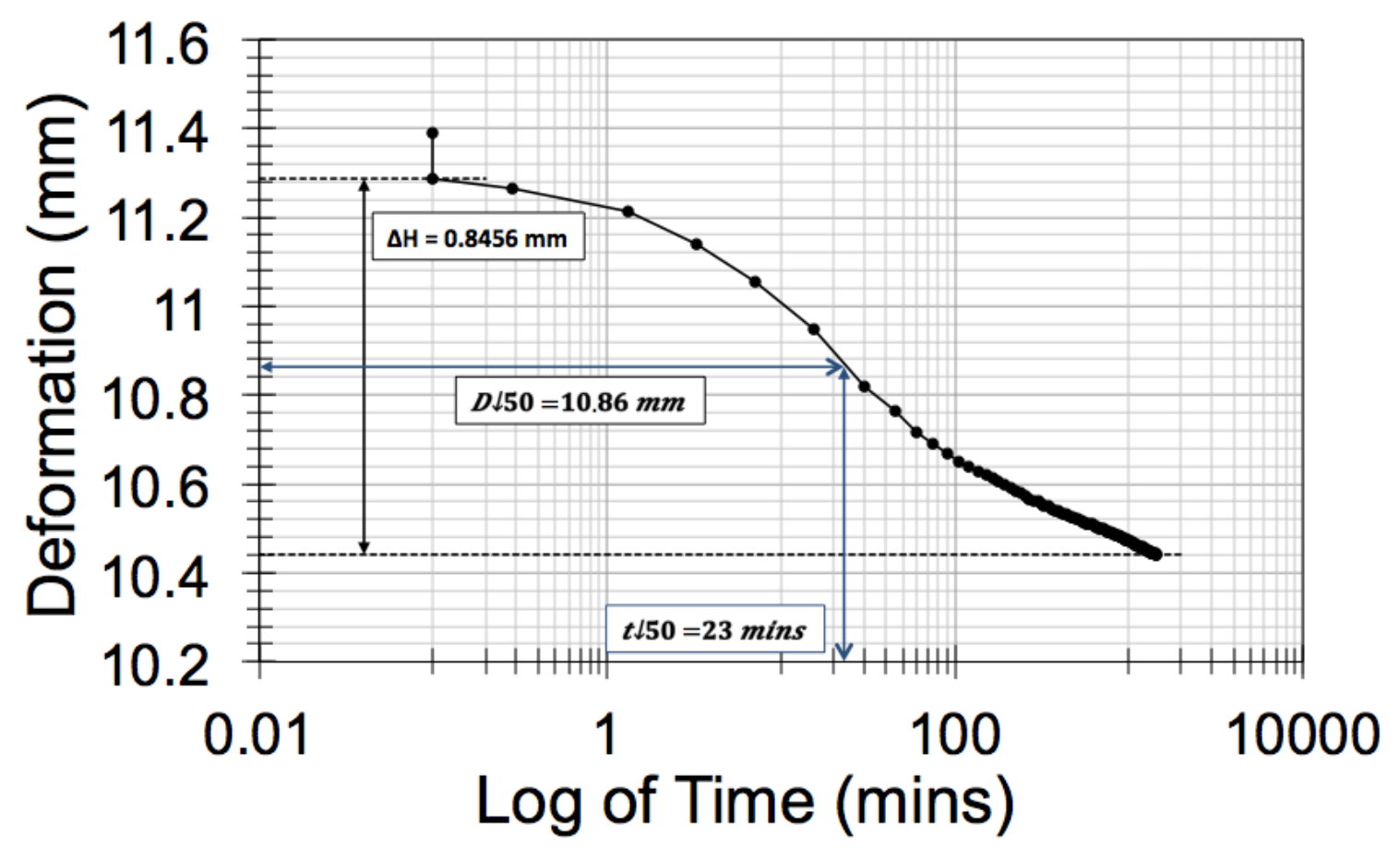

Figure 228. Casagrande analysis for $8 \mathrm{~kg}$ - Column Test \#2.

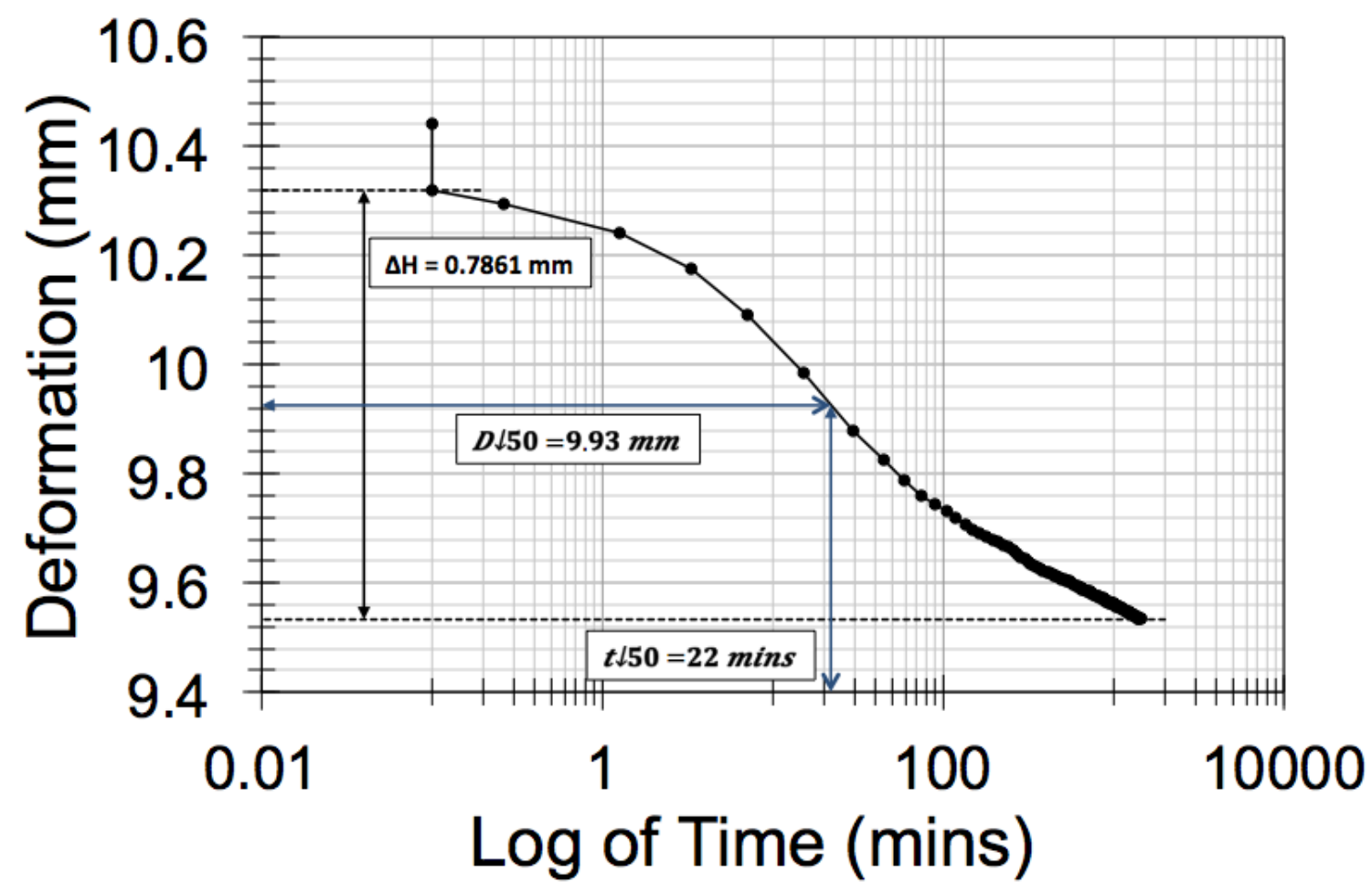

Figure 229. Casagrande analysis for $16 \mathrm{~kg}$ - Column Test \#2. 


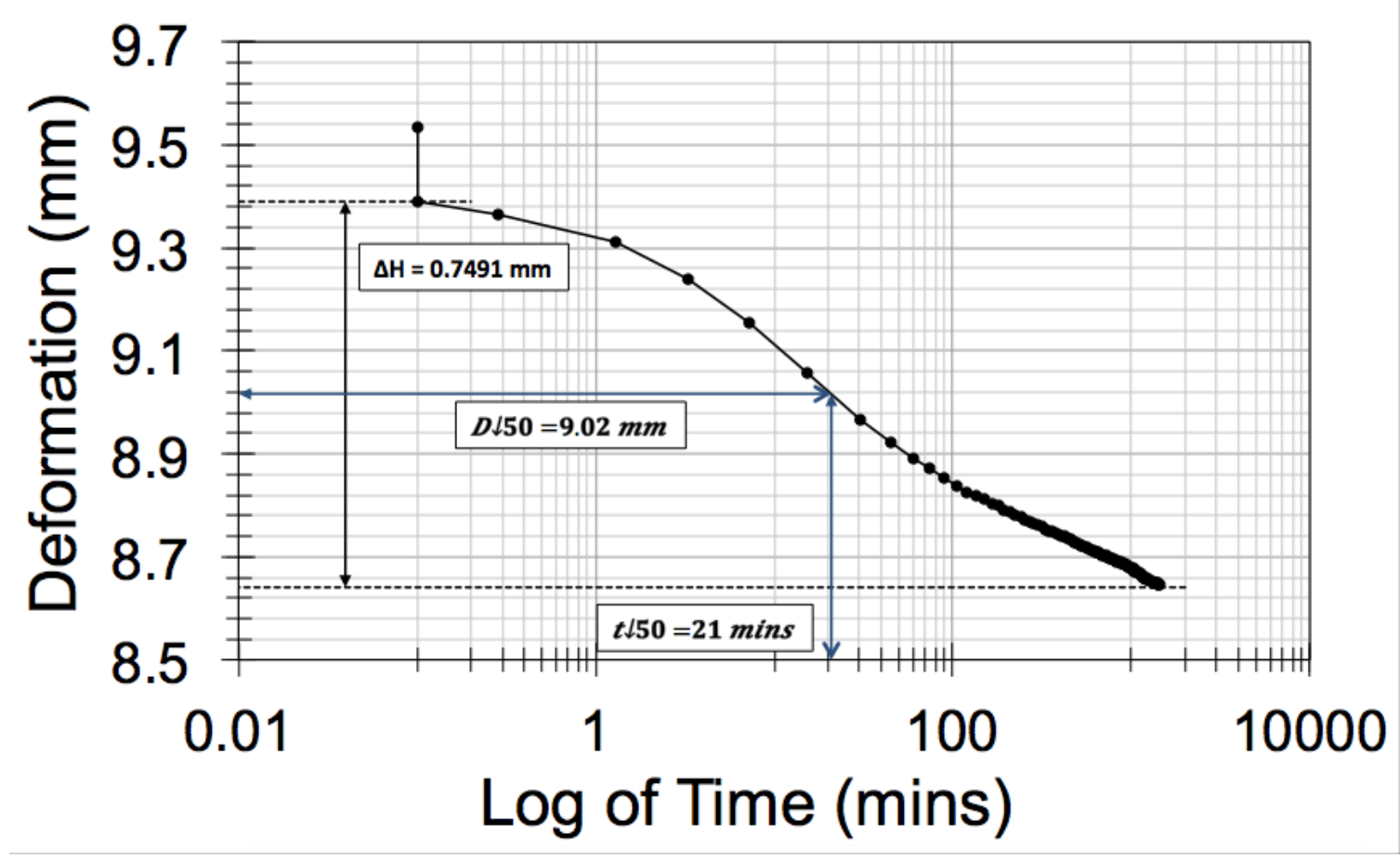

Figure 230. Casagrande analysis for $32 \mathrm{~kg}$ - Column Test \#2.

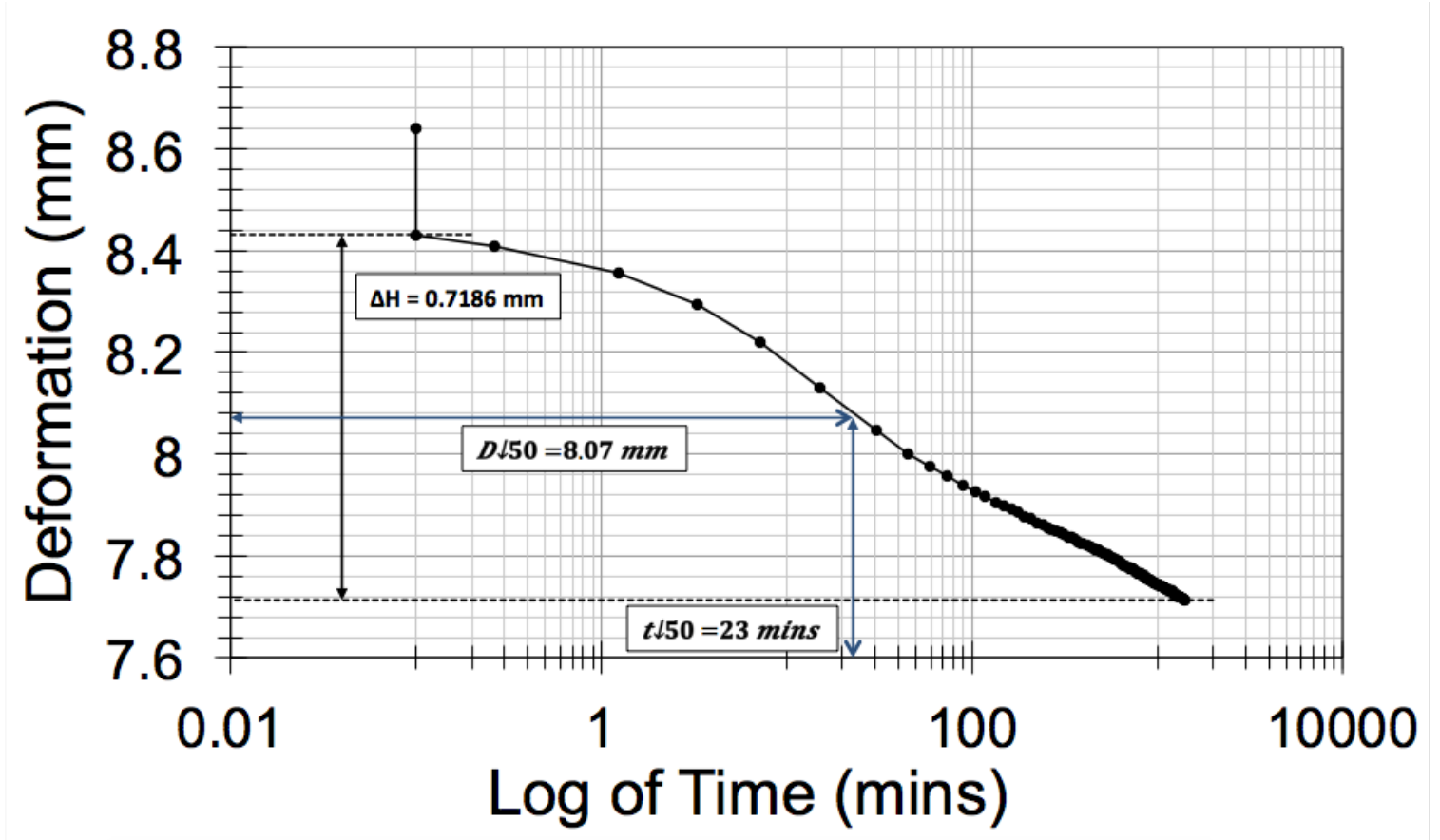

Figure 231. Casagrande analysis for $64 \mathrm{~kg}$ - Column Test \#2. 


\section{Appendix C : Consolidation Data for Column Test \#3}

\section{C.1 Consolidation Test Calculations}

Table 34. Calculations prior test - Column Test \#3

\begin{tabular}{|c|c|c|c|c|c|c|c|c|}
\hline \multicolumn{2}{|c|}{} & \multicolumn{6}{|c|}{ Before Consolidation } \\
\hline $\begin{array}{c}\text { Sample } \\
\#\end{array}$ & $\begin{array}{c}\text { Station } \\
\text { Number }\end{array}$ & $\begin{array}{c}\text { Depth } \\
(\mathbf{c m})\end{array}$ & $\begin{array}{c}\text { Mass of the } \\
\text { Consolidation } \\
\text { Ring (gr) }\end{array}$ & $\begin{array}{c}\text { Mass of the } \\
\text { Consolidation } \\
\text { Ring + Sample } \\
(\mathbf{g r})\end{array}$ & $\begin{array}{c}\text { Initial } \\
\text { Height of } \\
\text { the Sample } \\
\text { Ho (cm) }\end{array}$ & $\begin{array}{c}\text { Inner } \\
\text { Diameter of } \\
\text { the Ring } \\
\text { (cm) }\end{array}$ & $\begin{array}{c}\text { Wet Mass } \\
\text { of } \\
\text { Specimen } \\
\text { (gr): Mto }\end{array}$ & $\begin{array}{c}\text { Initial } \\
\text { Volume of } \\
\text { the specimen } \\
\text { (cm3): Vo }\end{array}$ \\
\hline $\mathbf{3}$ & $\mathrm{F}$ & 12.75 & 70.00 & 130.63 & 2.00 & 5.08 & 60.63 & 40.54 \\
\hline $\mathbf{4}$ & $\mathrm{A}$ & 6.25 & 68.55 & 129.13 & 2.00 & 5.08 & 60.58 & 40.54 \\
\hline
\end{tabular}

Table 35. Calculations post test (a) - Column Test \#3

\begin{tabular}{|c|c|c|c|c|c|}
\hline & & \multicolumn{4}{|c|}{ After Consolidation } \\
\hline $\begin{array}{c}\text { Sample } \\
\#\end{array}$ & $\begin{array}{c}\text { Station } \\
\text { Number }\end{array}$ & $\begin{array}{c}\text { Depth } \\
(\mathbf{c m})\end{array}$ & $\begin{array}{c}\text { Mass of the } \\
\text { Consolidation } \\
\text { Ring + Sample } \\
\text { (gr) }\end{array}$ & $\begin{array}{c}\text { Moist Mass of } \\
\text { Total } \\
\text { Specimen } \\
\text { Mtf }\end{array}$ & $\begin{array}{c}\text { Final Height } \\
\text { of Sample } \\
\text { (cm):Hf }\end{array}$ \\
\hline $\mathbf{3}$ & F & 12.75 & 119.61 & 49.61 & 1.08 \\
\hline $\mathbf{4}$ & A & 6.25 & 116.89 & 48.34 & 1.25 \\
\hline
\end{tabular}

Table 36. Calculations post test (b) - Column Test \#3

\begin{tabular}{|c|c|c|c|c|c|c|c|c|c|c|c|c|}
\hline \multirow[b]{2}{*}{$\begin{array}{c}\text { Sample } \\
\#\end{array}$} & \multirow[b]{2}{*}{$\begin{array}{l}\text { Station } \\
\text { Number }\end{array}$} & \multirow[b]{2}{*}{$\begin{array}{l}\text { Depth } \\
\text { (cm) }\end{array}$} & \multicolumn{10}{|c|}{ Calculations } \\
\hline & & & $\begin{array}{l}\text { Dry Mass } \\
\text { (gr): Md }\end{array}$ & $\begin{array}{c}\text { Initial } \\
\text { water } \\
\text { content } \\
\text { (\%): Wo }\end{array}$ & $\begin{array}{c}\text { Final } \\
\text { water } \\
\text { content } \\
\text { (\%): Wf }\end{array}$ & $\begin{array}{l}\text { Initial Dry } \\
\text { Density } \\
\text { (g/cm3): pd }\end{array}$ & $\begin{array}{c}\text { Dry Unit } \\
\text { Weight } \\
\text { (KN/m3): } \\
\text { rd }\end{array}$ & $\begin{array}{c}\text { Volume of } \\
\text { Solids } \\
(\mathrm{cm} 3): \text { Vs }\end{array}$ & $\begin{array}{c}\text { Equivalent } \\
\text { Height of } \\
\text { Solids }(\mathrm{cm}): \\
\text { Hs }\end{array}$ & $\begin{array}{l}\text { Initial } \\
\text { Void } \\
\text { Ratio: } \\
\text { eo }\end{array}$ & $\begin{array}{l}\text { Final } \\
\text { Void } \\
\text { Ratio: } \\
\text { ef }\end{array}$ & $\begin{array}{c}\text { Initial } \\
\text { Degree of } \\
\text { Saturation } \\
\text { (\%): So }\end{array}$ \\
\hline 3 & $\mathrm{~F}$ & 12.75 & 40.05 & 51.4 & 23.9 & 0.99 & 9.68 & 18.21 & 0.90 & 1.23 & 0.20 & 92.15 \\
\hline 4 & $A$ & 6.25 & 40.96 & 47.9 & 18.0 & 1.01 & 9.90 & 18.62 & 0.92 & 1.18 & 0.36 & 89.50 \\
\hline
\end{tabular}




\section{C.2 Depth of $6.25 \mathrm{~cm}-$ A sample}

Table 37. Compressibility data at depth of $6.25 \mathrm{~cm}$ - Column Test \#3

\begin{tabular}{|c|c|c|c|c|c|c|c|}
\hline Weight & Load Increment & $\Sigma \Delta \mathrm{H} / \mathrm{mm}$ & $\mathrm{H}$ & e & Cv & av & K \\
\hline (Kg) & or ov (Kpa) & & $(H o-\Delta H)(m m)$ & (H-Hs)/Hs & $(\mathrm{mm} 2 / \mathrm{s})$ & (m2/KN) & $(\mathrm{m} / \mathrm{s})$ \\
\hline- & 0.1 & 0.0000 & 20.3261 & 1.2129 & - & - & - \\
\hline 1 & 4.8 & 1.8787 & 18.4474 & 1.0084 & 0.0093 & 0.0301 & $1.24 \mathrm{E}-09$ \\
\hline 2 & 9.7 & 2.6616 & 17.6645 & 0.9232 & 0.0074 & 0.0135 & $4.42 \mathrm{E}-10$ \\
\hline 4 & 19.4 & 3.5490 & 16.7771 & 0.8266 & 0.0078 & 0.0075 & $2.59 \mathrm{E}-10$ \\
\hline 8 & 38.7 & 4.5071 & 15.8190 & 0.7222 & 0.0087 & 0.0040 & $1.53 \mathrm{E}-10$ \\
\hline 16 & 77.4 & 5.5039 & 14.8222 & 0.6137 & 0.0084 & 0.0020 & 7.49E-11 \\
\hline 32 & 154.9 & 6.4909 & 13.8352 & 0.5063 & 0.0077 & 0.0010 & $3.44 \mathrm{E}-11$ \\
\hline 64 & 309.8 & 7.5037 & 12.8224 & 0.3960 & 0.0060 & 0.0007 & $1.87 \mathrm{E}-11$ \\
\hline
\end{tabular}

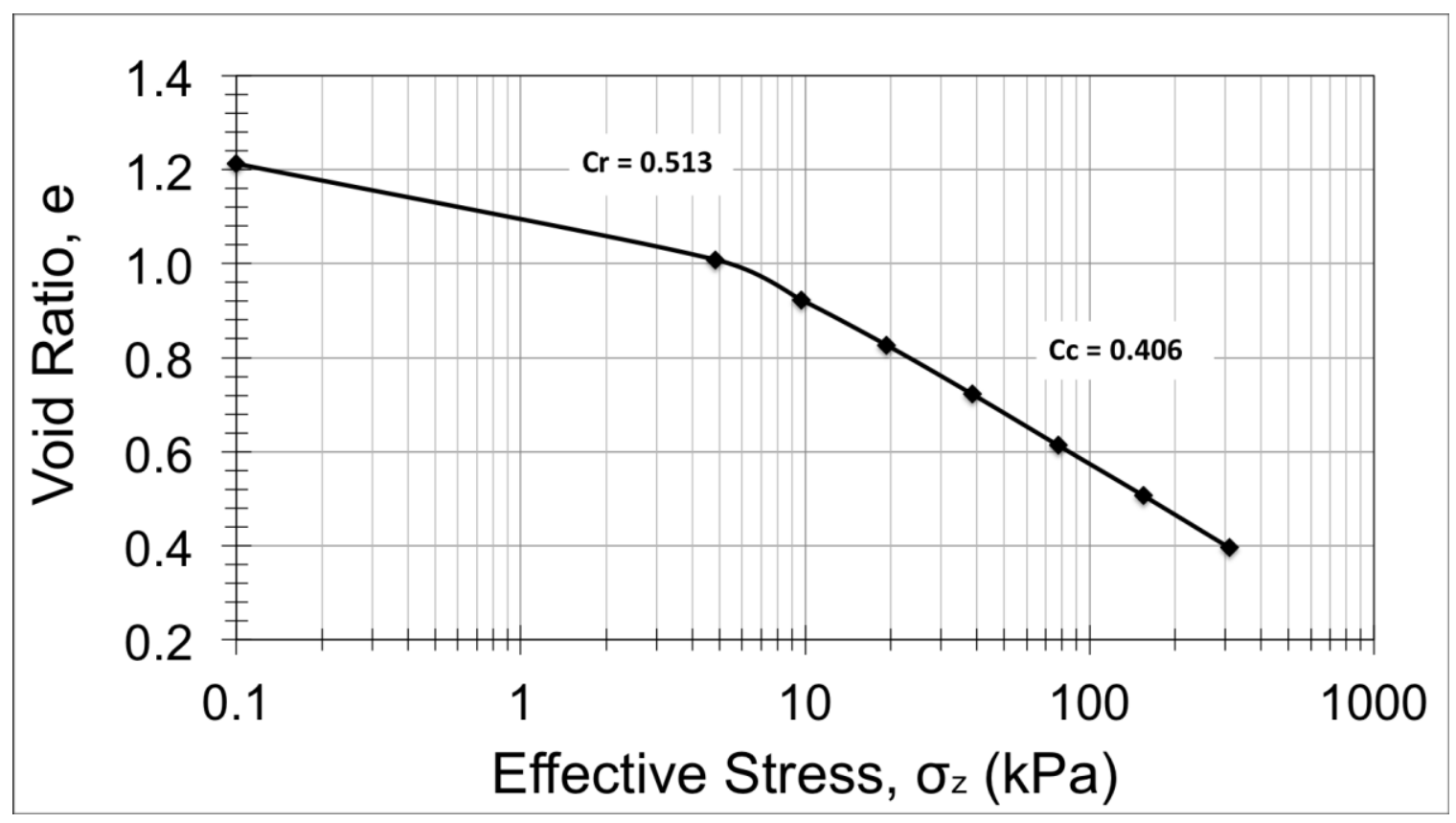

Figure 232. Void ratio vs Effective stress (depth of $6.25 \mathrm{~cm}$ ) - Column Test \#3 


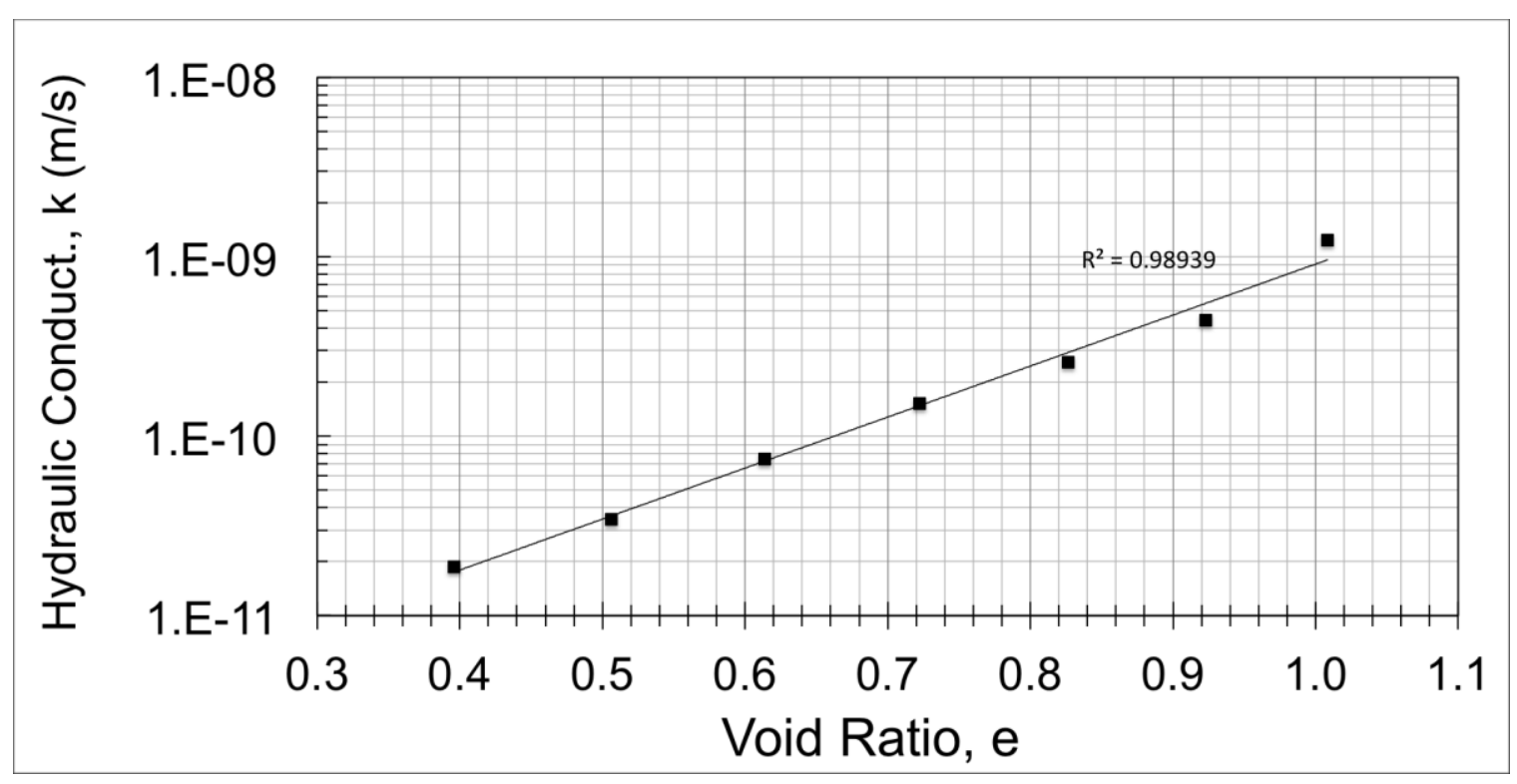

Figure 233. Permeability results (depth of $6.25 \mathrm{~cm}$ ) - Column Test \#3

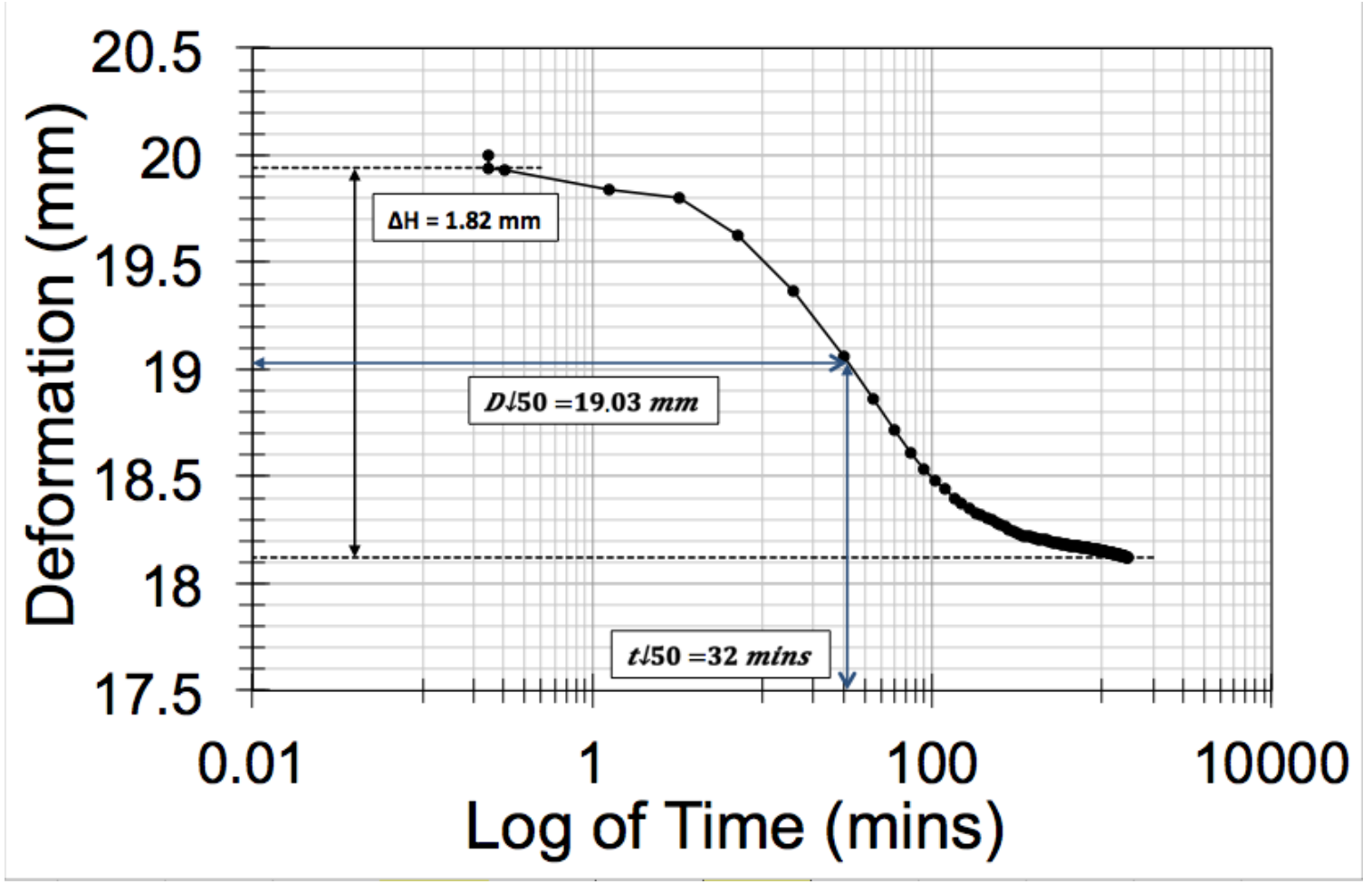

Figure 234. Casagrande analysis for $1 \mathrm{~kg}$ - Column Test \#3. 


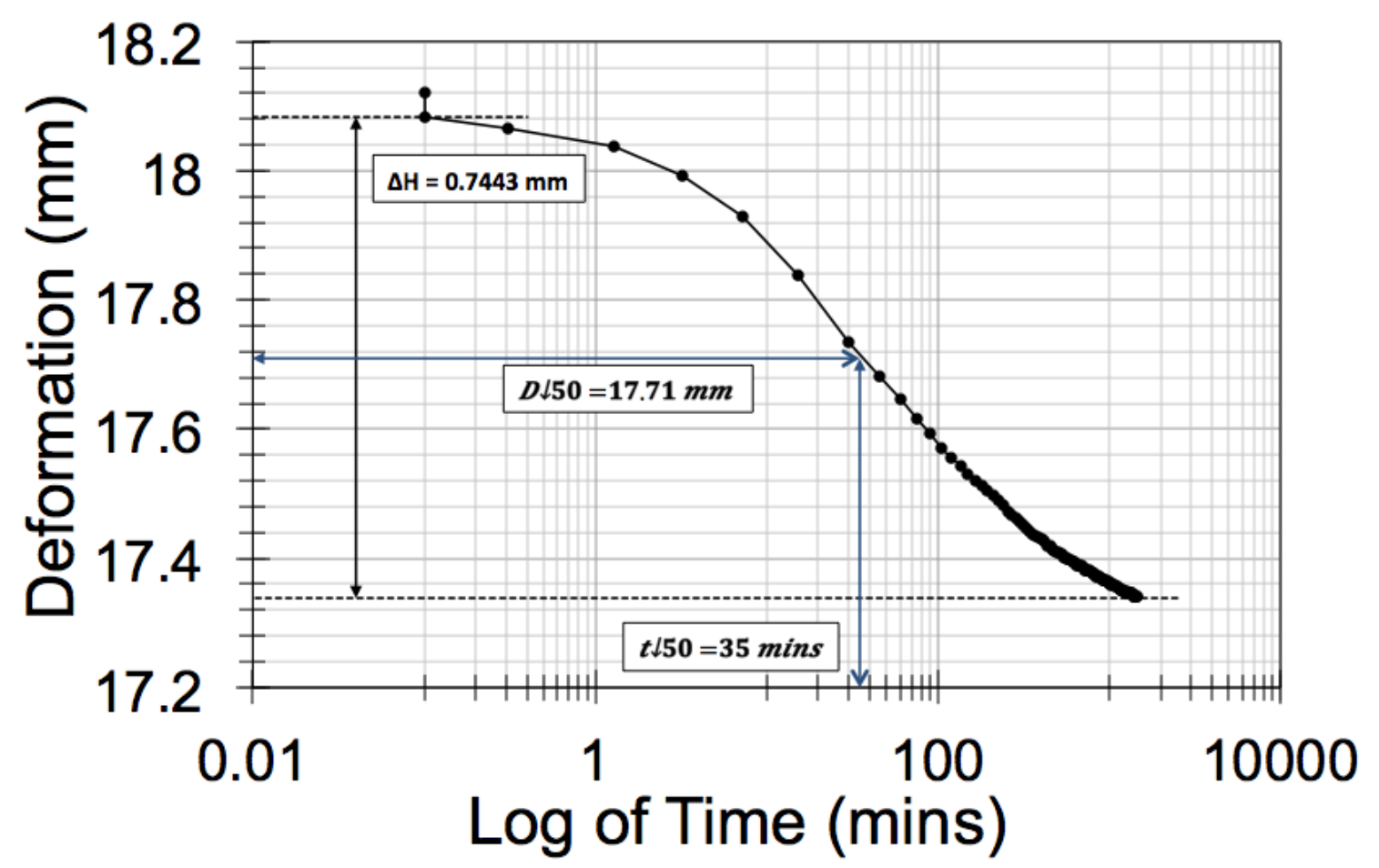

Figure 235. Casagrande analysis for $2 \mathrm{~kg}-$ Column Test \#3.

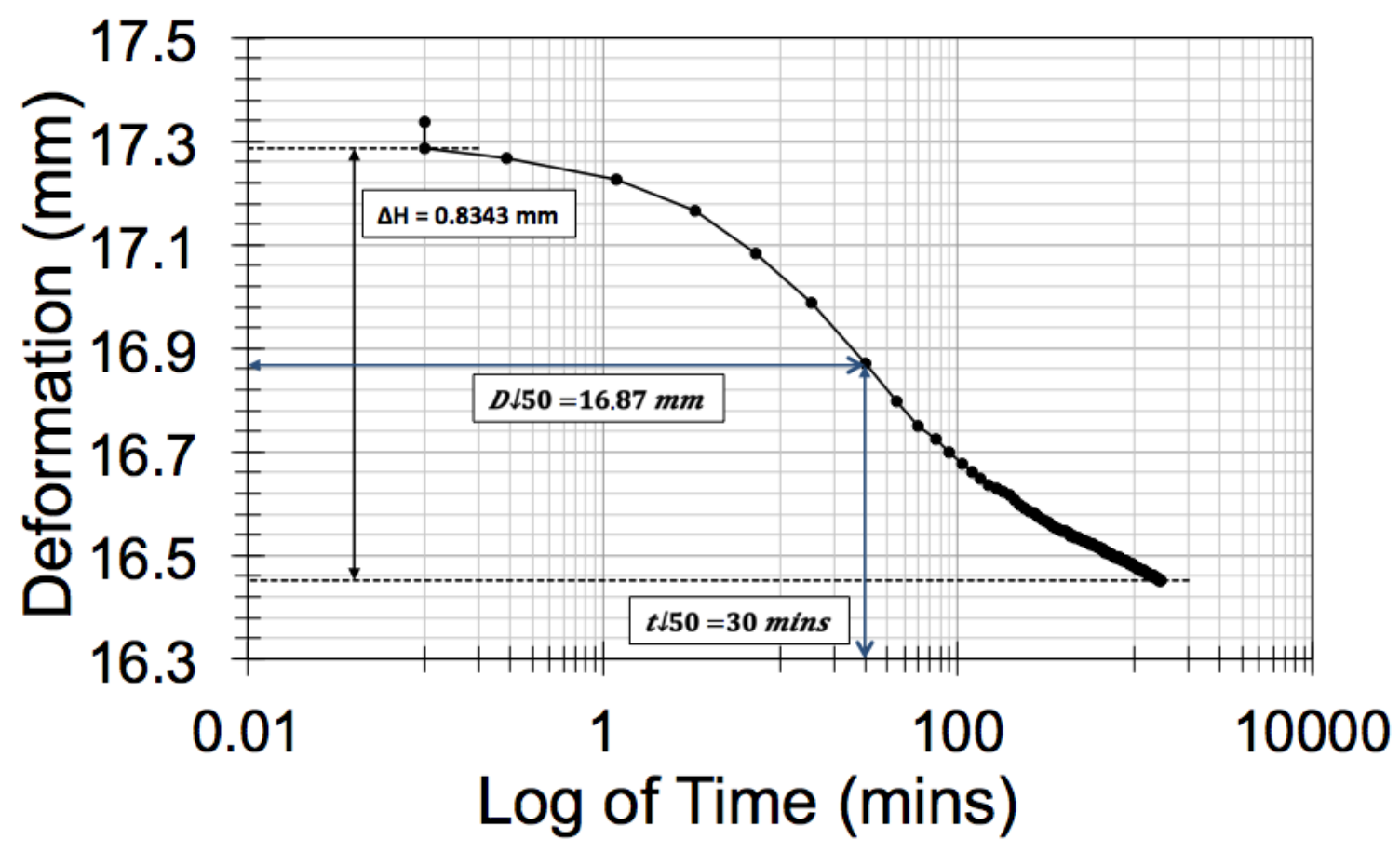

Figure 236. Casagrande analysis for $4 \mathrm{~kg}$ - Column Test \#3. 


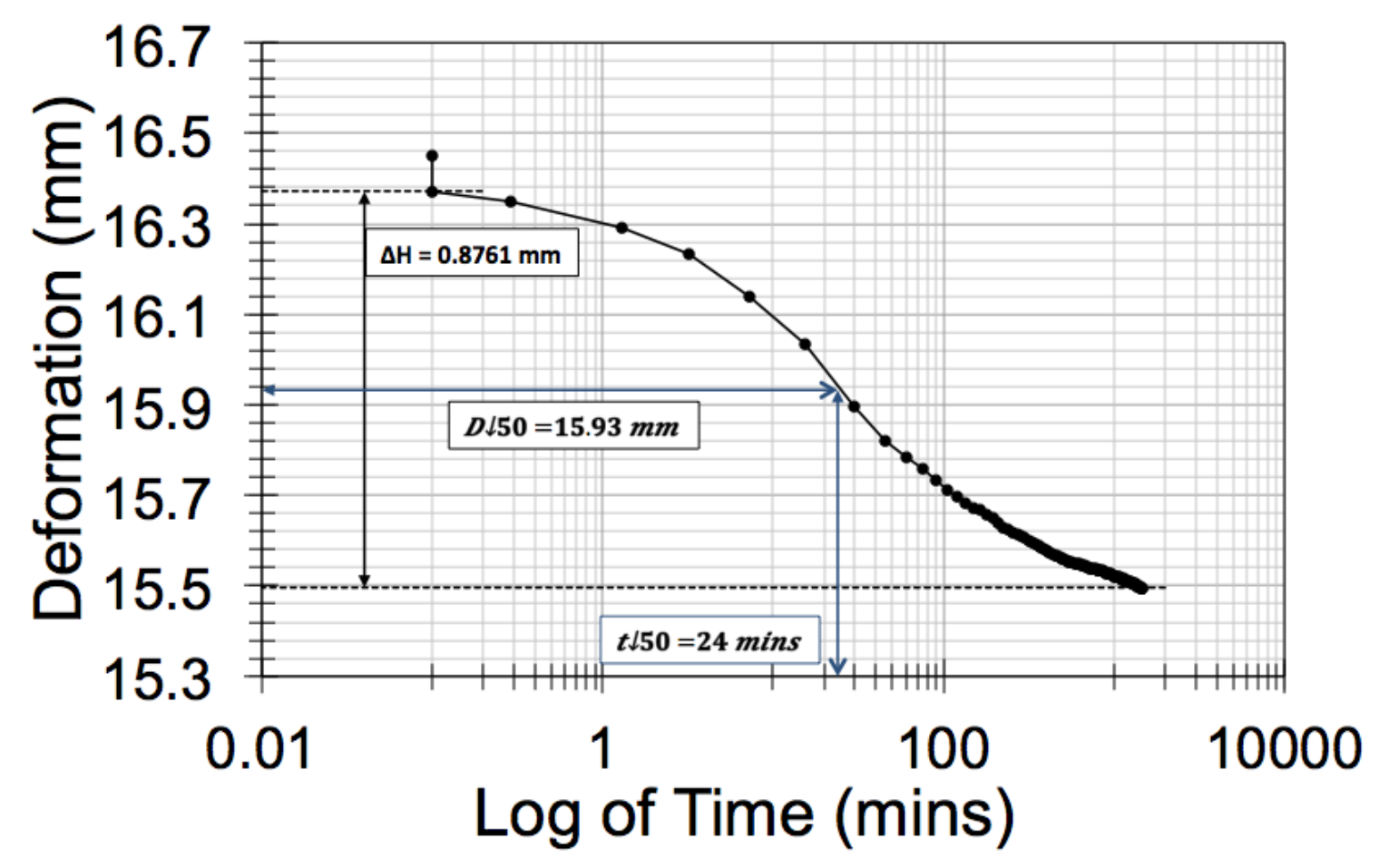

Figure 237. Casagrande analysis for $8 \mathrm{~kg}$ - Column Test \#3.

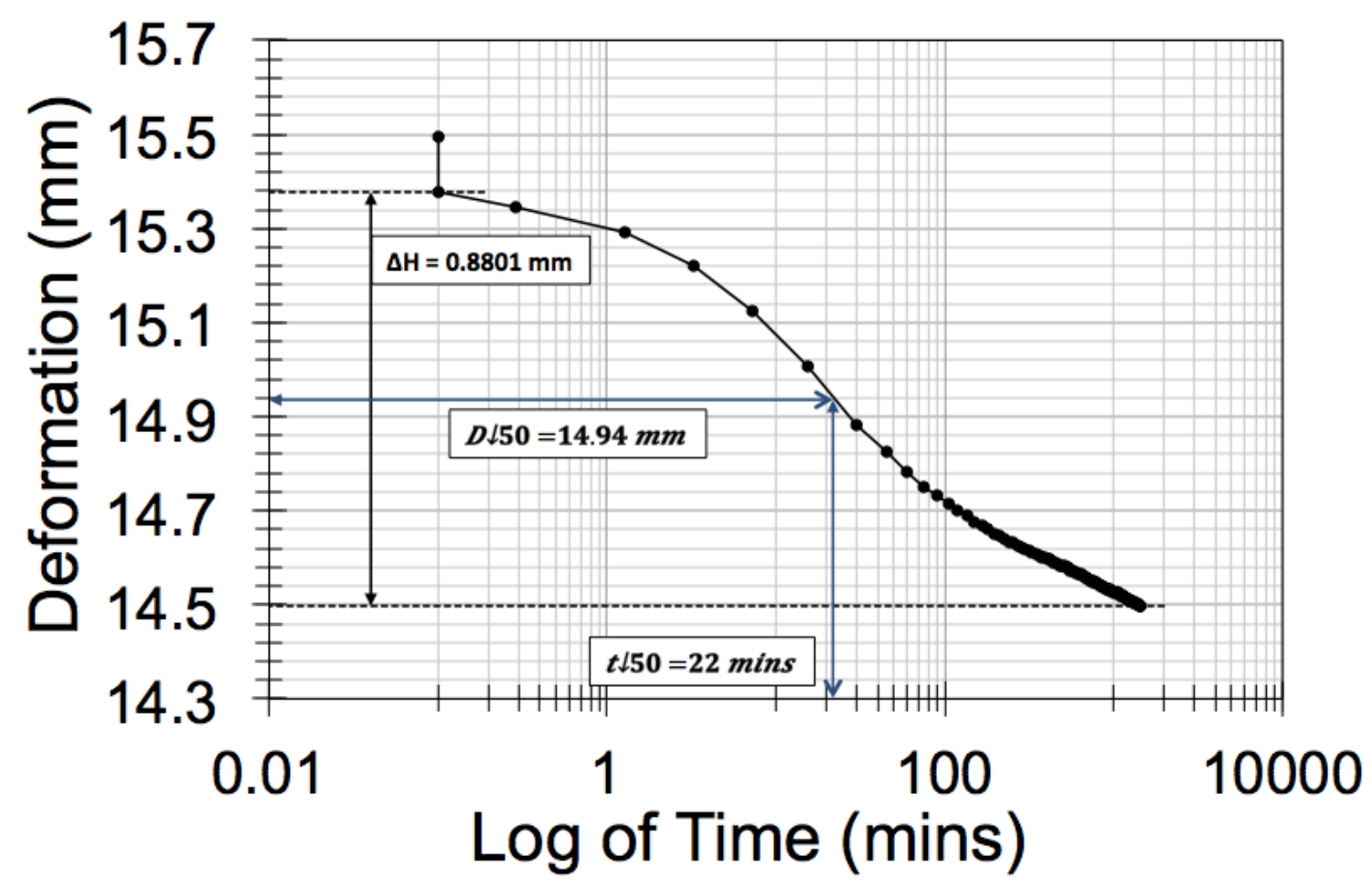

Figure 238. Casagrande analysis for $16 \mathrm{~kg}$ - Column Test \#3. 


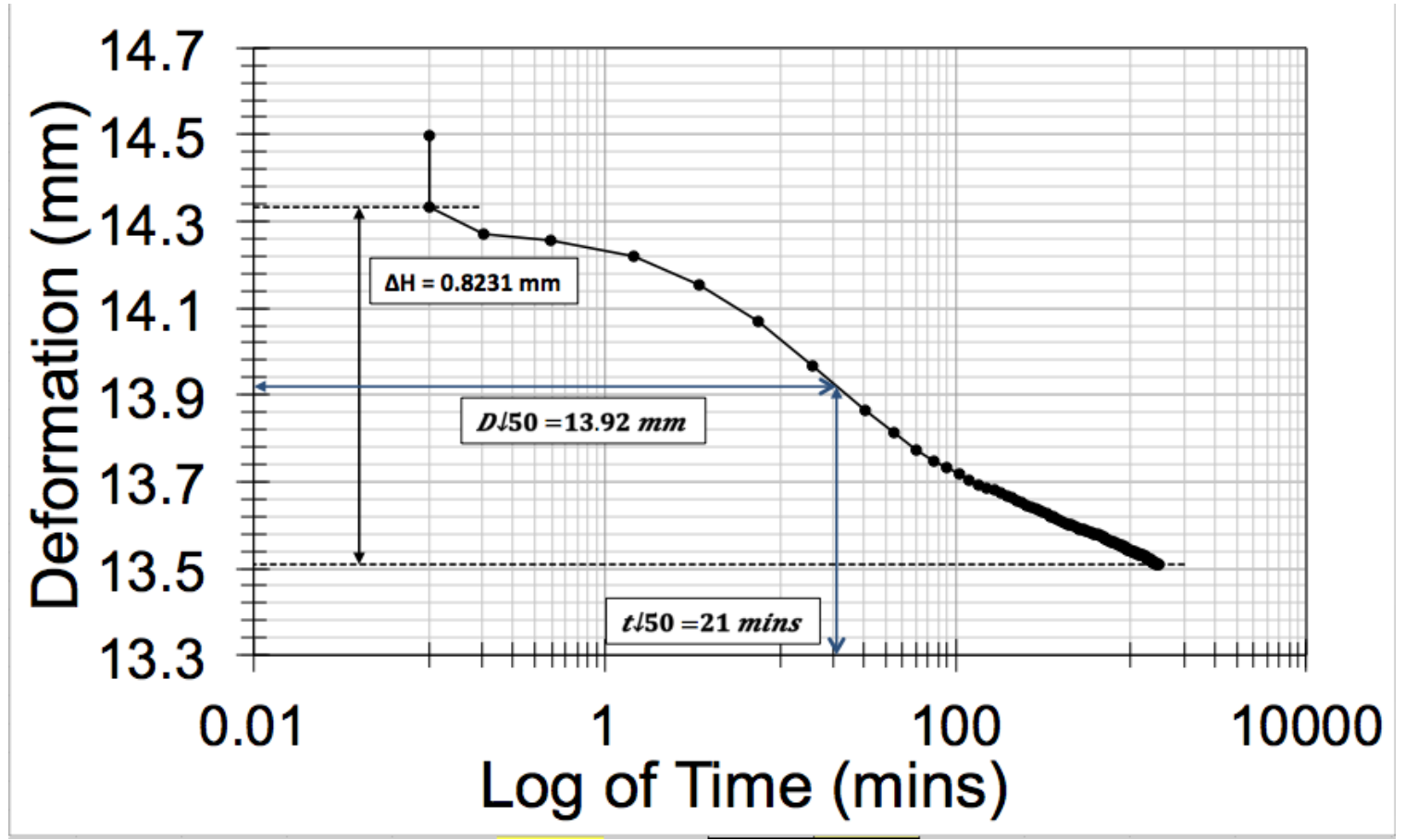

Figure 239. Casagrande analysis for $32 \mathrm{~kg}$ - Column Test \#3.

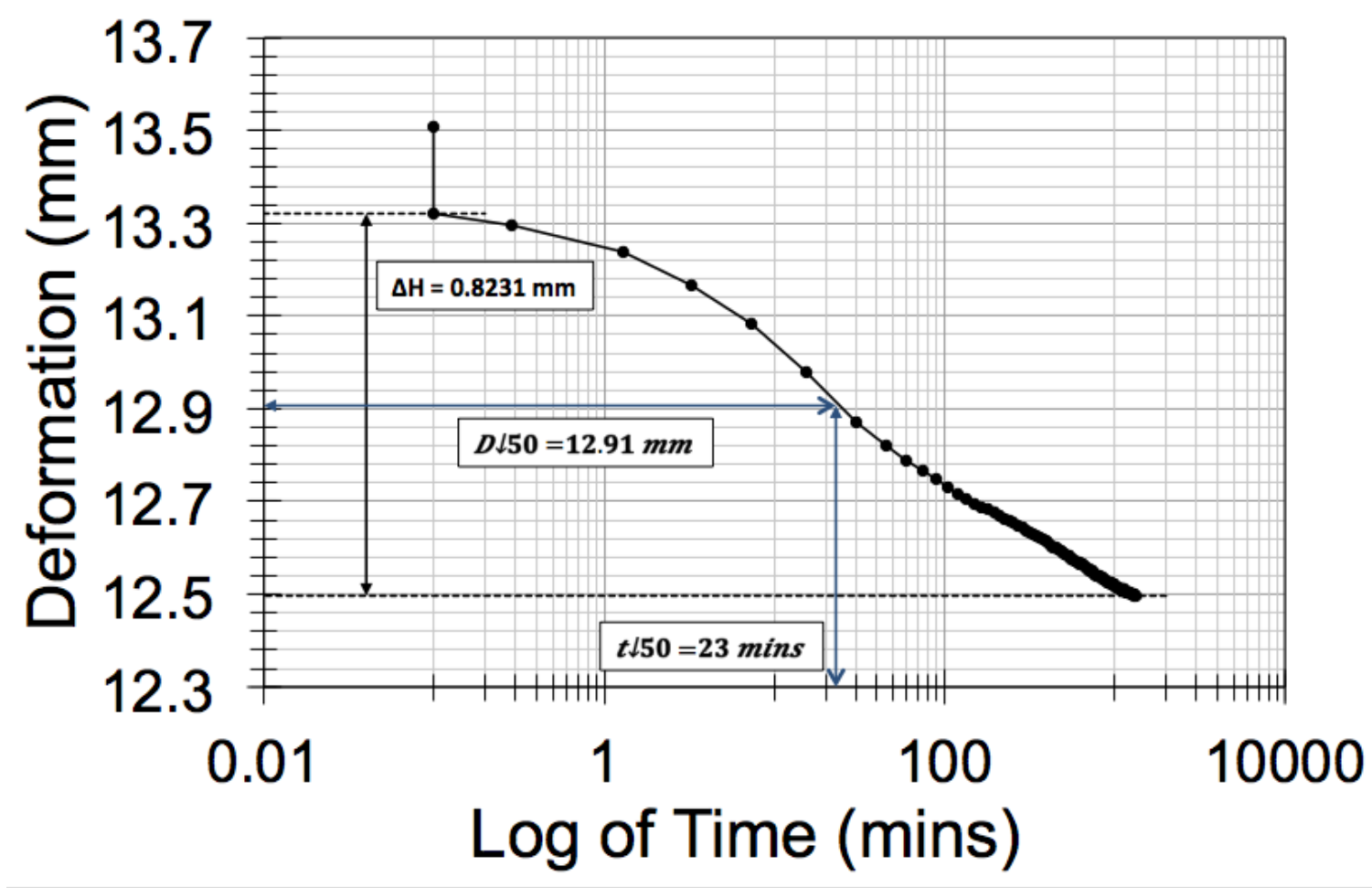

Figure 240. Casagrande analysis for $64 \mathrm{~kg}$ - Column Test \#3. 


\section{C.3 Depth of $12.75 \mathrm{~cm}-$ F sample}

Table 38. Compressibility data at depth of $12.75 \mathrm{~cm}$ - Column Test \#3

\begin{tabular}{|c|c|c|c|c|c|c|c|}
\hline Weight & Load Increment & $5 \mathrm{AH}(\mathrm{mm})$ & $\mathbf{H}$ & e & Cv & av & K \\
\hline$(\mathrm{Kg})$ & or ov (Кра) & $1^{2}$ & $(\mathrm{Ho}-\Delta \mathrm{H})(\mathrm{mm})$ & $(\mathrm{H}-\mathrm{Hs}) / \mathrm{Hs}$ & $(\mathrm{mm} 2 / \mathrm{s})$ & (m2/KN) & $(\mathrm{m} / \mathrm{s})$ \\
\hline- & 0.1 & 0.0000 & 23.4246 & 1.6082 & - & - & - \\
\hline 1 & 4.8 & 4.6026 & 18.8221 & 1.0958 & 0.0086 & 0.0724 & $2.33 \mathrm{E}-09$ \\
\hline 2 & 9.7 & 6.1700 & 17.2546 & 0.9212 & 0.0047 & 0.0248 & $4.42 \mathrm{E}-10$ \\
\hline 4 & 19.4 & 7.6007 & 15.8239 & 0.7619 & 0.0050 & 0.0093 & 1.77E-10 \\
\hline 8 & 38.7 & 8.4881 & 14.9365 & 0.6631 & 0.0053 & 0.0037 & 7.36E-11 \\
\hline 16 & 77.4 & 9.3723 & 14.0523 & 0.5647 & 0.0050 & 0.0011 & $2.15 \mathrm{E}-11$ \\
\hline 32 & 154.9 & 9.6488 & 13.7758 & 0.5339 & 0.0258 & 0.0002 & $1.94 \mathrm{E}-11$ \\
\hline 64 & 309.8 & 9.7214 & 13.7033 & 0.5258 & 0.0273 & 0.0001 & $5.13 \mathrm{E}-12$ \\
\hline
\end{tabular}

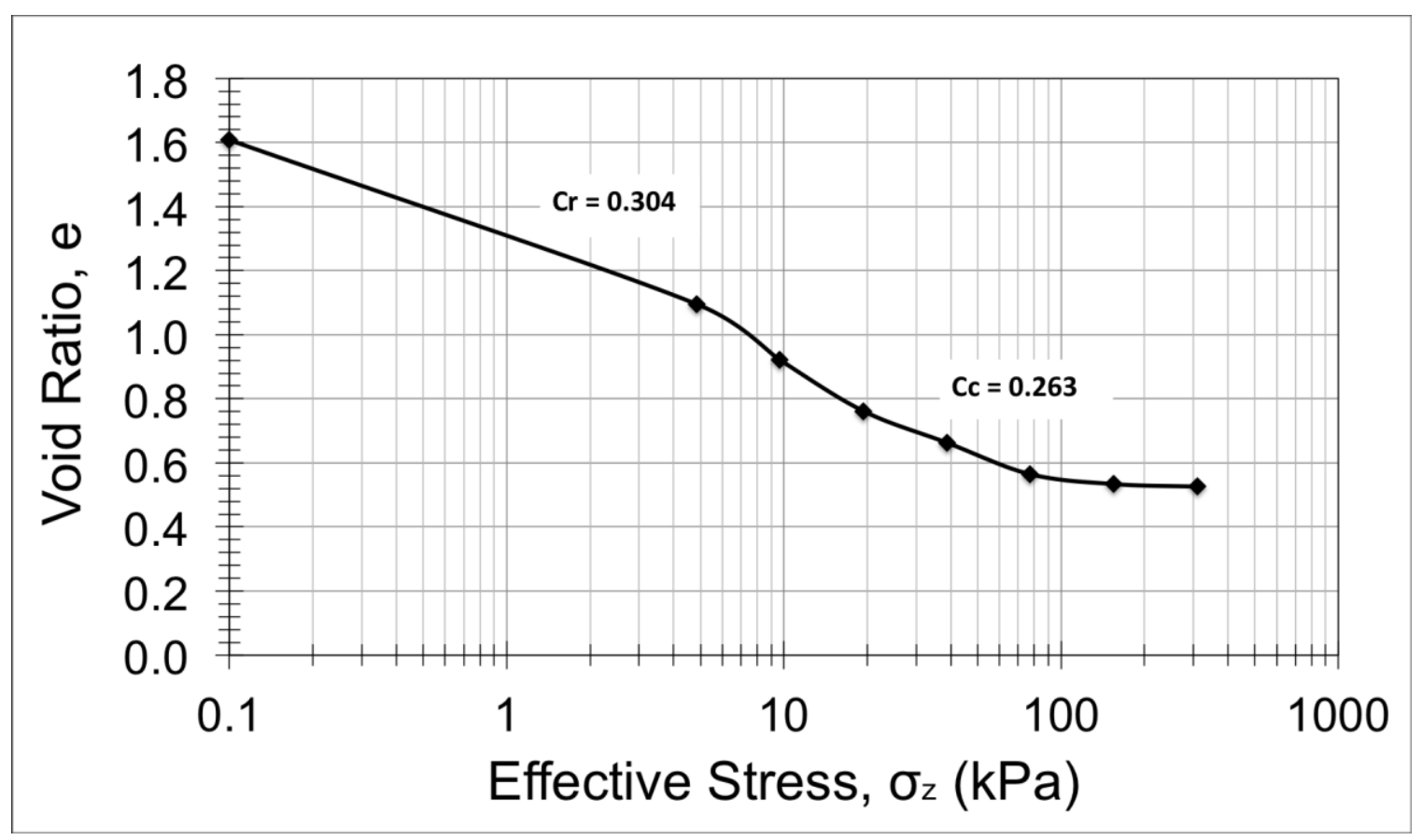

Figure 241. Void ratio vs Effective stress (depth of $12.75 \mathrm{~cm}$ ) - Column Test \#3 


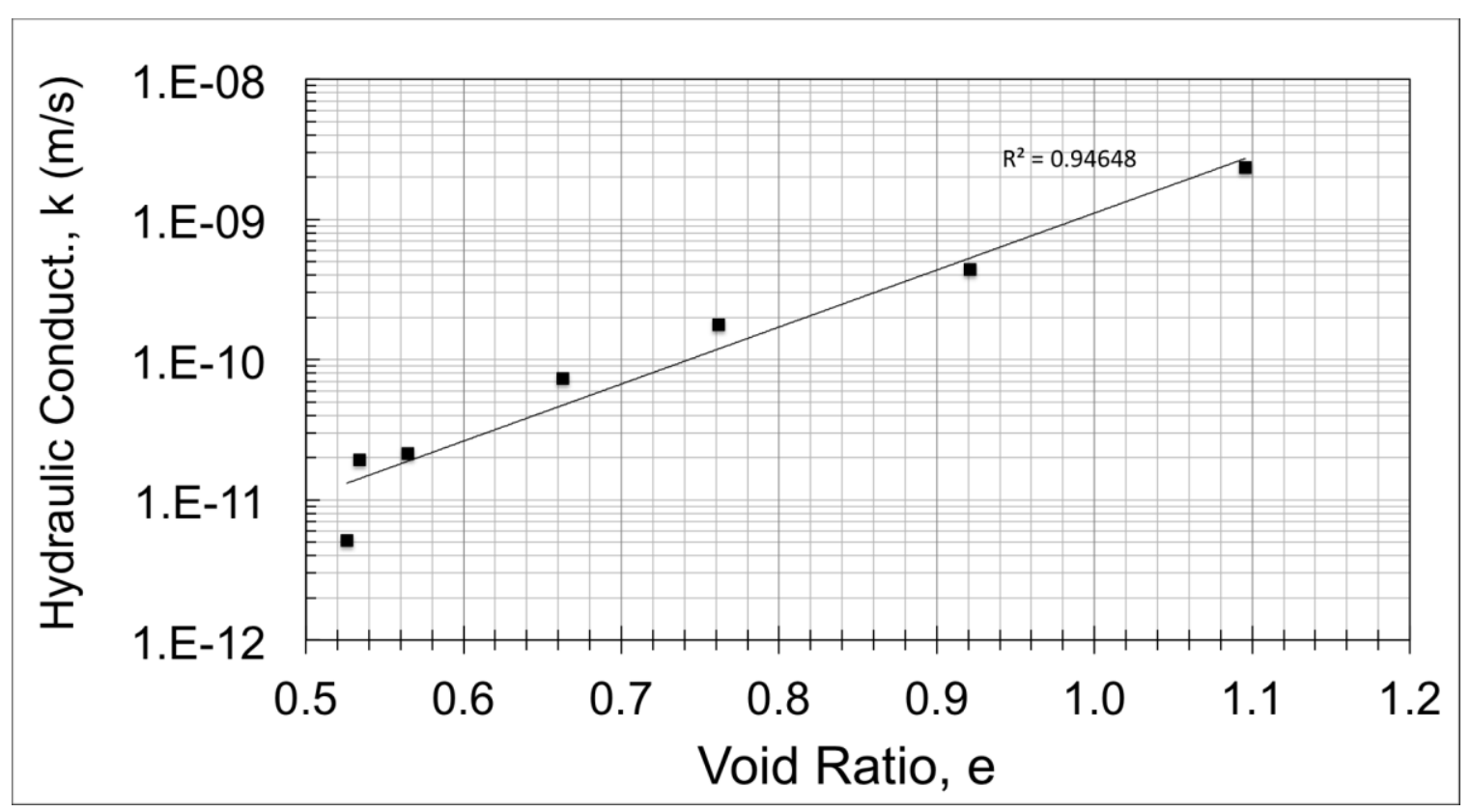

Figure 242. Permeability results (depth of $12.75 \mathrm{~cm}$ ) - Column Test \#3

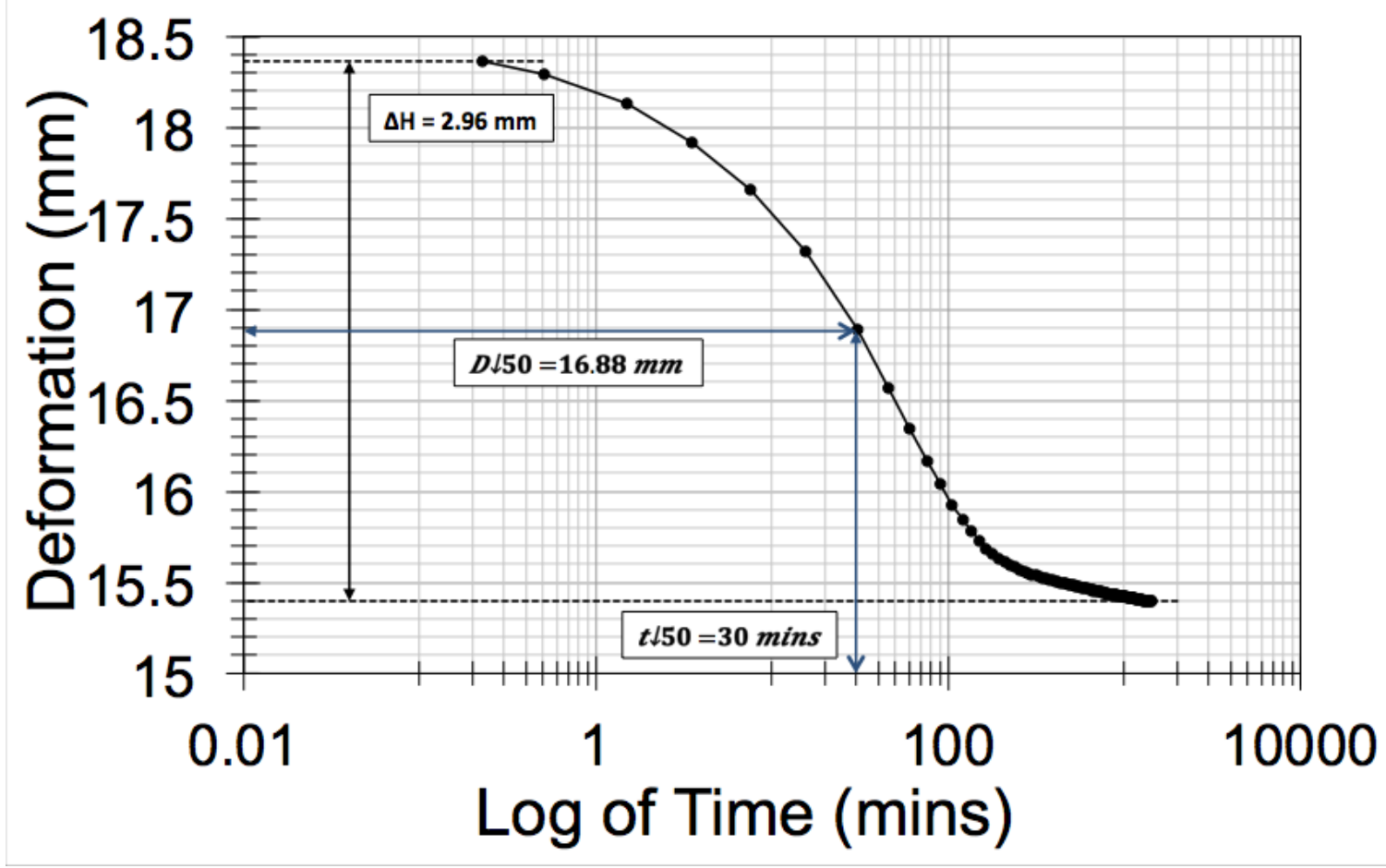

Figure 243. Casagrande analysis for $1 \mathrm{~kg}$ - Column Test \#3. 


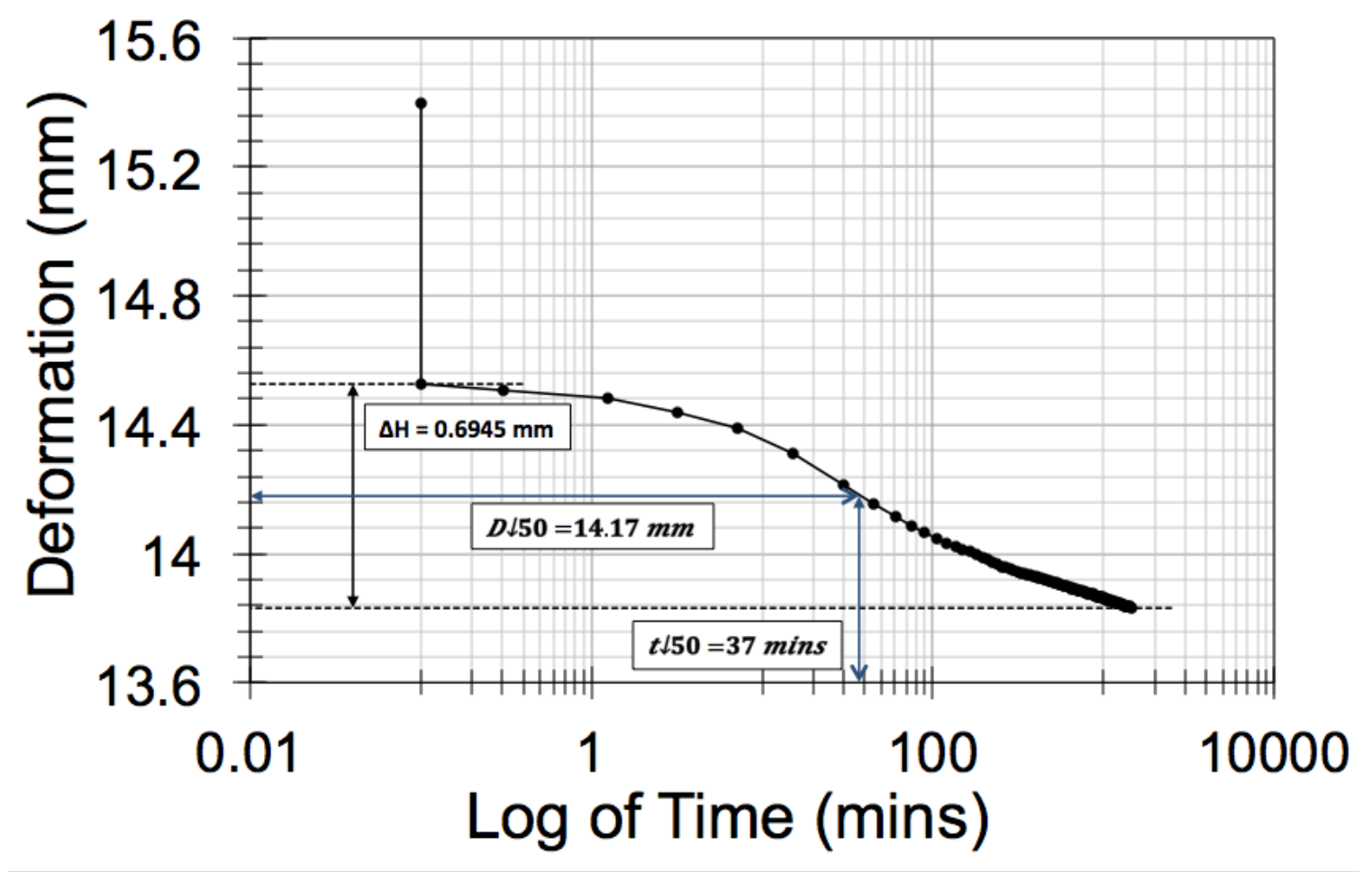

Figure 244. Casagrande analysis for $2 \mathrm{~kg}$ - Column Test \#3.

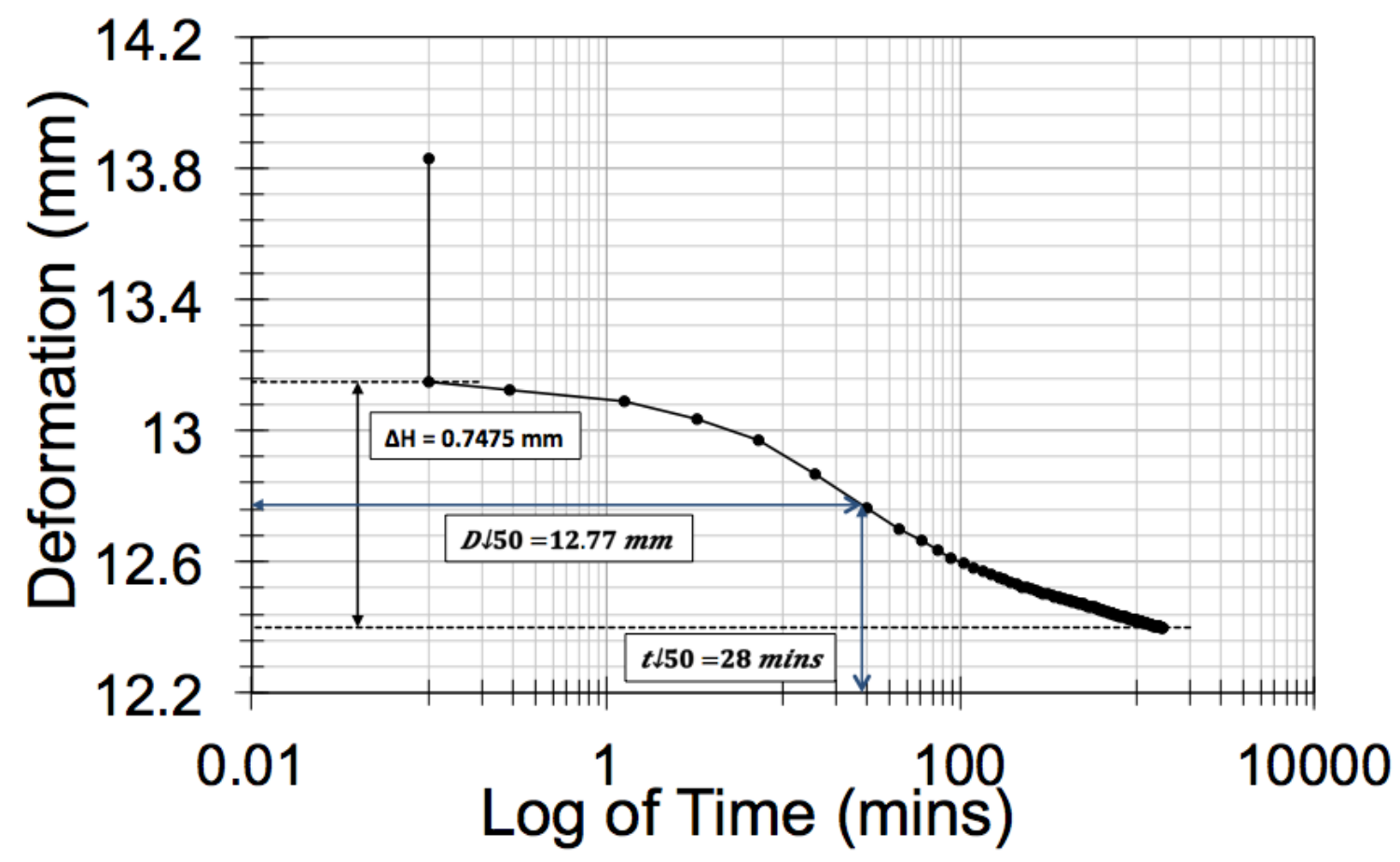

Figure 245. Casagrande analysis for $4 \mathrm{~kg}$ - Column Test \#3. 


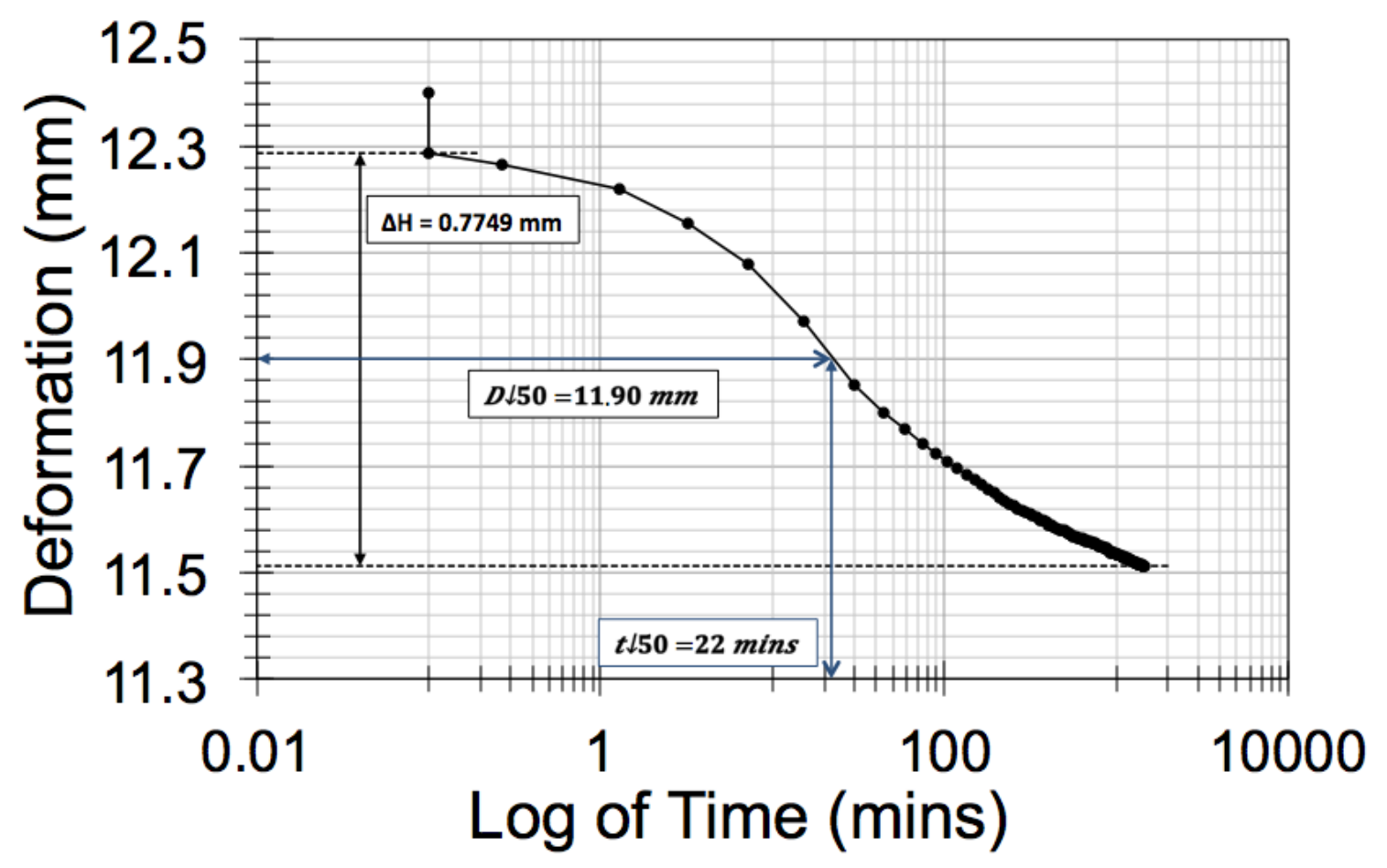

Figure 246. Casagrande analysis for $8 \mathrm{~kg}$ - Column Test \#3.

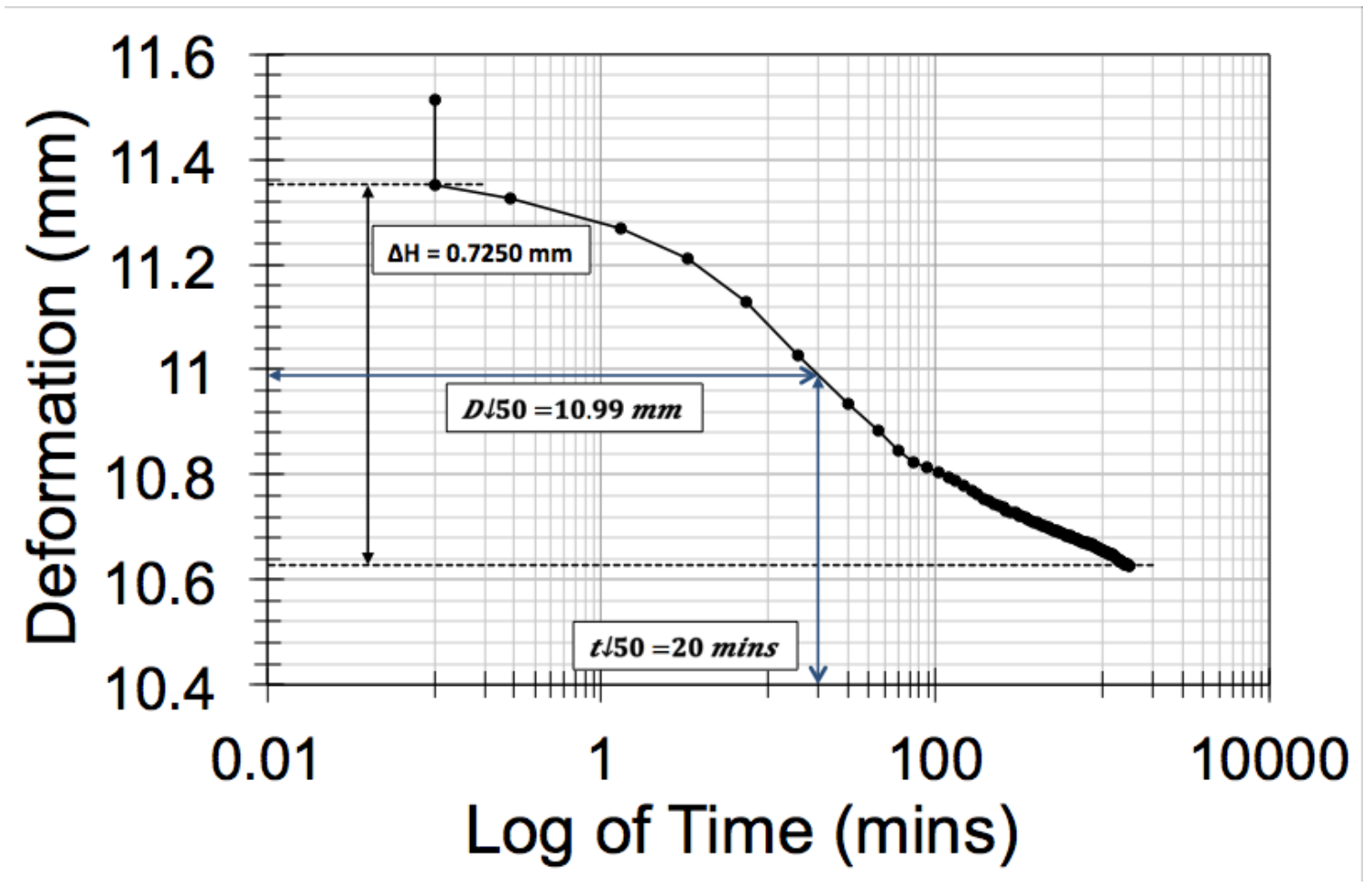

Figure 247. Casagrande analysis for $16 \mathrm{~kg}$ - Column Test \#3. 


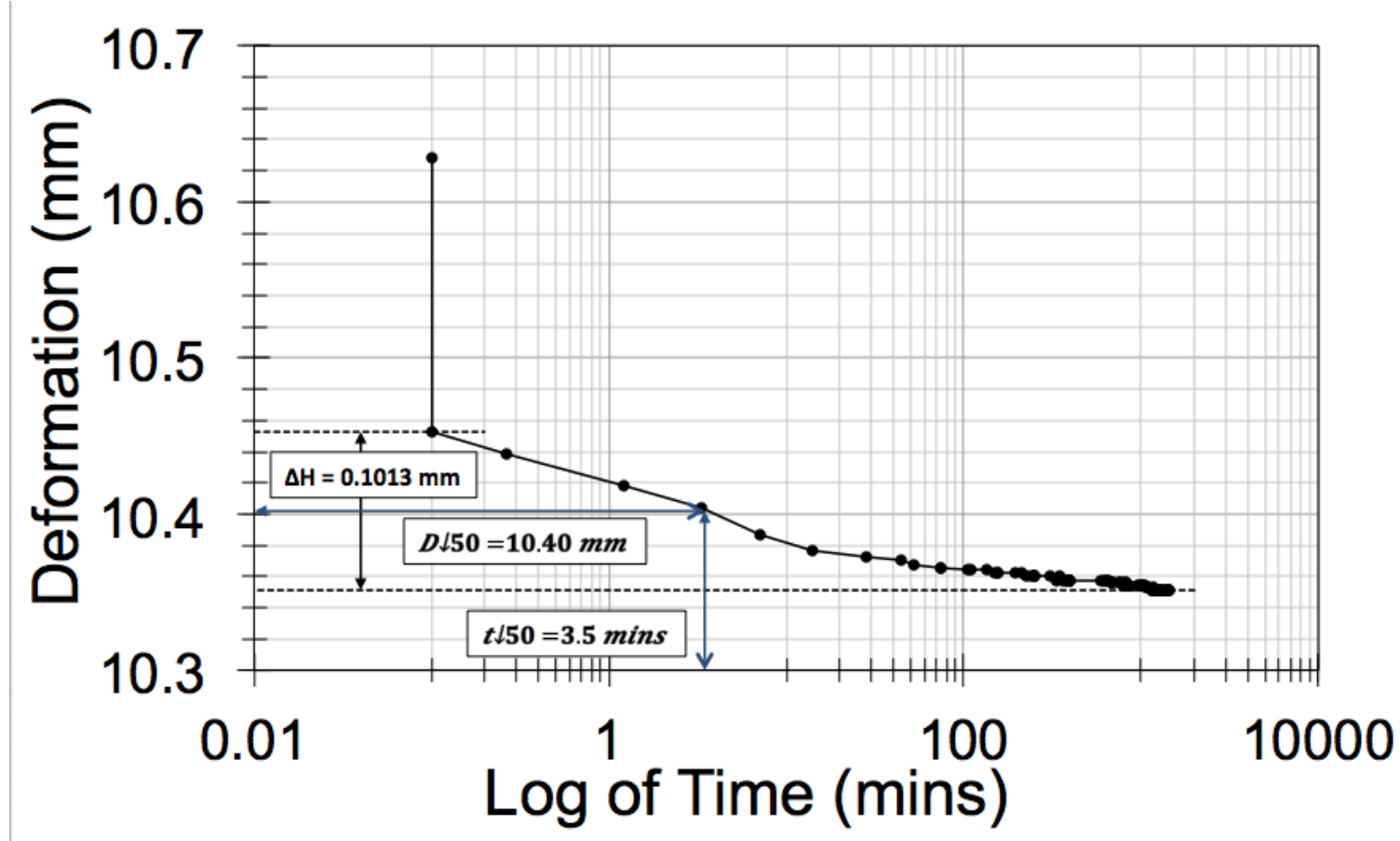

Figure 248. Casagrande analysis for $32 \mathrm{~kg}$ - Column Test \#3.

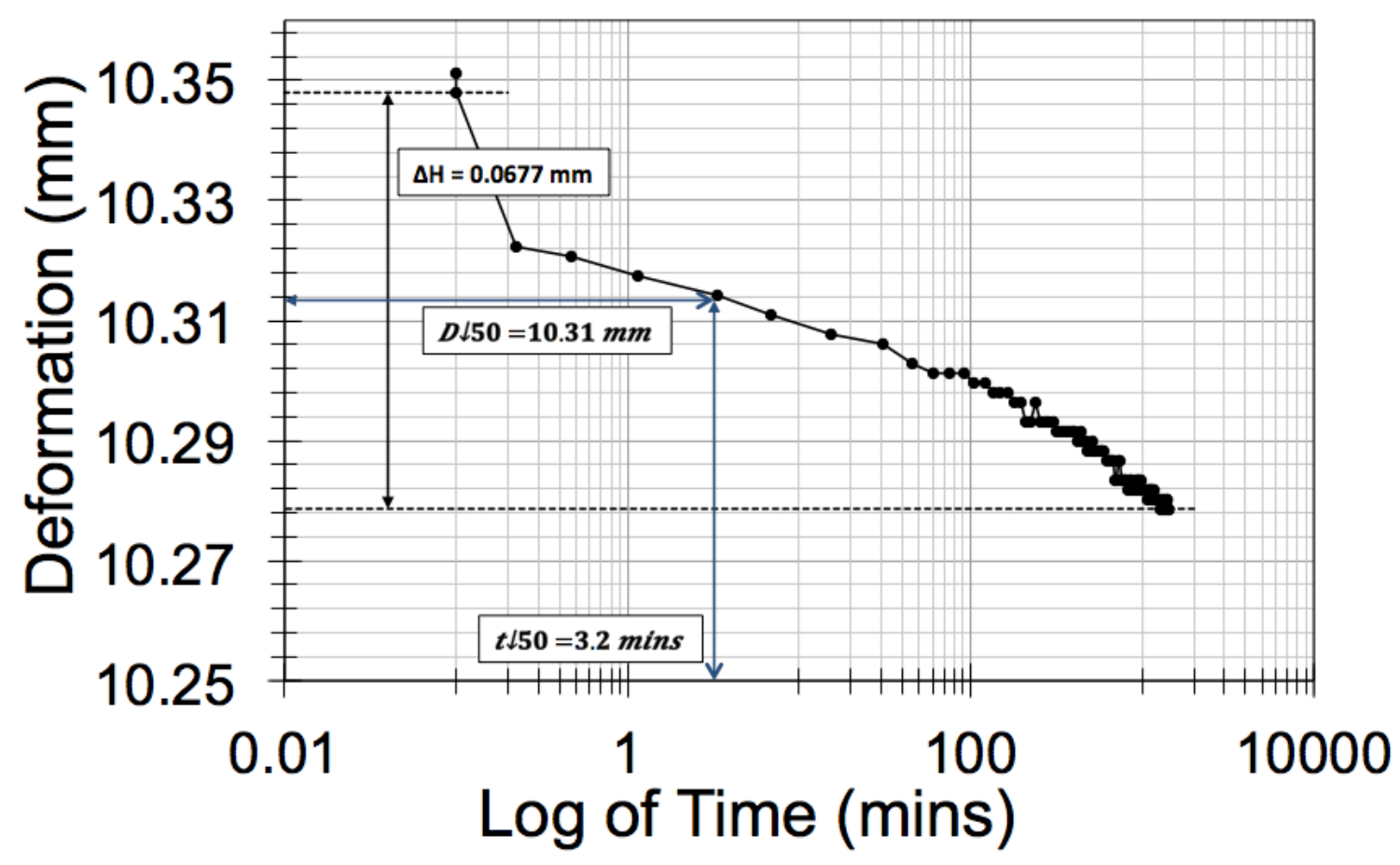

Figure 249. Casagrande analysis for $64 \mathrm{~kg}$ - Column Test \#3. 


\section{Appendix D : Other Tables and Graphs}

\section{D.1 Experiments Events Timeline}

Table 39. Events timeline for Column Test \#1.

\begin{tabular}{|c|c|c|}
\hline Date & Time & Event \\
\hline May 6, 2015 & $6: 50 \mathrm{pm}$ & Column test started. \\
\hline May 21,2015 & $4: 47 \mathrm{pm}$ & Tensiometer was replaced due to malfunction. \\
\hline May 22,2015 & $5: 40 \mathrm{pm}$ & Freezing tests started (no fridge) \\
\hline May 26, 2015 & $7: 10 \mathrm{pm}$ & Freezing Stops (No effective freezing - ice buildup) \\
\hline June 18, 2015 & $12: 47 \mathrm{pm}$ & Tensiometer was replaced due to malfunction. \\
\hline June 26, 2015 & $4: 13 \mathrm{pm}$ & Freezing starts again (no fridge). \\
\hline July 10,2015 & $11 \mathrm{am}$ & Sample was removed (1cm) from the top. Freezing cont. \\
\hline July 22, 2015 & $11: 11 \mathrm{am}$ & Ice buildup was removed. \\
\hline August 21, 2015 & $11: 15 \mathrm{am}$ & Power outage occurred. Melting started. \\
\hline August 28,2015 & $4 \mathrm{pm}$ & Column put into fridge and freezing started again. \\
\hline Nov. 18,2015 & noon & Freezing ends and thaw starts. \\
\hline Nov. 26, 2015 & $10: 28 \mathrm{pm}$ & Experiment Ends. \\
\hline
\end{tabular}

Table 40. Events timeline for Column Test \#2.

\begin{tabular}{|c|c|c|}
\hline Date & Time & Event \\
\hline Feb. 19,2016 & $5: 10 \mathrm{pm}$ & Column test started. Consolidation only. \\
\hline April 18,2016 & $2: 32 \mathrm{pm}$ & MPS-6 sensor added at the surface as tailings dry. \\
\hline June 13,2016 & $2: 46 \mathrm{pm}$ & Experiment ends. \\
\hline
\end{tabular}

Table 41. Events timeline for Column Test \#3.

\begin{tabular}{|c|c|c|}
\hline Date & Time & Event \\
\hline Feb. 20, 2016 & $6: 55 \mathrm{pm}$ & Column test started. \\
\hline March 08,2016 & $3 \mathrm{pm}$ & Fan was installed on top of column. \\
\hline March 08,2016 & $3: 45 \mathrm{pm}$ & Water added to surface to measure evaporation rate. \\
\hline March 09,2016 & $5 \mathrm{pm}$ & Desiccation phase started. \\
\hline March 22,2016 & $6 \mathrm{pm}$ & Freezing starts. \\
\hline April 02, 2016 & $1: 30 \mathrm{pm}$ & Freezing ends. Melting starts. \\
\hline June 14, 2016 & $10: 40 \mathrm{am}$ & Experiment ends. \\
\hline
\end{tabular}




\section{D.2 Slump Test Data}

Table 42. Slump tests summary for all three column tests.

\begin{tabular}{|c|c|c|c|}
\hline & Column Test \#1 & Column Test \#2 & Column Test \#3 \\
\hline Sample 1 & $8.7 \mathrm{~cm}$ & $8.3 \mathrm{~cm}$ & $8.1 \mathrm{~cm}$ \\
\hline Sample 2 & $8.4 \mathrm{~cm}$ & $8.0 \mathrm{~cm}$ & $7.8 \mathrm{~cm}$ \\
\hline Sample 3 & $8.6 \mathrm{~cm}$ & $7.9 \mathrm{~cm}$ & $8.2 \mathrm{~cm}$ \\
\hline Average & $8.6 \mathrm{~cm}$ & $8.1 \mathrm{~cm}$ & $8.0 \mathrm{~cm}$ \\
\hline
\end{tabular}

\section{D.3 Summary of Other Freeze-Thaw Tests by Henry (2007)}

\begin{tabular}{|c|c|c|c|c|c|c|c|}
\hline Reference & System & Topic & Soil depth (cm) & $\begin{array}{l}\text { Soil } \\
\text { quantity }\end{array}$ & $\begin{array}{l}\text { Cycle length } \\
\text { (day) }\end{array}$ & $\begin{array}{l}\text { Number of } \\
\text { cycles }\end{array}$ & Collection date \\
\hline $\begin{array}{l}\text { (a) Homogenized soil } \\
\text { 1. Christensen and } \\
\text { Christensen (1991) }\end{array}$ & Agricultural & $\mathrm{N}_{2} \mathrm{O}$ & 20 & $0.12 \mathrm{~L}$ & $46-72$ & 1 or 2 & September \\
\hline 2. Deluca et al. (1992) & Agricultural & $\mathrm{N}$ & Not available & $\begin{array}{l}\text { Not } \\
\text { available }\end{array}$ & 14 & 1 & Not available \\
\hline 3. Vaz et al. (1994) & Pasture & $\mathrm{P}$ & $10-15$ & $0.20 \mathrm{~L}$ & 0.8 & 1 or 8 & Not available \\
\hline 4. Wang and Bettany (1994) & Agricultural & $\mathrm{N}$ & 13 & $1.24 \mathrm{~L}$ & 14 & 1 & Not available \\
\hline 5. Winter et al. (1994) & Agricultural & Microbial C, N & 10 & $0.08 \mathrm{~L}$ & 1 & 1,2 or 3 & Not available \\
\hline 6. Schimel and Clein (1996) & $\begin{array}{l}\text { Tundra, } \\
\text { taiga }\end{array}$ & $\mathrm{CO}_{2}, \mathrm{~N}$ & Not available & $10 \mathrm{~g}$ & 10 & 3 & June \\
\hline 7. Skogland et al. (1988) & Beech forest & $\mathrm{CO}_{2}$ & 15 & $0.05 \mathrm{~L}$ & 2 & 1 & Not available \\
\hline 8. Lipson et al. (2000) & Alpine & Microbial biomass & 10 & $0.12 \mathrm{~L}$ & 2 & 1 & Snow melt \\
\hline 9. Neilson et al. (2001) & $\begin{array}{l}\text { Hardwood } \\
\text { forest }\end{array}$ & $\mathrm{CO}_{2}, \mathrm{~N}$ & Top 3 horizons & $0.20 \mathrm{~L}$ & 31 & 1 & June \\
\hline $\begin{array}{l}\text { 10. Herrmann and Witter } \\
(2002)\end{array}$ & Agricultural & $\mathrm{C}, \mathrm{N}$ & 7 & $0.05 \mathrm{~L}$ & 2 & 1 & $\begin{array}{l}\text { May and } \\
\text { November }\end{array}$ \\
\hline $\begin{array}{l}\text { 11. Oztas and Fayetorbay } \\
(2003)\end{array}$ & Various & Soil aggregates & 20 & $500 \mathrm{~g}$ & 2 & 3,6 or 9 & Not available \\
\hline $\begin{array}{l}\text { 12. Sulkava and Huhta } \\
(2003)\end{array}$ & Pine forest & $\begin{array}{l}\text { Faunal } \\
\text { decomposers }\end{array}$ & Humus & $0.38 \mathrm{~L}$ & 10 & 3 & $\begin{array}{l}\text { November, } \\
\text { February, May } \\
\text { and October }\end{array}$ \\
\hline 13. Yanai et al. (2004a) & Various & Microbial C, N & 10 & $0.05 \mathrm{~L}$ & 1 & 4 & Not available \\
\hline 14. Yanai et al. (2004b) & Various & $\mathrm{N}$ & 10 & $0.05 \mathrm{~L}$ & 1 & 4 & Not available \\
\hline 15. Bechmann et al. (2005) & Agricultural & $\mathrm{P}$ & 20 & $0.25 \mathrm{~L}$ & 8.5 & 0,1 or 8 & Not available \\
\hline 16. Ferrick and Gatto (2005) & Hanover silt & Soil erosion & Not available & $38 \mathrm{~L}$ & $2-10$ & 1 & Not available \\
\hline $\begin{array}{l}\text { 17. Peltovuori and Soinne } \\
(2005)\end{array}$ & Agricultural & $\mathrm{P}$ & Not available & $500 \mathrm{~g}$ & 14 & 3 & Not available \\
\hline $\begin{array}{l}\text { 18. Soinne and Peltovuori } \\
(2005)\end{array}$ & Agricultural & $\mathrm{P}$ & Not available & $\begin{array}{l}\text { Not } \\
\text { available }\end{array}$ & $\begin{array}{l}\text { Not } \\
\text { available }\end{array}$ & $\begin{array}{l}\text { Not } \\
\text { available }\end{array}$ & Spring and fall \\
\hline 19. Stenrød et al. (2005) & Agricultural & Microbial activity & 10 & $0.16 \mathrm{~L}$ & 1 & 40 & Mid-October \\
\hline 20. Sharma et al. (2006) & Grassland & $\begin{array}{l}\mathrm{N}_{2} \mathrm{O} \text {, microbial } \\
\text { community }\end{array}$ & 35 & $5.39 \mathrm{~L}$ & 2 & 1 & Early May \\
\hline 21. Walker et al. (2006) & Agricultural & $\begin{array}{l}\text { Microbial } \\
\text { community }\end{array}$ & 2 & $1 \mathrm{~g}$ & 0.084 & 49 & Not available \\
\hline \multicolumn{8}{|l|}{ (b) Intact soil cores } \\
\hline $\begin{array}{l}\text { 22. Lipson and Monson } \\
\text { (1998) }\end{array}$ & $\begin{array}{l}\text { Alpine } \\
\text { tundra }\end{array}$ & $\begin{array}{l}\mathrm{N} \text {, microbial } \\
\text { biomass }\end{array}$ & 15 & $0.29 \mathrm{~L}$ & 1 & 1 & Not available \\
\hline 23. Larsen et al. (2002) & Arctic heath & Microbial C, N & $4-6$ & $0.75-1.12 \mathrm{~L}$ & 1 & 18 & July \\
\hline 24. Grogan et al. (2004) & $\begin{array}{l}\text { Heath } \\
\text { tundra }\end{array}$ & $\mathrm{C}, \mathrm{N}$ & $12-17$ & $4.16-7.69 \mathrm{~L}$ & 2 & 5 & 26 July \\
\hline $\begin{array}{l}\text { 25. Koponen and } \\
\text { Martikainen (2004) }\end{array}$ & Organic soil & $\mathrm{N}_{2} \mathrm{O}$ & 15 & $1.18 \mathrm{~L}$ & 10 & 2 & 20 September \\
\hline 26. Ludwig et al. (2004) & Agricultural & $\mathrm{N}_{2} \mathrm{O}$ & 10 & $1.65 \mathrm{~L}$ & 2 or 4 & 1 & Not available \\
\hline 27. Teepe and Ludwig (2004) & Forest & $\mathrm{N}_{2} \mathrm{O}, \mathrm{CO}_{2}$ & $9-13$ & $1.49-2.15 \mathrm{~L}$ & $4-12$ & 1 & Not available \\
\hline 28. Sjursen et al. (2005) & Sub-Arctic & Microarthropods & $4-5$ & $0.4-0.5 \mathrm{~L}$ & 4 & $1,4,8$ or 16 & Late August \\
\hline
\end{tabular}

Figure 250. Summary of previous freeze-thaw experiments gathered by Henry (2007). 


\section{D.4 Soil Freezing Characteristic Curve (SFCC) Data}

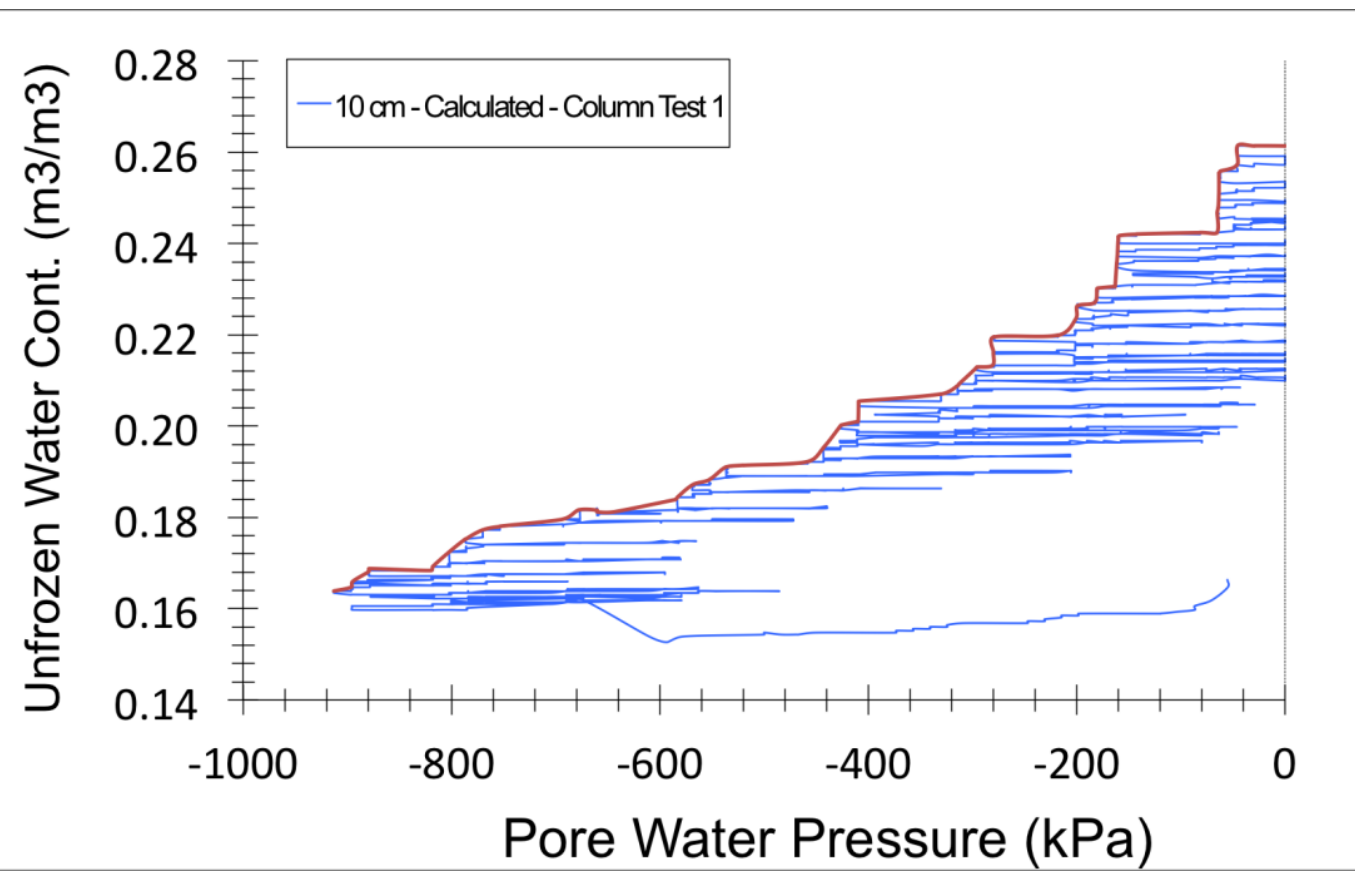

Figure 251. Trend line (red) show the increasing negative pore water pressures in the SFCC at a height of $10 \mathrm{~cm}$ in Column Test 1.

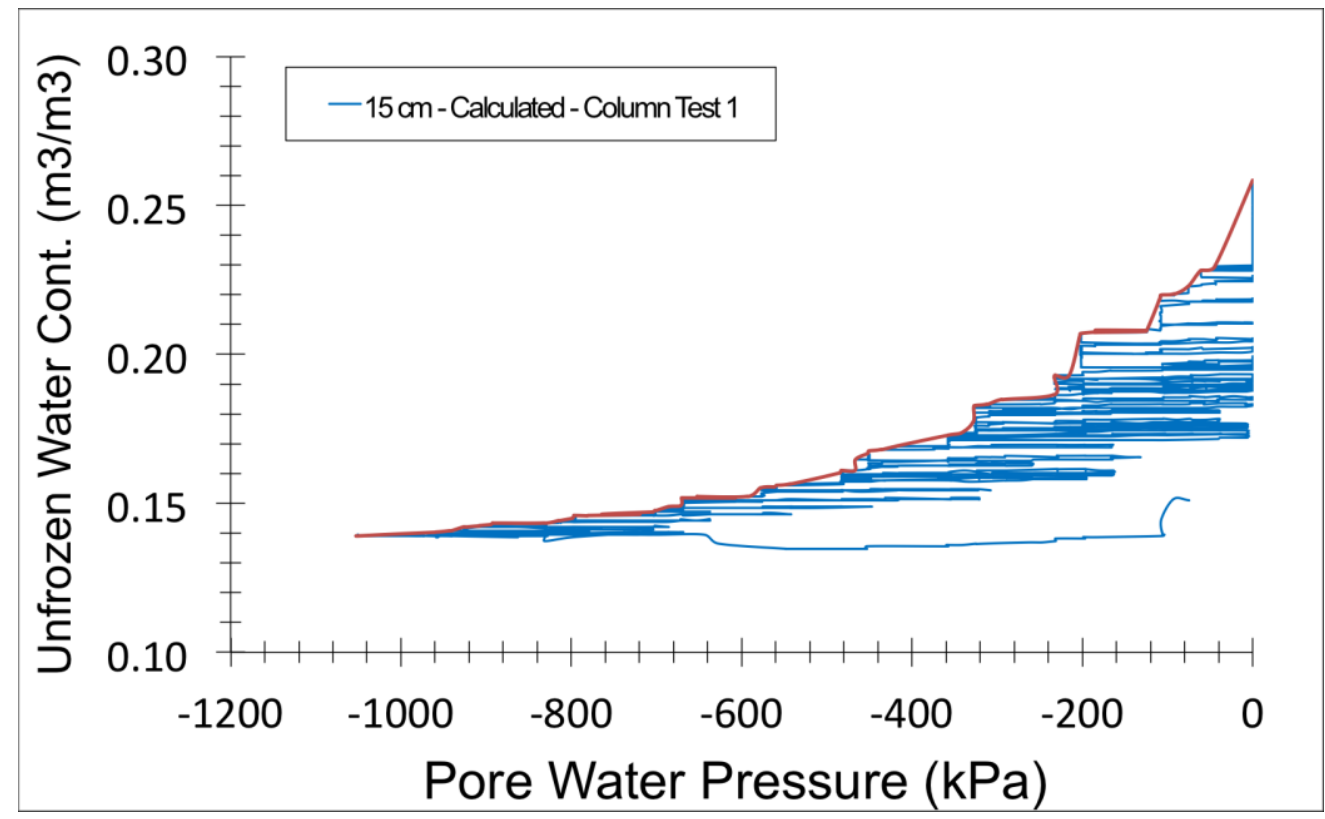

Figure 252. Trend line (red) show the increasing negative pore water pressures in the SFCC at a height of $15 \mathrm{~cm}$ in Column Test 1. 


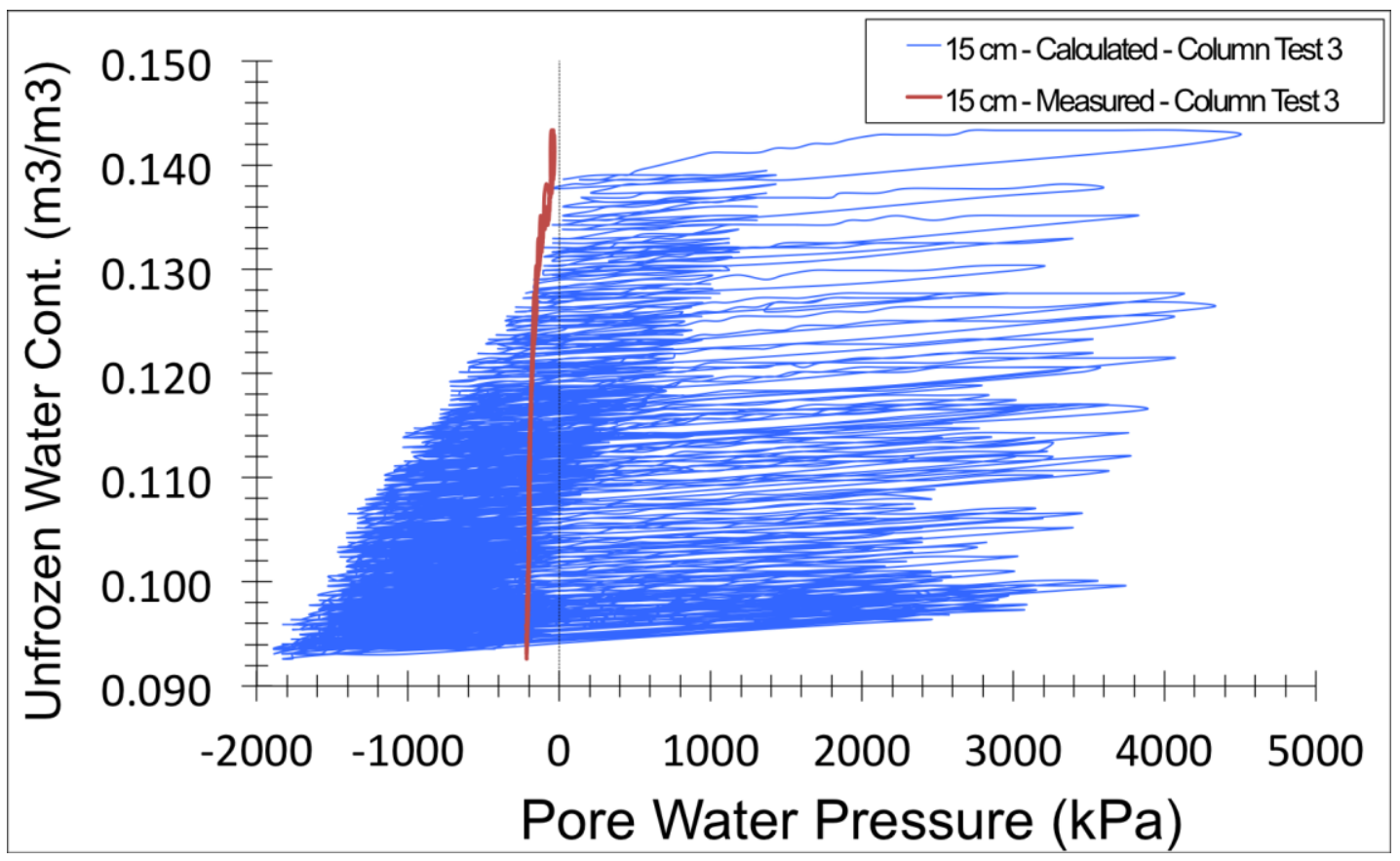

Figure 253. Measured and calculated soil freezing characteristic curve (SFCC) at a height of $15 \mathrm{~cm}$ for Column Test 3.

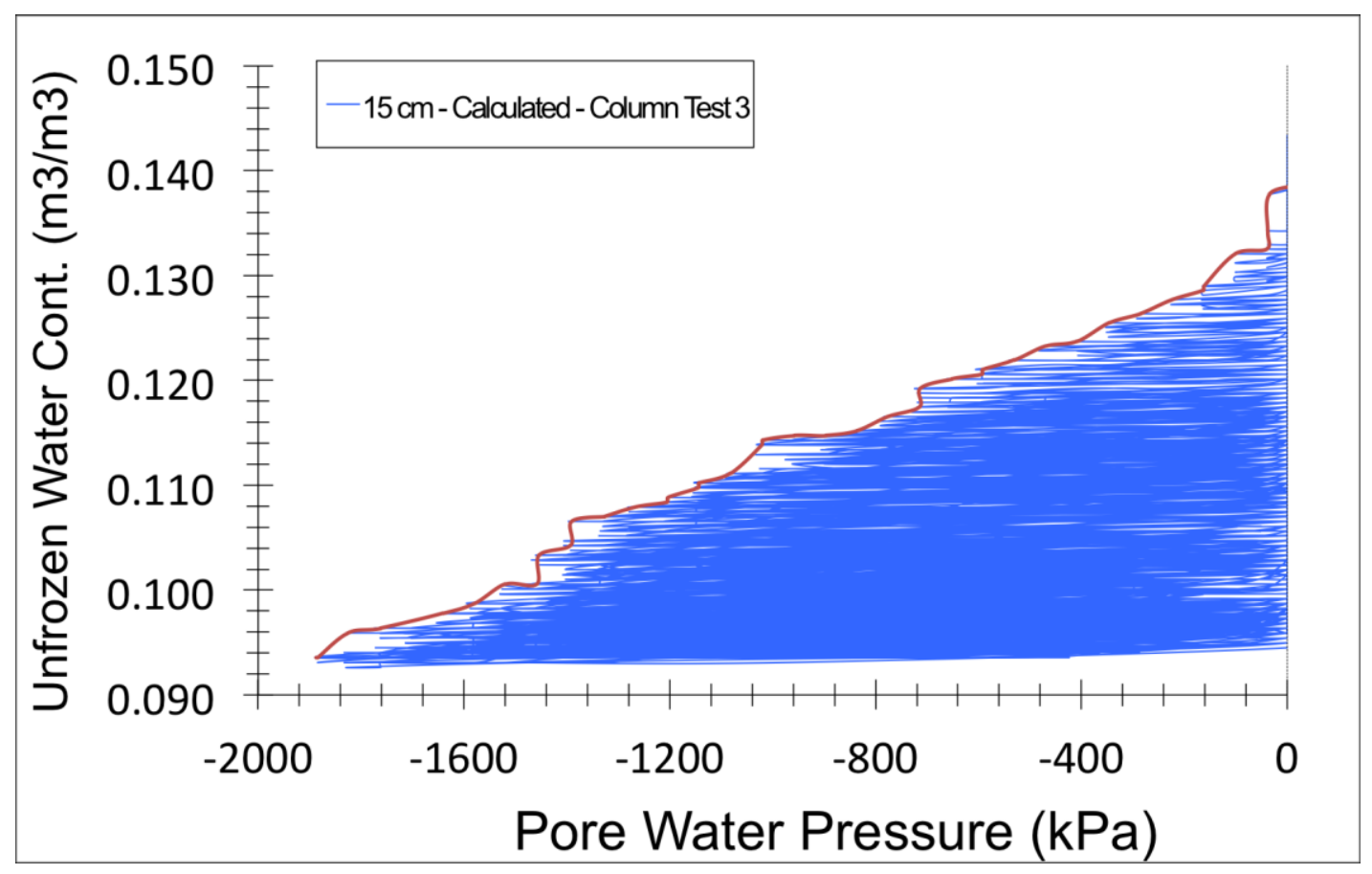

Figure 254. Trend line (red) show the increasing negative pore water pressures in the SFCC at a height of $15 \mathrm{~cm}$ in Column Test 3. 